\section{ADVANCED STEEL CONSTRUCTION}

An International Journal

Volume 17 Number 3

September 2021

CONTENTS

\section{Technical Papers}

Hysteretic Performance of We

Finite Element Analysis of U

Ankur Kumar, Krishanu

Study on Force Mechanism of Cable-Truss Frame and Jumped Layout of Annular Crossed Cable-Truss Structure

Jian Lu, Xiong-Yan Li, Su-Duo Xue, Ren-Jie Liu and Majid Dezhkam

Numerical Study on Shear Behaviour of Enhanced C-Channels in Stet
Chang-Hui Li, Jia-Bao Yan, Hui-Ning Guan and Hong-Long Wang

Experimental Study on Seismic Performance of $P$ PeC

Jin Feng, Jing Jin, Jun Xia and You-Zhen Fang

\section{Ehsan Ahmadi and Seied Ahmad Hossein}

A Study of Collapse Susceptibility and Resistance of Loaded Cable-Suppo
Marvin Paul Agwoko, Zhi-Hua Chen, Hong-Bo Liu and Xiao-Dun Wang

Mechanical Behavior and Catenary Action of Restrained Steel Beam Under Fire

Run-Min Ding, Sheng-Gang Fan, He-Yang Gui, Cheng-Liang Liu and Hang Zhou

Stress Response and Initial Stiffness of Side Plate Connections to WCFT Columns

Han-Chao Liu, Ji-Ping Hao, Qiang Xue and Yu-Qi Huang

Progressive Collapse Resistance of Steel Framed Buildings Under Extreme Events
Guo-Qiang Li, Jing-Zhou Zhang, Liu-Lian Li, Bin-Hui Jiang, Tao-Chun Yang and Jian Jiang

Copyright $\odot 2021$ by :

The Hong Kong Institute of
Website: http://wwwu.hkis.org

Website: $h t p p: / /$
ISSN $1816-112 x$

ISSN 1816-112X
Science Citation

政

Cover: Project: Beijing Daxing International Airport; Steel Design: Beijing Institute of Architectural Design (Group) Co., LTD

Clith. Beijing Daxing airport construction headquarters.

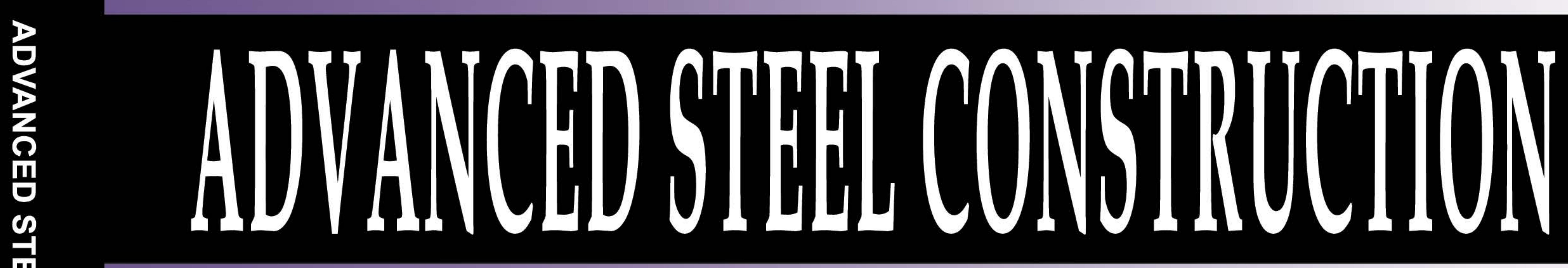

an International Jownal

ISSN 1816-112X

Volume 17 Number 3

September 2021

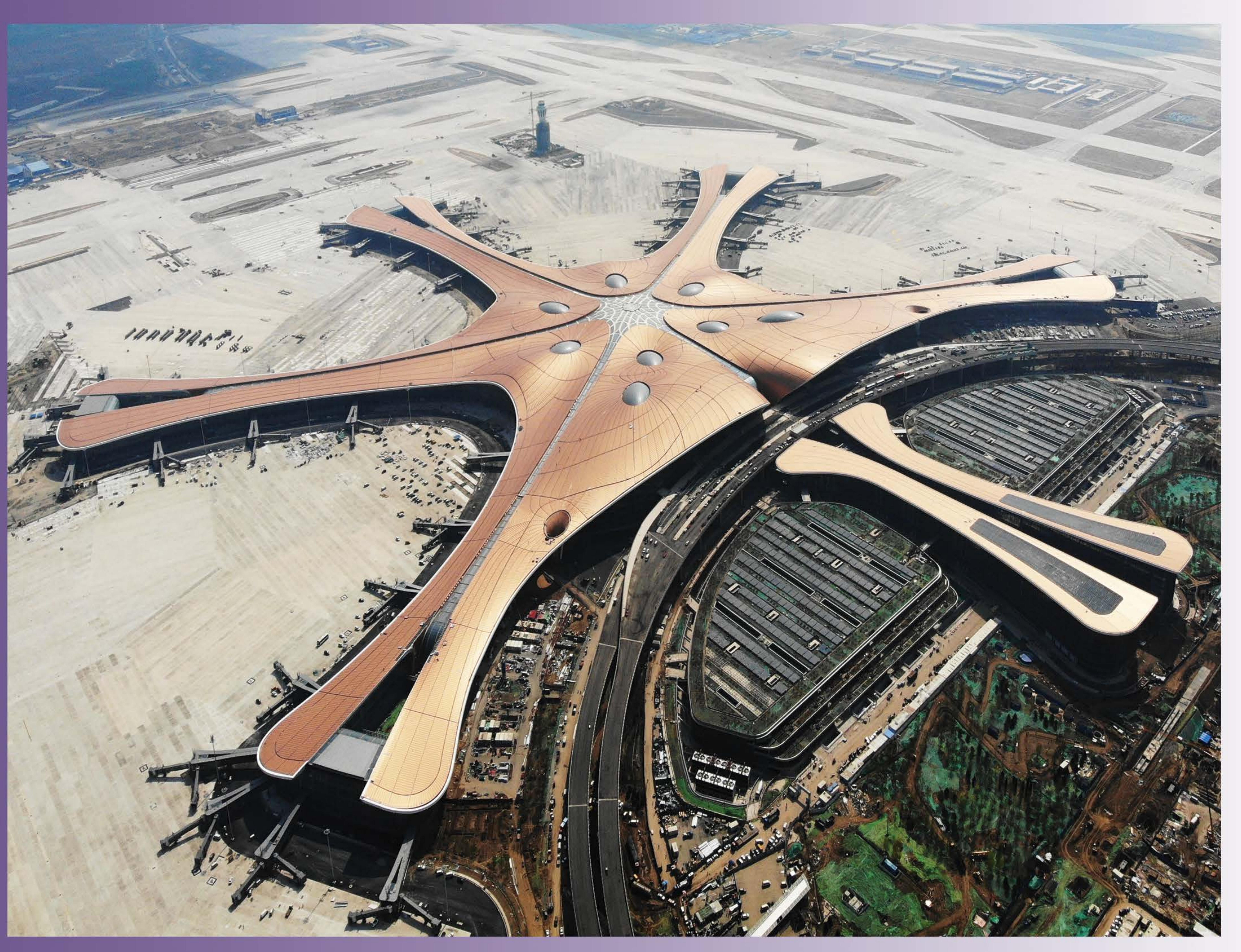

Editors-in-Chief

S.L. Chan, The Hong Kong Polytechnic University, Hong Kong, China

W.F. Chen, University of Hawaii at Manoa, USA

R. Zandonini, Trento University, Italy 


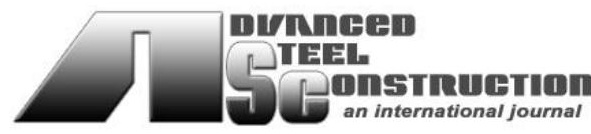

ISSN 1816-112X

Science Citation Index Expanded, Materials Science Citation Index and ISI Alerting

EDITORS-IN-CHIEF
Asian Pacific, African
and organizing Editor
S.L. Chan
The Hong Kong Polyt. Univ.,
Hong Kong, China
American Editor
W.F. Chen
Univ. of Hawaii at Manoa, USA
European Editor
R. Zandonini
Trento Univ., Italy
ASSOCIATE EDITORS

Y.P. Liu
The Hong Kong Polyt. Univ., Hong Kong, China

The Hong Kong Polyt. Univ., Hong Kong, China

S.W. Liu

Sun Yat-Sen Univ., China

INTERNATIONAL

EDITORIAL BOARD

F.G. Albermani

Central Queensland Univ., Australia

I. Burgess

Univ. of Sheffield, UK

F.S.K. Bijlaard

Delft Univ. of Technology, The Netherlands

R. Bjorhovde

The Bjorhovde Group, USA

M.A. Bradford

The Univ. of New South Wales, Australia

D. Camotim

Technical Univ. of Lisbon, Portugal

C.M. Chan

Hong Kong Univ. of Science \& Technology, Hong Kong, China

T.H.T. Chan

Queensland Univ. of Technology, Australia

T.M. Chan

The Hong Kong Polyt. Univ., Hong Kong, China

Z.H. Chen

Tianjin Univ., China

S.P. Chiew

Nanyang Technological Univ., Singapore

W.K. Chow

The Hong Kong Polyt. Univ., Hong Kong, China

G.G. Deierlein

Stanford Univ., California, USA

L. Dezi

Univ. of Ancona, Italy

D. Dubina

The Politehnica Univ. of Timosoara, Romania

R. Greiner

Technical Univ. of Graz, Austria

L. Gardner

Imperial College of Science, Technology and Medicine, UK

Y. Goto

Nagoya Institute of Technology, Japan

\section{Advanced Steel \\ Construction an international journal}

H. Han

singhua Univ. China

S. Herion

University of Karlsruhe, Germany

G.W.M. Ho

Ove Arup \& Partners Hong Kong Ltd., Hong Kong, China

B.A. Izzuddin

Imperial College of Science, Technology and

Medicine, UK

J.P. Jaspart

Univ. of Liege, Belgium

S. A. Jayachandran

IIT Madras, Chennai, India

S.E. Kim

Sejong Univ., South Korea

S. Kitipornchai

The Univ., of Queensland, Australia

D. Lam

Univ. of Bradford, UK

H.F. Lam

City Univ. of Hong Kong, Hong Kong, China

G.Q. Li

Tongji Univ., China

J.Y.R. Liew

National Univ. of Singapore, Singapore

E.M. Lui

Syracuse Univ., USA

Y.L. Mo

Univ. of Houston, USA

J.P. Muzeau

CUST, Clermont Ferrand, France

D.A. Nethercot

Imperial College of Science, Technology and

Medicine, UK

Y.Q. Ni

The Hong Kong Polyt. Univ., Hong Kong, China

D.J. Oehlers

The Univ. of Adelaide, Australia

J.L. Peng

Yunlin Uni. of Science \& Technology, Taiwan, China

K. Rasmussen

The Univ. of Sydney, Australia

J.M. Rotter

The Univ. of Edinburgh, UK

C. Scawthorn

Scawthorn Porter Associates, USA

P. Schaumann

Univ. of Hannover, Germany

Y.J. Shi

Tsinghua Univ., China

G.P. Shu

Southeast Univ. China

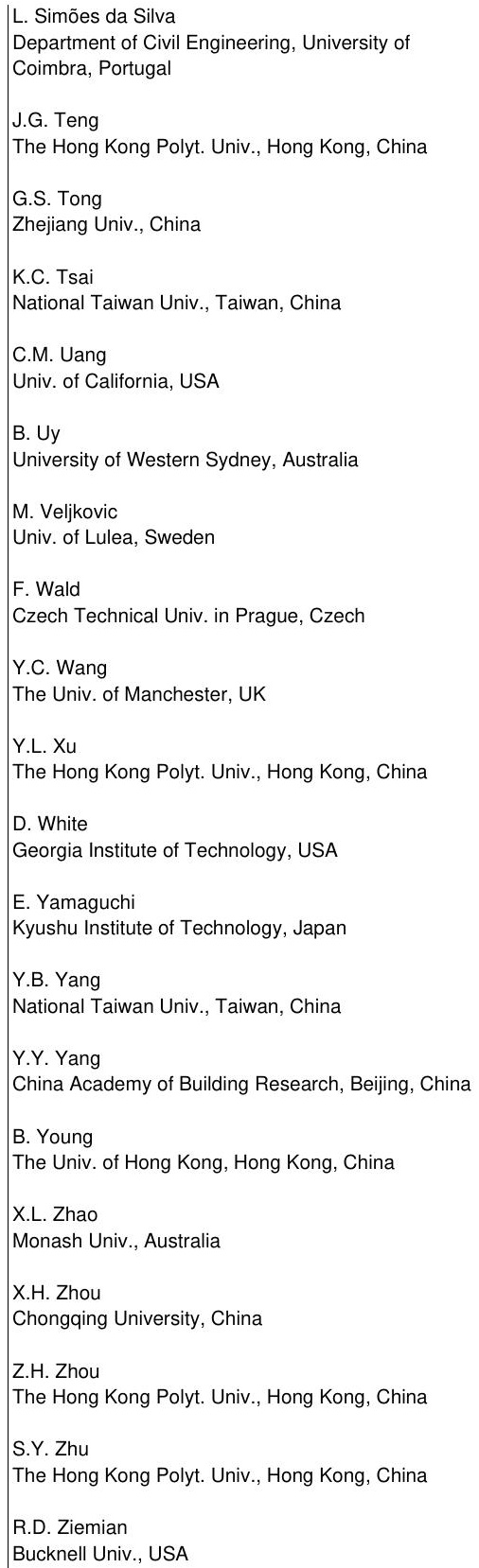

Cover: Project: Beijing Daxing International Airport; Steel Design : Beijing Institute of Architectural Design (Group) Co., LTD.; Client: Beijing Daxing airport construction headquarters. 


\section{General Information Advanced Steel Construction, an international journal}

\section{Aims and scope}

The International Journal of Advanced Steel Construction provides a platform for the publication and rapid dissemination of original and up-to-date research and technological developments in steel construction, design and analysis. Scope of research papers published in this journal includes but is not limited to theoretical and experimental research on elements, assemblages, systems, material, design philosophy and codification, standards, fabrication, projects of innovative nature and computer techniques. The journal is specifically tailored to channel the exchange of technological know-how between researchers and practitioners. Contributions from all aspects related to the recent developments of advanced steel construction are welcome. 


\section{DIMARER 거달느. \\ DISTRURTID \\ 1 an international journal}

\section{ISSN 1816-112X}

Science Citation Index Expanded, Materials Science Citation Index and ISI Alerting

\section{EDITORS-IN-CHIEF}

\section{Asian Pacific, African and organizing Editor}

S.L. Chan

The Hong Kong Polyt. Univ., Hong Kong, China

Email:ceslchan@polyu.edu.hk

\section{American Editor}

W.F. Chen

Univ. of Hawaii at Manoa, USA

Email:waifah@hawaii.edu

\section{European Editor}

R. Zandonini

Trento Univ., Italy

Email: riccardo.zandonini@ing.unitn.it

\section{Advanced Steel \\ Construction an international journal}

VOLUME 17 NUMBER 3

September 2021

Technical Papers

Hysteretic Performance of Weak-Axis Connection With I-Shaped Plates in Steel 221 Frame

Ying-Lu Xu* and Ji-Ping Hao

Finite Element Analysis of Unfastened Cold-Formed Steel Channel Sections with 231 Web Holes Under End-Two-Flange Loading at Elevated Temperatures

Ankur Kumar, Krishanu Roy*, Asraf Uzzaman and James B.P. Lim

Study on Force Mechanism of Cable-Truss Frame and Jumped Layout of Annular 243 Crossed Cable-Truss Structure

Jian Lu, Xiong-Yan Li*, Su-Duo Xue, Ren-Jie Liu and Majid Dezhkam

Numerical Study on Shear Behaviour of Enhanced C-Channels in 253 Steel-UHPC-Steel Sandwich Structures

Chang-Hui Li, Jia-Bao Yan*, Hui-Ning Guan and Hong-Long Wang

Experimental Study on Seismic Performance of Pec Composite Column-Steel 264 Beam Frame with Welded T-Stub Strengthened Connections

Jin Feng*, Jing Jin, Jun Xia and You-Zhen Fang

Capacity Evaluation of Eight Bolt Extended Endplate Moment Connections 273 Subjected to Column Removal Scenario

Ehsan Ahmadi and Seied Ahmad Hosseini*

A Study of Collapse Susceptibility and Resistance of Loaded Cable-Supported 283 Pipe Structure Subject to A Sudden Break of Cable Member

Marvin Paul Agwoko, Zhi-Hua Chen*, Hong-Bo Liu and Xiao-Dun Wang

Mechanical Behavior and Catenary Action of Restrained Steel Beam Under Fire 294 Run-Min Ding, Sheng-Gang Fan*, He-Yang Gui, Cheng-Liang Liu and Hang Zhou

Stress Response and Initial Stiffness of Side Plate Connections to WCFT Columns 306 Han-Chao Liu, Ji-Ping Hao*, Qiang Xue and Yu-Qi Huang

Progressive Collapse Resistance of Steel Framed Buildings Under Extreme Events 318 Guo-Qiang Li, Jing-Zhou Zhang, Liu-Lian Li, Bin-Hui Jiang, Tao-Chun Yang and Jian Jiang* 



\title{
HYSTERETIC PERFORMANCE OF WEAK-AXIS CONNECTION WITH I-SHAPED PLATES IN STEEL FRAME
}

\author{
Ying-Lu Xu ${ }^{1,2,3, *}$ and Ji-Ping Hao ${ }^{1,2,3}$ \\ ${ }^{1}$ School of Civil Engineering, Xi' an University of Architecture \& Technology, Xi'an, 710055, China \\ ${ }^{2}$ Key Lab of Structural Engineering and Earthquake Resistance, Ministry of Education (XAUAT) , Xi' 'an, 710055, China \\ ${ }^{3}$ Shaanxi Key Lab of Structure and Earthquake Resistance (XAUAT) , Xi'an, 710055, China \\ *(Corresponding author: E-mail: 564319073@qq.com)
}

\section{A B S T RA C T}

This paper elucidates numerically the behavior of weak-axis moment connections proposed by welding I-shaped plates in the H-section column to increase connection strength and ductility in steel frame. After validating the numerical methods through comparing the results of numerical analysis and experiments, the effectiveness of the proposed weak-axis connection were examined through comparing to the traditional weak-axis connection. The proposed weak-axis connection could move the highest stresses away from the start-stop points of a weld, and thus preventing the premature brittle fracture of the beam flange welds. The plastic hinge formed away from the beam-column interface, while the local buckling occurred in the weld access holes region in the traditional weak-axis connection. The proposed weak-axis connections can be classified as rigid in a strong-bracing system, and be classified as semi-rigid in weak-supported or unsupported system. And then a series of parametric studies was conducted to better understand the behavior of proposed weak-axis moment connections. The force-displacement relationships, location of the plastic hinge, Mises index (MI), triaxiality index (TI) and rupture index (RI) distributions at the beam flange welds were reported in detail. According to the numerical analysis, the design variables of I-shaped plates and widened flange plate are suggested, along with a design procedure.

Copyright $\odot 2021$ by The Hong Kong Institute of Steel Construction. All rights reserved.

\section{Introduction}

Steel moment-resisting frame is considered to have superior ductility, and therefore, it has been widely used in earthquake-prone regions. However, in the 1994 Northridge earthquake and 1995 Kobe earthquake, unexpected and widespread brittle failures were observed, generating concerns regarding the design of connections and construction details of connections, as numerous failures occurred in the welded connections whilst the structure remained in elastic state in the earthquake. Causes for the poor performance of these welded connections of Pre-Northridge were mainly conjectured as the poor workmanship leading to weld defects, and poor detailing connections leading to stress concentrations in welds.

To avoid such unexpected failure, the seismic performance of various moment connections has been extensively investigated since the Northridge earthquake to alleviate the stress concentrations in welds and thus providing reliable ductile performance. Various alternatives to beam-to-column connections by strengthening [1-4] or weakening [5-8] the beam section have been proposed to force the plastic hinge a small distance away from the beam-column interface under cyclic loading. However, most of these studies are related to strong-axis connections [1-8] with less attention being paid to the weak-axis connections. For strong-axis moment connections, the highest stresses always concentrate on the center of the groove weld, while the condition is opposite in the weak-axis moment connections, as the highest stresses always concentrate on the edge of the beam flange groove weld, as shown in Fig. 1, described by Gilton and Uang [9]. As the start-stop points are the most vulnerable parts of a weld, the beam flange weld stresses distribution pattern of weak-axis moment connections in Fig. $1 \mathrm{~b}$ would make the welds more prone to brittle fracture.

The pertinent study concerning weak-axis moment connections to my knowledge was performed by several researchers, and their studies are as follows. FEMA-355D [10] and Guo [11] pointed out that the traditional weak-axis connections has poor plastic rotation less than 0.03 rad. Gilton and Uang [9] conducted an experimental study for two full-scale weak-axis reduced beam section (RBS) moment connections and also a series of parametric studies. It was found that comparing to specimens without RBS, RBS specimens could significantly reduce the critical strain concentration. While in the experimental study of RBS weak-axis connections conducted by Yu et al. [12], the specimen failed to move out the plastic hinge, and the beam flange welds fractured. Oh et al. [13] conducted an experimental study on weak-axis column-tree connections and results showed that the RBS specimen or the tapered beam flange specimen exerted superior ductile performance and no brittle fracture occurred until 0.05 rad story drift angle. Kim et al. [14], Li et al. [15], and Wang et al. [16] proposed different weak-axis connections mainly connected through bolts and conducted related experimental study to investigate the rotating capacity and bearing capacity.

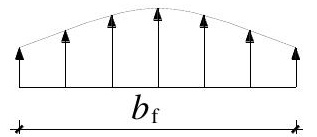

(a) strong-axis connection

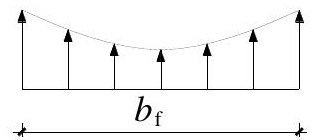

(b) weak-axis connection
Fig. 1 Stress distribution of the beam flange

According to the connection requirements of Code for seismic design of buildings (GB50011-2010), the box section column should be adopted when the column is rigidly connected to beams in two mutually perpendicular directions. While the structure cost will be increased when the box section column is used in the project where the I-section column is sufficient to meet the requirements of force and deformation. It is difficult to avoid the weld damage of beam flange welds in the traditional I-section weak-axis connections. Thus, it is necessary to propose a more suitable connection form for the weak-axis connection of I-section column.

Our team conducted an experimental study about a developed weak-axis connection with box-strengthened panel zone in the past years, including five pure steel beam-column connection specimens and five corresponding composite connection specimens [17]. Test results showed that most specimens failed due to the welding fracture, indicating that the connection details needs to be improved. Based on the previous research, this paper proposed a novel weak-axis connection from, as shown in Fig. 2, which is suitable for the weak-axis connections of I-section column in low and multi-layer steel structure frame. The main feature of the proposed weak-axis moment connections is welding the I-shaped plates (Fig. 2b) in the H-section column. And then the widely adopted in the engineering project flange-welded and web-bolted connection is used as it's easy to fabricate and economical, and the widened flange plate is adopted. In this way, the widened flange plate are able to extend out of the column flanges, and thus this developed weak-axis connection can move the highest stresses away from the start-stop points of a weld, which is obviously different from the traditional weak-axis connections (Fig. 1b). Therefore, the developed weak-axis connection can reduce the fracture potential of the beam flange welds. Meanwhile, the extending parts of I-shaped plates also strengthen the strong-axis connections that the widened flange plates can be arranged between the beam flanges and the I-shaped steel plates in strong-axis connections. And thus, the proposed connection could realize the seismic design criteria of "strong joint and weak component", and move the plastic hinge away from the beam flange welds in both strong-axis and weak-axis connections. 


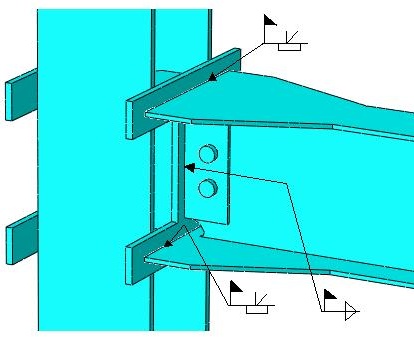

(a) weak-axis connection

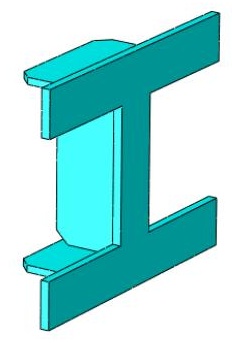

(b) I-shaped plates
Fig. 2 Configuration of developed weak-axis connection

The proposed weak-axis moment connections can be constructed by the following procedure:

(1) Cut the steel plates for horizontal stiffeners and vertical stiffeners with the thickness slightly greater than the beam flange and beam web respectively.

(2) Cut two I-shaped steel plates using the anti-lamellar tearing steel plate with the thickness slightly greater than the thickness of the column flange.

(3) Weld two horizontal stiffeners and one vertical stiffener to the I-shaped steel plate, as displayed in Fig. 2b. And the horizontal stiffeners and vertical stiffener aligned with the beam flange and web respectively, as displayed in Fig. 2a.

(4) Weld the I-shaped plates to the column flanges and web, and weld a shear plate to the I-shaped steel plate.

(5) Weld widened flange plates to the end of beam flanges with the thickness same to the beam flange.

(6) Use flange-butt-welded and web-bolted connection method to connect the beam and the I-shaped plate attached to the column.

Based on the general finite element analysis software ABAQUS, a refined tridimensional weak-axis connection model was conducted to replicate the connection specimens in the experimental study depicted in references [11] and [12], parametric studies were undertaken in developing a better understanding of the cyclic performance of the proposed weak-axis connections. This paper is organized as follows. Section 2 introduces the simulation and validation of experimental results. The comparative analysis of the traditional weak-axis connection and the proposed weak-axis connection is conducted in Section 3. Successively, Section 4 presents the parameter analysis of the proposed weak-axis connection. Then, Section 5 discusses the design procedure of the proposed weak-axis connection, and verifies the applicability of the proposed dimensions to other beam and column sections. Finally, conclusions and future developments are drawn in Section 6.

\section{Simulation and verification of experimental results}

Comparing to the experimental study, the numerical modelling has many advantages such as reducing the time and costs, and could explore large numbers of parameters, which has become common in academia. The experimental results of the weak-axis beam-column connection specimen CW-1 in reference [11] and specimen RBS-3 in reference [12] were used as references to verify the effectiveness of the numerical model through comparing the failure mode, and the load versus displacement hysteretic curves.

\subsection{Modeling techniques and assumptions}

Three-dimensional eight-node solid nonconforming elements (element C3D8I in ABAQUS) were employed for specimens CW-1 and RBS-3 to model the steel profiles. Both material and geometric nonlinearity was considered in the finite element model (FEM). The true stress and plastic strain of the steel profiles was adopted according to the tension coupon tests results described in [11] and [12] respectively. Considering the convergence problem and computational efficiency, different mesh sizes was tried to determine the appropriate meshing methods and conduct the grid sensitivity analysis. The mesh division of the connection and RBS regions was more intensive, and a coarser mesh was adopted elsewhere. Specimens CW-1 and RBS-3 both had one column and one beam, and loading points were at the beam end. Web-bolted flange-welded connection was used for specimens CW-1 and RBS-3. Lateral bracing of the beam was provided for the beam to prevent the lateral deformation of the beam.

\subsection{3-D finite element model of $C W-1$}

For specimen $\mathrm{CW}-1$, the column and beam section was $\mathrm{W} 14 \times 398$ and W36 $\times 150$ respectively, both of A572 Grade 50 steel. 3-D finite element model of CW-1 was display in Fig. 3a. The boundary conditions adopted were the $x$ $\mathrm{y}$, and $\mathrm{z}$ directional displacement restrictions at the top and bottom of the column followed closely those used in the tests. Length of column and beam was $3810 \mathrm{~mm}$ and $3581 \mathrm{~mm}$ respectively. Same as the modeling method described in Gilton and Uang [11], weld access holes and bolt-related assembly were not considered in the FEM.

\subsection{3-D finite element model of RBS-3}

The specimen RBS-3 consisted of one $1400 \mathrm{~mm}$ height HW $250 \times 250 \times 9 \times 14$ column with one $1500 \mathrm{~mm}$ long $\mathrm{HN} 300 \times 150 \times 6.5 \times 9$ beam attached to the weak-axis of column, both of Grade Q235B steel. 3-D finite element model of RBS-3 and grid partition was shown in Fig. 3b. The boundary conditions adopted were the $\mathrm{x}, \mathrm{y}$, and $\mathrm{z}$ directional displacement restrictions at the column base and the $\mathrm{x}$, $\mathrm{y}$ directional displacement restrictions at the column tip followed closely those used in the tests. Axial compression of $786 \mathrm{kN}$, corresponding to 0.4 times of axial compression ratio, was applied at the top of the column during the test. Weld access holes and bolt-related assembly were considered in this model. Contact between the beam web, shear plate and bolts was explicitly modeled on the basis of the normal and tangential contact property: the normal contact in the contacting surfaces was chosen as "hard"; the tangential contact in the contacting surfaces was defined by penalty function with the frictional coefficient of 0.3 .

\subsection{Verification of the created models}

The experimental results of specimen CW-1 and specimen RBS-3 were used as references to verify the effectiveness of the numerical model through comparing the failure mode, and the load versus displacement hysteretic curves of the test and FEM, as depicted in Figs. 4 and 5 respectively.

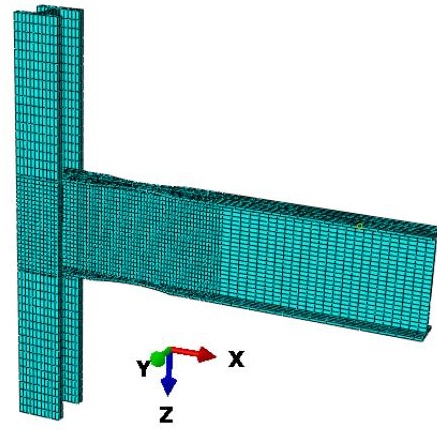

(a) specimen $\mathrm{CW}-1$

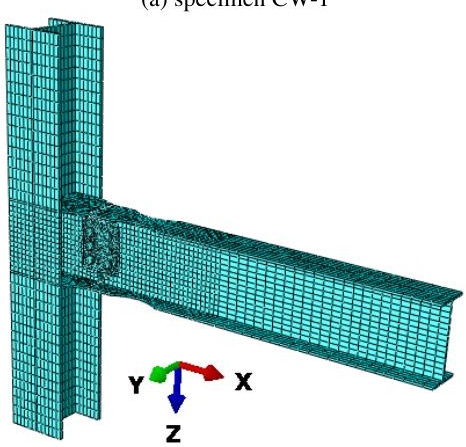

(b) specimen RBS-3

Fig. 3 3-D finite element model

As seen in Fig. 4, reasonable correlation between the test and FEM was observed, especially in the elastic part that the divergences of the initial stiffness are negligible. The inelastic response of the connection in FEM shows the same trend as test results. Unexpectedly, one can observe from Fig. 4a that the modelling results for specimen CW-1 was basically lower than that of the test, similar with the modelling results conducted by Gilton and Uang [11]. The reason may be that the boundary conditions (through connection plates) in the test were not exactly hinged, resulting in a certain constraint to the rotation of beam and column ends, while the hinge constraint in the FEM was idealized.

As illustrated in Fig. 4b, the numerical curves for specimen RBS-3 were was slightly higher than that of the test, and also smoother and plumper than the experimental curves, which was common and principally caused by ignoring the material damage. 


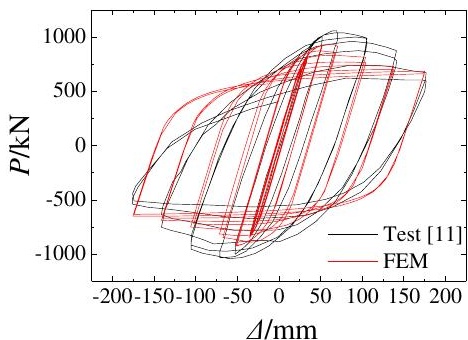

(a) specimen CW-1

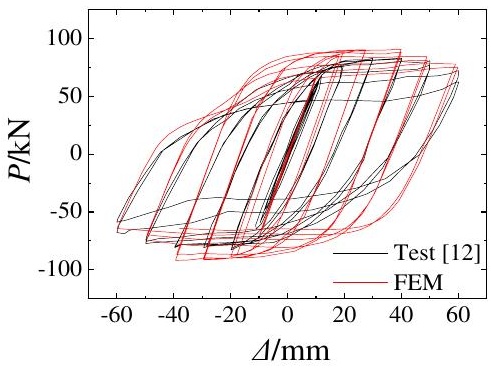

(b) specimen RBS-3

Fig. 4 Force-displacement hysteretic loops comparison

As evidenced from Figs. 5 and 6, the failure modes of specimen CW-1 and RBS-3 in FEM both demonstrated good correlation with the test results. For specimen CW-1, notably, extensive yielding could be observed in the RBS region. For specimen RBS-3, severe local buckling took place in the portion of weld access holes, indicating that the specimen RBS-3 did not realize the expected target of moving the plastic hinge away from the beam-column connection, and thus leading to the weld fracture in the experimental study.

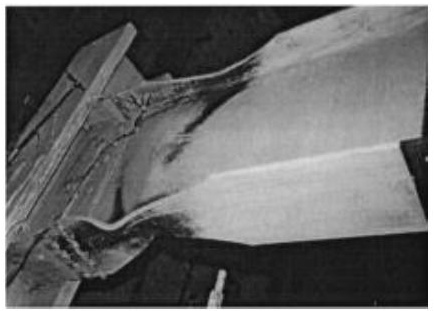

(a) test [11]

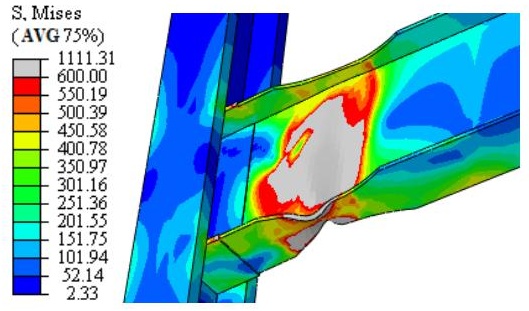

(b) FEM

Fig. 5 Failure mode comparison of specimen CW-1

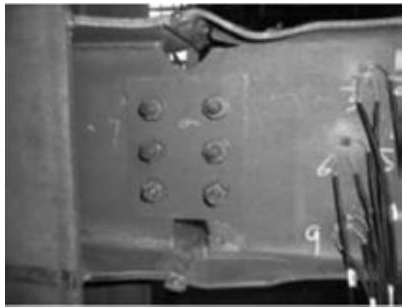

(a) test [12]

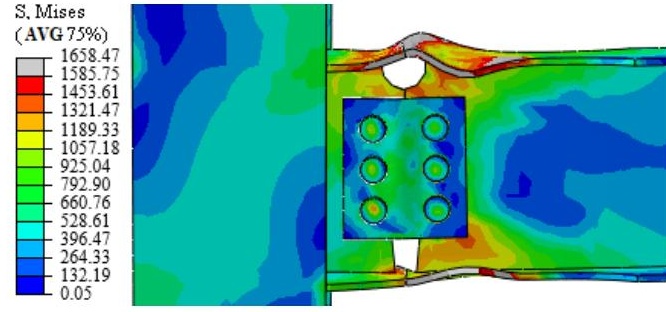

(b) FEM

Fig. 6 Failure mode comparison of specimen RBS-3

A reasonable agreement between the results of FEM and test for weak-axis connections was generally achieved. Based on this satisfactory correlation study, the modeling methods of specimen RBS-3 was then used to conduct the parametric analysis.

\section{Comparative analysis of the traditional and developed weak-axis} connection

A comparison analysis of the traditional and developed weak-axis connection using numerical methods was performed to discuss the effectiveness of the proposed weak-axis connection. The base model represented an exterior beam-column weak-axis connection in typical moment-resisting frame, which was isolated from the moment inflection points close to the mid-height of the column and mid-span of the beam respectively. Building structure design software PKPM was used to create the steel frame prototype, including four floors with $3000 \mathrm{~mm}$ story height, three spans with $4500 \mathrm{~mm}$ beam span. The considered load was $6 \mathrm{kN} / \mathrm{m}^{2}$ for dead load and 2 $\mathrm{kN} / \mathrm{m}^{2}$ for live load respectively, and thus the internal forces of the structure can be obtained. The substructure was the exterior beam-to-column weak-axis connection prototype in the three floor, and consisted of one $3000 \mathrm{~mm}$ height HW $250 \times 250 \times 9 \times 14$ column with one $2250 \mathrm{~mm}$ long HN $300 \times 150 \times 6.5 \times 9$ beam connected through welded-flange and bolted-web connection method, a most widely used connection in Chinese practice engineering.

\subsection{3-D finite element model of the traditional connection and developed} connection

The steel grade of column and beam was Q235B, same as the specimen RBS-3, and thus the material properties of the steel profiles in the parametric analysis were the same as those in the validated model RBS-3, described as tri-linear constitutive model, as shown in Fig. 7, with $2.06 \times 10^{5} \mathrm{MPa}$ elastic modulus. Welds were not considered in FEM as the strength of welds is higher than that of steel plates found in our previous experimental study [17]. The actual beam flange welds are usually defective, and thus the welds material properties were simplified to be the same as steel for the sake of timesaving. Tri-linear constitutive model was also adopted for the material properties of bolts. Table 1 lists the specific values of the material properties. Other modeling methods were the same as described above. Fig. 8 illustrates the traditional weak-axis connection and the developed weak-axis connection in this paper. And the dimensions for two connections were chose to make the end of the connection at basically the same location to make an equivalent comparison.

In order to reflect the actual loading situations, three loading steps were applied in FEM. First, the bolts pretension force was applied through the "bolt load" option in FEM. Second, column axial load of $412 \mathrm{kN}$, extracted from the PKPM software, was applied to the top of the column. Third, beam tip cyclic loading was applied, as depicted in Fig. 9, whereby the vertical displacement was expressed in the way of the story drift angle, calculated by dividing the beam tip vertical displacement by the length from the beam tip to the column centerline.

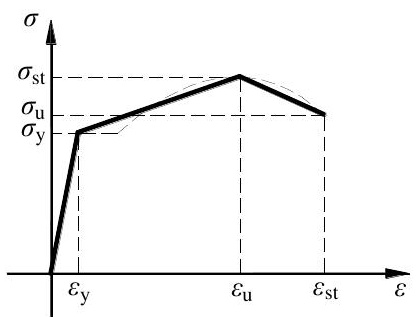

Fig. 7 Tri-linear constitutive model 
(a) traditional connection

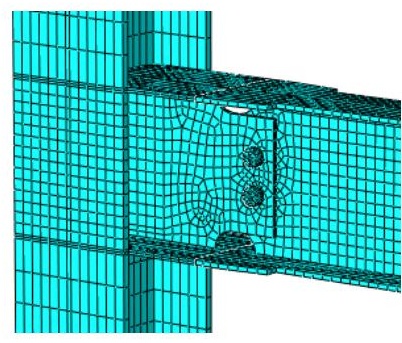

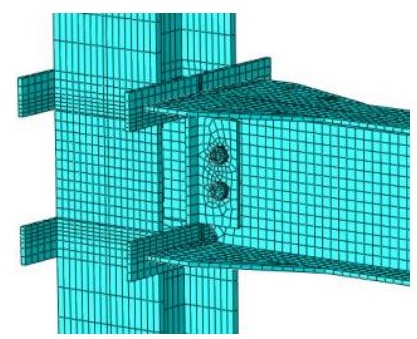

(b) developed connection
Fig. 8 Mesh partition of connection region

Table 1

Material properties

\begin{tabular}{ccccccc}
\hline Material & Yield & Yield & Ultimate & Ultimate & Failure & Failure \\
& stress & strain & stress & strain & stress & strain \\
& $\sigma_{\mathrm{y}} / \mathrm{MPa}$ & $\varepsilon_{\mathrm{y}} / \%$ & $\sigma_{\mathrm{u}} / \mathrm{MPa}$ & $\varepsilon_{\mathrm{u}} / \%$ & $\sigma_{\mathrm{st}} / \mathrm{MPa}$ & $\varepsilon_{\mathrm{st}} / \%$ \\
\hline Steel & 298.8 & 0.045 & 435.7 & 19.8 & 370.3 & 34.0 \\
Bolt & 940 & 0.024 & 1130 & 9.54 & 960 & 12.54 \\
\hline
\end{tabular}

3.2. Results comparison of the traditional connection and developed connection

The force-displacement hysteretic response comparison of the traditional weak-axis connection (TWAC) and developed weak-axis connection (DWAC) under cyclic loading was recorded in Fig. 10. As illustrated in Fig. 10, both the strength and the initial stiffness, determined by the inclination at the elastic stage, of the connection DWAC were slightly greater than those of the connection TWAC. The hysteretic curves of the two connections were stable and repetitive, and the gradual strength degradation was because of the beam buckling. One of the important indexes in evaluation of the seismic performance of beam-column moment connections is its energy dissipation capacity, and it could be measured through the area enclosed by the hysteretic curves. It is obvious that the connection DWAC dissipated more energy than the connection TWAC.

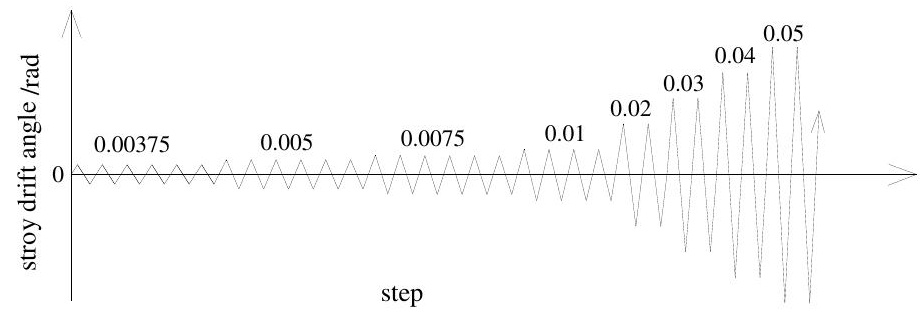

Fig. 9 Loading protocol

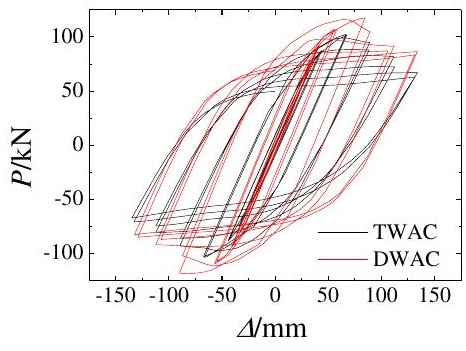

Fig. 10 Hysteretic loops comparison of specimens TWAC and DWAC

According to the requirement of AISC Seismic Provisions [18], beam-column connections of special moment frame shall be capable of accommodating a story drift angle of at least $0.04 \mathrm{rad}$. And thus $0.04 \mathrm{rad}$ story drift angle was chosen to elucidate the weak-axis connections response. Figs. 11 and 12 illustrate the Mises stress distribution and equivalent plastic strain (PEEQ) distribution comparison respectively. The stress distribution, strain demand in the beam flange welds indicated the likelihood of potential brittle fracture of the connection. Concentrated stresses and strains were noticed in the weld access holes region for connection TWAC, where the weld fractured in the experimental study [12]. While concentrated stresses and strains were noticed in the beam section at the tips of the widened flange plates for connection DWAC, indicating that the proposed connection details could move the plastic hinge away from the beam-column connection region, and thus protect the beam flange butt welds, and achieve a more reliable structural characteristics.

In summary, comparison results demonstrated that the developed connection details could improve the stiffness, bearing capacity, and energy dissipation ability of weak-axis connection, and also mitigate the stress concentration in the beam flange welds, thus diminishing the possibility of brittle fracture of beam flange welds.

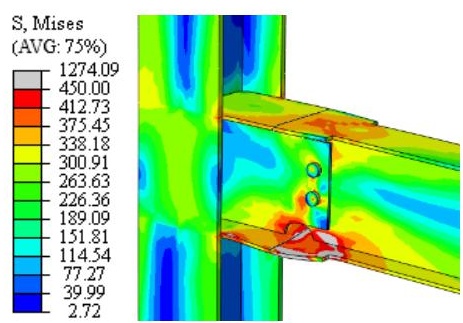

(a) connection TWAC

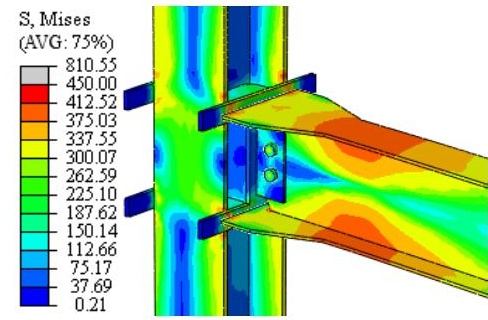

(b) connection DWAC

Fig. 11 Mises stresses distribution comparison of connections TWAC and DWAC

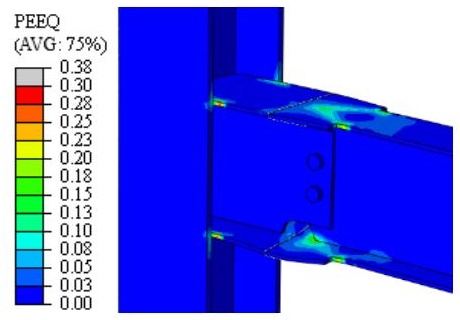

(a) connection TWAC

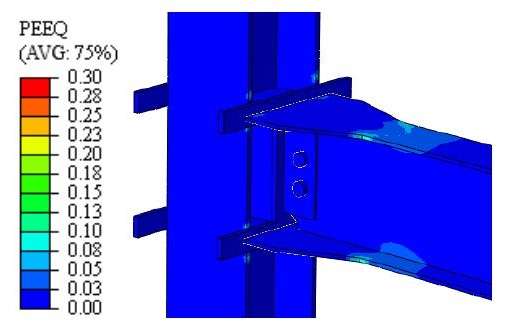

(b) connection DWAC

Fig. 12 Equivalent plastic strain distribution comparison of connections TWAC and DWAC

\subsection{Classification of beam-column weak-axis connections based on stiffness}

According to the regulations of Eurocode 3 [19], the steel frame beam-column joints can be classified by stiffness into three categories: rigid, semi-rigid and nominally pinned, as shown in Fig. 13. The abscissa $\theta$ denotes the rotation of a joint, and the ordinate $M$ denotes the moment of a joint at the center of a column. The joint rotation $\theta$ could be obtained through deducting the rotation of a column from the relative rotation of the top and bottom flange of the beam at the joint region [20]. Fig. 14 compares the $M-\theta$ hysteretic curves of specimens TWAC and DWAC. As evidenced in Fig. 14, the initial rotational stiffness $S_{\mathrm{j}, \text { ini }}$ of specimen DWAC was superior to the specimen TWAC, and was 35620 and $33768 \mathrm{kN} \cdot \mathrm{m} / \mathrm{rad}$ respectively. It is cleared that the 
area of the $M-\theta$ hysteretic loops of specimen TWAC was much larger than that of specimen DWAC, indicating that the specimen TWAC dissipated more energy through the joint rotation. This is attributed to that the specimen DWAC has stronger joint region than specimen TWAC, and the specimen DWAC mainly dissipated energy through the plastic hinge rotation on the beam section.

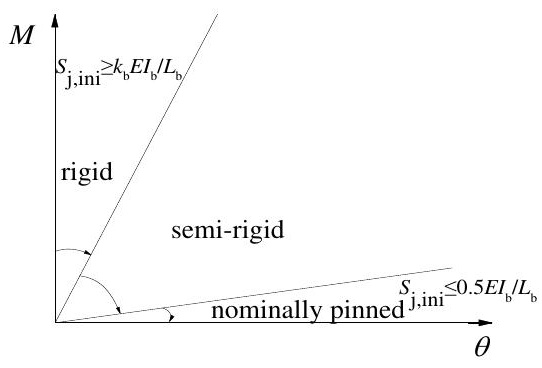

Fig. 13 Classification of beam-column joints by stiffness

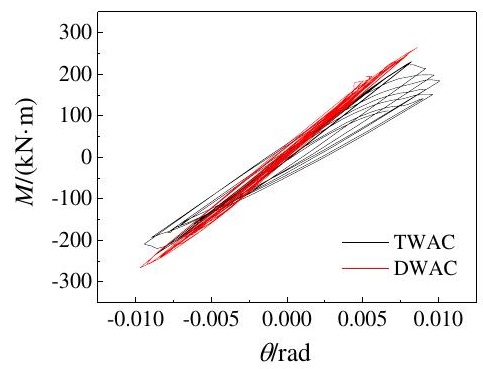

Fig. $14 M-\theta$ hysteretic curves comparison

When the initial rotational stiffness $S_{\mathrm{j}, \text { ini }}$ is larger than $k_{\mathrm{b}} E I_{\mathrm{b}} / L_{\mathrm{b}}$, joints can be classified as rigid, where $E$ represents the elastic modulus, $I_{\mathrm{b}}$ represents the second moment of area of a beam, $L_{\mathrm{b}}$ represents the span of a beam. And the parameter $k_{\mathrm{b}}$ is 8 for frames where the bracing system reduces the horizontal displacement by at least $80 \%$, and 25 for other frames. This reflects that the

Table 2

Model number and parameter values

\begin{tabular}{ccccccc}
\hline Model & $a / \mathrm{mm}$ & $b / \mathrm{mm}$ & $c / \mathrm{mm}$ & $t / \mathrm{mm}$ & $d / \mathrm{mm}$ & $e / \mathrm{mm}$ \\
\hline A50 & 50 & 50 & 75 & 14 & 100 & 100 \\
A75 & 75 & 50 & 75 & 14 & 100 & 100 \\
A100 & 100 & 50 & 75 & 14 & 100 & 100 \\
B50 & 100 & 50 & 75 & 14 & 100 & 100 \\
B75 & 100 & 75 & 75 & 14 & 100 & 100 \\
B100 & 100 & 100 & 75 & 14 & 100 & 100 \\
C50 & 100 & 75 & 50 & 14 & 100 & 100 \\
C75 & 100 & 75 & 75 & 14 & 100 & 100 \\
C100 & 100 & 75 & 100 & 14 & 100 & 100 \\
T10 & 100 & 75 & 75 & 10 & 100 & 100 \\
\hline
\end{tabular}

To evaluate the local stress concentration, strain demand, as well as the potential for welds cracking, the hysteretic response of the developed weak-axis connection is presented in terms of the Mises index (MI), triaxiality index (TI) and rupture index (RI), which have been used by other researchers [22-23], to reflect the equivalent stress, the triaxial state of stress, and the possibility of fracture at beam flange welds respectively. Based on the report of El-Tawil et al. [22], the fracture strain of the steel material decreases when the value of TI is between -0.75 and -1.5 , and the steel material is prone to brittle fracture when the value of $\mathrm{TI}$ is less than -1.5 . It is more vulnerable to fracture at the beam bottom flange when the flange welds were pulled, and thus the MI, TI and RI distributions at the beam bottom flange welds at the story drift angle -0.04 rad were selected.

\subsection{Influence of parameters $a$ and $b$}

requirement for rigid joints in weak-support or unsupported frame is stricter. Through comparing the results to the formula in Fig. 13, this two weak-axis connections can be classified as rigid in a strong-bracing system, and be classified as semi-rigid in weak-supported or unsupported system.

\section{Parametric analysis of the developed weak-axis connection}

In order to gain more insight into the mechanical behavior of the proposed weak-axis connection, the influence of geometrical variables of the I-shaped steel plate, widened flange plate on the cyclic behavior was analyzed, and different emphases are adopted for each series. Fig. 15 depicted the dimension parameters of $a, b, c, t, d$, and $e$, and Table 2 summarizes the model number and parameter values. For the series A, the variable $a$ was the distance between the column flange edge and the I-shaped steel plate edge, and obviously the dimension $2 a+h_{\mathrm{c}}$ corresponds to the width of the I-shaped steel plate. For the series $\mathrm{B}$, the variable $b$ was the height of flange plate of the I-shaped steel plate. For the series $\mathrm{C}$, the variable $c$ was the width of web plate of the I-shaped steel plate. For the convenience of welding between the vertical stiffener and the column web, the variable $c$ should not be too wide. For the series T, the variable $t$ was the thickness of the I-shaped steel plate. For the series $\mathrm{D}$, the variable $d$ was the width of the widened flange plate. For the series $\mathrm{E}$, the variable $e$ was the length of the short side of the widened flange plate. In order to realize the smooth transition of the seam section, the ratio of the right side was 1:2.5 based on the Code for seismic design of buildings (GB 50011-2010) [21], thus reducing the stress concentration. As described above, the thickness of widened flange plate was the same as the beam flange. The created models in the parametric analysis changed one parameter at a time while the other conditions are kept the same for the sake of comparison.

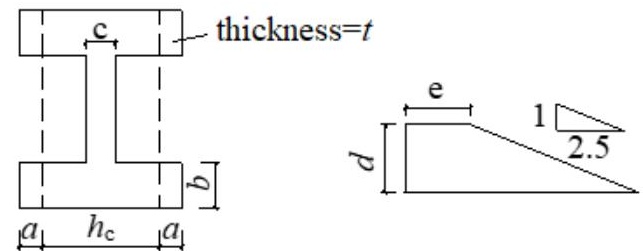

(a) I-shaped steel plate

(b) widened flange plate

Fig. 15 Dimension parameters in the developed weak-axis connection

\begin{tabular}{ccccccc}
\hline Model & $a / \mathrm{mm}$ & $b / \mathrm{mm}$ & $c / \mathrm{mm}$ & $t / \mathrm{mm}$ & $d / \mathrm{mm}$ & $e / \mathrm{mm}$ \\
\hline T12 & 100 & 75 & 75 & 12 & 100 & 100 \\
T14 & 100 & 75 & 75 & 14 & 100 & 100 \\
T16 & 100 & 75 & 75 & 16 & 100 & 100 \\
T18 & 100 & 75 & 75 & 18 & 100 & 100 \\
D50 & 100 & 75 & 75 & 14 & 50 & 100 \\
D75 & 100 & 75 & 75 & 14 & 75 & 100 \\
D100 & 100 & 75 & 50 & 14 & 100 & 100 \\
E50 & 100 & 75 & 75 & 14 & 100 & 50 \\
E75 & 100 & 75 & 75 & 14 & 100 & 75 \\
E100 & 100 & 75 & 75 & 14 & 100 & 100 \\
\hline
\end{tabular}

Figs. 16 and 17 plots the hysteretic loops of the beam tip load versus beam tip displacement relationship to elucidate the cyclic behavior of series A and B connections respectively. It is observed from Figs. 16 and 17 that the curves almost coincided with each other, indicating that the parameter $a$ and $b$ slightly affect the connection behavior. And the plastic hinge could all develop in the beam section at the tips of the widened flange plates.

Then the MI, TI and RI distributions at the beam bottom flange welds were compared as recorded in Figs.18 and 19 for series A and B connections respectively. As evidenced from Figs. 18 and 19, the maximum value of MI, TI and RI indexes was not at the tips of beam flange welds, which was not consistent with the distribution showed in Fig. 1b, and thus moving the highest stresses away from the start-stop points of a weld, and reducing the potential of the fracture of beam flange welds. This is attributed to the fact that the widened flange plates are able to extend out of the column flanges in the developed weak-axis connection. In comparing these connections, there were 
no dramatic differences in MI, TI and RI distributions. The maximum value of MI was less than 1.3, indicating no obvious stress concentration at beam flange welds. The distributions of MI, TI and RI were not completely symmetric, which was due to the bucking deformation of beam flanges.

It can be observed from Fig. 18 that the minimum value of TI was not less than -0.8 , indicating that it is less likely to trigger brittle fracture. While Fig. 19 shows clearly that as the parameter $b$ increased, the TI and RI values decreased.
Lower TI value could cause the reduction in the steel material rupture strain, while larger RI value could increase the potential of weld fracture. That is, too large or too small value for parameter $b$ has its negative effects. And too large value for parameter $b$ is unfavorable for welding the I-shaped plates to the $\mathrm{H}$-section column. Parameter $b=75 \mathrm{~mm}$, corresponding to $b_{\mathrm{f}} / 2$, was recommended, where $b_{\mathrm{f}}$ represents the width of the beam flange.

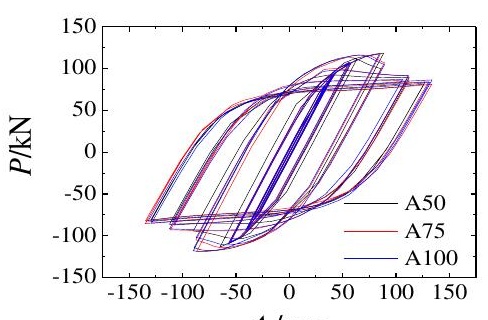

$\Delta / \mathrm{mm}$

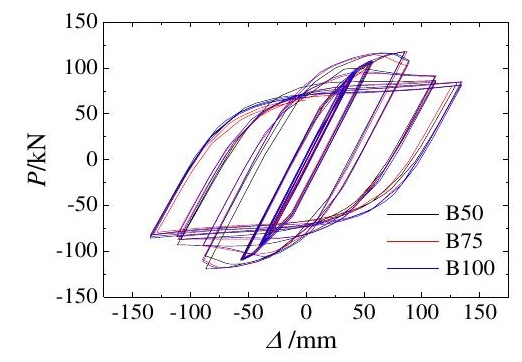

Fig. 17 Hysteretic loops of series B connections

Fig. 16 Hysteretic loops of series A connections

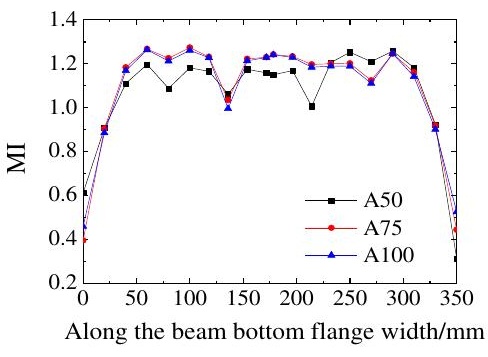

(a) MI distribution

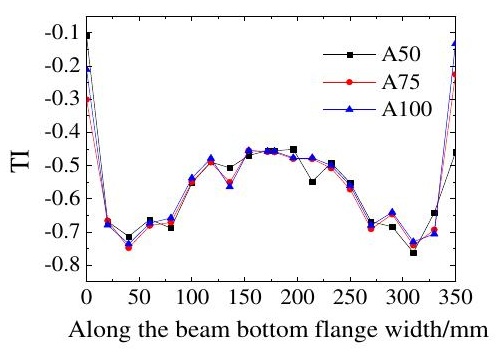

(b) TI distribution

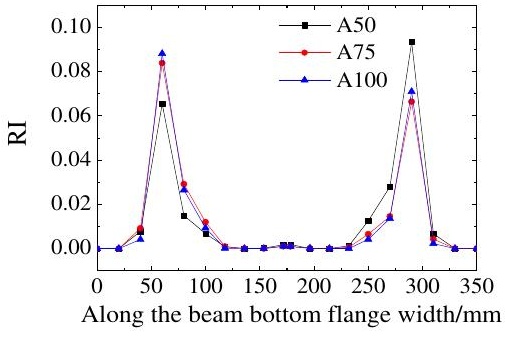

(c) RI distribution

Fig. 18 Three indexes distribution of beam bottom flange weld for series A connections

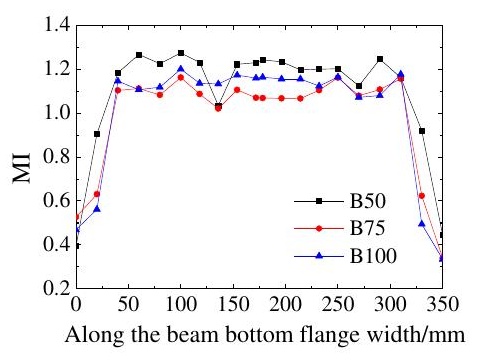

(a) MI distribution

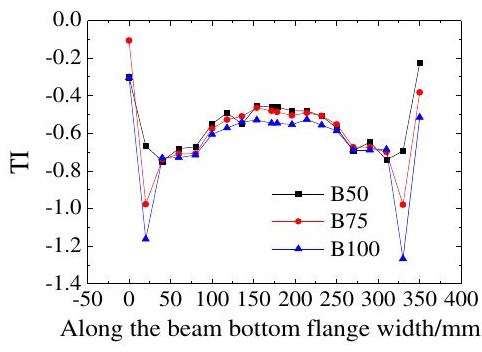

(b) TI distribution

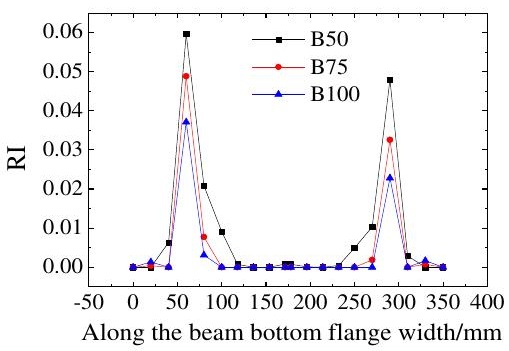

(c) RI distribution

Fig. 19 Three indexes distribution of beam bottom flange weld for series B connections

As presented by the FEM, the hysteretic loops, MI, TI, and RI distributions are not very sensitive to the changes in parameter $a$, thus it is only necessary to extend the I-shaped connection plate out of the column flange surface a certain distance. The value of parameter $a$ could be adjusted according to the parameter $d$.

\subsection{Influence of parameter $c$ and $t$}

Figs. 20 and 21 show the hysteretic loops recorded at the beam end for

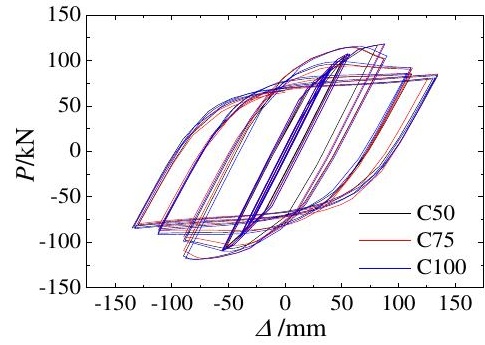

Fig. 20 Hysteretic loops of series $\mathrm{C}$ connections series $\mathrm{C}$ and $\mathrm{T}$ connections respectively, As the increase of parameter $c$ and $t$, the bearing capacity increased slightly.

Fig. 22 compares the MI, TI and RI distribution at the beam bottom flange welds for series $\mathrm{C}$ connections. The $\mathrm{MI}$ is basically minimal for specimen $\mathrm{C} 75$, and little deviation was observed in the TI and RI distributions. The values of MI, TI and RI are acceptable for the weak-axis connection due to highest plastic equivalent strain appeared a certain distance away from the beam-column interface (see Fig. 12b).

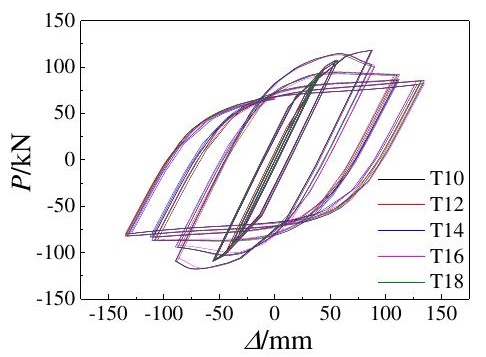

Fig. 21 Hysteretic loops of series T connections 


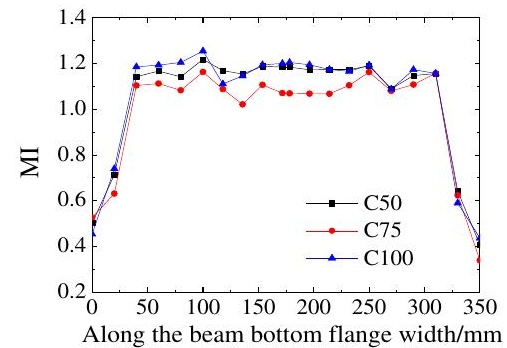

(a) MI distribution

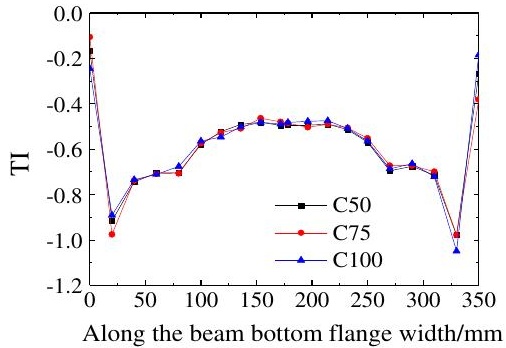

(b) TI distribution

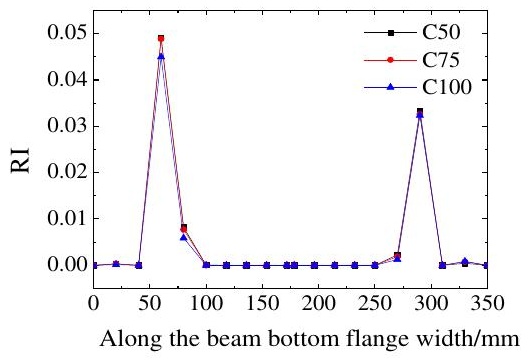

(c) RI distribution

Fig. 22 Three indexes distribution of beam bottom flange weld for series $\mathrm{C}$ connections

Fig. 23 depicts the $\sigma_{\text {Mises }}$, Mises stress, and $\sigma_{\mathrm{s} 11}, \mathrm{X}$-axial stress, which is the stress along the thickness of the I-shaped steel plate, distribution at beam flange welds for series $\mathrm{T}$ connections. As we can see, $\sigma_{\mathrm{Mises}}$ and $\sigma_{\mathrm{S} 11}$ distribution of the I-shaped steel plate was consistent for the location at the beam top and bottom flange welds. At the column flange edges, there was the maximum $\sigma_{\text {Mises }}$ and $\sigma_{\mathrm{S} 11}$ stresses, consistent with the Fig. $1 \mathrm{~b}$. As the widened flange plate could extend out of the column flanges in the novel weak-axis connection from, the weld edge had minor $\sigma_{\text {Mises }}$ and $\sigma_{\mathrm{S} 11}$ stresses, which was beneficial to reduce the fracture potential of the beam flange welds. As evidenced from Fig. 23, the maximum stress along the thickness of the I-plate $\sigma_{\mathrm{S} 11}$ was more than $200 \mathrm{MPa}$, thus the anti-lamellar tearing steel plate was recommended for the I-plate to prevent lamellar tearing which was occurred in our previous experimental study [17]. The stresses of $\sigma_{\mathrm{Mises}}$ and $\sigma_{\mathrm{S} 11}$ are almost the same at the centerline of the I-plate width, indicating that there was only the $\mathrm{X}$-axial stress along the thickness of the I-plate and the stresses in the other two directions are negligible. The trend suggests that the thicker the I-plate, the smaller the maximum stresses at the beam flange groove welds. Hence, the parameter $t$ can be taken as slightly greater than the thickness of the column flange.

\subsection{Influence of parameter $d$ and $e$}

Figs. 24 and 25 show the hysteretic curves of series D and E connections respectively. Fig. 24 indicates that a larger parameter $d$ can increase the initial stiffness and also the bearing capacity. Fig. 25 demonstrates that as parameter $e$ increased, the bearing capacity increased slightly.

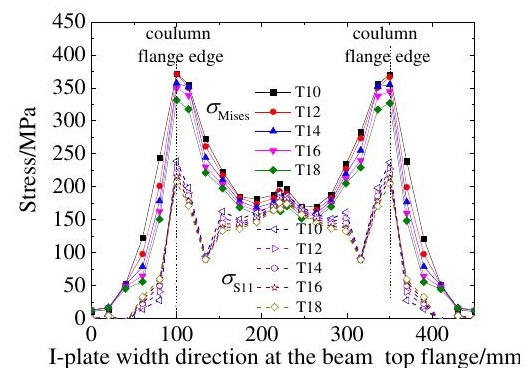

(a) At the beam top flange

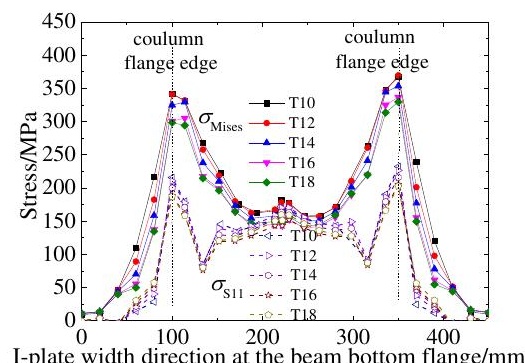

(b) At the beam bottom flange

Fig. 23 Mises stress and X-axial stress distribution of I-plate at beam flange welds for

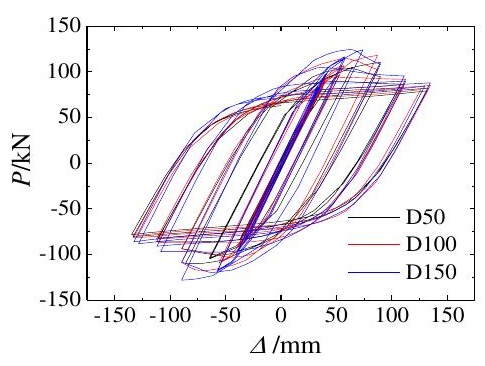

Fig. 24 Hysteretic loops of series D connections

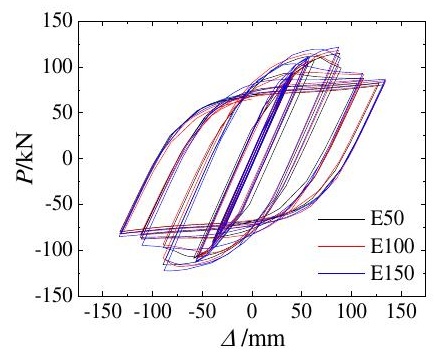

Fig. 25 Hysteretic loops of series E connections

The MI, TI and RI distribution comparison at beam bottom flange welds for series D connections is included in Fig. 26. It can be seen that the variation of parameter $d$ has significant effect on the local stress and strain demand. With the increase of parameter $d$, the length of beam flange welds increases. Due to the aligned edge of widened flange plate and column flange, the most dangerous was at the tips of flange welds for connection D50, similar to Fig. 1b. For connection D100 and D150, the widened flange plate extended 50 and $100 \mathrm{~mm}$ respectively out of the column flange, the connection can move the highest stresses away from the start-stop points of a weld. On the other hand, excessive extension of the widened flange plate could not further reduce the stress and strain concentration in the beam flange welds. And thus the widened flange plate extended $50 \mathrm{~mm}$ out of the column flange was recommended in the developed weak-axis connection.

Fig. 27 depicts the MI, TI and RI distributions at beam bottom flange welds for series E connections. These figures demonstrate that different values of $e$ had relatively small influence on the MI, TI and RI distributions.

Equivalent plastic strain distribution comparison of series $\mathrm{E}$ connections and traditional weak-axis connection (TWAC) at the end of 0.06 rad story drift angle loading is summarized in Fig. 28. As observed that extensive local buckling took place in the beam flanges and web at the tips of the widened flange plates for series $\mathrm{E}$ connections, indicating the plastic hinge shifted away from the beam-column interface, while the plastic hinge connection TWAC formed at the region of weld access holes, which was more vulnerable to fracture. As the parameter $e$ increased, the plastic hinge was further away from the beam-column interface. Based on numerical results, the value of parameter $e$ can be set to $100 \mathrm{~mm}$. 

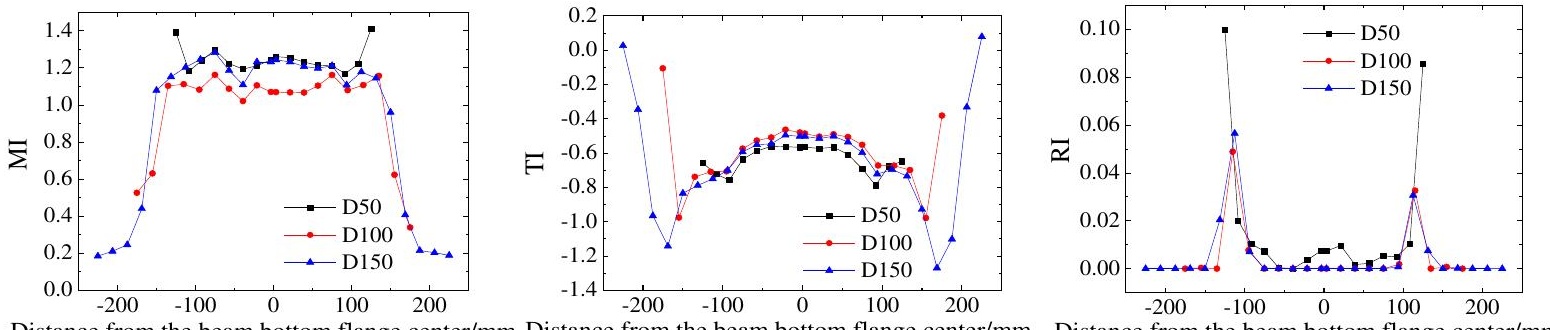

Distance from the beam bottom flange center/mm Distance from the beam bottom flang

(a) MI distribution

(b) TI distribution

(c) RI distribution

Fig. 26 Three indexes distribution of beam bottom flange weld for series D connections

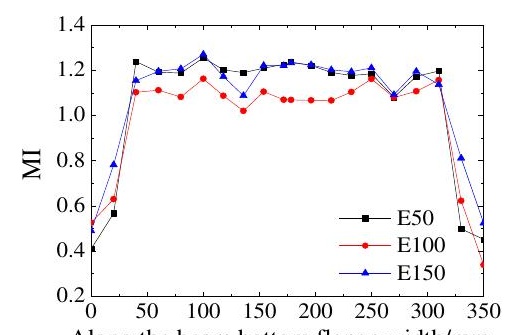

Along the beam bottom flange width $/ \mathrm{mm}$

(a) MI distribution

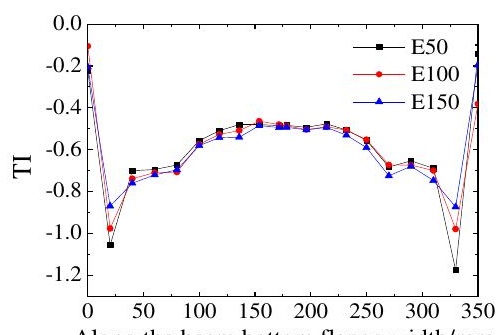

Along the beam bottom flange width $/ \mathrm{mm}$

(b) TI distribution

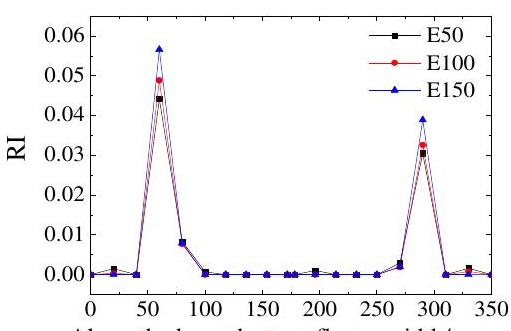

Along the beam bottom flange width/mm

(c) RI distribution

Fig. 27 Three indexes distribution of beam bottom flange weld for series E connections

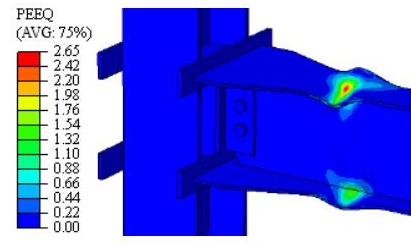

(a) connection E50

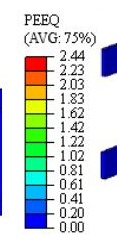

(b) connection E100

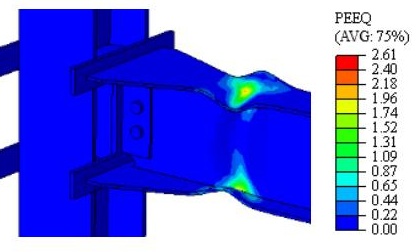

(c) connection E150
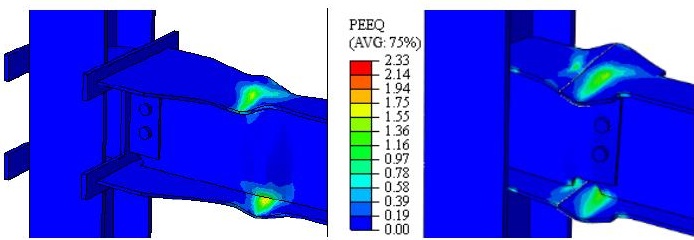

(d) connection TWAC

Fig. 28 Equivalent plastic strain distribution comparison of series E connections and traditional connection

A parametric analysis was conducted to investigate the influence of I-shaped steel plate and widened flange plate dimension variables on the developed weak-axis connection behavior. From the above discussion, it is suggested that the value of parameters $b$ and $c$ can be set to $75 \mathrm{~mm}$ (about $b_{\mathrm{f}} / 2$ ). And the value of parameters $d$ and $e=100 \mathrm{~mm}$ is reasonable for use in the adopted connection details and sizes of beam and column. That is, it is judged that extending the widened flange plate $50 \mathrm{~mm}$ out of the column flange is enough to move the highest stresses away from the start-stop points of a weld and thus avoiding brittle failure of the beam bottom flange groove welds. The widened flange plate extended $50 \mathrm{~mm}$ out of the column flange was recommended, and thus the parameter $a$ can be set to $50 \mathrm{~mm}$ or slightly larger. The parameter $t$ can be taken as slightly greater than the thickness of the column flange.

\section{Design procedures of the developed weak-axis connections}

\subsection{Design procedures}

Based on the results of FEM, design procedures for the developed weak-axis moment connections was proposed.

First, for designed steel beam and column section, the horizontal stiffeners and vertical stiffeners of I-shaped plates (see Fig. 2b) can be determined with the thickness slightly greater than the beam flange and beam web respectively.

Second, the anti-lamellar tearing steel plate can be used for the I-shaped steel plate with the thickness slightly greater than the thickness of the column flange. The distance between the column flange edge and the I-shaped steel plate edge $a$ can be set to $50 \mathrm{~mm}$ or slightly larger, and thus the width of the I-shaped steel plate can be set to $h_{\mathrm{c}}+2 a$, where $h_{\mathrm{c}}$ represents the height of the column section. The height of flange plate of the I-shaped steel plate $b$, and the width of web plate of the I-shaped steel plate $c$ can be set to $b_{\mathrm{f}} / 2$, where $b_{\mathrm{f}}$ represents the width of the beam flange.

Then, it is reasonable to extend the widened flange plate $50 \mathrm{~mm}$ out of the column flange for design purposes, and thus the width $d$ of the widened flange plate can be set to $\left[\left(h_{\mathrm{c}}-b_{\mathrm{f}}\right) / 2+50\right] \mathrm{mm}$. The length $e$ of the short side of the widened flange plate can be set to $100 \mathrm{~mm}$, and then the ratio of the right side can be set to $1: 2.5$ to realize the smooth transition of the beam section. And thus the length of the long side of the widened flange plate is $e+2.5\left[\left(h_{\mathrm{c}}-b_{\mathrm{f}}\right) / 2+50\right]$.

To ensure that the designed weak-axis connections can meet the seismic design requirement of "strong joint and weak member", and move the plastic hinge away from the beam-column interface, the following checking calculation need to be conducted.

1) Determine the maximum plastic moment $M_{\mathrm{pr}}$ of steel beam at the location of the expected plastic hinge:

$$
M_{\mathrm{pr}}=C_{\mathrm{pr}} Z_{\mathrm{b}} R_{\mathrm{y}} F_{\mathrm{y}}
$$

Where, $C_{\mathrm{pr}}$ is the enhancement coefficient considering strain strengthening, local constraints, etc, and can be set to 1.15 for China's steel products [24]; $Z_{\mathrm{b}}$ represents the plastic section modulus of the beam section; $R_{\mathrm{y}}$ is a multiplier accounting for expected material overstrength, and can be set to 1.1 for China's steel products [24]; $F_{\mathrm{y}}$ represents the nominal yield strength.

2) Calculate the moment demand at the beam-column interface according to the bending moment distribution gradient on the beam:

$$
M_{\mathrm{dem}, \mathrm{j}}=\frac{L_{\mathrm{b}}}{L_{\mathrm{b}}-L_{\mathrm{p}}} M_{\mathrm{pr}}
$$

Where, $L_{\mathrm{b}}$ and $L_{\mathrm{p}}$ is the distance from the beam span center to the beam end and the distance from the plastic hinge center to the beam end. And the $L_{\mathrm{p}}$ can be set to the length of the widened flange plate plus $1 / 4 h_{\mathrm{b}}$ [110], where $h_{\mathrm{b}}$ represents the height of the beam section.

3) Determine the design flexural capacity $M_{\text {cap,j }}$ at the beam-to-column 
interface:

$$
M_{\text {cap }, \mathrm{j}}=\alpha M_{\mathrm{dem}, \mathrm{j}}
$$

Where, parameter $\alpha$ is a multiplier and can be set to 1.1 based on the recommendation of Chen et al. [25].

4) Check the beam end reinforcement section based on the design flexural capacity $M_{\text {cap.j }}$

$$
M_{\text {cap }, \mathrm{j}} \leq C_{\mathrm{pr}} Z_{\mathrm{b}}{ }^{\prime} R_{\mathrm{y}} F_{\mathrm{y}}
$$

Where, $Z_{\mathrm{b}}$ 'represents the plastic section modulus of the steel beam section and the widened flange plates section at the beam-to-column interface.

If the results doesn't meet the formula (4), the parameters of the widened flange plates need to be further adjusted. Meanwhile, as the widened flange plates are adopted, it is necessary to check the requirement of "strong column and weak beam" based on GB 50011-2010 [21].

\subsection{Numerical example}

To verify the applicability of the proposed dimensions to other beam and column sections, a developed beam-column weak-axis connections DWAC-2 with different beam-column sections were modelled and analyzed through FEM. The beam section HN $350 \times 175 \times 7 \times 11$ and column section HW $300 \times 300 \times 10 \times 12$ were taken from test specimens in our previous study [26]. Based on the results of FEM, the parameter $a=50 \mathrm{~mm}, b=c=b_{\mathrm{f}} / 2$, $d=\left(h_{\mathrm{c}}-b_{\mathrm{f}}\right) / 2+50$, and $e=100 \mathrm{~mm}$ was adopted for connection DWAC- 2 . The modeling methods and loading system were exactly the same as described above

Fig.29 shows the load-displacement hysteretic curves and also the Equivalent plastic strain (PEEQ) distribution of the joint region at the story drift angle of $0.04 \mathrm{rad}$. We can observe that the load-displacement hysteretic curves of connection DWAC-2 were stable and repetitive, and the gradual strength degradation was due to the beam buckling at the end of widened flange plates. Plastic strain was basically concentrated at the beam section away from the beam-column interface, indicating that the recommended dimensions of I-shaped plates were also applicable to DWAC-2 with different beam-column sections.

\section{Conclusions}

In this paper, a parametric study was conducted to verify the cyclic behavior of the proposed weak-axis connections using an innovative solution to enhance the beam-column connection. The following conclusions can be drawn on the basis of the finite element analysis results

1) A good correlation between the test and FEM is obtained.

2) The proposed weak-axis connections could move the highest stresses away from the start-stop points of a weld, and then shift the plastic hinge away from the beam-column interface to prevent premature brittle flange weld failure, while the local buckling occurred in the weld access holes region in the traditional weak-axis connection.

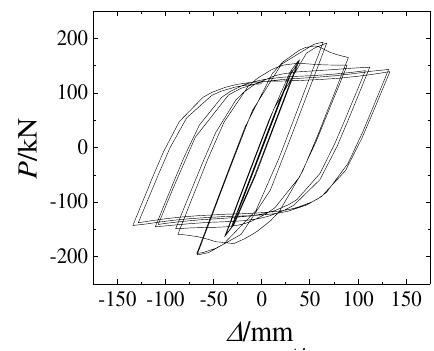

(a) Load-displacement hysteretic curves
PEEQ

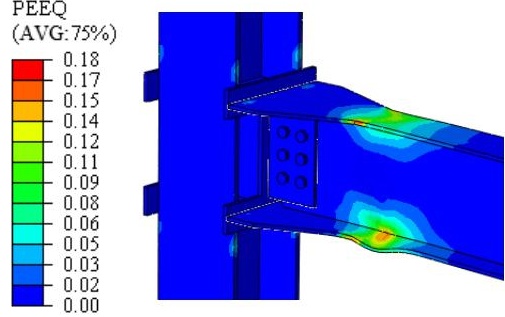

(b) Equivalent plastic strain distribution

Fig. 29 Hysteresis performance of connection DWAC-2

3) The developed weak-axis connections can be classified as rigid in a strong-bracing system, and be classified as semi-rigid in weak-supported or unsupported system.

4) As there is greater stress in the thickness direction of the I-shaped steel plate, the anti-lamellar tearing steel plate is recommended for the I-shaped steel plate. The parameter $t$ can be taken as slightly greater than the thickness of the column flange.

5) The hysteretic loops, the MI, TI and RI distributions are not very sensitive to the changes of parameter $a, b, c$, and $e$. It is suggested that the value of parameters $b, c$ and $e$ can be set to $b_{\mathrm{f}} / 2, b_{\mathrm{f}} / 2$ and $100 \mathrm{~mm}$ respectively, where $b_{\mathrm{f}}$ represents the width of the beam flange. With the increase of parameter $d$, the greater the bearing capacity of connections, and also the greater the distance between the start-stop points of welds and the peek stresses, which could reduce the premature brittle failure of flange welds. Extending the widened flange plate $50 \mathrm{~mm}$ out of the column flange is recommended in the developed weak-axis connection, and thus the parameter $a$ can be set to $50 \mathrm{~mm}$ or slightly larger.

6) The parametric study presented in this paper provides a first insight into the hysteretic responses of the developed weak-axis connection with I-shaped plates. More experimental investigation is required to fully assess this behavior.

\section{Acknowledgements}

The authors would like to thank the financial support provided by Basic Research Plan Project of Natural Science of Shaanxi Province (2019JQ-272) and the Special Scientific Research Plan Project of Education Department of Shaanxi (19JK0481) for the financial support.

\section{References}

[1] T. Kim, A.S. Whittaker, A.S.J. Gilani, et al., Cover-plate and flange-plate steel moment-resisting connections, J. Struct. Eng. ASCE 128 (2002) 474-482.

[2] C.H. Lee, J.H. Jung, M.H. Oh, et al., Cyclic seismic testing of steel moment connections reinforced with welded straight haunch, Eng. Struct. 25 (2003) 1743-1753.

[3] C.C. Chen, C.C. Lin, Seismic performance of steel beam-to-column moment connections with tapered beam flanges, Eng. Struct. 48 (2013) 588-601.

[4] X. Chen, G. Shi, Experimental study on seismic behavior of cover-plate joints in high strength steel frames, Eng. Struct. 191 (2019) 292-310.

[5] J. Jin, S. EI-Taxil, Seismic performance of steel frames with reduced beam section connections, J. Constr. Steel Res. 61 (2005) 453-471.

[6] S.L. Jones, G.T. Fry, M.D. Engelhardt, Experimental evaluation of cyclically loaded reduced beam section moment connections, J. Struct. Eng. ASCE 128 (2002) 441-451.

[7] D.T. Pachoumis, E.G. Galoussis, C.N. Kalfas, et al., Cyclic performance of steel moment-resisting connections with reduced beam sections-experimental analysis and finite element model simulation, Eng. Struct. 32 (2010) 2683-23102.

[8] S. Momenzadeh, M.T. Kazemi, M.H. Asl, Seismic performance of reduced web section moment connections, Int. J. Steel Struct. 17 (2017) 413-425.

[9] C.S. Gilton, C.M. Uang, Cyclic response and design recommendations of weak-axis reduced beam section moment connections, J. Struct. Eng. ASCE 128 (2002) 452-463.

[10] FEMA-355D State of the art report on connection performance, Federal Emergency Management Agency, Washington, DC, 2000.

[11] B.S. Guo, Hysteretic behavior and design criterion of beam-to-column web connections in steel moment frames under cyclic load, Xi'an University of Architecture \& Technology, Xi'an, 2004. (in Chinese)

[12] Y.S. Yu, J. Wang, W.P. Huang, et al., Experimental study on the failure mode of reduced beam section connections of the bolted-welded connection of steel frame beam-column about minor axis, Building Structure, 44 (2014) 30-33. (in Chinese)

[13] K. Oh, K. Lee, L. Chen, et al., Seismic performance evaluation of weak-axis column-tree moment connections with reduced beam section, J. Constr. Steel Res. 105 (2015) 28-38.

[14] S.D. Kim, S.S. Kim, Y.K. Ju, Strength evaluation of beam-column connection in the weak axis of H-shaped column, Eng. Struct. 30 (2008) 1699-1710.

[15] W.L. Li, J.P. Hao, L.K. Wang, et al., Experimental and analytical study on stiffness of beam-to-column minor axis top-and seat angle connection in steel frames, Journal of Building Structures, 29 (2008) 125-131.

[16] Z. Wang, T. Wang, Experimental and finite element analysis for the end plate minor axis connection of semi-rigid steel frames, China Civil Engineering Journal, 45 (2012) 83-89.

[17] L.F. Lu, Y.L. Xu, H. Zheng. Investigation of composite action on seismic performance of weak-axis column bending connections, J. Constr. Steel Res. 129 (2017) 286-300 
[18] ANSI/AISC 341-10 Seismic provisions for structural steel buildings, AISC, Chicago, 2010 [19] Eurocode 3 Design of steel Structures Part 1-8: Design of joints, London, 2003.

[20] G. Shi, F. Yuan, D. Huo, et al., The theoretical model and measuring calculation method of the beam-to-column joint rotation in steel frame, Engineering Mechanics, 29 (2012) 52-60. (in Chinese)

[21] GB 50011-2010 Code for seismic design of buildings, China Architecture \& Building Press, Beijing, 2010. (in Chinese)

[22] S. El-Tawil, T. Mikesell, E. Vidarsson, et al., Strength and ductility of FR welded-bolted connection, SAC Rep. No. 108-01, SAC Joint Venture, Sacramento, Calif, 1998.
[23] F. Hu, G. Shi, B. Yu, et al., Seismic performance of prefabricated steel beam-to-column connections, J. Constr. Steel Res. 102 (2014) 204-216.

[24] Y.Y. Cai, Beam-column connection design of steel frame considering shift away of plastic hinge, Building Structure, 34 (2004) 3-10. (in Chinese)

[25] C.C. Chen, C.A. Lu, C.C. Lin, Parametric study and design of rib-reinforced steel moment connections, Eng. Struct. 27 (2005) 699-708.

[26] L.F. Lu, Y.L. Xu, T.H. Zhou, et al., Experimental research on box strengthened joint connection for weak axis of I-section column-H-shaped beam, Journal of Building Structures, 37 (2016) 73-80. 


\title{
FINITE ELEMENT ANALYSIS OF UNFASTENED COLD-FORMED STEEL CHANNEL SECTIONS WITH WEB HOLES UNDER END-TWO-FLANGE LOADING AT ELEVATED TEMPERATURES
}

\author{
Ankur Kumar ${ }^{1}$, Krishanu Roy ${ }^{2,}$, Asraf Uzzaman ${ }^{3}$ and James B.P. Lim ${ }^{2}$ \\ Department of Mechanical Engineering, Indian Institute of Technology Delhi, India \\ ${ }^{2}$ Department of Civil and Environmental Engineering, The University of Auckland, New Zealand \\ ${ }^{3}$ School of Computing, Engineering and Physical Sciences, University of the West of Scotland, Paisley, PA1 2BE, United Kingdom \\ * (Corresponding author: E-mail: kroy405@aucklanduni.ac.nz)
}

\section{A B S T R A C T}

This paper presents the results of a finite element investigation on cold-formed steel (CFS) channel sections with circular web holes under end-two-flange (ETF) loading condition and subjected to elevated temperatures. The stress strain curve for G250 CFS with $1.95 \mathrm{~mm}$ thickness at elevated temperatures was taken from Kankanamge and Mahendran and the temperatures were considered up to $700 \mathrm{oC}$. To analyse the effect of web hole size and bearing length on the strength of such sections at elevated temperatures, a parametric study involving a total of $288 \mathrm{FE}$ models was performed. The parametric study results were then used to assess the applicability of the strength reduction factor equation presented by Uzzaman et al. for CFS channel-sections with web holes under ETF loading from ambient temperature to elevated temperatures. It is shown that the reduction factor equation is safe and reliable at elevated temperatures.

\section{A R T I CLE H IS T O RY}

\begin{tabular}{ll}
\hline & \\
Received: & 30 June 2020 \\
Revised: & 9 February 2021 \\
Accepted: & 28 February 2021
\end{tabular}

\section{K E Y W O D S}

\section{Cold-formed steel;}

Channel sections;

End-two-flange;

Web crippling;

Finite element analysis

Elevated temperatures;

Web holes

\section{Introduction}

Cold-formed steel (CFS) sections are used increasingly in commercial and residential buildings because of its superior strength to weight ratio, and ease of installation [1-4]. These sections usually have web holes for installation of electrical and plumbing services.

Web crippling is a well-known problem associated with these CFS sections, particularly when these sections are subjected to concentrated load near the web holes. This problem is exacerbated when such sections are subjected to elevated temperatures.

Significant information is available in the literature for design guidance of $\mathrm{CFS}$ channel-sections, to be referred to as $\mathrm{C}$ sections, at ambient temperature under web crippling [5-10]. However, limited research is available on the web crippling capacity of such perforated CFS channel sections subject to concentrated load near the holes and under elevated temperatures. This lack of design information for $\mathrm{C}$-sections at elevated temperatures makes it difficult for practising engineers and researchers to predict the web crippling capacity of Csections under elevated temperatures.

Recently published research studies have focussed on the material behaviour of CFS sections at elevated temperatures. Imran et al. [11] recently proposed a set of equations to evaluate the mechanical property reduction factors for square, rectangular and circular CFS hollow sections at elevated temperatures. Coupons were cut from such hollow sections with temperatures ranging from $20^{\circ} \mathrm{C}$ to $800^{\circ} \mathrm{C}$ under steady state condition. The aim was to determine the reduction in material properties. Kankanamge and Mahendran [12] also proposed equations to predict the material property reduction factors and the stress-strain relationship of low and high strength steel (different grades and thicknesses) at elevated temperatures. A similar study was then reported by Ranawaka and Mahendran [13], who proposed empirical equations in order to determine the stress-strain relationship of both the high and low strength steels at elevated temperatures. Furthermore, Chen and Young [14] reported data for mechanical properties of G550 and G450 grades of CFS sections under both the steady and transient temperature conditions. Lim and Young [15] used the stress-strain relationships determined from the equations of Chen and Young [14] and investigated the behaviour of CFS bolted connections at elevated temperatures.

Alongside understanding the change in mechanical properties of CFS sections at elevated temperatures, researchers are also focussing on understanding the structural behaviour of different CFS sections at elevated temperatures. A number of investigations have been carried out to determine the effect of elevated temperatures on CFS beams. Landesmann and Camotim [16] presented a FE investigation on the distortional buckling behaviour of CFS C-sections under elevated temperatures. Laim et al. [17] studied the structural behaviour of $\mathrm{C}$-sections loaded under elevated temperatures. Kankanamge and Mahendran [18] presented a study using a validated FE model to determine the structural behaviour of CFS lipped C-sections under bending at elevated temperatures.

A number of studies have also been reported in the literature which investigated the behaviour of CFS columns at elevated temperatures. Gunalan et al. [19] studied the local buckling behaviour of CFS lipped and unlipped Csections under simulated fire loadings. Gunalan et al. [19] also presented a study on flexural-torsional buckling capacity of CFS lipped C-sections at ambient and elevated temperatures. Ranawaka and Mahendran [20] presented a study to determine the distortional buckling strength of CFS lipped C-sections at elevated temperatures. Chen and Young [14] conducted a numerical study to understand the behaviour of CFS lipped C-sections at elevated temperatures. Feng and Wang [21] presented a study to evaluate the axial strength of CFS Csections under ambient and elevated temperatures.

It is to be noted that most of the research studies available in the literature focussed on the behaviour of CFS sections under compression and torsional loadings and not even a single research is available in the literature which investigated the effects of web holes on the web crippling strength of CFS Csections under ETF loading conditions and at elevated temperatures. Furthermore, the current design specifications such as ASCE [22], EC3 [23] and BS5950 [24] do not provide any guidelines for CFS C-sections with web holes at elevated temperatures under web crippling. The issue is addressed in this paper.

Fig. 1 shows the definition of symbols used for the dimensions of the Csections considered in this study. AS/NZ:4600 [25] offers reduction factor equations for C-sections with web holes. However, these equations focus on Csections with web holes offset to the bearing edge and applicable only at normal temperature.

The main objective of this study is to determine the feasibility of the design equations proposed in the literature for CFS C-sections with web holes at ambient temperature to be used at elevated temperatures. The strength reduction factor proposed by Uzzaman et al. [26] for determining the web crippling capacity of unfastened CFS C-sections with centred web holes under ETF loading at ambient temperature, is as follows:

$\mathrm{R}=0.90+0.12(\mathrm{~N} / \mathrm{h})-0.60(\mathrm{a} / \mathrm{h}) \leq 1$ 
The limits for equation 1 are: $\mathrm{h} / \mathrm{t} \leq 156, \mathrm{~N} / \mathrm{h} \leq 0.63$, a/h $\leq 0.8, \mathrm{~N} / \mathrm{t} \leq 84$ and $\theta=90^{\circ}$. Where, $\mathrm{h}$ is the depth of the flat portion of the web, $\mathrm{t}$ is the thickness, $\mathrm{N}$ is the bearing length, and a is the web-hole diameter.

Equation (1), however, is applicable at ambient temperature and there is no information available in the literature on whether this equation can be used for elevated temperature too. This paper considers if the same reduction factor equation is applicable to G250 grade of CFS C-sections subjected to ETFloading at elevated temperatures. Kankanamge and Mahendran [12] provided the stress-strain curves of G250 grade of CFS sections with $1.95 \mathrm{~mm}$ thickness at elevated temperatures (Fig. 2). These stress-strain curves were adopted in the present study.
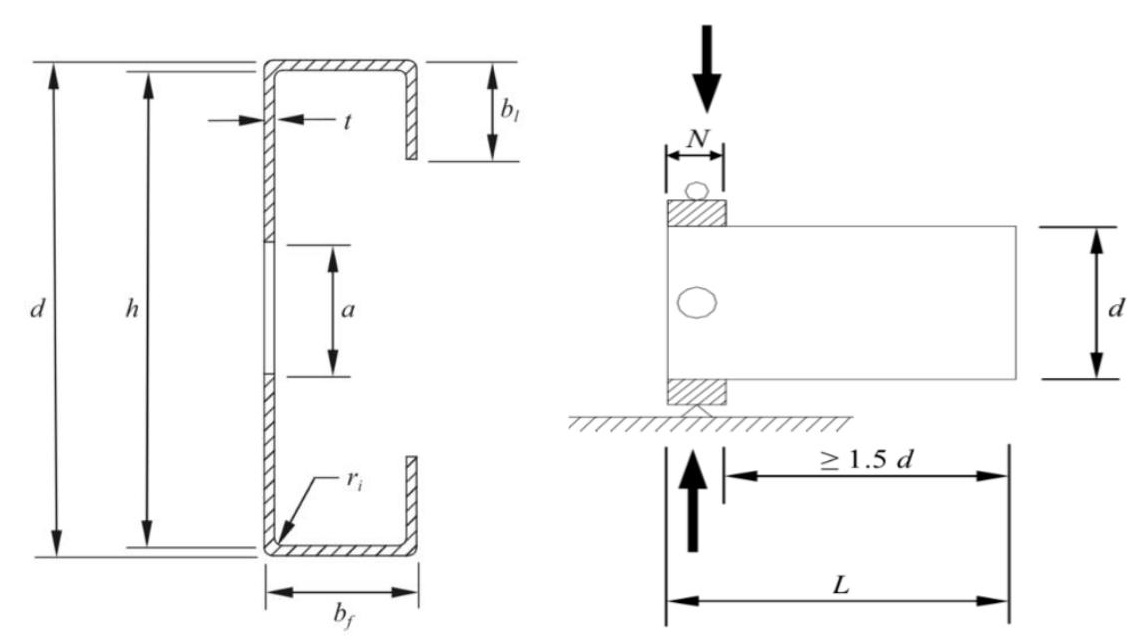

Fig. 1 Definition of symbols

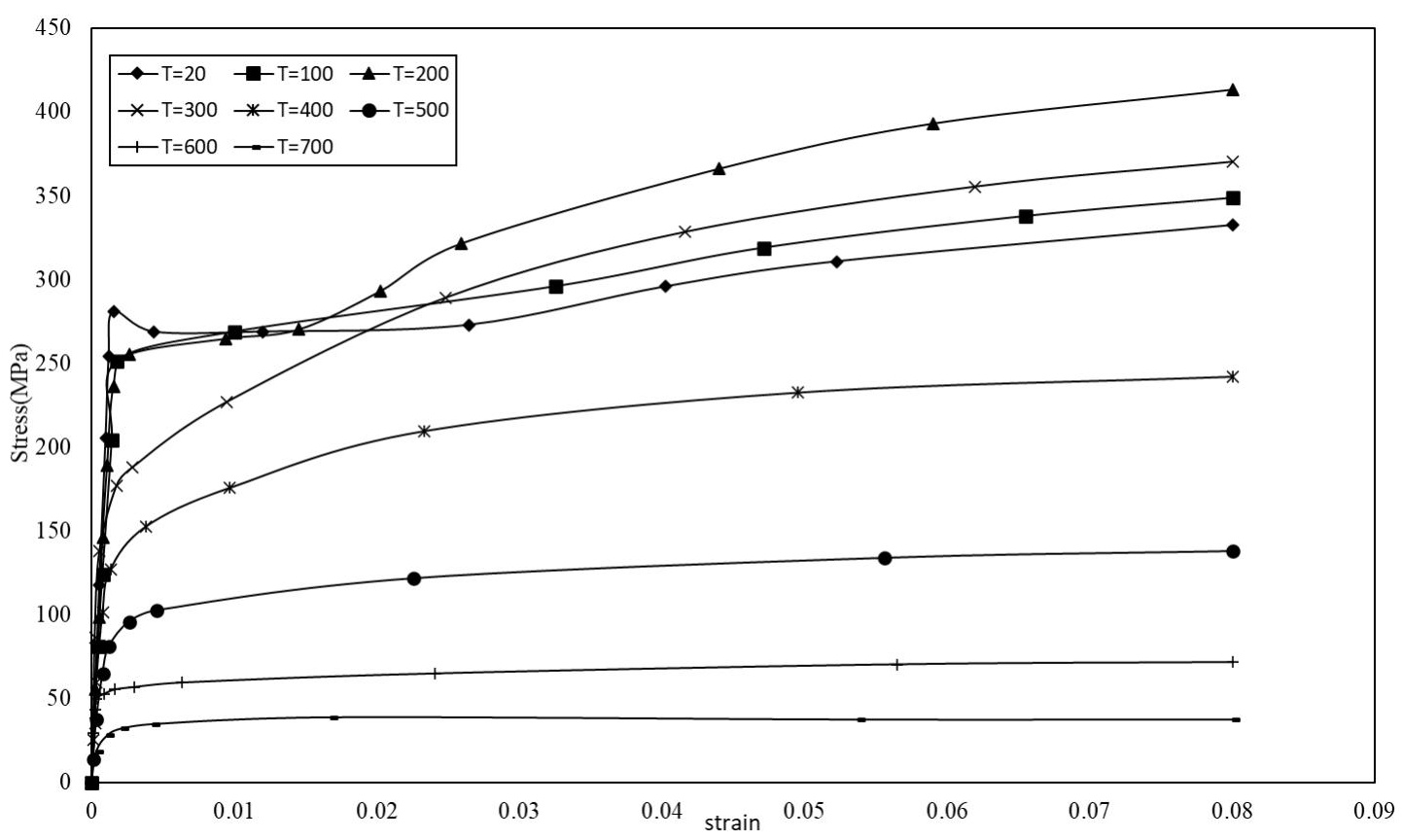

Fig. 2 Stress-strain curves (Kankanamge and Mahendran [12])

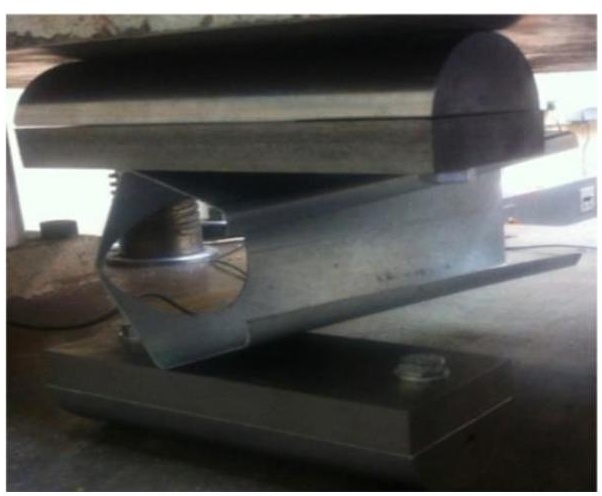

(a) centred circular web hole

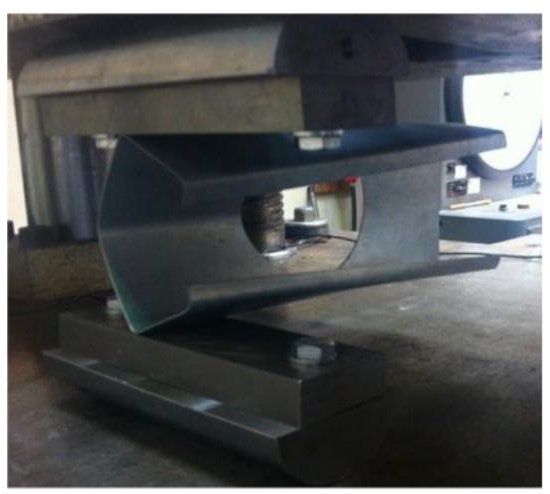

(b) offset circular web hole

Fig. 3 Experimental analysis of lipped CFS C-sections (unfastened flanges) under ETF loading condition from Uzzaman et al. [26] 
in order to determine its effect on web crippling strength of such sections. Five different specimens were used with varying parameters such as nominal thickness, web depth, flange width, and web slenderness (h/t). To validate the developed nonlinear FE model (details are given in Uzzaman et al. [27]), laboratory test results were used. The validated FE model was then used to determine the strength reduction factor for CFS C-sections with web holes under ETF loading condition. More details of the experimental study can be found in Uzzaman et al. [27].

\section{Numerical investigation}

\subsection{General}

The general-purpose finite element software ANSYS [28] was used to develop a finite element model for CFS C-sections with web holes under elevated temperatures and subject to web crippling. The bearing plates, Csections with and without the web holes and the interface between the lipped Csections and bearing plates were modelled appropriately. More details of the FE model are summarised in the following sections.

\subsection{Specimen Labelling}

The dimensions of the $\mathrm{C}$-sections are presented in Table 1. Fig. 1 shows the definition of symbols used for the dimensions of $\mathrm{C}$-sections considered in this study. The specimens were labelled in such a way that the loading condition, specimen dimensions, bearing length as well as the $(\mathrm{a} / \mathrm{h})$ ratio can be identified by the specimen label. For example, the label "ETF100 x 40 x 15 x 5 t-1.95 N50" can be explained as follows:

- The first notation 'ETF' indicates the loading condition which is End-two flange loading.

- The next three notations define the nominal dimensions of the C-section: ' $100 \times 40 \times 15$ ' indicates the nominal depth, flange width and overall lip width of the section in millimetres.

- 't-1.95' indicates the thickness of the C-section; and

- 'N50' shows the bearing length (i.e. $50 \mathrm{~mm}$ ).

- The notation 'A0.4' indicates the value of $(\mathrm{a} / \mathrm{h})$ ratio as 0.4 . 'A0' denotes the C- sections without web holes. Only unfastened flanges were considered in this study.

\section{Table 1}

Dimension of specimens considered in the study

\begin{tabular}{|c|c|c|c|c|c|c|c|c|c|c|c|c|}
\hline Specimen & $\begin{array}{c}\text { Web } \\
\mathrm{d}(\mathrm{mm} \\
)\end{array}$ & $\begin{array}{c}\text { Flang } \\
\mathrm{e} \\
b_{f}(\mathrm{~mm} \\
) \\
\end{array}$ & $\begin{array}{c}\text { Lip } \\
\mathrm{h}_{(}(\mathrm{mm} \\
)\end{array}$ & $\begin{array}{c}\text { Lengt } \\
h \\
\mathrm{~L}(\mathrm{~mm} \\
\quad) \\
\end{array}$ & $\begin{array}{c}\text { Thicknes } \\
\text { s } \\
\mathrm{t}(\mathrm{mm})\end{array}$ & $\begin{array}{c}\text { Fillet } \\
r_{i}(\mathrm{~mm})\end{array}$ & $\begin{array}{c}\text { Web } \\
\text { depth } \\
\text { h(mm) }\end{array}$ & $\begin{array}{c}\text { Web } \\
\text { slenderne } \\
\text { ss } \\
\text { h/t }\end{array}$ & $\begin{array}{l}\text { Bearing } \\
\text { length } \\
\mathrm{N}(\mathrm{mm})\end{array}$ & $\begin{array}{c}\text { Bearing } \\
\text { Length } \\
\text { ratio } \\
\mathrm{N} / \mathrm{h}\end{array}$ & $\begin{array}{c}\text { Web hole } \\
\text { Ratio } \\
\text { a/h }\end{array}$ & $\begin{array}{c}\text { Diameter } \\
\text { of web } \\
\text { hole } \\
\mathrm{a}(\mathrm{mm})\end{array}$ \\
\hline ETF100x40x15-t-1.95N50A0 & 100 & 40 & 15 & 350 & 1.95 & 5 & 98.1 & 50.3 & 50 & 0.51 & 0 & 0 \\
\hline ETF100x40x 15t-1.95N50A0.4 & 100 & 40 & 15 & 350 & 1.95 & 5 & 98.1 & 50.3 & 50 & 0.51 & 0.4 & 39.22 \\
\hline ETF100x40x15-t-1.95N75A0 & 100 & 40 & 15 & 375 & 1.95 & 5 & 98.1 & 50.3 & 75 & 0.76 & 0 & 0 \\
\hline ETF100x40x 15-t-1.95N75A0.4 & 100 & 40 & 15 & 375 & 1.95 & 5 & 98.1 & 50.3 & 75 & 0.76 & 0.4 & 39.22 \\
\hline ETF $125 \times 40 \times 15-t-1.95 \mathrm{~N} 50 \mathrm{~A} 0$ & 125 & 40 & 15 & 425 & 1.95 & 5 & 123.1 & 63.1 & 50 & 0.41 & 0 & 0 \\
\hline ETF $125 \times 40 x 15-t-1.95 \mathrm{~N} 50 \mathrm{~A} 0.4$ & 125 & 40 & 15 & 425 & 1.95 & 5 & 123.1 & 63.1 & 50 & 0.41 & 0.4 & 49.22 \\
\hline ETF $125 \times 40 \times 15-t-1.95 \mathrm{~N} 50 \mathrm{~A} 0.6$ & 125 & 40 & 15 & 425 & 1.95 & 5 & 123.1 & 63.1 & 50 & 0.41 & 0.6 & 73.83 \\
\hline ETF $125 \times 40 \times 15-t-1.95 N 50 A 0.8$ & 125 & 40 & 15 & 425 & 1.95 & 5 & 123.1 & 63.1 & 50 & 0.41 & 0.8 & 98.44 \\
\hline ETF $125 \times 40 \times 15-t-1.95 N 75 \mathrm{~A} 0$ & 125 & 40 & 15 & 450 & 1.95 & 5 & 123.1 & 63.1 & 75 & 0.61 & 0 & 0 \\
\hline ETF $125 \times 40 x 15-\mathrm{t}-1.95 \mathrm{~N} 75 \mathrm{~A} 0.4$ & 125 & 40 & 15 & 450 & 1.95 & 5 & 123.1 & 63.1 & 75 & 0.61 & 0.4 & 49.22 \\
\hline ETF $125 \times 40 x 15-t-1.95 N 75 A 0.6$ & 125 & 40 & 15 & 450 & 1.95 & 5 & 123.1 & 63.1 & 75 & 0.61 & 0.6 & 73.83 \\
\hline ETF $125 \times 40 \times 15-t-1.95 N 75 A 0.8$ & 125 & 40 & 15 & 450 & 1.95 & 5 & 123.1 & 63.1 & 75 & 0.61 & 0.8 & 98.44 \\
\hline ETF $125 \times 40 \times 15-t-1.95 \mathrm{~N} 100 \mathrm{~A} 0$ & 125 & 40 & 15 & 475 & 1.95 & 5 & 123.1 & 63.1 & 100 & 0.81 & 0 & 0 \\
\hline ETF $125 \times 40 \times 15-\mathrm{t} 1.95 \mathrm{~N} 100 \mathrm{~A} 0.4$ & 125 & 40 & 15 & 475 & 1.95 & 5 & 123.1 & 63.1 & 100 & 0.81 & 0.4 & 49.22 \\
\hline ETF $125 \times 40 \times 15-\mathrm{t} 1.95 \mathrm{~N} 100 \mathrm{~A} 0.6$ & 125 & 40 & 15 & 475 & 1.95 & 5 & 123.1 & 63.1 & 100 & 0.81 & 0.6 & 73.83 \\
\hline ETF $125 \times 40 \times 15-t 1.95 \mathrm{~N} 100 \mathrm{~A} 0.8$ & 125 & 40 & 15 & 475 & 1.95 & 5 & 123.1 & 63.1 & 100 & 0.81 & 0.8 & 98.44 \\
\hline ETF $150 \times 40 \times 15-t-1.95 N 50 A 0$ & 150 & 40 & 15 & 500 & 1.95 & 5 & 148.1 & 75.9 & 50 & 0.34 & 0 & 0 \\
\hline ETF $150 x 40 x 15-t-1.95 \mathrm{~N} 50 \mathrm{~A} 0.4$ & 150 & 40 & 15 & 500 & 1.95 & 5 & 148.1 & 75.9 & 50 & 0.34 & 0.4 & 59.22 \\
\hline ETF $150 x 40 x 15-t-1.95 \mathrm{~N} 50 \mathrm{~A} 0.6$ & 150 & 40 & 15 & 500 & 1.95 & 5 & 148.1 & 75.9 & 50 & 0.34 & 0.6 & 88.83 \\
\hline ETF $150 \times 40 \times 15-t-1.95 \mathrm{~N} 50 \mathrm{~A} 0.8$ & 150 & 40 & 15 & 500 & 1.95 & 5 & 148.1 & 75.9 & 50 & 0.34 & 0.8 & 118.44 \\
\hline ETF $150 \times 40 x 15-t-1.95 \mathrm{~N} 75 \mathrm{~A} 0$ & 150 & 40 & 15 & 525 & 1.95 & 5 & 148.1 & 75.9 & 75 & 0.51 & 0 & 0 \\
\hline ETF 150x40x15-t-1.95N75A0.4 & 150 & 40 & 15 & 525 & 1.95 & 5 & 148.1 & 75.9 & 75 & 0.51 & 0.4 & 59.22 \\
\hline ETF $150 \times 40 x 15-t-1.95 N 75 A 0.6$ & 150 & 40 & 15 & 525 & 1.95 & 5 & 148.1 & 75.9 & 75 & 0.51 & 0.6 & 88.83 \\
\hline ETF $150 x 40 x 15-\mathrm{t}-1.95 \mathrm{~N} 75 \mathrm{~A} 0.8$ & 150 & 40 & 15 & 525 & 1.95 & 5 & 148.1 & 75.9 & 75 & 0.51 & 0.8 & 118.44 \\
\hline ETF $150 \times 40 \times 15-t-1.95 \mathrm{~N} 100 \mathrm{~A} 0$ & 150 & 40 & 15 & 550 & 1.95 & 5 & 148.1 & 75.9 & 100 & 0.68 & 0 & 0 \\
\hline ETF 150x40x15-t1.95N100A0.4 & 150 & 40 & 15 & 550 & 1.95 & 5 & 148.1 & 75.9 & 100 & 0.68 & 0.4 & 59.22 \\
\hline ETF $150 \times 40 \times 15-\mathrm{t} 1.95 \mathrm{~N} 100 \mathrm{~A} 0.6$ & 150 & 40 & 15 & 550 & 1.95 & 5 & 148.1 & 75.9 & 100 & 0.68 & 0.6 & 88.83 \\
\hline ETF $150 x 40 x 15-t 1.95 \mathrm{~N} 100 \mathrm{~A} 0.8$ & 150 & 40 & 15 & 550 & 1.95 & 5 & 148.1 & 75.9 & 100 & 0.68 & 0.8 & 118.44 \\
\hline
\end{tabular}
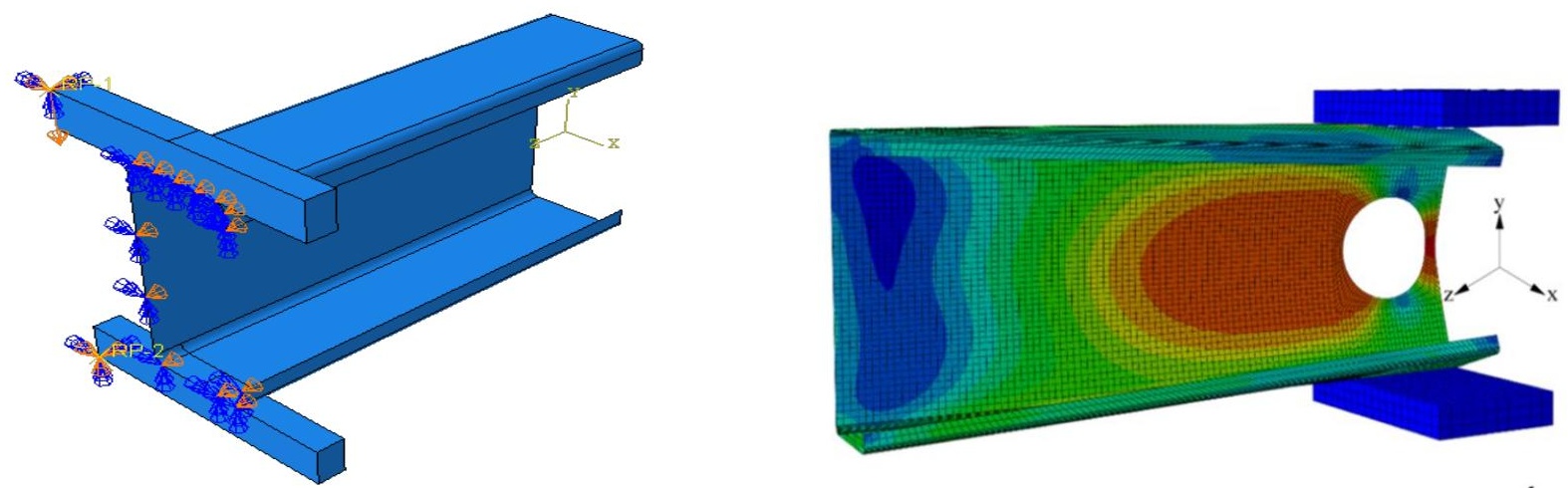


\subsection{Mesh sensitivity and element type}

Fig. 4 shows the FE mesh of the C-sections and the bearing plate. As the number of elements in the FE mesh increases, the accuracy of the results increases. In order to obtain the results within the acceptable limits, very fine mesh sizes were used for all the FE models developed in this study. The mesh sizes were varied from $3 \mathrm{~mm} \times 3 \mathrm{~mm}$ (width by length) to $5 \mathrm{~mm} \times 5 \mathrm{~mm}$, based on the computational time and accuracy of the results.

In order to incorporate corner strength enhancements of CFS C-sections, it is important to use finer meshing at the corners of $\mathrm{C}$-sections. The number of FE elements in the corner between the web and flange was chosen as 9 . This value was maintained at 3 , while modelling the corners of lip and the flange. The regions near the web holes were finely meshed. To optimise the mesh size and its numbers, mesh sensitivity analysis was performed.

Four-noded shell element SHELL 181 available in theANSYS library [28] was used to model the C-sections. Eight-noded solid element SOLID45 was used to model the bearing plates. In order to model the surface interface between the flanges and the bearing plates, CONTAT173 and TARGET170 elements were used.

\section{Table 2}

Material properties of G250 grade of CFS having a section thickness of 1.95 mm (Kankanamge and Mahendran [12])

\begin{tabular}{cccc}
\hline Temp $\left({ }^{\circ} \mathrm{C}\right)$ & $\sigma \mathrm{u}(\mathrm{T})(\mathrm{MPa})$ & $\mathrm{E}(\mathrm{Mpa})$ & fy(Mpa) \\
\hline 20 & 356.1 & 188220 & 270.5 \\
100 & 369.0 & 179640 & 267.3 \\
200 & 435.2 & 171745 & 257.0 \\
300 & 385.0 & 154330 & 196.4 \\
400 & 240.0 & 121230 & 147.7 \\
500 & 137.5 & 90631 & 95.8 \\
600 & 71.4 & 57777 & 54.1 \\
700 & 37.7 & 31363 & 34.4 \\
\hline
\end{tabular}

Table 3

Comparison of finite element analysis with the experiment results for flanges unfastened under ETF loading condition

\begin{tabular}{|c|c|c|c|c|c|c|c|c|c|c|}
\hline Specimen & $\begin{array}{l}\text { Web } \\
d \\
(\mathrm{~mm})\end{array}$ & $\begin{array}{l}\text { Flange } \\
b_{f} \\
(\mathrm{~mm})\end{array}$ & $\begin{array}{l}\text { Lip } \\
b_{l} \\
(\mathrm{~mm})\end{array}$ & $\begin{array}{l}\text { Thickness } \\
t \\
(\mathrm{~mm})\end{array}$ & $\begin{array}{l}\text { Fillet } \\
r_{i} \\
(\mathrm{~mm})\end{array}$ & $\begin{array}{l}\text { Holes } \\
a \\
(\mathrm{~mm})\end{array}$ & $\begin{array}{l}\text { Length } \\
L \\
(\mathrm{~mm})\end{array}$ & $\begin{array}{l}\text { Exp. load per } \\
\text { web } \\
P_{\text {EXP }} \\
(\mathrm{kN})\end{array}$ & $\begin{array}{l}\text { Web Crippling Strength } \\
\text { per web predicted from } \\
\text { PFEA } \\
(\mathrm{kN})\end{array}$ & $\begin{array}{l}\text { Comparison } \\
P_{E X P} / P_{F E A}\end{array}$ \\
\hline ETF142x60x13-t1.3N90A0 & 142.2 & 58.6 & 15.9 & 1.23 & 4.8 & 0.0 & 337.5 & 2.21 & 2.18 & 1.01 \\
\hline ETF142x60x13-t1.3N90A0.2 & 142.2 & 58.6 & 15.9 & 1.23 & 4.8 & 27.9 & 337.5 & 1.98 & 1.94 & 1.02 \\
\hline ETF142x60x13-t1.3N90A0.4 & 142.2 & 59.5 & 16.3 & 1.25 & 4.8 & 55.8 & 337.5 & 1.62 & 1.69 & 0.96 \\
\hline ETF142x60x13-t1.3N90A0.6 & 142.2 & 59.5 & 16.3 & 1.25 & 4.8 & 83.6 & 337.5 & 1.32 & 1.41 & 0.94 \\
\hline ETF $172 \times 65 \times 13-t 1.3 \mathrm{~N} 120 \mathrm{~A} 0$ & 172.8 & 64.1 & 15.6 & 1.27 & 5.0 & 0.0 & 400.0 & 2.37 & 2.28 & 1.04 \\
\hline ETF172x65x13-t1.3N120A0.4 & 172.3 & 63.6 & 15.5 & 1.27 & 5.0 & 67.6 & 400.0 & 1.70 & 1.81 & 0.94 \\
\hline ETF172x65x13-t1.3N120A0.6 & 172.6 & 64.3 & 15.3 & 1.28 & 5.0 & 101.6 & 400.0 & 1.36 & 1.48 & 0.92 \\
\hline ETF202x65x13-t1.4N120A0 & 202.1 & 63.1 & 17.5 & 1.45 & 5.0 & 0.0 & 425.0 & 2.70 & 2.87 & 0.94 \\
\hline ETF202x65x13-t1.4N120A0.2 & 202.7 & 64.3 & 16.3 & 1.45 & 5.0 & 39.8 & 425.0 & 2.41 & 2.46 & 0.98 \\
\hline ETF202x65x13-t1.4N120A0.4 & 202.4 & 64.2 & 16.5 & 1.45 & 5.0 & 79.5 & 425.0 & 1.88 & 2.01 & 0.94 \\
\hline ETF202x65x13-t1.4N150A0 & 202.1 & 63.1 & 17.5 & 1.45 & 5.0 & 0.0 & 450.0 & 2.84 & 3.29 & 0.86 \\
\hline ETF202x65x13-t1.4N150A0.4 & 202.7 & 64.3 & 16.3 & 1.45 & 5.0 & 79.5 & 450.0 & 2.19 & 2.35 & 0.93 \\
\hline ETF202x65x13-t1.4N150A0.6 & 202.4 & 64.2 & 16.5 & 1.45 & 5.0 & 119.5 & 450.0 & 1.77 & 1.90 & 0.93 \\
\hline
\end{tabular}

\section{Parametric study}

In this study, $288 \mathrm{FE}$ models of C-sections with and without web holes with varying parameters such as sizes of web holes, bearing length and temperature ranging from $20{ }^{\circ} \mathrm{C}$ to $700{ }^{\circ} \mathrm{C}$ at an interval of 100 degrees were analysed. The aim of this parametric study was to investigate the effects of such parameters on the web crippling strength of CFS C-sections with web hole at elevated temperatures subjected to ETF crippling.

Lian et al. [6-7] and Uzzaman et al. [26] showed that the web crippling strength depends on the $\mathrm{a} / \mathrm{h}$ ratio, and $\mathrm{N} / \mathrm{h}$ ratio. To determine the effects of $\mathrm{a} / \mathrm{h}$ ratio and $\mathrm{N} / \mathrm{h}$ ratio at different elevated temperatures on the web crippling

\subsection{Material and Geometry Properties}

The FE model used in this study was developed by Uzzaman et al. [27] for CFS C-channels at ambient temperature (Fig. 3). The stress-strain curves of $1.95 \mathrm{~mm}$ thick G250 grade of CFS C-sections at elevated and ambient temperatures were taken from the Kankanamge and Mahendran [12] (Fig. 2) and used in this study. The considered material properties are summarised in Table 2. Equations 2 and 3 were used to convert the engineering stress-strain relationship to the true stress-strain relationship as described in the ANSYS manual [28].

$$
\sigma_{\text {true }}=\sigma_{\text {eng }}\left(\varepsilon_{\text {eng }}+1\right)
$$

$$
\varepsilon_{\text {true }}=\ln \left(\varepsilon_{\text {eng }}+1\right)
$$

\subsection{Loading and Boundary Condition}

The surface-to-surface interaction was modelled between the load bearing plates and the flanges of $\mathrm{C}$-sections using the surface contact option available in the ANSYS library [28]. The two contact surfaces were constrained to avoid any penetration between the two surfaces. Displacement control was used to apply the vertical load to the $\mathrm{C}$-sections.

\subsection{Verification of the FE Model}

The results of FE analysis for CFS lipped C-sections with centred web holes subjected to ETF loading are presented in Table 3. The ratio of the load per web determined from the FEA and experiments shows good agreement between each other. For further verification purpose, the load displacement curves of specimen ETF142x60x13t-1.3N120 with a/h ratios ranging from 0 to 0.4 generated by FEA analysis was compared with the load displacement curve of same specimen obtained from the experimental study (Fig. 5). From the comparison, it was found that the FEA results were very close to the experimental results, confirming the validity of the FE model. 
obtaining the reduction factor values for every particular temperature, the reduction factor values were compared with the reduction factor values predicted using the equation of Uzzaman et al. [26] (see Tables 5(a), 5(b) and 5(c), and Figs. 7(a) and 7(b)).
Fig. 6(a) presents the variation of strength reduction factor with the $\mathrm{a} / \mathrm{h}$ ratio. Fig. 6(b) presents the variation of strength reduction factor with the $\mathrm{N} / \mathrm{h}$ ratio. It was found that the strength reduction is insensitive to the $\mathrm{N} / \mathrm{h}$ ratio for temperatures ranging from $20^{\circ} \mathrm{C}$ to $700^{\circ} \mathrm{C}$.

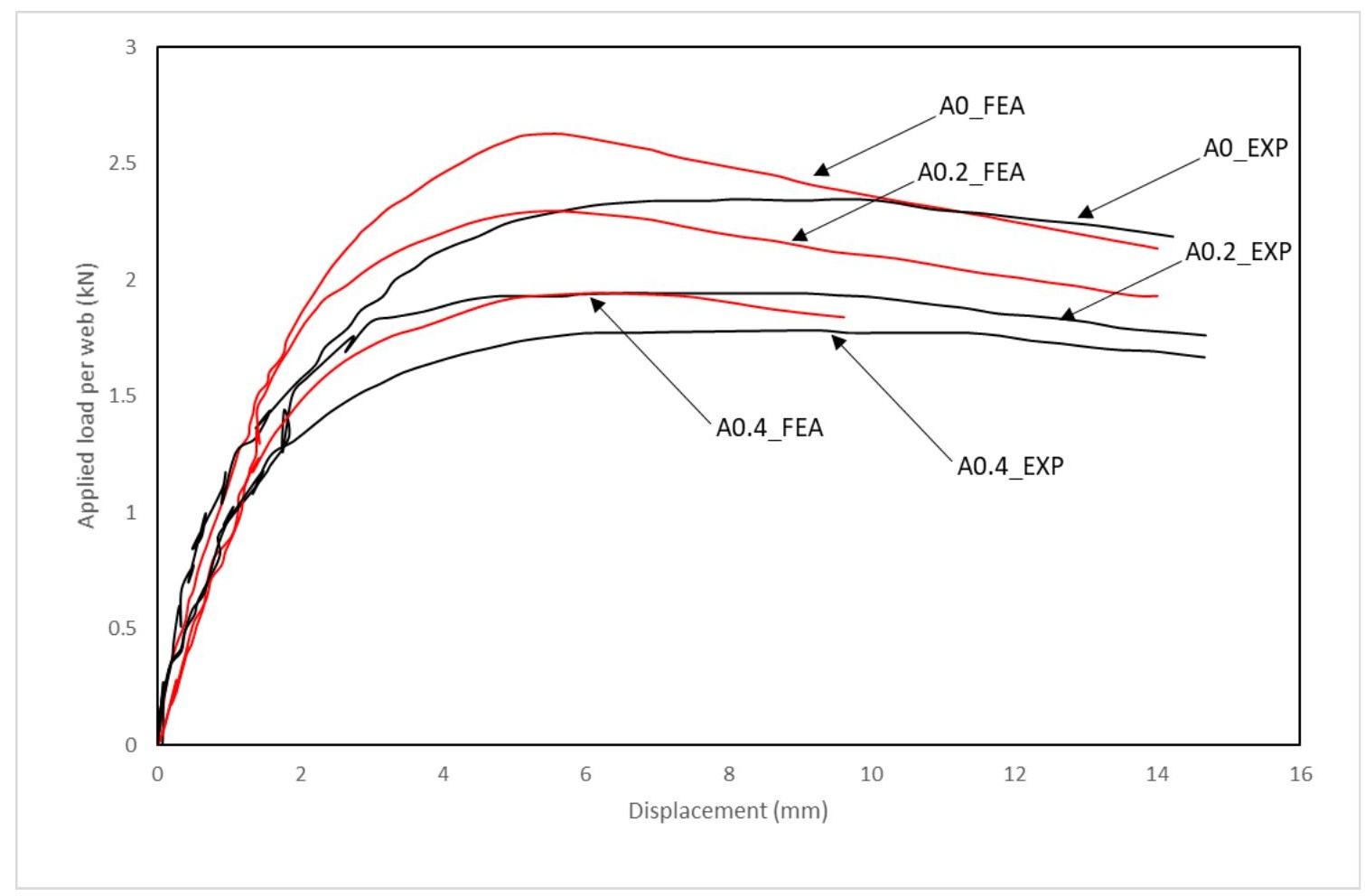

Fig. 5 Comparison of web deformation curves for ETF142x60x13t-13N120 from experiments and FEA

Table 4

Web crippling strengths of CFS C-sections at elevated temperatures

4(a) ETF100x45x15-t1.95

\begin{tabular}{|c|c|c|c|c|c|c|}
\hline \multirow[b]{2}{*}{ Temperature $\left({ }^{\circ} \mathrm{C}\right)$} & \multirow[b]{2}{*}{$\mathrm{N}(\mathrm{mm})$} & \multirow[b]{2}{*}{$\mathrm{N} / \mathrm{h}$} & \multicolumn{4}{|c|}{ FEA Load per Web $(\mathrm{kN})$ at $(\mathrm{a} / \mathrm{h})$} \\
\hline & & & $\mathrm{A} 0$ & $\mathrm{~A} 0.4$ & A0.6 & A 0.8 \\
\hline 20 & & & 4.12 & 3.13 & 2.66 & 2.24 \\
\hline 100 & & & 3.84 & 3.02 & 2.60 & 2.22 \\
\hline 200 & & & 4.35 & 3.33 & 2.87 & 2.43 \\
\hline 300 & 50 & 0.51 & 3.23 & 2.50 & 2.15 & 1.82 \\
\hline 400 & & & 2.61 & 2.02 & 1.74 & 1.47 \\
\hline 500 & & & 1.85 & 1.43 & 1.23 & 1.04 \\
\hline 600 & & & 1.13 & 0.87 & 0.75 & 0.64 \\
\hline 700 & & & 0.62 & 0.48 & 0.41 & 0.35 \\
\hline 20 & & & 4.97 & 3.85 & 3.35 & 2.88 \\
\hline 100 & & & 4.60 & 3.68 & 3.23 & 2.79 \\
\hline 200 & & & 5.25 & 4.08 & 3.57 & 3.10 \\
\hline 300 & & & 3.90 & 3.07 & 2.68 & 2.32 \\
\hline 400 & 75 & 0.76 & 3.14 & 2.48 & 2.16 & 1.87 \\
\hline 500 & & & 2.21 & 1.74 & 1.53 & 1.32 \\
\hline 600 & & & 1.34 & 1.06 & 0.93 & 0.81 \\
\hline 700 & & & 0.74 & 0.58 & 0.51 & 0.44 \\
\hline 20 & & & 5.82 & 4.62 & 4.09 & 3.56 \\
\hline 100 & & & 5.35 & 4.37 & 3.88 & 3.38 \\
\hline 200 & & & 6.16 & 4.90 & 4.32 & 3.77 \\
\hline 300 & & & 4.59 & 3.69 & 3.25 & 2.83 \\
\hline 400 & 100 & 1.02 & 3.68 & 2.96 & 2.62 & 2.28 \\
\hline 500 & & & 2.57 & 2.07 & 1.84 & 1.61 \\
\hline 600 & & & 1.56 & 1.25 & 1.12 & 0.98 \\
\hline 700 & & & 0.87 & 0.69 & 0.62 & 0.54 \\
\hline
\end{tabular}


4(b) ETF125x45x15-t1.95

\begin{tabular}{|c|c|c|c|c|c|c|}
\hline \multirow[b]{2}{*}{ Temperature $\left({ }^{\circ} \mathrm{C}\right)$} & \multirow[b]{2}{*}{$\mathrm{N}(\mathrm{mm})$} & \multirow[b]{2}{*}{$\mathrm{N} / \mathrm{h}$} & \multicolumn{4}{|c|}{ FEA Load per Web (kN) at (a/h) } \\
\hline & & & A0 & A0.4 & A0.6 & A0.8 \\
\hline 20 & & & 3.80 & 2.85 & 2.38 & 1.94 \\
\hline 100 & & & 3.63 & 2.77 & 2.34 & 1.93 \\
\hline 200 & & & 4.08 & 3.02 & 2.54 & 2.07 \\
\hline 300 & & & 2.98 & 2.23 & 1.87 & 1.53 \\
\hline 400 & 50 & 0.41 & 2.43 & 1.83 & 1.54 & 1.26 \\
\hline 500 & & & 1.76 & 1.32 & 1.12 & 0.92 \\
\hline 600 & & & 1.08 & 0.81 & 0.69 & 0.56 \\
\hline 700 & & & 0.59 & 0.44 & 0.37 & 0.30 \\
\hline 20 & & & 4.49 & 3.41 & 2.91 & 2.46 \\
\hline 100 & & & 4.26 & 3.29 & 2.83 & 2.42 \\
\hline 200 & & & 4.83 & 3.61 & 3.08 & 2.62 \\
\hline 300 & & & 3.54 & 2.67 & 2.28 & 1.93 \\
\hline 400 & 75 & 0.61 & 2.87 & 2.18 & 1.87 & 1.59 \\
\hline 500 & & & 2.06 & 1.57 & 1.36 & 1.15 \\
\hline 600 & & & 1.27 & 0.96 & 0.83 & 0.71 \\
\hline 700 & & & 0.69 & 0.52 & 0.45 & 0.38 \\
\hline 20 & & & 5.21 & 4.02 & 3.48 & 2.99 \\
\hline 100 & & & 4.92 & 3.85 & 3.35 & 2.89 \\
\hline 200 & & & 5.63 & 4.27 & 3.68 & 3.16 \\
\hline 300 & & & 4.14 & 3.16 & 2.72 & 2.33 \\
\hline 400 & 100 & 0.81 & 3.34 & 2.57 & 2.22 & 1.91 \\
\hline 500 & & & 2.38 & 1.85 & 1.61 & 1.39 \\
\hline 600 & & & 1.46 & 1.13 & 0.99 & 0.85 \\
\hline 700 & & & 0.80 & 0.62 & 0.53 & 0.46 \\
\hline
\end{tabular}

4(c) ETF150x45x15-t1.95

\begin{tabular}{|c|c|c|c|c|c|c|}
\hline \multirow[b]{2}{*}{ Temperature $\left({ }^{\circ} \mathrm{C}\right)$} & \multirow[b]{2}{*}{$\mathrm{N}(\mathrm{mm})$} & \multirow[b]{2}{*}{$\mathrm{N} / \mathrm{h}$} & \multicolumn{4}{|c|}{ FEA Load per Web $(\mathrm{kN})$ at $(\mathrm{a} / \mathrm{h})$} \\
\hline & & & A0 & A 0.4 & A0.6 & A 0.8 \\
\hline 20 & & & 3.53 & 2.62 & 2.16 & 1.72 \\
\hline 100 & & & 3.45 & 2.56 & 2.13 & 1.71 \\
\hline 200 & & & 3.83 & 2.76 & 2.28 & 1.81 \\
\hline 300 & & & 2.77 & 2.01 & 1.66 & 1.32 \\
\hline 400 & 50 & 0.34 & 2.28 & 1.67 & 1.38 & 1.10 \\
\hline 500 & & & 1.67 & 1.23 & 1.03 & 0.82 \\
\hline 600 & & & 1.04 & 0.76 & 0.63 & 0.50 \\
\hline 700 & & & 0.56 & 0.41 & 0.34 & 0.27 \\
\hline 20 & & & 4.09 & 3.07 & 2.58 & 2.14 \\
\hline 100 & & & 3.98 & 2.99 & 2.53 & 2.11 \\
\hline 200 & & & 4.45 & 3.24 & 2.71 & 2.24 \\
\hline 300 & & & 3.23 & 2.37 & 1.98 & 1.64 \\
\hline 400 & 75 & 0.51 & 2.65 & 1.96 & 1.64 & 1.36 \\
\hline 500 & & & 1.93 & 1.44 & 1.22 & 1.01 \\
\hline 600 & & & 1.20 & 0.89 & 0.75 & 0.62 \\
\hline 700 & & & 0.64 & 0.48 & 0.40 & 0.33 \\
\hline 20 & & & 4.69 & 3.56 & 3.02 & 2.56 \\
\hline 100 & & & 4.56 & 3.45 & 2.95 & 2.51 \\
\hline 200 & & & 5.13 & 3.76 & 3.19 & 2.68 \\
\hline 300 & & & 3.73 & 2.76 & 2.33 & 1.96 \\
\hline 400 & 100 & 0.68 & 3.05 & 2.27 & 1.93 & 1.63 \\
\hline 500 & & & 2.21 & 1.66 & 1.42 & 1.21 \\
\hline 600 & & & 1.37 & 1.02 & 0.88 & 0.74 \\
\hline 700 & & & 0.74 & 0.55 & 0.47 & 0.40 \\
\hline
\end{tabular}




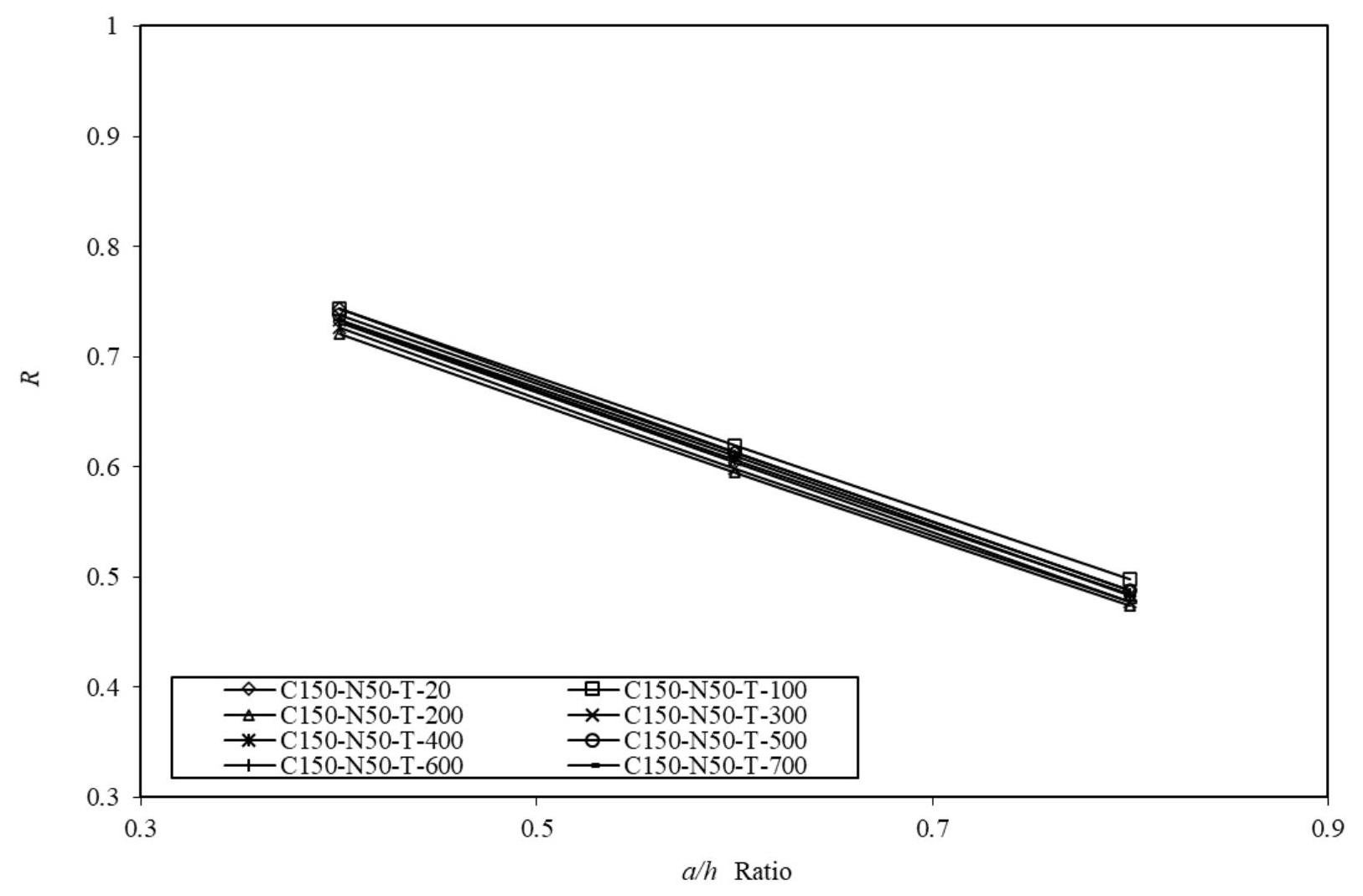

(a) with a/h ratio

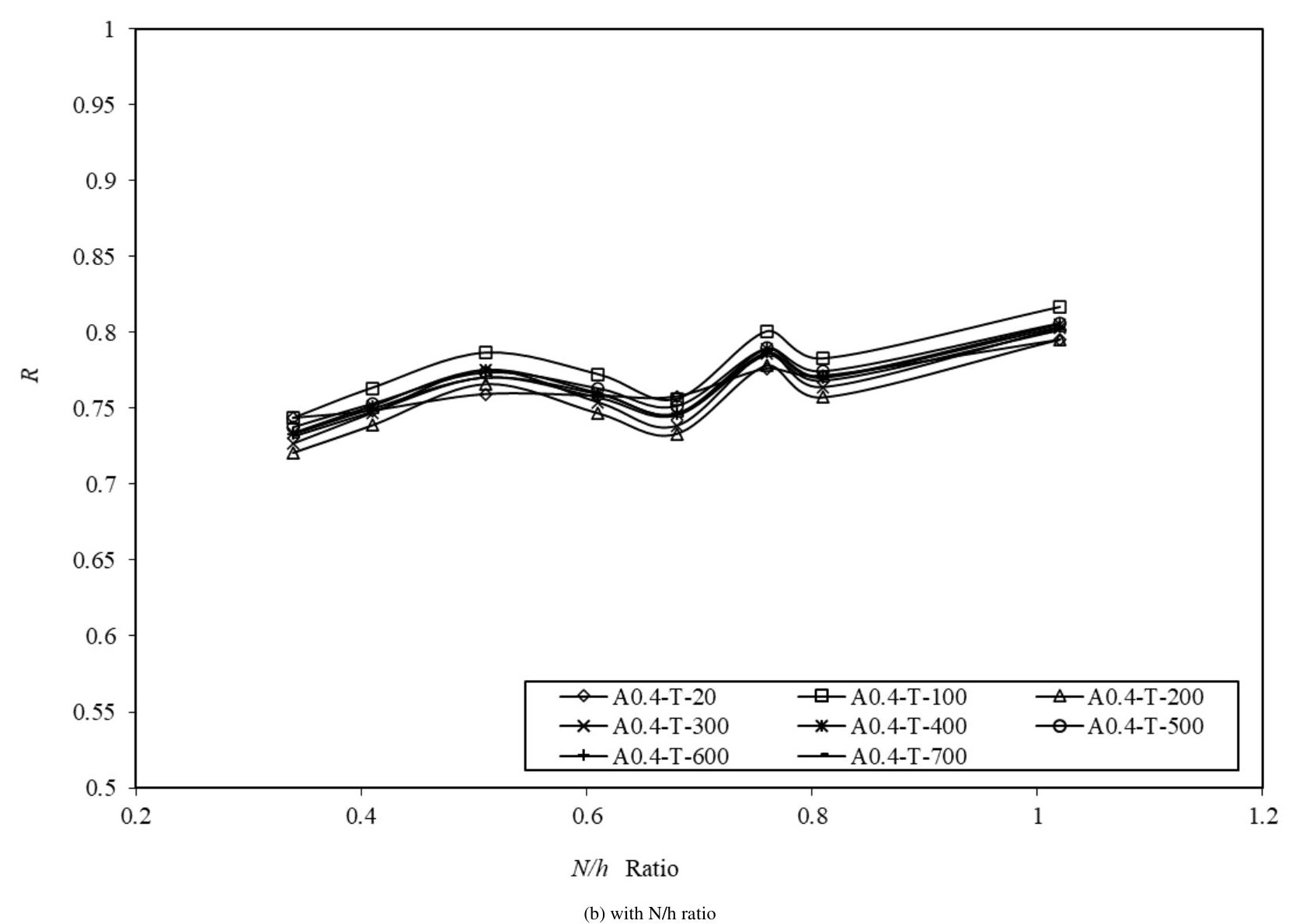

Fig. 6 Variation of reduction factors 
Table 5

Comparison of the web crippling strength reduction factor with the reduction factor equation proposed by Uzzaman et al. [26] 5(a) ETF-100x45x15-t1.95

\begin{tabular}{|c|c|c|c|c|c|c|c|c|}
\hline \multirow[b]{2}{*}{ Temperature $\left({ }^{\circ} \mathrm{C}\right)$} & \multirow[b]{2}{*}{$\mathrm{N}(\mathrm{mm})$} & \multirow[b]{2}{*}{$\mathrm{N} / \mathrm{h}$} & \multicolumn{3}{|c|}{ Reduction Factor } & \multicolumn{3}{|c|}{$\begin{array}{l}\text { Comparison with resistance from Uzzaman et al. [26] } \\
\qquad\left(\mathrm{R} / \mathrm{R}_{\text {Uzzaman }}\right)\end{array}$} \\
\hline & & & $\mathrm{R}=\mathrm{P}(\mathrm{A} 0.4) / \mathrm{P}(\mathrm{A} 0)$ & $\mathrm{R}=\mathrm{P}(\mathrm{A} 0.6) / \mathrm{P}(\mathrm{A} 0)$ & $\mathrm{R}=\mathrm{P}(\mathrm{A} 0.8) / \mathrm{P}(\mathrm{A} 0)$ & A0.4 & A0.6 & A 0.8 \\
\hline 20 & & & 0.76 & 0.65 & 0.54 & 1.05 & 1.07 & 1.13 \\
\hline 100 & & & 0.79 & 0.68 & 0.58 & 1.09 & 1.13 & 1.20 \\
\hline 200 & & & 0.77 & 0.66 & 0.56 & 1.06 & 1.10 & 1.16 \\
\hline 300 & & & 0.77 & 0.67 & 0.57 & 1.07 & 1.11 & 1.17 \\
\hline 400 & 50 & 0.51 & 0.78 & 0.67 & 0.56 & 1.08 & 1.11 & 1.17 \\
\hline 500 & & & 0.77 & 0.67 & 0.57 & 1.07 & 1.11 & 1.18 \\
\hline 600 & & & 0.77 & 0.66 & 0.56 & 1.07 & 1.10 & 1.17 \\
\hline 700 & & & 0.77 & 0.66 & 0.56 & 1.07 & 1.10 & 1.16 \\
\hline 20 & & & 0.78 & 0.68 & 0.58 & 1.03 & 1.07 & 1.13 \\
\hline 100 & & & 0.80 & 0.70 & 0.61 & 1.07 & 1.11 & 1.19 \\
\hline 200 & & & 0.78 & 0.68 & 0.59 & 1.04 & 1.08 & 1.16 \\
\hline 300 & & & 0.79 & 0.69 & 0.59 & 1.05 & 1.09 & 1.16 \\
\hline 400 & 75 & 0.76 & 0.79 & 0.69 & 0.60 & 1.05 & 1.09 & 1.17 \\
\hline 500 & & & 0.79 & 0.69 & 0.60 & 1.05 & 1.10 & 1.17 \\
\hline 600 & & & 0.79 & 0.69 & 0.60 & 1.05 & 1.10 & 1.18 \\
\hline 700 & & & 0.79 & 0.69 & 0.60 & 1.05 & 1.09 & 1.16 \\
\hline 20 & & & 0.79 & 0.70 & 0.61 & 1.02 & 1.06 & 1.13 \\
\hline 100 & & & 0.82 & 0.72 & 0.63 & 1.04 & 1.09 & 1.16 \\
\hline 200 & & & 0.80 & 0.70 & 0.61 & 1.02 & 1.06 & 1.13 \\
\hline 300 & & & 0.80 & 0.71 & 0.62 & 1.03 & 1.07 & 1.13 \\
\hline 400 & 100 & 1.02 & 0.81 & 0.71 & 0.62 & 1.03 & 1.07 & 1.14 \\
\hline 500 & & & 0.81 & 0.72 & 0.63 & 1.03 & 1.08 & 1.16 \\
\hline 600 & & & 0.80 & 0.72 & 0.63 & 1.03 & 1.08 & 1.16 \\
\hline 700 & & & 0.80 & 0.71 & 0.62 & 1.02 & 1.07 & 1.15 \\
\hline
\end{tabular}

\section{5(b) ETF125x45x15t1.95}

\begin{tabular}{|c|c|c|c|c|c|c|c|c|}
\hline \multirow[b]{2}{*}{ Temperature $\left({ }^{\circ} \mathrm{C}\right)$} & \multirow[b]{2}{*}{$\mathrm{N}(\mathrm{mm})$} & \multirow[b]{2}{*}{$\mathrm{N} / \mathrm{h}$} & \multicolumn{3}{|c|}{ Reduction Factor } & \multicolumn{3}{|c|}{$\begin{array}{c}\text { Comparison with resistance from Uzzaman et al. [26] } \\
\qquad\left(\mathrm{R} / \mathrm{R}_{\text {Uzzaman }}\right)\end{array}$} \\
\hline & & & $\mathrm{R}=\mathrm{P}(\mathrm{A} 0.4) / \mathrm{P}(\mathrm{A} 0)$ & $\mathrm{R}=\mathrm{P}(\mathrm{A} 0.6) / \mathrm{P}(\mathrm{A} 0)$ & $\mathrm{R}=\mathrm{P}(\mathrm{A} 0.8) / \mathrm{P}(\mathrm{A} 0)$ & A 0.4 & A0.6 & A 0.8 \\
\hline 20 & & & 0.75 & 0.63 & 0.51 & 1.06 & 1.06 & 1.09 \\
\hline 100 & & & 0.76 & 0.65 & 0.53 & 1.08 & 1.10 & 1.14 \\
\hline 200 & & & 0.74 & 0.62 & 0.51 & 1.04 & 1.05 & 1.08 \\
\hline 300 & & & 0.75 & 0.63 & 0.51 & 1.05 & 1.06 & 1.10 \\
\hline 400 & 50 & 0.41 & 0.75 & 0.63 & 0.52 & 1.06 & 1.07 & 1.10 \\
\hline 500 & & & 0.75 & 0.64 & 0.52 & 1.06 & 1.08 & 1.11 \\
\hline 600 & & & 0.75 & 0.63 & 0.52 & 1.06 & 1.08 & 1.10 \\
\hline 700 & & & 0.75 & 0.63 & 0.51 & 1.05 & 1.07 & 1.09 \\
\hline 20 & & & 0.76 & 0.65 & 0.55 & 1.03 & 1.05 & 1.11 \\
\hline 100 & & & 0.77 & 0.67 & 0.57 & 1.05 & 1.08 & 1.15 \\
\hline 200 & & & 0.75 & 0.64 & 0.54 & 1.02 & 1.04 & 1.10 \\
\hline 300 & & & 0.75 & 0.64 & 0.55 & 1.03 & 1.05 & 1.11 \\
\hline 400 & 75 & 0.61 & 0.76 & 0.65 & 0.55 & 1.04 & 1.06 & 1.12 \\
\hline 500 & & & 0.76 & 0.66 & 0.56 & 1.04 & 1.07 & 1.13 \\
\hline 600 & & & 0.76 & 0.66 & 0.56 & 1.04 & 1.07 & 1.13 \\
\hline 700 & & & 0.76 & 0.65 & 0.55 & 1.03 & 1.06 & 1.12 \\
\hline 20 & & & 0.77 & 0.67 & 0.57 & 1.02 & 1.05 & 1.11 \\
\hline 100 & & & 0.78 & 0.68 & 0.59 & 1.03 & 1.07 & 1.14 \\
\hline 200 & & & 0.76 & 0.65 & 0.56 & 1.00 & 1.03 & 1.09 \\
\hline 300 & & & 0.76 & 0.66 & 0.56 & 1.01 & 1.03 & 1.09 \\
\hline 400 & 100 & 0.81 & 0.77 & 0.67 & 0.57 & 1.02 & 1.05 & 1.11 \\
\hline 500 & & & 0.77 & 0.67 & 0.58 & 1.02 & 1.06 & 1.13 \\
\hline 600 & & & 0.77 & 0.67 & 0.58 & 1.02 & 1.06 & 1.13 \\
\hline 700 & & & 0.77 & 0.67 & 0.57 & 1.01 & 1.05 & 1.11 \\
\hline
\end{tabular}




\begin{tabular}{|c|c|c|c|c|c|c|c|c|}
\hline \multirow[b]{2}{*}{ Temperature $\left({ }^{\circ} \mathrm{C}\right)$} & \multirow[b]{2}{*}{$\mathrm{N}(\mathrm{mm})$} & \multirow[b]{2}{*}{$\mathrm{N} / \mathrm{h}$} & \multicolumn{3}{|c|}{ Reduction Factor } & \multicolumn{3}{|c|}{$\begin{array}{l}\text { Comparison with resistance from Uzzaman et al. [26] } \\
\qquad\left(\mathrm{R} / \mathrm{R}_{\text {Uzzaman }}\right)\end{array}$} \\
\hline & & & $\mathrm{R}=\mathrm{P}(\mathrm{A} 0.4) / \mathrm{P}(\mathrm{A} 0)$ & $\mathrm{R}=\mathrm{P}(\mathrm{A} 0.6) / \mathrm{P}(\mathrm{A} 0)$ & $\mathrm{R}=\mathrm{P}(\mathrm{A} 0.8) / \mathrm{P}(\mathrm{A} 0)$ & A 0.4 & A0.6 & $\mathrm{A} 0.8$ \\
\hline 20 & & & 0.74 & 0.61 & 0.49 & 1.06 & 1.06 & 1.06 \\
\hline 100 & & & 0.74 & 0.62 & 0.50 & 1.06 & 1.07 & 1.08 \\
\hline 200 & & & 0.72 & 0.59 & 0.47 & 1.03 & 1.02 & 1.03 \\
\hline 300 & & & 0.73 & 0.60 & 0.48 & 1.04 & 1.03 & 1.04 \\
\hline 400 & 50 & 0.34 & 0.73 & 0.61 & 0.48 & 1.05 & 1.04 & 1.05 \\
\hline 500 & & & 0.74 & 0.61 & 0.49 & 1.05 & 1.05 & 1.06 \\
\hline 600 & & & 0.73 & 0.61 & 0.48 & 1.05 & 1.05 & 1.05 \\
\hline 700 & & & 0.73 & 0.60 & 0.48 & 1.04 & 1.04 & 1.04 \\
\hline 20 & & & 0.75 & 0.63 & 0.52 & 1.04 & 1.05 & 1.08 \\
\hline 100 & & & 0.75 & 0.63 & 0.53 & 1.04 & 1.06 & 1.10 \\
\hline 200 & & & 0.73 & 0.61 & 0.50 & 1.01 & 1.01 & 1.05 \\
\hline 300 & & & 0.73 & 0.61 & 0.51 & 1.02 & 1.02 & 1.05 \\
\hline 400 & 75 & 0.51 & 0.74 & 0.62 & 0.51 & 1.03 & 1.03 & 1.07 \\
\hline 500 & & & 0.74 & 0.63 & 0.52 & 1.03 & 1.05 & 1.09 \\
\hline 600 & & & 0.74 & 0.63 & 0.52 & 1.03 & 1.04 & 1.08 \\
\hline 700 & & & 0.74 & 0.62 & 0.51 & 1.02 & 1.03 & 1.07 \\
\hline 20 & & & 0.76 & 0.64 & 0.55 & 1.02 & 1.04 & 1.09 \\
\hline 100 & & & 0.76 & 0.65 & 0.55 & 1.02 & 1.04 & 1.10 \\
\hline 200 & & & 0.73 & 0.62 & 0.52 & 0.99 & 1.00 & 1.04 \\
\hline 300 & & & 0.74 & 0.62 & 0.53 & 1.00 & 1.00 & 1.05 \\
\hline 400 & 100 & 0.68 & 0.75 & 0.63 & 0.53 & 1.01 & 1.02 & 1.07 \\
\hline 500 & & & 0.75 & 0.64 & 0.55 & 1.01 & 1.03 & 1.09 \\
\hline 600 & & & 0.75 & 0.64 & 0.54 & 1.01 & 1.03 & 1.08 \\
\hline 700 & & & 0.75 & 0.63 & 0.54 & 1.00 & 1.02 & 1.07 \\
\hline
\end{tabular}

Table 6

Statistical analysis for determining the applicability of strength reduction factor equation proposed by Uzzaman et al. [26] for CFS C-sections loaded under ETF loading from ambient temperature to elevated temperatures.

\begin{tabular}{|c|c|c|c|c|}
\hline \multirow[b]{2}{*}{ Temperature $\left({ }^{\circ} \mathrm{C}\right)$} & \multirow[b]{2}{*}{ Mean, $\mathrm{P}_{\mathrm{m}}$} & \multicolumn{2}{|c|}{$\begin{array}{c}\text { Statistical Parameters } \\
\mathrm{R}_{\mathrm{FEA}} / \mathrm{R}_{\mathrm{p}} \\
((0.90-0.60(\mathrm{a} / \mathrm{h})+0.12(\mathrm{~N} / \mathrm{h}))\end{array}$} & \multirow[b]{2}{*}{$\begin{array}{c}\text { Resistance Factor } \\
\phi\end{array}$} \\
\hline & & $\begin{array}{c}\text { Coefficient of Variation } \\
V_{\mathrm{p}} \\
\end{array}$ & $\begin{array}{c}\text { Reliability index } \\
\beta \\
\end{array}$ & \\
\hline 20 & 1.07 & 0.03 & 2.85 & 0.90 \\
\hline 100 & 1.09 & 0.04 & 2.93 & 0.90 \\
\hline 200 & 1.05 & 0.04 & 2.77 & 0.90 \\
\hline 300 & 1.06 & 0.04 & 2.81 & 0.90 \\
\hline 400 & 1.07 & 0.04 & 2.85 & 0.90 \\
\hline 500 & 1.08 & 0.04 & 2.88 & 0.90 \\
\hline 600 & 1.07 & 0.04 & 2.86 & 0.90 \\
\hline 700 & 1.07 & 0.04 & 2.83 & 0.90 \\
\hline
\end{tabular}

\section{Comparison of the reduction factors}

The reduction factor equation proposed by Uzzaman et al. [26] for unfastened CFS C-sections with centred web holes under ETF loading was determined (see equation 1). The feasibility of the proposed equation of Uzzaman et al. [26] was assessed in this study for extending its application from ambient temperature to elevated temperatures. Tables 5(a), 5(b) and 5(c) (see Figs. 7(a) and 7(b)) compare the reduction factors determined from the equation 1 for the case of unfastened C-sections with centred web holes at elevated temperatures.

The reliability of the reduction factor equation proposed by Uzzaman et al. [26] for its application at elevated temperatures was also checked. In order to calculate the reliability index, a resistance factor $(\phi)$ of 0.90 was used. The load combination of 1.2DL + 1.6LL ( $\mathrm{DL}=$ Dead load, $\mathrm{LL}=$ Live load $)$ as mentioned in the NAS specification [28] was used in the reliability study. The mean $\left(\mathrm{M}_{\mathrm{m}}\right)$ and coefficient of variation $\left(\mathrm{V}_{\mathrm{m}}\right)$ of the material properties were considered as 1.10 and 0.10 , respectively. As can be seen from Table 6 , for every specific temperature ranging from $20^{\circ}$ to $700^{\circ} \mathrm{C}$, the $\beta$ (reliability factor) value was greater than 2.5 (see Fig. 8). This is the target reliability index value for CFS structural members and is recommended by the North American specification [29] as the lower limit. This shows that the proposed strength reduction factor equation of Uzzaman et al. [26] is acceptable in determining the effect of circular web holes on the web crippling strength of CFS C-sections at elevated temperatures. 


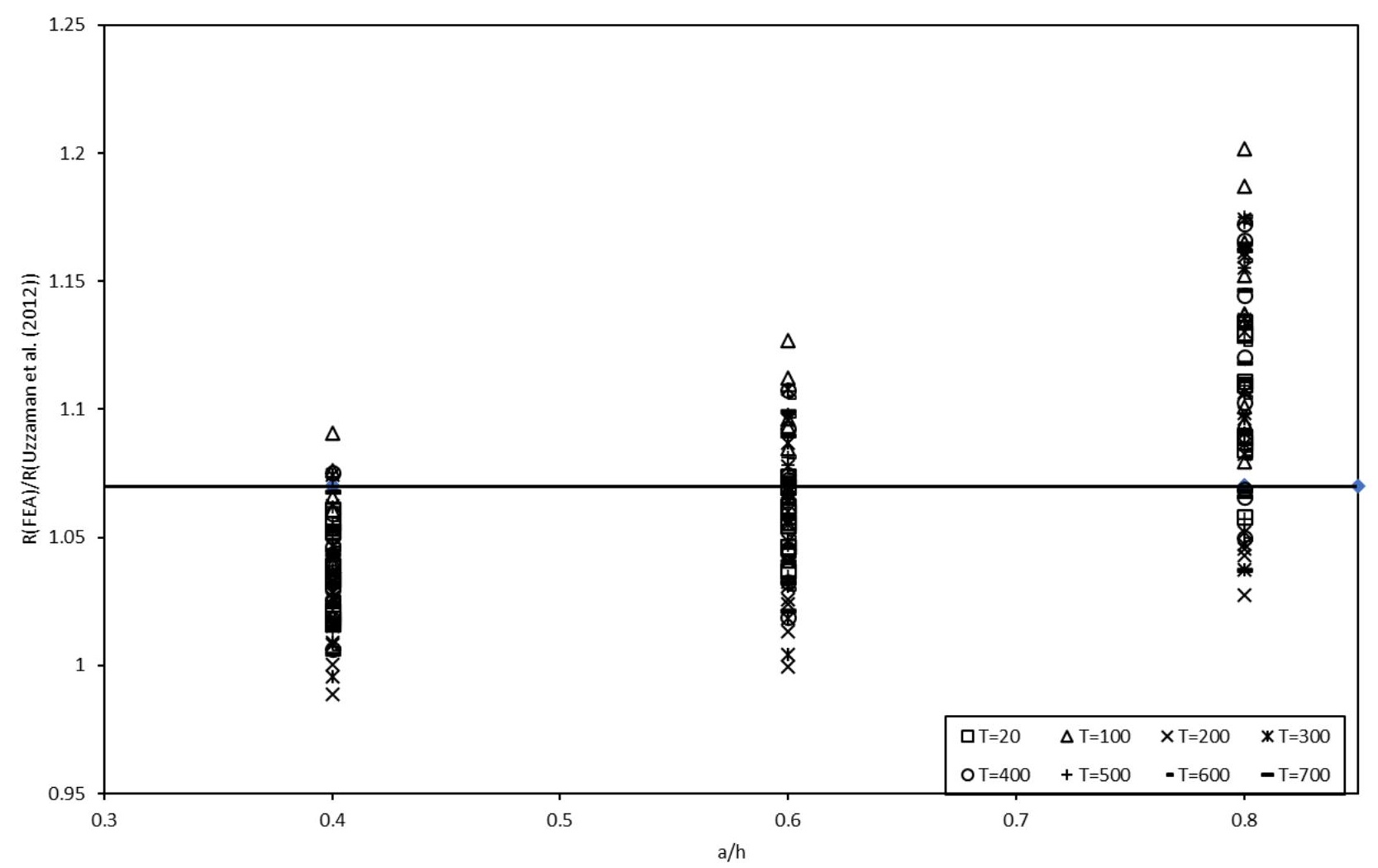

(a) $\mathrm{R}$ (FEA)/RUzzaman et al. vs a/h ratio

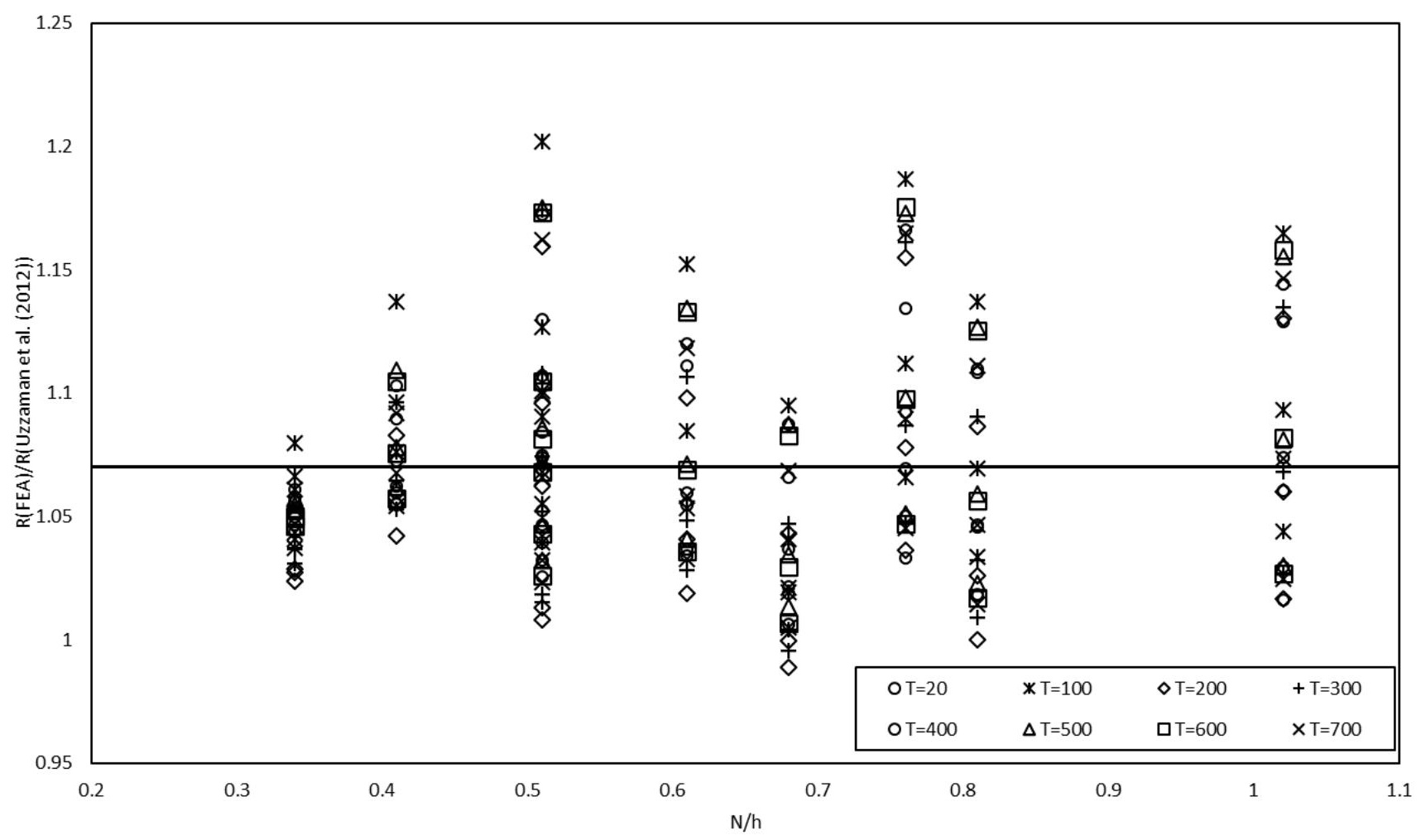

(b) R(FEA)/RUzzaman et al. vs N/h ratio

Fig. 7 Strength reduction factor comparison with centred circular web holes 


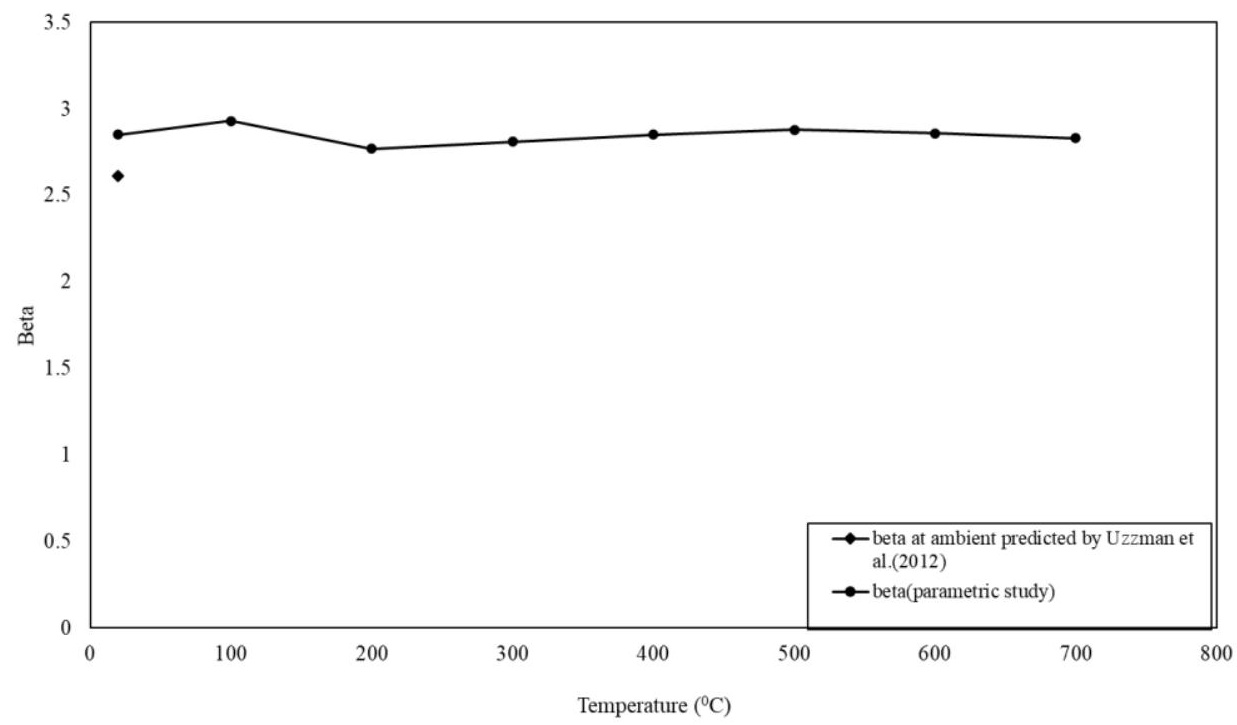

Fig. 8 Comparison of the beta value obtained from the parametric study and the beta value at the ambient temperature by Uzzaman et al. [26]

\section{Conclusion}

This study investigated the influence of circular web holes and bearing length on the web crippling strength of G250 grade of CFS C-sections when subjected to ETF loading at elevated temperatures. A finite element model was developed for CFS C-sections under ETF loading conditions and validated against the corresponding experimental results available in the literature. The validated finite element model was then used to conduct an extensive parametric study comprising 288 models. The aim of this parametric study was to investigate the effects of different parameters such as the sizes of the web holes, bearing length and temperature ranging from $20{ }^{\circ} \mathrm{C}$ to $700{ }^{\circ} \mathrm{C}$ at an interval of 100 degrees, on the web crippling capacity of CFS C-sections under ETF loading. Both the cases of $\mathrm{C}$-sections with and without web holes were considered.

The parametric study results were then used to assess the applicability of the strength reduction factor equation proposed by Uzzaman et al. [26] for CFS channel-sections with web holes under ETF loading from ambient temperature to elevated temperatures. After statistical analysis in the form of reliability analysis, it was found that the reduction factor equation of Uzzaman et al. [26] is safe and reliable to be used at elevated temperatures.

\section{Notations}

$a / h$

$b_{f}$

$b_{l}$

$d$

E

FEA

$h$

$L$

$N$

$\mathrm{N} / \mathrm{h}$

$P_{\text {EXP }}$

$P_{\text {FEA }}$

$\mathrm{P}_{\mathrm{m}}$

$r_{\mathrm{q}}$

$r_{\mathrm{i}}$

$R_{F E A}$

$R_{U z z a m a n}$

$t$

$\mathrm{f}_{u}$
Diameter of circular web hole;

Web hole ratio;

flange width;

lip width;

Depth of cross-section;

Young's modulus of elasticity;

Finite element analysis;

Depth of the web's flat portion;

Specimen length;

Bearing plate length;

Bearing length ratio;

Experimental ultimate web crippling load per web;

Web crippling strength per web predicted from FEA;

Mean;

Inside fillet radius between web and hole;

Inside fillet radius of section;

Reduction factor obtained from FEA study;

Reduction factor obtained from Uzzaman et al. (2012);

Thickness of the section;

Static ultimate tensile strength;

\section{$\mathrm{f}_{\mathrm{y}}$}

$\beta$

$\mathrm{V}_{\mathrm{p}}$

$\phi$

$\sigma_{\text {true }}$

$\sigma$

$\varepsilon$

$\varepsilon_{\text {true,pl }}$

Yield stress;

Reliability index;

Coefficient of variation;

Resistance factor;

True stress;

Engineering stress;

Engineering strain;

True plastic strain;

\section{References}

[1] Javed, F. M., Hafizah , N., Memon , A. S., Jameel , M., \& Aslam , M. (2017). Recent research on cold formed steel beams and columns at elevated temperature: A review. Construction and Building Materials, 144, 686-701.

[2] Darcy, G., \& Mahendran, M. (2008). Development of a new cold formed steel building system. Advances in Structural Engineering, 11(6), 661-677.

[3] Schafer, B. (2002). Local, distortional and euler buckling of thin-walled columns. Journal of Structural Engineering, 128(3), 289-299.

[4] Roy, K., Lim, J. B., Lau, H. H., Yong, P., Clifton, G., Johnston, R. P., . . Mei, C. C. (2019). Collapse Behaviour of a Fire Engineering Designed Single-Storey Cold Formed Steel Building in Fires. Thin Walled structures, 142, 340-357.

[5] Uzzaman , A., Lim , J. B., Nash, D., Rhodes , J., \& Young , B. (2013). Effect of offset web holes on web crippling strength cold-formed steel channel sections under end-two flange loading condition. Thin Walled Structures, 65, 34-48.

[6] Lian, Y., Uzzaman, A., Lim, J., Abdelal, G., Nash, D., \& Young, B. (2017). Effect of Web holes on web crippling strength of cold formed steel channel sections under interior-oneflange loading condition - Part I: Tests and finite element analysis. Thin Walled Structures, $111,103-12$.

[7] Lian, Y., Uzzaman, A., Lim, J., Abdelal, G., Nash, D., \& Young, B. (2017). Effect of Web holes on web crippling strength of cold formed steel channel sections under end-one-flange loading condition - Part II Parametric study and proposed design equation. Thin Walled Structures, 111, 103-12.

[8] Gunalan, S., Heva, Y. B., \& Mahendran, M. (2015). Local buckling studies of cold formed steel compression members at elevated temperatures. Journal of Constructional Steel Research, 108, 31-45.

[9] Gunalan, S., Mahendran, M. (2019). Experimental study of unlipped channel beams subject to web crippling under one flange load case. Journal of Advanced Steel Construction, 15, 165-172

[10] Elilarasi, K., Kasturi, S., Janarthan, B. (2020). Effect of Circular openings on Web Crippling of Unlipped channel sections under End-two-flange load case. Journal of Advanced Steel Construction, 16, 310-320

[11] Imran, M., Mahendran, M., \& Poologanathan, K. (2018). Mechanical properties of cold formed steel tubular sections at elevated temperatures. Journal of Constructional Steel Research, 143, 131-147.

[12] Kankanamge, N. D., \& Mahendran, M. (2011). Mechanical properties of cold formed steel at elevated temperatures. Thin Walled Structures, 49, $26-44$.

[13] Ranawaka, T., \& Mahendran, M. (2009). Experimental study of the mechanical properties of light gauge cold formed steels at elevated temperatures. Fire Safety Journal, 44, 219-229.

[14] Chen, J., \& Young, B. (2007). Experimental investigation of cold formed steel material at elevated temperatures. Thin Walled Structures, 45(1), 96-110.

[15] Lim, J.B.P, \& Young, B. (2007). Effects of elevated temperatures on bolted moment connections between cold formed steel members. Engineering Structures, 29, 2419-2427.

[16] Landesmann, A., \& Camotim, D. (2016). Distortional failure and DSM design of cold-formed steel lipped channel beams under elevated temperatures. Thin Walled Structures, 98, 75-93.

[17] Laim L. Rodrigues Joao Paulo C., Craveiro Helder D. (2016). Flexural behaviour of axially and rotationally re-strained cold-formed steel beams subjected to fire. Thin Walled Structures, 98, 39-47 
[18] Kankanamge, N. D., \& Mahendran M. (2012). Behavior and design of cold formed steel beams subjected to lateral torsional buckling at elevated temperatures. 61, 213-228.

[19] Gunalan, S., Heva, B. Y., \& Mahendran, M. (2014). Flexural-Torsional buckling behaviour and design of cold formed steel compression members at elevated temperatures. Engineering Structures, 79, 149-168.

[20] Ranawaka, T., \& Mahendran, M. (2010). Numerical modelling of light gauge cold formed steel compression members subjected to distortional buckling at elevated temperatures. Thin Walled Structures, 48, 334-344.

[21] Feng, M., \& Wang, Y. (2003). Structural behaviour of cold-formed thin-walled short steel channel columns at elevated temperatures. Part I experiments. Thin-Walled Structures, 41, 543-570.

[22] ASCE. ((2005)). Minimum design loads for buildings and other structures. American Society of Civil Engineers Standard.

[23] BS EN 1993-1-1 Eurocode 3. Design of Steel Structures. General requirements, British Standards Institutions;2005
[24] BS5950 (1998). Structural use of steelwork in buildings. Part 5 Code of practice for the design of cold-formed sections, London: British Standard Institution

[25] AS/NZS Standards Australia. Cold Formed Steel Structures, AS/NZS 4600:2018, Standards Australia/Standards New Zealand, 2018

[26] Uzzaman, A., Lim, J.B.P., Nash, D., Rhodes, J., \& Young, B. (2012). Cold-formed steel sections with web openings subjected to web crippling under two-flange loading conditions - Part II: Parametric study and proposed design equations. Thin-Walled Structures, 56, 7987.

[27] Uzzaman, A., Lim, J.B.P, Nash, D., Rhodes, J., \& Young, B. (2012). Cold-formed steel sections with web openings subjected to web crippling under two-flange loading conditions - Part I: Tests and Finite element analysis. Thin-Walled Structures, 56, 38-48

[28] ANSYS. (2017). User's Manual, revision 17.0. Swanson Analysis System.

[29] NAS, North American Specification for the design of cold-formed steel structural members. AISI S100-2007, AISI Standard. American Iron and Steel Institute;2007. 


\title{
STUDY ON FORCE MECHANISM OF CABLE-TRUSS FRAME AND JUMPED LAYOUT OF ANNULAR CROSSED CABLE-TRUSS STRUCTURE
}

\author{
Jian $\mathrm{Lu}^{1}$, Xiong-Yan Li ${ }^{1,}{ }^{*}$, Su-Duo Xue ${ }^{1}$, Ren-Jie Liu ${ }^{2}$ and Majid Dezhkam ${ }^{1}$ \\ ${ }^{I}$ College of Civil and Architecture Engineering, Beijing University of Technology, China \\ ${ }^{2}$ Civil Engineering College Institute, Yantai University, Yantai, Shandong 264000, China \\ *(Corresponding author: E-mail: xiongy2006@126.com)
}

\section{A B S T RA C T}

A new type of cable-strut tension structure named Annular Crossed Cable-truss Structure(ACCTS) comprises a series of planar cable-truss frames crossed each other. To investigate the force mechanism of ACCTS, a cable-truss frame model with 2-bar and 6-cable has been developed, and its initial stiffness formula has been derived as well. The model is further simplified to make it is upper and lower vector heights equal, and then the initial stiffness formula and the critical slack load formula are further deduced. Based on ANSYS software and cable-truss frame with a span of $60 \mathrm{~m}$, the influences of the number of struts and position of jumped layout on the cable-truss frame are studied. According to the former $60 \mathrm{~m}$ span cabletruss frame's research results, the jumped layout of ACCTS with a span of $100 \mathrm{~m}$ is studied. The static and dynamic performances of two schemes, the optimal jumped layout scheme and the original scheme, are systematically studied. It is shown that the number of struts would be about $6 \sim 8$ for the planar cable-truss frame and the optimal order of jumped layout is strut $6-7 \rightarrow$ strut $4-5 \rightarrow$ strut 2-3. The optimal order of jumped layout of ACCTS agrees with that of the cable-truss frame, verifying the feasibility of conclusions. In the condition of no variation in the original structure's static and dynamic performance, the optimal scheme of the jumped layout will lower the steel consumption and enhance the buckling loads Moreover, it also simplifies structure for easy construction.

\section{A R T I C L E H I S T O R Y}

$\begin{array}{ll}\text { Received: } & \text { 16 May 2020 } \\ \text { Revised: } & \text { 8 March 2021 } \\ \text { Accepted: } & \text { 13 March 2021 }\end{array}$

\section{K E Y W O R D S}

Planar cable-truss frame

Annular Crossed Cable-truss

structure (ACCTS);

Force mechanism;

Jumped layout;

Static and dynamic performance

\section{Introduction}

Cable-strut tension structure [1-2], an essential part of large-span spatial structures, is well known in the construction industry for its lightweight, beautiful appearance, fast construction speed, considerable spanning ability, and so on. Furthermore, cable-truss tension structure is one of the most competitive structure types in cable-truss tension structures [3-4]. Cable-truss tension structure refers to the integral tension structure formed by the same kind of planar cable-truss frames according to certain layout principles. This kind of structure's common point is that the integral structure can be divided into the same kind of planar cable-truss frames. Meanwhile, planar cable-truss frames share the same characteristics, such as lightweight, high stiffness, sizeable spanning ability, and simple construction. At present, cable-truss tension structures mostly include two genres: Spoke Cable-truss Structure [5] and Annular Crossed Cable-truss Structure (ACCTS) [6-8].

Spoke Cable-truss Structure cases involve Foshan Stadium, Shenzhen Baoan Stadium, Yueqing Stadium [5], Busan Stadium in South Korea [9], and so on. But ACCTS is still at the stages of theoretical and experimental research, and there are no any project cases in the world. So, there are still lots of unfinished studies about ACCTS, including how to solve self-stress modes, how to construct, how to simplify structure, and so on.

ACCTS as a novel cable-truss tension structure is composed of a series of planar cable-truss frames interwoven with each other [6-7]. It shares two load transfer paths that strengthen the structure's anti-collapse capacity [6,10-11]. The form of ACCTS results in its strong anti-collapse capacity; however, its form also leads to the difficulty of erection. In the further studies, it is found that although ACCTS has a strong anti-collapse capacity, its construction forming is too difficult. With the increase of ACCTS's span, the strut number and length will be enlarged, and serious collision and winding of struts occur during construction due to ACCTS formed by a series of planar cable-truss frames interwoven with each other, which cause many difficulties in construction. If there is a way to reduce struts number, it will simplify its construction process, and the structural self-weight will be reduced as well. Thus it is necessary to evaluate the effect on struts being removed from ACCTS

In the paper, a cable-truss frame finite element model with a span of $60 \mathrm{~m}$ is established, and the influences of the number of struts and position of jumped layout on the cable-truss frame are studied. And then the jumped layout for ACCTS is studied. Finally, based on the optimal scheme of jumped layout, the optimal scheme's static and dynamic performance are studied. Research methods and results provide simplified methods and theoretical basis for the construction of ACCTS and provide a new method to simplify cable-truss frame and ACCTS.

\subsection{Theory analysis of planar cable-truss frame}

Take the 2-bar and 6-cable planar cable-truss frame in Fig.1 as an example, and study its force mechanism under concentrated load. Assuming that:

(1) The two terminals of the cable-truss frame are rigid, the same below;

(2) The angles between cables and struts are unchanged in a small elastic range;

(3) The cables and struts are not slipped at nodes.

In Fig. 1, the initial pre-stresses of upper and lower chord cables of cable truss frames are $T_{1}$ and $T_{2}$, respectively. The angles between $T_{1} \sim T_{2}$ and the axis are the $\theta_{1}$ and $\theta_{2}$. Under load $\mathrm{P}$, the vertical deformations of two terminals of the strut are $\delta_{1}$ and $\delta_{2}$. Meanwhile, the variation of internal forces of upper and lower cables are the $\triangle T_{1}$ and $\triangle T_{2}$. The modulus and section area of cable is $E_{c}$ and $A_{c}$, respectively. The modulus and section area of the strut are $E_{s}$ and $A_{s}$, respectively.

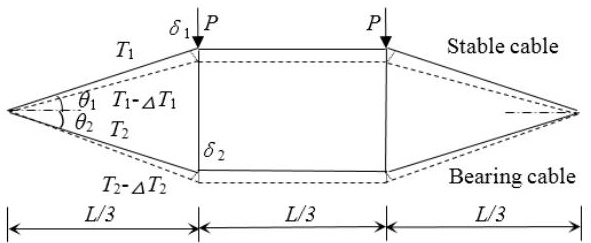

Fig. 1 Force diagram of planar cable-truss frame

Under load $\mathrm{P}$, the vertical deformations of two terminals of strut are $\delta_{1}$ and $\delta_{2}$, the length variations of upper and lower chord cables are as follows:

$\left\{\begin{array}{l}\Delta l_{1}=\delta_{1} \sin \theta_{1} \\ \Delta l_{2}=\delta_{2} \sin \theta_{2}\end{array}\right.$

According to the length variations of upper and lower chord cables, its variations of cable forces are as follows:

$\left\{\begin{array}{l}\Delta T_{1}=E_{c} A_{c} \frac{3 \delta_{1}}{L} \sin \theta_{1} \cos \theta_{1} \\ \Delta T_{2}=E_{c} A_{c} \frac{3 \delta_{2}}{L} \sin \theta_{2} \cos \theta_{2}\end{array}\right.$

The internal forces of upper and lower chord cables are: 
$\left\{\begin{array}{l}\overline{T_{1}}=T_{1}-\Delta T_{1}=T_{1}-E_{c} A_{c} \frac{3 \delta_{1}}{L} \sin \theta_{1} \cos \theta_{1} \\ \overline{T_{2}}=T_{2}+\Delta T_{2}=T_{2}+E_{c} A_{c} \frac{3 \delta_{2}}{L} \sin \theta_{2} \cos \theta_{2}\end{array}\right.$

From the equilibrium relation of upper and lower nodes of struts, it can be gained as follows:

$$
P+\bar{T}_{1} \sin \theta_{1}=\overline{T_{2}} \sin \theta_{2}
$$

Sustitute Eq.(3) into Eq.(4), the relation between external loads and structural displacements are as follows:

$$
\begin{aligned}
& P=\left(T_{2} \sin \theta_{2}-T_{1} \sin \theta_{1}\right) \\
& +E_{c} A_{c} \frac{3}{L}\left(\delta_{1} \sin ^{2} \theta_{1} \cos \theta_{1}+\delta_{2} \sin ^{2} \theta_{2} \cos \theta_{2}\right)
\end{aligned}
$$

It can be gained according to the forced relation of struts:

$$
\frac{\delta_{1}-\delta_{2}}{\left(\tan \theta_{1}+\tan \theta_{2}\right) L / 3}=\frac{\Delta T_{2} \sin \theta_{2}}{E_{s} A_{s}}
$$

Combining Eq.(5) and Eq.(6), it can be gained as follows:

$P=\left(T_{2} \sin \theta_{2}-T_{1} \sin \theta_{1}\right)+$

$\frac{3 E_{c} A_{c} \delta_{1}}{L} \sin ^{2} \theta_{1} \cos \theta_{1}+\frac{3 E_{c} A_{c}}{L} \sin ^{2} \theta_{2} \cos \theta_{2} \times$

$$
\frac{\delta_{1} E_{s} A_{s}}{E_{s} A_{s}+E_{c} A_{c} \sin ^{2} \theta_{2} \cos \theta_{2}\left(\tan \theta_{1}+\tan \theta_{2}\right)}
$$

When the angles between upper and lower chord cables and center axis are the same $\left(\theta_{1}=\theta_{2}\right)$, the Eq.(7) can be simplified as follows:

$$
P=\frac{3 E_{c} A_{c} \delta_{1}}{L} \sin ^{2} \theta_{1} \cos \theta_{1}\left(1+\frac{E_{s} A_{s}}{E_{s} A_{s}+2 E_{c} A_{c} \sin ^{3} \theta_{1}}\right)
$$

When the stable cables (upper chord cables) are slack under external laods, use the above analysis method and the slack stiffness of cable-truss frame can be obtained as follows:

$$
K=\frac{3 E_{c} A_{c}}{L} \sin ^{2} \theta_{1} \cos \theta_{1} \frac{E_{s} A_{s}}{E_{s} A_{s}+2 E_{c} A_{c} \sin ^{3} \theta_{1}}
$$

From Eq.(3) and Eq.(4), when upper chord cables are slack, the critical slack load of the cable-truss frame can be gained as follows:

$$
P_{c r}=T_{1} \sin \theta_{1}\left(1+\frac{E_{s} A_{s}}{E_{s} A_{s}+2 E_{c} A_{c} \sin ^{3} \theta_{1}}\right)
$$

Eq.(8) is the initial stiffness equation of the cable-truss frame, and it can be seen from Eq.(8) that the pre-stresses have no effects on the initial stiffness of the cable-truss frame. Eq.(9) is the slack stiffness equation when upper chord cables are slack. From Eq.(8) and Eq.(9), it can be known that the initial stiffness and slack stiffness have mainly consisted of structural material and shape parameter $\sin ^{2} \theta_{1} \cos \theta_{1}$ of the cable-truss frame. It can be seen from Eq.(10) that the critical slack load is linear with the initial pre-stress of a cable when the upper chord cable is slack.

\subsection{FEM analysis of cable-truss frame}

Take the example in Ref. [12] as a research objective. The planar cable-truss frame is shown in Fig. 2. Element 2-3 and element 4-5 are the struts, and the others are the cables. The material parameters of cable and strut are shown in Table 1.

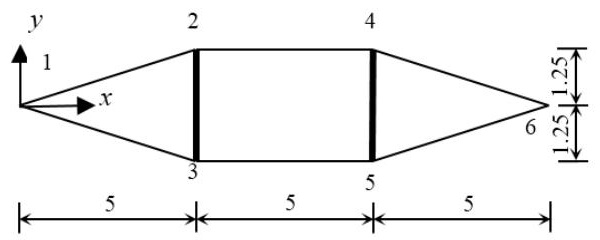

Fig. 2 Schematic diagram of planar cable-truss frame Unit:m

Table 1

Material parameter of cable-strut frame

\begin{tabular}{cccc}
\hline Material & Section area $/ \mathrm{mm}^{2}$ & Elastic modulus/MPa & Poisson's ratio \\
\hline Cable & 28.2743 & $1.80 \times 10^{5}$ & 0.3 \\
Strut & 7.0686 & $2.06 \times 10^{5}$ & 0.3 \\
\hline
\end{tabular}

When initial pre-stresses are $2.5 \mathrm{kN}, 5 \mathrm{kN}, 7.5 \mathrm{kN}, 10 \mathrm{kN}, 12.5 \mathrm{kN}, 15 \mathrm{kN}$, respectively, the comparsion results between Eq.(10) and FEM method are shown in Fig. 3. The relation of load-displacement of cable-truss frame under different initial pre-stresses is shown in Fig. 4.

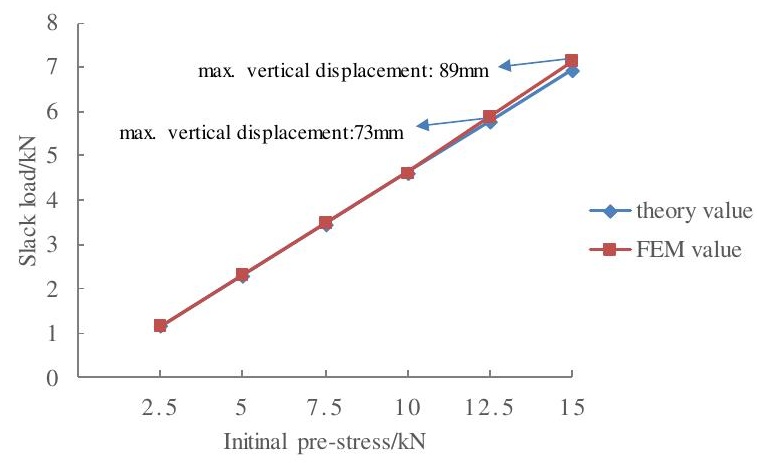

Fig. 3 Critical slack loads $P_{\mathrm{cr}}$

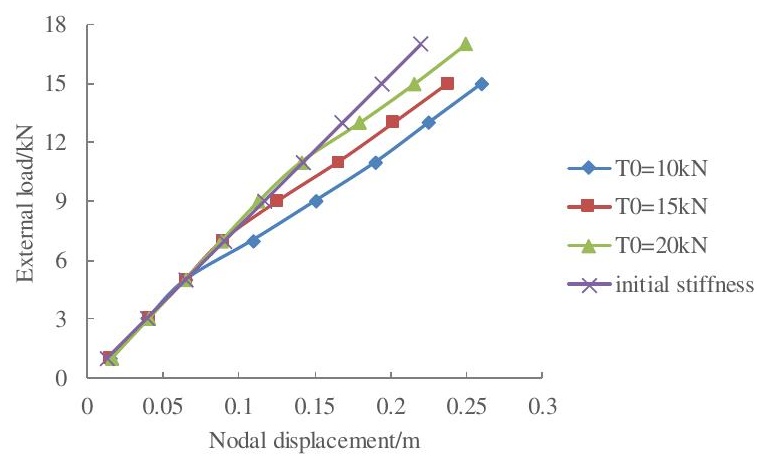

Fig. 4 Load-displacement curve of cable-truss frame

From Fig. 3, it can be seen that the theoretical values are linear with the FEM values, which verifies that the theory equations are correct. When the pre-stresses are higher, the FEM values are larger than the theoretical values. The reason is that the larger the critical slack loads are, the larger deformations of the cabletruss frame are under critical slack loads, shown in Fig. 3. 《Technical Specification for Cable Structure $》$ JGJ257-2012 [13] specifies that the maximum allowable displacement is $[\sigma]=l / 200=7.5 \mathrm{~mm}(l$ is the span of the cabletruss frame.). When the $\mathrm{T}_{0}$ is $15 \mathrm{kN}$, the maximum displacement is $8.9 \mathrm{~mm}$, which does not meet the requirements. So the initial pre-stresses of the cable-truss frame should not be too large.

It can be seen from Fig. 4 that the load-displacement curves of cable-truss frames under different pre-stresses are composed of two sections. The first section is the change law of stiffness when the upper chord cable is not slack, which shows that stiffness variation has no connection with initial pre-stresses and the change law is the same as Eq.(8). When the upper chord cable is not slack, 
the cable-truss frame's load-displacement curve is the same as the initial stiffness curve. The second section is the change law of stiffness when the upper chord cable is slack, which shows that adding the initial pre-stresses of cables can increase the cable-truss frame's critical slack loads.

\section{Study the influences of the position of struts on cable-truss frame}

\subsection{The case is that the position of middle struts is fixed}

Design a cable-truss frame with a span of $60 \mathrm{~m}$ and keep the position of two middle struts fixed. The influences of the number of struts on the cable-truss frame are studied when the number of struts is $2,4,6$, and 8 (the lengths of two sides of middle struts are equally divided by the newly added struts). By Ref. [14], the economic rise-span ratio of stable cable and bearing cable is $1 / 25 \sim 1 / 20$ and $1 / 20 \sim 1 / 15$, respectively. So, the rise-span ratio of stable cable and bearing cable is $1 / 20$. Namely, the vector heights of upper and lower chord cables are all $3 \mathrm{~m}$. Taking model 2 as an example, considering the integral cable-truss frame's reasonable forces, the lengths of struts should satisfy $h_{2}<h_{1}<2 h_{2}$. The four models of the cable-truss frame are shown in Fig.5. The cable forces of middle cable sections for four models are all $300 \mathrm{kN}$, and the material parameters of cable and strut are shown in Table 2.

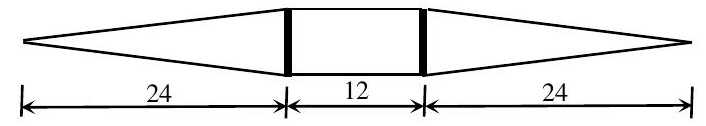

(a) Model $1-2$ struts model

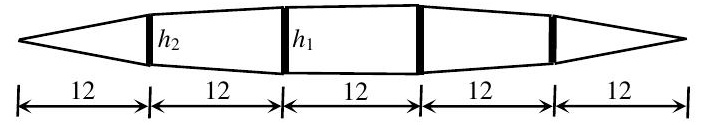

(b) Model $2-4$ struts model

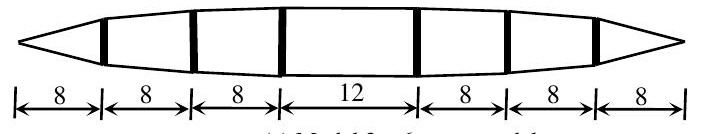

(c) Model 3 - 6 struts model

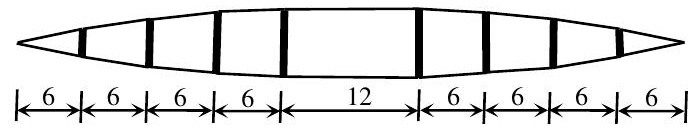

(d) Model $4-8$ struts model

Fig. 5 Four cable-truss frame models when middle struts are fixed Unit: $m$

Table 2

Material parameters of cable and strut

\begin{tabular}{ccccc}
\hline Material & $\begin{array}{c}\text { Cross- } \\
\text { section/mm }\end{array}$ & $\begin{array}{c}\text { Elastic } \\
\text { modulus/MPa }\end{array}$ & $\begin{array}{c}\text { Thermal } \\
\text { expansion } \\
\text { coefficient }\end{array}$ & $\begin{array}{c}\text { Poison's } \\
\text { ratio }\end{array}$ \\
\hline Cable & 731.00 & $1.80 \times 10^{5}$ & $1.2 \times 10^{5}$ & 0.3 \\
Strut & 1414.00 & $2.06 \times 10^{5}$ & $1.2 \times 10^{5}$ & 0.3 \\
\hline
\end{tabular}

Under external loads, the nodal load-displacement curves of four cable-truss frame models with or without self-weight are shown in Figs. 6 7. The first six frequencies are shown in Fig. 8.

From Fig. 6, when the two middle struts are fixed, the cable-truss frame's displacements increase with the increase of the number of struts. When the number of struts is more than 6 , the number of struts on the cable-truss frame's displacements are small. So, it is not that the more struts are, the more advantageous it is to reduce the displacement of the cable-truss frame. The number of struts should be controlled within a specific range. It is suggested that the number of struts should be about $6 \sim 8$ for that kind of cable-truss frame.

From Figs. 6 7, the load-displacement curves of four cable-truss frame models with or without self-weight are identical, showing self-weight has little effects on the cable-truss frame. From Fig. 8, the frequencies of model 1 are the largest, and the frequencies of model 2 and model 3 are close to each other. The vibration modes of the four models are identical (the vibration modes of the cable-truss frame are mainly upper and lower vibration accompanied by local torsion of cable-truss frame), which shows that the number of struts does not change its vibration features.

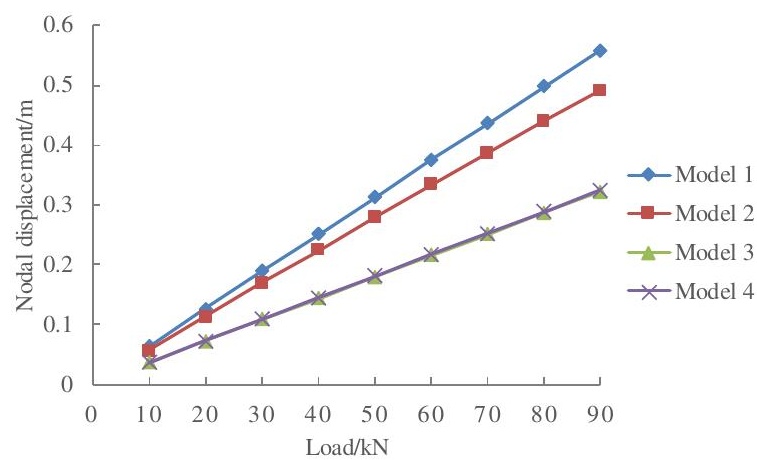

Fig. 6 Nodal load-displacement curves without self-weight

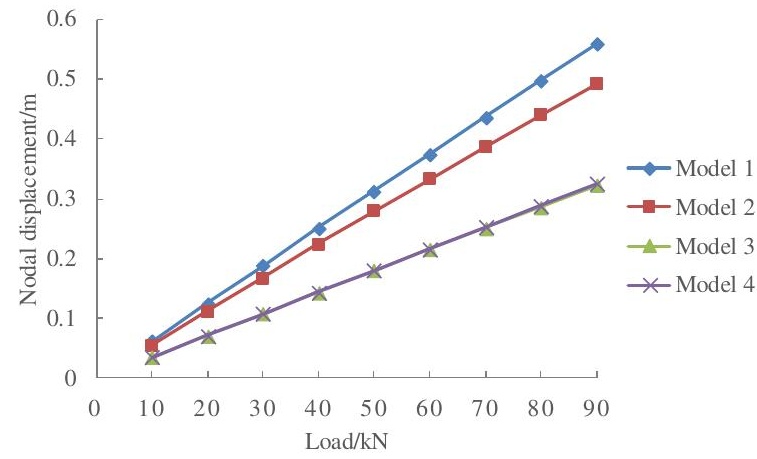

Fig. 7 Nodal load-displacement curves with self-weight

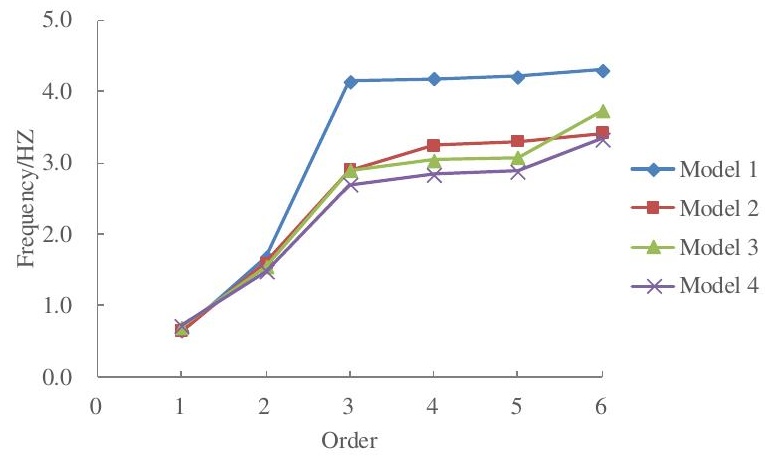

Fig. 8 First sixth frequencies of four models

\subsection{The case is that the position of middle struts is not fixed}

The case that middle struts' position is not fixed refers to taking all struts to equalize the span of the cable-truss frame. When the number of struts is not equal, the distance between every two struts is also different. When the middle struts position is not fixed, the four models of the cable-truss frame are shown in Fig. 9 , and the material parameters are shown in Table 2.

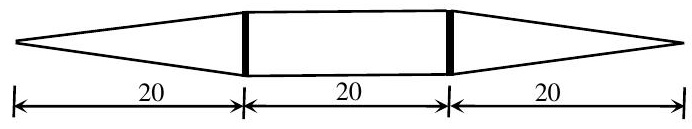

(a) Model $1-2$ struts model

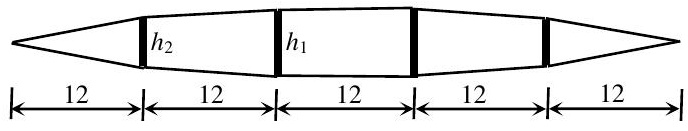

(b) Model $2-4$ struts model

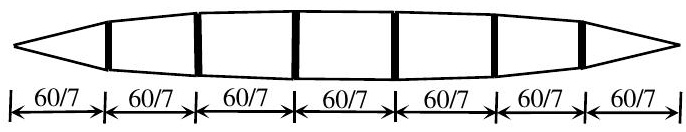

(c) Model 3-6 struts model 


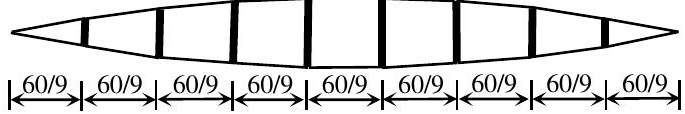

(d) Model 4-8 struts model

Fig. 9 Four cable-truss frame models when middle struts are not fixed Unit: $m$

Under external loads, the nodal load-displacement curves of four cable-truss frame models are shown in Fig. 10, and the first six frequencies are shown in Fig. 11.

From Fig. 10, with the increase of the number of struts, the displacement variations of the four models are not the same. However, when the number of struts is more than 4 , the four models' displacement variations are minimal, and the maximum displacement difference is $18.08 \mathrm{~mm}$. Therefore, when the number of struts exceeds a specific range, it is not apparent to reduce the cable-truss frame's displacement by increasing the number of struts. It suggests that the number of struts should be about 6 8. Moreover, it is known from Fig. 11 that the first six frequencies and vibration modes are identical.

It can be seen from Fig. 10 11 that when the span of the cable-truss frame is fixed, the first-order frequency of the cable-truss frame is lower whether the position of the middle struts is fixed or not, which shows that the cable-truss frame is soft. The external excitation can easily disturb the cable-truss frame. So, planar cable-truss frames are mostly arranged in the form of positive, oblique, or additional linked cables to form spatial cable-truss tension structure in practical engineering to improve the lateral stiffness and integral stability of the cabletruss frame.

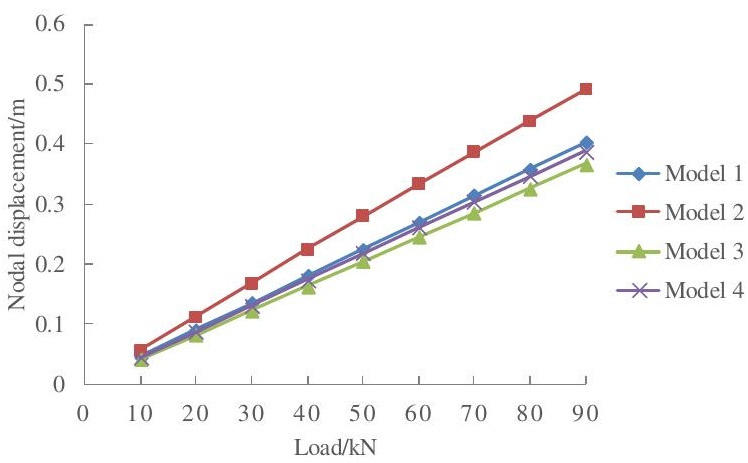

Fig. 10 Load-displacement curves of nodes

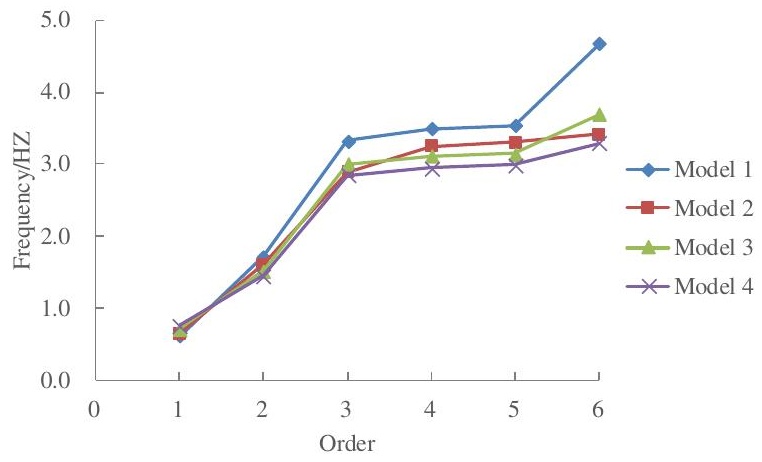

Fig. 11 First 6th frequencies of four models

\section{Study on the effects of jumped layout on cable-truss frame}

Taking model 4 in Section 3.1 as a research objective (shown in Fig. 5d). Jumped layout refers to studying the effects of jumped layout on the cable-truss frame's mechanical behaviors when 2-3, 4-5, 6-7, as well as its symmetrical position, are separately removed (shown in Fig. 13b, Fig. 13c, and Fig. 13d, respectively).

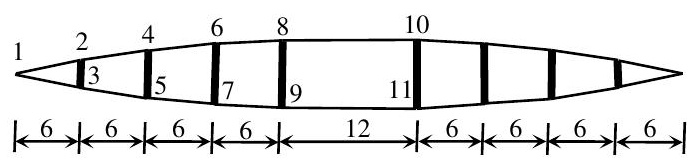

Fig. 12 Model 4 - eight struts model Unit: $m$
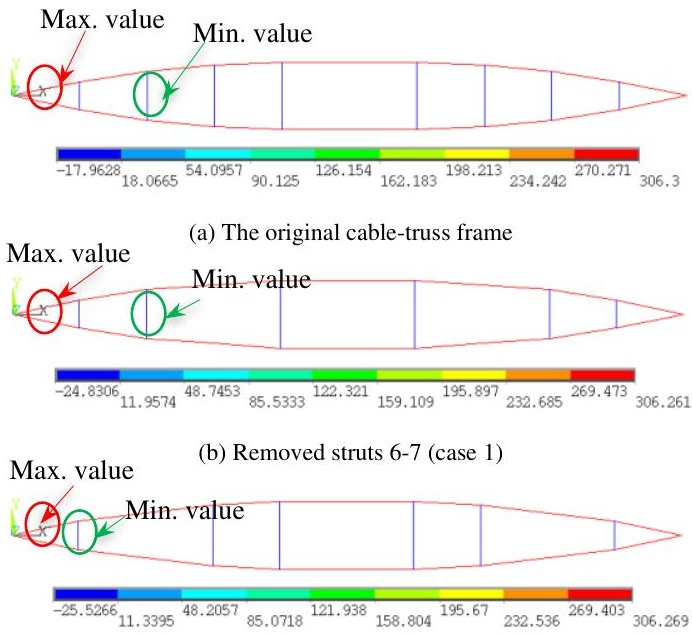

(c) Removed struts 4-5 (case 2)

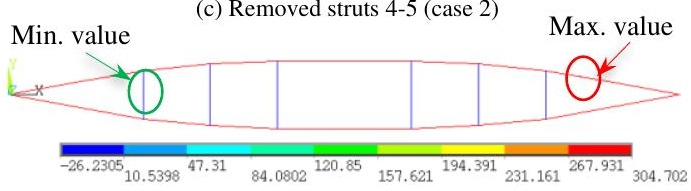

(d) Removed struts 2-3 (case 3)

Fig. 13 Internal force diagrams of cable-truss frame after jumped layout Unit: kN

It can be seen from Fig. 13 that the changes of pre-stress values are small under the pre-stress condition, and the position of maximum pre-stress value does not change. However, the changes of internal forces of struts are large, and the maximum displacement position also changes. From the changes of internal forces and position of cables and struts, the influence of the struts' position on the cable-truss frame is: strut 2-3>strut 4-5>strut 6-7. Therefore, when optimizing the cable-truss frame's struts, the optimal order of jumped layout is: strut 6$7 \rightarrow$ strut $4-5 \rightarrow$ strut $2-3$.

The original cable-truss frame and the upper chord cable 8-10 and lower chord cable 9-11 in case 1 3 are taken to study under different loads. The comparison results are shown in Fig. 14. Meanwhile, the internal forces of strut 2-3 and strut 4-5 in the original cable-truss frame are compared with those of strut 4-5 in case 1, strut 2-3 in case 2 , strut 4-5 in case 3 . The comparison results are shown in Fig. 15. Under different loads, the cable-truss frame's displacements after jumped layout are compared with those of the original cable-truss frame, shown in Fig. 14.

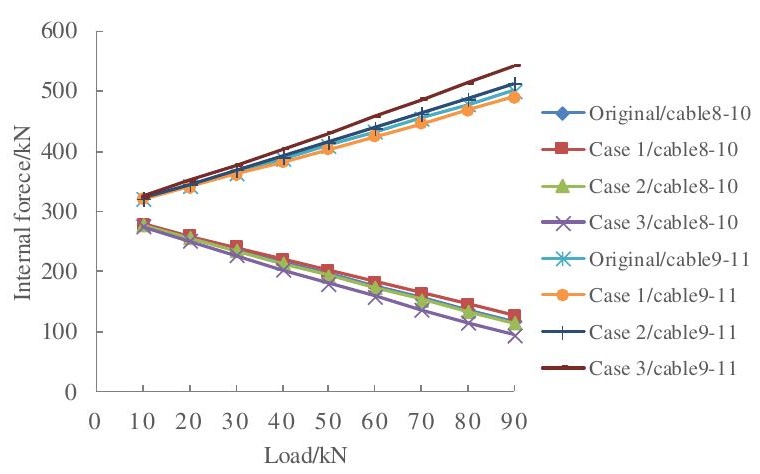

Fig. 14 Draw of cable force under various conditions

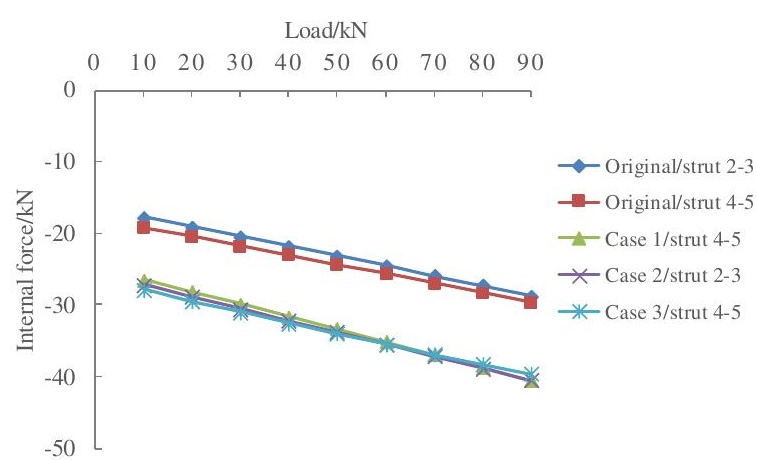

Fig. 15 Draw of internal force of struts under various conditions (In Figs. 14 15, "Original" refers to "the original scheme", the same below.) 


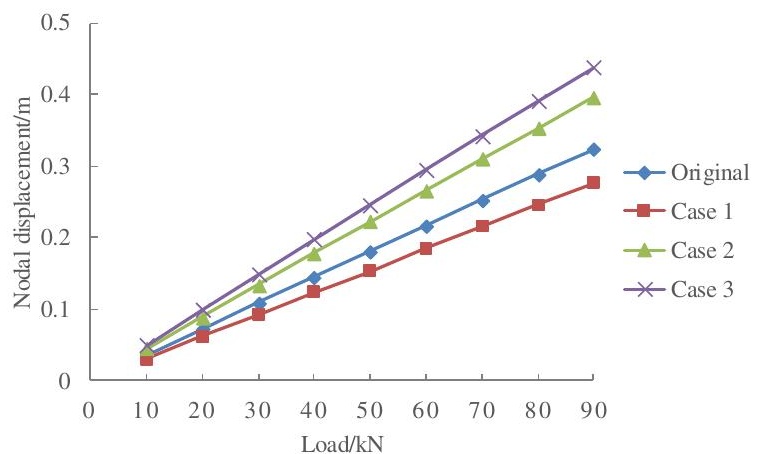

Fig. 16 Load-displacement curves under various conditions

From Fig. 14, although the positions of jumped layout are different, the changes of upper and lower chord cables for all models are small. For the three cases, the cable force in case 3 changes in larger, but it still can be controlled. Namely, the effects of position of jumped layout on cable-truss frame is small. From Fig. 15, it is known that the internal forces of struts in jumped layout model have changed significantly. The maximum internal force occurs at strut 2-3. The maximum internal forces range from $9.381 \sim 11.713 \mathrm{kN}$ under different external loads. So, the cross-section areas of struts should be rechecked after jumped layout. From Fig. 16, the load-displacement curves of jumped layout model and the original model linearly change. Namely, jumped layout does not change the mechanical performance of the cable-truss frame.

Meanwhile, the displacement variation in case $3>$ case $2>$ original model $>$ case 1 . So, when the number of struts is large, there are more redundant struts in the cable-truss frame, which cannot improve structural performance but increase the self-weight, the number of joints, and the difficulty of construction. So, the optimal order of jumped layout is case $1 \rightarrow$ case $2 \rightarrow$ case 3 .

\section{Study on the influence of struts on ACCTS}

In further studies, it is found that although ACCTS has a strong anti-collapse capacity, its construction forming is very difficult. The main reasons are that when the ACCTS's span is large, there are lots of struts and its lengths are longer. A structure is formed by a series of planar cable-truss frames interwoven with each other; serious collision and winding of struts occur during construction, which leads to lots of difficulties in construction. If partial struts of ACCTS can be removed, it can simplify construction, reduce construction difficulty, and structural self-weight. Nevertheless, the influence of jumped layout on ACCTS needs further studies.

Design an ACCTS with a span of $100 \mathrm{~m}$ shown in Fig. 17, which is constituted by 15 planar cable-truss frames interwoven with each other. The size of a single cable-truss frame is shown in Fig. 18. The elastic modulus and density of cable are $1.38 \times 10^{5} \mathrm{MPa}$ and $7.85 \mathrm{~g} / \mathrm{cm}^{3}$, respectively. The elastic modulus and density of the strut are $2.06 \times 10^{5} \mathrm{MPa}$ and $7.85 \mathrm{~g} / \mathrm{cm}^{3}$, respectively. The crosssections of the cable and strut are shown in Table 3 .

\subsection{The influences of the position of jumped layout on ACCTS}

Because the coordinates of the virtual inner ring of ACCTS decide the outer shape, the rise-span ratio of upper and lower chord cables and drainage slope, the vector height of ACCTS is not changed. Namely, the struts in the virtual inner ring are not removed, shown in Fig. 19. The jumped layout positions are located in the inner ring 1 , the inner ring 2 , and the inner ring 3, respectively, corresponding to scheme 1 , scheme 2 , and scheme 3 .

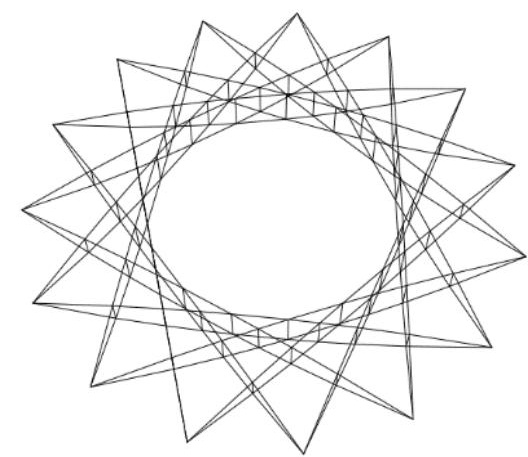

Fig. 17 Perspective of ACCTS

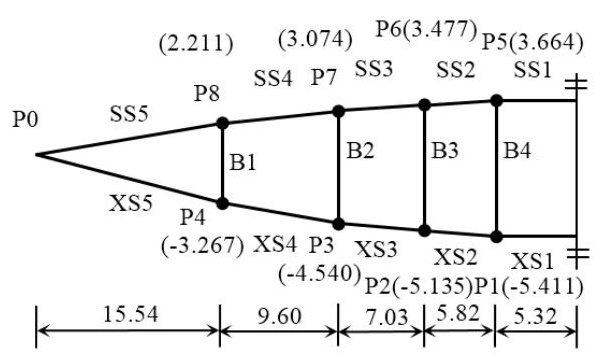

Fig. 18 Half cable-truss frame Unit:m

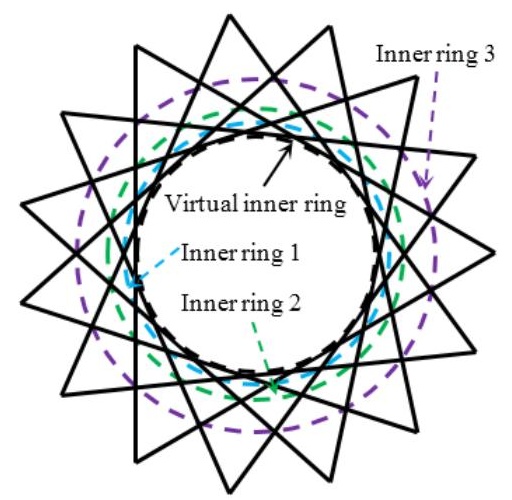

Fig. 19 Plane diagram of jumped layout

\subsubsection{Feasible prestress comparison}

From Table 3, the distribution law and values of feasible pre-stresses are identical among the original scheme and three jumped layout schemes. The internal forces of elements near the position of jumped layout change in larger. The internal force changes of scheme 2 and scheme 3 are more extensive than those of scheme 1 . The force changes of scheme 2 and scheme 3 are dramatically mostly for internal forces of struts. Such as the internal force of strut B3 in scheme two changes from $-18.26 \mathrm{kN}$ to $-32.13 \mathrm{kN}$, and the internal force of strut B2 changes from $-23.62 \mathrm{kN}$ to $-47.68 \mathrm{kN}$, so removed struts has the greatest influence on struts.

Table 3

Pre-stress distribution of all kinds of components of ACCTS Unit: kN

\begin{tabular}{|c|c|c|c|c|c|c|c|c|c|c|c|c|c|c|}
\hline Element number & $\mathrm{XS} 1$ & $\mathrm{XS} 2$ & XS3 & XS4 & XS5 & SS1 & SS2 & SS3 & SS4 & SS5 & B1 & B2 & B3 & B4 \\
\hline $\begin{array}{c}\text { Cross-section } \\
\text { areas } / \mathrm{mm}^{2} \\
\end{array}$ & 1360.9 & 1360.9 & 1360.9 & 1360.9 & 1360.9 & 1360.9 & 1360.9 & 1360.9 & 1360.9 & 1360.9 & 3078.7 & 3078.7 & 3078.7 & 3078.7 \\
\hline Original scheme & 270.86 & 271.26 & 271.96 & 273.36 & 276.84 & 327.23 & 327.39 & 327.68 & 328.39 & 330.38 & -38.23 & -23.62 & -18.26 & -23.32 \\
\hline Scheme 1 & 266.73 & 267.18 & 267.39 & 269.06 & 272.51 & 329.52 & 326.73 & 329.21 & 329.52 & 331.47 & -37.93 & -31.69 & - & -33.07 \\
\hline Scheme 2 & 270.49 & 270.94 & 272.18 & 272.37 & 276.45 & 333.08 & 333.21 & 334.05 & 333.86 & 336.29 & -48.57 & - & -32.13 & -23.48 \\
\hline Scheme 3 & 272.2 & 272.63 & 273.34 & 276.4 & 276.77 & 332.02 & 332.17 & 332.46 & 334.57 & 334.28 & - & -47.68 & -18.43 & -23.53 \\
\hline
\end{tabular}




\subsubsection{The comparison of structural responses under external loads}

Firstly applying loads of $0.6 \mathrm{kN} / \mathrm{m} 2$ to ACCTS, and then transforming the surface loads into the equivalent nodal load $F$, the equivalent nodal loads of all kinds of nodes are calculated $F_{\mathrm{P} 1}=-12.42 \mathrm{kN}, \quad F_{\mathrm{P} 2}=-22.88 \mathrm{kN}, \quad F_{\mathrm{P} 3}=-47.952 \mathrm{kN}$, $F_{\mathrm{P} 4}=-86.571 \mathrm{kN}$, respectively. The structure's total loads $\operatorname{are} \boldsymbol{F}=15^{*}\left[F_{\mathrm{P} 1}, F_{\mathrm{P} 2}, F_{\mathrm{P} 3}, F_{\mathrm{P} 4}\right]$ (The negative sign indicates the downward direction of load). The original scheme's structural responses and three jumped layout schemes under load $\boldsymbol{F}$ are shown in Fig. 20 and Table 4.

It can be seen from Table 4 that the maximum and minimum internal forces of cables change slightly and appear in the same position under load $\boldsymbol{F}$. From the changes of cable forces, scheme 1 is the closest to the original scheme. The maximum and minimum internal forces of struts have changed obviously, and the position of struts has also changed. The internal forces of struts of three jumped layout schemes have changed to a certain extent. The cross-section areas of struts should be rechecked to meet the design requirements after jumped the layout. In the three schemes, the maximum structural displacement position is unchanged, roughly to the three inner rings, but the maximum displacements change considerably. The maximum displacement in scheme 1 is very close to that of original scheme. The maximum displacement of scheme 2 is $-0.489 \mathrm{~m}$, but it still satisfies the allowable deformation value $[\sigma]=0.5 \mathrm{~m}$ in $《$ Technical Specification for Cable Structure 》 JGJ257-2012 [13]. The maximum displacement value in scheme 3 is $-0.679 \mathrm{~m}$, which exceeds allowable value in code. So, the mechanical performance of scheme 1 is similar to that of the original scheme.

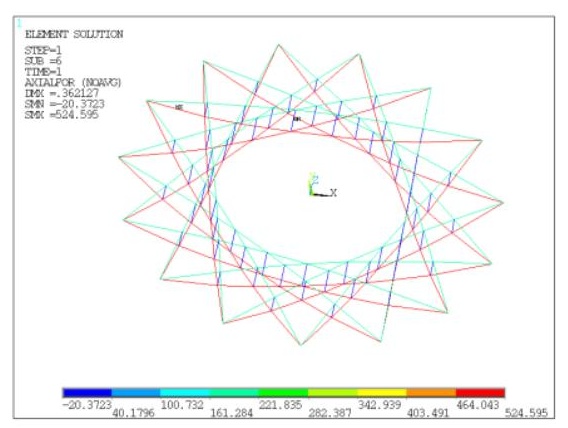

(a) Original scheme

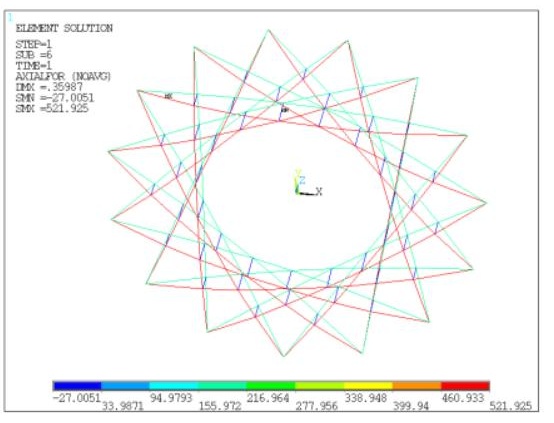

(b) Scheme 1

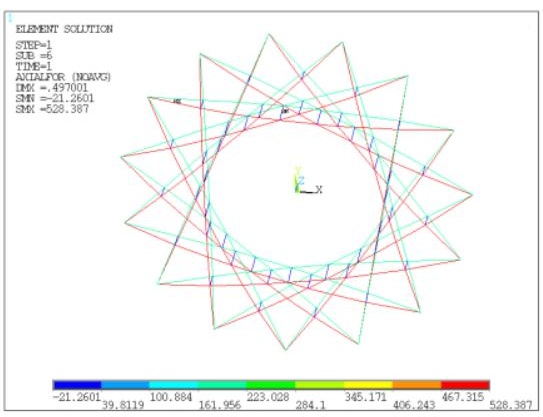

(c) Scheme 2

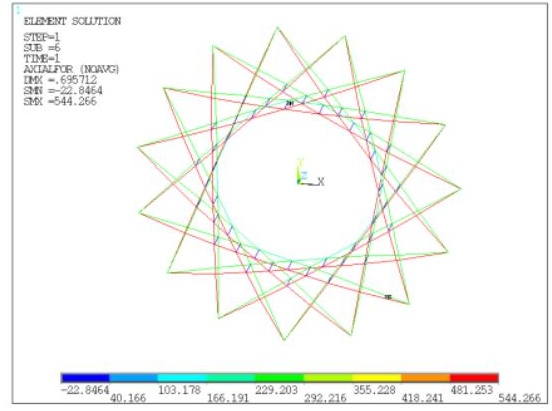

(d) Scheme 3

Fig. 20 Internal forces of original scheme and three jumped layout schemes

Table 4

Comparison results of structural responses of original scheme and three jumped layout schemes

\begin{tabular}{ccccc}
\hline Type and position & $\begin{array}{c}\text { Original } \\
\text { scheme }\end{array}$ & Scheme 1 & Scheme 2 & Scheme 3 \\
\hline Max. force of cable/kN & 524.59 & 521.9 & 528.39 & 544.25 \\
Position & XS5 & XS5 & XS5 & XS5 \\
Min. force of cable/kN & 195.50 & 198.63 & 207.98 & 228.58 \\
Position & SS1 & SS1 & SS1 & SS1 \\
Max. force of strut/kN & -10.67 & -14.52 & -19.09 & -13.94 \\
Position & Inner ring 2 & Virtual & Virtual & Virtual \\
ring & & ring & ring \\
Min. force of cable/kN & -20.37 & -27.00 & -21.26 & -22.85 \\
Position & Virtual ring & Inner ring & Inner ring & Inner ring \\
Vertical & & 3 & 1 & 1 \\
displacement/m & -0.356 & -0.354 & -0.489 & -0.679 \\
Position & Inner ring & Inner ring & Inner ring & Inner ring \\
& 3 & 3 & 2 & 3 \\
\hline
\end{tabular}

5.1.3. The comparison of steel consumption

The steel consumption of original scheme and three jumped layout schemes is shown in Table 4.

Table 5

The steel consumption of the original scheme and three jumped layout schemes

\begin{tabular}{ccccc}
\hline Type & $\begin{array}{c}\text { Original } \\
\text { scheme }\end{array}$ & Scheme 1 & Scheme 2 & Scheme 3 \\
\hline $\begin{array}{c}\text { Steel consumption/t } \\
\begin{array}{c}\text { Saving steel } \\
\text { consumption/t }\end{array}\end{array}$ & 39.13 & 36.007 & 36.369 & 37.144 \\
Percent/\% & - & 3.123 & 2.761 & 1.986 \\
\hline
\end{tabular}

Note: Percent=saving steel consumption/total steel consumption

From Table 5, the total amount of steel used in scheme 1 3 is smaller than the original scheme, but the total amount of steel used in scheme 1 is the smallest, saving $8.0 \%$ compared with the original scheme. The total the amount of steel used in scheme 3 is the largest. Therefore, scheme 1 saves the most amount of steel.

\subsubsection{Comparison of buckling analysis}

Nonlinear buckling analysis of the original scheme and three jumped layout schemes is carried out using the nonlinear FEM [15]. The comparison results are shown in Table 6.

From Table 6, the buckling loads of the original scheme and three jumped layout schemes have little change with or without self-weight, so the influence of self-weight on the buckling loads of structure are limited, and the large the self-weight is, the smaller the buckling loads are. 
Table 6

Buckling loads of original scheme and three jumped layout schemes.

\begin{tabular}{ccccc}
\hline Type & $\begin{array}{c}\text { Original } \\
\text { scheme }\end{array}$ & $\begin{array}{c}\text { Scheme } \\
1\end{array}$ & $\begin{array}{c}\text { Scheme } \\
2\end{array}$ & $\begin{array}{c}\text { Scheme } \\
3\end{array}$ \\
\hline $\begin{array}{c}\text { Buckling load without } \\
\text { self-weight/kN }\end{array}$ & 4536 & 4536 & 4454 & 4446 \\
$\begin{array}{c}\text { Buckling load with self- } \\
\text { weight /kN }\end{array}$ & 4266 & 4428 & 4284 & 4158 \\
\hline
\end{tabular}

Not considering self-weight, the structural buckling loads decrease gradually from the original scheme to scheme 3, which shows that the structural stiffness decreases gradually, but the reduction degree is limited. Considering self-weight, the structural self-weight decreases continuously from the original scheme to scheme 3. In contrast, the structural buckling loads increase first and then decrease, which shows that reducing structural self-weight can compensate for reducing structural stiffness for schemes 1 and scheme 2 . In contrast, the reduction of structural self-weight cannot compensate for reducing structural stiffness for scheme 3. From the nonlinear buckling analysis, scheme 1 reduces structural self-weight and increases structural buckling capacity.

It can be known from Section 5.1, comparing scheme 1 with scheme 2 and scheme 3:

(1) The distribution of pre-stress in scheme 1 is close to that of the original scheme.

(2) The maximum internal force of cables and their position is unchanged compared with the original scheme, and the internal forces of struts have changed. The cross-sections of struts should be rechecked after jumped layout.

(3) Jumped layout reduces not only structural self-weight but also improves structural buckling capacity.

The optimal order of jumped layout of ACCTS: scheme $1>$ scheme $2>$ scheme 3, which is identical to the optimal order of planar cable-truss frame.

For the jumped layout of ACCTS, it is suggested that the struts close to the virtual inner ring should be removed first, and the integral or partial symmetrical jumped layout should be adopted to maintain the symmetry of the structure.

\subsection{The influences of jumped layout on the static performance of ACCTS}

It is known from Section 5.1 that scheme 1 is the optimal scheme of jumped layout, so study on static and dynamic performance based on scheme 1 .

It is known the equivalent nodal loads calculated in Section 5.1.2 are $\boldsymbol{F}$. The internal forces and nodal displacements of the structure under full span and half span loads of $0.7 F, 0.9 F, 1.1 F, 1.3 F, 1.5 F, 1.7 F$ are studied.

\subsubsection{Under full-span loads}

It can be seen from Fig. 21 that under full-span loads, the internal forces of upper chord cables decrease gradually, and the internal forces of lower chord cables increase gradually with the increase of loads, which is linearly related to loads. The internal forces of upper and lower chord cables in scheme 1, so the influence of jumped layout on cables' internal forces is minimal. From Fig. 21(c), it is known that after jumped layout of strut B3, the variations of internal forces of strut B2 and strut B4 close to strut B3 are dramatically more extensive than the internal force of strut B1. Meanwhile, it is known

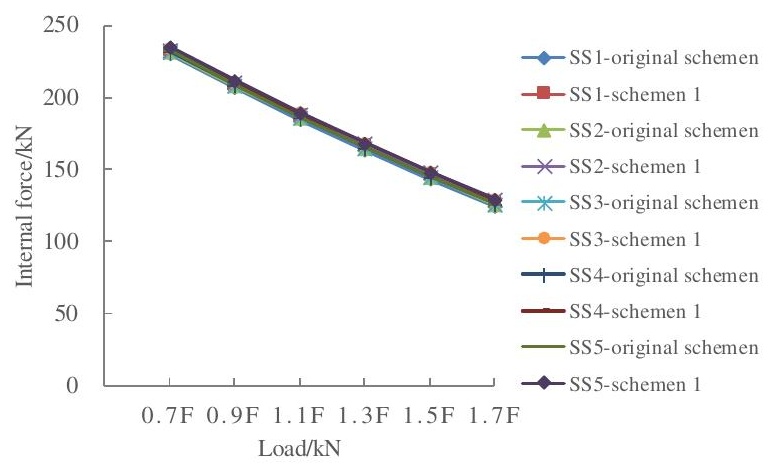

(a) Internal forces of upper cables

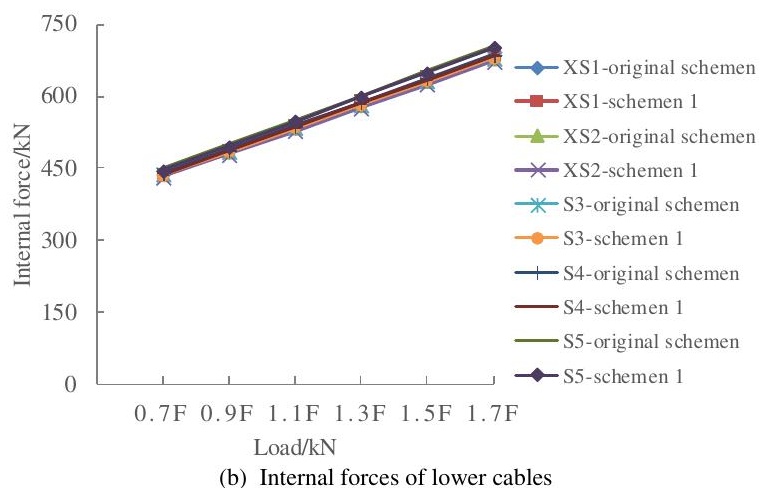

(b) Internal forces of lower cables $\mathrm{Load} / \mathrm{kN}$

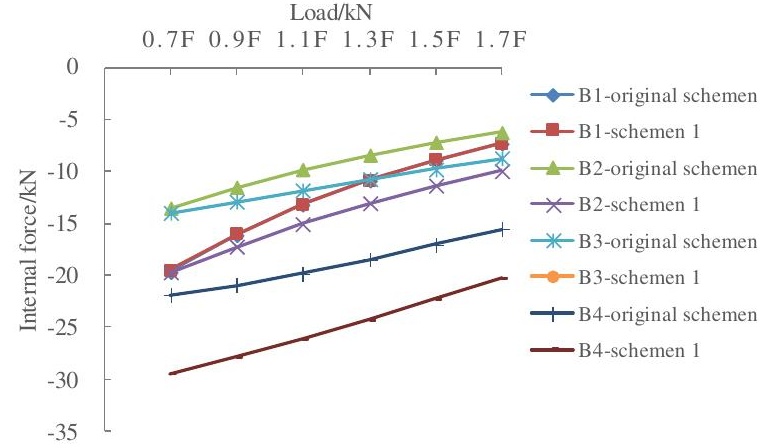

(c) Internal forces of struts

$\mathrm{load} / \mathrm{kN}$

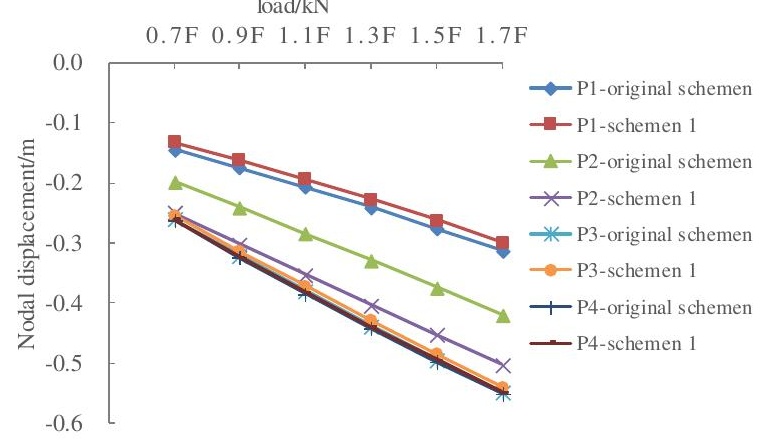

(d) Internal displacements of nodes

Fig. 21 Relation of internal force and nodal displacement of original scheme and scheme 1 under full-span loads

from Fig. 21(d) that the displacement of node P2 corresponding to the strut B2 has also changed significantly. Hence, the effect of jumped layout on struts' mechanical performance is greater than that of cables.

\subsubsection{Under half-span loads}

The computational results under half-span loads are shown in Fig. 22.

It is known from Fig. 22 that the change laws of internal forces and nodal displacements for all components are the same under half-span loads and fullspan loads. The influence of jumped layout on the internal forces of cables is minimal; forces of struts are more extensive, so the influence of removed struts on struts' mechanical performance is excellent.

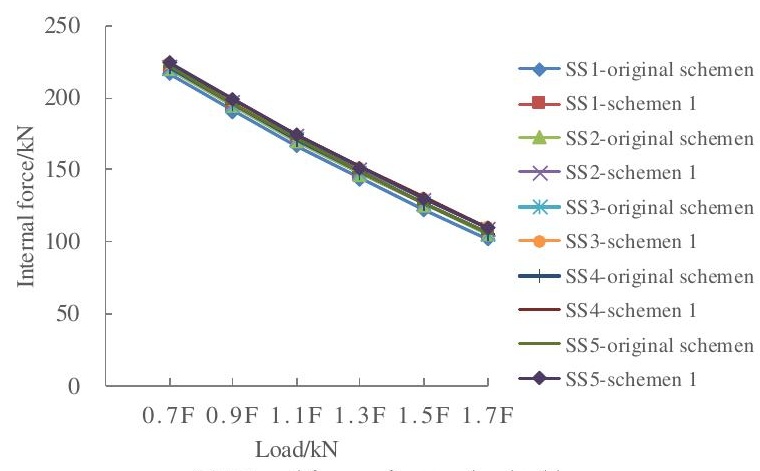

(a) Interanl forces of upper chord cables 


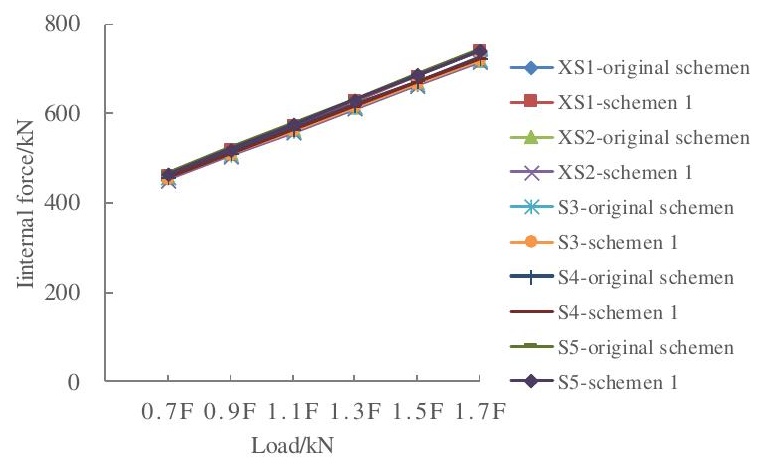

(b) Internal forces of lower chord cables

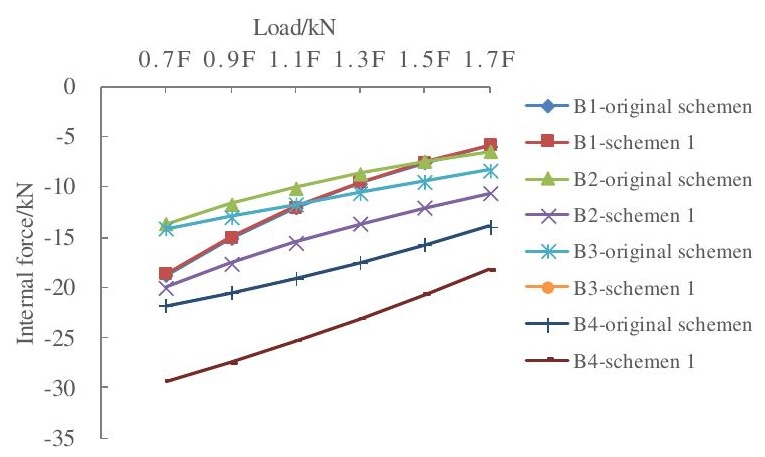

(c) Internal forces of struts

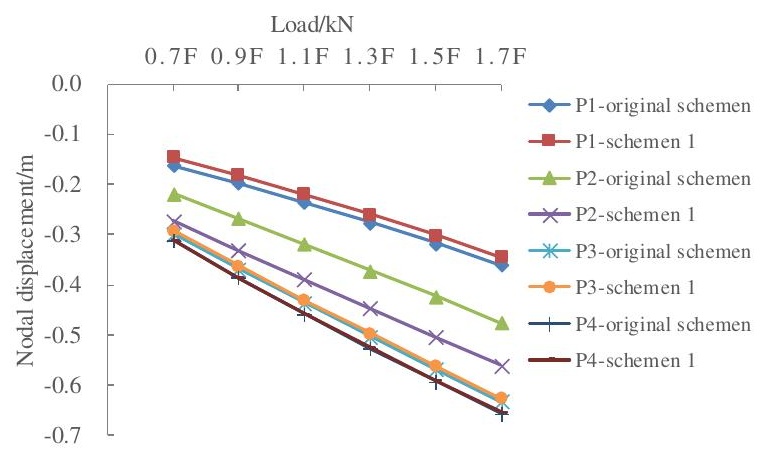

(d) The displacements of nodes

Fig. 22 Relation of internal force and nodal displacement of original scheme and scheme 1 under half-span loads performance is excellent.

5.2.3. The influence of jumped layout on the importance of structural components

From Sections 5.2.1 5.2.2, it is known that under full-span loads and halfspan loads, the change laws of the internal forces and nodal displacement of the original scheme and scheme 1 are identical. Although the displacement of the nodes at the jumped layout and the internal force of struts near it have changed, it can be seen from the numerical calculation results that when the external loads of the two schemes increases from $0.7 \boldsymbol{F}$ to $1.7 \boldsymbol{F}$, the mechanical characteristics of the structure remain unchanged. It shows that the static performances of structure do not change substantially after jumped layout, so structural components' importance does not change after jumped layout.

\subsection{The influence of jumped layout on the dynamic performance on ACCTS}

Natural vibration frequency, vibration mode, and damping ratio of the structure are three critical parameters that reflect dynamic load capacity and valuate dynamic structural features. It also includes the basis of structural wind spectrum analysis and seismic response spectrum analysis. ACCTS is a flexible structure, and large deformation and pre-stress effects are taken into account when carrying out mode analysis. In ANSYS software, pre-stress effects and large deformation are considered by setting stress stiffness and large deformation commands.

\subsubsection{Basic theory of model analysis}

Being similar to the general cable-net structures, when ACCTS has small amplitude vibration at the static equilibrium position, the un-damped motion equation of structure system according to the Hamiltonian Variation Principle can be described as:

$$
[M]\{\ddot{U}\}+[K]\{U\}=\{0\}
$$

$[\boldsymbol{M}]$ is the structure's mass matrix; $[\boldsymbol{K}]$ is the tangential stiffness matrix when the structure is in the current static equilibrium state.

Assuming that structure is in simple harmonic motion with frequency $\omega$, and which is substituted into the Eq.(1), the generalized feature equation of structure can be obtained as:

$$
\left([K]-\omega^{2}[M]\right)\{U\}=\{0\}
$$

Due to arbitrariness of displacements, Eq.(2) should satisfy:

$$
\left|[K]-\omega^{2}[M]\right|=\{0\}
$$

By solving Eq.(3), every order frequency of structure can be obtained. When the frequencies obtained are substituted into the Eq.(2), the vibration modes can be obtained. Block Lanczos Method (LANB) is used to solve Eq.(3). The method has the obvious advantages of fast calculation speed, few input parameters and high accuracy of results, and is especially suitable for large span spatial structure with symmetry.

\subsubsection{The comparison of vibration performance of original scheme and scheme} 1

Thought studying on the dynamic performance of original scheme and scheme 1, the first 6 order frequencies and modes are given, shown in Table 7 and Figs. 23 24.

\begin{tabular}{|c|c|c|c|}
\hline \multirow{2}{*}{ Order } & \multicolumn{2}{|c|}{ Frequency / HZ } & \multirow{2}{*}{$\begin{array}{c}\text { Vibration mode } \\
\text { Original scheme / scheme 1 }\end{array}$} \\
\hline & Original scheme & Scheme 1 & \\
\hline 1st order & 1.733 & 1.796 & Two-direction positive symmetric upper and lower vibration \\
\hline 2nd order & 1.733 & 1.796 & Two-direction positive symmetric upper and lower vibration \\
\hline 3 rd order & 2.049 & 2.157 & Integral upper and lower vibration \\
\hline 4 th order & 2.072 & 2.180 & Three-direction positive antisymmetric upper and lower vibration \\
\hline 5 th order & 2.072 & 2.180 & Three-direction positive antisymmetric upper and lower vibration \\
\hline 6 th order & 2.114 & 2.251 & Integral antisymmetric upper and lower vibration \\
\hline 7 th order & 2.114 & 2.251 & Integral antisymmetric upper and lower vibration \\
\hline
\end{tabular}

Table 7

First 6 order frequencies of original scheme and scheme 1 


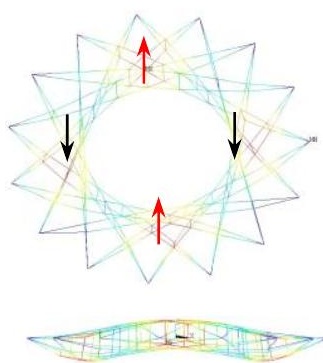

1st Mode

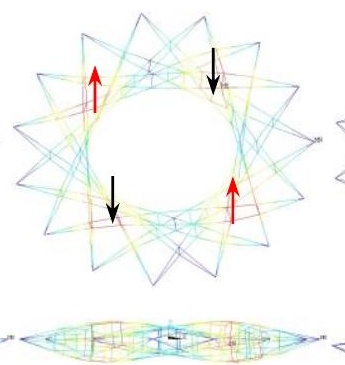

2nd Mode

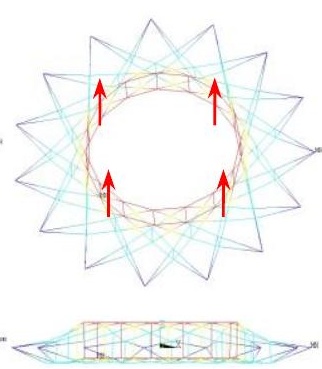

3rd Mode
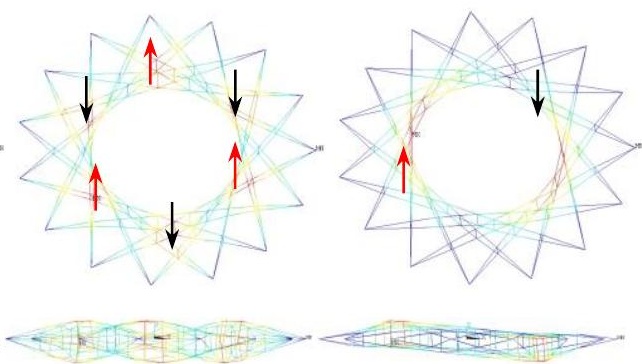

4th Mode

6th Mode

Fig. 23 First 6 vibration modes of original scheme (scale factor=10)

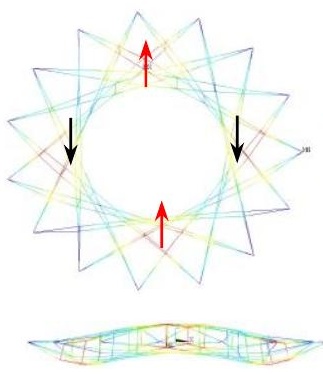

1st Mode

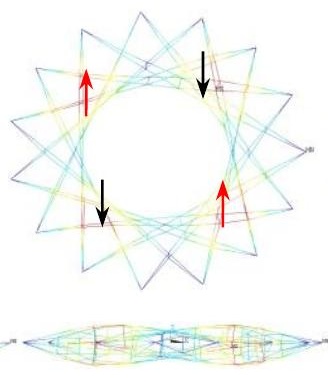

2nd Mode
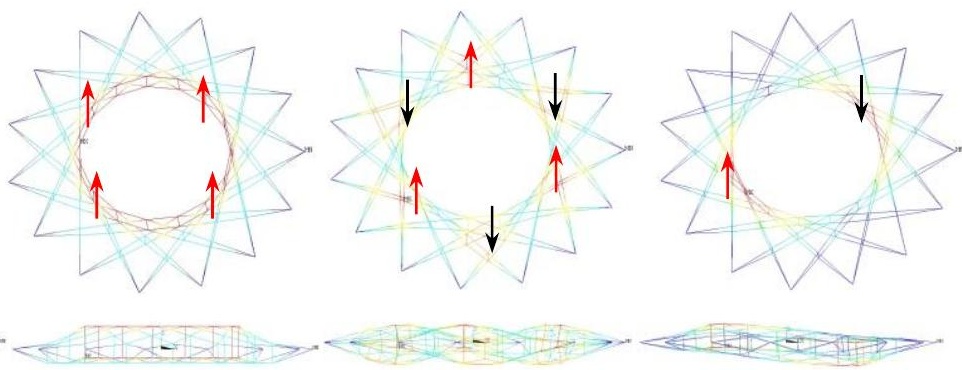

3rd Mode

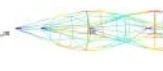

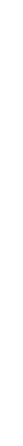

Fig. 24 First 6 order vibration modes of scheme 1 (scale factor=10)

Table 7 and Figs. 23 24 show that the natural vibration frequencies of the original scheme and scheme 1 are densely distributed and slightly different. In contrast, the first seven order modes of the two schemes are identical. The 1st and 2 nd modes of the original scheme and scheme 1 are two-direction positive symmetric upper and lower vibration (about XY axis symmetrical vibration). The difference between the 1st and 2nd modes is that an angle is changed based on the 1st mode (caused by multiple symmetrical axes of structure). The first three order modes of the two schemes are all integrally upper and lower vibration. The 4th and 5th order modes of the two schemes are all three-direction antisymmetric upper and lower vibrations (only give the 4 th order mode). The difference between the 5 th and 4 th order modes is that they also change an angle based on the 4th order modes. The 6 th and 7 th order modes of the two schemes are all integrally asymmetric (only the 6th is given). The difference between the 7 th-order and 6th-order modes is that they change an angle based on the 6th order mode.

Meanwhile, it can be seen from 1st to seventh order modes that the structural vibration is accompanied by local torsion of different degrees of the planar cabletruss frame. By observing the first ten modes, the vibration modes of ACCTS can be divided into the leading cable system structure's coupled vibration in the horizontal plane. The upper and lower vibration of the leading cable system structure in the vertical plane was accompanied by the planar cable-truss frame's local torsion.

Continuing to observe the first 100 order frequencies of original scheme and scheme 1, shown in Fig. 25.

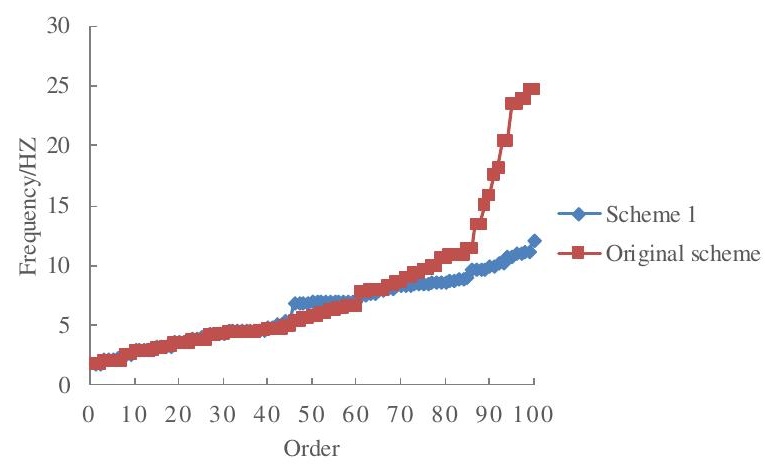

Fig. 25 Trend diagram of first 100 order frequencies of the original scheme and scheme 1

It can be seen from Fig. 25 that the trend of the first 45 order frequencies of the original scheme and scheme 1 is similar, and there is a difference between the original scheme and scheme 1 after the 46th order frequency. After the 46th order frequency, the frequencies of scheme 1 increase steadily and continually with the order. However, the original scheme's frequencies increased by leaps and bounds, and the frequencies of occurrence are higher, especially after the 80 th order frequency.

For the rigid structure, the 1st order vibration model is an integral torsional model, which is generally bad for structure seismic, and it should be avoided as far as possible [16]. For ACCTS, the 1st order model shape is up and down vibration and out-of-plane local rotation of plane cable-truss, which is not bad for the integral structure, consistent with the planar results cable-truss frame.

\section{Conclusion}

Through the studies of planar cable-truss frame and ACCTS, the conclusions are as follows:

(1) When upper chord cables are slack, the initial stiffness equation and the critical slack load equation of the 2-bar and 6-cable planar cable-truss frame model were deduced. The theoretical values are identical to FEM values, which verifies the correctness of the theoretical equation.

(2) Based on ANSYS software, the influence of the position of middle struts on the cable-truss frame is studied when the middle struts are fixed or not. When the number of struts is more than a specific range, increasing struts does not improve the structural stiffness. It suggests that the number of struts should be about 6 8.

(3) According to the research results, the impact of jumped layout on the cabletruss frame's internal forces is small. However, it dramatically influences the internal forces of struts near jumped layout. The optimal order of jumped layout: strut 2-3>strut 4-5>strut 6-7.

(4) After the jumped layout, the self-weight of ACCTS is reduced, improves the structure's buckling capacity, and decreases the construction difficulty. The optimal order of jumped layout: scheme $1>$ scheme $2>$ scheme 3 , which is similar to the planar cable-truss frame's optimal order.

(5) From the static analysis results, the influence of jumped layout on cable forces is minimal, but it dramatically influences the internal forces of struts near jumped layout. The static performance of both the original scheme and scheme 1 is similar.

(6) For ACCTS, the 1st order model is upper and lower vibration accompanied out-of-plane local rotation of plane cable-truss frame, which is not bad for the integral structure, consistent with the results gained from the planar cable-truss frame. 


\section{Acknowledgments}

The authors would like to acknowledge the financial support of the National Natural Science Foundation of China (51778017), the financial support of the National Natural Science Foundation of China (51878014), the Natural Science Foundation of Beijing Municipality (8172011).

\section{References}

[1] Guo J M, Jiang J Q. An algorithm for calculating the feasible pre-stress of cable-struts structure. Engineering Structure, 2016, 118(1), 228-39.

[2] Chen L M, Hu D, Gao W F, Dong S L, Zhou Y Y, Zhang F B. (2018). Support node construction error analysis of a cable-strut tensile structure based on the reliability. Advances in Structural Engineering, 2008, 21(10), 1553-1516.

[3] Zhang A L, Sun C, Jiang Z Q. Experimental study on the construction shape-forming process and static behavior of a double strut cable dome. Journal of Zhejiang University-Science (Applied Physics and Engineering), 2018, 19(03), 225-239.

[4] Ge J Q, Zhang A L, Liu X G, Zhang G J, Ye X B, Wang S, Liu X C. Analysis of tension formfinding and whole loading process simulation of cable dome structure. Journal of building structures, 2012, 33(4):1-11.

[5] Deng H, Zhang M R, Liu H C, Dong S L, Zhang Z H, Chen L Q. (2016). Numerical analysis of the pretension deviations of novel Crescent-shaped tensile canopy structural system, Engineering Structures, 2016, 119, 24-33.

[6] Liu R J, Li X Y, Xue S D. Experimental and numerical research on Annular Crossed CableTruss Structure under cable rupture, Earthquake Engineering and Engineering Vibration, 2017, 16(3), 557-569.

[7] Xue S D, Liu R J, Li X Y. Concept proposal and feasibility verification of the annular crossed cable-truss structure, International Journal of Steel Structures, 2017, 17(4), 1549-60.

[8] Lu J, Xue S D, Li X Y, Liu R J. Study on membrane roof schemes of annular crossed cabletruss structure[J]. International Journal of Space Structures, 2019, 34(3-4):85-96.

[9] Jeon B, Lee J. Cable membrane roof structure with oval opening of stadium for 2002 FIFA world Cup in Busan. In: Proceedings of sixth Asian-Pacific conference on shell and spatial structures, 2000, 2, 1037-42.

[10] Liu R J, Xue S D, Li X Y. Static behavior analysis for annular crossed cable-truss structures. Spatial Structure, 2004, 20(01), 89-96.

[11] Liu R J, Xue S D, Li X Y. Preventing disproportionate displacements in an annular crossed cable-truss structure, International Journal of Space Structures, 2007, 32(1), 3-10.

[12] Xue S, Lu J, Li X, et al. Method of shape determination and solving self-stress mode of cabletruss tensioned structure based on constraints move method[J]. Advanced Engineering Sciences , 2020,52(2):1-8.

[13] Technical Specification for Cable Structure, JGJ257-2012 [S]. Beijing: China Architecture \& Building Press, 2008.

[14] Shen S D,Xu C B, Zhao C, W Y. Suspension structure design. Beijing:China Architecture \& Building Press, 2006.

[15] Liang X T, Yuan X F. Perfermance analysis of buckling in compressive strut supported by prestressed cables. Journal of Zhejiang University (Engineering Science), 2016, 29(03), $505-510$.

[16] Guo Y L, Tian G Y. Cable structure system, design theory and construction control. Beijing: Science Press, 2014. 


\title{
NUMERICAL STUDY ON SHEAR BEHAVIOUR OF ENHANCED C-CHANNELS IN STEEL-UHPC-STEEL SANDWICH STRUCTURES
}

\author{
Chang-Hui Li ${ }^{1}$, Jia-Bao Yan ${ }^{2,}{ }^{*}$, Hui-Ning Guan ${ }^{2,3}$ and Hong-Long Wang ${ }^{3}$ \\ ${ }^{1}$ School of Transportation Science and Engineering \& Airport engineering research base, Civil Aviation University of China,Tianjin 300300, China \\ ${ }^{2}$ School of Civil Engineering, Tianjin University, Tianjin 300350, China \\ ${ }^{3}$ Tianjin Municipal Engineering Design \& Research Institute, Tianjin 300392, China \\ *(Corresponding author: E-mail: ceeyanj@163.com)
}

\section{A B S T RA C T}

This paper firstly developed a three-dimensional (3D) finite element model (FEM) for enhanced C-channels (ECs) in steelUHPC-steel sandwich structures (SUSSSs). The FEM was validated by 12 push-out tests on ECs with UHPC. With the validated FEM, this paper performed in-depth parametric studies on shear behaviours of ECs with ultra-high performance concrete (UHPC). These investigated parameters included bolt-hole gap $(a)$, grade $(\mathrm{M})$ and diameter $(d)$ of bolt, core strength $\left(f_{\mathrm{c}}\right)$, length of C-channel $\left(L_{\mathrm{c}}\right)$, and prestressing force ratio on bolt $(\rho)$ in ECs. Under shear forces, the ECs in UHPC exhibited successive fractures of bolts and C-channels. Increasing the bolt-hole gap within 0-2 mm has no harm on the ultimate shear resistance, but greatly improves the slip capacity of ECs. Increasing grade and diameter of bolts improves the shear resistance and ductility of ECs through increasing the $P_{\mathrm{B}} / P_{\mathrm{C}}$ (shear strength of bolt to that of C-channel) ratio. Increasing the core strength increased the shear resistance, but reduced the ductility of ECs due to the reduced $P_{\mathrm{B}} / P_{\mathrm{C}}$ ratio. The ECs with $L_{\mathrm{c}}$ value of $50 \mathrm{~mm}$ offer the best ductility. Prestressing force acting on the bolts reduced the shear strength and ductility of ECs with UHPC. Analytical models were proposed to estimate the ultimate shear resistance and shear-slip behaviours of ECs with UHPC. The extensive validations of these models against 12 tests and 31 FEM analysis cases proved their reasonable evaluations on shear behaviours of ECs with UHPC.

Copyright $\odot 2021$ by The Hong Kong Institute of Steel Construction. All rights reserved.
A R T I C LE H ISTORY

$\begin{array}{ll}\text { Received: } & \text { 24 January } 2021 \\ \text { Revised: } & \text { 4 May } 2021 \\ \text { Accepted: } & \text { 4 May } 2021\end{array}$

\section{K E Y W O R D S}

Steel-concrete-steel sandwich structure;

Connectors;

Finite element;

Push-out tests:

Shear strength;

Damage plasticity model;

Composite structure;

ABAQUS.

\section{Introduction}

The applications of steel-concrete-steel (SCS) sandwich structures (SCSSSs) as the high performance structural members in engineering constructions keep increasing in recent several decades. This relative new type of structure, consisting of two faceplates and a sandwiched core, was firstly used as the undersea cylindrical shell oil containers [1]. Due to the extensive advantages received, e.g., relatively high structural performance, savings of formworks for casting, and reducing detailing works, the application of SCSSSs was gradually extended to the bridge deck [2], immersed tunnels [3], shear walls for nuclear constructions [4] and skyscraper [5], shielding tunnels [6], and protective structures against impact and blast loadings [7-9]. Recently, ultrahigh performance concrete (UHPC) with a compressive strength over $120 \mathrm{MPa}$ has been developed and used in the SCSSSs, i.e., steel-UHPC-steel sandwich structures (SUSSSs), e.g., SUSSS developed for nuclear constructions [10] and high-rise buildings [11].

Since the SCSSS (or SUSSS) is a composite structure with a multi-layer cross section, the bonding measures act essentially on the structural composite action. Adhesive or mechanical bonding was usually taken in SCSSS/SUSSS structure. The typical adhesive bonding (e.g., epoxy) proved to be effective on improving the steel-concrete bonding in SCSSSs [12], and its critical disadvantage is that it could not provide cross-sectional shear resistance [13]. According to the linking methods of the two faceplates in SCSSSs/SUSSSs, there are three types of mechanical shear connectors, namely indirect link, direct link, and semi-direct link connectors [13]. The direct link connectors mainly connect the two faceplates in a direct way, e.g., through bolt connectors [14], friction-welded connectors [15], and laser-welded connectors [16]. These direct-link connectors tend to be very costing that brings difficulties on their applications in civil engineering infrastructures, e.g., friction-welded connectors. Moreover, the dimensions of the SCSSSs/SUSSSs with the laser/friction- welded connectors were restricted by the welding equipment, e.g., the thickness of friction-welded SCSSSs/SUSSSs was restricted within 0.2-0.7 m. The indirect-link connectors bond these three layers of materials through welding the connectors to faceplates and their embedment in concrete. Overlapped headed studs [17], angles and C-channels [18] are the typical indirect-link connectors. The transparent disadvantage of these indirect-link connectors is that their bonding effects greatly depend on the integrity of core. The spalled core would lose the bonding and greatly reduce the load carrying capacity of SCSSSs/SUSSS with such type of connectors. Double J-hooks [7] are representative semi-direct link connectors that their bonding is partially achieved through direct mechanical interlocking and partially through their embedment in the concrete core. However, these semi-direct link connectors (e.g. J-hooks) may cause the assembling difficulties. Thus, it is of importance to develop direct-link connectors with relative low costing. Enhanced Cchannels (ECs) (see Fig. 1) make up this blank, which possess strong faceplateconcrete interfacial bonding, but low costing [19]. Previous studies on SCSSSs/SUSSSs with ECs (SCSSS-EC/SUSSS-EC) concentrated on shear behaviours of ECs in normal weight concrete (NWC) [19], structural behaviours of SUSSS beams with ECs [20-21], and compressive behaviours of SUSSS walls with ECs [22]. However, as the key components in the SUSSS-ECs, the in-depth studies on shear behaviour of ECs in the UHPC have not been performed. It becomes necessary to carry out in-depth studies on shear behaviours of ECs in SUSSS-ECs and investigated their key influencing parameters.
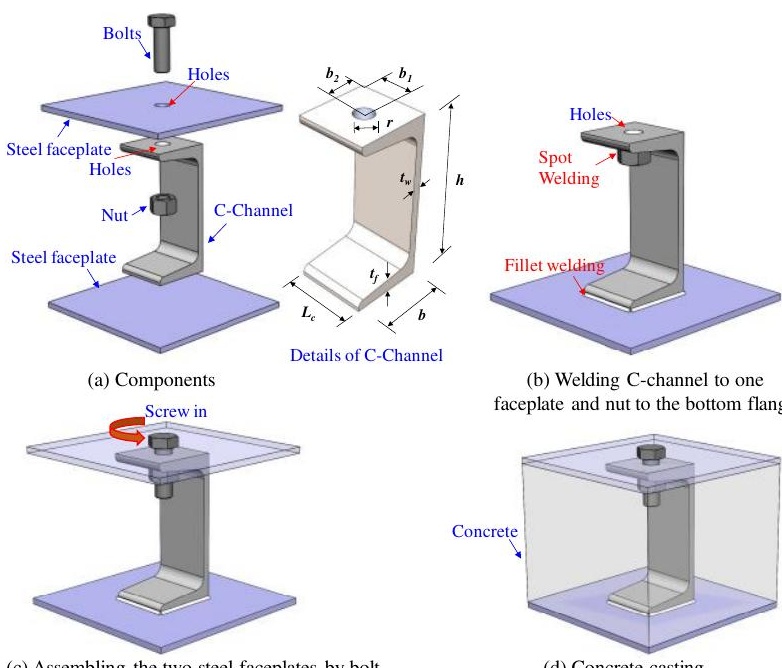

(b) Welding C-channel to one faceplate and nut to the bottom flange

(c) Assembling the two steel faceplates by bolt

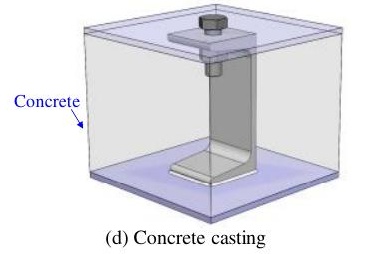

Fig. 1 Details of Enhanced C-channel (EC) connectors in SCSSS

This paper is a companion study of the tests on shear behaviours of ECs in UHPC using the numerical simulation method. A detailed 3D finite element model (FEM), adopting the continuum damage material models, was firstly developed to simulate the ECs in SUSSS-ECs. Twelve push-out tests on ECs in UHPC were used for the validations of FEM simulation. With the validated FEM, shear behaviour of ECs in UHPC was studied as well as their key influencing parameters. Finally, analytical models were proposed for shear-slip behaviour and ultimate shear resistance of ECs in the UHPC. 


\section{Push-out tests on ECs in SUSSS-ECs}

\subsection{Details of ECs in SUSSS-ECS}

The developed ECs in SUSSS-ECs is plotted in Fig. 1. The main components in each EC are a C-channel, an externally-screwed bolt, and a nut. Before the fabrication, the holes in the top flange of the $\mathrm{C}$-channel and its connecting faceplate were drilled as shown in Fig. 1(a). After that, the bottom flange of the $\mathrm{C}$-channel is connected to the bottom faceplate using fillet welding, and the nut was attached to the bottom surface of top flange of C-channel using the spot welding [see Fig. 1(b)]. After installation of the top faceplate through externally-screwed bolts [see Fig. 1(c)], concrete casting ends the fabrication procedures of ECs [see Fig. 1(d)].

\subsection{Push-out tests on ECs in SUSSSs}

Twelve push-out tests were performed on ECs that simulate a segment of the SUSSSs. Fig. 2 illustrates details of a specimen for push-out test that include two pairs of ECs, faceplates, UHPC block, and reinforcement mesh. These 12 specimens with the same two specimens in one group can be categorized into six groups regarding their designed different parameters, namely U1 U6 (The two specimens for each group were denoted as -A or -B, e.g., U1A and U1B for group one specimens). The studied parameters were the length of $\mathrm{C}$-channel flange $\left(L_{\mathrm{c}}\right)$, depth of C-channel $(h)$, and layout of C-channel. Specimens U1A/B, $\mathrm{U} 2 \mathrm{~A} / \mathrm{B}$, and $\mathrm{U} 3 \mathrm{~A} / \mathrm{B}$ were prepared with $\mathrm{Lc}$ values of 50,30 , and $70 \mathrm{~mm}$ to check the influence of Lc. Specimens U1A/B, U4A/B and U5A/B were prepared with different $\mathrm{h}$ of 120,100 , and $140 \mathrm{~mm}$, respectively. Specimens U1A/B and $\mathrm{U} 6 \mathrm{~A} / \mathrm{B}$ were designed with different layout of the C-channels, i.e., the web of the C-channel was horizontally or vertically installed.

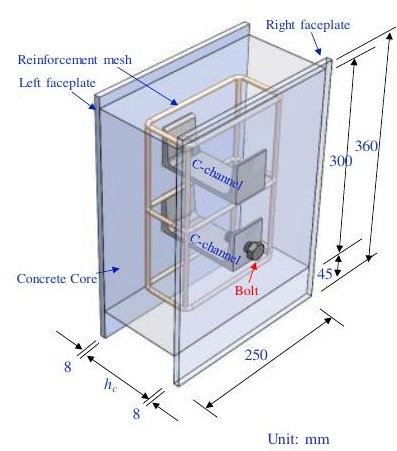

(a) 3D-view

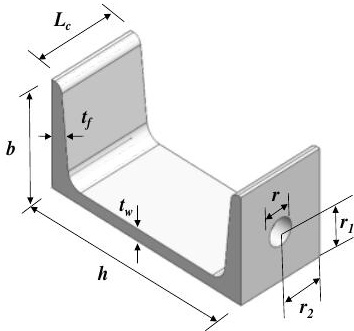

(c) Details of C-channels used in the push-out tests

2 Geometry of SUSSS with ECs

The geometry of the push-out test specimen is depicted in Fig. 2(a)-(b). Fig. 2(c) illustrates the geometry of different $\mathrm{C}$-channels used in the push-out test specimens. The UHPC was used in the push-out test specimen, and its mix proportions equal to 898: 202: 225: $988: 270: 17 \mathrm{~kg} / \mathrm{m}^{3}$ for cement: water: silica fume: quartz sand: quartz powder: superplasticizer. More detailed information on mechanical properties of UHPC are given by Yan et al. [20-22] and Zhu et al. [23]. Fig. 3 shows the UHPC compression/tensile stress-strain curves.

The 8mm-thick faceplates in the push-out test specimens adopted Q345 mild steel with a yield strength of $355 \mathrm{MPa}$. Chinese standard M8.8 bolts and mild steel Q235B C-channels with different heights of 100, 120, and $140 \mathrm{~mm}$ were used in ECs. The tensile stress-strain curves of involved bolts and Cchannels are given in Fig. 4(a). The reinforcement mesh adopts the $\phi 8 \mathrm{~mm}$ HRB400 rebar with a yield strength of $400 \mathrm{MPa}$.
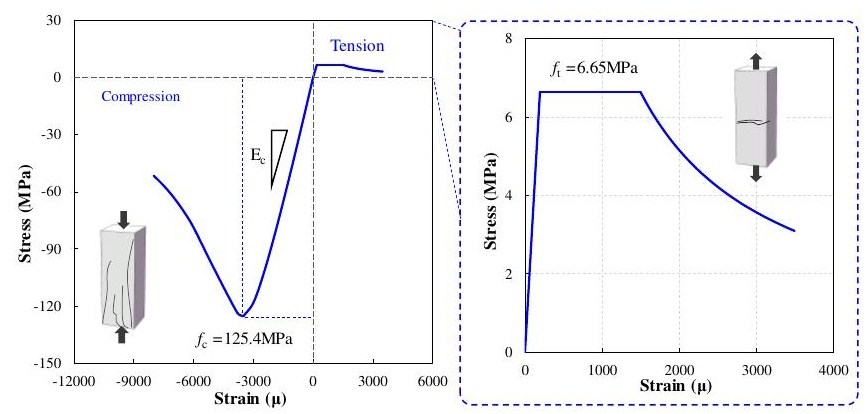

Fig. 3 Uniaxial compressive and tensile stress-strain curves of UHPC
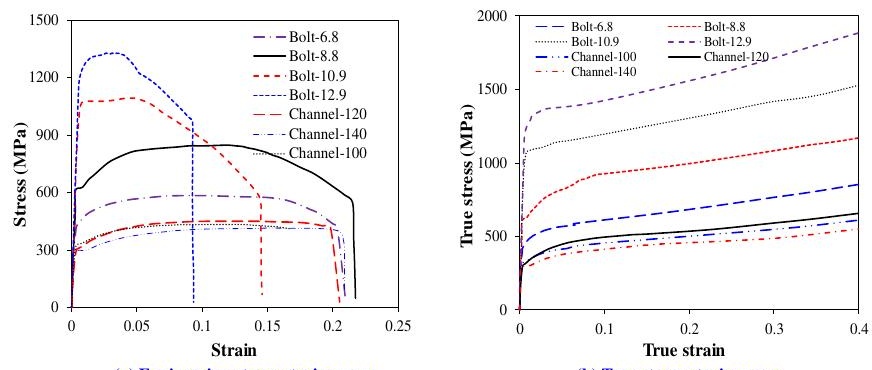

(a) Engineering stress-strain curve
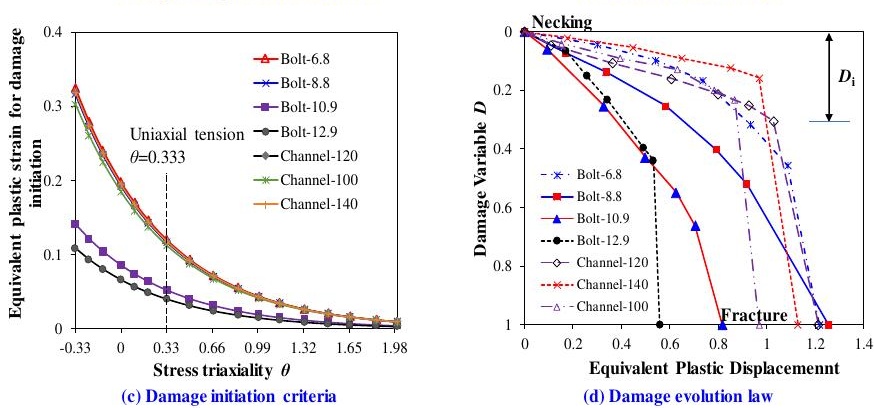

Fig. 4 Engineering and true stress-strain curve, damage initiation laws, and damage

evovution laws for DPM of steel materials

\subsection{Test setup}

The testing setup of push-out tests on ECs in UHPC is illustrated in Fig. 5. The specimens were directly put on the rigid base, and only loaded on the centre UHPC core in the displacement mode. Thus, the concrete-faceplate interfacial slips at the top and bottom of specimens were measured by four LVDTs working in pairs. The reaction force of the specimen was instrumented by the load cell integrated in the testing machine.

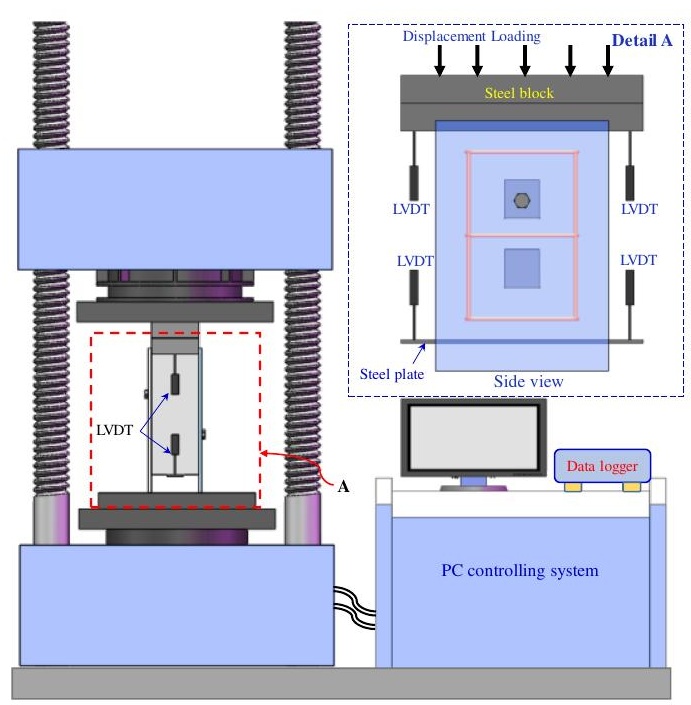




\section{Finite element model (FEM) on push-out tests on ECs}

\subsection{Introductions on FEM}

The developed FEM for push-out tests with UHPC and ECs adopted general commercial software ABAQUS/CAE [24]. Fig. 6 shows the developed FEM. It detailed simulates the push-out test specimens using a $1 / 2$ model considering the symmetric geometry and loading pattern. Different components were detailed modelled, e.g, the steel faceplates, reinforcement mesh, C-channel, bolt, UHPC core, base plate and the loading platen. Considering the influences of the local geometry and channel-UHPC core interaction on shear behaviours of ECs, the holes were reserved in the overlapped positions between the $\mathrm{C}$ channel and the core [see Fig. 6(d)].

Regarding the solution of the FE analysis (FEA), ABAQUS/Explicit solver was used in this FE simulation [24].
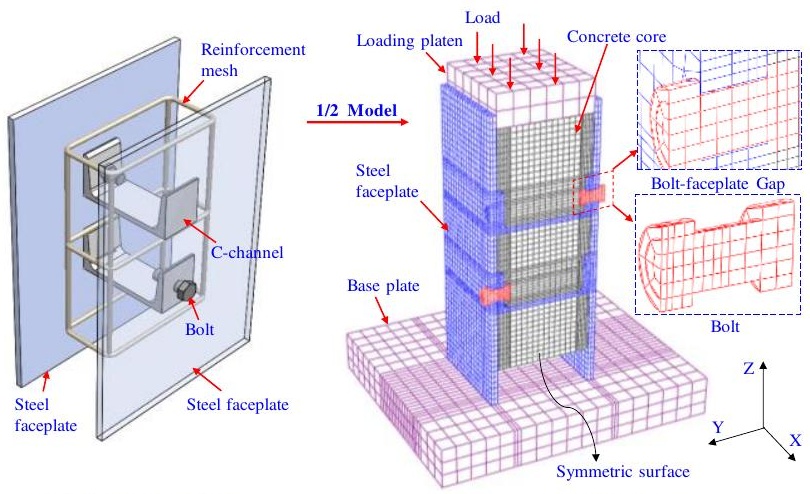

(a) Push-out test specimen

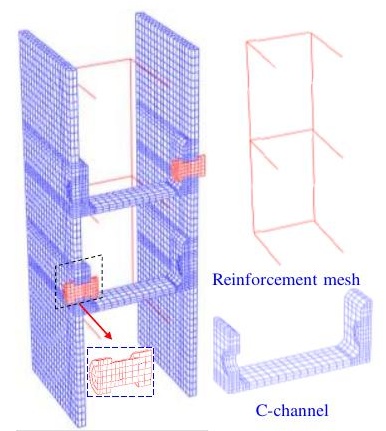

(c) Steel components in FEM

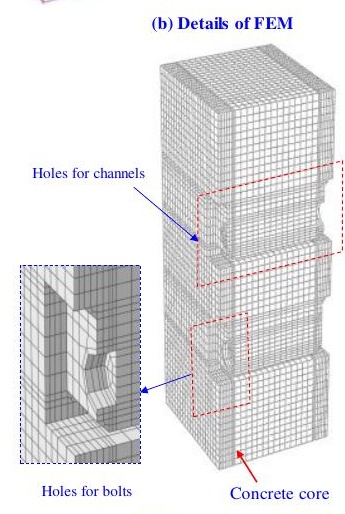

(d) Concrete core in FEM
Fig. 6 FEM for push-out test specimen with ECs

\subsection{Material models of steels}

The steel faceplates and reinforcements adopt the nonlinear isotropic model with kinematic hardening, which follows the von-Mises yielding criteria. They also adopt the bilinear elastic-plastic constitutive model. This model requires the definitions of elasticity and plasticity behaviours for the steel materials. The definition of elasticity requires the input of elastic modulus of steels whilst the definition of plasticity requires the input of yield and ultimate strengths and their corresponding plastic strains. This paper adopted the bilinear model, which defines the modulus after yielding equalling to $1 \%$ elastic modulus.

Considering the occurrence of shear fracture to bolts in ECs, continuum damage model (CDM) was adopted for the channels and bolts. Following the methods developed by Yan et al. [25, 26], the CDM was built for C-channels and bolts. The elasticity of ECs and bolts can be defined by the elastic modulus. The definition of CDM includes three main steps, i.e., true stress-strain behaviour of steel, damage initiation, and damage evolution laws.

The true stress-strain $\left(\sigma_{\text {true }}-\varepsilon_{\text {true }}\right)$ curves of C-channels and bolts can be obtained from converting their engineering stress-strain curves following the models in Refs. [25-26] as follows;

$\varepsilon_{\text {true }}=\ln \left(1+\varepsilon_{\text {nom }}\right)$

$\sigma_{\text {true }}=\ln \left(1+\sigma_{\text {nom }}\right)$ where, $\varepsilon_{\text {nom }}$ denotes nominal strain; $\sigma_{\text {nom }}$ is nominal stress.

$\varepsilon_{\text {nom }}$ and $\sigma_{\text {nom }}$ can be obtained from engineering stress-strain curves as recommended in Refs. [25-26]. The determined $\sigma_{\text {true }}-\varepsilon_{\text {true }}$ curves for bolts and Cchannels are given in Fig. 4(b).

The damage initiation strain $\left(\bar{\varepsilon}_{0, p l}\right)$ greatly relates to the stress triaxiality $(\theta)$ of the steels. Their relationships are given by Yan et al. [25-26] as the following;

$\bar{\varepsilon}_{0, \mathrm{pl}}=\varepsilon_{0, \mathrm{pl}} e^{-1.5(\theta-0.333)}$

where, $\bar{\varepsilon}_{0, p l}$ is the uniaxial damage initiation strain can be determined from uniaxial tensile tests on coupons.

Based on the uniaxial stress-strain curves, Fig. 4(c) depicts the damage initiation evolution relationships with $\theta$ for the bolts and $\mathrm{C}$-channels in this numerical study.

The damage coefficient $(D)$ in CDM is an index within 0-1.0 describing the damage from the necking $(D=0)$ to the fracture point $(D=1.0)$ as shown in Fig 4(d). The definition of $D$ ratio at any point between the necking and fracture point follows the model proposed by Yan et al. [25-26] as follows;

$D_{\mathrm{i}}= \begin{cases}1.5\left(1-\sigma_{\mathrm{i}} / \bar{\sigma}_{\mathrm{i}}\right) & i_{\mathrm{D}} \leq i \leq i_{\mathrm{R}} \\ \left(1-D_{\mathrm{R}}\right) \frac{\varepsilon_{\mathrm{i}, \mathrm{pl}}-\varepsilon_{\mathrm{R}, \mathrm{pl}}}{\varepsilon_{\mathrm{F}, \mathrm{pl}}-\varepsilon_{\mathrm{R}, \mathrm{pl}}} & i_{\mathrm{R}} \leq i \leq i_{\mathrm{F}}\end{cases}$

where, $\sigma_{\mathrm{i}}$ is engineering stress at $\mathrm{i} ; \bar{\sigma}_{i}$ is true stress at $\mathrm{i} ; D_{\mathrm{R}}$ is damage ratio at rupture point as shown in Fig. $3(\mathrm{~d}) ; \varepsilon_{\mathrm{i}, \mathrm{pl}}, \varepsilon_{\mathrm{F}, \mathrm{pl}}$ and $\varepsilon_{\mathrm{R}, \mathrm{pl}}$ are plastic strains at points i, fracture, and rupture as illustrated in Fig. 3(d), respectively.

For the CDM definition, the $D_{\mathrm{i}}$ evolution versus equivalent plastic displacement $\left(\bar{u}_{\mathrm{i}, \mathrm{pl}}\right)$ relationship is required, which can be determined using the method in Refs. [25-26]. Finally, Fig. 4(d) plots the determined $D_{\mathrm{i}}-\bar{u}_{\mathrm{i}, \mathrm{s}}$ relationships for bolts and C-channels.

The shear damage criteria was also used in the ABAQUS CDM. The shear damage criteria requires the definitions of shear damage initiation strains ( $\varepsilon_{F \text {,shear }}^{\mathrm{pl}}$ )and evolution laws. Following the method in Refs. [25-26], the $\varepsilon_{F \text {,shear }}^{\mathrm{pl}}$ ratios for the M-6.8, 8.8, 10.9, 12.9 bolts and C-channels equal to 0.12 , $0.095,0.06,0.05$, and 0.118 , respectively. The shear damage evolution follows a displacement mode.

\subsection{Material models of UHPC}

The FEM used the concrete damage plasticity model (CDPM) for the simulation of UHPC slab. The CDPM adopted the yielding function proposed by Lee and Fenves [27] for UHPC. The plasticity parameters of flow potential eccentricity, biaxial-to-uniaxial compressive strength ratio, the dilation angels, and viscosity coefficient of UHPC CDPM were taken as $0.1,1.16,30^{\circ}$, and 0 , respectively. In the CDPM, the uniaxial compression crushing and tensile cracking required to be defined. The tensile and compressive stress-strain behaviours were determined as the following [21];

$$
\sigma_{t}=\left\{\begin{array}{lr}
f_{t} \frac{\varepsilon_{t}}{\varepsilon_{t 0}} & 0 \leq \varepsilon \leq \varepsilon_{t 0} \\
f_{t} & \varepsilon_{t 0}<\varepsilon \leq \varepsilon_{t p} \\
f_{t} \frac{1}{\left(1+w / w_{p}\right)^{p}} & 0<w
\end{array}\right.
$$

$\sigma_{c}=\left\{\begin{array}{cc}f_{c} \frac{k \gamma-\gamma^{2}}{1+(k-2) \gamma} & 0<\varepsilon_{c} \leq \varepsilon_{c 0} \\ f_{c} \frac{\gamma}{2(\gamma-1)^{2}+\gamma} & \varepsilon_{c 0}<\varepsilon_{c} \leq \varepsilon_{u 0}\end{array}\right.$

where, $f_{\mathrm{t}}$ is the UHPC ultimate tensile strength; $\varepsilon_{t 0}$ denotes strain at $f_{\mathrm{t}} ; f_{\mathrm{c}}$ is the UHPC compressive strength; $\varepsilon_{\mathrm{c} 0}$ denotes strain at $f_{\mathrm{c}} ; w_{\mathrm{p}}=0.25 \mathrm{~mm}$, and $p=0.95$; $\gamma=\varepsilon_{\mathrm{c}} / \varepsilon_{\mathrm{c} 0} ; k=E_{\mathrm{c}} / E_{\mathrm{c} 0}$, and equals to 1.19 [21]; $E_{\mathrm{c} 0}$ is the secant modulus at $f_{\mathrm{c}} ; E_{\mathrm{c}}$ denotes initial elastic modulus. 
The developed FEM adopts the continuum element (C3D8R) in ABAQUS to simulate the different components in push-out test specimens except the reinforcement mesh, which used the truss element (T3D2). The C3D8R element in ABAQUS element library is a $3 \mathrm{D}$ element with eight nodes and one integration point. The truss element T3D2, with two nodes and translational degree freedom, was used for the simulation of the reinforcement mesh.

In the explicit solver, the simulation accuracy tends to be influenced by the element size. Thus, a comparative study was performed on the influences of different mesh sizes on the FE simulation results. Fig. 7 compares three types of mesh size studied in the FEM, namely fine, intermediate, and coarse mesh sizes. For the FEM with fine mesh size, the continuum element sizes for the bolt, steel faceplate, and concrete core equal to $2.5 \times 2.5 \times 3 \mathrm{~mm}^{3}, 4.5 \times 4.5 \times 3 \mathrm{~mm}^{3}$, and $7 \times 7 \times 7 \mathrm{~mm}^{3}$, respectively; for the FEM with intermediate mesh size, the continuum element sizes for the bolt, steel faceplate, and concrete core are $2.5 \times 2.5 \times 3 \mathrm{~mm}^{3}, 7 \times 7 \times 3 \mathrm{~mm}^{3}$, and $15 \times 15 \times 15 \mathrm{~mm}^{3}$, respectively; meanwhile, for the FEM with coarse mesh size, the continuum element sizes for the bolt, steel faceplate, and concrete core are $2.5 \times 2.5 \times 3 \mathrm{~mm}^{3}, 8 \times 8 \times 3 \mathrm{~mm}^{3}$, and $20 \times 20 \times 20$ $\mathrm{mm}^{3}$, respectively. Fig. 8 compares the experimental load-slip curves of representative specimens U1A/B and U6A/B with the simulated curves of FEM with different types of mesh sizes. It shows that the FEMs with intermediate $\left(15 \times 15 \times 15 \mathrm{~mm}^{3}\right)$ and fine mesh sizes $\left(7 \times 7 \times 7 \mathrm{~mm}^{3}\right)$ offer more accurate simulation results compared with that of FEM with coarse mesh size $(20 \times 20 \times 20$ $\mathrm{mm}^{3}$ ). Finally, the FEM with fine element size is recommended for the developed FEM for push-out test specimens with UHPC and ECs.

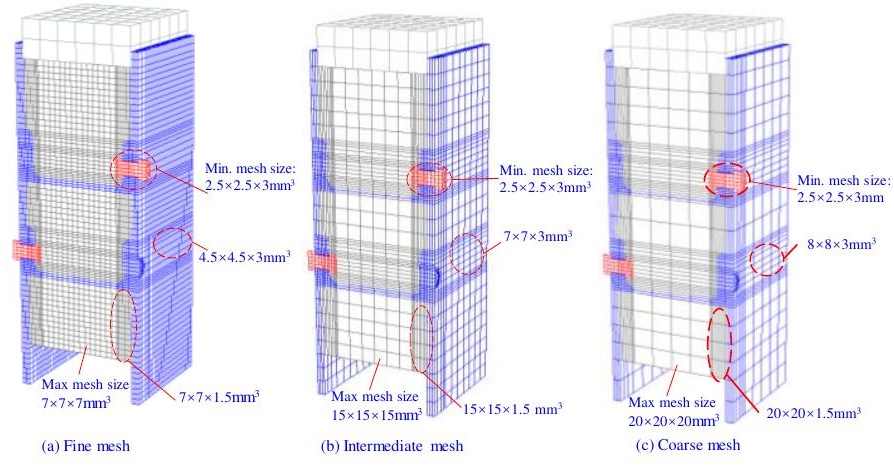

Fig. 7 Different mesh size used in the FEM
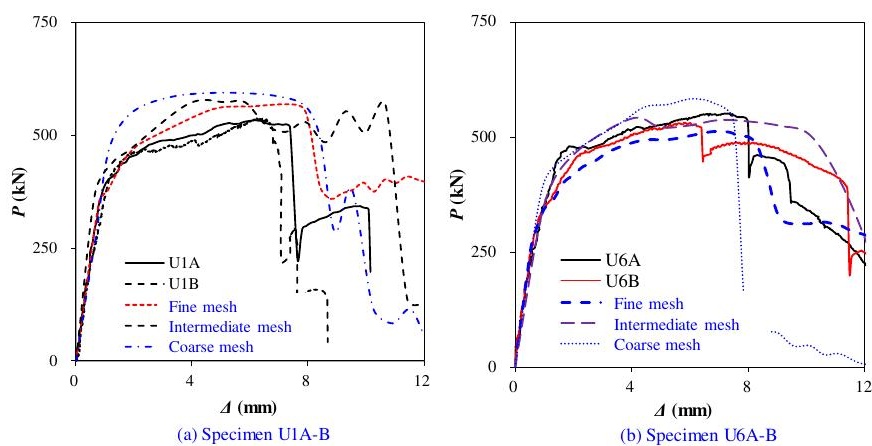

Fig. 8 Different mesh size for the FEM and their influences on FEA

\subsection{Boundary and interactions}

Displacement loading is applied to the top of the loading platen [see Fig. 6 (b)]. Since the symmetric modelling technique was used in the FEM, the symmetric restraints were defined to the mid-plane section, i.e., $\mathrm{Ux}=\mathrm{Ry}=\mathrm{Rz}=0$ ( $\mathrm{U}$ and $\mathrm{R}$ denotes translation and rotation, respectively). The bottom of the specimen was directly put on the bottom rigid base plate. The surface-to-surface (SS) interaction algorithm was adopted for the simulation of faceplate-base interactions. The SS interaction algorithm was also adopted for the simulations on interactions among different components in push-out test specimens, e.g., bolt-faceplate, channel-UHPC core, faceplate-UHPC, and loading platenUHPC core interaction. The SS interaction adopted the "hard contact" and "Coulomb friction model" for the interaction behaviours in the normal and tangential direction at the interaction surface. A friction coefficient of 0.4 was used in the definition of the friction model.

\subsection{Validations}

Fig. 9 compares the numerical failure modes with the experimental failure modes for representative specimens U1A and U6A. It shows that the FEM precisely simulated the failure modes observed from tests, which include the shear off of bolt and shear fracture of the C-channel web as well as their failure sequences. In addition, no failure was found in the UHPC, which implies the shear fracture of the bolts and C-channel web govern the failure of ECs.

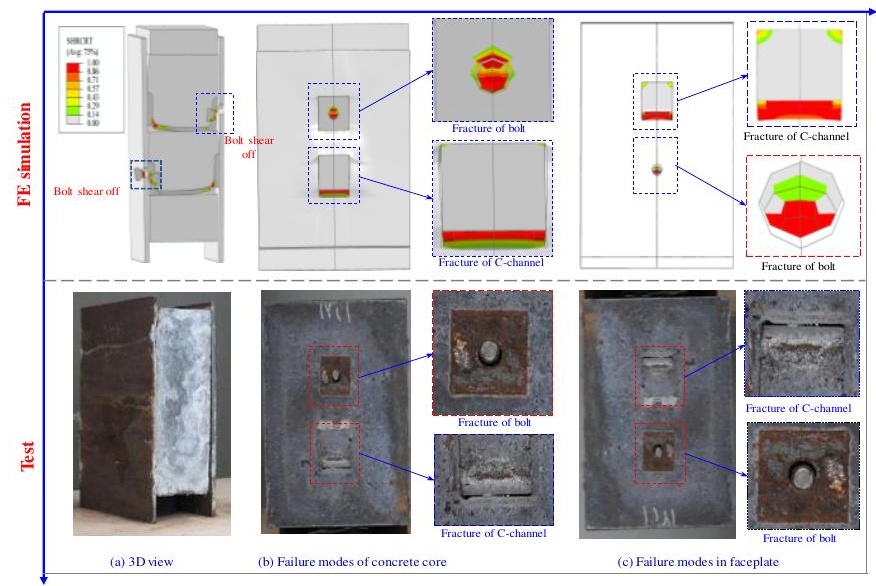

(a) Comparison of specimen U1A

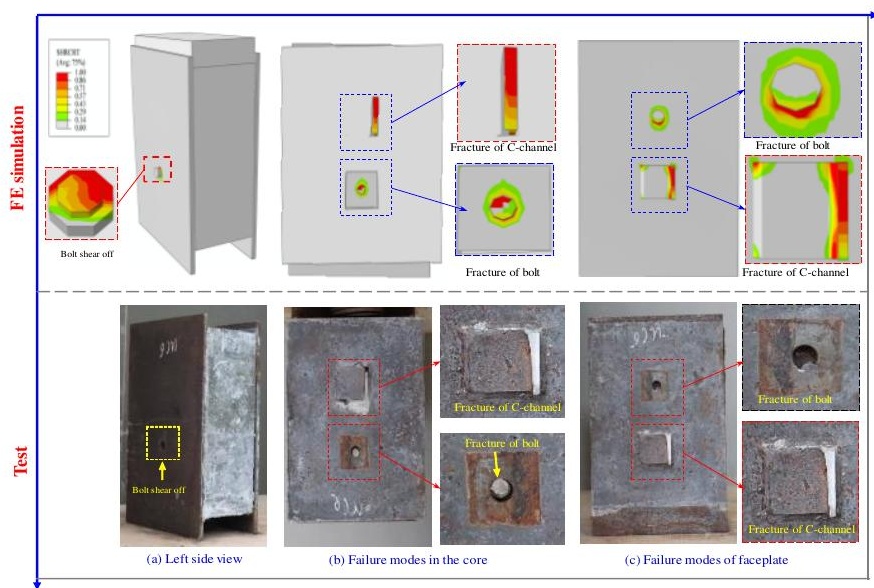

(b) Comparison of specimen U6A

Fig. 9 Comparison of numerical simulatd failure mode with test results
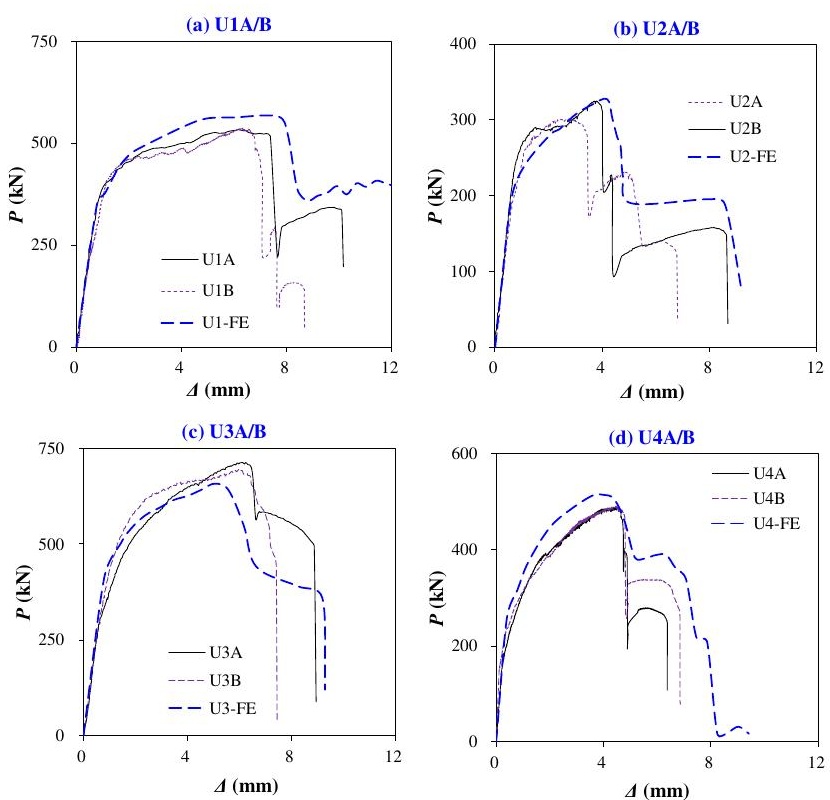

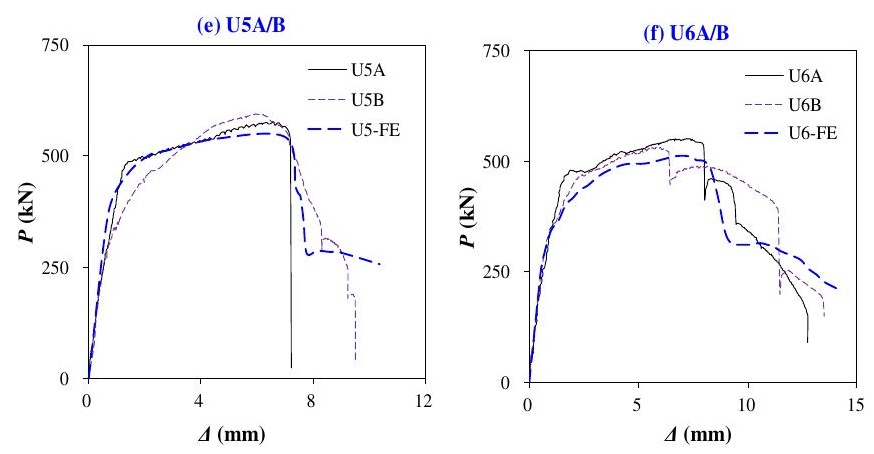

It shows that the developed FEM simulates reasonably well $P$ - $\Delta$ behaviours of ECs embedded in the UHPC slab. Table 1 makes further quantified comparisons of FEM predicted initial stiffness $\left(K_{\mathrm{e}}\right)$, ultimate shear resistance $\left(P_{\mathrm{u}}\right)$, slip $\Delta_{\mathrm{a}}$ at $P_{\mathrm{u}}$, and slip capacity $\left(\Delta_{\mathrm{u}}\right)$ with those results of 12 push-out tests. The $K_{\mathrm{e}}$ is taken as the ratio of $50 \% P_{\mathrm{u}}$ to its corresponding slip at the ascending branch of $P-\Delta$ curve, and the $\Delta_{\mathrm{u}}$ is taken as the slip at $90 \% P_{\mathrm{u}}$ at the recession branch of $P$ - $\triangle$ curve. The comparisons in Table 1 show that the average test-toprediction ratios (and COVs) for the $K_{\mathrm{e}}, P_{\mathrm{u}}, \Delta_{\mathrm{a}}$, and $\Delta_{\mathrm{u}}$ equal to $0.95(0.06)$, 1.01(0.06), 1.03(0.16), and 0.94(0.11), respectively.

These comparisons confirmed that the FEM could reasonably estimate the shear behaviours of ECs in UHPC including failure mode, $P$ - $\triangle$ behaviour, and different strength and slip indexes. Thus, this validated FEM can be further used in the FE parametric study.

Fig. 10 Comparison between the FEM simulated $P$ - $\Delta$ curves with experimental curves.

Table 1

Details and test results of push-out test specimens with EC connectors

\begin{tabular}{|c|c|c|c|c|c|c|c|c|c|c|c|c|c|c|c|}
\hline Item & Web-direction & $h(\mathrm{~mm})$ & $b(\mathrm{~mm})$ & $L_{\mathrm{c}}(\mathrm{mm})$ & $t_{\mathrm{f}}(\mathrm{mm})$ & $t_{\mathrm{w}}(\mathrm{mm})$ & $r(\mathrm{~mm})$ & $r_{1}(\mathrm{~mm})$ & $r_{2}(\mathrm{~mm})$ & $a_{1}(\mathrm{~mm})$ & $a_{2}(\mathrm{~mm})$ & $b_{1}(\mathrm{~mm})$ & $b_{2}(\mathrm{~mm})$ & $f_{\mathrm{c}}(\mathrm{MPa})$ & $E_{\mathrm{c}}(\mathrm{GPa})$ \\
\hline U1A & H-Web & 120 & 53 & 50 & 9 & 5.5 & 14 & 25 & 25 & 100 & 100 & 87 & 120 & 125 & 48.5 \\
\hline U1B & H-Web & 120 & 53 & 50 & 9 & 5.5 & 14 & 25 & 25 & 100 & 100 & 87 & 120 & 125 & 48.5 \\
\hline $\mathrm{U} 2 \mathrm{~A}$ & H-Web & 120 & 53 & 30 & 9 & 5.5 & 14 & 25 & 25 & 110 & 110 & 87 & 120 & 125 & 48.5 \\
\hline U2B & H-Web & 120 & 53 & 30 & 9 & 5.5 & 14 & 25 & 25 & 110 & 110 & 87 & 120 & 125 & 48.5 \\
\hline U3A & H-Web & 120 & 53 & 70 & 9 & 5.5 & 14 & 25 & 25 & 90 & 90 & 87 & 120 & 125 & 48.5 \\
\hline U3B & H-Web & 120 & 53 & 70 & 9 & 5.5 & 14 & 25 & 25 & 90 & 90 & 87 & 120 & 125 & 48.5 \\
\hline U4A & H-Web & 100 & 48 & 50 & 8.5 & 5.3 & 14 & 25 & 25 & 100 & 100 & 82 & 120 & 125 & 48.5 \\
\hline U4B & H-Web & 100 & 48 & 50 & 8.5 & 5.3 & 14 & 25 & 25 & 100 & 100 & 82 & 120 & 125 & 48.5 \\
\hline U5A & H-Web & 140 & 58 & 50 & 9.5 & 6 & 16 & 28 & 25 & 100 & 100 & 92 & 120 & 125 & 48.5 \\
\hline U5B & H-Web & 140 & 58 & 50 & 9.5 & 6 & 16 & 28 & 25 & 100 & 100 & 92 & 120 & 125 & 48.5 \\
\hline U6A & V-Web & 120 & 53 & 50 & 9 & 5.5 & 14 & 25 & 25 & 100 & 100 & 87 & 120 & 125 & 48.5 \\
\hline U6B & V-Web & 120 & 53 & 50 & 9 & 5.5 & 14 & 25 & 25 & 100 & 100 & 87 & 120 & 125 & 48.5 \\
\hline \multicolumn{16}{|c|}{ Table 1 Continued } \\
\hline Item & $\begin{array}{c}K_{\mathrm{e}, \mathrm{T}} \\
\mathrm{kN} / \mathrm{mm}\end{array}$ & $K_{\mathrm{e}, \mathrm{FE}} \mathrm{kN} / \mathrm{mm}$ & $K_{\mathrm{e}, \mathrm{T}}$ & $K_{\mathrm{e}, \mathrm{FE}}$ & $\begin{array}{l}P_{\mathrm{u}, \mathrm{T}} \\
(\mathrm{kN})\end{array}$ & $\begin{array}{l}P_{\mathrm{u}, \mathrm{FE}} \\
(\mathrm{kN})\end{array}$ & $\begin{array}{l}P_{\mathrm{u}, \mathrm{T}} / \\
P_{\mathrm{u}, \mathrm{FE}}\end{array}$ & $\begin{array}{c}\Delta_{\mathrm{a}, \mathrm{T}} \\
(\mathrm{mm})\end{array}$ & $\begin{array}{l}\Delta_{\mathrm{a}, \mathrm{FE}} \\
(\mathrm{mm})\end{array}$ & $\begin{array}{l}\Delta_{\mathrm{a}, \mathrm{T}} / \\
\Delta_{\mathrm{a}, \mathrm{FE}}\end{array}$ & $\begin{array}{c}\Delta \mathrm{u}, \mathrm{T} \\
(\mathrm{mm})\end{array}$ & $\begin{array}{l}\Delta_{\mathrm{u}, \mathrm{FE}} \\
(\mathrm{mm})\end{array}$ & $\begin{array}{l}\Delta_{\mathrm{u}, \mathrm{T} /} \\
\Delta_{\mathrm{u}, \mathrm{FE}}\end{array}$ & $\begin{array}{l}P_{\mathrm{u}, \mathrm{a}} \\
(\mathrm{kN})\end{array}$ & $\begin{array}{l}P_{\mathrm{u}, \mathrm{T}} / \\
P_{\mathrm{u}, \mathrm{a}}\end{array}$ \\
\hline U1A & 431.0 & 445.6 & & 97 & 534.0 & 563.4 & 0.95 & 6.2 & 5.9 & 1.04 & 7.7 & 8.0 & 0.96 & 494 & 1.08 \\
\hline U1B & 439.0 & 445.6 & & 99 & 538.0 & 563.4 & 0.95 & 6.3 & 5.9 & 1.06 & 7.1 & 8.0 & 0.88 & 494 & 1.09 \\
\hline $\mathrm{U} 2 \mathrm{~A}$ & 311.0 & 324.3 & & 96 & 302.0 & 328.2 & 0.92 & 3.1 & 4.2 & 0.74 & 3.5 & 4.6 & 0.77 & 330 & 0.92 \\
\hline U2B & 332.0 & 324.3 & & 02 & 325.0 & 328.2 & 0.99 & 3.7 & 4.2 & 0.89 & 4.0 & 4.6 & 0.88 & 330 & 0.98 \\
\hline U3A & 534.0 & 513.8 & & 04 & 714.0 & 657.8 & 1.09 & 6.1 & 5.1 & 1.21 & 6.6 & 6.2 & 1.07 & 658 & 1.09 \\
\hline U3B & 504.0 & 513.8 & & 98 & 694.0 & 657.8 & 1.06 & 6.1 & 5.1 & 1.21 & 6.7 & 6.2 & 1.08 & 658 & 1.05 \\
\hline U4A & 350.0 & 397.0 & & 88 & 489.0 & 515.0 & 0.95 & 4.8 & 4.0 & 1.20 & 5.1 & 5.2 & 0.99 & 446 & 1.09 \\
\hline U4B & 327.0 & 397.0 & & 82 & 492.0 & 515.0 & 0.96 & 4.9 & 4.0 & 1.22 & 5.2 & 5.2 & 1.00 & 446 & 1.10 \\
\hline U5A & 483.0 & 532.5 & & 91 & 576.0 & 542.1 & 1.06 & 6.6 & 7.0 & 0.94 & 7.2 & 7.4 & 0.98 & 574 & 1.00 \\
\hline U5B & 490.0 & 532.5 & & 92 & 595.0 & 542.1 & 1.10 & 6.1 & 7.0 & 0.87 & 7.2 & 7.4 & 0.98 & 574 & 1.03 \\
\hline U6A & 464.0 & 477.1 & & 97 & 551.0 & 511.0 & 1.08 & 7.2 & 6.7 & 1.07 & 8.0 & 8.6 & 0.93 & 494 & 1.12 \\
\hline U6B & 446.0 & 477.1 & & 93 & 531.0 & 511.0 & 1.04 & 6.0 & 6.7 & 0.90 & 6.4 & 8.6 & 0.74 & 494 & 1.07 \\
\hline Mean & & & & 95 & & & 1.01 & & & 1.03 & & & 0.94 & & 1.05 \\
\hline Cov & & & & 06 & & & 0.06 & & & 0.16 & & & 0.11 & & 0.06 \\
\hline
\end{tabular}

$h$ denotes the depth of the C-channels; $b$ denotes length of the flange of C-channel; $t_{\mathrm{f}}$ denotes the thickness of flange of $\mathrm{C}$-channel; $t_{\mathrm{w}}$ denotes the thickness of web of $\mathrm{C}$-channel; $r, r_{1}, r_{2}, a_{1}$, $a_{2}, b_{1}$, and $b_{2}$ are depicted in Fig. $1 ; f_{\mathrm{c}}$ and $E_{\mathrm{c}}$ denotes compressive strength and modulus of elasticity of UHPC; $K_{\mathrm{e}, \mathrm{T}}, K_{\mathrm{e}, \mathrm{FE}}$ denotes the experimental and numerical initial stiffness of ECs; $P_{\mathrm{u}, \mathrm{T}}, P_{\mathrm{u}, \mathrm{FE}}, P_{\mathrm{u}, \mathrm{a}}$ denotes the experimental and numerical ultimate shear resistance of ECs; $\Delta_{\mathrm{a}, \mathrm{T}}, \Delta_{\mathrm{a}, \mathrm{FE}}$ denotes the experimental and numerical slip at $P_{\mathrm{u}} ; \Delta_{\mathrm{u}, \mathrm{T}}, \Delta_{\mathrm{u}, \mathrm{FE}}$ denotes the experimental and numerical slip capacity.

\section{Numerical parametric studies on shear behaviours of ECs}

\subsection{Introduction on different numerical cases for parametric studies}

With the developed FEM, parametric studies were then carried out to study the key influencing parameters on shear behaviour of ECs in UHPC. Thirty-one cases, namely C1-C31, were prepared in this parametric study. The studied parameters are the gap between the bolt and bolt hole in faceplate (a), diameter $(d)$ and grades $(\mathrm{M})$ of the externally connected bolt, concrete core strength $\left(f_{\mathrm{c}}\right)$, length of C-channel $\left(L_{\mathrm{c}}\right)$, and prestressing ratio of the externally connected bolt $(\rho)$. For the FE push-out studying cases with $d=14 / 18 \mathrm{~mm}$ bolts, different a values of $0,0.5,1.0,1.5,2$, and $3 \mathrm{~mm}$ were prepared, i.e., numerical studying cases $\mathrm{C} 1-\mathrm{C} 6$ or $\mathrm{C} 7-\mathrm{C} 13$. Since the diameter and grade of bolts affects the shear behaviour of ECs, Chinese standard M6.8, 8.8, 10.9, and 12.9 grade of blots were investigated in this study. To investigate the strength of core materials on shear behaviour of ECs, different cases with grade C30, C45, C60, C80, and C120 (UHPC) core were prepared in this study. To study the effect of $L_{\mathrm{c}}$, cases with different $L_{\mathrm{c}}$ values of $25,40,50$, and $75 \mathrm{~mm}$ were also investigated. Finally, 
considering the prestressing force may act on the externally-connected bolts in

investigation. Finally, Table 2 lists the details of these studied 32 cases.

ECs, two cases with a prestressing ratio of 0.2 were prepared for this

Table 2

Details and results of different cases in FE parametric studies

\begin{tabular}{|c|c|c|c|c|c|c|c|c|c|c|c|}
\hline Case & Channel & $L_{\mathrm{c}}(\mathrm{mm})$ & $f_{\mathrm{c}}(\mathrm{MPa})$ & $r(\mathrm{~mm})$ & & $d(\mathrm{~mm})$ & $a(\mathrm{~mm})$ & $\mathrm{M}$ & $\rho$ & $f_{\mathrm{y}}(\mathrm{MPa})$ & $f_{\mathrm{u}}(\mathrm{MPa})$ \\
\hline $\mathrm{C} 1$ & $\mathrm{C} 120$ & 50 & 125.4 & 14 & & 14 & 0 & 8.8 & 0 & 677.6 & 847 \\
\hline $\mathrm{C} 2$ & $\mathrm{C} 120$ & 50 & 125.4 & 15 & & 14 & 0.5 & 8.8 & 0 & 677.6 & 847 \\
\hline $\mathrm{C} 3$ & $\mathrm{C} 120$ & 50 & 125.4 & 16 & & 14 & 1 & 8.8 & 0 & 677.6 & 847 \\
\hline $\mathrm{C} 4$ & $\mathrm{C} 120$ & 50 & 125.4 & 17 & & 14 & 1.5 & 8.8 & 0 & 677.6 & 847 \\
\hline C5 & $\mathrm{C} 120$ & 50 & 125.4 & 18 & & 14 & 2 & 8.8 & 0 & 677.6 & 847 \\
\hline C6 & $\mathrm{C} 120$ & 50 & 125.4 & 20 & & 14 & 3 & 8.8 & 0 & 677.6 & 847 \\
\hline $\mathrm{C} 7$ & $\mathrm{C} 120$ & 50 & 125.4 & 18 & & 18 & 0 & 8.8 & 0 & 677.6 & 847 \\
\hline $\mathrm{C} 8$ & $\mathrm{C} 120$ & 50 & 125.4 & 19 & & 18 & 0.5 & 8.8 & 0 & 677.6 & 847 \\
\hline C9 & $\mathrm{C} 120$ & 50 & 125.4 & 20 & & 18 & 1 & 8.8 & 0 & 677.6 & 847 \\
\hline $\mathrm{C} 10$ & $\mathrm{C} 120$ & 50 & 125.4 & 21 & & 18 & 1.5 & 8.8 & 0 & 677.6 & 847 \\
\hline $\mathrm{C} 11$ & $\mathrm{C} 120$ & 50 & 125.4 & 22 & & 18 & 2 & 8.8 & 0 & 677.6 & 847 \\
\hline $\mathrm{C} 12$ & $\mathrm{C} 120$ & 50 & 125.4 & 24 & & 18 & 3 & 8.8 & 0 & 677.6 & 847 \\
\hline $\mathrm{C} 13$ & $\mathrm{C} 120$ & 50 & 125.4 & 14 & & 14 & 0 & 6.8 & 0 & 468.5 & 585.6 \\
\hline $\mathrm{C} 14$ & $\mathrm{C} 120$ & 50 & 125.4 & 14 & & 14 & 0 & 10.9 & 0 & 984.8 & 1094.2 \\
\hline $\mathrm{C} 15$ & $\mathrm{C} 120$ & 50 & 125.4 & 14 & & 14 & 0 & 12.9 & 0 & 1183 & 1314.4 \\
\hline $\mathrm{C} 16$ & $\mathrm{C} 120$ & 50 & 125.4 & 18 & & 18 & 0 & 6.8 & 0 & 468.5 & 585.6 \\
\hline $\mathrm{C} 17$ & $\mathrm{C} 120$ & 50 & 125.4 & 18 & & 18 & 0 & 10.9 & 0 & 984.8 & 1094.2 \\
\hline C18 & $\mathrm{C} 120$ & 50 & 125.4 & 18 & & 18 & 0 & 12.9 & 0 & 1183 & 1314.4 \\
\hline C19 & $\mathrm{C} 120$ & 50 & 30 & 14 & & 14 & 0 & 8.8 & 0 & 677.6 & 847 \\
\hline $\mathrm{C} 20$ & $\mathrm{C} 120$ & 50 & 45 & 14 & & 14 & 0 & 8.8 & 0 & 677.6 & 847 \\
\hline $\mathrm{C} 21$ & $\mathrm{C} 120$ & 50 & 60 & 14 & & 14 & 0 & 8.8 & 0 & 677.6 & 847 \\
\hline $\mathrm{C} 22$ & C120 & 50 & 80 & 14 & & 14 & 0 & 8.8 & 0 & 677.6 & 847 \\
\hline $\mathrm{C} 23$ & C120 & 50 & 30 & 18 & & 18 & 0 & 8.8 & 0 & 677.6 & 847 \\
\hline $\mathrm{C} 24$ & C120 & 50 & 45 & 18 & & 18 & 0 & 8.8 & 0 & 677.6 & 847 \\
\hline $\mathrm{C} 25$ & $\mathrm{C} 120$ & 50 & 60 & 18 & & 18 & 0 & 8.8 & 0 & 677.6 & 847 \\
\hline $\mathrm{C} 26$ & $\mathrm{C} 120$ & 50 & 80 & 18 & & 18 & 0 & 8.8 & 0 & 677.6 & 847 \\
\hline $\mathrm{C} 27$ & C120 & 75 & 125.4 & 14 & & 14 & 0 & 8.8 & 0 & 677.6 & 847 \\
\hline C28 & $\mathrm{C} 120$ & 40 & 125.4 & 14 & & 14 & 0 & 8.8 & 0 & 677.6 & 847 \\
\hline $\mathrm{C} 29$ & C120 & 25 & 125.4 & 14 & & 14 & 0 & 8.8 & 0 & 677.6 & 847 \\
\hline C30 & $\mathrm{C} 120$ & 50 & 125.4 & 16 & & 14 & 1 & 8.8 & 0.2 & 677.6 & 847 \\
\hline C31 & $\mathrm{C} 120$ & 50 & 125.4 & 20 & & 18 & 1 & 8.8 & 0.2 & 677.6 & 847 \\
\hline \multicolumn{12}{|c|}{ Table 2 Continued } \\
\hline Case & $K_{\mathrm{e}, \mathrm{FE}}(\mathrm{kN} / \mathrm{mm})$ & $P_{\mathrm{u}, \mathrm{FE}}(\mathrm{kN})$ & $\Delta_{\mathrm{a}, \mathrm{FE}}(\mathrm{mm})$ & $\Delta_{\mathrm{u}, \mathrm{FE}}(\mathrm{mm})$ & a/d & $A_{s}\left(\mathrm{~mm}^{2}\right)$ & $P_{\mathrm{c}}(\mathrm{kN})$ & $P_{\mathrm{B}}(\mathrm{kN})$ & $P_{\mathrm{B}} / P_{\mathrm{C}}$ & $P_{\mathrm{u}, \mathrm{a}}(\mathrm{kN})$ & $P_{\mathrm{u}, \mathrm{FE}} / P_{\mathrm{u}, \mathrm{a}}$ \\
\hline $\mathrm{C} 1$ & 811.8 & 597.7 & 2.6 & 3.9 & 0 & 115 & 234.3 & 58.4 & 0.25 & 585.51 & 1.02 \\
\hline $\mathrm{C} 2$ & 589.7 & 616.8 & 3.9 & 5.2 & 0.04 & 115 & 234.3 & 58.4 & 0.25 & 585.51 & 1.05 \\
\hline $\mathrm{C} 3$ & 573.6 & 608.4 & 5.8 & 7.6 & 0.07 & 115 & 234.3 & 58.4 & 0.25 & 585.51 & 1.04 \\
\hline $\mathrm{C} 4$ & 567 & 629.9 & 7.6 & 8.8 & 0.11 & 115 & 234.3 & 58.4 & 0.25 & 585.51 & 1.08 \\
\hline $\mathrm{C} 5$ & 549.2 & 618.8 & 8.8 & 9.7 & 0.14 & 115 & 234.3 & 58.4 & 0.25 & 585.51 & 1.06 \\
\hline C6 & 505.2 & 536.3 & 9.7 & 10.3 & 0.21 & 115 & 234.3 & 58.4 & 0.25 & 585.51 & 0.92 \\
\hline $\mathrm{C} 7$ & 892.5 & 693.6 & 6.2 & 7.9 & 0 & 193 & 234.3 & 98.1 & 0.42 & 664.79 & 1.04 \\
\hline $\mathrm{C} 8$ & 579.8 & 736.7 & 7.5 & 8.7 & 0.03 & 193 & 234.3 & 98.1 & 0.42 & 664.79 & 1.11 \\
\hline C9 & 563.3 & 752.1 & 8.7 & 9.8 & 0.06 & 193 & 234.3 & 98.1 & 0.42 & 664.79 & 1.13 \\
\hline $\mathrm{C} 10$ & 566.5 & 737 & 9.3 & 10.5 & 0.08 & 193 & 234.3 & 98.1 & 0.42 & 664.79 & 1.11 \\
\hline C11 & 590.9 & 725.2 & 12.4 & 13.5 & 0.11 & 193 & 234.3 & 98.1 & 0.42 & 664.79 & 1.09 \\
\hline C12 & 575.9 & 611.4 & 10.7 & 11.4 & 0.17 & 193 & 234.3 & 98.1 & 0.42 & 664.79 & 0.92 \\
\hline C13 & 714.8 & 500.7 & 2.6 & 3.3 & 0 & 115 & 234.3 & 40.4 & 0.17 & 549.43 & 0.91 \\
\hline C14 & 848 & 625.6 & 2.6 & 3.9 & 0 & 115 & 234.3 & 75.5 & 0.32 & 619.63 & 1.01 \\
\hline C15 & 850 & 643.1 & 4.4 & 5.1 & 0 & 115 & 234.3 & 90.7 & 0.39 & 650.01 & 0.99 \\
\hline C16 & 778.5 & 545.6 & 1.9 & 2.6 & 0 & 193 & 234.3 & 67.8 & 0.29 & 604.25 & 0.9 \\
\hline $\mathrm{C} 17$ & 912.9 & 746.1 & 7.3 & 8.9 & 0 & 193 & 234.3 & 126.7 & 0.54 & 722.05 & 1.03 \\
\hline C18 & 912.2 & 824.3 & 11 & 13.1 & 0 & 193 & 234.3 & 152.2 & 0.65 & 773.04 & 1.07 \\
\hline C19 & 558.1 & 413.8 & 6.3 & 7.4 & 0 & 115 & 117.5 & 58.4 & 0.5 & 351.79 & 1.18 \\
\hline $\mathrm{C} 20$ & 646.4 & 465.2 & 5.4 & 6.9 & 0 & 115 & 143.8 & 58.4 & 0.41 & 404.58 & 1.15 \\
\hline $\mathrm{C} 21$ & 710 & 552.1 & 4.4 & 5.6 & 0 & 115 & 166.1 & 58.4 & 0.35 & 449.09 & 1.23 \\
\hline
\end{tabular}




\begin{tabular}{|c|c|c|c|c|c|c|c|c|c|c|c|}
\hline $\mathrm{C} 22$ & 751.4 & 584.3 & 3.5 & 4.5 & 0 & 115 & 191.8 & 58.4 & 0.3 & 500.48 & 1.17 \\
\hline $\mathrm{C} 23$ & 620.9 & 534.4 & 14.4 & 15.3 & 0 & 193 & 117.5 & 98.1 & 0.84 & 431.07 & 1.24 \\
\hline $\mathrm{C} 24$ & 703.6 & 575 & 10.6 & 12.8 & 0 & 193 & 143.8 & 98.1 & 0.68 & 483.86 & 1.19 \\
\hline $\mathrm{C} 25$ & 792.4 & 647.9 & 8.1 & 9.8 & 0 & 193 & 166.1 & 98.1 & 0.59 & 528.37 & 1.23 \\
\hline $\mathrm{C} 26$ & 843 & 669.4 & 6.2 & 8.4 & 0 & 193 & 191.8 & 98.1 & 0.51 & 579.76 & 1.15 \\
\hline $\mathrm{C} 27$ & 1468.4 & 699.9 & 2.4 & 2.9 & 0 & 115 & 351.5 & 58.4 & 0.17 & 819.82 & 0.85 \\
\hline C28 & 684.6 & 465.1 & 2 & 3 & 0 & 115 & 187.4 & 58.4 & 0.31 & 491.78 & 0.95 \\
\hline $\mathrm{C} 29$ & 628.9 & 344.7 & 2.3 & 3 & 0 & 115 & 117.2 & 58.4 & 0.5 & 351.2 & 0.98 \\
\hline C30 & 567.8 & 564.1 & 3.9 & 5.2 & 0 & 115 & 234.3 & 58.4 & 0.25 & 585.51 & 0.96 \\
\hline $\mathrm{C} 31$ & 563.3 & 658.5 & 6.7 & 8.1 & 0 & 193 & 234.3 & 98.1 & 0.42 & 664.79 & 0.99 \\
\hline Mean & & & & & & & & & & & 1.06 \\
\hline Cov & & & & & & & & & & & 0.11 \\
\hline
\end{tabular}

$f_{c}$ denotes the ultimate compressive strength of UHPC; $r$ denotes the diameter of the holes in the channels and steel faceplates; $d$ denotes the diameter of the external bolts; $a$ denotes the gap between the channel and bolt; $M$ denotes the grades of the bolts; $\rho$ denotes the preload ratio of the bolts, which can be defined as $T / A_{s} f_{\mathrm{y}} ; f_{\mathrm{y}}$ and $f_{\mathrm{u}}$ denote the yield and ultimate stress of the bolts; $K_{\mathrm{e}, \mathrm{FE}}$ denotes the numerical initial stiffness of the ECs in parameter studies; $P_{\mathrm{u}, \mathrm{FE}}$ denotes the ultimate strength of ECs in parametric studies; $\Delta_{\mathrm{a}, \mathrm{FE}}$ denotes the slip at $P_{u}$; $\Delta_{\mathrm{u}, \mathrm{FE}}$ denotes the slip capacity of ECs; $A_{s}$ denotes the area of cross section for bolts; $P_{\mathrm{c}}$ denotes shear strength of C-channel in UHPC core; $P_{\mathrm{B}}$ denotes the shear strength of bolts; $P_{\mathrm{u}, \mathrm{a}}$ denotes the analytical ultimate strength of ECs

\subsection{Generalize load-slip behaviour and failure mechanism of ECs in UHPC}

Based on $P-\Delta$ curves of 12 push-out tests and 31 numerical cases, the generalized $P-\triangle$ curve and failure mechanisms are shown in Fig. 11. As reflected in Fig. 11(a), the general $P-\triangle$ curve exhibits three working stages that includes elastic, nonlinear developing, and recession working stages. During the first stage [curve OA in Fig. 11(a)], every component in the push-out specimen behaves elastically until Point A, i.e., stage I end. At point A in Fig. 11(b), the conjunction between the web of $\mathrm{C}$-channel and its flange (welding side rather than the other side with the connected bolts) starts to yield. Thus, in the working stage II, the web of C-channel, connected bolts, flange of C-channel, and faceplates yield as shown in Fig. 11(c), which lead to the nonlinear branch of $P-\triangle$ curve at working stage II. Finally, at the point B in Fig. 11(a), the bottom externally-connected bolt fails in shear fracture [see Fig. 11(c)]; meanwhile, the push-out testing specimen achieves its ultimate shear resistance $\left(P_{\mathrm{u}}\right)$. After point $\mathrm{B}$, the $P-\Delta$ curve enters into its third recession working stage. In stage III, the $P$ - $\triangle$ curve recesses in a zigzag manner with two or three steps. In Fig. 11(a), the load carrying capacity firstly drops to its first step due to fracture of bottom bolt, i.e., curve BC. At the first dropping step end, i.e., point $\mathrm{C}$, shear fracture occurs to the second bolt as shown in Fig. 11(d). After that, the reaction force of specimen drops to the second step, and the $P-\Delta$ curve exhibits a yielding plateau due to the plastic deformation of the C-channel, i.e., curve CD in Fig. 11(a). At Point D, the shear fracture occurs to the web toe of C-channel [see Fig. 11(e)]. In some cases, the webs of two C-channels in ECs failed in a successive way. Thus, the recession $P-\triangle$ curves exhibit two or three steps due to the fracture and plastic deformation of bolts and C-channels.
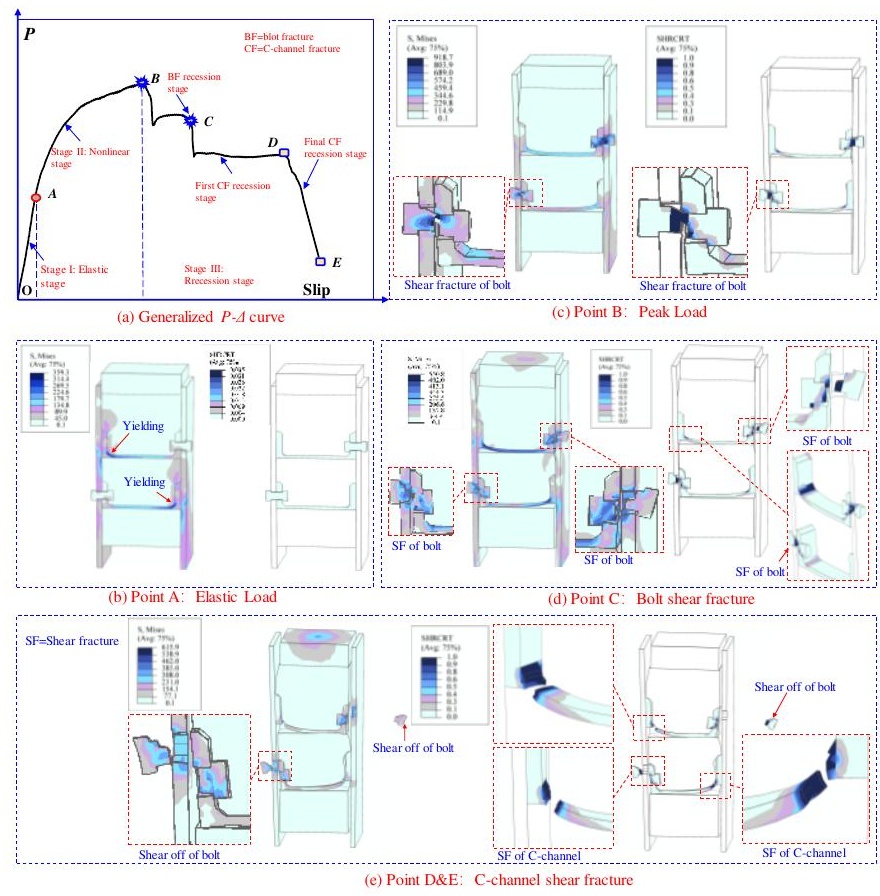

Fig. 11 Generalized load-slip behaviour and failure mechnism of ECs in UHPC

\subsection{Effect of gap between bolt hole and bolt (a)}

Fig. 12(a) and (b) plots the effects of a on $P$ - $\triangle$ curves of push-out numerical cases with $d=14$ and $18 \mathrm{~mm}$, respectively. Fig. 13(a)-(b) illustrates the effect of $a$ on strength and slip capacity indexes of $P_{\mathrm{u}}, K_{\mathrm{e}}, \Delta_{\mathrm{a}}$, and $\Delta_{\mathrm{u}}$. These figures show that;

(1) As the $a$ value increases from 0 to $0.5,1.0 .1 .5,2.0$, and $3 \mathrm{~mm}$, the shear stiffness of ECs with $d=14 \mathrm{~mm}$ bolts was reduced by $18 \%, 20 \%, 21 \%, 23 \%$, and $29 \%$, respectively; meanwhile, these reductions for ECs with $d=18 \mathrm{~mm}$ bolts equal to $35 \%, 37 \%, 37 \%, 34 \%$, and $36 \%$, respectively. This is due to that the bolt-faceplate gap (a) requires the additional slip before the full touch of faceplates to the externally-connected bolts, which compromises the shear stiffness of ECs.

(2) The increasing a value from 0 to $2 \mathrm{~mm}$ exhibits marginal influences on the $P_{\mathrm{u}}$ of ECs, but the increasing a value from 2 to $3 \mathrm{~mm}$ significantly reduces the $P_{\mathrm{u}}$ of ECs. As the $a$ value increases from 0 to $0.5,1.0 .1 .5,2.0$, and $3 \mathrm{~mm}$, the $P_{\mathrm{u}}$ of ECs with $d=14 \mathrm{~mm}$ bolts was slightly reduced by $5 \%, 4 \%, 4 \%, 4 \%$, and $14 \%$, respectively; meanwhile, the $P_{\mathrm{u}}$ of ECs with $d=18 \mathrm{~mm}$ bolts was reduced by $-6 \%,-8 \%,-6 \%,-5 \%$, and $12 \%$, respectively (negative increments means increment). This is because that setting the bolt-hole gap could be tolerated by the ductile C-channel as $a$ is less than $2.0 \mathrm{~mm}$. However, as the $a$ is beyond $2.0 \mathrm{~mm}$, the shear resistance of the C-channel tends to be compromised. Thus, from this point of view, the $a$ value needs to be controlled within $2 \mathrm{~mm}$ for the developed ECs.

(3) Increasing the $a$ value in ECs significantly improves the slip capacity of ECs with both $d=14 \mathrm{~mm}$ and $18 \mathrm{~mm}$ bolts in UHPC. As the $a$ value increases from 0 to $0.5,1.0 .1 .5,2.0$, and $3 \mathrm{~mm}$, the $\Delta_{\mathrm{u}}$ (or $\Delta_{\mathrm{a}}$ ) of ECs with $d=14 \mathrm{~mm}$ bolts is increased by $127 \%(114 \%), 172 \%(161 \%), 215 \%(248 \%), 261 \%(273 \%)$, and $336 \%(333 \%)$, respectively; meanwhile, the the $\Delta_{\mathrm{u}}\left(\right.$ or $\Delta_{\mathrm{a}}$ ) of ECs with $d=18 \mathrm{~mm}$ bolts is increased by $10 \%(21 \%), 25 \%(40 \%), 33 \%(50 \%), 52 \%(85 \%)$, and $68 \%(106 \%)$, respectively. The improvements on the ECs with bolts in smaller diameter is more significant. This is because that the shear deformation capacity of the bolts at their ultimate shear resistance is smaller than that of the $\mathrm{C}$-channel. The reserving bolt-faceplate hole gap could delay the shear deformation of bolts that could avoid the bolts fail prior to the development of full plastic deformation of bolts.

The above findings reveal that reserving the bolt-faceplate hole gap within $2 \mathrm{~mm}$ does not harm the shear resistance of ECs in UHPC, but greatly improves the slip capacity of ECs. However, as the gap $a$ is beyond $3 \mathrm{~mm}$, the shear capacity of ECs will be affected even though the slip capacity is still improved. Moreover, reserving the bolt-faceplate hole gap will be beneficial for the installation of the ECs that could tolerate the fabrication errors.
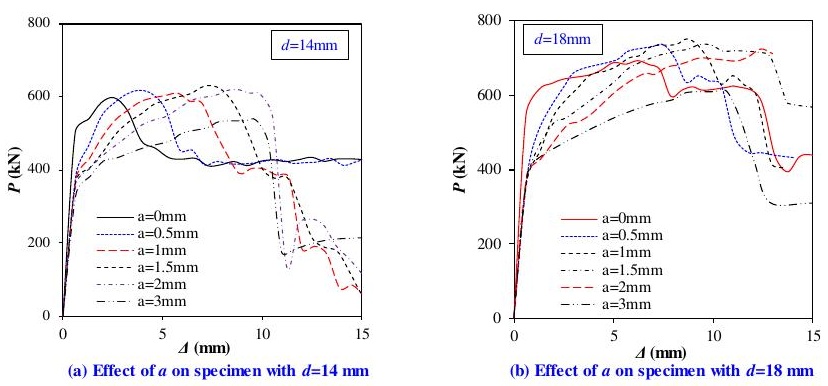

Fig. 12 Effect of $a$ on load-slip behaviours of ECs 

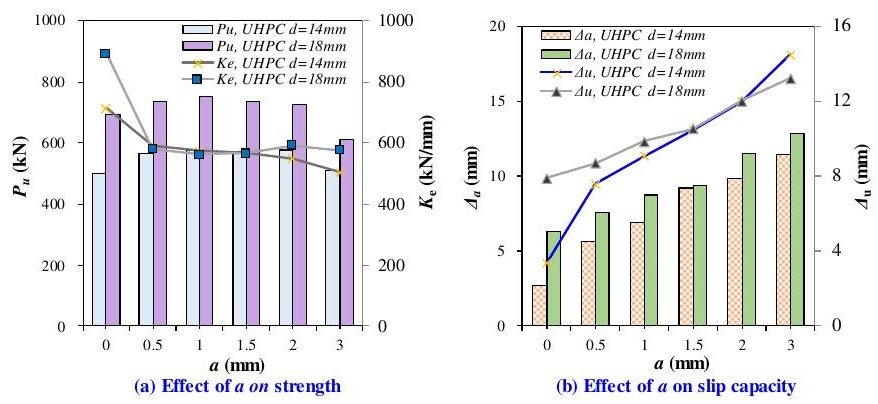

Fig. 13 Effects of gap between bolt and bolt holes $(a)$

\subsection{Effect of diameter of grades $(M)$ and diameter (d) of bolts}

Fig. 14(a)-(b) depicts the effects of $M$ on $P$ - $\triangle$ curves of push-out numerical cases with $d=14$ and $18 \mathrm{~mm}$, respectively. Fig. 15(a)-(b) plots the influences of $\mathrm{M}$ on the strength and slip capacity, i.e., $P_{\mathrm{u}}, K_{\mathrm{e}}, \Delta_{\mathrm{a}}$, and $\Delta_{\mathrm{u}}$. These figures show that increasing the $M$ of externally-connected bolts generally improves both shear resistance and ductility of ECs with UHPC. As the grade of the bolts increases from M6.8 to M8.8, M10.9, and M12.9, the $P_{\mathrm{u}}$ (or $K_{\mathrm{e}}$ ) of ECs with $d=14 \mathrm{~mm}$ bolts was increased by $19 \%(14 \%), 25 \%(19 \%)$, and $28 \%(19 \%)$, respectively; meanwhile, the $P_{\mathrm{u}}$ (or $K_{\mathrm{e}}$ ) of ECs with $d=18 \mathrm{~mm}$ bolts was increased by $27 \%(15 \%), 37 \%(17 \%)$, and $51 \%(17 \%)$, respectively; the $\Delta_{\mathrm{u}}$ (or $\left.\Delta_{\mathrm{a}}\right)$ of ECs with $d=14 \mathrm{~mm}$ bolts was increased by $19 \%(-2 \%), 17 \%(-2 \%)$, and $54 \%(69 \%)$, respectively; and the $\Delta_{\mathrm{u}}$ (or $\Delta_{\mathrm{a}}$ ) of ECs with $d=18 \mathrm{~mm}$ bolts was increased by $205 \%(221 \%), 246 \%(278 \%)$, and $408 \%(469 \%)$, respectively. Moreover, it can be also found that the improvements on strength and ductility for ECs with larger diameter bolts are more significant. In addition, the ECs was gradually changed from the brittle to ductile connectors as the $\mathrm{M}$ of externallyconnected bolts increases. These improvements received from the increasing the grade of bolts is due to the increased shear strength of bolts $\left(P_{\mathrm{B}}\right)$. Since the Cchannel is more ductile compared with the bolts, the $P_{\mathrm{B}}$ to shear resistance of the C-channel $\left(P_{\mathrm{C}}\right)$ are required to be well controlled to make sure the full utilization of the plastic deformation of C-channels. The $P_{\mathrm{B}}$ and $P_{\mathrm{C}}$ can be determined as the following:

$P_{B}=\sigma_{u} A_{s b}$

$P_{C}=0.25 \alpha f_{c} L_{c} h+\frac{t_{w}^{2} L_{c}}{0.52 h} f_{u}$

where, $t_{\mathrm{w}}$ is the web thickness; $L_{\mathrm{c}}$ denotes the channel length; $f_{\mathrm{c}}$ is the UHPC compressive strength; $f_{\mathrm{u}}$ is the ultimate strength of $\mathrm{C}$-channel.

Thus, the $P_{\mathrm{B}}, P_{\mathrm{C}}$, and the $P_{\mathrm{B}} / P_{\mathrm{C}}$ ratios for each numerical case are calculated in Table 2. It can be found that as the grade of the bolts increases from M6.8 to M8.8, M10.9, and M12.9, the $P_{\mathrm{B}} / P_{\mathrm{C}}$ ratio of ECs with $d=14 \mathrm{~mm}$ bolts is increased from 0.17 to $0.25,0.32$, and 0.39 , respectively; meanwhile, the $P_{\mathrm{B}} / P_{\mathrm{C}}$ ratio of ECs with $d=14 \mathrm{~mm}$ bolts is increased from 0.25 to $0.42,0.54$, and 0.65 , respectively. This explains the improvements on strength and deformation capacity of ECs through using higher grade bolts. Moreover, this also explains the larger improvements on the shear resistance and slip capacity of ECs with $d=18 \mathrm{~mm}$ bolts than those of ECs with $d=14 \mathrm{~mm}$ bolts since the $P_{\mathrm{B}} / P_{\mathrm{C}}$ ratios for ECs with $d=18 \mathrm{~mm}$ bolts are much larger than those with $d=14 \mathrm{~mm}$ bolts. In addition, one interesting finding in Fig. 14 is that as the $P_{\mathrm{B}} / P_{\mathrm{C}}$ ratio is larger than 0.5 the slip capacity of the ECs with UHPC could meet the minimum required slip capacity of $6 \mathrm{~mm}$ for the ductile connectors as specified in Eurocode 4 [28].

Thus, increasing the diameter $(d)$ of bolts in ECs also improves the shear strength and slip capacity of ECs [see Fig. 15(c)-(d)]. With the increase of $d$ value of bolts from 14 to $18 \mathrm{~mm}$, the Ke is slightly increased by $10 \%, 8 \%$, and $7 \%$ for ECs with grade M8.8, M10.9, and M12.9 bolts, respectively; the $K_{\mathrm{e}}$ is significantly increased by $16 \%, 19 \%$, and $28 \%$ for ECs with grade M8.8, M10.9, and M12.9 bolts, respectively; and the $\Delta_{\mathrm{u}}$ (or $\Delta_{\mathrm{a}}$ ) of ECs are dramatically increased by $100 \%(140 \%), 131 \%(184 \%)$, and 155\%(148\%) for ECs with grade M8.8, M10.9, and M12.9 bolts, respectively. The reason is similar to that of increasing $\mathrm{M}$ of bolts, which increased the $P_{\mathrm{B}} / P_{\mathrm{C}}$ ratios of ECs.

Thus, the $P_{\mathrm{B}} / P_{\mathrm{C}}$ ratios of ECs required to be well controlled that make sure the full use of the plastic deformation of C-channels, i.e., the $P_{\mathrm{B}}$ should match the $P_{\mathrm{C}}$ to guarantee a ductile connector or the shear fracture of the $\mathrm{C}$-channel should be prior to the shear fracture of bolts. This can be realized through adjusting the $P_{\mathrm{B}} / P_{\mathrm{C}}$ ratio.
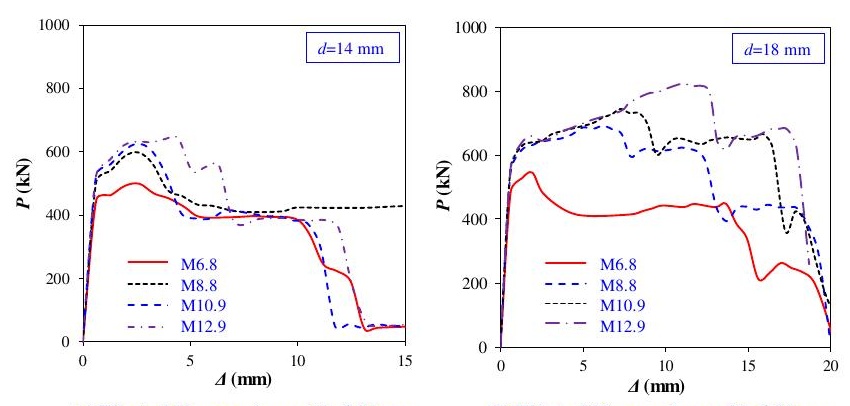

(a) Effect of $M$ on specimen with $d=14 \mathrm{~mm}$

Fig. 14 Effect of $M$ and $d$ on load-slip behaviours of ECs

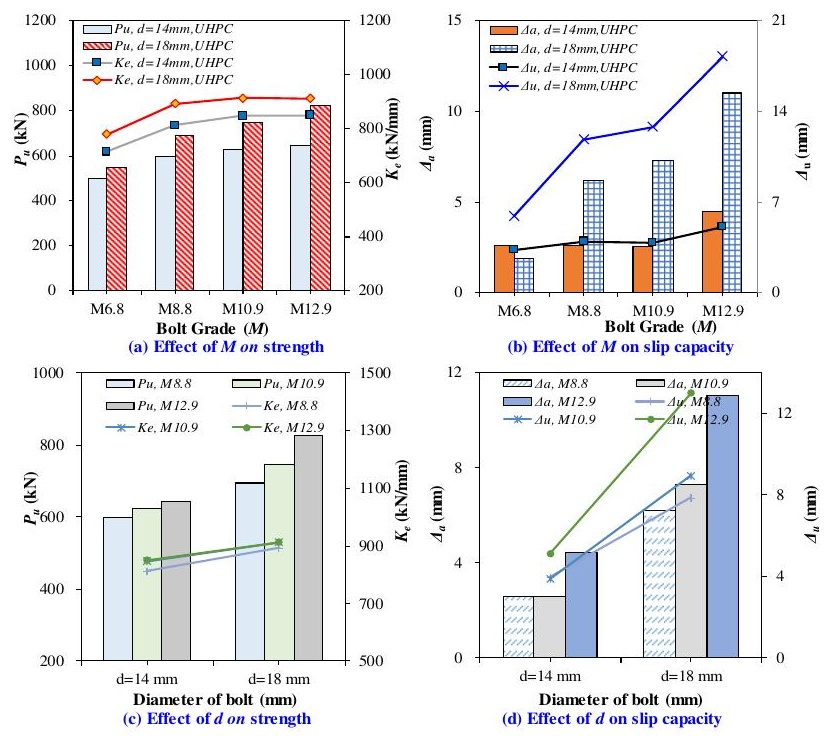

Fig. 15 Effect of $M$ and $d$ on load-slip behaviours of ECs

\subsection{Effect of concrete strength $\left(f_{\mathrm{c}}\right)$}

Fig. 16(a) and (b) plots the effects of $f_{\mathrm{c}}$ on $P$ - $\triangle$ curves of push-out numerical cases with $d=14$ and $18 \mathrm{~mm}$, respectively. Fig. 17(a) and (b) plots the influences of $f_{\mathrm{c}}$ on the strength and slip capacity, i.e., $P_{\mathrm{u}}, K_{\mathrm{e}}, \Delta_{\mathrm{a}}$, and $\Delta_{\mathrm{u}}$. These figures show that increasing the grade of concrete from $\mathrm{C} 30$ to $\mathrm{C} 120$ (UHPC) improves the shear resistance but reduces the slip capacity of ECs. As the grade of concrete increases from C30 to C45, C60, C80, and C120(UHPC), the $P_{\mathrm{u}}\left(\right.$ or $\left.K_{\mathrm{e}}\right)$ of ECs with $d=14 \mathrm{~mm}$ bolts was increased by $12 \%(16 \%), 33 \%(27 \%), 41 \%(35 \%)$, and $44 \%(45 \%)$, respectively; meanwhile, the $P_{\mathrm{u}}$ ( or $K_{\mathrm{e}}$ ) of ECs with $d=18 \mathrm{~mm}$ bolts was increased by $8 \%(13 \%), 21 \%(28 \%), 25 \%(36 \%)$, and $30 \%(44 \%)$, respectively; however, the $\Delta_{\mathrm{u}}$ ( or $\Delta_{\mathrm{a}}$ ) of ECs with $d=14 \mathrm{~mm}$ bolts was reduced by $6 \%(15 \%), 24 \%(31 \%), 39 \%(45 \%)$, and $477 \%(59 \%)$, respectively; and the $\Delta_{\mathrm{u}}$ (or $\Delta_{\mathrm{a}}$ ) of ECs with $d=18 \mathrm{~mm}$ bolts was reduced by $16 \%(26 \%), 36 \%(44 \%)$, $45 \%(57 \%)$, and $49 \%(57 \%)$, respectively. This is because increasing the core strength increases the shear resistance of C-channel, but reduces the $P_{\mathrm{B}} / P_{\mathrm{C}}$ ratios of ECs that results in reduced slip capacity of the ECs. As the grade of concrete core increases from $\mathrm{C} 30$ to $\mathrm{C} 45, \mathrm{C} 60, \mathrm{C} 80$, and $\mathrm{C} 120$ (UHPC), the $P_{\mathrm{B}} / P_{\mathrm{C}}$ ratio of ECs with $d=14$ (or 18) mm bolts are reduced from $0.50(0.84)$ to $0.41(0.68)$, $0.35(0.59), 0.30(0.51)$, and $0.25(0.42)$, respectively. This implies using high strength concrete core requires using higher strength bolts to match the increased shear resistance of C-channel in the ECs to make sure the ductility of ECs, which is realized through increasing the $P_{\mathrm{B}} / P_{\mathrm{C}}$ ratio of ECs.
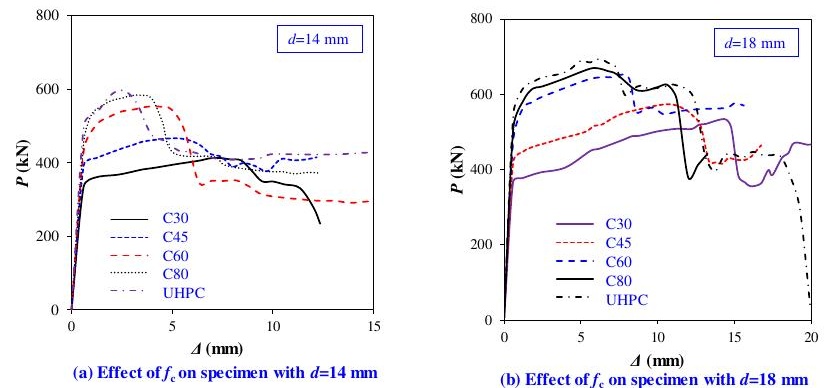

Fig. 16 Effect of $f_{\mathrm{c}}$ on load-slip behaviours of ECs 


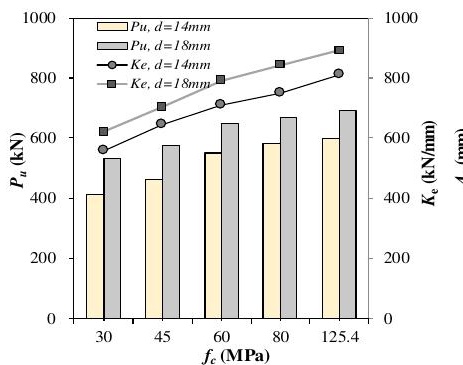

(a) Effect of $f_{\mathrm{c}}$ on strength

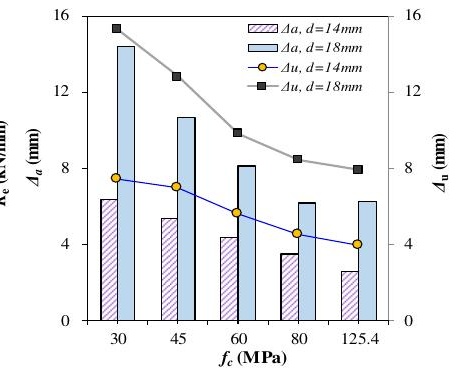

(b) Effect of $f_{\mathrm{c}}$ on slip capacity
Fig. 17 Effect of strength of concrete on strength and ductility index of Ecs

\subsection{Effect of length of C-channel $\left(L_{\mathrm{c}}\right)$}

Fig. 18(a) depicts the effects of $L_{\mathrm{c}}$ on $P-\triangle$ curves of push-out numerical cases. Fig. 19(a)-(b) illustrates the influences of $L_{\mathrm{c}}$ on the strength and slip capacity. These figures show that increasing the $L_{\mathrm{c}}$ from $25 \mathrm{~mm}$ to 40,50 , and $75 \mathrm{~mm}$ improvs the $P_{\mathrm{u}}$ (or $K_{\mathrm{e}}$ ) of ECs by $35 \%(9 \%), 45 \%(14 \%)$, and $103 \%(134 \%)$, respectively; meanwhile, the $\Delta_{\mathrm{u}}$ (or $\Delta_{\mathrm{a}}$ ) of ECs is slightly reduced by $1 \%(14 \%),-10 \%(-16 \%)$, and $6 \%(-6 \%)$, respectively (negative value means increase). The increasing length of $L_{\mathrm{c}}$ increases the shear resistance of Cchannel and thus increased the shear resistance of ECs. However, the ECs with $L_{\mathrm{c}}$ value of $50 \mathrm{~mm}$ offers the best slip capacity. Thus, in the developed ECs, the optimized $L_{\mathrm{c}}$ value of $50 \mathrm{~mm}$ is recommended for ECs with UHPC.

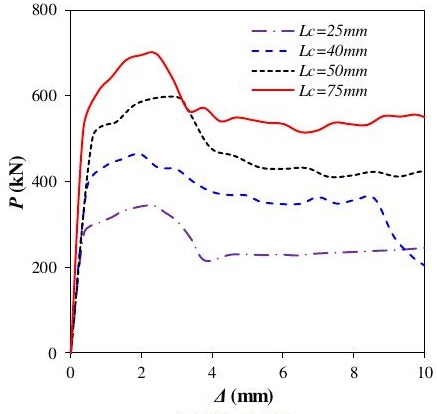

(a) Effect of $L_{c}$

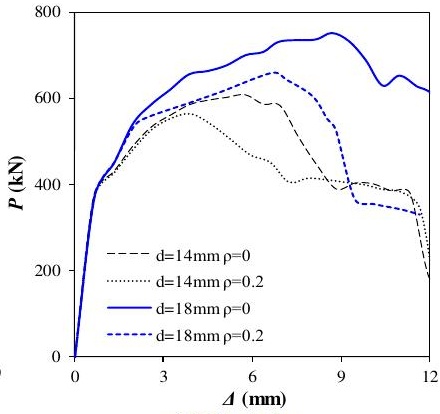

(b) Effect of $\rho$
Fig. 18 Effect of $L_{\mathrm{c}}$ and $\rho$ on load-slip behaviours of ECs

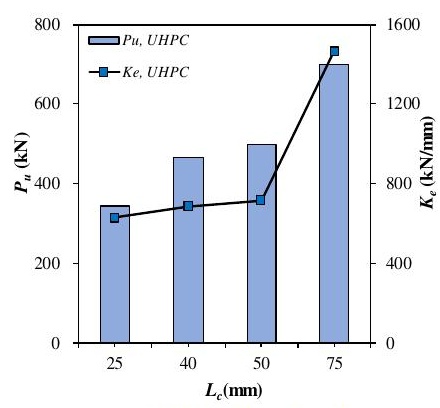

(a) Effect of $L_{\mathrm{c}}$ on strength

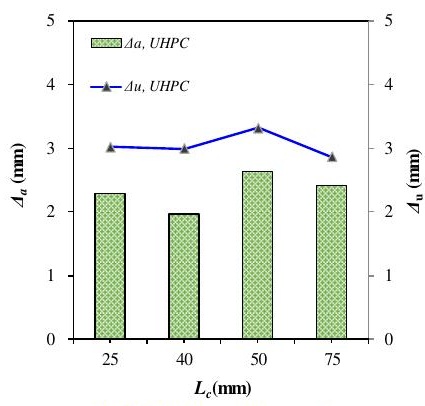

(b) Effect of $L_{\mathrm{c}}$ on slip capacity
Fig. 19 Effect of length of C-channel $\left(L_{\mathrm{c}}\right)$

\subsection{Effect of prestressing ratio of bolt ( $\rho)$}

The prestressing force is usually applied to the bolt during the installation of ECs. This study designed two cases with $\rho=0.2\left(\rho=T / \sigma_{\mathrm{y}} A_{\mathrm{sb}}\right)$. Fig. 18(b) plots the effects of $\rho$ on $P$ - $\Delta$ curves of push-out numerical cases. Fig. 20(a) and (b) shows the influences of $\rho$ on the strength and slip capacity. These figures reflect that increasing the prestressing force on the bolts reduces both the shear resistance and ductility of ECs. Applying $\rho=0.2$ prestressing force reduces the $P_{\mathrm{u}}$ and $\Delta_{\mathrm{u}}\left(\right.$ or $\Delta_{\mathrm{a}}$ ) of ECs with $d=14 \mathrm{~mm}$ bolts by $7 \%$ and $31 \%(32 \%)$, respectively meanwhile, applying $\rho=0.2$ prestressing force reduces the $P_{\mathrm{u}}$ and $\Delta_{\mathrm{u}}\left(\right.$ or $\Delta_{\mathrm{a}}$ ) of ECs with $d=18 \mathrm{~mm}$ bolts by $13 \%$ and $18 \%(23 \%)$, respectively. Thus, controlling the prestressing force acting on the bolts in ECs within 0.2 is still important on maintaining the shear performance of ECs in UHPC.
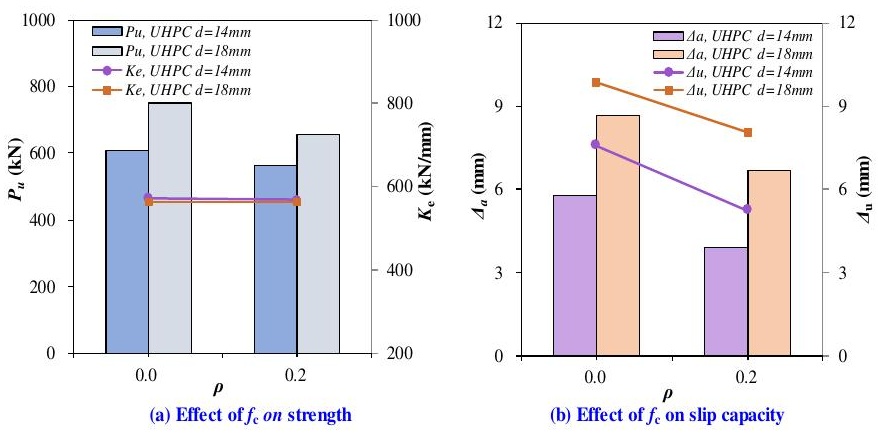

Fig. 20 Effect of length of C-channel $\left(L_{\mathrm{c}}\right)$

\section{Analytical models on ultimate shear resistance and shear-slip} behaviours of ECs with UHPC

\subsection{Introduction on different numerical cases for parametric studies}

Based on the recommended models by Yan et al. [29], the $P_{\mathrm{u}}$ of ECs with UHPC is calculated as follows:

$P_{\mathrm{u}}=P_{\mathrm{c}}+P_{\mathrm{B}}$

$P_{\mathrm{B}}=\sigma_{\mathrm{u}} A_{\mathrm{sb}} ; P_{\mathrm{C}}=0.25 \alpha f_{\mathrm{c}} L_{\mathrm{c}} h+\frac{t_{\mathrm{w}}^{2} L_{\mathrm{c}}}{0.52 h} f_{\mathrm{u}}$

where, $t_{\mathrm{w}}$ is the web thickness; $L_{\mathrm{c}}$ is the channel length; $f_{\mathrm{c}}$ is the UHPC compressive strength; $f_{\mathrm{u}}$ is the ultimate strength of C-channel.

Based on the reported generalized $P / P_{\mathrm{u}}-\Delta$ curves of 12 tests and 31 numerical simulations, this paper developed an empirical equation to describe the $P / P_{\mathrm{u}}-\Delta$ curves of ECs with UHPC by the regression analysis method. Moreover, the developed analytical model also considers the influence of the bolt-hole gap ( $a$ ) as the following:

$\frac{P}{P_{\mathrm{u}}}=\frac{\left(6.23 \frac{a}{d}+0.13\right)^{-1} \Delta}{1+\left[\left(6.23 \frac{a}{d}+0.13\right)^{-1}-0.1\right] \Delta}$

where, $a$ is the bolt-hole gap and less than $2 \mathrm{~mm}$; $d$ is the bolt diameter; $\Delta$ is the slip, in $\mathrm{mm}$.

For the 12 push-out tests with the a/d of $1 / 28$, Eqn. (11) is changed as the following:

$\frac{P}{P_{u}}=\frac{2.26 \Delta}{1+2.16 \Delta}$

\subsection{Validations}

The predicted ultimate shear resistances of numerical cases and tests are given in Table 1. Fig. 21 compared the analytical predictions of $P_{\mathrm{u}}$ with those of 31 numerical analysis and 12 test results. These table and figure show that the average test/FE-to-prediction ratio and COV (coefficient of variation) for these 43 cases equal to 1.06 and 0.09 , respectively. The developed analytical model offers a $6 \%$ average underestimation on $P_{\mathrm{u}}$ of ECs in UHPC. Fig. 22 compared the test/FE generalized load-slip curves with those predicted curves by Eqn. (11). It shows that the proposed equations, i.e., Eqn. (11) offer reasonable simulations on generalized $P-\Delta$ behaviours of ECs in UHPC. Moreover, the influences of different bolt-hole gap were considered in the developed models. 


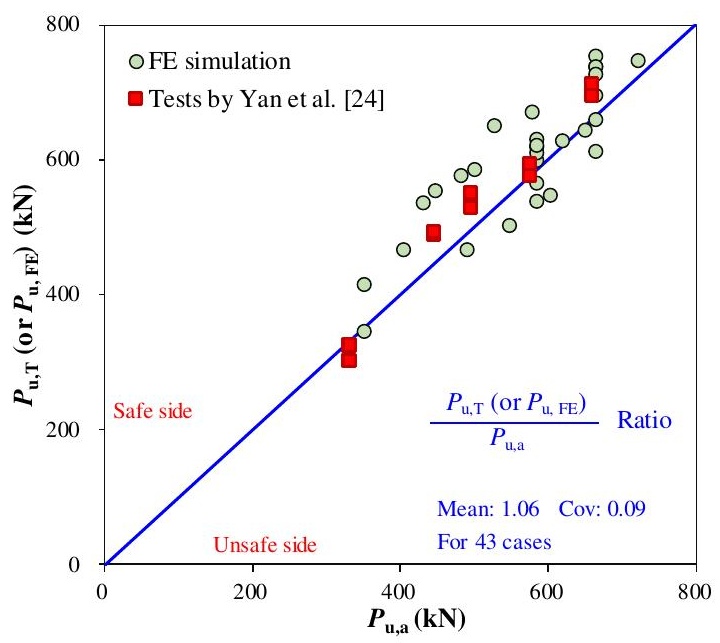

Fig. 21 Comparisons of predicted ultimate shear resistances with test/FE results
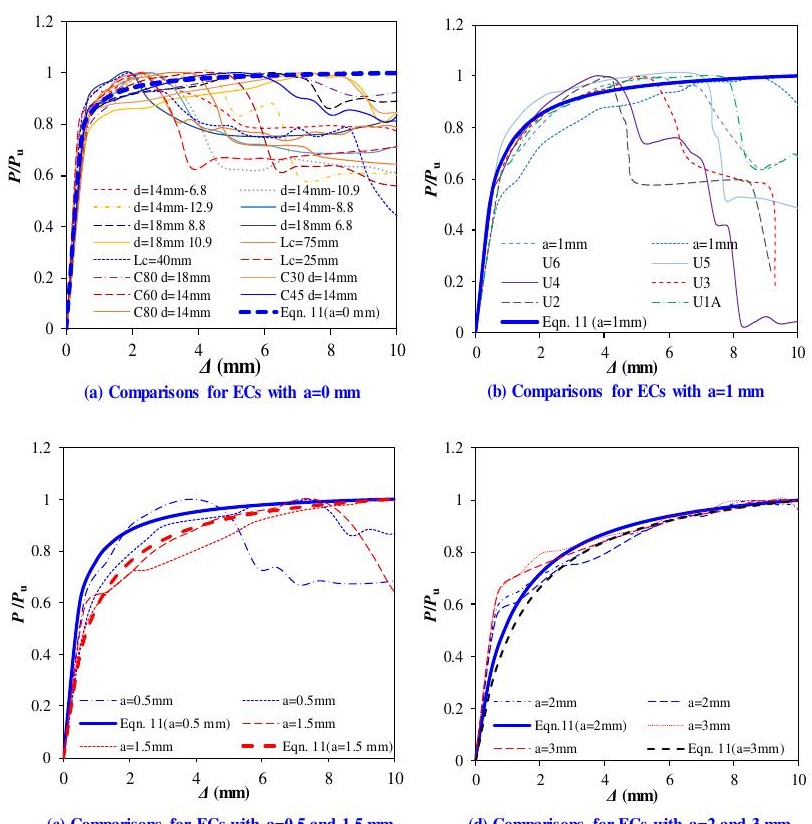

(c) Comparisons for ECs with $\mathrm{a}=0.5$ and $1.5 \mathrm{~mm}$

(d) Comparisons for ECs with $\mathrm{a}=2$ and $3 \mathrm{~mm}$

Fig. 22 Validations of analytical predicted gerneralzied load-slip curves against test and numerical ones

\subsection{Discussions and recommendations on design of ECs in UHPC}

To tolerate the fabrication and installation errors of different components in ECs, the bolt-hole gap (a) is recommended for the SUSSS-ECs. The recommended bolt-hole gap $(a)$ is less than $2 \mathrm{~mm}$, which showed improved slip capacity and no influence on $P_{\mathrm{u}}$ of ECs with UHPC.

For design on SUSSS-ECs, the $P_{\mathrm{B}} / P_{\mathrm{C}}$ ratio of the ECs requires to be increased to make sure the slip capacity of ECs. From the load-slip curves in Fig. 12, the $P_{\mathrm{B}} / P_{\mathrm{C}}$ ratio is recommended to be larger than 0.5 .

\section{Conclusions}

This paper firstly developed a 3D nonlinear FEM for ECs with UHPC. The developed FEM was validated by 12 push-out tests on ECs with UHPC. Followed in-depth parametric studies were performed to study the key influencing parameters on shear behaviours of ECs with UHPC. Analytical studies were also performed on ultimate shear resistance and shear-slip behaviours of ECs with UHPC. These studies support the following conclusions:

(1) The proposed FEM could simulate well shear behaviours of ECs as well as the shear fracture of C-channel and bolts using the CDM. The validations of FE simulations against 12 push-out tests show that the average prediction errors for strength and ductility indexes of $P_{\mathrm{u}}, K_{\mathrm{e}}, \Delta_{\mathrm{u}}$, and $\Delta_{\mathrm{a}}$ are $1 \%, 5 \%, 3 \%$, and $6 \%$, respectively.

(2) Under interfacial shear force, the ECs with UHPC firstly yielded at the toe of C-channel web, and then yielded at the bolt. At the ultimate shear load point, shear fracture occurred to the bolt. The recession branch of the shear-slip curves exhibited a zigzag way with several steps due to the successive shear fracture of bolts and C-channels.

(3) Reserving the bolt-hole gap (a) less than $2 \mathrm{~mm}$ did not reduce the ultimate shear resistance of ECs with UHPC, but greatly improved their slip capacities. As the a is beyond $2 \mathrm{~mm}$, the ultimate shear resistance of ECs was significantly reduced.

(4) Increasing the grades and diameter of externally-connected bolts improves the shear behaviour of ECs with UHPC through increasing the $P_{\mathrm{B}} / P_{\mathrm{C}}$ ratio. The $P_{\mathrm{B}} / P_{\mathrm{C}}$ ratio is recommended to be larger than 0.5 for ECs with UHPC to make a ductile connector.

(5) The increasing core strength improved the C-channel shear resistance, but reduced the $P_{\mathrm{B}} / P_{\mathrm{C}}$ ratio that resulted in reduced ductility of ECs. Increasing the core strength required using stronger externally-connected bolt to maintain the slip capacity through increasing the $P_{\mathrm{B}} / P_{\mathrm{C}}$ ratio of ECs.

(6) The length of C-channels in ECs at $50 \mathrm{~mm}$ offered the best slip capacity, which is a recommended optimized dimension for the ECs with UHPC.

(7) Prestressing force acting on the externally-connected bolts reduces both the shear resistance and ductility of ECs with UHPC. Controlling the prestressing force acting on the bolts in ECs within 0.2 is still important on maintaining the shear performance of ECs in UHPC.

(8) Analytical models incorporating the influences of bolt-hole gaps were developed to describe the $P / P_{\mathrm{u}}-\Delta$ curves and $P_{\mathrm{u}}$ of ECs with UHPC. Validations against the 12 push-out tests and 31 FEM analysis results proved that these developed analytical models predicted well shear behaviour of ECs with UHPC.

\section{Nomenclature}

$A_{\mathrm{sb}} \quad$ Area of cross section for bolt

$B \quad$ Width of flange of C-channel

$D$ Damage coefficient

$D_{\mathrm{R}} \quad$ Damage ratio at rupture point

$E_{\mathrm{c} 0}$ the secant modulus at $f_{\mathrm{c}}$

$E_{\mathrm{c}}$ denotes initial elastic modulus of concrete

$E_{\mathrm{s}} \quad$ Elastic modulus of steel

$K_{e, T} \quad$ Experimental initial stiffness of ECs

$K_{e, F E} \quad$ Numerical initial stiffness of ECs

$L_{c} \quad$ Length of the flange of C-channel

$M \quad$ Grade of externally connected bolt

$P \quad$ Load

$P_{\mathrm{B}} \quad$ Shear strength of bolt

$P_{\mathrm{C}} \quad$ Shear strength of C-channel in UHPC core

$P_{\mathrm{u}} \quad$ Ultimate shear resistance

$P_{\mathrm{u}, \mathrm{T}} \quad$ Ultimate shear resistance of specimen in the test

$P_{\mathrm{u}, \mathrm{FE}} \quad$ Ultimate shear resistance of specimen in the finite analysis

$P_{\mathrm{u}, \mathrm{a}} \quad$ Ultimate shear resistance of specimen in theoretical analysis

$T \quad$ Prestressing force acting on the bolt

a Gap between the bolt and hole in faceplate

$d \quad$ Diameter of bolts

$h \quad$ Depth of the C-channel

$f_{c} \quad$ UHPC compressive strength

$f_{\mathrm{t}} \quad$ UHPC ultimate tensile strength;

$f_{\mathrm{u}} \quad$ the ultimate strength of C-channel.

$r \quad$ Diameter of bolt hole

$t_{\mathrm{f}} \quad$ Thickness of flange

$t_{\mathrm{w}} \quad$ Web thickness

$\Delta \quad$ Slip

$\triangle_{\mathrm{a}} \quad$ Slip at $P_{\mathrm{u}}$

$\Delta_{\mathrm{a}, \mathrm{T}} \quad$ Experimental slip at $P_{\mathrm{u}}$

$\Delta_{\mathrm{a}, \mathrm{FE}} \quad$ Numerical slip at $P_{\mathrm{u}}$

$\Delta_{\mathrm{u}} \quad$ Slip capacity of ECs

$\Delta_{\mathrm{u}, \mathrm{T}} \quad$ Test slip capacity of ECs

$\Delta_{\mathrm{u}, \mathrm{FE}} \quad$ FE slip capacity of ECs

$\varepsilon_{\mathrm{c} 0} \quad$ Strain at $f_{\mathrm{c}}$

$\varepsilon_{\mathrm{t} 0} \quad$ Strain at $f_{\mathrm{t}}$

$\varepsilon_{\mathrm{i}, \mathrm{pl}} \quad$ Plastic strains at point $i$

$\varepsilon_{\mathrm{F}, \mathrm{pl}} \quad$ Plastic strains at fracture point

$\varepsilon_{\mathrm{R}, \mathrm{pl}} \quad$ Plastic strains at rupture point

$\varepsilon_{F \text {,shear }}^{\mathrm{pl}}$ Initiation ratios of shear damage

$\varepsilon_{\text {nom }}$ Nominal strain

$\varepsilon_{\text {true }} \quad$ True strain of steel materials

$\varepsilon_{0, \mathrm{pl}} \quad$ The uniaxial damage initiation strain

$\bar{\varepsilon}_{0, p l}$ Three-dimensional damage initiation strain of steel material

$\bar{u}_{\mathrm{i}, \mathrm{pl}} \quad$ Equivalent plastic displacement 
$\theta \quad$ Stress triaxiality of the steels

$\rho \quad$ Prestressing ratio of the externally connected bolt

$\sigma_{i} \quad$ Engineering stress at $i$

$\bar{\sigma}_{i} \quad$ True stress at $i$

$\sigma_{\text {nom }} \quad$ Nominal stress

$\sigma_{\text {true }}$ True stress curves of steel materials

$\sigma_{\mathrm{y}}, \sigma_{\mathrm{u}}$ Yield and ultimate strength of bolts

\section{Acknowledgment}

The authors would like to acknowledge the financial supports by Science Project of Tianjin Municipal Education Commission (No.2019KJ122). The authors gratefully express their gratitude for the financial supports.

\section{References}

[1] Montague P., "A simple composite construction for cylindrical shells subjected to external pressure", J Mech. Eng. Sci., 17 (2), 105-113, 1975.

[2] Solomon S.K., Smith D.W., Cusens A.R., "Flexural tests of steel-concrete-steel sandwiches", Mag. Concr. Res., 28 (94), 13-20, 1976.

[3] Lin M., Lin W., Wang Q., Wang X., "The deployable element, a new closure joint construction method for immersed tunnel", Tunn. Undergr. Sp. Tech., 80, 290-300, 2018.

[4] Foundoukos N., Xie M., and Chapman J.C., "Behaviour and design of steel-concrete-steel sandwich construction", Adv. Steel Constr., 4(2), 123-133, 2008.

[5] Yan J.B., Chen A.Z., Wang T., "Developments of double skin composite walls using novel enhanced C-channel connectors", Steel Compos. Struct., 33(6) 877-889, 2019

[6] Zhang W.J., Koizumi A., "Behavior of composite segment for shield tunnel", Tunn. Undergr. Sp. Tech., 25 (4), 325-332, 2010.

[7] Yan J.B., Liew J.Y.R., Zhang M.H., "Shear-tension interaction strength of J-hook connectors in steel-concrete-steel sandwich structure", Adv. Steel Constr., 11(1), 72-93, 2015.

[8] Yan J.B., Liu X.M., Liew J.Y.R., Qian X., Zhang M.H., "Steel-concrete-steel sandwich system in Arctic offshore structures: materials, experiments, and design", Mater. Design., 91, $111-121,2016$

[9] Yan J.B., Wang Z., Wang X., "Behaviour of steel-concrete-steel sandwich plates under different ice-contact pressure", Adv. Steel Constr., 15(1), 116-122, 2019

[10] Lin Y.Z., Yan J.C., Cao Z.G., Zeng X.Z., Fan F., Zou C.Y., "Ultimate strength behaviour of S-UHPC-S and SCS sandwich beams under shear loads", J. Constr. Steel Res., 149, 195-206, 2018.

[11] Yan J.B., Chen A.Z., Guan H.N., Wang T., "Experimental and numerical studies on ultimate strength behaviour of SCS sandwich beams with UHPFRC", Constr. Build. Mater., 256,
119464, 2020.

[12] Marshall P.W., Palmer A.C., Liew J.Y.R., Wang T.Y., Thein M.K.W., "Bond Enhancement for Sandwich Shell Ice Wall", International Conference and Exhibition on Performance of Ships and Structures in Ice, 20-23, 2010

[13] Yan J.B., Liew J.Y.R., Zhang M.H., Sohel K.M.A., "Experimental and analytical study on ultimate strength behaviour of steel-concrete-steel sandwich composite beam structures", Mater. Struct., 48(5), 1523-1544, 2015.

[14] Ji X., Cheng X., Jia X., Varma A.H., "Cyclic in-plane shear behavior of double-skin composite walls in high-rise buildings. ASCE J. Struct. Eng., 143 (6), 04017025, 2017.

[15] Xie M., Foundoukos N., Chapman J.C., "Experimental and numerical investigation on the shear behaviour of friction-welded bar-plate connections embedded in concrete", J. Constr. Steel Res., 61, 625-649, 2004.

[16] Kolsters H., Wennhage P., "Optimisation of laser welded sandwich panels with multiple design constraints. Mar. Struct., 22(2), 154-171, 2009.

[17] Yan J.B., Li Z.X., Wang T., "Seismic behaviour of double skin composite shear walls with overlapped headed studs", Constr. Build. Mater., 191, 590-607, 2018.

[18] Chen L., Wang S., Lou Y., Xia D., "Seismic behavior of double-skin composite wall with Lshaped and C-shaped connectors", J. Constr. Steel Res., 160, 255-270, 2019.

[19] Yan J.B., Hu H.T., Wang T., "Shear behaviour of novel enhanced C-channel connectors in steel-concrete-steel sandwich composite structures", J. Constr. Steel Res., 166, 105903, 2020.

[20] Yan J.B., Guan H.N., Wang T., "Steel-UHPC-steel sandwich composite beams with nove enhanced C-channel connectors: Tests and analysis", J. Constr. Steel Res., 170, 106077, 2020.

[21] Yan J.B., Guan H.N., Wang T., "Numerical studies on steel-UHPC-steel sandwich beams with novel enhanced C-channels", J. Constr. Steel Res., 170, 106070, 2020.

[22] Yan J.B., Chen A.Z., Wang T., "Compressive behaviours of steel-UHPC-steel sandwich composite walls using novel EC connectors", J. Constr. Steel Res., 173, 106244. 2020.

[23] Zhu J.S., Wang Y.G., Yan J.B., "Shear behaviour of steel-UHPC composite beams in waffle bridge deck", Compos. Struct., 234, 111678, 2020

[24] ABAQUS. ABAQUS Standard User's Manual, Version 6.12, RI (USA): Dassault Systemes Corp, Providence, 2012

[25] Yan J.B., Qian X., Liew J.Y.R., Zong L., "Damage plasticity based numerical analysis on steel-concrete-steel sandwich shells used in the Arctic offshore structure", Eng. Struct., 117, 542-559, 2016.

[26] Yan J.B., Zhang W., "Numerical analysis on steel-concrete-steel sandwich plates by damage plasticity model: From materials to structures", Constr. Build. Mater., 149,801-815, 2017.

[27] Lee J., Fenves G.L., "Plastic-damage model for cyclic loading of concrete structures", J. Eng Mech. ASCE, 124(8), 892-900, 1998

[28] Eurocode 4 (2004). EN 1994-1-1-Design of composite steel and concrete structures. Part 1.1, General rules and rules for buildings, BS.

[29] Yan J.B., Hu H.T., Wang T., "Shear behaviour of enhanced C-channel connectors in double skin composite structures with UHPC", Structures, 31, 266-285, 2021. 


\title{
EXPERIMENTAL STUDY ON SEISMIC PERFORMANCE OF PEC COMPOSITE COLUMN-STEEL BEAM FRAME WITH WELDED T-STUB STRENGTHENED CONNECTIONS
}

\author{
Jin Feng ${ }^{1,}{ }^{*}$, Jing Jin ${ }^{1}$, Jun Xia ${ }^{2}$ and You-Zhen Fang ${ }^{1}$ \\ ${ }^{1}$ Jiangsu Key Laboratory of Structure Engineering, Suzhou University of Science and Technology, Suzhou 215011, China \\ ${ }^{2}$ Xi'an Jiaotong-Liverpool University, Suzhou 215123, China \\ *(Corresponding author: E-mail: fengjin@mail.usts.edu.cn)
}

\section{A B S T RA C T}

Seismic performance of innovative Partially Encased Composite (PEC) column-steel beam composite frame was investigated, where the connection was strengthened by the welded T-stub. A $1 / 2$ scale, two-storey, and one bay composite frame specimen was designed and fabricated for the quasi-static test. Through the experimental observation and measurements, the seismic performance were evaluated, including hysteretic characteristic, lateral stiffness, seismic energy dissipation, and ductility. The plastic damage evolution process and ductile failure mode were clarified. The results indicated that the welded T-stud strengthened connection enhanced the integrity of the frame and led to higher seismic strength and larger lateral stiffness. The plastic hinge was observed away from the beam end due to the welded T-stud and the specimen exhibited an approximately completed hysteretic loop. Without significant decreasing of the ultimate bearing capacity, its overall drift, ductility efficient and equivalent viscous damping ratio were $3.63 \%$ (push) / 4.07\% (pull), 3.21 (push) / 3.70 (pull) and 0.261 respectively. The proposed structure possesses sound deformation, ductility, and energy-dissipation capacity with the desired plastic failure mode induced by the plastic hinges formed in all beam sections near the T-stud end and column section at the bottom, successively. It was demonstrated an ideal ductile energy-dissipation mode of the frame structure.

\section{A R T I C L E H I S T O R Y}

$\begin{array}{ll}\text { Received: } & \text { 24 June } 2020 \\ \text { Revised: } & \text { 16 March 2021 } \\ \text { Accepted: } & \text { 18 March 2021 }\end{array}$

\section{K E Y W O R D S}

Welded T-stud strengthened connection;

PEC column with crimping steel panel composite section; Composite frame structure; Seismic performance; Quasi-static test

\section{Introduction}

Partially Encased Composite Column (PEC column [1]) is a new type of composite member proposed to enhance the lateral stiffness and bearing capacity of conventional I-shaped or $\mathrm{H}$-shaped steel columns in steel structures. Tremblay R [2], Prickett BS [3], Zhao Gentian [4], and Fang Youzhen [5, 6] conducted monotonic axial compression tests under unbiased or biased loading, and quasi-static experiments on PEC columns. The results showed that the PEC column fully utilized concrete and the concrete-filled steel tube structure to achieve higher axial bearing capacity, greater lateral stiffness, and superior seismic resistance. This new type of structural component with a straightforward connection design is also convenient to construct. Laterally, the PEC column reduced noticeable stiffness inequality in principal axes and improved seismic ductility. An innovative crimping PEC column with curving steel panels was suggested. Test results showed it can be applied in various cases with different steel dimensions. Its construction is further simplified because the use of steel panel links between the flanges of the curing end. The steel plate further mitigates the defects of unbalanced bidirectional stiffness.

The $\mathrm{T}$-stud connection is a rigid connection proposed in the current design code of China [7], and it exhibits a large bending rigidity and strength. The plastic hinge usually forms at the location away from the beam end region to meet the seismic requirements of "strong joints". Therefore, the T-stud connection has been listed as one of the common connection types for concrete-filled rectangular tubular columns [8]. He et al. [9] carried out an experimental investigation on beam-column joints connected by T-stubs. The calculation equations for shear resistance were also proposed. Hao et al. [10] investigated the seismic performance of steel frame with beams connected by T-stubs. It was concluded that the bolt-on connection was the most reasonable connection type to ensure the force transfer at the beam-column joint of composite structure. Peng [11], Wang [12], and Fang [13, 14] tested a series of beam-column joints under seismic loading with a bolt-on connection. Their study showed that the tensile force in the beam was converted into the compressive force of the concrete in the joint, due to the presence of the bolt-on connection. The concrete in the joint transfer forced through an inclined compressive strip, which had a high shear resistance. The bolt-on connections also presented a partial self-alignment effect, which also reduced the residual deformation of the joint connection.

Fang $[15,16]$ studied the seismic behavior of the interlayer substructure specimens welded with T-stubs extracted from a PEC column-steel beam composite frame. Their results showed that the T-stub connection joint exhibited a large bending stiffness. The design target of forming the plastic hinge away from the joint was achieved since the plastic yielded at the beam end.
It was also found that the integrity of the interlayer substructure was well maintained. The horizontal lateral stiffness was evenly distributed along with the height, and the specimen exhibited an ideal reversed triangular shear deformation mode. Furthermore, the interlayer substructure displayed the ductile failure mode through the plastic hinge formed near the end of the T-stubs Through the experiments and numerical simulation, the performance of T-stud with different flange thicknesses were also investigated. For the connection under monotonic loading mode, it was concluded that the existing design standards underestimated the resistance of the T-stub connection [17]. Sebbagh [18] performed the monotonic and cyclic loading tests on the t-stub connection with two and four bolts per row. It was found out that the outer row of the bolts prevented the reduction of stiffness and the uplifting of the end part of the t-stub plate, therefore, are highly recommended.

New types of connections for steel and composite steel frame have been proposed by researchers, such as improved direct-welded connections [19], and double-ribbed reinforced connections [20], as well as new testing methods, such as bi-axial lateral loading [20]. This study revisited the T-stub connections and conducted the quasi-static test on a $1 / 2$ scale, two-storey single-span PEC column-steel beam composite frame with T-stud welded reinforced jointed and rolled steel plates. Along with previous investigations on PEC column components, joints, and interlayer substructures, the seismic performance of large-scale PEC column structures was studied, including hysteretic behavior, lateral stiffness, energy dissipation, ductility, and failure modes.

\section{Experiment program}

\subsection{Specimen design}

The detailed design of the PEC column specimen is illustrted in Fig 1. The span of the test piece was $2000 \mathrm{~mm}$, and the column of first and second floor are both $1500 \mathrm{~mm}$ in height. The top of the PEC column was connected to the rigid loading beam by planar hinges to achieve an even load, while the bottom of column was rigidly anchored to the floor beam. The steel member in the PEC column was made by welded Q235 steel plates. The flange was $310 \times 5$ steel plate with $30 \mathrm{~mm}$ sides curl and the web was $240 \times 5$ steel plate. The dimension of the drawbar plate was $220 \times 30 \times 4$. I20a section was used for the steel beams. T-stud was used to connect the PEC column and steel beam by a combined approach of welding and high-strength bolt connection. The nominal diameter of the bolt was $20 \mathrm{~mm}$, and the material strength grade was 10.9 with a designed preload at $10 \mathrm{kN}$. The T-stud was welded by three sides fillet weld to connect to the steel beam. Representative specimens were cut from the steel frame of the PEC column, the steel beam flange, and the corresponding part of the web for 
the determination of tensile properties. The material properties of steel are summarized in Table 1. The compressive strength of concrete used in the PEC column was determined by three $150 \mathrm{~mm}$ cubes following Chinese Code standard. The average compressive strength of the concrete used for the column is $\mathrm{f}_{\mathrm{m}}=19.6 \mathrm{MPa}$.

\subsection{Experimental setup}

The experimental setup is shown in Fig 2a). Displacement gauges DT1 to DT5 were used to obtain the horizontal displacement of the frame. The rotation angle of the connection between the PEC column and steel beam was measured by displacement gauges DT6 to DT9, and the rotation at the beam end can be obtained from displacement gauges DT10 to DT13. The stress state of the PEC column and beam at the end critical sections and joint can be derived from the strain measurements.

\subsection{Loading protocol}

The Displacement of the loading beam was limited by the pressure beam and the hydraulic actuator. The out-of-plane deformation of the loading beam is limited by the supports, as shown in Fig. 2b).

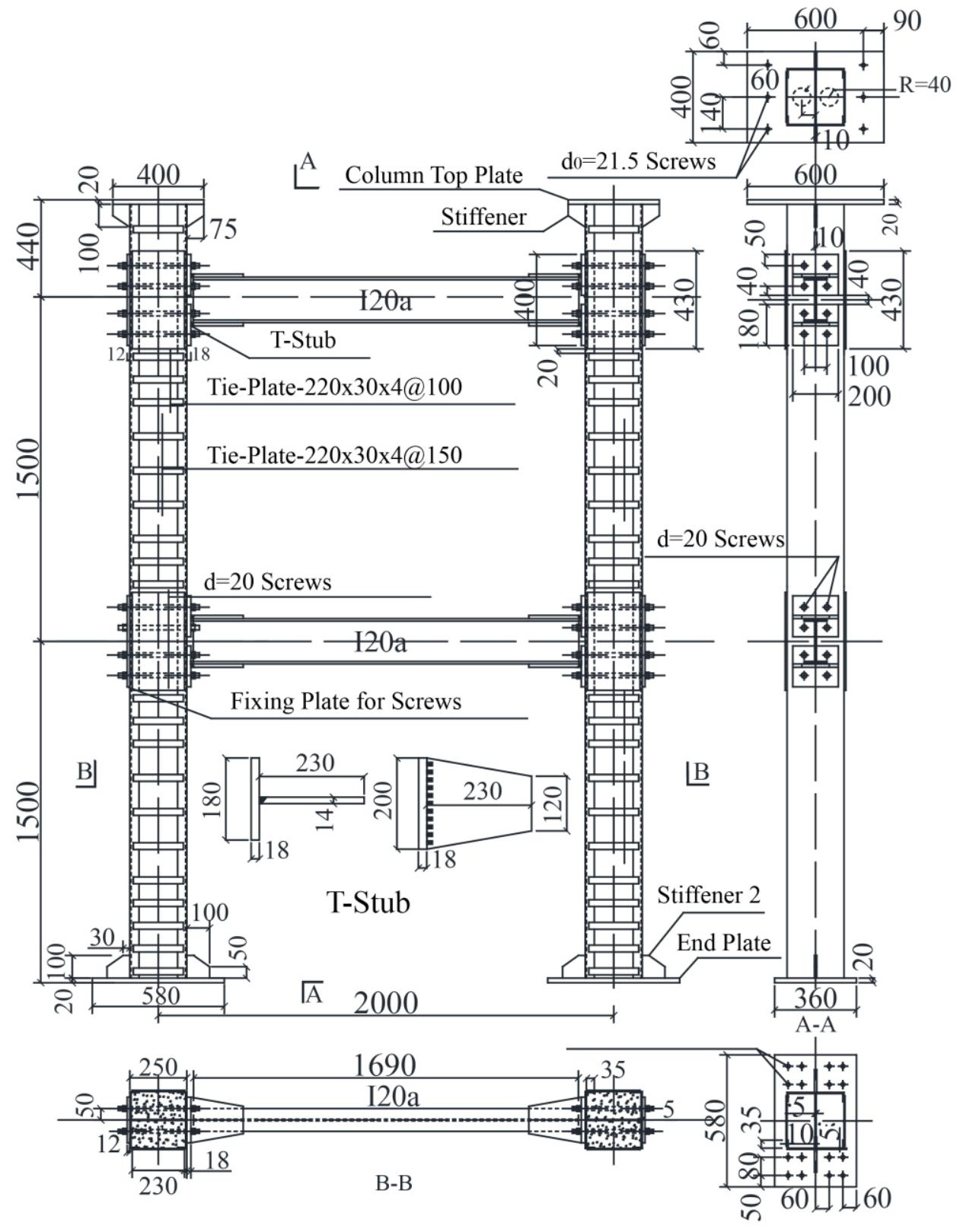

Fig. 1 Construction details of the Test specimen

Table 1

Mechanical properties of steel specimens

\begin{tabular}{|c|c|c|c|c|}
\hline Location & $\begin{array}{c}\text { Yield Strength } \\
f_{\mathrm{y}} \\
\mathrm{MPa} \\
\end{array}$ & $\begin{array}{c}\text { Tensile Strength } \\
f_{\mathrm{u}} \\
\mathrm{MPa} \\
\end{array}$ & $\begin{array}{c}\text { Modulus of elasticity } \\
E \\
\mathrm{MPa} \\
\end{array}$ & $\begin{array}{c}\text { Elongation } \\
\delta \\
\% \\
\end{array}$ \\
\hline Column Web and Flange & 294 & 414 & 2.00 & 22.8 \\
\hline Beam Flange & 294 & 447 & 2.00 & 22.8 \\
\hline Beam Web & 293 & 440 & 1.98 & 19.9 \\
\hline
\end{tabular}




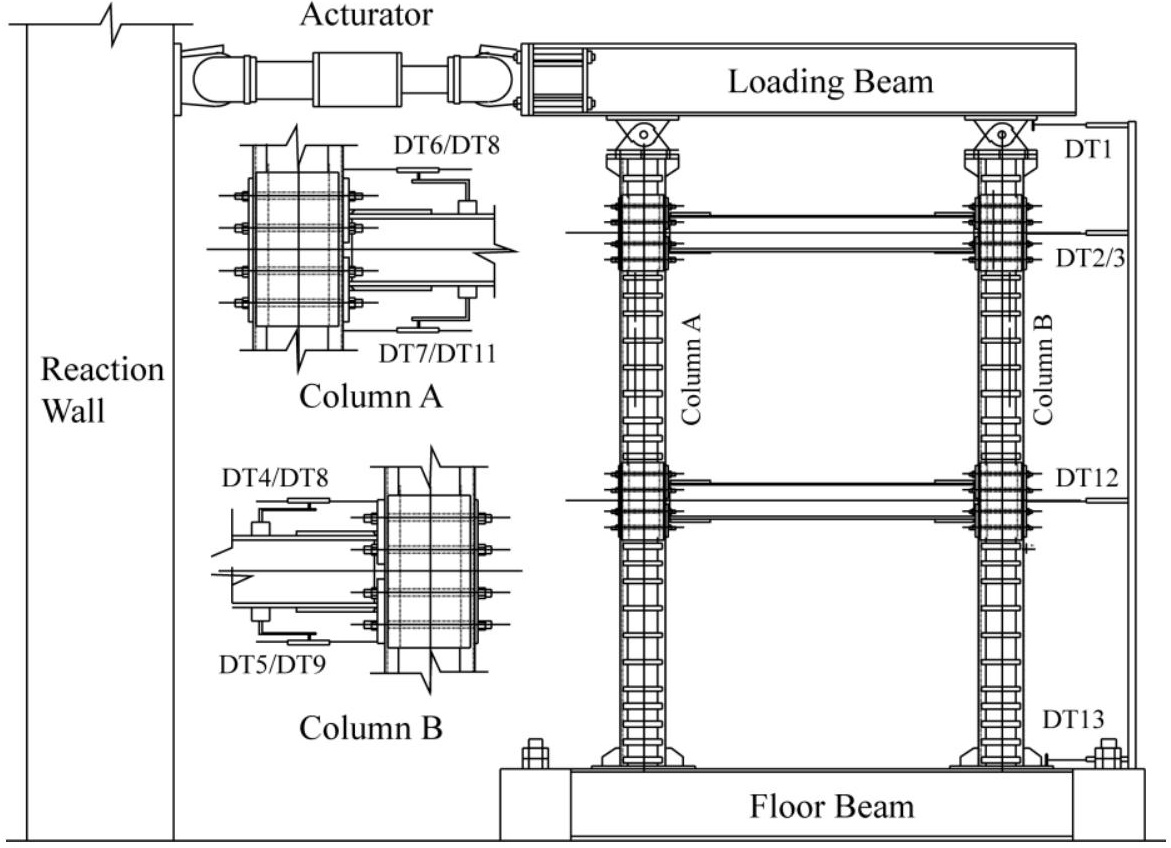

(a) Measurement and Instrumentation

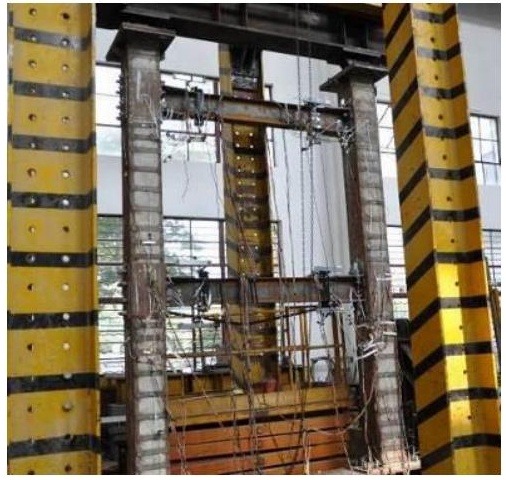

(b) Test setup and specimen configuration

Fig. 2 Loading scheme of test

Similar to previous studies [21], the displacement control loading mode is adopted. However, the actual seismic characteristics were considered, which means frequent earthquakes with higher probability were enforced for a higher number of cycles and rare earthquakes with less probability were enforced with lower number of cycles as shown in Table 2. Before the seismic loading test, the frame was preloaded to ensure the proper working condition of all measuring instruments. The loading test was terminated when the bearing capacity of the frame had dropped to $85 \%$ of its ultimate bearing capacity or the lateral displacement exceeded the lateral drift limit, which was 1/30 of the floor height under a rare earthquake scenario. The full loading protocol is shown in Table 2 .

\section{Experimental observations and failure mode}

The column specimen remained elastic state during the initial stage of loading, so there was no obvious deformation. When the specimen was loaded to the displacement of $34 \mathrm{~mm}(\delta=0.958 \%)$, obvious peeling off was observed at the inner surface of the cross-section flange near the T-stub (as shown in Fig 3 (a)). When reaching the displacement of $51 \mathrm{~mm}(\delta=1.437 \%)$, the yielding line of the web near the T-stub initiated at the beam ends and then gradually extended to the inner side of the cross-section. The T-stub of the beam was eventually pulled out from the PEC column and thus debonded, as shown in Fig 3 (b). Further loading to a displacement of $68 \mathrm{~mm}(\delta=1.915 \%)$, the cross-section yield line at the beam end near the T-stub penetrated the entire section and finally formed a plastic hinge (as shown in Fig 3(c)). When displacement reached $102 \mathrm{~mm}(\delta=2.873 \%)$, the plastic hinge area near the T-stub of all beam ends was continuously extended along the span (see Fig. 3(d)), and the concrete of the PEC column was crushed due to great deformation of the external flange of the frame components (see Fig. 3(e)). The concrete at the bottom of PEC column was also crushed at a displacement of $136 \mathrm{~mm}(\delta=3.831 \%)$, due to the intensive deformation of the steel flange. The plastic hinge was formed at the bottom of PEC column, which presented a plastic failure mechanism. The plastic hinge area developed severely into the span after reaching the displacement of $153 \mathrm{~mm}(\delta=4.310 \%)$. The outer flange of the bottom of column A is torn near the joint with the welded bottom plate (see Fig 3(f)). The lateral displacement of the specimen exceeded the requirement of $1 / 30$ of the floor height under the rare earthquake level, and the loading test was thus terminated

Table 2

Loading protocol

\begin{tabular}{cccc}
\hline $\begin{array}{c}\text { Loading } \\
\text { Stages }\end{array}$ & $\begin{array}{c}\text { Displacement } \\
\Delta / \mathrm{mm}\end{array}$ & $\begin{array}{c}\text { Shifting } \\
\delta / \%\end{array}$ & $\begin{array}{c}\text { Number of } \\
\text { cycles }\end{array}$ \\
\hline 1 & 13 & 0.366 & 6 \\
2 & 17 & 0.479 & 6 \\
3 & 26 & 0.732 & 6 \\
4 & 34 & 0.958 & 4 \\
5 & 51 & 1.437 & 2 \\
6 & 68 & 1.915 & 2 \\
7 & 85 & 2.394 & 2 \\
8 & 102 & 2.873 & 2 \\
9 & 119 & 3.352 & 2 \\
10 & 136 & 3.831 & 2 \\
11 & 153 & 4.310 & 2 \\
\hline
\end{tabular}

Note: shifting $\delta=\Delta / H$, where $\Delta$ is the displacement of the actuator, $H$ is the distance between the specimen and the actuator.

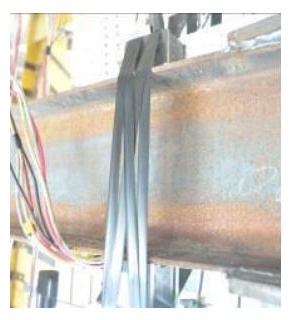

(a) Buckling of steel flange

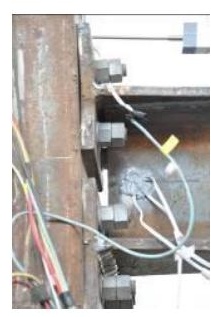

(b) Dislocation of $\mathrm{T}$ shape connector

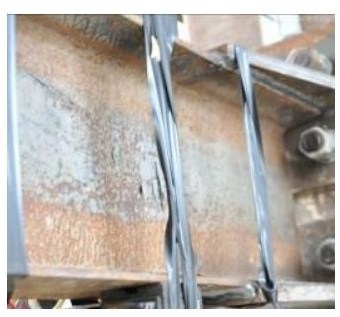

(c) Yielding line of the section 


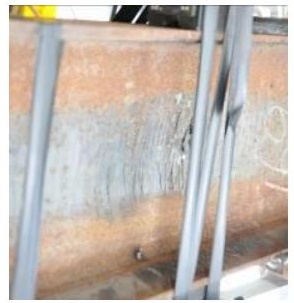

(d) Development of yielding region

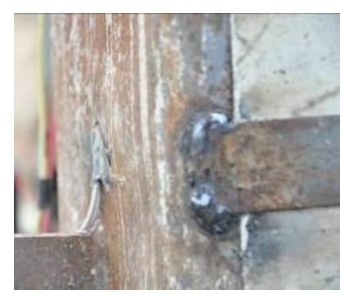

(e) Outbouncing of column bottom

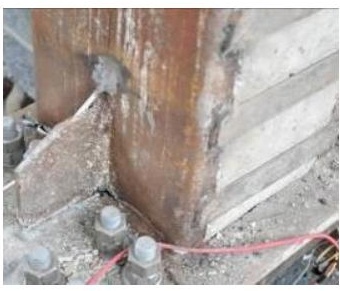

(f) Tensile fracture of the exterior column

Fig. 3 Local damage patterns

\section{Experimental results and discussion}

\subsection{Measured lateral load versus drift}

The lateral load- drift hysteresis curves are obtained, as shown in Fig 4. In the figure: $\delta_{\mathrm{PEC}}, \delta_{\text {whole }}, \delta_{1}$ and $\delta_{2}$ are the ratio of lateral displacement to height and

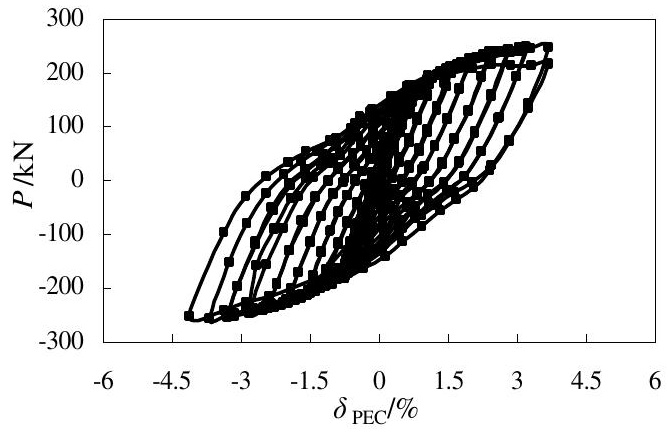

(a) PEC Column Top

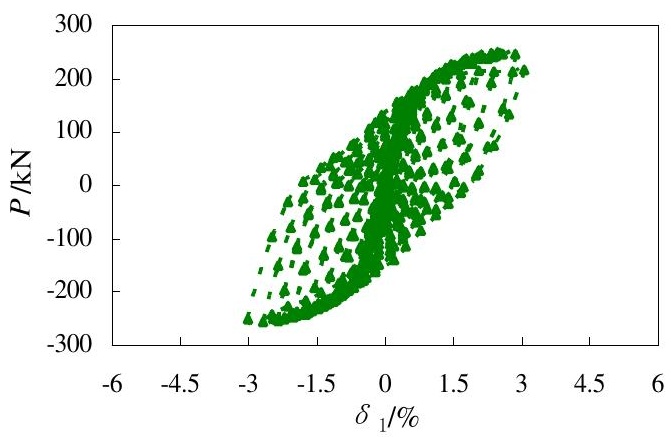

(c) First Floor areexpressed as $\delta_{\mathrm{PEC}}=\Delta_{\mathrm{PEC}} / \mathrm{h}_{\mathrm{PEC}}, \delta_{\text {overall }}=\Delta_{\text {overall }} / \mathrm{h}$ overall, $\delta_{1}=\Delta_{1} / \mathrm{h}_{1}, \delta_{2}=\Delta_{4} / \mathrm{h}_{2} . h_{\mathrm{PEC}}$, $h_{\text {overall }}, \mathrm{h}_{1}$ and $\mathrm{h}_{2}$ are the height of the top of the column, the overall height of the test piece, the height of the first floor and the height of the second floor, respectively. $\Delta_{\mathrm{PEC}}, \Delta_{\text {overall }}, \Delta_{1}$, and $\Delta_{2}$ are calculated from the displacement measurement of DT1, DT2, DT4, and DT5. To be specific, $\Delta_{\mathrm{PEC}}=\mathrm{DT} 1-\mathrm{DT} 5, \Delta$ overall $=\mathrm{DT} 2-\mathrm{DT} 5, \Delta_{1}=\mathrm{DT} 4-\mathrm{DT} 5, \Delta_{2}=\mathrm{DT} 2-\mathrm{DT} 4$

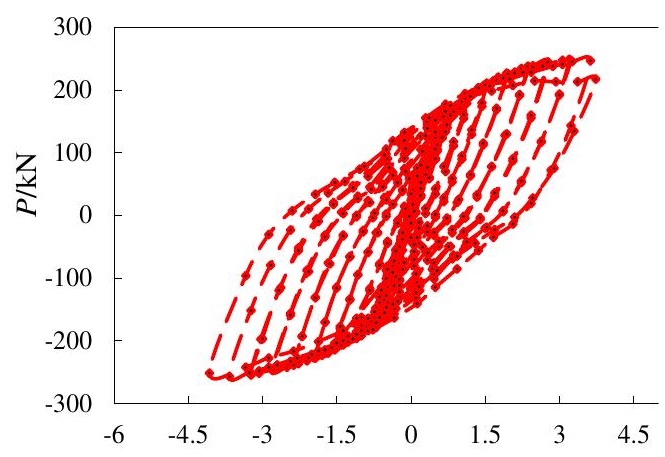

(b) Overall Specimen

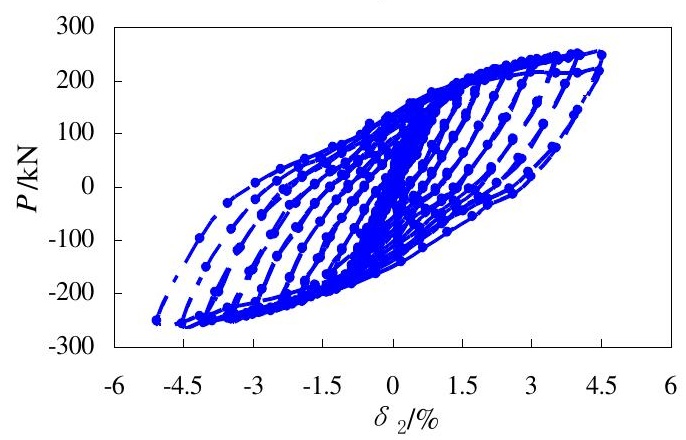

(d) Second Floor

Fig. 4 Hysteretic curves of lateral loading versus lateral drift

Table 3

Lateral resistance and frame responses at various stage of loading

\begin{tabular}{|c|c|c|c|c|c|}
\hline Stage & $\begin{array}{l}\text { Displacement } \\
\qquad / \mathrm{mm}\end{array}$ & $\begin{array}{l}\text { Shift } \\
\delta / \%\end{array}$ & $\begin{array}{l}\text { Lateral } \\
\text { resistance } \\
\text { push }(\mathrm{kN})\end{array}$ & $\begin{array}{l}\text { Lateral } \\
\text { resistance } \\
\text { pull }(\mathrm{kN})\end{array}$ & Observations \\
\hline 1 & 26 & 0.732 & 127.29 & 123.76 & Flange near the T-stub of the beam began to yield. \\
\hline 2 & 34 & 0.958 & 152.92 & 149.46 & The outer flange of the bottom of the PEC column successively entered yielding. \\
\hline 3 & 51 & 1.437 & 185.93 & 189.90 & $\begin{array}{l}\text { The yielding region of the beam extended to the web, and the T-stub of the beam was pulled } \\
\text { out. }\end{array}$ \\
\hline 4 & 68 & 1.915 & 210.93 & 211.75 & $\begin{array}{l}\text { The section near the T-stub of the beam was completely yielded to form a plastic hinge, and } \\
\text { the inner flange of the steel frame of the bottom of the PEC column also began to yield. }\end{array}$ \\
\hline 5 & 102 & 2.873 & 238.07 & 238.62 & $\begin{array}{l}\text { The plastic hinge region near the T-stub of all beam-ends was continuously developed to the } \\
\text { mid-span and yielding was further developed at the bottom of PEC column foot section. }\end{array}$ \\
\hline 6 & 136 & 3.831 & 249.27 & 256.84 & $\begin{array}{l}\text { Plastic hinges were formed at the beam ends and the bottom of PEC column near the T-stub, } \\
\text { and a plastic failure mechanism was formed. }\end{array}$ \\
\hline 7 & 153 & 4.310 & 246.51 & 251.99 & $\begin{array}{l}\text { The plastic hinge region near the T-stub of all beam-ends developed to the mid-span, } \\
\text { consequent concrete crushing observed at the bottom of PEC column and led to the obvious } \\
\text { bugleof the steel column flanges. }\end{array}$ \\
\hline
\end{tabular}


It can be seen from Fig. 4 that in the initial stage of loading, the T-stub and the PEC column were tightly connected by the pre-tightened bolts. Obviously, the load-displacement curve is linear in this stage. Along with the increasing of loading, the flange near the T-stub of the beam, the outer flange of the PEC column footing began to yield after reaching a displacement of $26 \mathrm{~mm}$ $(\delta=0.732 \%)$, and $34 \mathrm{~mm}(\delta=0.958 \%)$, respectively. The lateral resistance in the push and pull directions for those two stages is summarized in Table 3 . Debonding of the column was observed when reaching a displacement of $51 \mathrm{~mm}$ $(\delta=1.437 \%)$, thus the hysteresis curve exhibited a pinching phenomenon. The pinching phenomenon became more noticeable when displacement increased to $68 \mathrm{~mm}(\delta=1.915 \%)$, because the debonding of T-stub and column became more and more severe. Concrete crushing was observed because of the bulge of the flange when displacement reached $102 \mathrm{~mm}(\delta=2.873 \%)$. Lateral resistance of frame at various displacement levels is presented in Table 3, along with descriptions of frame performances based on the strain measurements and test observations.

Based on comparisons, it was found that the first floor was constrained due to the consolidation enhancement??? of the PEC column. The lateral deformation development rate was slower than that in the early stage of loading. As the loading progress continued, the lateral displacement deformation was accelerated. At the end of the loading, the lateral drift values of the top of the PEC column, the entire specimen, and the second layer all meet the requirements of inter-storey drift limit (i.e., within 1/30 of the frame structure at rare earthquake level). The lateral drift of the first floor also exceeds inter-storey drift limit (i.e., 1/50 of the frame structure at the design earthquake level). The tested structure exhibited excellent ductility under the seismic loading.

\subsection{Skeleton Curve}

The skeleton curves are shown in Fig 5. The skeleton curves of the top of PEC column and the entire specimen are coincident. The initial lateral stiffness of the first floor is the greatest, while the initial lateral stiffness of the second floor is the lowest. This is mainly because of the fixed constraint at the bottom of the PEC column. The constraint of the first floor of specimen is stronger than that of the second floor. The corresponding lateral displacements $\delta_{\mathrm{PEC}}, \delta_{\text {overall }}, \delta_{1}$ and $\delta_{2}$ of the specimen are $3.67 \%$ (4.12\%), 3.63\% (4.07\%), 2.87\% (3.00\%) and $4.53 \%(5.07 \%)$, respectively. The resistance of the specimen decreases insignificantly, which further indicated that the specimen presents good ductility.

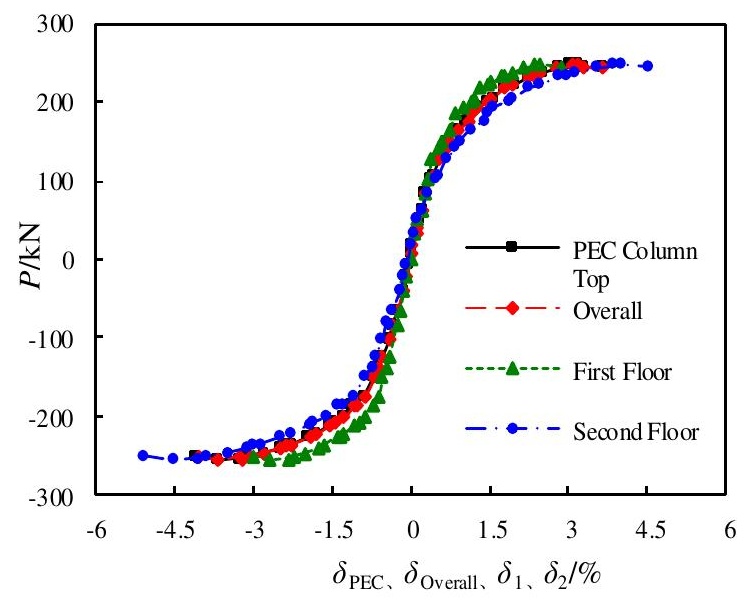

Fig. 5 Skeleton curves of the specimen

\subsection{Lateral Resistant Stiffness}

The reverse lateral stiffness of the specimen attenuates with the increasing number of cyclic loading, which reflecting the damage accumulated in the loading process. The lateral stiffness of the specimen is described by the peak secant stiffness $K_{\mathrm{p}}$ and the equivalent secant stiffness $K_{\mathrm{eq}}$. According to Eq. (1), the peak and the equivalent lateral stiffness of the specimens (i.e., at the same loading level) are depicted in Fig. 6.

$$
K_{\mathrm{p} i}=\frac{\left|P_{i}^{+}\right|+\left|P_{i}^{-}\right|}{\left|\Delta_{i}^{+}\right|+\left|\Delta_{i}^{-}\right|}
$$

$$
K_{e q i}^{+}=\frac{\left|P_{i}^{+}\right|}{\left|\Delta_{i}^{+}\right|+\left|\Delta_{i \mathrm{r}}^{+}\right|} \quad \text { or } \quad K_{e q i}^{-}=\frac{\left|P_{i}^{-}\right|}{\left|\Delta_{i}^{-}\right|+\left|\Delta_{i \mathrm{r}}^{-}\right|}
$$

where: $\Delta_{i}^{+} 、 \Delta_{i}^{-}$is the maximum lateral displacements in the push and pull directions of the loading cycle, respectively; $\Delta_{i r}{ }^{+}$and $\Delta_{i r}{ }^{-}$are the residual lateral displacements of the starting points in the push and pull directions of the loading cycle, respectively; $P_{i}^{+}$and $P_{i}$ are the lateral resistance corresponding to $\Delta_{i}^{+}$and $\Delta_{i}{ }^{-}$in the push and pull directions of the loading cycle.
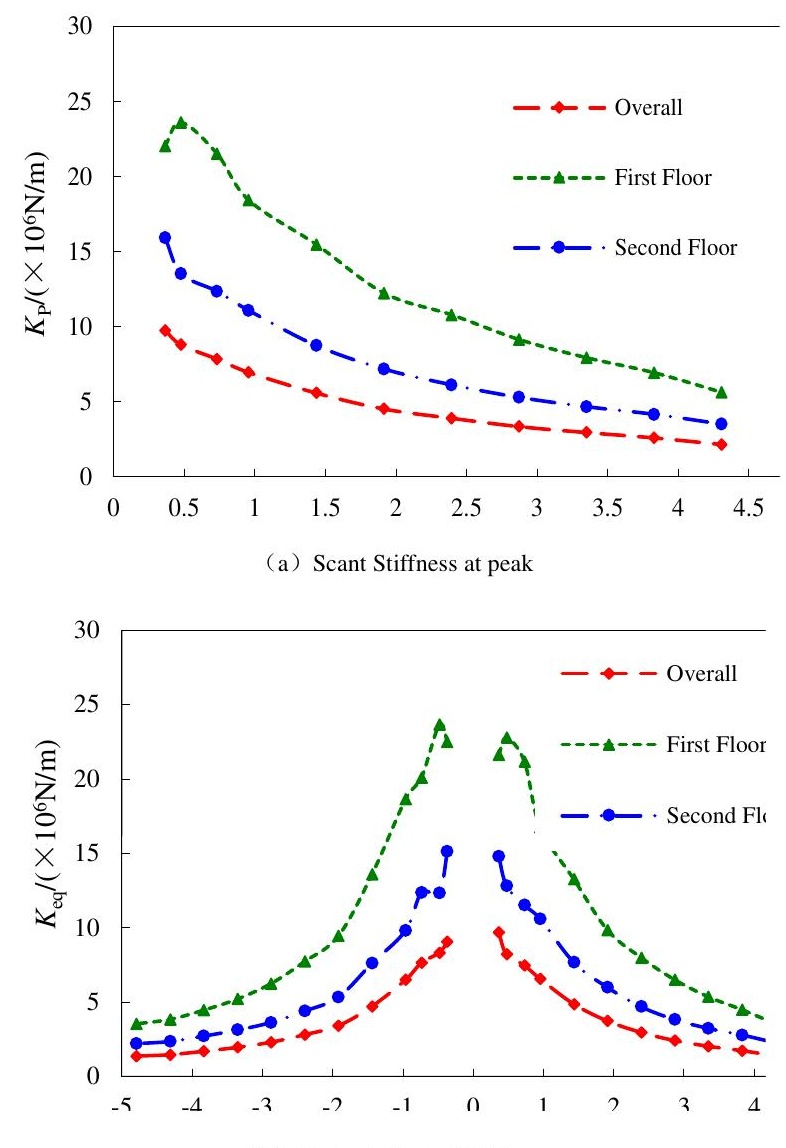

(b) Equivalent scant Stiffness

Fig. 6 Lateral stiffness degradation

It can be seen from Fig. 6 that, at the initial stage of loading, the anti-lateral stiffness of the first floor is greater due to the enhanced constrains at the bottom of PEC column,. The peak and equivalent secant stiffness of the overall frame, first floor, and second floor are summarized in Table 4 at various loading stages It was observed that when loaded to a displacement of $26 \mathrm{~mm}(\delta=0.732 \%)$, the cross-section flange near the T-stub of the beam began to yield, the lateral stiffness of the specimen showed a significant attenuation trend; When the displacement increased to $68 \mathrm{~mm}(\delta=1.915 \%)$, the section near the T-stub of the beam was completely yielded and formed a plastic hinge, and the inner flange of the steel frame of the PEC column was also yielded at this time. The attenuation rates of the lateral stiffness of the specimen became smaller. The corresponding attenuations for peak secant stiffness were 54\%, 45\%, and 55\%, respectively, for the overall frame, first and second floor. The corresponding values of the equivalent secant stiffness were $62 \%, 55 \%$ and $60 \%$ for pushing direction, and $62 \%, 58 \%$ and $65 \%$ for pulling direction, respectively. When loaded to a displacement of $102 \mathrm{~mm}(\delta=2.873 \%)$, the plastic hinge area of the section near the T-stub of all beam ends continuously extended to the PEC column, the steel frame yielding cross-section center and the concrete began to crush, and the lateral stiffness attenuation tendency of the specimen became gentle. Subsequently, when the lateral displacement reached $153 \mathrm{~mm}(\delta=4.310 \%)$, The corresponding attenuations were $78 \%, 75 \%$, and $78 \%$, respectively for peak secant stiffness. The equivalent scant stiffness were $86 \%, 84 \%$, and $85 \%$ for pushing direction and $84 \%, 85 \%$ and $82 \%$ for pulling direction, respectively. 
Table 4

Peak and equivalent secant stiffness

\begin{tabular}{|c|c|c|c|c|c|c|c|c|c|}
\hline \multirow{3}{*}{ Stages } & \multicolumn{3}{|c|}{ Peak secant stiffness $(\mathrm{N} / \mathrm{m})$} & \multicolumn{6}{|c|}{ Equivalent Scant Stiffness (N/m) } \\
\hline & \multirow[b]{2}{*}{$\begin{array}{l}\text { Overall } \\
\text { frame }\end{array}$} & \multirow[b]{2}{*}{$\begin{array}{l}\text { First } \\
\text { floor }\end{array}$} & \multirow[b]{2}{*}{ Second floor } & \multicolumn{3}{|c|}{ Push Direction } & \multicolumn{3}{|c|}{ Pull Direction } \\
\hline & & & & $\begin{array}{l}\text { Overall } \\
\text { frame }\end{array}$ & $\begin{array}{l}\text { First } \\
\text { floor }\end{array}$ & Second floor & Overall frame & $\begin{array}{l}\text { First } \\
\text { floor }\end{array}$ & Second floor \\
\hline Initial & $9.75 \times 10^{6}$ & $22.05 \times 10^{6}$ & $15.93 \times 10^{6}$ & $9.68 \times 10^{6}$ & $21.61 \times 10^{6}$ & $14.80 \times 10^{6}$ & $9.05 \times 10^{6}$ & $22.49 \times 10^{6}$ & $15.12 \times 10^{6}$ \\
\hline $\begin{array}{c}68 \mathrm{~mm} \\
(\delta=1.915 \%)\end{array}$ & $4.52 \times 10^{6}$ & $12.23 \times 10^{6}$ & $7.17 \times 10^{6}$ & $3.72 \times 10^{6}$ & $9.83 \times 10^{6}$ & $5.98 \times 10^{6}$ & $3.40 \times 10^{6}$ & $9.43 \times 10^{6}$ & $5.32 \times 10^{6}$ \\
\hline $\begin{array}{c}153 \mathrm{~mm} \\
(\delta=4.310 \%)\end{array}$ & $2.15 \times 10^{6}$ & $5.61 \times 10^{6}$ & $3.49 \times 10^{6}$ & $1.27 \times 10^{6}$ & $3.52 \times 10^{6}$ & $2.25 \times 10^{6}$ & $1.35 \times 10^{6}$ & $3.52 \times 10^{6}$ & $2.20 \times 10^{6}$ \\
\hline
\end{tabular}

\subsection{Mechanical Performance of connection Joints}

In the conventional structural system, the joint is the key part to ensure structural integrity and the force transfer mechanism. In this section, the mechanical properties of connection joints and joint regions are analyzed.

\subsubsection{Configuration of joints}

The rotation angle of the connection joints was measured by the displacement gauge. $\theta_{1}$ is the relative rotation at the upper and lower joints between the end of the west beam and the PEC column. $\theta_{2}$ is the relative rotation
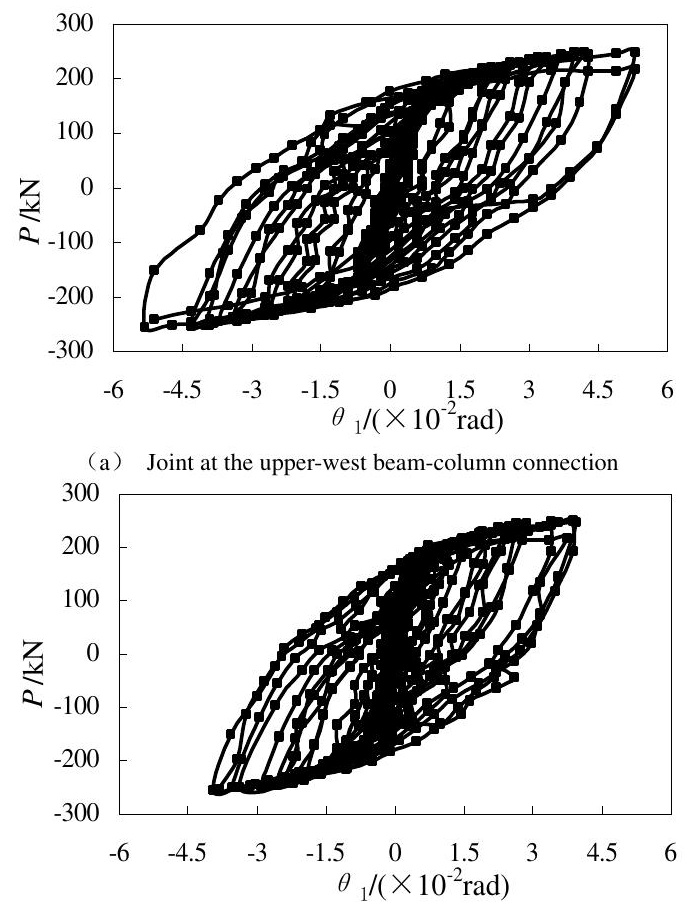

(c) Joint at the lower-west beam-column connection at the upper and lower joints between the edge of beams and T-stub flange plate, which can be calculated according to Eq (2),

$\theta_{1 / 2}=\frac{4_{\text {upper }}-\Delta_{\text {lower }}}{l}$

where: $\Delta_{\text {upper }}, \Delta_{\text {lower }}$ is the upper and lower displacements of the joint; $l$ is the distance between the upper and lower displacement measurement points. The calculated rotation angle results are shown in Fig. 7.
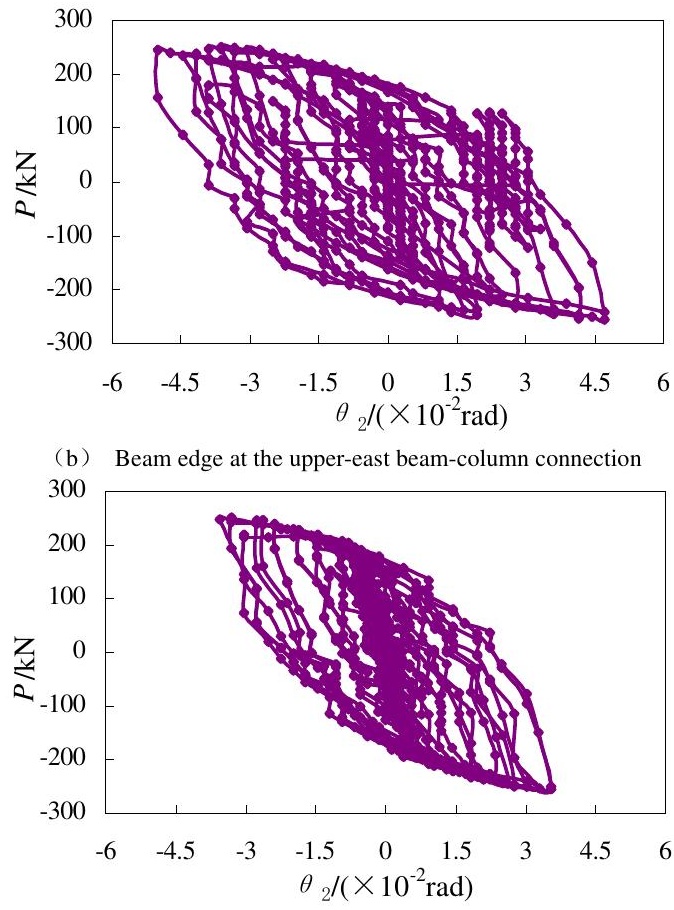

(d) Beam edge at the lower-east beam-column connection

Fig.7 P- $\theta$ hysteresis loops of connection or beam-end
It can be seen from Fig. 7 that the specimen was elastic state in the initial stage of loading, , and the rotation angle between the joint and the beam end were quite small. When the specimen was loaded to a displacement of $34 \mathrm{~mm}(\delta$ $=0.958 \%$ ), the rotation angle between the joint and the beam end increased significantly, because the cross-section flange near the beam end T-stub started to yield as well as the outer flange of the steel frame at the bottom of the PEC column. When the displacement reached $68 \mathrm{~mm}(\delta=1.915 \%)$, the cross-section of the T-stub part near the beam was substantially yielded and formed a plastic hinge. The inner flange at the bottom of the PEC column also began the yielding state, and the bond between the T-stub and the PEC column at the tension side of the beam was obviously damaged. The rotation angle and the beam end angle thus increased obviously. When the specimen was loaded to a displacement of $102 \mathrm{~mm}(\delta=2.873 \%)$, the plastic hinge area near the T-stub of all beam ends was continuously developed in the middle of the span. The yielding zone of the steel frame at the bottom of the PEC column further developed towards the middle of the section, and the concrete began to crush. The stiffness distribution along the height of the specimen tended to be uniform, and the increasing trend of rotation angle between the joint and the beam end angle was delayed.

When the specimen was loaded to a displacement of $136 \mathrm{~mm}(\delta=3.831 \%)$, the plastic mechanism was formed as aforementioned. The structure was transformed into a plastic failure mechanism, and the rotation angle at the connection joint and the beam end increased dramatically. When the specimen was loaded to $153 \mathrm{~mm}$ level $(\delta=4.310 \%)$, the plastic hinge area near the T-stub of all beam ends developed seriously in the middle of the span, and the concrete crushed at the bottom of the PEC column. The resistance of the specimen was reduced. At this time, the rotation angles of the upper and lower joint of the west PEC column were respectively $0.053 \mathrm{rad}$ and $0.395 \mathrm{rad}$. The equivalent rotation values for the east side were $0.052 \mathrm{rad}$ and $0.0356 \mathrm{rad}$, respectively. All rotations exceeded the inter-storey drift limit, that is, 1/30 of the frame structure at the considered maximum earthquake level. In addition, the bottom of PEC column was just connected with the ground beams, and the steel skeleton at the bottom entered the yielding after the yielding of the beam ends. Therefore, the yielding process of the beam section near the end of the second-floor T-stub developed faster. The loading and unloading effects were obvious in the later stages, which led to the achievement of the full rotational capacity of the second-floor beam end joint.

\subsubsection{Performance of the joint region}

The shear strain $\gamma$ of the joint region is calculated based on Eq. (3). The calculation results are depicted in Fig. 8.

$\gamma=2 \times \varepsilon_{45^{\circ}}-\varepsilon_{90^{\circ}}-\varepsilon_{0}$

Where: $\varepsilon_{45^{\circ}}{ }^{\circ}, \varepsilon_{90^{\circ}}$, and $\varepsilon_{0}$ correspond to the measured strain of the $45^{\circ}, 90^{\circ}$, and $0^{\circ}$ in the joint region. 


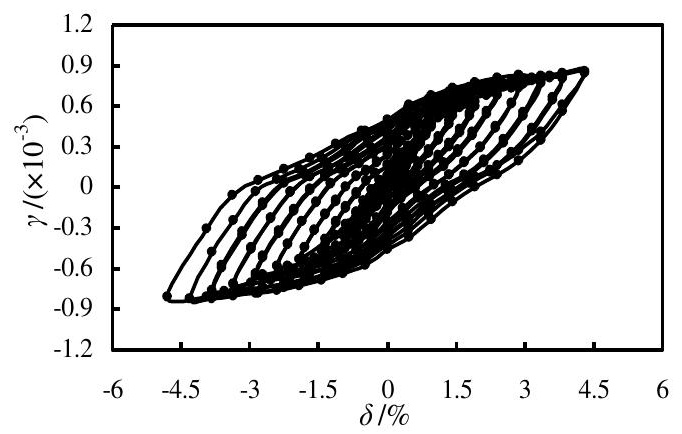

(a) upper-west beam-column region

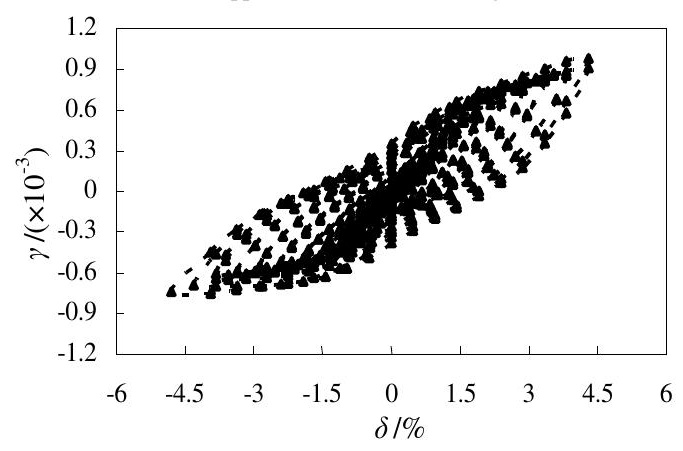

(c) lower-west beam-column region

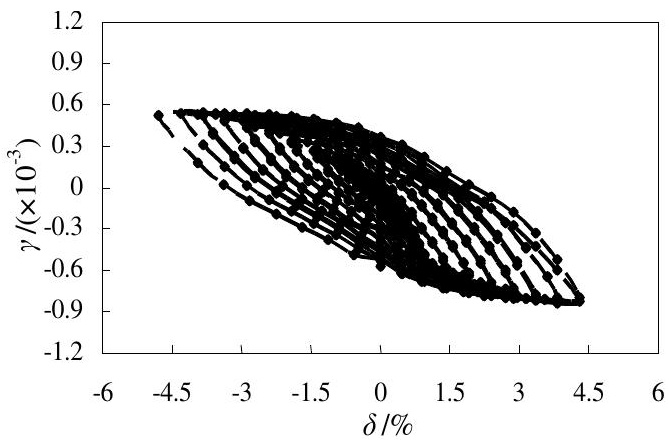

(b) upper-east beam-column region

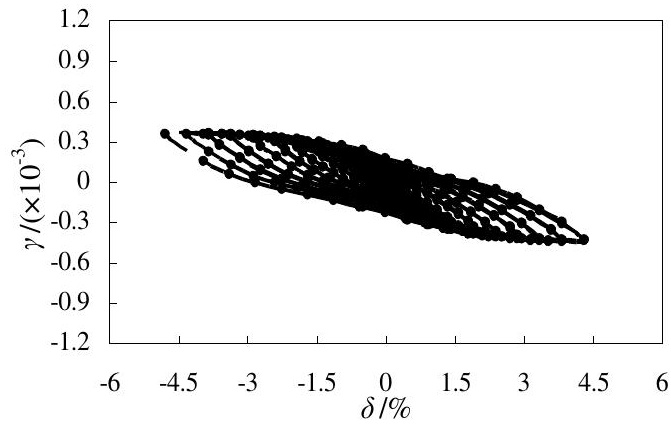

(d) lower-east beam-column region

Fig. 8 Hysteretic loops of shear deformation in the panel zone

It can be seen from Fig. 8 that in the initial stage of loading, the shear deformation hysteretic curve in the panel zone was quite small. After the specimen was loaded to a displacement of $34 \mathrm{~mm}(\delta=0.958 \%)$, the cross-section flange at the beam end near the T-stub, and the outer flange of the steel frame at the bottom of the PEC column began to yield. The shear deformation in the joint region significantly increased. When the specimen was loaded to a displacement of $153 \mathrm{~mm}(\delta=4.310 \%)$, all beam ends near the T-stub formed plastic hinge at the nearby section developed to the middle span. The concrete crushed at the bottom of the PEC column and resulted in an obvious bulge of the steel skeleton flange. The resistance of the specimen was reduced. The maximum shear deformation of all joint regions $\gamma_{\max }$ was $979 \mu \varepsilon$, which indicates that strengthening plate at the joint significantly improved the confinement effect of the concrete in the joint region of the specimen. The force transfer mechanism of the concrete diagonal zone in the joint zone was achieved through the bolt connection. The shear resistance of the joint region met the seismic resistance requirements of achieving the "strong joint".

\subsection{Ductility and energy dissipation capacity}

\subsubsection{Ductility}

The ductility of the structure is generally evaluated by the dimensionless coefficient of displacement ductility $\mu$, which can be calculated using Eq. (4).

$\mu=\frac{\delta_{u}}{\delta_{y}}$

Where $\delta_{\mathrm{y}}$ is the corresponding lateral displacement when the specimen begins to yield, which is determined based on the test observation and the measured strain results; $\delta_{\mathrm{u}}$ is the lateral drift limit corresponded to $85 \%$ of the peak load of the specimen.

Table 5 summarizes the coefficients of displacement ductility of the overall specimen and each floor. It can be seen from Table 5 that the overall coefficients of displacement ductility is between the those of the first and the second floor. In addition, the first-floor coefficient of displacement ductility is greater than that of the second floor. This may due to the bottom of the PEC column were fully restrained. Therefore, the constraint of column at first floor is greater than that of the second floor. At the termination of the loading test, the resistance of the specimen has not reduced to below $85 \%$ of the ultimate bearing capacity, and the coefficient of displacement ductility of the overall test frame and each floor are still greater than 3 . This indicates that the tested structure presents good ductility when subjected to seismic loading.
Table 5

Ductility coefficients of the specimen

\begin{tabular}{ccccc}
\hline \multirow{2}{*}{ Component } & Loading & $\delta_{\mathrm{y}} / \%$ & $\delta_{\mathrm{u}} / \%$ & $\mu$ \\
\hline \multirow{2}{*}{ Overall } & Direction & 1.133 & 3.633 & $>3.21$ \\
& Positive & 1.100 & 4.067 & $>3.70$ \\
& Negative & 0.867 & 2.867 & $>3.308$ \\
\multirow{2}{*}{ First Floor } & Positive & 0.733 & 3.000 & $>4.091$ \\
& Negative & 1.467 & 4.533 & $>3.091$ \\
& Positive & 1.400 & 5.067 & $>3.619$ \\
\hline
\end{tabular}

\subsubsection{Energy dissipation}

In general, the energy dissipation capacity of a structure is used to characterize the plastic damage when subjected to cyclic loading. Under the low-cycle cyclic loading, the degree of damage of structure can be represented by the area of the hysteresis loop. A larger the hysteresis loop area indicates the structure exhibits more excellent energy-dissipation capacity and better seismic resistance. In this study, the energy dissipation of the specimen is analyzed by hysteretic energy dissipation (i.e., hysteresis loop area) and equivalent viscous damping ratio.

\section{(1) Hysteresis energy-dissipation}

The evolution curve of the hysteretic energy $A_{\mathrm{E}}$ is the mean area of the hysteresis loop at various loading stages of the specimen. Based on the measured lateral load- drift relationship in Fig. 4, the evolution curve of the hysteretic energy $A_{\mathrm{E}}$ is calculated, as shown in Fig. 9.

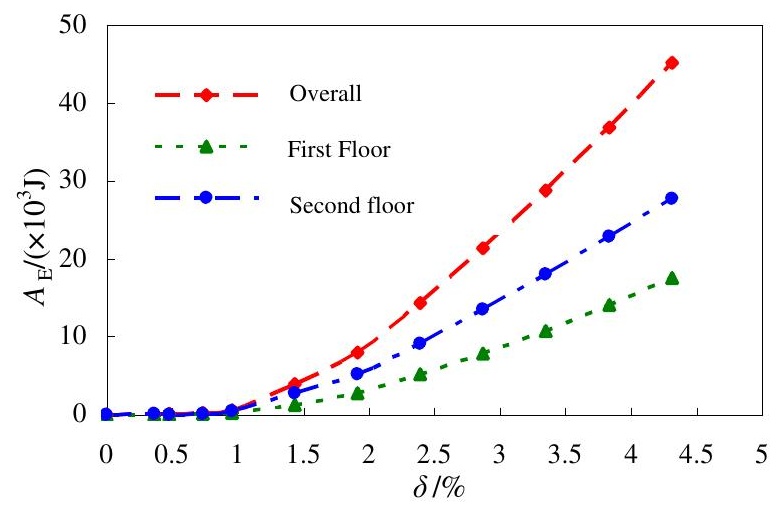

Fig. 9 Hysteretic energy dissipation curves 
It can be concluded from Fig. 9 that before the specimen was loaded to the displacement of $34 \mathrm{~mm}(\delta=0.958 \%)$, no significant energy consumption was observed. Then, the specimen started to dissipate energy through the yielding of the cross-section at the T-stub near the beam end and through the yielding at the bottom of PEC column. The yielding of the steel frame also obviously increased the energy dissipation. When the specimen was loaded to the displacement of 68 $\mathrm{mm}(\delta=1.915 \%)$, the full cross-section of the T-stub near the beam was yielded to form a plastic hinge, and the inner flange of the steel frame at the bottom of PEC column was also in the yielding state, more energy was dissipated. Because the PEC column was fully fixed at the bottom, the restraint of first-floor footing was higher than that of the second floor. Therefore, the evolution process of plastic damage to the first floor lag behind the second floor. The energy consumption of the second floor of the specimen was obviously greater than that of the first floor.

(2)Equivalent viscous damping ratio

The equivalent viscous damping ratio $\zeta_{\mathrm{eq}}$ is calculated according to Eq. (5)

$\zeta_{\mathrm{eq}}=\frac{1}{2 \pi} \cdot \frac{A_{E i}}{\left(4_{i}^{+} \times P_{i}^{+}+4_{i}^{-} \times P_{i}^{-}\right) / 2}$

Where: $A_{E i}$ is the area covered by the hysteresis loop, $\Delta_{i}^{+}$and $\Delta_{i}^{-}$are the maximum lateral displacements in the push and pull directions of the hysteresis loop. $P_{i}^{+}$and $P_{i}^{-}$are the lateral resistance of the specimen corresponding to $\Delta_{i}^{+}$and $\Delta_{i}{ }^{-}$, respectively.

Based on the measured lateral load- drift relationship in Fig. 4, the curves of the equivalent viscous damping coefficient during the loading process can be calculated. It can be seen from Fig. 10 that at the initial stage of the test loading, the test specimen was in the elastic state, and a small amount of energy was dissipated through the joint compaction, frictional slip at the joint, and the concrete compression of the PEC column, but the equivalent viscous damping ratios of the overall frame and each floor were all less than 0.05 , which is consistent with the recommended values by the Code for Seismic Design of Buildings [7]. When the specimen was loaded to a displacement of $34 \mathrm{~mm}$ $(\delta=0.958 \%)$, the cross-section flange near the T-stub of the beam began to yield, and the outer flange of the steel frame at the bottom of the PEC column began to yield, and the equivalent viscous damping ratios of the whole frame and the floors increased significantly. When the specimen was loaded to a displacement of $68 \mathrm{~mm}(\delta=1.915 \%)$, the cross-section of the T-stub near the beam end yielded and formed a plastic hinge. The inner flange of the steel frame at the PEC column also was in the yielding state. The effect of the viscous damping ratio tended to be minor. Before the specimen was loaded to the displacement of 68 $\mathrm{mm}(\delta=1.915 \%)$, the equivalent viscous damping ratio of the layer was slightly smaller than the second floor. The yielding development in the structure and concrete crushing were dramatic. The equivalent viscous damping ratio of the first floor was slightly faster than that of the second floor. At the termination of the loading, the equivalent viscous damping ratio of the overall frame, first and second floors of the specimen were $0.261,0.264$, and 0.259 , respectively. The evolution process of the equivalent viscous damping ratio of the overall frame and the floors exhibited similar trends.

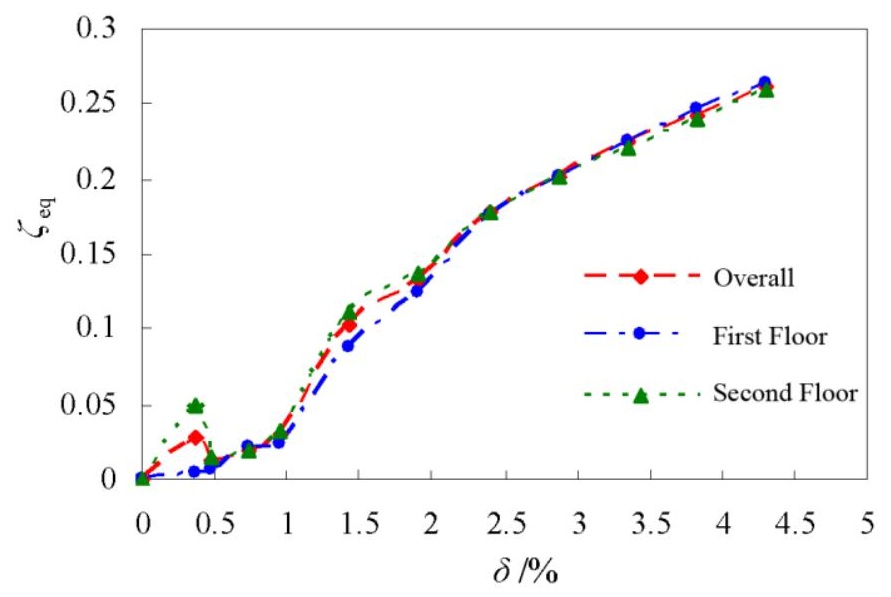

Fig. 10 Equivalent viscous damping ratios

\section{Plastic collapse mechanism}

Based on the experimental observations and the analysis of the measured data, the evolution process of the plastic structure of the specimen under low cyclic loading is described as follows. The specimen was loaded to a displacement of $68 \mathrm{~mm}(\delta=1.915 \%)$, and the cross-section of the T-stub near the beam substantially yielded for all section and formed a plastic hinge. When the specimen was loaded to a displacement of $136 \mathrm{~mm}(\delta=3.831 \%)$, the steel skeleton at the bottom of the PEC column was fully yielded, and the concrete was crushed and peeled off to form a plastic hinge. Corresponding details can be found in Fig. 3. The ideal ductile energy dissipation model of the frame structure. The structure of the specimen was transformed into a plastic failure mechanism, as shown in Fig 11.

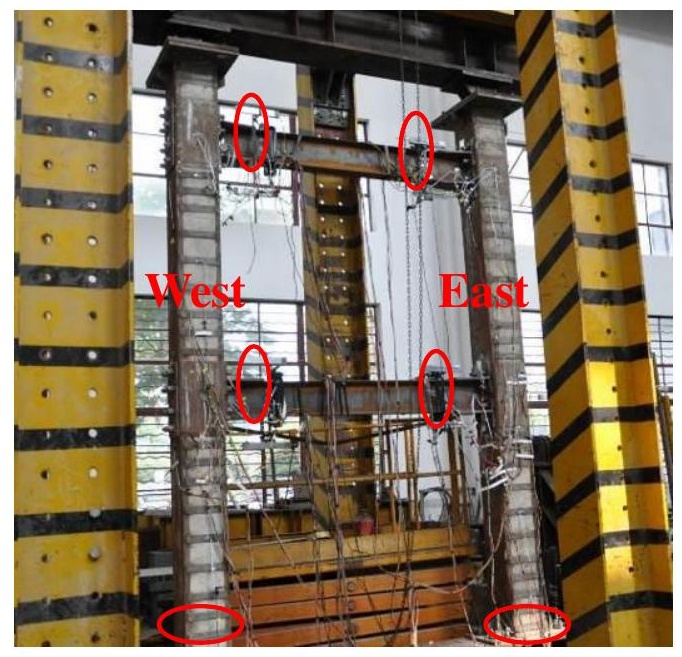

Fig. 11 The ductile failure mode of the specimen

\section{Conclusions}

1) T-stub welding reinforced connection enhanced the integrity, lateral resistance, and initial lateral stiffness of the specimen. The specimen's ultimate lateral resistance was $249.27 \mathrm{kN}$ (push) and $256.84 \mathrm{kN}$ (pull), respectively. The initial peak secant stiffness was $9.68 \times 10^{6} \mathrm{~N} / \mathrm{m}$.

2) The beam-column joint region of the specimen provides good confinement of the concrete by installing the joint reinforcement plate. Force transfer mechanism through the forming of concrete diagonal pressure zone was achieved due to the bolt connection. It enhanced the shear resistance of the joint and better met the requirements of seismic resistance by forming the "strong joints".

3) The shape of the hysteresis curve of the specimen was full. At the end of the test, the lateral resistance did not drop below $85 \%$ of the ultimate bearing capacity. The overall lateral drifting, ductility coefficient, and equivalent viscous damping ratio reached 3.63\% (push) / 4.07\% (pull), 3.21 (push)/3.70 (pull), and 0.261 , respectively, which indicated that the specimen exhibited superior deformation and seismic resistance, excellent ductility, and energy dissipation capacity.

4) T-stub welding reinforced connection PEC column-steel beam composite frame specimen developed plastic failure mechanism because the T-stub end beam section and PEC column footing successively form plastic hinges, which realizes the ideal ductility energy dissipation mode of the frame structure.

Along with previous investigations on PEC column components, joints, and interlayer substructures, the seismic performance of large-scale PEC column structures were verified in this study. The test results revealed that the proposed frame structure had good potential to be implemented in the seismic sign for enhancing strong lateral stiffness, better ductility, and energy dissipation capacity. However, more experiments on this new type of structure might be necessary, especially the seismic performance under the biaxial lateral loading.

\section{Acknowledgment}

This study was finally supported by the National Natural Science Foundation of China (No. 51478286 and 51078247). The views and findings reported here, however, are those of the writers alone, and not necessarily the views of the sponsoring agency.

\section{Reference}

[1] MUISE J. Behaviour of Simple Framing Connections to Partially Concrete Encased H Section Columns.Master's Thesis, the University of Toronto, Torroto, Canada, 2000. 
[2] CHICOINE T, MASSICOTTE B, TREMBLAY R. Long-Term Behavior and Strength of Partially Encased Composite Columns with Built-up Shapes. ASCE Journal of Structural Engineering, 2003, 129(2):141-150.

[3] PRICKETT B S, DRIVER RG. Behaviour of Partially Concrete Encased Columns Made with High-Performance Concrete. Structural Engineering Report 262, Dept. of Civil and Environment Engineering, University of Alberta, Edmonton Canada, 2006.

[4] YIN Yingzi, ZHAO Gentian, SHEN Xiangdong. Test study of PEC column with welding H shapes under concentric axial loading. Journal of Industry Buildings, 2008, 38(7): 89-91(in Chinese)) 2008, 29(2): 51-62. (in Chinese)

[5] FANG Youzhen, GU Qiang, SHEN Lin, et al. Hysteretic behavior study of PEC columns (weak axis) fabricated with thin-walled built-up section by full scale. Journal of Building Structures, 2012, 33(4):113-120. (in Chinese)

[6] FANG Youzhen, LU Chengduo, MA Ji, et al. Experimental study on hysteretic behaviors of PEC columns(weak axis) fabricated with crimping thin-walled built-up section by full scale. Journal of Civil Engineering, 2013, 46(1):24-33. (in Chinese)

[7] GB50011-2010. Code for seismic design of buildings, China Architecture \& Building Press, Beijing, China, 2010.

[8] Chen Z, Qin Y, Wang X. Development of connections to concrete-filled rectangular tubular columns. Adv Steel Constr. 2015;11(4):408-26.

[9] HE Yibin, LI Yi, CAO Haixin, et al. Experimental research on and calculation method for the shear strength of composite column-to-beam connections through T-stubs. Journal of Hunan University (Natural Sciences), 2012, 39(11): 1-6. (in Chinese)

[10] RICES J M, PENG S W, LU L W. Seismic behavior of composite concrete filled steel tube column-wide flange beam moment connections. ASCE Journal of Structural Engineering, 2004, 130(2):223-232.

[11] CAO Xianlei, HAO Jiping, SHEN Chenjun. Analysis of the anti-seismic capacity of T-stub beam-column joint of the steel frame under cyclic load. Steel Construction, 2008, 23(7):30-33、38. (in Chinese)

[12] WANG Xiantie. Behavior research and aseismic design criterion on new type connections of concrete-filled square tubular column and steel beam. Master's Thesis, Xi'an University of
Architecture and Technology, Xi'an, China, 2007. (in Chinese)

[13] FANG Youzhen, GU Qiang, YAO Jiangfeng, et al. Experimental study on Seismic Performance of new PEC column fabricated with crimping thin-walled built-up section—steel beam interior connections. Journal of Building Structures, 2014, 47(7):53-62. (in Chinese)

[14] FANG Youzhen, GU Qiang, LU Senqiang, et al. Experimental investigation on node Seismic Performance of a new PEC column - steel beam with T-shape welding strengthened connection. Journal of Experimental Mechanics, 2016, 31(1):103-112. (in Chinese)

[15] FANG Youzhen, WANG Yuxi, NIU Rongbin, et al. Experimental study on collapse mechanism of interstory substructure of PEC column-steel beam composite frame with welded T-stud strengthened connection. Journal of Xi'an Univ. of Arch. \& Tech.(Natural Science Edition), 2016, 48(4):468-476. (in Chinese)

[16] WANG Yuxi, FANG Youzhen, SHEN Xiaoming et al. Numerical simulation of interstory seismic performance of composite frame with new type PEC column-steel beam T-type jointer. World Earthquake Engineering, 2017, 31(1):100-109. (in Chinese)

[17] Bezerra LM, Bonilla J, Silva WA, Matias WT. Experimental and numerical studies of bolted T-stub steel connection with different flange thicknesses connected to a rigid base. Eng Struct. 2020; 218 (December 2019): 110770.

[18] Sebbagh HR, Kerdal DED, Abidelah A, Bouchaïr A. T-stubs with two and four bolts under monotonic and cyclic loading. J Constr Steel Res. 2021;178.

[19] Ma HW, Zheng H, Zhang W, Tang ZZ. Experimental and numerical study of mechanical properties for the double-ribbed reinforced beam-column connection. Adv Steel Constr. 2020;16(4):297-309.

[20] Tjahjanto H, Macrae G, Abu A. Behaviour of improved direct-welded connections in square cfst column moment frames under bidirectional loading. Adv Steel Constr. 2020;16(2):156-69.

[21] MATHEW D S. Seismic testing and analytical studies for development of new seismic force resisting systems for metal buildings.Master's Thesis, : University of California-San Diego, San Diego, USA, 2013 


\title{
CAPACITY EVALUATION OF EIGHT BOLT EXTENDED ENDPLATE MOMENT CONNECTIONS SUBJECTED TO COLUMN REMOVAL SCENARIO
}

\author{
Ehsan Ahmadi ${ }^{1,2}$ and Seied Ahmad Hosseini ${ }^{3, *}$ \\ ${ }^{1}$ Department of Civil Engineering, Islamic Azad University, Tehran, Iran \\ ${ }^{2}$ Beton Wall Co., Tehran, Iran \\ Faculty of Passive Defense, Malek Ashtar University of Technology, Iran \\ *(Corresponding author: E-mail: hoseini@mut.ac.ir)
}

\section{A B S T R A C T}

The extended stiffened endplate (8ES) connection is broadly used in the seismic load-resisting parts of steel structures. This connection is prequalified based on the AISC 358 standard, especially for seismic regions. To study this connection's behaviors, in the event of accidental loss of a column, the finite element model results were verified against the available experimental data. A parametric study using the finite element method was then carried out to investigate the se numerical models' maximum capacity and effective parameters' effect on their maximum capacity in a column loss scenario. This parametric analysis demonstrated that these connections fail at the large displacement due to the catenary action mode at the rib stiffener's vicinity. The carrying capacity, PEEQ, Von-Mises stress, middle column force-displacement, critical bolt axial load, and the beam axial load curves were discussed. Finally, using the Least Square Method (LSM), a formula is presented to determine the displacement at the maximum capacity of these connections. This formula can be used in this study's presented method to determine the maximum load capacity of the 8ES connections in a column loss scenario.

\section{ART I C LE H I S T O RY}

\begin{tabular}{|c|c|}
\hline Received: & 9 July 2020 \\
\hline Revised: & 25 March 2021 \\
\hline Accepted: & 30 March 2021 \\
\hline
\end{tabular}

\section{K E Y W O R D S}

Bolted endplate connection;

Finite element analysis;

Catenary action;

Column loss scenario;

Theoretical model

\section{Introduction}

The need for structural resistance against progressive failure became obvious after the progressive collapse of famous towers globally, and structural safety has become one of the most significant worries in the design of structures. Based on the definition of progressive collapse in the GSA design code [1], progressive collapse is the local damage of a structural element that causes connected components' failure. Therefore, the overall failure of the structure is much greater than the initial damage. In the last few decades, researchers realized that by providing sufficient continuity, ductility, and indeterminacy in the structures, they could prevent this phenomenon. Besides, different standards development committees were attracting to revising the standards' design procedure that only local failure was happening in the structure. The GSA [1] and the US Department of Defense (DOD), and the UFC [2] conducted comprehensive research in this field.

One of the effective solutions mentioned in these guidelines to decreasing the damage caused by progressive collapse is the alternate load path method (APM). In this method, after abnormal load damage a middle column, the structure seeks an alternative load path to survive from major collapse by redistributing this load on damaged members with a catenary action mechanism. Fig. 1 shows the formation of catenary behavior in the beams due to the column's sudden removal. At the first stage, the beams resist the vertical loads through their flexural stiffness, and then as the displacements increase downwards, the beams act as cables between the columns, creating significant tensile forces that the beam-column joints must be able to resist [3]. It should be noted that the demand created in a column removal scenario is different from the earthquake situation. In fact, in these two situations, the internal forces generated to affect the structure's behavior. Therefore, evaluating beam to column joints in a column removal scenario is essential to preventing progressive collapse [4]. Although extensive research studies have been done according to the behavior of connections under different loading type and boundary conditions, up to now, many of these research are related to welded joints or connections under seismic loads, and very few ones are about beam to column bolted steel joints under column removal scenario. In the following paragraphs, some of these research are reviewed.

AstanehAsl et al. [5] have conducted four full-scale tests to investigate the cable-supported floor's catenary action in a column removal scenario. The test indicates that using the cable on the floor could extend the middle column's catenary action and displacement. Khandelwal and El-Tawil [6] carried out the numerical investigation on the welded connections to evaluate the parameters which affect the formation of catenary action. Their study shows that in the special steel moment frame, which is designed seismically, parameters like the beam depth or detail of the beam's web to column play a significant role in a column removal scenario. Also, Sadek et al. [7] conducted a comprehensive study of steel moment connections subjected to column removal scenario to investigate welded connections similar to Khandelwal and El-Tawil [6]. In 2008, Demonceau [8] carried out an experimental test to investigate two main objects: the progress of catenary action and the study of the behavior of connections subjected to conventional loading. The performance of welded moment connection and side-plate moment connections subjected to blast load was investigated by Karns et al. [9] in experimental test and numerical modeling analysis. Yang and Tan [10-13] investigated experimental and numerical simulations to evaluate the behavior of various simple and semi-rigid connections. They indicated that as the current acceptance criteria consider connections test for flexural only, the rotation capacity for these connections is too conservative, and component-based models are essential to designing structures in a column removal scenario. In 2018, Meng et al. [14] conducted an experimental and numerical analysis on welded unreinforced flange-bolted web connections to investigate these connections' performance with two beams and three columns with different span ratios against column removal scenario. According to the progressive collapse and column removal scenario, further studies can be found in [15-20].

Also, some experimental tests were done by Yan et al. at the University of Sydney to investigate the behavior of steel connections such as bolted endplate and double web angle connections. The tests were conducted until the failure of connections to investigate their behavior's full range [21]. Faridmehr et al. [22] done some experimental tests for examining the classification index of endplate connections. They suggested a new classification index for these connections based on the rigidity, ductility requirement, and capacity level. More experimental and numerical investigation was done by Jayachandran et al. [23] to evaluate the behavior of bolted endplate connections. Their study had eight endplate connections with extended endplate in tension side, which then simulated using ABAQUS software and validated by experimental data to reconsider the Frye-Morris polynomial model.

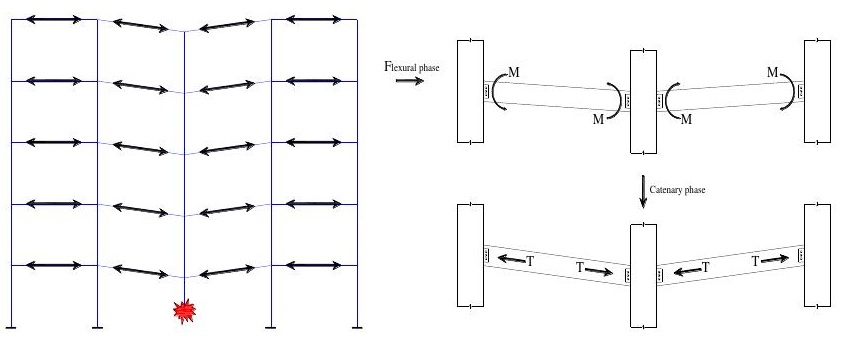

Fig. 1 Schematic formation of catenary action in beams [3] 
Regarding the presented previous paragraphs, an insignificant number of researchers investigated the behavior of bolted steel moment connections against the column removal scenario, and most research has been done on welded joints. Moreover, the literature review recommends that one of the key mechanisms is considering catenary action in the column removal analysis, which leads to extending a system's capacity in progressive collapse. Therefore, the finite element models of an endplate connection with two beams and three columns were established using ABAQUS software to verify the numerical model. Material constitutive models, element types, material and geometric nonlinearity, and contact models for bolts and endplates were well proposed. Based on the numerical verification, nine $8 \mathrm{ES}$ connections subjected to catenary action under a middle column-removal scenario were created using ABAQUS software. These connections are made by welding the beam to an endplate section with the endplate's attachment to a column flange using fully tensioned bolts. Finally, the behavior of these nine numerical models, Von-Mises stresses, plastic equivalent strain (PEEQ), vertical load-displacement curves, the fracture modes, and their maximum capacity under removal of the middle column was evaluated, and at the end, a proposed formula to calculate the maximum capacity of these connections under column removal scenario has been conducted.

\section{Finite element verification}

The FEM assumptions were verified with the experimental test conducted by Dinu et al. [24]. These experimental tests contain four different connections designed and fabricated to investigate the behavior of steel frame joints subjected to the column removal scenario. They were extracted from a three-bay, four-span plan, and six-story structure with a height of $4000 \mathrm{~mm}$ for each story. The beam length was decreased from $8000 \mathrm{~mm}$ to $3000 \mathrm{~mm}$ as there was space limitation in the laboratory [24]. Also, in all experimental tests, the HEB260 was used for column sections with the reduced flange's width of 160 $\mathrm{mm}$, and the beam section was IPE220. Fig. 2 illustrates the test setup and the lateral braces' locations in the test setup, which resist the specimen's out-of-plane movements in ref [24].

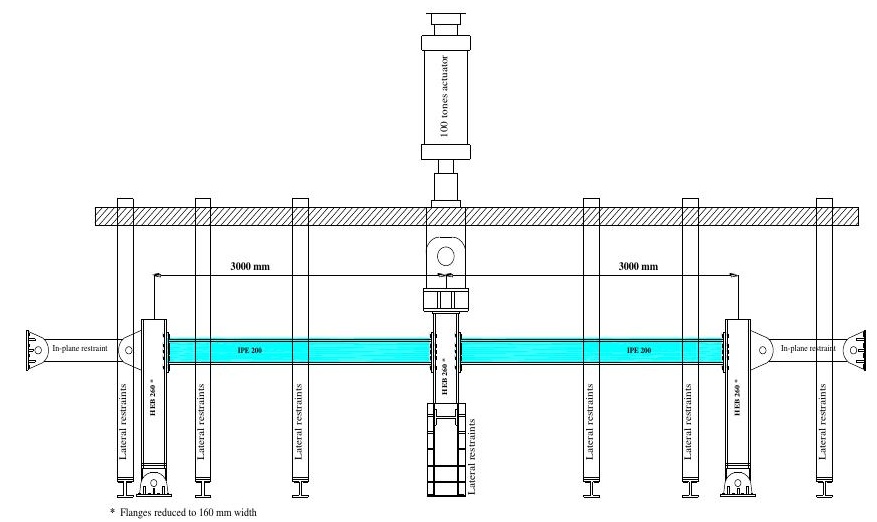

Fig. 2 The test setup used in ref [24]

\subsection{Generality}

The specimen EP of Ref. [24] was model by ABAQUS software [25] to verify the adopted assumptions for FE modeling. For this specimen, the geometrical properties are shown in Table 1. It was an interior connection that a 100 tons actuator on top of the middle column used to test the specimen under monotonic loading. Fig. 3 presents the geometrical details of specimen $\mathrm{EP}$ in mm dimensions and its photo before loading.

Table 1

Geometrical properties of specimen EP in ref [24]

\begin{tabular}{llll}
\hline Specimen & EP & Beam section & IPE 220 \\
\hline Connection type & Interior & Column section & HEB 260* \\
\hline End-plate & & Dimensions $(\mathrm{mm})$ & $370 \times 130 \times 16$ \\
\hline \multirow{2}{*}{ Bolts } & & No. & 10 \\
\cline { 2 - 4 } & & Diameter $(\mathrm{mm})$ & 16 \\
\hline
\end{tabular}

"The width of the flanges reduced to $160 \mathrm{~mm}$.

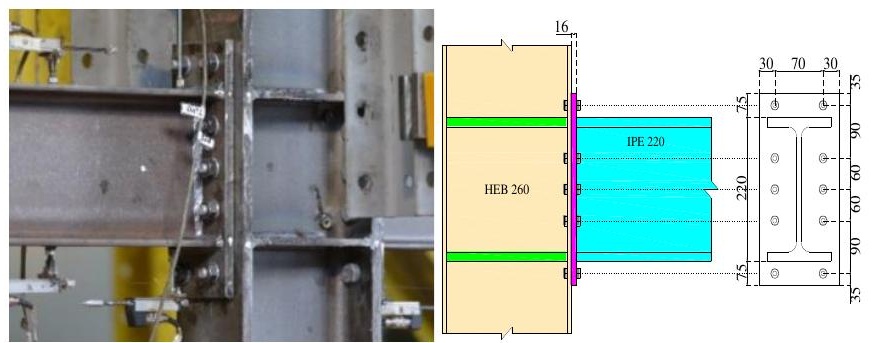

Fig. 3 Photos of specimen EP before the test and geometrical details used by [21]

(dimensions are in $\mathrm{mm}$ )

Fig. 4 shows the finite element model of specimen EP, which contains four main parts: columns, beams, endplates, and bolts. The bolts are modeled as a single part made of three partitioned zones: the shank, the head, and the nut The welds are considered rigid and modeled by a tie contact tool, and they are used to connect the beam to the endplate.

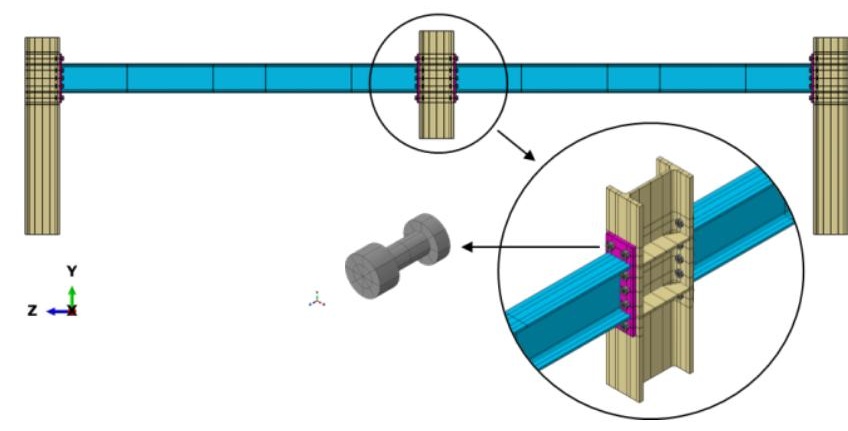

Fig. 4 Finite element model of specimen EP

Due to complex numerical problems in finite element modeling, contacts between system components usually need special care, so small surface-to-surface sliding was used in all system component interactions. In this sliding process, only in the initial stage, the contact defined between the master and slave nodes [26]. It should be noted that the contacts were defined between different part of the system like the column flange and endplate, the bolt nuts and heads with column flange and endplate, and the hole and bolt shanks of both column flange and end plate by surface to surface formulation to simulate component's interaction. In normal behavior, the "hard" contact law with allowed separation after contact was defined. Besides, tangential behavior contacts with "Penalty" law with a slip coefficient of 0.3 is assumed.

The general static procedure was used in finite element modeling using the ABAQUS standard solver. In the "Initial" step, boundary conditions are defined. In the "Pretension" step, the force in a tightened bolt is modeled using the bolt load tool. Two methods can apply this load: Applying specification force or a change in the shank length of bolts. In this study, using the apply force method and the minimum pre-tensioning load presented in table J3.1 of AISC 360-16 [27], the tension in a tightened bolt is modeled. Finally, monotonic loading was applied to the middle column section to simulate the column loss action.

The C3D8R elements with a reduced integration point are used for the verification model. Also, to have a regular shape for elements, especially in critical locations like bolt shanks, holes, and connection locations $(200 \mathrm{~mm}$ from left and right of connection), the structured meshing technique is used. The mesh sensitivity analysis shows that accurate simulation results can be achieved with the $5 \mathrm{~mm}$ mesh size for bolt and hole regions. Also, the mesh size was increased from $10 \mathrm{~mm}$ in connection regions to $50 \mathrm{~mm}$ in the regions with low strain. The other important part of specimens was modeled with three, two, and two elements in their thickness. Fig. 5 shows the typical finite element mesh of the test specimen. 


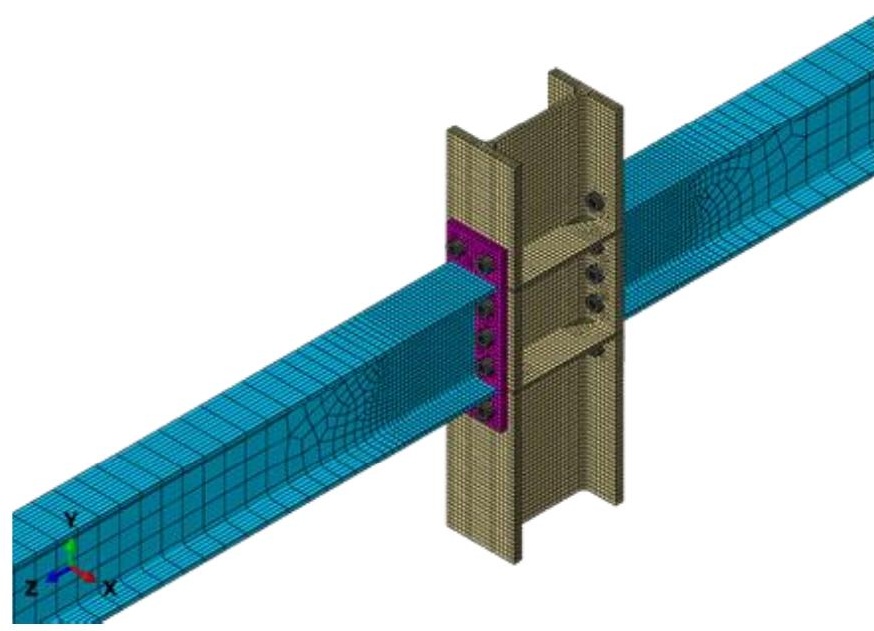

Fig. 5 Typical finite element mesh of the specimen EP

\subsection{Materials properties and boundary conditions}

The material properties were defined from the basis of given test results in ref [24]. Table 2 presents engineering stress-strain values for specimen EP. These values converted to the true stress-strain relationship using Eq. 1 to Eq. 3 with combined isotropic/kinematic hardening rule. In these equations, $\varepsilon_{\text {norm }}$ and $\sigma_{\text {norm }}$ are the strain and stress obtained from the coupon test, $\varepsilon_{\text {true }}$ and $\sigma_{\text {true }}$ are the true strain and stress, and $\varepsilon_{\text {true }}^{p l}$ is the true plastic mechanical strain.

Table 2

Engineering stress-strain values for different elements of specimen EP used in ref [24]

\begin{tabular}{llccc}
\hline & Component & $\mathrm{F}_{\mathrm{y}}(\mathrm{Mpa})$ & $\mathrm{F}_{\mathrm{u}}(\mathrm{Mpa})$ & Efracture $(\%)$ \\
\hline \multirow{2}{*}{ Beam } & Flange & 351 & 498 & 22.1 \\
\cline { 2 - 5 } & Web & 370 & 497 & 25.2 \\
\hline \multirow{2}{*}{ Column } & Flange & 393 & 589 & 19.5 \\
\cline { 2 - 5 } & Web & 402 & 583 & 20.2 \\
\hline \multirow{2}{*}{ Endplate } & & 305 & 417 & 30.9 \\
\hline \multirow{2}{*}{ Bolt } & & 965 & 1080 & 10.21 \\
\hline
\end{tabular}

$\varepsilon_{\text {true }}=\ln \left(1+\varepsilon_{\text {norm }}\right)$

$\sigma_{\text {true }}=\sigma_{\text {norm }}\left(1+\varepsilon_{\text {norm }}\right)$

$\varepsilon_{\text {true }}^{p l}=\varepsilon_{\text {true }}-\frac{\sigma_{\text {true }}}{E}$

The boundary conditions are defined similarly to those shown in Fig. 6 to model the appropriate structural behavior under a column removal event. The column tip section at both ends of exterior columns and the top of the interior column are attached to a point and placed into the center of their cross-section. All DOFs of the exterior column are restrained, and the column loss action is simulated by applying static vertical displacement at the interior column reference point until the connection failure.

\subsection{Fracture mechanisms}

Generally, metals and alloys' failure can be divided into two main categories; ductile and brittle failure. The ductile fracture usually involves a large amount of plastic deformation, warning before fracture, and displays in various ways depending on the material classification, boundary conditions, and constraint level.

On the other hand, brittle failure has small deformation and occurs suddenly in a location. The specimen Ep, which is used in the verification section, may experience various modes of failure (e.g.) the rupture of the weld line at the bottom of the beam flange, net section rupture at the endplate, bolt fracture, or beam flange rupture. Despite different types of fracture mechanisms and methods to simulate the damage in the finite element model, which can be found in the previous work done by Hedayat et al. [28], the focus of this paper is on the two types of methods to capture these damages. Firstly, the extended finite element method (XFEM) [29] use to capture the brittle fracture in the model (fracture of bolts), and secondly, the PEEQ index captures the highest fracture potential locations, especially for ductile fracture.

In the first category, a predefine failure mechanism was used to capture the fracture of bolts. This mechanism consists of two-part: the damage initiation and damage evolution law. Regarding these two parts of the failure mechanism, a nominal quadratic strain (QUADE) for damage initiation and energy-based damage for evolution law was used to verify the specimen [28]. An element's damage initiation can be captured in the second category by observing the stress or strain level at different components. Based on the Hedayat et al. [28] research, the value of PEEQ in the critical parts can be monitored to recognize the fracture's initiate of elements and obtained with the results of coupon tests. The average PEEQ for these components was 0.6 and 0.4 for two steel types of A36 and A572 plates. In this research, the fracture initiates when any location reaches the mentioned PEEQ limits. The plastic equivalent strain index is defined as Eq. 4. This index is used to evaluate nonlinear strain damage and is defined as follows:

$P E E Q=\frac{\sqrt{\frac{2}{3} \varepsilon_{i j}^{p} \varepsilon_{i j}^{p}}}{\varepsilon_{y}}$

Where $\varepsilon_{i j}^{p}$ and $\varepsilon_{\mathrm{y}}$ are the plastic strain and yield strain, respectively. This method had used to identify the failure of steel components such as shear tab and bolt in simple conventional connections, and in welded connections, beam flange, and web, in other researcher's studies [30-36].

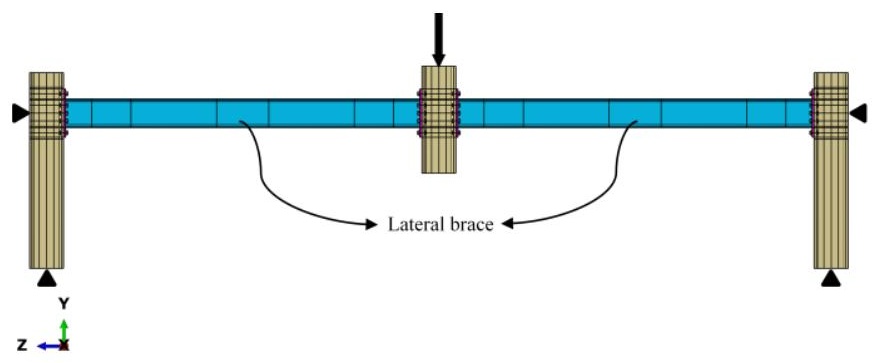

Fig. 6 Boundary conditions applied to finite element models

\subsection{Verification results}

The finite element model was built using strategies mentioned in previous sections and validated against the experimental results of specimen EP presented in reference [24] regarding the force and displacement relationship. As shown in Fig. 7, the initial stiffness, yield strength, accumulated plastic deformation, and local buckling have good agreement in both experimental and analytical results.

According to experimental results, the bending deformation of the endplate near the central column connection was caused yielding to initiate at vertical displacement and an applied load of $39 \mathrm{~mm}$ and $117 \mathrm{kN}$. After that, flexural stiffness started to decrease dramatically and reach the purely flexural stage (the axial force in the beams was nearly zero) with vertical displacement of 154 $\mathrm{mm}$ and applies a load of $175 \mathrm{kN}$. Finally, the specimen experiences a sudden strength loss by initiating fracture in the bolts in the right beam connection's external bottom row (near the central column). These failure modes are similar to the numerical results, as shown in Fig. 8a and Fig. 8b. As shown in this figure, the proposed fracture mechanism explained in previous sections could provide a quite accurate prediction for bolts' fractures.

Overall, the analytical model shows sound accuracy to predict the experimental results. Also, it is used to investigate the failure mechanism of extended endplate connections. 


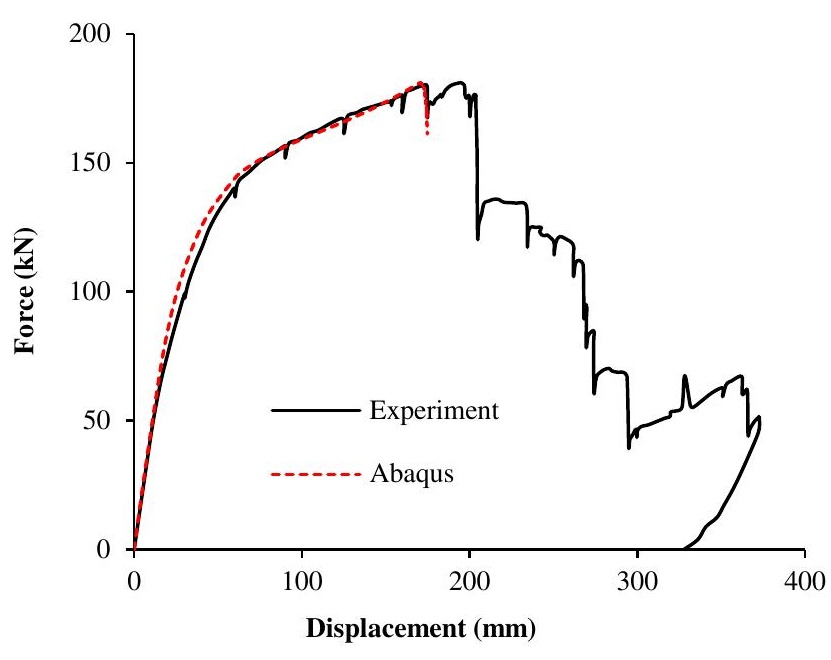

Fig. 7 Comparison between the numerical and experimental results of specimen EP presented in ref [24]

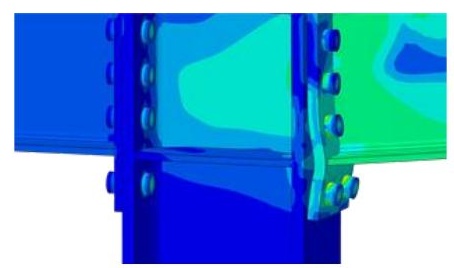

Simulation

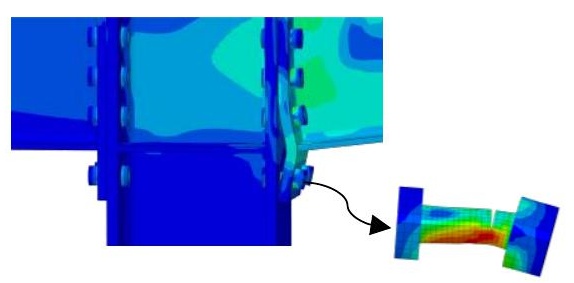

Simulation

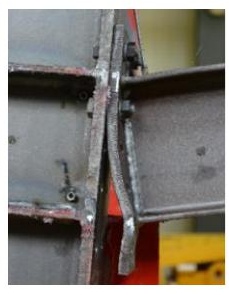

Test

(b)

Fig. 8 Comparison of experimental test and simulation result's failure modes: a) bending

deformation of the endplate, $b$ ) fracture of the bolt in the middle column connection

\section{Connection design and modeling}

In the previous sections, the numerical simulation was described for verifying the experimental test done by reference [24]. To investigate the capacity of different $8 \mathrm{ES}$ connections in a column removal scenario, a set of nine connections were designed with the lateral load-bearing system of the special moment-resisting frame. For the design of steel elements and the connections AISC 360-16 [27], AISC 341-16 [37], and AISC 358-16 [38] have been used. In the connections design, three different beam sections of W21, W24, and W30 with the column section of W14 were used. The bolts are A490 bolts with diameters of $1,11 / 8$, and $11 / 4$ inch, and their threads are excluded from the shear plane. The beams length calculated with the ratio of $\mathrm{L}_{\text {beam }} / \mathrm{d}_{\text {beam }}=$ 12 and column length consider as $13 \mathrm{ft}$ for each specimen. A dead and live load of $96 \mathrm{psf}$ and $50 \mathrm{psf}$ proposed for calculating gravity loads, respectively. Table 3 shows the geometry and connection parameters of nine specimens. According to this table, beams depth was varied from 530 to $767 \mathrm{~mm}$, which cause to have a beam length of 6400 to $9083 \mathrm{~mm}$. It should be mentioned that width-to-thickness ratios for beam and column elements are limited to AISC 341-16 [37] criteria, which are related to highly ductile members.

According to the guidelines presented in the UFC [2], the frames during a column removal scenario can be divided to direct influence and indirect influence regions (see Fig. 9a). In this study, the primary region for capacity evaluation of connections is the direct influence area. To this end, the simplified model with an interior column in the center of the model and two adjacent beams can be considered a double full-span assembly, which can be seen in Fig. 9a. Due to the column's small horizontal deformation and compression, the side columns' boundary conditions are simplified to fixed hinge constraints [16, 39-41]. As there is symmetry in the geometry and loading, for all specimens in this study, the boundary conditions for numerical models were considered as those shown in Fig. $9 \mathrm{~b}$.

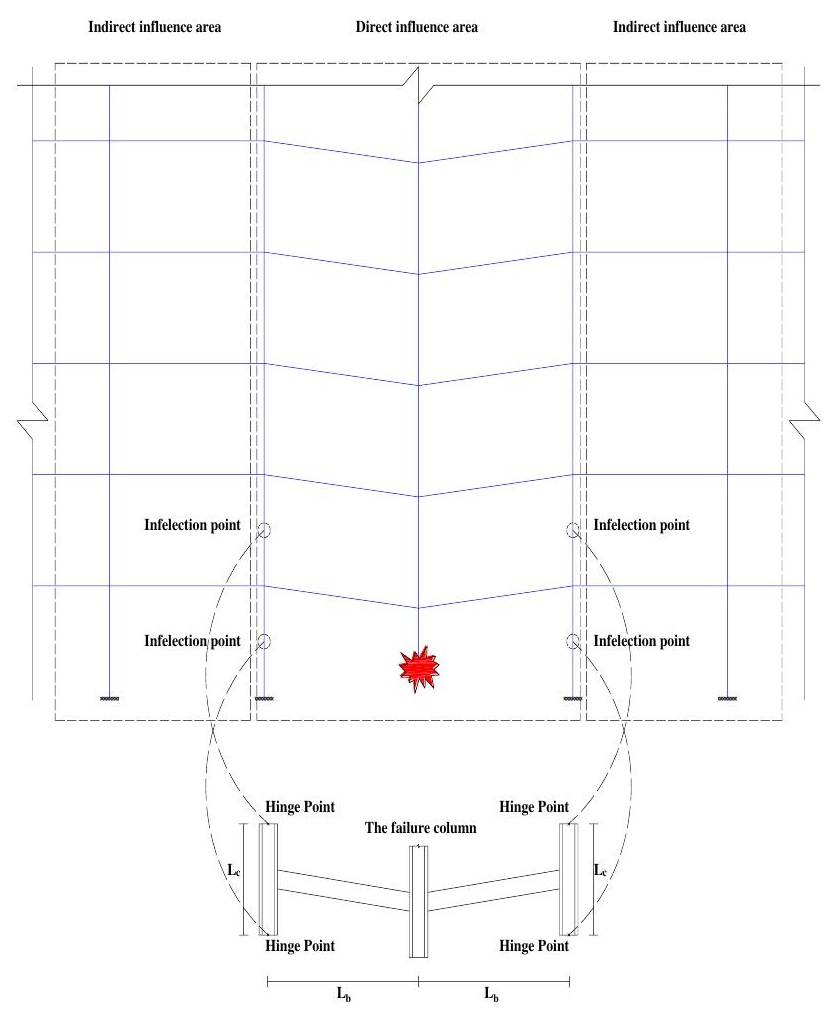

(a)

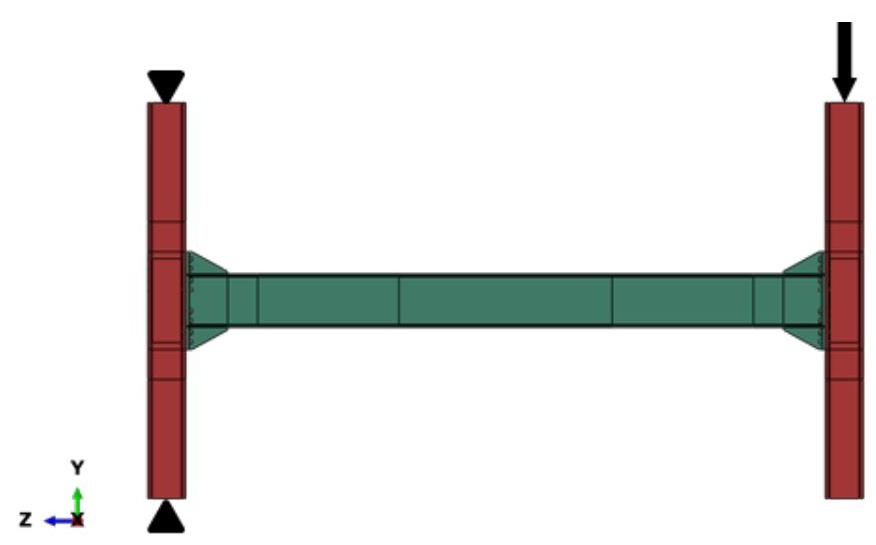

(b)

Fig. 9 a) The double full-span assembly extracted from steel frame b) The typical FE model of numerical specimens

The displacement-controlled loading was considered in the analysis procedure, so a vertical displacement was gradually applied to the removed column until the fracture occurred. It should be noted that this column could only have vertical displacement. Besides, in FE modeling, beams' lateral bracing is provided following the AISC 341-16 [37] to resist the affected beams' out-of-plane movements. In this study, specimens were modeled and analyzed using ABAQUS software ver. 6.14 [25]. The finite element model overview with proposed boundary conditions and the connection components can be seen in Fig. 10. 
Table 3

Investigated specimens' details

\begin{tabular}{|c|c|c|c|c|c|c|c|c|c|c|c|}
\hline \multirow{2}{*}{ Model No. } & \multicolumn{5}{|c|}{ Beam } & \multicolumn{2}{|c|}{ Column } & \multicolumn{3}{|c|}{ Endplate } & \multirow{2}{*}{$\begin{array}{c}\text { Bolt } \\
\text { dbolt }(\mathrm{mm})\end{array}$} \\
\hline & Section & $\mathrm{d}_{\text {beam }}(\mathrm{mm})$ & $\mathrm{b}_{\mathrm{f}} / \mathrm{t}_{\mathrm{f}}$ & $\mathrm{Z}_{\mathrm{x}}\left(\mathrm{mm}^{3}\right)$ & Lbeam $(\mathrm{mm})$ & Section & $\mathrm{d}_{\text {column }}(\mathrm{mm})$ & $\mathrm{L}_{\mathrm{p}}(\mathrm{mm})$ & $\mathrm{b}_{\mathrm{p}}(\mathrm{mm})$ & $\mathrm{t}_{\mathrm{p}}(\mathrm{mm})$ & \\
\hline Specimen 1 & W21x62 & 533.4 & 6.699186992 & 2359737.216 & 6400.8 & $\mathrm{~W} 14 \times 159$ & 381 & 977.9 & 254 & 34.925 & 25.4 \\
\hline Specimen 2 & W21x73 & 538.48 & 5.608108108 & 2818575.008 & 6461.76 & W14x176 & 386.08 & 982.98 & 254 & 38.1 & 25.4 \\
\hline Specimen 3 & W21x93 & 548.64 & 4.52688172 & 3621541.144 & 6583.68 & $\mathrm{~W} 14 \times 233$ & 406.4 & 993.14 & 254 & 34.925 & 28.575 \\
\hline Specimen 4 & W24x76 & 607.06 & 6.610294118 & 3277412.8 & 7284.72 & W14x193 & 393.7 & 1051.56 & 304.8 & 31.75 & 25.4 \\
\hline Specimen 5 & W24x94 & 617.22 & 5.182857143 & 4162314.256 & 7406.64 & $\mathrm{~W} 14 \times 257$ & 416.56 & 1061.72 & 304.8 & 34.925 & 28.575 \\
\hline Specimen 6 & W24x103 & 622.3 & 4.591836735 & 4588377.92 & 7467.6 & $\mathrm{~W} 14 \times 283$ & 424.18 & 1066.8 & 304.8 & 34.925 & 31.75 \\
\hline Specimen 7 & W30x108 & 756.92 & 6.907894737 & 5669924.144 & 9083.04 & $\mathrm{~W} 14 \times 311$ & 434.34 & 1201.42 & 304.8 & 34.925 & 31.75 \\
\hline Specimen 8 & W30x116 & 762 & 6.176470588 & 6194310.192 & 9144 & $\mathrm{~W} 14 \times 342$ & 444.5 & 1206.5 & 304.8 & 38.1 & 31.75 \\
\hline Specimen 9 & W30x124 & 767.08 & 5.64516129 & 6685922.112 & 9204.96 & $\mathrm{~W} 14 \times 370$ & 454.66 & 1211.58 & 304.8 & 38.1 & 31.75 \\
\hline
\end{tabular}

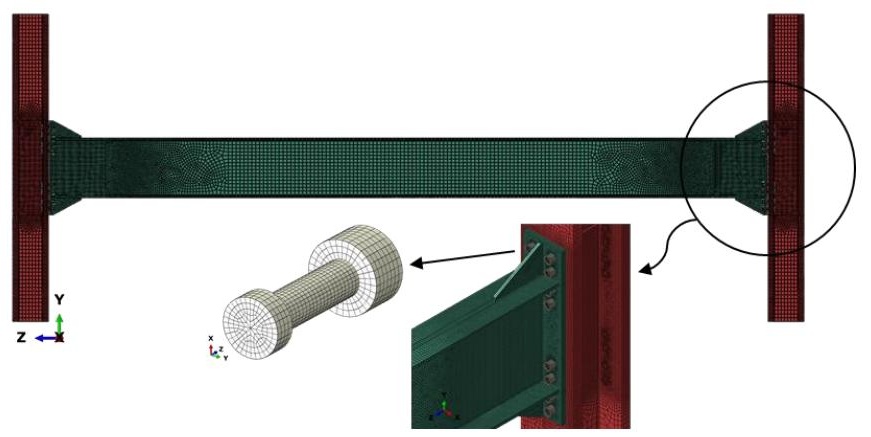

Fig. 10 Typical finite element model of a connection

\section{Results and discussion}

Nine numerical models for investigating the behavior of $8 \mathrm{ES}$ connections were designed and model using ABAQUS software. In this section, these nine models' behavior under the column removal scenario and the effects of effective parameters on connections capacity are discussed. The parameters which directly or indirectly can affect the connection behavior could be $\mathrm{d}_{\text {beam }}$, $\mathrm{b}_{\mathrm{f} \text {-beam }} / \mathrm{t}_{\text {-beam }}$, and $\mathrm{Z}_{\mathrm{x} \text {-beam. }}$. The performance of specimen 1 depicts in Fig. 11. Equivalent plastic strain (PEEQ) contours and Von-Mises stress contours are shown for the overall finite element modeling at the first fracture time step of the analysis for this specimen in Fig. 11a and Fig. 11b, respectively. Based on the research done by $[30,31]$ and the present study, the high plastic strain and stress demands in the beam flange near the stiffener rib make the 8ES connections susceptible to fracture. According to damage mechanisms, which are supposed in section 2.3, as PEEQ in half of beam flanges width reaches 0.4 , fracture initiated and specimen experience the maximum deflection. Understanding the local failure mechanism is highly dependent on the design of these connections, hence based on the design of the connections, it can be seen in Fig. 11a, the plastic hinge in specimens is near the rib stiffener, and plastic deformations are mainly in this region. Due to the plastic hinge formation, local buckling occurred in the beam's flange and web near the stiffener rib. Fig. 17 plotted the deformation, PEEQ, and Von-Mises stress contour for nine specimens.

The Force-displacement curve illustrates specimen 1 at the onset of the first fracture in the bottom beam flange in Fig. 11c. Also, the maximum and fracture point of the specimen has shown in this figure. These points indicate the maximum ductility and strength capacity of this specimen, which later derives the proposed formula. Another important curve to monitoring the critical bolt fracture is Fig. 11d, which illustrates the bolt axial load versus connection displacement at the first fracture's onset. As can be seen in this figure, at the first stage, the bolt pretension load was applied $(285000 \mathrm{~N})$ based on the type (A490) and diameter (1 inch) of the bolt. Then, increasing the middle column's deflection, the bolt axial force has increased to the maximum point at the pure flexural stage (no tensile force in beams). After that, due to the plasticization of beam flange elements, the bolt axial force becomes constant. Finally, by the initiation of fracture in the beam flange, the bolt axial load starts to decrease until the full fracture of the beam flange.
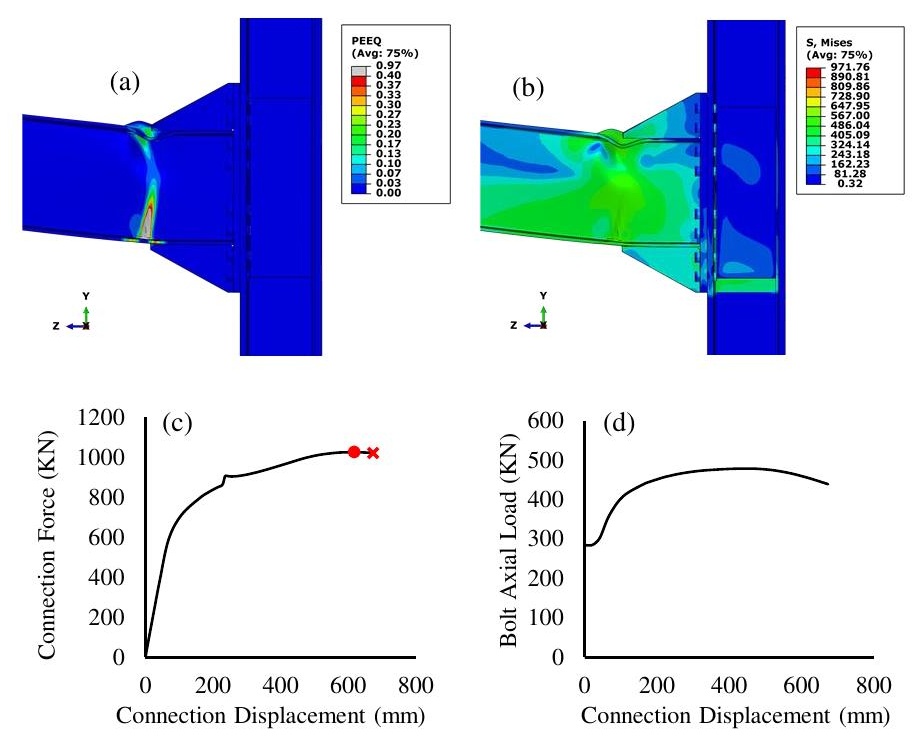

Fig. 11 Performance of the specimen 1 a) Equivalent plastic strain distributions (PEEQ) b)

Von-Mises stress c) Force-displacement curve, d) Bolt axial load versus connection

displacement at the onset of the first fracture

Comparison of the vertical displacement-force diagrams are shown in Fig. 12 for nine connections with different properties. Based on the connection's properties presented in Table 3, they were divided into three main groups with different beam depths (W21, W24, and W30). It should be noted that the significant effect of the plastic section modulus and the value of the beam flange width to its thickness $\left(\mathrm{b}_{\mathrm{f}} / \mathrm{t}_{\mathrm{f}}\right)$ has caused a capacity increased in specimen 3 compared to specimens 4 and 5 .

\subsection{The effect of parameter $d_{\text {beam }}, Z_{x}, b_{f} t_{f}$, and $d_{\text {bolt }}$ on the maximum capacity of specimens}

As noted earlier, these connections act so that the major capacity depends on the beam properties due to beam flange failure in a column removal scenario. As a result, four parameters of $d_{\text {beam }}, Z_{x}, b_{f} / t_{f}$, and $d_{\text {bolt }}$ that mainly affect these connections' capacity have been studied. According to Fig. 13, the value of these four parameters versus each specimen's maximum capacity $\left(\mathrm{P}_{\mathrm{FE}-\mathrm{max}}\right)$ is plotted. For instance, Fig. 13a shows that with increasing parameter $d_{\text {bean }}$, the system's overall capacity increases. Also, one of the significant parameters is the beam plastic section modulus $\left(\mathrm{Z}_{\mathrm{x}}\right)$. As can be seen in Fig. 13b, the maximum values of the system capacity are directly related to the plastic section modulus, and even in specimen 3 , the system capacity has increased compared to the specimens with higher beam depth which shows the significant role of this parameter in the capacity of connections in the column removal scenario.

Moreover, increasing the size of bolts diameter, the rigidity of connections, and the overall capacity of connections increased. On the other hand, the ratio of the beam's parameter flange width to its thickness $\left(b_{\mathrm{f}} / \mathrm{t}_{\mathrm{f}}\right)$ has a vice versa 
effect on the maximum capacity of specimens (Fig. 13c). As this ratio increases, the slenderness of flanges increases, and buckling in the beam flange section will happen sooner.

Fig. 14 shows the regression method results and the values of multiple $\mathrm{R}$ regarding these connections' capacity. As can be seen in this figure, parameters like the cross-section of the beam (A), beam depth $\left(\mathrm{d}_{\text {beam }}\right)$, flange Width $\left(\mathrm{b}_{\mathrm{f}}\right)$, plastic section modulus $\left(\mathrm{Z}_{\mathrm{x}}\right)$, and bolt diameter $\left(\mathrm{d}_{\text {bolt }}\right)$ have a correlation coefficient of more than $80 \%$. It shows, in these connections, the properties of the beam and the diameter of the bolt have a great effect on the connections' capacity.

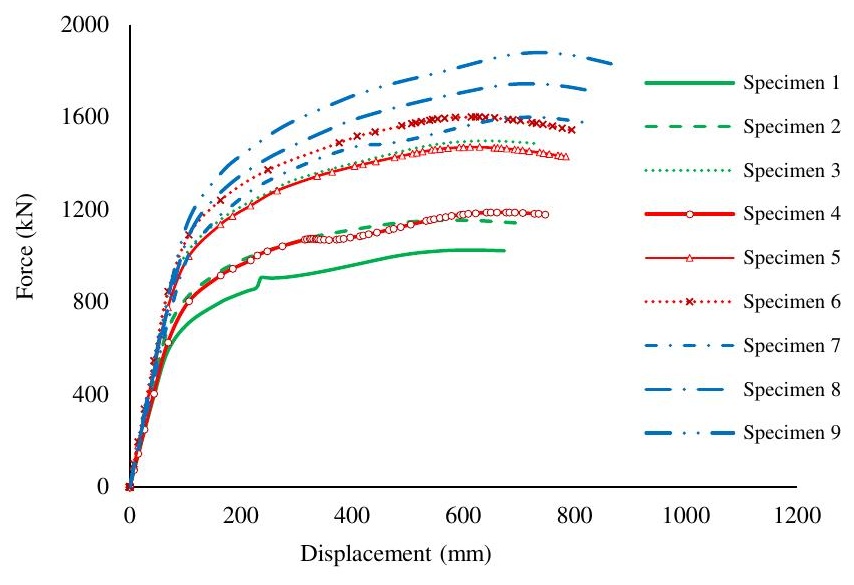

Fig. 12 Connection force-displacement curve of the nine numerical model
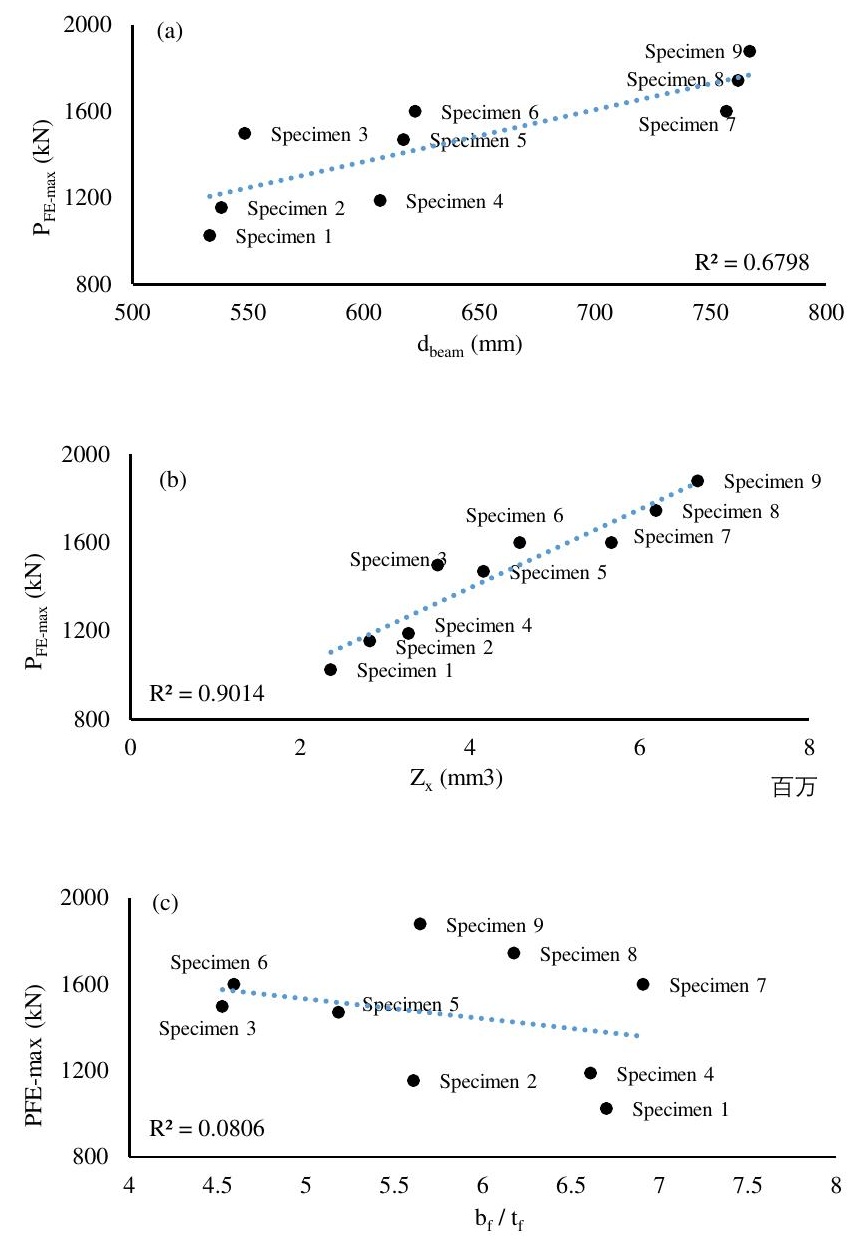

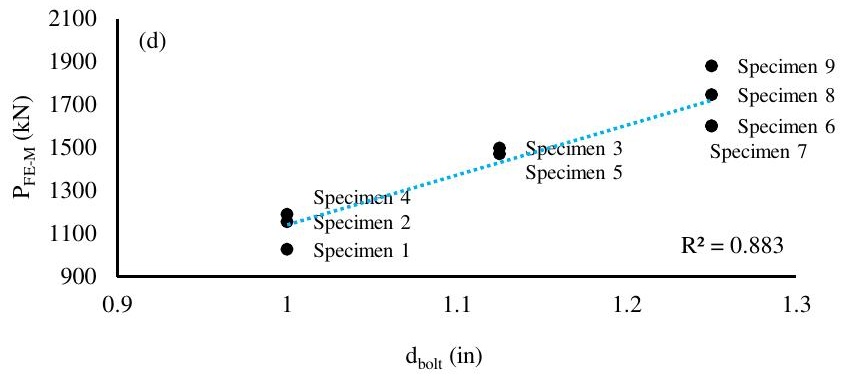

Fig. 13 The effect of parameter a) $d_{\text {beam }}$, b) $\left.Z_{x}, c\right) b_{f} / t_{f}$, and d) $d_{\text {bolt }}$ on the maximum capacity of specimens

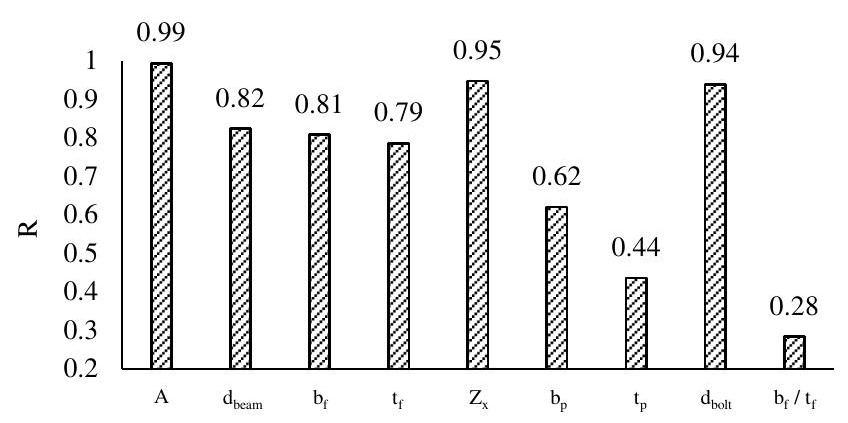

Fig. 14 The values of multiple R regarding the capacity of 8ES endplate connections

Table 4 summarized the connection force and displacement of specimens at the maximum and fracture points. In this table, the second and third columns represent the displacement at the maximum force point and the maximum capacity of different specimens. The two last columns of this table show the displacement and force at the fracture point for specimens.

Table 4

Summary of the force and displacement of all specimens in the maximum and fracture points

\begin{tabular}{ccccc}
\hline Model No. & $\Delta_{\text {FE-max }}(\mathrm{mm})$ & PFE-max $_{(\mathrm{kN})}$ & $\Delta_{\mathrm{FE}}(\mathrm{mm})$ & $\mathrm{P}_{\mathrm{FE}}(\mathrm{kN})$ \\
\hline Specimen 1 & 618.72 & 1025.32 & 673.71 & 1022.03 \\
Specimen 2 & 573.05 & 1154.41 & 697.47 & 1141.81 \\
Specimen 3 & 636.44 & 1497.59 & 734.83 & 1484.65 \\
Specimen 4 & 659.83 & 1188.48 & 747.14 & 1179.48 \\
Specimen 5 & 611.77 & 1470.46 & 784.71 & 1428.38 \\
Specimen 6 & 614.37 & 1600.18 & 794.88 & 1543.79 \\
Specimen 7 & 721.70 & 1599.93 & 826.77 & 1573.49 \\
Specimen 8 & 726.48 & 1744.25 & 843.41 & 1706.50 \\
Specimen 9 & 739.11 & 1879.32 & 867.26 & 1829.81 \\
\hline
\end{tabular}

\subsection{Effect of catenary action on the capacity of specimens}

If the connections have adequate ductility, under large deformations due to the column removal scenario, significant axial forces are created in the beams, which is very useful in increasing the system's resistance. This phenomenon is called catenary action. The formation and expansion of catenary action in beams remove the column due to an unusual event. The system is starting to move down due to heavy loads at the location of the removed column. Initially, the beams resist the vertical loads through their flexural stiffness, and as the displacements increase downwards, the upper and lower axis of beams are yielded, and then the range of tensile stresses in the beam axis will increase at the cross-section. At very high displacements, the compressive stresses are eliminated, and the entire cross-section of the beam is in tension. At this point, the beams act as cables between the columns, creating significant tensile forces that the joints must be able to resist.

According to the important role of catenary action in increasing the maximum structure's capacity in a column removal analysis, the system forces versus rotation capacity of specimen 1 is created in three states (see Fig. 15); the 
overall force (black line), beam axial force (blue dashed line), and force resulting from flexural stiffness (red dotted line). It should be noted that the P-catenary action obtains through the cut inserted in the cross-section of the beam and Eq.5 and the P-bending calculate by Eq.6 and Eq.7. In these equations the $M_{\text {left }}$ and $M_{\text {right }}$ are the moments which are obtained from an inserted cut near the stiffener and the $L_{h}$ is the distance between plastic hinge locations based on the AISC 358-16 [38].

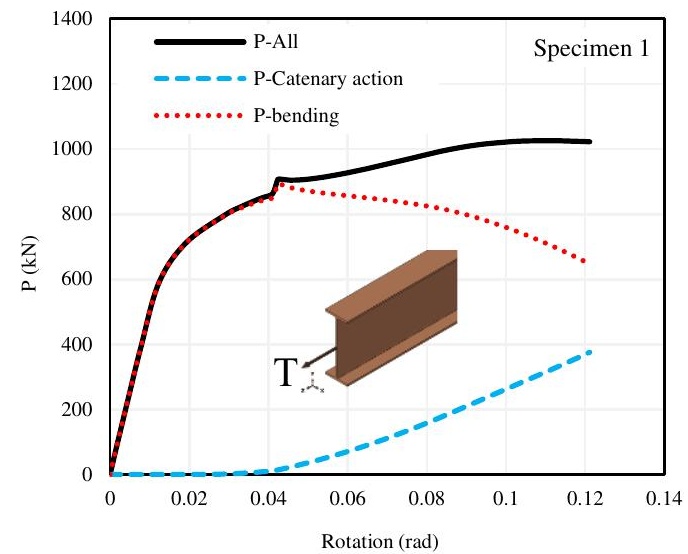

Fig. 15 Force-rotation angle curves of the specimen 1

$\mathrm{P}-$ Catenary action $=2 \times \mathrm{T} \times \sin \left(\theta^{*}\right)$

${ }^{*} \theta \rightarrow$ The rotation of connection (Fig. 16)

$\mathrm{P}-$ bending $=\frac{\left(M_{\text {left }}-M_{\text {right }}\right)}{L_{h}} \times 2 \times \cos (\theta)$

$\mathrm{L}_{h}=\mathrm{L}_{\text {Beam }}-2 \times \mathrm{S}_{h} \quad, \quad S_{h}=t_{p}+L_{\text {stiffner }}$

As shown in Fig. 18, specimens have approximately up to $4 \%$ rotational capacity without the catenary action, while this value is tripled and is about $12 \%$ with its presence. In these diagrams, as the amount of bending force increases, the catenary action load decreases, and they have a vice versa relationship with each other. As a result, the contribution of catenary action should be considered in the acceptance criteria of rotation capacities.

\section{Implementing the theoretical model for prediction of the connection's capacity}

In this section, according to the results obtained from numerical analyzes, a formula is presented to estimate the maximum capacity of systems with eight bolt stiffened end plate connections. Fig. 16 shows the free diagram assumed in the column removal analysis and the force equilibrium in the middle column. According to this figure, in a column removal scenario, two important forces in determining the amount of these connections capacity are the amount of plastic moment on the column face and the catenary action load in the beam.

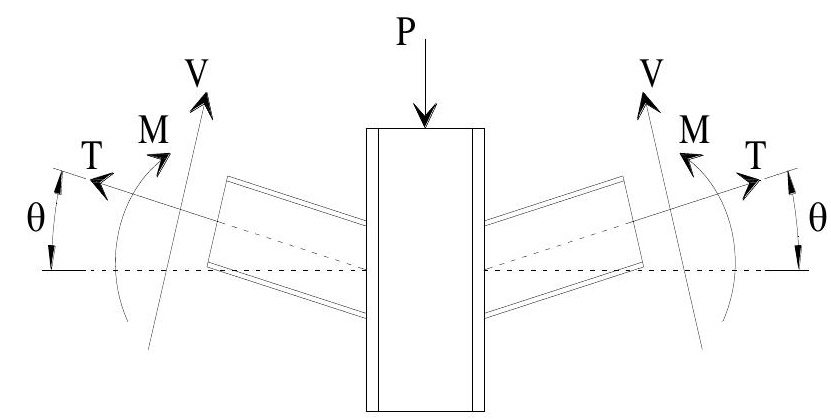

Fig. 16 The free body diagram showing force and moment in column removal analysis

Based on Fig. 16, the system's maximum capacity in a column removal scenario can be written as Eq. 8:
$\mathrm{P}_{\mathrm{T}}=\mathrm{V}^{\prime}+\mathrm{T}^{\prime}$

$\mathrm{V}^{\prime}$ is the axial force based on the force equation in the plastic hinge, and $\mathrm{T}^{\prime}$ is the corresponding force due to catenary action. The equal force with plastic hinge moment can be defined as Eq. 9:

$\mathrm{V}^{\prime}=\left(\frac{4 \times \lambda \times \mathrm{M}_{\mathrm{P}}}{\mathrm{L}_{\mathrm{h}}}\right) \times \operatorname{Cos}(\theta)$

Where $\mathrm{M}_{\mathrm{P}}$ is the plastic moment, $\lambda$ is a coefficient to consider the plastic interaction between bending moment $(\mathrm{M})$ and axial force $(\mathrm{N})$ at a plastic beam region which can be expressed by the Eq. $10, \mathrm{~L}_{\mathrm{h}}$ is the distance between plastic hinge locations, and $\theta$ is the beam rotation (rad) at the maximum capacity point of the specimen and can be written as Eq. 11:

$\left(\frac{\mathrm{M}}{\mathrm{M}_{\mathrm{P}}}\right)^{2}+\left(\frac{\mathrm{N}}{\mathrm{N}_{\mathrm{P}}}\right)^{2}=1$

$\theta=\operatorname{Arctan} \frac{\Delta}{L_{h}}$

$\mathrm{M}$ and $\mathrm{N}$ are the moments and axial force, $\mathrm{Mp}$ is the plastic bending capacity, and $\mathrm{Np}$ is the critical section's axial capacity and $\Delta$ is the vertical displacement at the maximum capacity point of the specimen. The corresponding force with catenary action can be computed by Eq. 12:

$\mathrm{T}^{\prime}=2 \times \mathrm{T} \times \sin (\theta)$

$\mathrm{T}$ is the tensile resistance of connection and obtains from Eq. 13. In this equation, $\beta$ is the ratio of the stress in the cross-section to the yield stress and is considered as 0.33 based on the numerical analysis. Also, A is the beam cross-section, and $\mathrm{F}_{\mathrm{y}}$ is the yield stress.

$\mathrm{T}=\beta \times \mathrm{F}_{\mathrm{y}} \times \mathrm{A}$

Up to this point, only one parameter, the vertical displacement at the maximum capacity point $\left(\Delta_{\text {predict-max }}\right)$, is unknown. The Least Square Method was used for predicting this parameter. When the number of equations is more than the number of unknowns in sets of equations, the LSM is a standard procedure in regression analysis to estimate this overdetermined systems' solution. This method is popular among researchers [42], and generally, the predictive model developed based on the LSM is simple; however, its accuracy should be investigated to be used as a reliable model. Hence, in this study, according to values in Table 5, the LSM was utilized to propose an alternative nonlinear model (see Eq. 14) to predict the vertical displacement at the maximum capacity point $\left(\Delta_{\text {predict-max }}\right)$.

Table 5

The predicted values of $\Delta$ FE-max and the performance of the proposed LSM-based model

\begin{tabular}{cccccc}
\hline Model No. & $\begin{array}{c}\mathrm{d}_{\text {beam }} \\
(\mathrm{mm})\end{array}$ & $\begin{array}{c}\mathrm{Z}_{\mathrm{x}} \\
\left(\mathrm{mm}^{3}\right)\end{array}$ & $\begin{array}{c}\Delta_{\text {FE-max }} \\
(\mathrm{mm})\end{array}$ & $\begin{array}{c}\Delta_{\text {predict-max }} \\
(\mathrm{mm})\end{array}$ & $\begin{array}{c}\text { Absolute } \\
\text { Error }(\%)\end{array}$ \\
\hline Specimen 1 & 533.40 & 2359737.22 & 618.72 & 613.23 & 0.9 \\
Specimen 2 & 538.48 & 2818575.01 & 573.05 & 592.16 & 3.23 \\
Specimen 3 & 548.64 & 3621541.14 & 636.44 & 625.87 & 1.69 \\
Specimen 4 & 607.06 & 3277412.80 & 659.83 & 640 & 3.1 \\
Specimen 5 & 617.22 & 4162314.26 & 611.77 & 611.17 & 0.1 \\
Specimen 6 & 622.30 & 4588377.92 & 614.37 & 626.55 & 1.94 \\
Specimen 7 & 756.92 & 5669924.14 & 721.70 & 747.68 & 3.47 \\
Specimen 8 & 762.00 & 6194310.19 & 726.48 & 728.53 & 0.28 \\
Specimen 9 & 767.08 & 6685922.11 & 739.11 & 714.79 & 3.4 \\
\hline
\end{tabular}

* The average absolute percentage error (AAE): $2.01 \%$

* The maximum absolute percentage error (MAE): $3.47 \%$ 
$\Delta_{\text {predict-max }}=1.745 \times \mathrm{A}^{6.253} \times \mathrm{d}^{7.124} \times \mathrm{b}_{\mathrm{f}}^{-1.226} \times \mathrm{Z}_{\mathrm{x}}^{-6.199}$

The proposed LSM-based model's performance was evaluated using performance measures $\mathrm{AAE}$ and $\mathrm{MAE}$, which are the average absolute percentage error (AAE) and the maximum absolute percentage error (MAE). The AAE was calculated using Eq. 15. In this equation, $\mathrm{T}_{\mathrm{i}}$ and $\mathrm{N}$ are the predicted output, the actual output obtained from the numerical analysis, and the number of samples. For the proposed predictive model, AAE and MAE values are $2.01 \%$ and $3.47 \%$, indicating the proposed model's accuracy.
$\mathrm{AAE}=\frac{1}{\mathrm{~N}} \sum_{\mathrm{i}=1}^{\mathrm{N}}\left[\frac{\left|\mathrm{Y}_{\mathrm{i}}-\mathrm{T}_{\mathrm{i}}\right|}{\mathrm{T}_{\mathrm{i}}} \times 100\right]$

Based on the formula presented for displacement at a maximum capacity of eight bolt stiffened extended endplate moment connections, the theoretical values $\left(\mathrm{P}_{\mathrm{T}}\right)$ of $\mathrm{P}_{\mathrm{FE}-\mathrm{max}}$ are obtained and presented in Table 6 . The values of $\mathrm{AAE}$ and MAE are $5.34 \%$ and $8.15 \%$, indicating the proposed model's high accuracy level.

Table 6

The predicted values of PFE-max

\begin{tabular}{|c|c|c|c|c|c|c|c|c|c|}
\hline Model No. & $\mathrm{L}_{\mathrm{h}}(\mathrm{mm})$ & $\mathrm{A}\left(\mathrm{mm}^{2}\right)$ & $\mathrm{P}_{\mathrm{FE}-\max }(\mathrm{kN})$ & $\mathrm{Mp}$ (N.mm) & $\theta(\mathrm{rad})$ & $\mathrm{T}(\mathrm{N})$ & $\mathrm{T}^{\prime}(\mathrm{N})$ & $\mathrm{P}_{\mathrm{T}}(\mathrm{kN})$ & Error $(\%)$ \\
\hline Specimen 1 & 5561.05 & 11806.43 & 1025.32 & 978288056.32 & 0.11 & 1404551.71 & 309138.85 & 969.36 & $5.46 \%$ \\
\hline Specimen 2 & 5615.66 & 13870.94 & 1154.41 & 1168510733.94 & 0.11 & 1650156.38 & 347368.86 & 1128.70 & $2.23 \%$ \\
\hline Specimen 3 & 5743.93 & 17612.87 & 1497.59 & 1501400419.77 & 0.11 & 2095314.84 & 455713.60 & 1436.85 & $4.06 \%$ \\
\hline Specimen 4 & 6451.32 & 14451.58 & 1188.48 & 1358733411.56 & 0.10 & 1719232.69 & 340553.87 & 1131.90 & $4.76 \%$ \\
\hline Specimen 5 & 6566.89 & 17870.93 & 1470.46 & 1725591432.68 & 0.09 & 2126015.43 & 395160.93 & 1383.07 & $5.94 \%$ \\
\hline Specimen 6 & 6627.85 & 19548.35 & 1600.18 & 1902226776.18 & 0.09 & 2325569.22 & 439032.44 & 1517.90 & $5.14 \%$ \\
\hline Specimen 7 & 8243.29 & 20451.57 & 1599.93 & 2350608802.00 & 0.09 & 2433021.26 & 440751.46 & 1513.05 & $5.43 \%$ \\
\hline Specimen 8 & 8297.90 & 22064.47 & 1744.25 & 2568006147.85 & 0.09 & 2624899.91 & 460325.30 & 1624.38 & $6.87 \%$ \\
\hline Specimen 9 & 8358.86 & 23548.34 & 1879.32 & 2771816159.58 & 0.09 & 2801428.27 & 478532.88 & 1726.06 & $8.15 \%$ \\
\hline
\end{tabular}

* The average absolute percentage error (AAE): $5.34 \%$

* The maximum absolute percentage error (MAE): $8.15 \%$
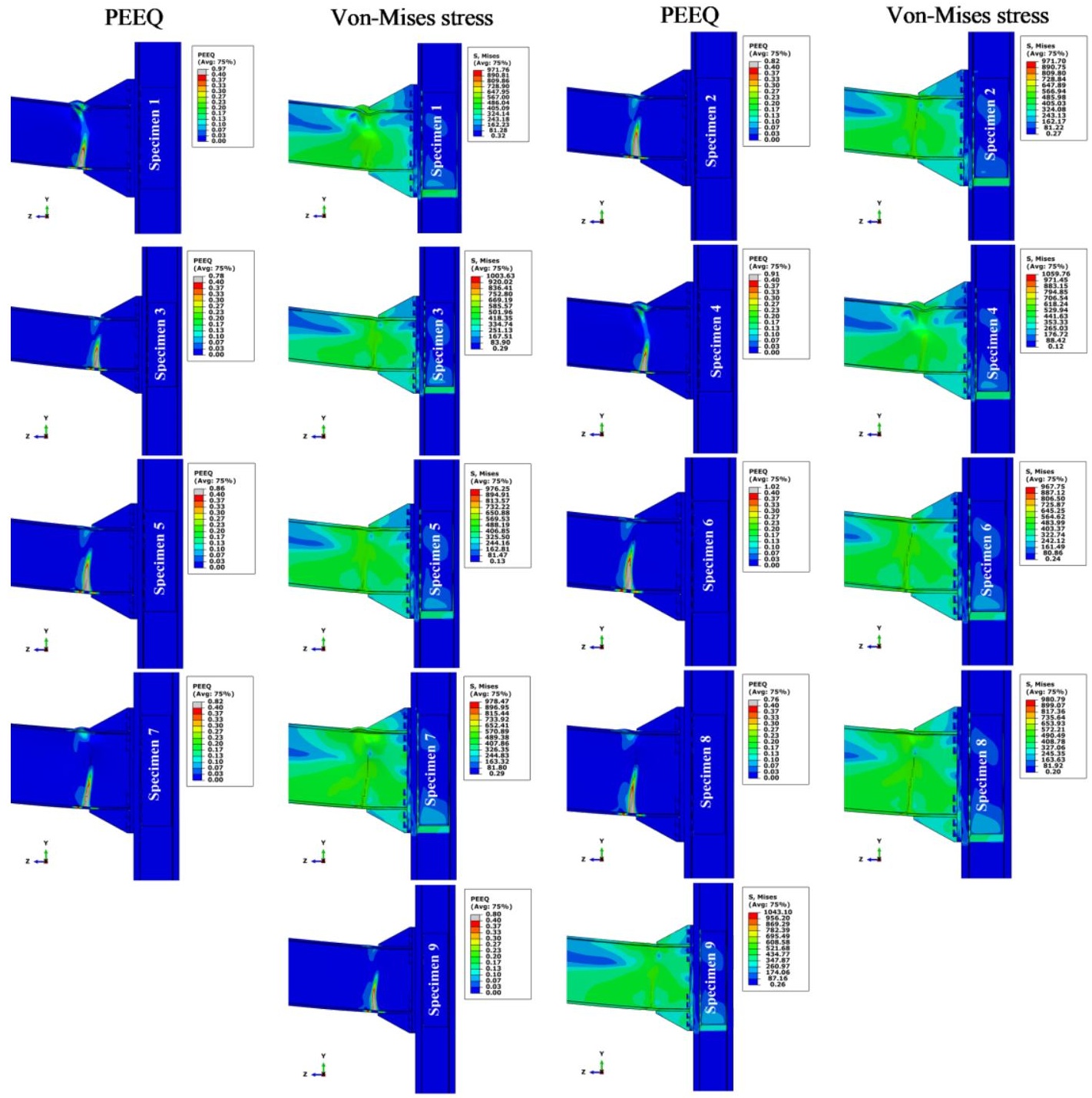

Fig. 17 The deformation, PEEQ, and Von-Mises stress contour for nine specimens 


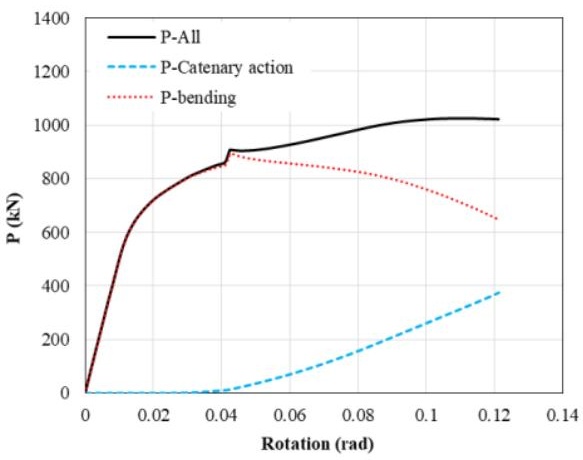

Specimen 1

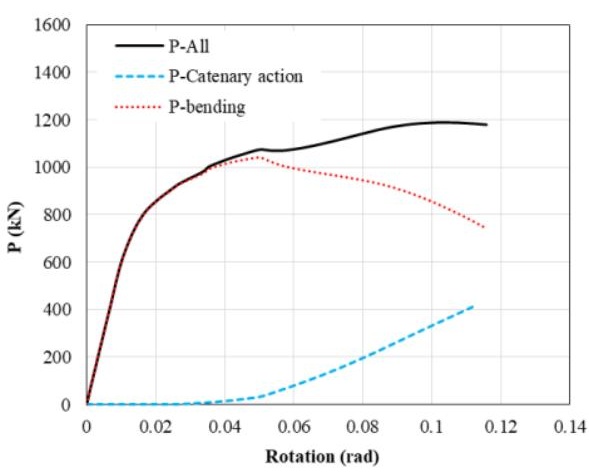

Specimen 4

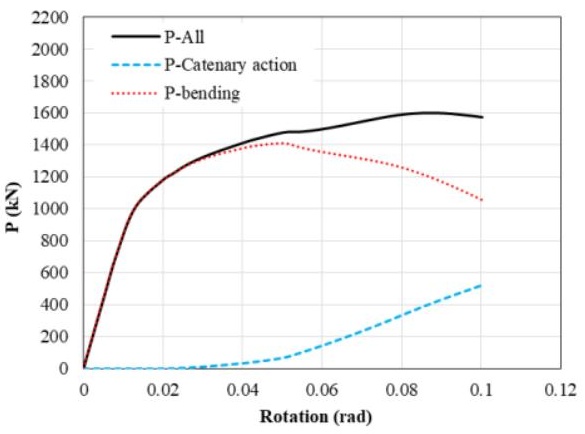

Specimen 7

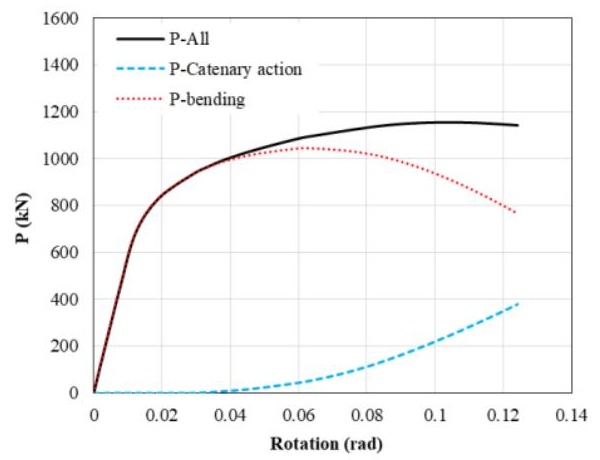

Specimen 2

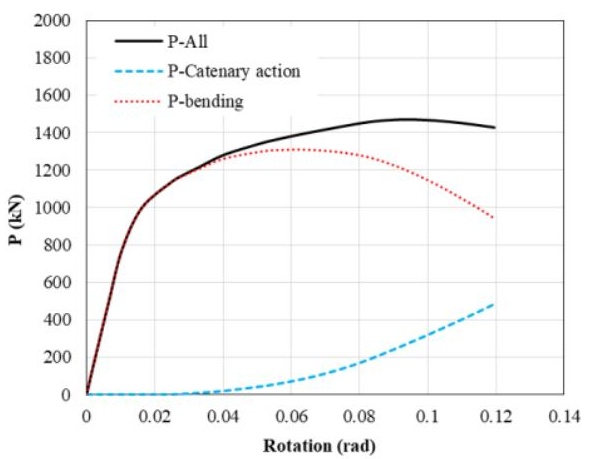

Specimen 5

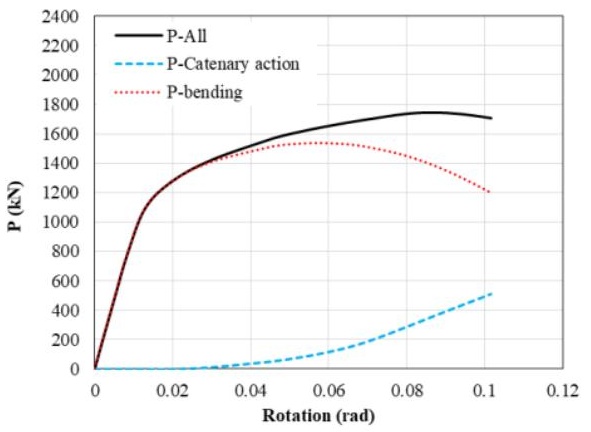

Specimen 8

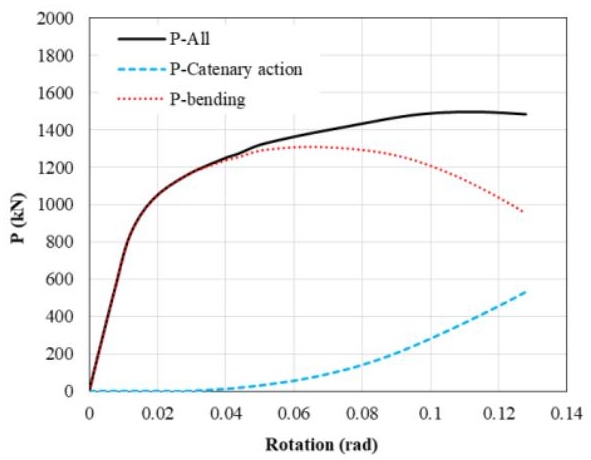

Specimen 3

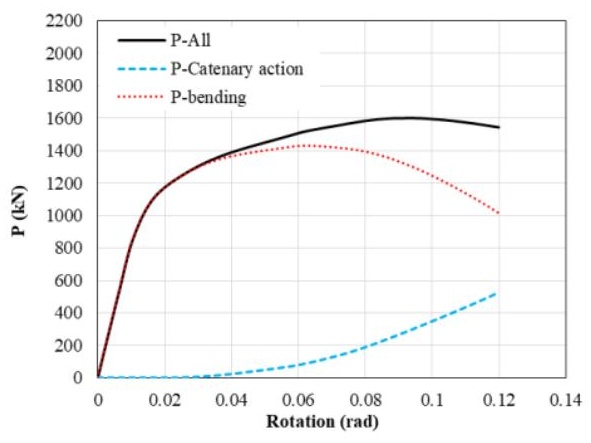

Specimen 6

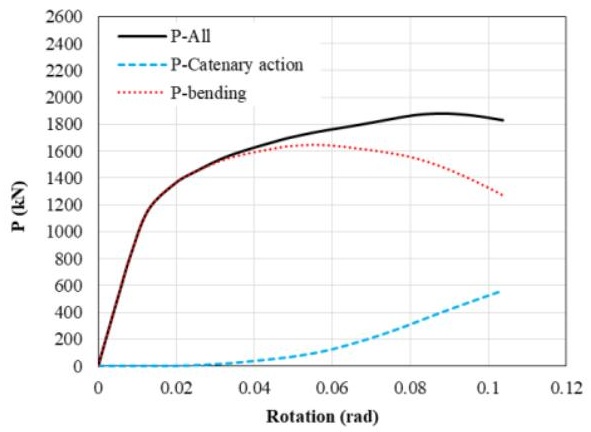

Specimen 9

Fig. 18 Summary of Force-rotation angle of nine numerical specimen

\section{Conclusion}

In this study, the behavior of eight bolt extended endplate moment connections and their maximum capacity subjected to the column removal scenario has been investigated. In this regard, a verification of composite of three columns and two beams under column removal scenario using finite element modeling against valuable experimental results presented by Dinu et al. [24] has done, and fracture modes of the analytical model have been discussed. Based on the verification model, nine $8 \mathrm{ES}$ endplate moment connections were designed by the [27, 37, 38]. The significant results of this research based on the FE results can be drawn:

1. Based on these nine specimens' failure mode, the beam properties significantly affect these connections' maximum capacity.

2. The effect of four parameters of $d_{\text {beam }}, Z_{x}, b_{f} / t_{f}$, and $d_{\text {bolt }}$ has been investigated on specimens' maximum capacity. It can be observed that based on the regression method results, parameters like the cross-section of the beam (A), beam depth $\left(\mathrm{d}_{\text {beam }}\right)$, flange width $\left(\mathrm{b}_{\mathrm{f}}\right)$, plastic section modulus $\left(\mathrm{Z}_{\mathrm{x}}\right)$, and bolt diameter $\left(\mathrm{d}_{\text {bolt }}\right)$ have a correlation coefficient of more than $80 \%$ unlike the parameter $b_{f} / t_{f}(R=28 \%)$ with a maximum capacity of specimens.

3. Regarding the Least Square Method, a formula derived to determine the displacement at the maximum force capacity of connections. The performance measures of $\mathrm{AAE}$ and MAE for this formula were $2.01 \%$ and $3.47 \%$, respectively.
4. According to the proposed theoretical model in section 5, a procedure has been conducted to determine the maximum capacity of $8 \mathrm{ES}$ connections. The performance measures of AAE and MAE for the proposed method were $5.34 \%$ and $8.15 \%$.

\section{References}

[1] Administration, T. U. S. G. S., "Progressive collapse analysis and design guidelines for new federal office buildings and major modernization projects", Journal, GSA, Issue, 2003.

[2] (UFC), U. f. c., "Design of building to resist progressive collapse", 2016.

[3] Daneshvar, H., "One-sided steel shear connections in column removal scenario", 2013.

[4] Brett, C. and Lu, Y., "Assessment of robustness of structures: Current state of research", Frontiers of Structural and Civil Engineering, 7, 4, 356-368, 2013.

[5] Astaneh-Asl, A., et al., "Progressive collapse resistance of steel building floors", Report Number UCB/CEE-Steel-2001, 3, 2001.

[6] Khandelwal, K. and El-Tawil, S., "Collapse behavior of steel special moment resisting frame connections", Journal of Structural Engineering, 133, 5, 646-655, 2007.

[7] Sadek, F., et al., "An experimental and computational study of steel moment connections under a column removal scenario", NIST Technical Note, 1669, 2010.

[8] Demonceau, J.-F., "Steel and composite building frames: sway response under conventional loading and developmet of membrane effects in beams further to an exceptional action", Université de Liège, 2008.

[9] Karns, J. E., et al., "Behavior of varied steel frame connection types subjected to air blast, debris impact, and/or post-blast progressive collapse load conditions“, Structures Congress 2009: Don't Mess with Structural Engineers: Expanding Our Role. 2009.

[10] Yang, B. and Tan, K., "Behaviour of steel beam-column joints subjected to catenary action under a column-removal scenario", Journal of Structural Engineering, ASCE. Submitted for 
publication, 2010

[11] Yang, B. and Tan, K. H., "Numerical analyses of steel beam-column joints subjected to catenary action", Journal of Constructional Steel Research, 70, 1-11, 2012.

[12] Yang, B. and Tan, K. H., "Robustness of bolted-angle connections against progressive collapse: Experimental tests of beam-column joints and development of component-based models", Journal of Structural Engineering, 139, 9, 1498-1514, 2013.

[13] Yang, B. and Tan, K. H., "Experimental tests of different types of bolted steel beam-column joints under a central-column-removal scenario", Engineering Structures, 54, 112-130, 2013.

[14] Meng, B., Zhong, W., and Hao, J., "Anti-collapse performances of steel beam-to-column assemblies with different span ratios", Journal of Constructional Steel Research, 140, 125-138, 2018

[15] Barmaki, S., Sheidaii, M. R., and Azizpour, O., "Progressive Collapse Resistance of Bolted Extended End-Plate Moment Connections", International Journal of Steel Structures, 1-15, 2020.

[16] Lew, H. S., et al., "Performance of steel moment connections under a column removal scenario. I: Experiments", Journal of Structural Engineering, 139, 1, 98-107, 2013.

[17] Li, L., et al., "Experimental investigation of beam-to-tubular column moment connections under column removal scenario", Journal of Constructional Steel Research, 88, 244-255, 2013.

[18] Li, L., et al., "Effect of beam web bolt arrangement on catenary behaviour of moment connections", Journal of Constructional Steel Research, 104, 22-36, 2015.

[19] Qin, X., et al., "Experimental study of through diaphragm connection types under a column removal scenario", Journal of Constructional Steel Research, 112, 293-304, 2015.

[20] Qin, X., et al., "A special reinforcing technique to improve resistance of beam-to-tubular column connections for progressive collapse prevention", Engineering Structures, 117, 26-39, 2016

[21] Yan, S., et al., "Experimental evaluation of the full-range behaviour of steel beam-to-column connections", Advanced Steel Construction, 16, 1, 77-84, 2020

[22] Faridmehr, I., et al., "An overview of the connection classification index", Advanced Steel Construction, 15, 2, 145-156, 2019.

[23] Arul Jayachandran, S., et al., "Investigations on the behaviour of semi-rigid endplate connections", Advanced Steel Construction, 5, 4, 432-451, 2009.

[24] Dinu, F., Marginean, I., and Dubina, D., "Experimental testing and numerical modelling of steel moment-frame connections under column loss", Engineering Structures, 151, 861-878, 2017.

25] "Abaqus 6.14 Analysis User's Manual”, Journal, Dassault Systems, Issue, 2014

[26] Krolo, P., Grandić, D., and Bulić, M., "The guidelines for modelling the preloading bolts in the structural connection using finite element methods", Journal of Computational Engineering, 2016, 2016
[27] ANSI, B., "AISC 360-16, Specification for Structural Steel Buildings", Chicago AISC, 2016

[28] Seif, M., et al., "Finite element modeling of structural steel component failure at elevated temperatures", Structures. 2016. Elsevier.

[29] Dolbow, J. E., "An extended finite element method with discontinuous enrichment for applied mechanics", 2000

[30] Abou-zidan, A. and Liu, Y., "Numerical study of unstiffened extended shear tab connections", Journal of Constructional Steel Research, 107, 70-80, 2015.

[31] Suleiman, M. F., "Non-Linear Finite Element Analysis of Extended Shear Tab Connections", Cincinnati, Ohio, USA, 2013.

[32] Morrison, M., Quayyum, S., and Hassan, T., "Performance enhancement of eight bolt extended endplate moment connections under simulated seismic loading", Engineering Structures, 151, 444-458, 2017.

[33] Naimi, S., Celikag, M., and Hedayat, A. A., "Ductility enhancement of post-Northridge connections by multilongitudinal voids in the beam web", The Scientific World Journal, 2013, 2013.

[34] Raftari, M., Mahjoub, R., and Hekmati, A., "Evaluation of Damage Indicators of Weld an Cyclic Response of Steel Moment Frame Connection Using Side Stiffener Plates", AUT Journal of Civil Engineering, 1, 1, 67-76, 2017.

[35] Rahnavard, R., Hassanipour, A., and Siahpolo, N., "Analytical study on new types of reduced beam section moment connections affecting cyclic behavior", Case Studies in Structural Engineering, 3, 33-51, 2015

[36] Ricles, J. M., et al., "Development of improved welded moment connections for earthquake-resistant design", Journal of Constructional Steel Research, 58, 5-8, 565-604, 2002.

[37] Seismic, A., "Seismic Provisions for Structural Steel Buildings,(ANSI/AISC 341-16)", Journal, American Institute of Steel Construction, Chicago, IL, Issue, 2016.

[38] AISC, A., "AISC 358-16", Prequalified connections for special and intermediate stee moment frames for seismic applications. Chicago (IL): American Institute of Stee Construction, 2016.

[39] Ahmadi, R., et al., "Experimental and numerical evaluation of progressive collapse behavior in scaled RC beam-column subassemblage", Shock and Vibration, 2016, 2016.

[40] Sadek, F., et al., "Performance of steel moment connections under a column removal scenario. II: Analysis", Journal of Structural Engineering, 139, 1, 108-119, 2013.

[41] Zhong, W., Meng, B., and Hao, J., "Performance of different stiffness connections against progressive collapse", Journal of Constructional Steel Research, 135, 162-175, 2017.

[42] Marquardt, D. W., "An algorithm for least-squares estimation of nonlinear parameters", Journal of the society for Industrial and Applied Mathematics, 11, 2, 431-441, 1963. 


\title{
A STUDY OF COLLAPSE SUSCEPTIBILITY AND RESISTANCE OF LOADED CABLE-SUPPORTED PIPE STRUCTURE SUBJECT TO A SUDDEN BREAK OF CABLE MEMBER
}

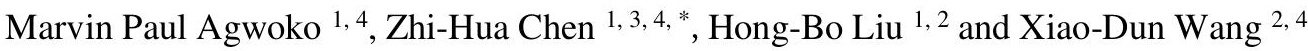 \\ ${ }^{1}$ State Key Laboratory of Hydraulic Engineering Simulation and Safety, Tianjin University, Tianjin 300072, China \\ ${ }^{2}$ Department of Civil Engineering, Hebei University of Engineering, Handan 056000, China \\ ${ }^{3}$ Key Laboratory of Coast Civil Structure Safety of China Ministry of Education, Tianjin University, Tianjin 300072, China \\ ${ }^{4}$ Department of Civil Engineering, Tianjin University, Tianjin 300072, China \\ * (Corresponding author: E-mail: zhchen@tju.edu.cn)
}

\section{A B S T RA C T}

Cable-supported pipe system (CSPS) provides a suitable system of structure for meeting the stringent structural requirements of pipeline bridges. However, due to a composite action of cable with truss and pipe members, the sudden failure of its structural member may lead to undesired vibratory response and collapse. The occurrence of a sudden break of the CSPS structural member is characterized by spontaneous dynamics and internal force rearrangement. The present study aims to investigate parametrically the collapse susceptibility and resistance of scaled down CSPS model in the event of a sudden break of the cable member by combined experimental and numerical procedures. The displacement of the structure, the pattern of internal force rearrangement, and dynamic responses were comparatively evaluated. Experimental results depict imminent cable failure under load and attendant dynamic response, but without a total collapse of the CSPS structure. Critical members causing large dynamic response amplitudes were identified and the mitigation of collapse was evaluated. Dynamic increasing factor (DIF) methods was utilized for the evaluation of the dynamic response of the sudden cable break resulting from the pattern of responses between the cable members and the rest of the CSPS structure. Comparison with provisions in other studies shows higher values DIF of the CSPS cable members which led to proposed evaluation using dynamic factor (DF). Thus, the dynamic factors for the sudden break of various cable members along the span and the errors were also estimated considering the parametric of design variables which will enable easy utilization during the structural process of CSPS

\section{A R T I C L E H I S T O R Y}

$\begin{array}{ll}\text { Received: } & \text { 23 June } 2020 \\ \text { Revised: } & \text { 3 March 2021 } \\ \text { Accepted: } & \text { 13 March 2021 }\end{array}$

\section{KEYWOR D S}

Cable-supported pipe system; Sudden break of cable; CSPS vibratory response; Collapse resistance;

Dynamic increasing factor; Dynamic factor

\section{Introduction}

Pipe structures are widely used as fluid conveyance systems which occasionally require bridging over a large space. Application can be found in the field requirement of agriculture, such as irrigation, application of fertiliser and pesticide [1], and other requirements in terminal buildings, onshore and offshore structures [2]. To meet responsive large span for elevated pipe structures, cable-supported pipe system (CSPS) is suggested as an alternative to the pipe bridge structure [3]. The CSPS structural composition is as shown in
Fig. 1(a) and the perspective view the typical model in Fig. 1(b). The CSPS is referred to as an innovative system of cable-truss structure possessing the combined arrangement of lattice trusses and cable to hold conveyance pipelines above the field. Thus, it offers the advantages of the spatial capability, economical and easy constructability when pipes are to be connected in a large space. These advantage confer great value of its application in irrigation structures such as the Centre pivot system [4]. However, a CSPS structural member may be at risk of collapse due to the sudden break of one or more cable members.

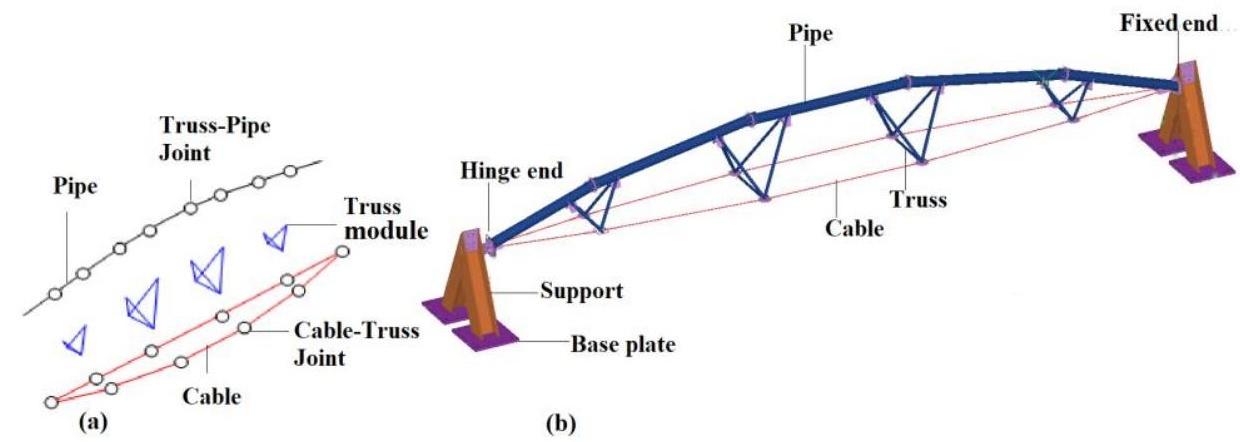

Fig. 1 Description of typical experimental model of Cable-supported pipe structure: (a) Schematic of the composition of the CSPS and (b) A typical CSPS experimental model

The sudden break of CSPS structural member may be encountered due to unforeseen design requirements, accident or natural disaster which consequently triggers vibratory responses and load redistribution on the structure. Consequently, the failure of more members and the imminent collapse of the CSPS structure may be encountered. It is thus crucial to consider the safety and robust behaviour of the structure during its service life in the event of sudden loss of member.

In the past, research mainly focused on cable-stayed bridges [5-7], cable roofs [8], and transmission line towers [9], among others. The study presented by Mozos deliberated on the internal force response of a cable-stayed bridge with a cable's sudden break and the influence of a single cable failure on the dynamic response of the entire bridge, $[5,6,10]$. Provision for the dynamic increasing factor for stay bridges is as provided by the post tension institute (PTI) [11]. The study was limited to shared influence between the rest bridge cables during the rupturing process. In Zhou, a time-progressive nonlinear dynamic analysis approach and a framework of nonlinear dynamic simulation to investigate the influence of an abrupt cable-breakage in a cable-stayed bridge and evaluate the safety of a cable-stayed bridge under cable loss scenarios was proposed [12-14]. With the increase in the application of cables as support for structures in recent years, more studies are conducted on suspendomes and cable-dome in China. Wang and Chen studied loaded suspendome subjected to sudden cable failure through numerical and experimental procedures and were able to propose indices that could be utilized for the structural design process $[8,15]$. 
Some design guides are obtainable in Europe and the United States codes for the mitigation of the progressive collapse of buildings. Such design guides include the design code of British Building Regulations (Office of the Deputy Prime Minister 2004), BS5950 [16], the procedures stipulated by Department of Defense (DoD) and the General Services Administration (GSA 2003) [17, 18]. Other institutions such as the Federal Emergency Management Agency (FEMA) [19] and the National Institute of Standards and Technology (NIST) [20] also provided general design guides, which necessitate provision of adequate redundancy and resilience of steel-framed structural systems [21, 22]. However, most of the design guides paid more attention to buildings leaving gap to be filled for the prevention of progressive collapse of CSPS structure.

This study focuses on the investigation of collapse susceptibility and mitigation strategy of CSPS structure. Thus, an experimental procedure is employed to determine the failure mode of the CSPS models with different boundary conditions. Owing to capital demands offered by the experimental processes, more parameteric studies are conducted by numercal processes after the validation. The experimental evaluation of a collapse resistance of a scaled down $8 \mathrm{~m}$ long loaded CSPS models were firstly achieved using loading platform setup in the laboratory. Then, explicit dynamic evaluation of the finite element (FE models) using finite-element analysis program ANSYS/LS-DYNA and validation with experimental data. Finally, the results of vibratory responses considering various parameters are evaluated and compared with the recommendation by PTI and possible adoption in the design process of the CSPS structures.

\section{Development of Models and procedures}

\subsection{Model geometric and design parameters}

In order to present typical structure, reference is made to other cable-supported structures having similar geometric configuration, including beam-string structure and cable-struts structures (CSS) [23]. Previous work is also available in the study of dynamic characteristics of the CSPS [3].

The mid-span depth is considered indispensable design parameter of systems. In Chinese code for design of steel structures (GB50017-2017), the limit of deformation is specified based on deflection-span ratio of beam-string 1/400 [24]. Consequently, some geometric parameters are presented in Fig. 2. The parameters can be identified as hogging depth of pipe system $(d)$ and sagging depth of cable supports $(f)$, depth at mid-span $(h)$ and the lateral width of cable support from pipe plane (w) as shown in Fig. 1(a) and (b) respectively. The width is related to the depth parameter and tied to $0.75 h \leq w \leq h$, upon which the lateral displacement is controlled.

Fig. 2(c) demonstrates the influence of loading due to both cable pretension and a vertical load of the CSPS structure. The mid-span deflection, lateral and longitudinal displacement on application of load are represented by $\delta z, \delta y$ and $\delta x$. In addition to the deflection, the study considers the effect of the structural member parameters on the CSPS model. Fig. 3 shows the node nomenclature, the cross-section of the CSPS model and the cross-section parameters of the structural members.

In Fig. 3, a CSPS model consisting of 4 truss modules is presented. The structural members consist of nine pipe segments labeled P1 to P9, twenty truss members labeled $\mathrm{T} 1$ to $\mathrm{T} 20$ and the cable members labeled $\mathrm{C} 11$ to $\mathrm{C} 15$ and $\mathrm{C} 21$ to $\mathrm{C} 25$ in respective runs. The parameter $t$ - $x p$ defines the pipe thickness, $r-x c$ the cable radius and $t-x t$ the truss member thickness. Six CSPS experimental models presented in Fig. 4 are considered for the evaluation. Consequently, each experimental model has the following similar design parameters: $L=8 \mathrm{~m}, r-x c=5.35 \mathrm{~mm}, t-x t=3 \mathrm{~mm}$ and $t-x p=3 \mathrm{~mm}$ were selected. The effect of the variables $r-x c, t-x t, t-x p$ were thus evaluated parametrically using finite element analysis (FEA). Details of the experimental model is presented in Table 1. Double tube pipe member is included as additional pipe parameter in the event of hydraulic modification. Thus, the study includes the evaluation of 3 single tube (ST) and 3 double tube (DT) CSPS models. (a)

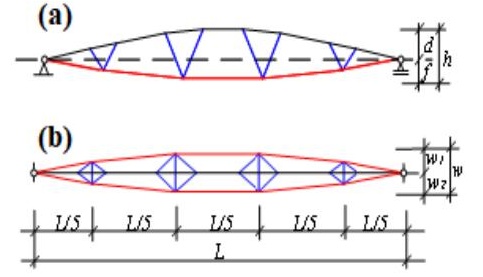
$0 \leq \frac{d}{L} \leq 0.05, \quad 0 \leq \frac{f}{L} \leq 0.05$
$h=d+f$

$w_{1}=w_{2}$
$w=w_{1}+w_{2}$
$0 \leq w \leq h$

(c)
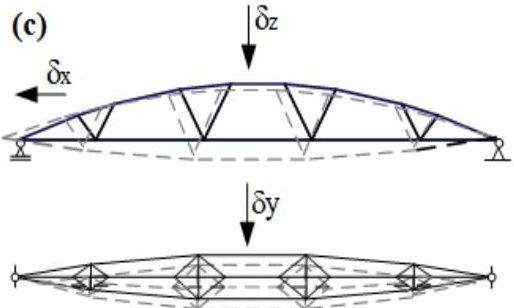

Fig. 2 CSPS geometric parameters: (a) Sketch of vertical profile, (b) Layout and (c) Deformation under load and (d) Lateral deformation

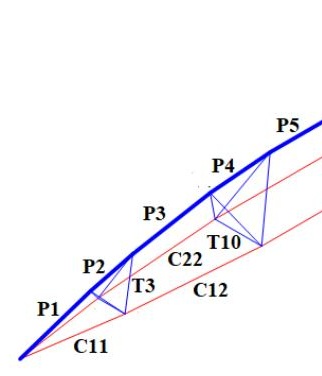

CISS model

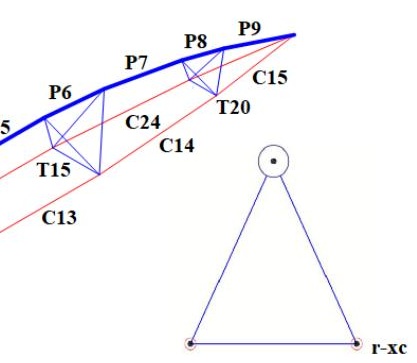

Cross-section

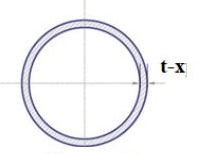

Pipe section
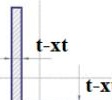

Truss section
Fig. 3 CSPS model with four truss modules and single tube pipe member

The section properties of the members consist: $114 \mathrm{~mm}$ outer diameter of pipe and $3 \mathrm{~mm}$ thickness, $36 \mathrm{~mm} \times 36 \mathrm{~mm} \times 3 \mathrm{~mm}$ angle cross-section of truss, and $10.8 \mathrm{~mm}$ cross-section diameter of cable. All materials are made of Chinese steel grade Q345 with tensile test results as follows: Modulus of elasticity, $E=199 \mathrm{MPa}$, Density, $\rho=7850 \mathrm{~kg} / \mathrm{m}^{3}$ and poison's ratio, $v=0.3$.

\subsection{Experimental setup}

The experimental setup includes the loading frame and the static load and reaction beams, as well as loading pad and the CSPS model as shown in Fig. 5. Detailed description of the method of applying the static load and measurements are presented in separate study with reference to works of Chen [15] and Wang [25] on suspendome structure. However, brief overview is provided hereunder.
The CSPS model is supported at one end with a fixed reaction support and at the other end with a roller reaction support both anchored onto a firm test platform at two ends. As depicted in Fig. 5, the experimental platform is made of adjustable loading frame and reaction beam placed above the loading positions of the CSPS models.

The first step of the experiment includes loading of the structure to simulate a static response. Point loads were applied at loading positions depicted in Fig. 5 with the aid of a pipe clamp loading pad (PCLP) through plunger rods that were connected to the top reaction beam. Details of the PCLP are provided in separate work on the research on the CSPS. In the next step of experiment, the CSPS is loaded until sudden break of a member is achieved. In some studies, the member breakage are undertaking using a break device at predefined structural member, and has been used successfully in the progressive collapse assessments of truss and steel dome model structures [8, 26]. In this study, the breaking of cable member was allowed to take place under load considering the resistance of the cable member joint (turnbuckle joint). This allow the advantage of a random selection of the breaking of cable member and allows the determination of the member removal time.

As earlier introduced, a sudden break of a cable member from a structure activates a time dependent vibratory response with consequent displacement and internal force redistribution. Observation of the vibratory time history was achieved with the aid of video records. The video was evaluated to extract time of response. The displacement and force are measured using displacement and strain data acquisition system.

\subsection{Numerical}

The 3-dimensional nonlinear model of the CSPS models presented in Fig. 
4 are developed in ANSYS Workbench. At first, an implicit model of the structure was developed in which BEAM188 element was applied to the pipe members and LINK180 element to the truss and cable members. Cable pretension was applied to reflect the measured tension on the cable members during the setup of the experimental model. Since tension rod were used as cable members, the influence of cable pretension was minimal, however, maximum pretension value was $0.9 \mathrm{KN}$. Thus, zero strain was considered in the cable member. The joints were considered as pin as adopted from the experimental models connection. To simplify the model, the support frames are replaced with fixed end and roller support. The tested modulus of elasticity of steel during the experiment was applied to the numerical model.

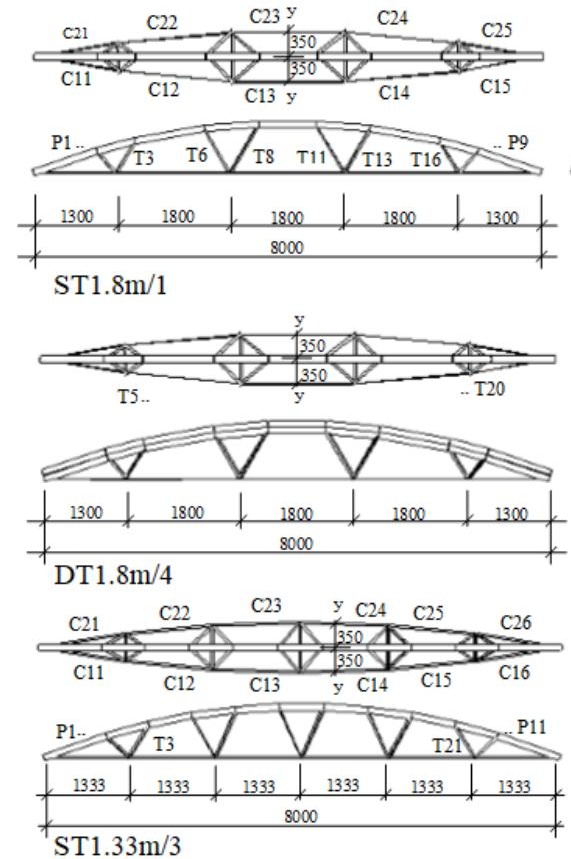

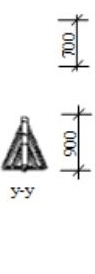

茟
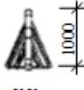
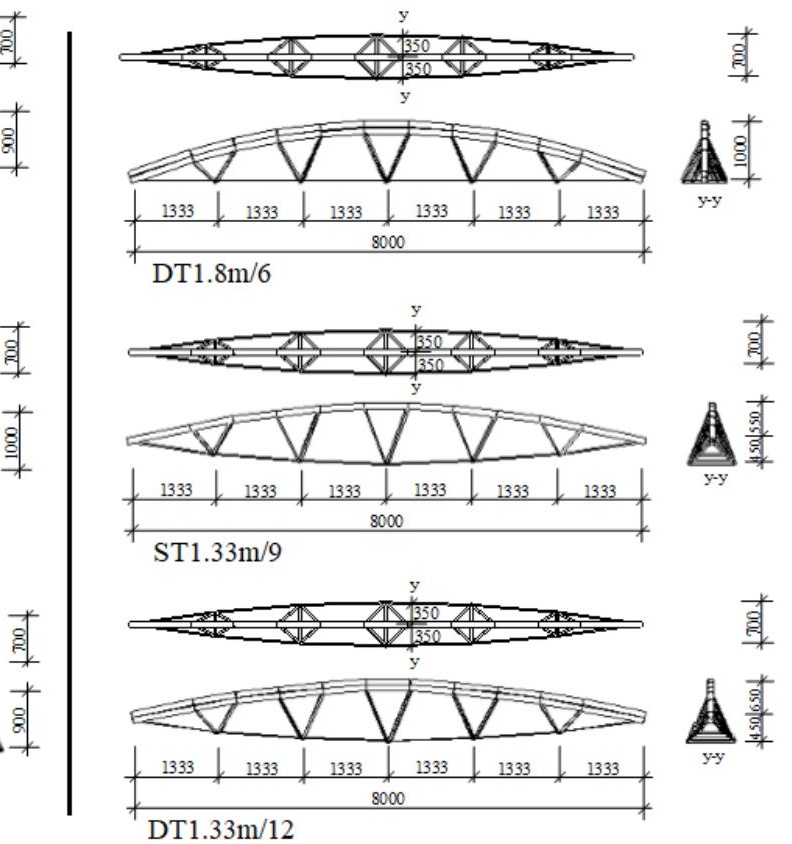

Fig. 4 Geometry diagram of the CSPS experimental models with both single and double tube pipe

Table 1

CSPS model parameters

\begin{tabular}{|c|c|c|c|c|c|c|c|c|}
\hline Model Ref. No. & Weight (kg) & $\begin{array}{l}\text { Truss max. spacing } \\
(\mathrm{mm})\end{array}$ & $\mathrm{d}(\mathrm{mm})$ & $\mathrm{f}(\mathrm{mm})$ & $\mathrm{h}(\mathrm{mm})$ & $\mathrm{h} / \mathrm{L}$ & No. of truss & No. of cable \\
\hline $\mathrm{ST} 1.8 \mathrm{~m} / 1$ & 102.2 & 1800 & 900 & 0 & 900 & 0.1125 & 20 & 10 \\
\hline DT $1.8 \mathrm{~m} / 4$ & 171.7 & 1800 & 1000 & 0 & 1000 & 0.1250 & 20 & 10 \\
\hline $\mathrm{ST} 1.33 \mathrm{~m} / 3$ & 106.9 & 1333 & 900 & 0 & 900 & 0.1125 & 25 & 12 \\
\hline DT $1.3 \mathrm{~m} / 6$ & 176.7 & 1800 & 1000 & 0 & 1000 & 0.1250 & 20 & 10 \\
\hline $\mathrm{ST} 1.33 \mathrm{~m} / 9$ & 108.9 & 1333 & 550 & 450 & 1000 & 0.1250 & 25 & 12 \\
\hline DT $1.33 \mathrm{~m} / 12$ & 177.2 & 1333 & 650 & 450 & 1100 & 0.1375 & 25 & 12 \\
\hline
\end{tabular}

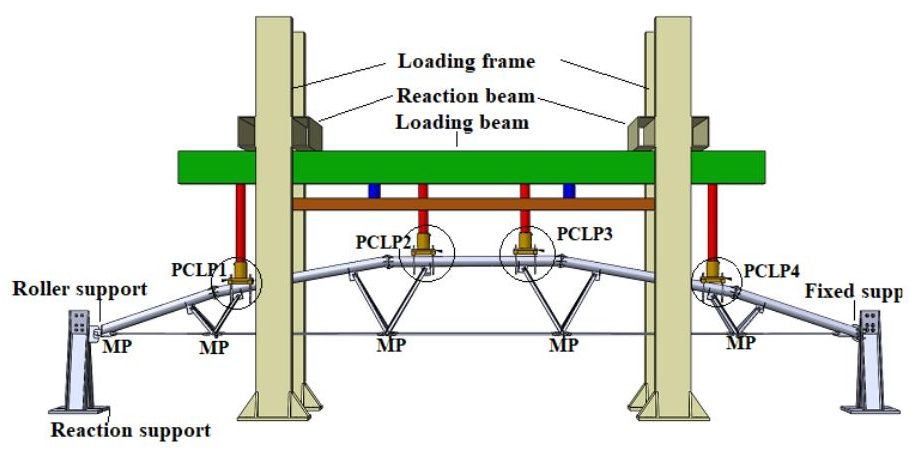

Fig. 5 Experimental setup

The general procedure for the analysis and design of structure against sudden failure of member and progressive collapse of structure are provided in design guidance of the General service Administration (GSA) and Unified Facilities Criteria (UFC) $[17,18]$. The proposed procedure by GSA is based on the Alternate Path Method (APM). The procedure places the condition of element removal scenarios for the analysis of structural response in the event of damage or sudden break of members, while the UFC procedure found on the provisions of GSA is a performance-based design approach. These procedures stipulate a set of analyses involving static nonlinear and nonlinear dynamic in the time integration steps, of which the process is tedious.
The explicit procedures of ANSYS/LS-DYNA [27] provides a facilitated and more concise approach for the analysis of structure in the occasion of sudden failure of a member. It also facilitates a process of application of different failure loads, including tie-break, blast and collision. The tie-break is defined as plastic kinematic model, which is dependent on strain for its failure [28]. Thus, when the member is strained beyond the defined limit, the member suddenly breaks from the rest of the structural model.

This study adopted the explicit procedure in which the implicit model was then changed to the explicit framework where the pipe members are model as BEAM161, the truss members as LINK160 and cable members as LINK167 elements. The analysis setting was made by applying the observed time duration from the experimental study and pre-processed in the Workbench interface while enabling post-processing of results in the LS-DYNA interface.

\section{Verification of the model}

\subsection{The member break phenomenon}

The setup of each CSPS model and the broken cable member are shown in Fig. 6. As earlier noted, the experimental setup is intended to have the failed cable member selected at random during the loading test. This is aided with the use of a single bolt connection to the cable-truss joint. The cable member joints are made of turnbuckle to provide resistance against shearing of the connecting bolt or sliding of the tension rod out of the turnbuckle through the tension control heads as depicted in Fig. 7(a). After the static loading reached the ultimate limit, the weakest joint fails by shearing of the 
connecting bolt/ buckling of the turnbuckle as shown in Fig. 7(b) or by the sliding of the tension rod out of the turnbuckle as shown in Fig. 7(c).

The experiment offered the advantage of identifying the structural member with the higher chance of sudden break when the structure is loaded. It was observed that the sudden break of the cable member of the CSPS resulted to transient response, large displacement and internal force redistribution. According to the arrangement of the models in Fig. 6(a), the broken cable members in models ST $1.8 \mathrm{~m} / 1$, DT $1.8 \mathrm{~m} / 4, \mathrm{ST} 1.33 \mathrm{~m} / 3$,
DT1.33m/6, ST1.33m/9 and DT1.33m/12 are C13, C13, C14, C16, C15 and C13, respectively. However, the structure exhibited some residual capacity to withstand the collapse of the extire structure. The observed vibratory response of all the models was in the time limit of 1s. Since the experimental process is tedious and economically unrealistic to excute more model within the available funds, further determination of the effect of a sudden break of each member were achieved through numerical procedures after the validation.

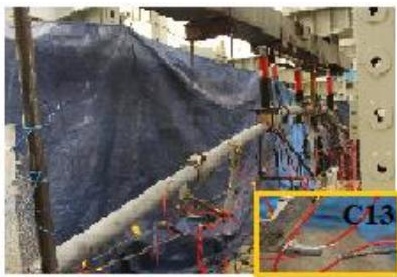

$\mathrm{ST} 1.8 \mathrm{~m} / 1$

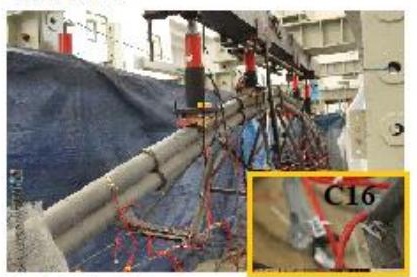

DT $1.33 \mathrm{~m} / 6$

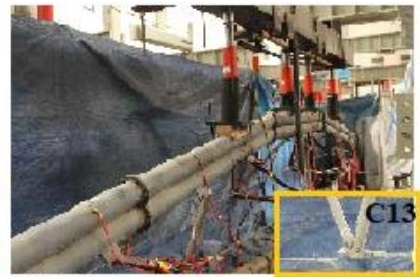

DT1.8m/4

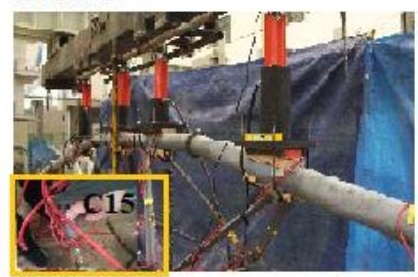

$\mathrm{ST} 1.33 \mathrm{~m} / 9$

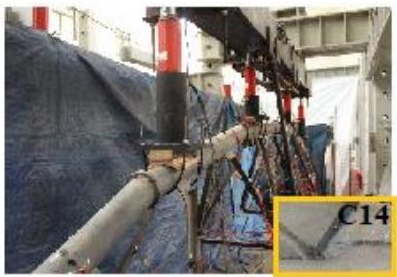

$\mathrm{ST} 1.33 \mathrm{~m} / 3$

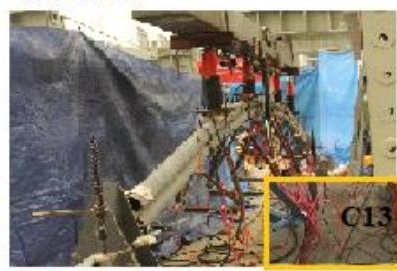

DT1.33m/12

Fig. 6 Loaded CSPS experimental models with broken members inset

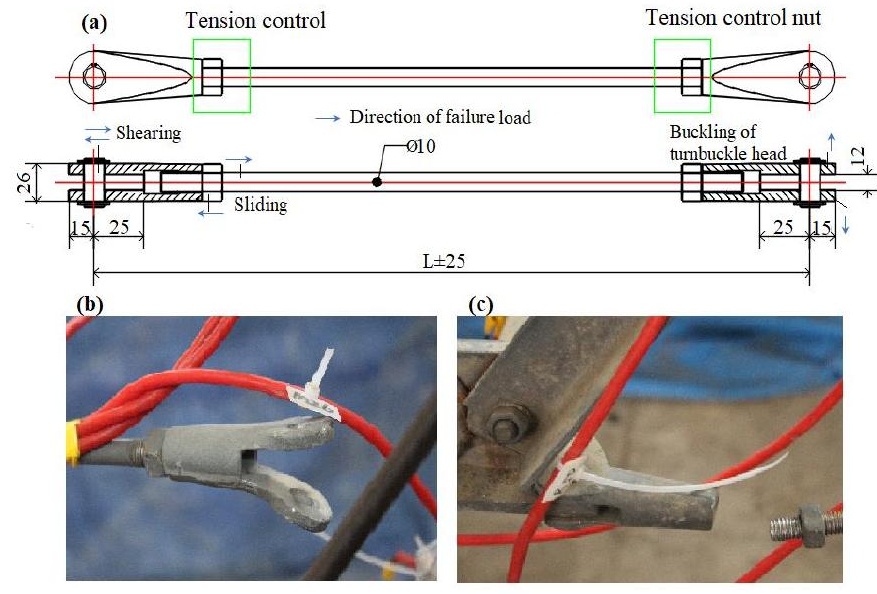

Fig. 7 Failure mode of the cable member: (a) Diagram of the cable member with direction of failure load, (b) Shear and buckling failure of turnbuckle joint and (c) slide failure of turnbuckle joint

\subsection{Validation of Model}

The result of the experiment provided the measured axial forces for a series of failed structural members. The shear and sliding resistance of the joint was designed as $75 \%$ of the cable ultimate load, representing the failure load of the cable member during the experiment. From both experimental and analytical models, the values of axial forces and displacement for the broken cable members were obtained. The values of axial forces in the mid-span cable members after redistribution and the joint failure modes taken from both the experimental and analytical are presented in Table 2. As shown in Table 2, the strain rate of 0.03 to 0.05 was applied as the break limit of the cable members according to the measured value from the experiment. The variation of the force between the experimental and analytical against the limit axial load $\left(S_{\text {lim }}\right)$ can be observed in Fig. 8 . While the maximum displacement for the corresponding broken cable members are presented in Table 3. In this study, the values obtained from both experimental and numerical models are in close agreement with the recorded ratios of experimental/analytical ranging from 0.81 to 0.95 as shown in Tables 2 and 3 .

As earlier noted, the transient response time of the experimental models is in the limit of $1 \mathrm{~s}$. According to the analytical results, the peak displacement for each models was reached within $0.1 \mathrm{~s}$ as shown in Fig. 9. For example, the peak displacement of model $\mathrm{ST} 1.8 \mathrm{~m} / 1$ was at a time duration of $0.06 \mathrm{~s}$. It was observed that the sudden break of the cable member and the resulting redistribution of force brought about local deformation behavior at the region of failure which reflects buckling characteristic of the CSPS structure. It is generally observed that the maximum displacement is recorded at the mid-span of the structure. The transient force redistribution and displacement response for the sudden break of various members are subsequently presented.

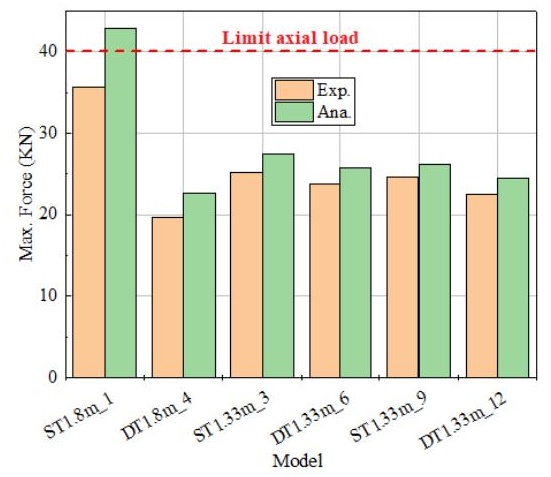

Fig. 8 Variation of axial force of mid-span cable after redistribution of force experimental and analytical models

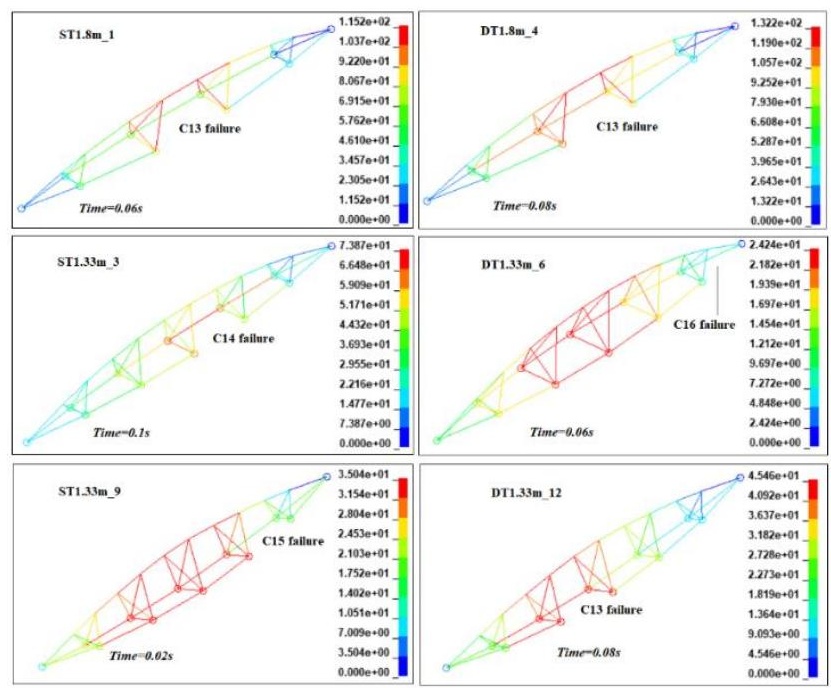

Fig. 9 Peak displacement (mm) of the analytical models 


\subsection{Effect of sudden failure of various cable members}

The break cases of the various cable members along the span are evaluated. Referring to Fig. 4, models ST1.8m/1 and DT1.8m/4 have 5 cases represented by the cable members $\mathrm{C} 11$ to $\mathrm{C} 15$ while models $\mathrm{ST} 1.33 \mathrm{~m} / 3$, DT $1.33 \mathrm{~m} / 6, \mathrm{ST} 1.33 \mathrm{~m} / 9$ and DT $1.33 \mathrm{~m} / 12$ have 6 cases represented by the cable member $\mathrm{C} 11$ to $\mathrm{C} 16$ along the spans. Following the numerical simulations, Fig. 10 presents the displacement responses of the CSPS models

ST1.8m_1

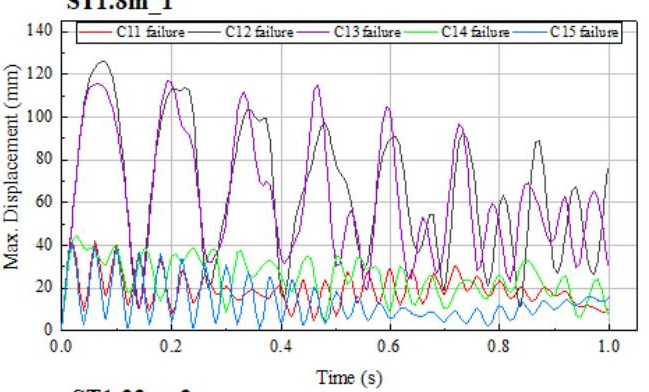

ST1.33m 3
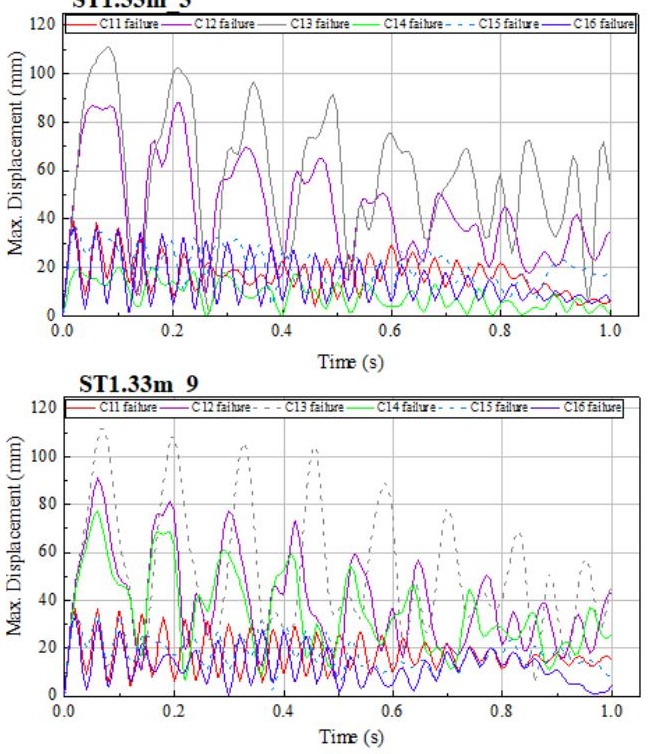

after different cable member removal. According to the results, the sudden break of cable member near the supports (cable members $\mathrm{C} 11$ and $\mathrm{C} 15$ for models ST1.8m/1 and DT1.8m/4, and C11 and C16 for the other models) induced a dissipated response, while the effect was more pronounced on the sudden break of the cable member near the roller support (i.e. cable member C11). Similar trend was recorded on all the models in which the sudden break of the mid-span cable yielded the highest vibratory responses.
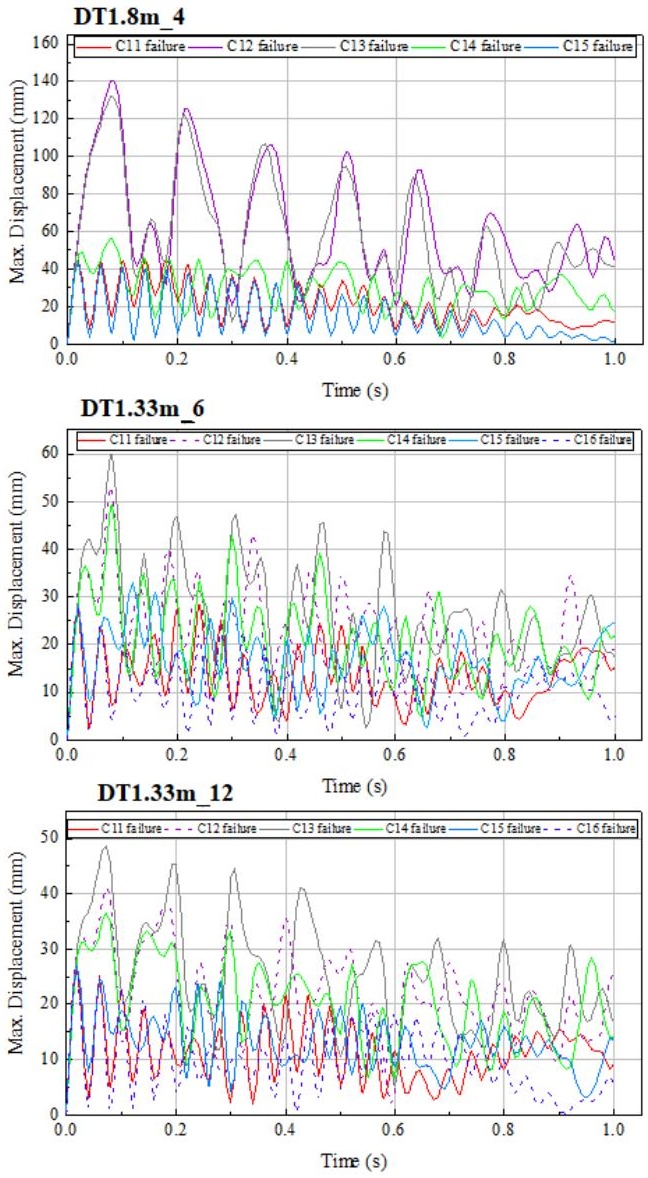

Fig. 10 Transient Displacement response considering the sudden break of various cable members

Table 2

Midspan cable force $(\mathrm{KN})$ of the CSPS Model after failure

\begin{tabular}{|c|c|c|c|c|c|c|}
\hline Model & Exp. & Ana. & Exp./Ana. & Strain rate of cable & Failed member & Mode of failure \\
\hline $\mathrm{ST} 1.8 \mathrm{~m} / 1$ & 35.7 & 42.9 & 0.84 & 0.05 & $\mathrm{C} 13$ & Sliding \\
\hline $\mathrm{DT} 1.8 \mathrm{~m} / 4$ & 19.6 & 22.6 & 0.86 & 0.05 & $\mathrm{C} 13$ & Shear \\
\hline $\mathrm{ST} 1.33 \mathrm{~m} / 3$ & 25.2 & 27.5 & 0.92 & 0.05 & $\mathrm{C} 14$ & Sliding \\
\hline DT $1.3 \mathrm{~m} / 6$ & 23.7 & 25.8 & 0.92 & 0.03 & $\mathrm{C} 16$ & Shear \\
\hline $\mathrm{ST} 1.33 \mathrm{~m} / 9$ & 24.6 & 26.1 & 0.94 & 0.05 & $\mathrm{C} 15$ & Sliding \\
\hline DT $1.33 \mathrm{~m} / 12$ & 22.5 & 24.4 & 0.93 & 0.05 & $\mathrm{C} 13$ & Sliding \\
\hline
\end{tabular}

Table 3

Displacement at midspan of the CSPS Model

\begin{tabular}{|c|c|c|c|c|c|c|c|c|c|}
\hline \multirow[t]{2}{*}{ Model } & \multicolumn{3}{|c|}{ Longitudinal (mm) } & \multicolumn{3}{|c|}{ Lateral (mm) } & \multicolumn{3}{|c|}{ Vertical (mm) } \\
\hline & Exp. & Ana. & Exp./Ana. & Exp. & Ana. & Exp./Ana. & Exp. & Ana. & Exp./Ana. \\
\hline $\mathrm{ST} 1.8 \mathrm{~m} / 1$ & 17.7 & 19.8 & 0.89 & 118.5 & 141.4 & 0.84 & 93.7 & 107.3 & 0.87 \\
\hline DT $1.8 \mathrm{~m} / 4$ & 16.1 & 17.7 & 0.91 & 99.8 & 123.0 & 0.81 & 75.9 & 91.7 & 0.83 \\
\hline $\mathrm{ST} 1.33 \mathrm{~m} / 3$ & 25.6 & 26.4 & 0.97 & 4.5 & 5.2 & 0.87 & 7.3 & 8.7 & 0.84 \\
\hline DT $1.3 \mathrm{~m} / 6$ & 18.1 & 20.35 & 0.89 & 3.5 & 4.1 & 0.85 & 6.1 & 7.5 & 0.81 \\
\hline $\mathrm{ST} 1.33 \mathrm{~m} / 9$ & 11.4 & 13 & 0.88 & 18.9 & 20 & 0.95 & 38.6 & 40.2 & 0.96 \\
\hline DT $1.33 \mathrm{~m} / 12$ & 9.5 & 10.5 & 0.91 & 16.8 & 18.2 & 0.92 & 31.4 & 34.7 & 0.91 \\
\hline
\end{tabular}


The evaluated results of the axial force redistribution is presented in Fig. 11. The results showed that all the cable members experienced vibratory response on the sudden break of a memeber, and the peak force during redistribution occurred when the mid-span cable is broken. Due to stiffening effects on models with double tube pipe and additional truss module, the force amplitude aggravated by the sudden break of cable member was attenuated. Similarly, in models with adjustment of the depth to span parameter
(ST1.33m/9 and DT1.33m/12) the force amplitude aggravated by the sudden break of cable member was attenuated. Generally, larger force amplitudes are recorded on cable members at the mid-span as compared to the members nearer to the supports. It is thus noted that the force variations of the members were associated to their positions as shown in the recorded results. It can be stated that the sudden break of mid-span cable member results in the increase of tensile load beyond the limit load.
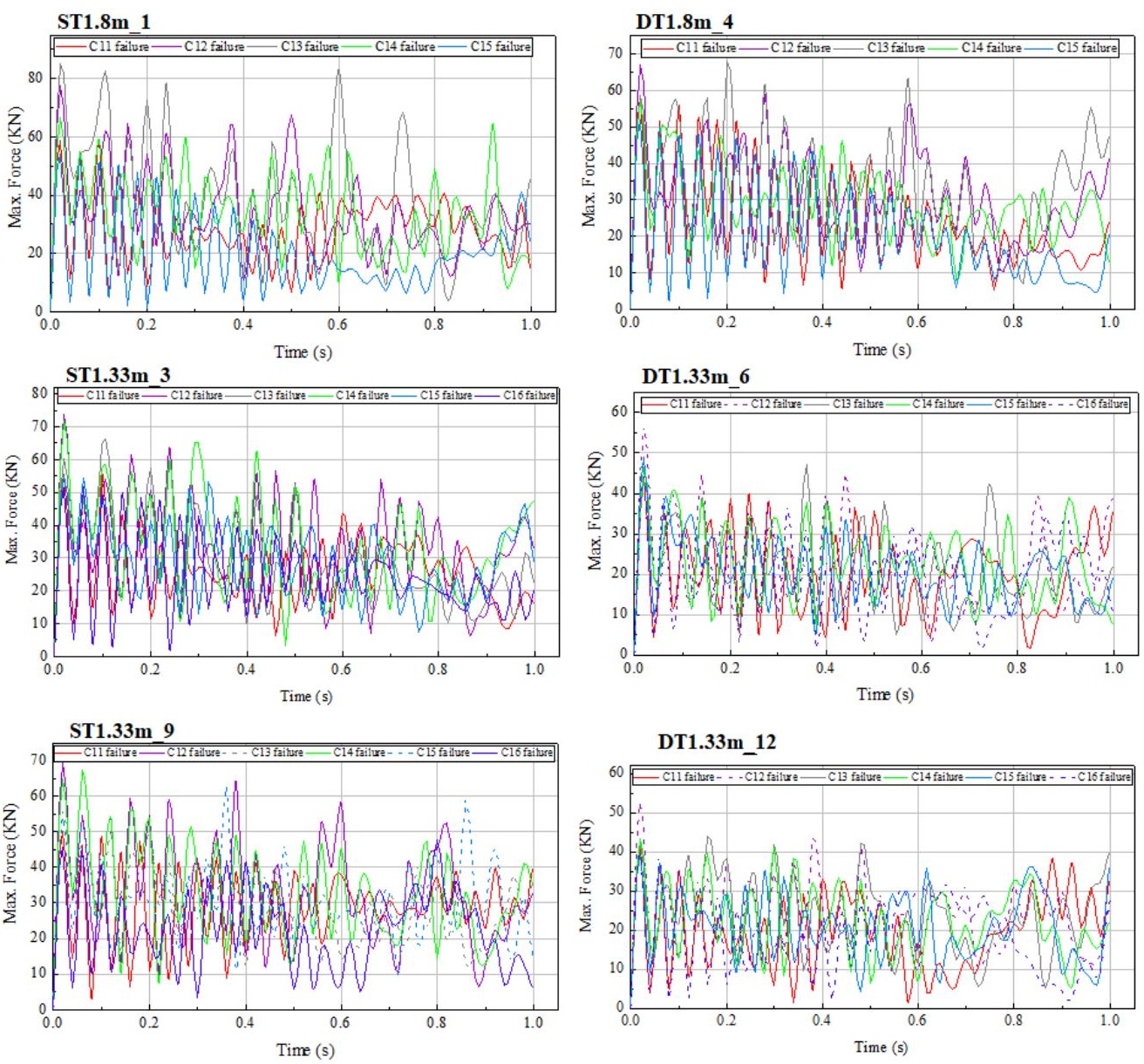

Fig. 11 Transient force response considering the sudden break of various cable members

The comparison of cable forces of implicit static loading before sudden break and corresponding explicit dynamic response after sudden break of the cable members are both presented in Fig. 12. As observed in Fig. 12(a), the internal forces in the cable members were kept within the limit of the axial force $\left(S_{\text {lim }}\right)$. However, in Fig 12(b) there was a rise in the internal forces in the cable members above $S_{\text {lim }}$ after the sudden break. Before the sudden break of a member, energy is conserved in the system and was released after the sudden break, thereby propagating transient vibratory response to achieve the redistribution of internal forces in the structure as shown in Fig. 11. Evaluation of the result of the variation of vibratory response of the explicit models and the sudden increase beyond implicit static $S_{\text {lim }}$ is attributed to the process of redistribution after the sudden break of a cable member. This phenomenon is only verifiable with the aid of explicit solver which can offer effective and precise solution to sudden break. It can be seen that the sudden break of any cable member for each CSPS model resulted in transient vibratory response with varying peaks. As earlier presented in Fig. 8, the internal force dissipated immediately the redistribution was achieved. For the cable members situated at the supports, there was internal forces increase with attendant vibratory response but with moderate effects compared to cable members away from the supports. The result also showed that the attenuation of the cable internal force increases from CSPS model ST1.8m/1 to DT $1.33 \mathrm{~m} / 12$ during break of any cable member. It is thus seen that the model DT $1.33 \mathrm{~m} / 12$ offered more resistance to the vibratory effect of sudden break of the CSPS members. The reduction in the peak displacement and dissipation of internal forces from ST1.8m/1 to DT $1.33 \mathrm{~m} / 12$ suggested that the modified structure offered more support against collapse. However, the results further suggested that the critical cable members are situated around the mid-span.
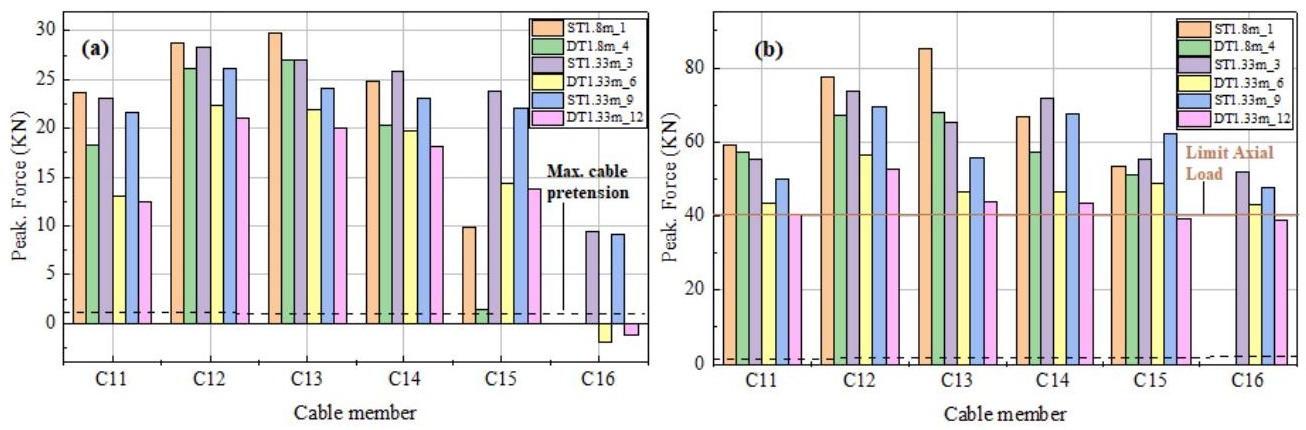

Fig. 12 Variation of peak cable force along the length of the structure: (a) during static loading and (b) considering sudden break of a member 


\section{Result of parametric evaluation}

The preceding discussion focused on the evaluation of dynamic effects of the modified CSPS model based on the various parameters. The results showed that the depth modification design parameters provide improved collapse resistance against sudden break of a cable member of the CSPS structure. Consequently, a comparison of the collapse resistance offered by member section parameter including the cable $(r-x c)$, truss $(t-x t)$ and pipe $(t-x p)$ of the models are evaluated considering the sudden break of critical cable member of model ST $1.8 \mathrm{~m} / 1$.

Comparison of the effect of the varying parameters of CSPS model under the sudden break of a critical member offered unique responses. Fig. 13 shows transient vibratory curves of the cable with depth modification parameters. The results suggest that the collapse resistance capacity is improved with modification of the pipe, the number of truss modules and the curvature of supporting cables. This is seen in the displacement response in Fig. 13(a) which suggests model DT1.33m/12 with combined modifications of the pipe, truss and curvature offers improved vibratory response. Similarly, the axial force redistribution as shown in Fig. 13(b) indicates dissipation of internal forces from the highest in model ST1.8m to lowest level in model DT $1.33 \mathrm{~m} / 12$. When double tube is applied in lieu of a single tube pipe member, the collapse resistance of the structure improves. However, it is yet to be concluded that the use of double tube is an improvement strategy as against the use of pipe thickness parameter. Thus, it is imperative to further evaluate the influence of various pipe thickness on the structure. Subsequent paragraphs deal with the parametric influence of the thickness of the members.
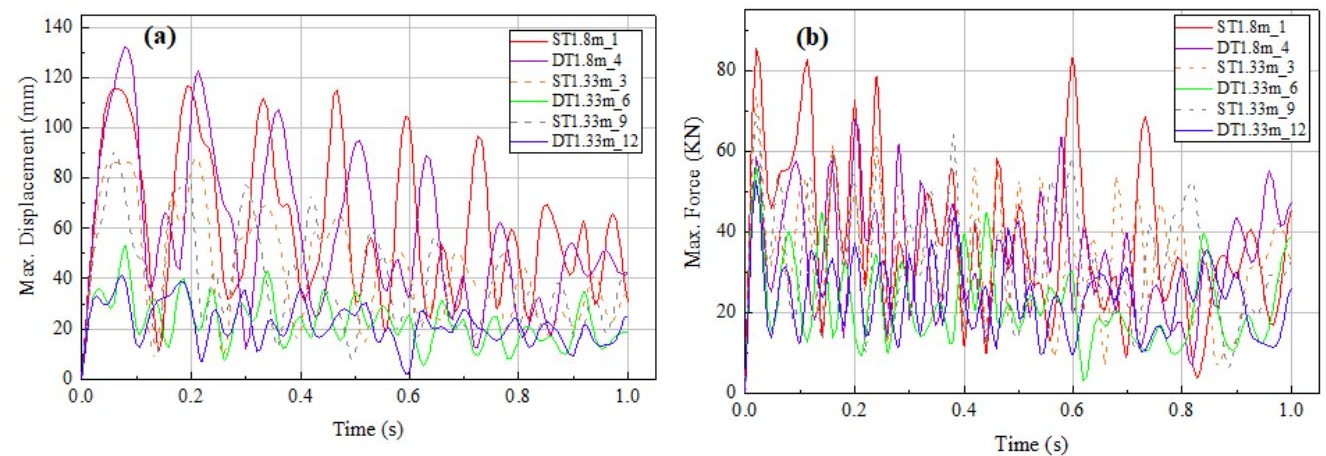

Fig. 13 Transient vibratory response of the CSPS models: (a) Displacement and (b) Axial force
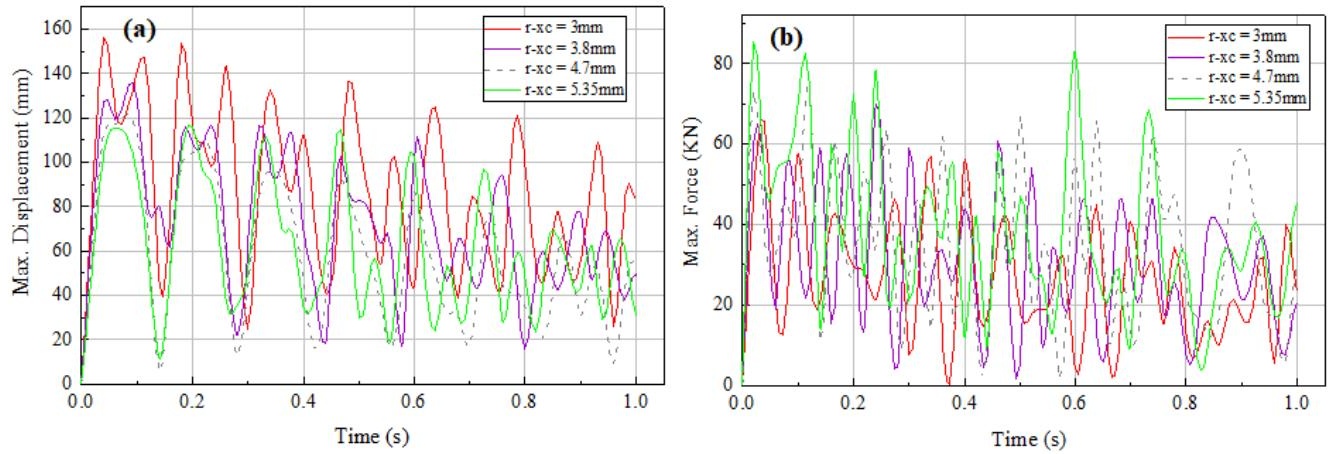

Fig. 14 Transient vibratory response of the cable parameters: (a) Displacement and (b) Axial force

Fig. 15 depicts the influence of the pipe parameter, $t-x p=2,3$ and $3.3 \mathrm{~mm}$ as well as DT $t-x p=3$ in improving the collapse resistance of the structure. The results also suggest that with higher values of $t-x p$ the structure offers more collapse resistance. As shown in Fig. 15(a), the largest displacement was recorded when the value of $t-x p$ is 2 and got dissipated when the value increased to 3.5. Similarly, the axial force increases, offering higher collapse resistance with higher values of $t-x p$ parameters as shown in Fig. 15(b). If a close look is taken at the values of $D T t-x p=3$ in both the displacement and axial force responses, it is once again verified that the application of a double tube pipe member, although increased the bearing capacity of the structure, offers improved collapse resistance by combined action with other measures. This was explained by the responses presented by model DT1.33m/12 in Fig. 13 .

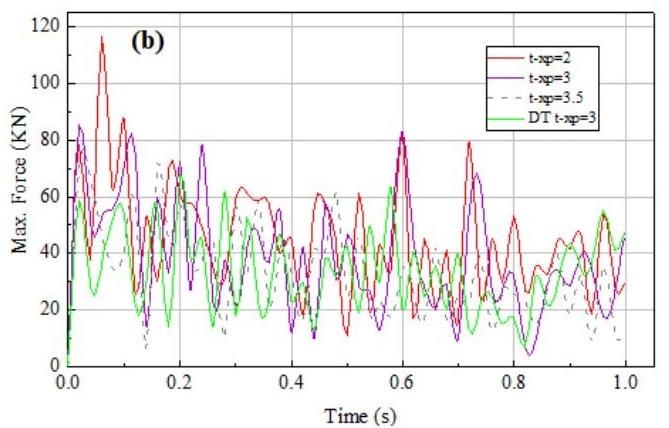

Fig. 15 Transient vibratory response of the pipe parameters: (a) Displacement and (b) Axial force 
Fig. 16 shows the displacement and axial force responses of the structure on the truss parameter $t-x t=2.4,3.0$ and $3.6 \mathrm{~mm}$. While adequate truss section is necessary for the overall performance of the structure, the results depict slight variation of both displacement and axial force response when a critical cable member is broken.
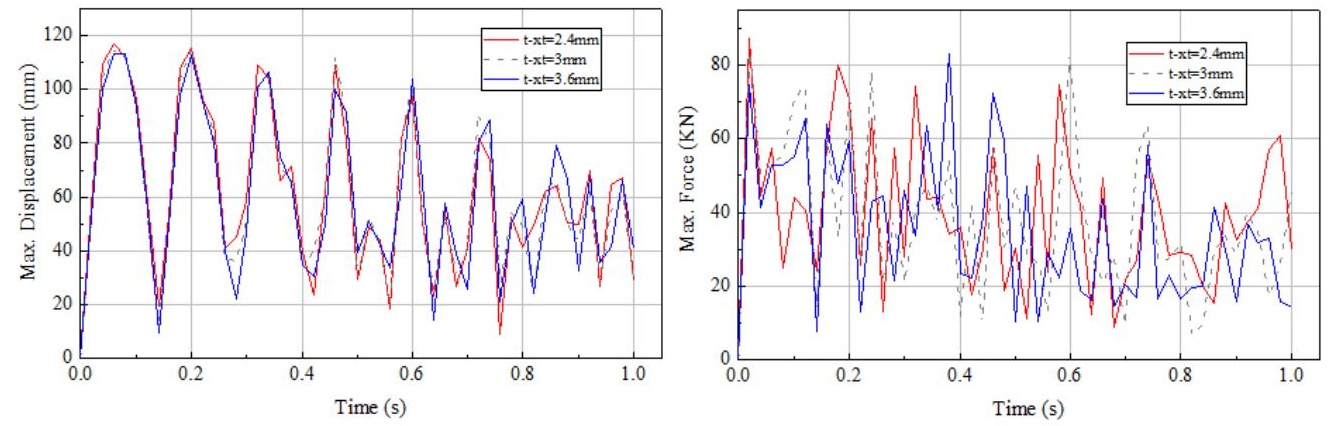

Fig. 16 Transient vibratory response of the truss parameters: (a) Displacement and (b) Axial force

The variations of peak axial force for various parameters after the sudden break of a critical member are presented in Fig. 17. Comparative assessment of the results of models revealed that the model with a double tube absorb the cable internal force more than the single tube models. It can be seen again that absorption increases from CSPS model ST1.8m/1 to DT1.33m/12 in the event of a sudden break of a critical cable member. Thus, the model DT1.33m/12 offered more resistance to the sudden break effect of the CSPS structure. The reduction in the peak axial forces from ST1.8m/1 to DT1.33m/12 in Fig. 17(a) further suggested that the modified structure offered more resistance to progressive collapse. However, the increase of the parameter $r$ - $x c$ depicted the ability to carry more axial force as shown in Fig. 17(b). Further evaluation of the parameter $t-x p$ revealed that the variation of axial force for the pipe thickness in the event of a sudden break of key cable member. Fig. 17(c) depicts a trend of absorption of internal forces with higher thickness of pipe and the use of double tube in lieu of single tube pipe members. Further evaluation with parameter $t-x t$ reals the variation of axial force as depicted in Fig. 17(d). It is obvious from the result that the section of truss member can be useful in improving the performance of the structure in the event of a sudden break. Overall, the parametric results placed emphasis on adequate member section when designing against the collapse of the CSPS structure.
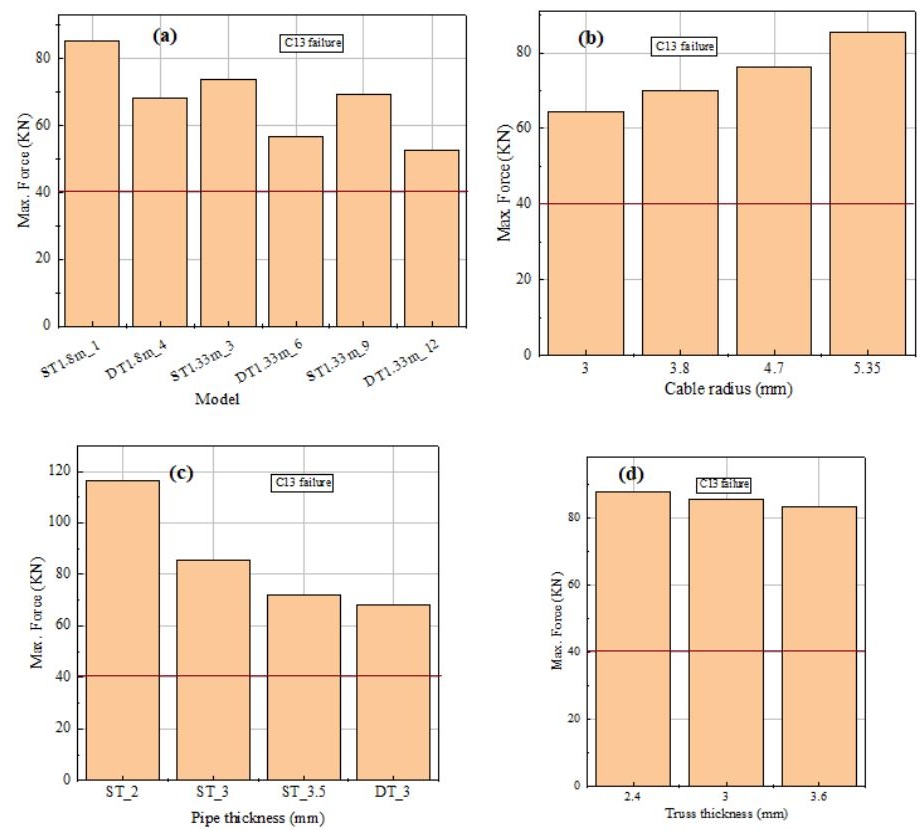

Fig. 17 Variation of peak axial force after the loss of a critical cable member: (a) CSPS models, (b) Cable parameters, (c) Pipe parameters and (d) Truss parameters

\section{Dynamic effect of sudden cable break}

\subsection{Dynamic increasing factor}

The method provided by most codes, standards and research work for the analysis and design against progressive collapse of most structures is to employ the dynamic increasing factor (DIF), commonly referred to as a dynamic amplifying factor, as a multiplier of the static. Other methods have been studied, including the method for evaluating the progressive collapse resistance of long-span single-layer spatial grid structures [29]. However, DIF reduces the rigorous process offered by the evaluation of dynamic event of the structure during the sudden break of a member. The dynamic increasing factor in every structural member is calculated separately considering all state variables $S$ [11]. Considering the sudden break of each of the cable members and the transient vibratory responses, the values of $S_{d y n}$ are determined as the peak dynamic response. From the static results obtained from implicit analysis, $S_{\text {stat }}$ is as the peak static response while the responses in the initial state $S_{0}$ are determined and subtracted from both $S_{d y n}$ and $S_{\text {stat }}$. Thus, DIF is obtained by comparing the dynamic and static responses expressed in equation (1) as follows:

$D I F=\frac{S_{d y n}-S_{0}}{S_{s t a t}-S_{0}}$

Given consideration to the specified design processes, the $D I F$ of 2.0 is provided to augment dynamic effect from the results of static analysis. However, the guide would not be suitable for inelastic structures. Thus, there is the requirement for further investigation due to nonlinear effect and flexibility induced by cable and truss members. Fig. 18 presents the calculated $D I F$ from the numerical results for the sudden break of various cable members of the CSPS models. Results revealed that the DIF data of the various members varied from the specified value of 2.0. The DIF results also revealed a dramatic effect of dynamic axial forces at the fixed supports with records of higher magnitudes above 2.0. This is attributed to the relatively smaller static forces arising from the application of double tube pipe members.

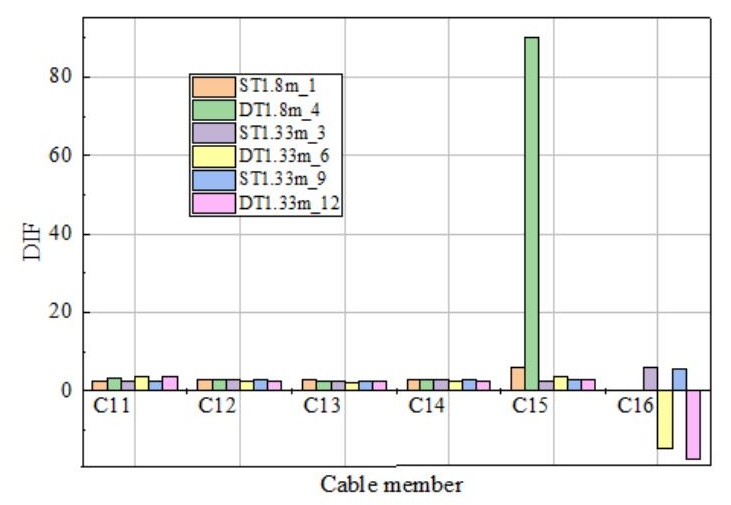

Fig. 18 Dynamic increasing factor $(D I F)$ after the loss of various cable member

In Fig. 19, the DIFs arising from a sudden break of a critical member for the parametric analysis of the models are presented. Fig. 19(a) shows the variation of $D I F$ for the various models. The results further verify the influence of the modification of the CSPS model. As reorded, all the modified models relatively reduce the value of the DIF. It is observed that with an increase in the absorption of axial force from CSPS model ST1.8m/1 to DT $1.33 \mathrm{~m} / 12$ in the event of a sudden break of a critical cable member, there is 
a corresponding decrease in the value of DIF. The trend slightly differs on model DT $1.33 \mathrm{~m} / 12$ which was presumed to have offered more resistance to the sudden break effect of the CSPS structure. However, in Fig. 19(b) with the larger value of parameter $r-x c$, the result depicts a rise in the DIF attributed to the increasing capacity to carry more axial force. Based on the evaluations above, it is obvious that the cable parameter exhibits internal force absorption due to the release of the most portion of its stored energy. With smaller value of $r-x c$, a relatively large tension, less vibratory response and low DIF values are recorded. The values of $D I F$ were also increased in the event of lower values of $S_{\text {stat }}$. Consequently, in the consideration of the sudden break of cable members of the CSPS structure, it is assumed that the DIF method offered more useful results for the vibratory responses of the pipe and truss member modifications.

The $D I F$ values of both the pipe and truss members parameters subject to sudden break of a critical member are also presented in Fig. 19. In Fig. 19(c), the decreasing values of $D I F$ arising from increase in the parameter $t-x p$ depicts an improvement in the collapse resistance. The modification with double tube in lieu of single tube pipe members is obviously useful in improving the collapse resistance in the event of hydraulic demand. In the context of $t$-xt, the variation of DIF depicted in Fig. 19(d) shows slight improvement in the collapse resistance due to the increase in section of truss member.

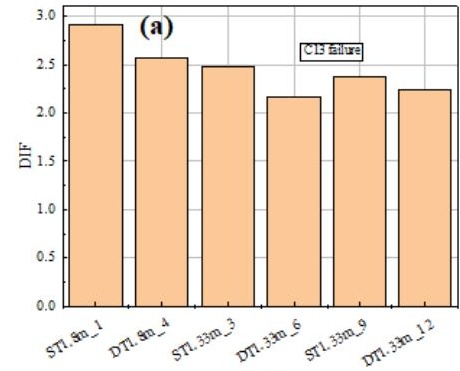

Model

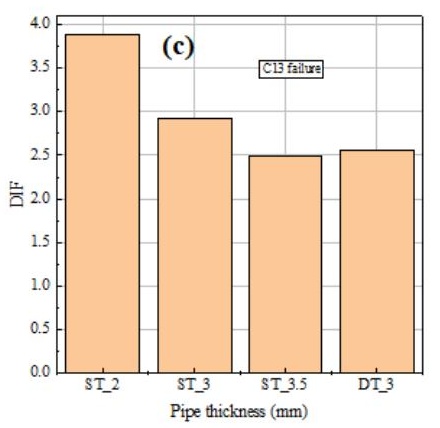

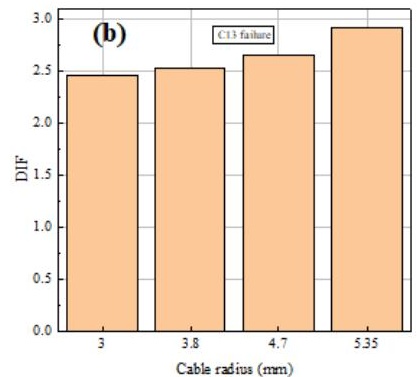

(d)

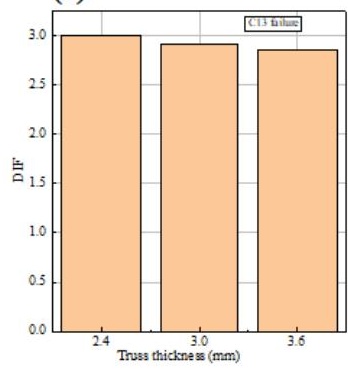

Fig. 19 Dynamic increasing factor $(D I F)$ after the loss of a critical cable member: (a) CSPS models, (b) Cable parameters, (c) Pipe parameters and (d) Truss parameters

\subsection{Revision of dynamic incearsing factor}

Since the application of DIF in the evaluation cable members is presumed to offer less suitable index for collapse resistance design of the CSPS structure, a revised index is hereby considered. Owing to the fact that the cable members are made of tension rods, the pretension varied from 0 to $0.9 \mathrm{KN}$ along the span amounting to less than $3 \%$ of the limiting axial load, thus, the application of $S_{0}$ in equation (1) was considered to be negligible. Thus, the DIF expression was modified and expressed as a dynamic factor $(D F)$ to account for the effect of the vibratory response and peak axial load during the sudden break of a cable member. $D F$ is expressed in equation (2) as follows:

$D F=\frac{S_{d y n}}{S_{\text {stat }}}$

Fig. 20 presents the values $D F s$ from the numerical results for the sudden break of various cable members of the CSPS models. The recorded $D F$ values of the various members are relatively closer to the specified $D I F$ value of 2.0. The results also showed a dramatic effect of $D F$ for the values at the fixed support arising from the modified effect of the double tube pipe members.

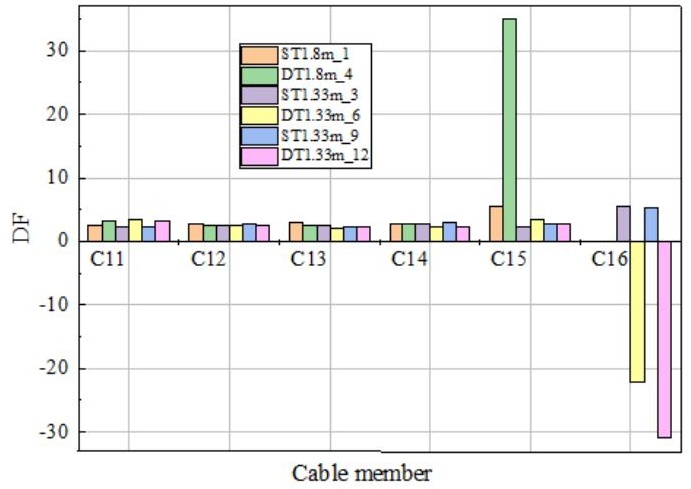

Fig. 20 Dynamic factor $(D F)$ after the loss of various cable member

Fig. 21 shows the DFs arising from a sudden break of a critical member for the parametric analysis of the models. In Fig. 21(a), the results show the effect of modified CSPS models on the values of $D F$. All the modified models relatively reduce the value of the $D F$. The $D F$ of other parameters also shows a similar trend with reduced index. In Fig. 21(b), larger value of parameter $r-x c$ results in a rise in the $D F$. Similarly, Fig. 21(c) shows the DF values of various $t-x p$ parameter, also depicting reduce index. Similar trends of reduced index is also seen in the results of $t$-xt parameters, as shown in Fig. 21(d).

It can be seen in Fig. 21(a) that all the DFs for the sudden break of any cable member along the span ranged from 2.4 to 5.5, except for the influence of double tube pipe members in which much greater values were recorded at the fixed supports. The fall in the DIF from St $1.8 \mathrm{~m} / 1$ to DT1.33m/12 once again suggested that the modified structure can offer improved resistance to progressive collapse. In comparison to $D I F$, it is deduced that the $D F$ offers a more realistic value for the evaluation of the vibratory response for the design of CSPS structure.

\subsection{Evaluation of incurred error}

It is noted that the $D I F$ and $D F$ defer from the specified value by most studies and codes in which the dynamic analysis is replaced by the results of simplified static analysis factored by a $D I F=2.0$. Considering the variation from the values, it is necessary to evaluate the error incurred by application of the simplified approach. Mozos utilized the empirical method of PTI in the parametric study on the dynamic response of cable-stayed bridges subjected to the sudden failure of a stay considering the bending moment of deck. The results which were evaluated as a function of the bending due to dynamic loads were obtained and finally expressed as a percentage of the envelope of the ultimate limit states for permanent and transitory loads [5]. In this study, the error is evaluated in the same model, as qualitative error $\left(E_{q}\right)$ according to the equation (3), taken as $E_{\text {stat }}$ in which the variation between the peak vibratory response and the static result factored by a $D I F=2.0$ is expressed as a percentage of the limit load $S_{\text {lim }}$.
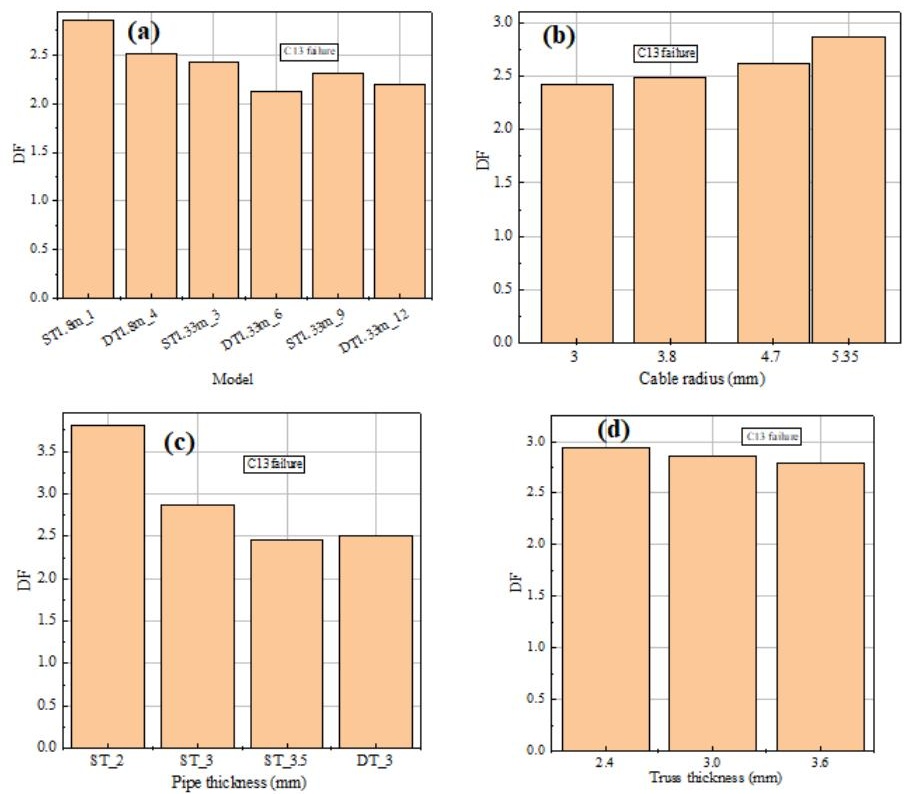

Fig. 21 Dynamic factor $(D F)$ after the loss of a critical cable member: (a) CSPS models, (b) Cable parameters, (c) Pipe parameters and (d) Truss parameters 
$E_{S t a t}=\frac{S_{d y n}-S_{D I F=2}}{S_{\lim }} \times 100$

However, the expression of $E_{\text {stat }}$ was used to evaluate the results of the implicit solver. The evaluation using $E_{\text {stat }}$ is considered unsuitable for the present study, thus, the revision of error model is evaluated. To account for the dynamic effect using the explicit solver, the revised error is expressed as $E_{d y n}$ in which static result factored by a $D I F=2.0$ is expressed as a percentage of the peak vibratory response $S_{d y n}$ as shown in equation (4).

$E_{d y n}=\frac{S_{d y n}-S_{D I F=2}}{S_{d y n}} \times 100$

The comparative evaluation of the results of both $E_{\text {stat }}$ and $E_{d y n}$ revealed higher error margin from the $E_{\text {stat }}$. Fig. 22 depicts the case of a sudden break of cable members along the span of the models. As shown is Fig. 22(a), the $E_{\text {stat }}$ increases at the fixed support with values of $84.4 \%, 120.8 \%, 82.3 \%$, $117.7 \%, 73.5 \%$ and $103.6 \%$ of the respective models. Comparative evaluation of $E_{d y n}$ in Fig. 22(b) reveals drop in the values to $63.2 \%, 94.3 \%, 63.7 \%$,
$109.0 \%, 61.8 \%$ and $106.5 \%$ respectively. The higher values recorded at the fixed support cables C5 and C6 can be attributed to the limited vibratory response.

Fig. 23 shows the results of the parametric study of a sudden break of a critical member. Fig. 23(a) presents the error variations corresponding to the effect of the modified models. Except for the modified models, the error dropped from $64.2 \%$ to $30.1 \%$. The results also showed marginal drop at models DT1.33m/12 and DT1.33m/6. Thus, the model ST1.8m/1 will have a larger error compared to the others. Fig. 23(b) shows that by increasing the parameter $r$ - $x c$ of $\mathrm{ST} 1.8 \mathrm{~m} / 1$, the error increases in a nonlinear pattern. Conversely, increasing the parameter $t$ - $x p$ cause decrease in the error as shown in Fig. 23(c). Furthermore, increasing the parameter $t$ - $x t$ causes decrease in the error in a linear pattern as shown in Fig. 23(d).

Based on all the evaluated $D F$ values in 5.1 and 5.2 and the corresponding errors when compared to the static amplified by a factor of 2 , the dependable value of the $D I F$ is in the range of 2.4 to 3.8 except for the extreme values recorded by the models with DT pipe members. These values can be increased by considering a factor of safety during the design process of the CSPS structure. In practice, DIF of 1.2 is recommended, however, this study recorded increased values in the range of 2.88 to 4.56 .
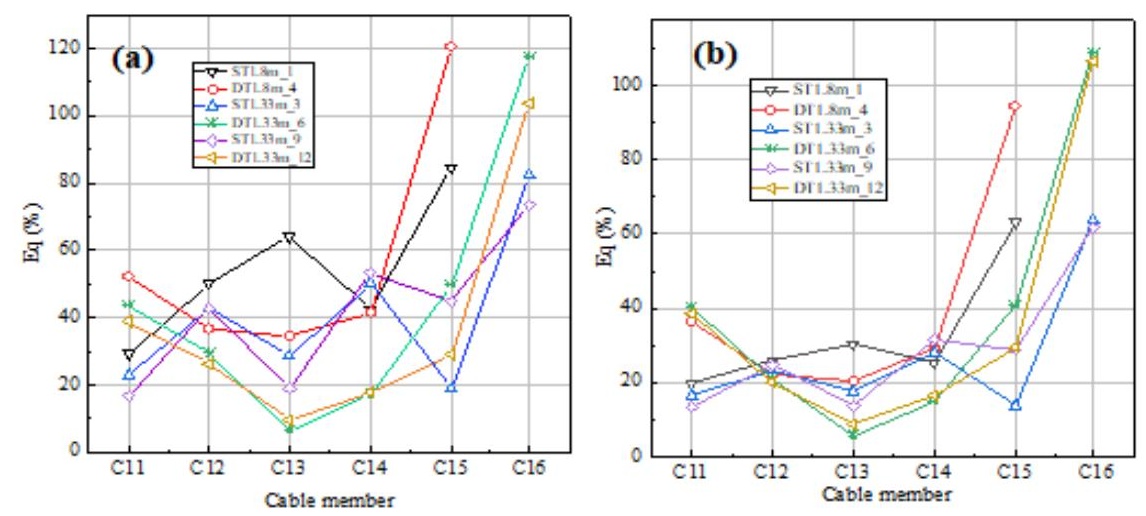

Fig. 22 Error incurred considering DIF=2 for static load as against the proposed Dynamic factor due to the sudden loss of

various cable member of the CSPS models: (a) $E_{s t a t}$ and (b) $E_{d y n}$
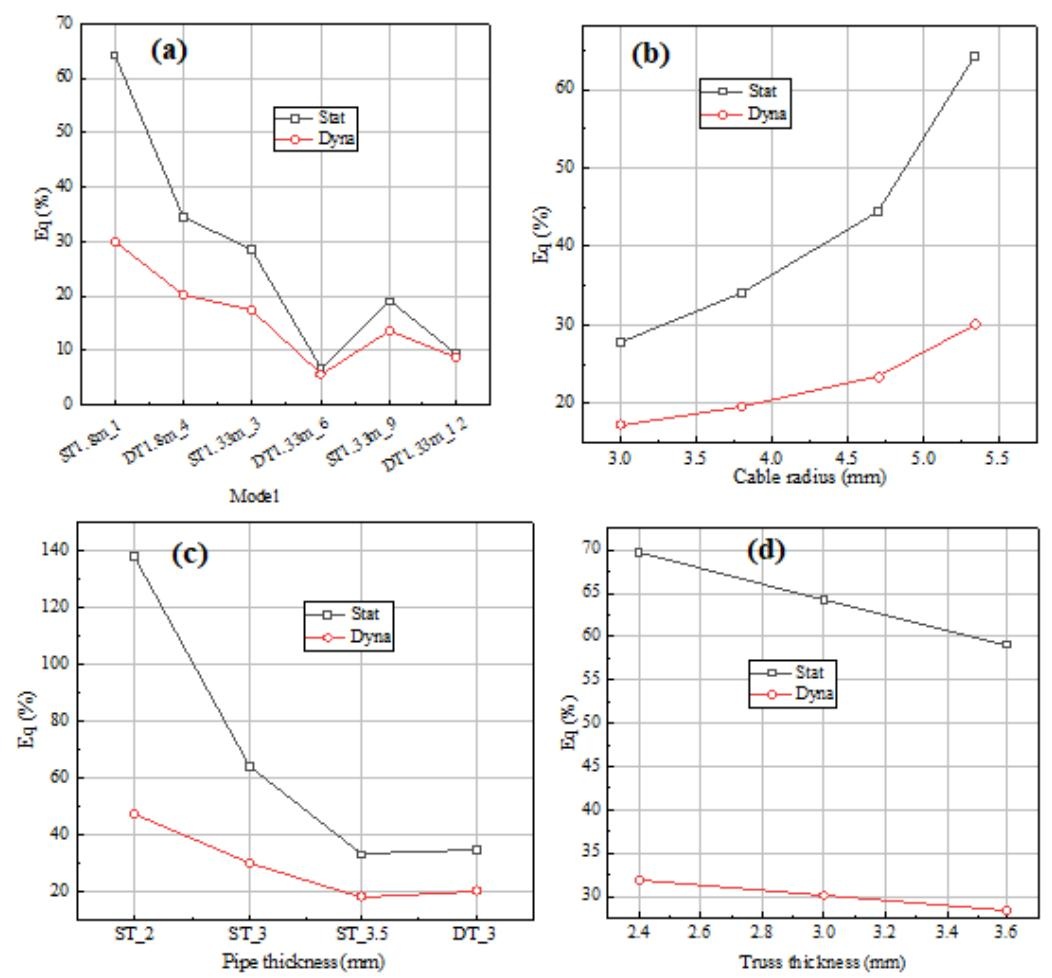

Fig. 23 Error incurred considering DIF=2 for static load as against the proposed Dynamic factor due to the sudden loss of a critical cable member: (a) CSPS models, 


\section{Conclusion}

This study presented a parametric study on the response of cable-supported pipe system (CSPS) subjected to the sudden break of cable members. The study covered the collapse resistance offered by the modification of the geometric features such as the number of truss modules, mid-span depth, single and double tube pipe members, as well as the cross-section of cable, pipe and truss members of the CSPS structure. The models were investigated using the limit axial load, $S_{\text {lim }}$ established from static loading experimental processes leading to the sudden break of the turnbuckle joints. The loading test was used to establish the break duration and vibratory response phenomenom. After verifying the explicit analysis with the loading test results, the models were subjected to further numerical study, and the results were further evaluated by comparison with the simplified static analysis in which the recommended $D I F$ value of 2.0 was factored to the static load. The objectives of the study are to establish suitable dynamic indices for cable members and qualitatively obtain the residual of value the CSPS structure after the redistributed axial force in the event of a sudden break of a cable member in the design process of the CSPS structure. The main conclusions of the study are:

1) Once sudden break of cable member occurs in a CSPS structure, vibratory response process and redistribution of internal forces are experienced. The results of the response process of the experiment suggested that the numerical procedure can be considered as an effective tool for the prediction of the sudden break, vibratory response and internal force redistribution of the CSPS structural members. In the response, the sudden break of a cable member caused large displacement which obviously reflected in the obtained results of both the analytical and experimental models. This displacement is more pronounced in the $\mathrm{ST} 1.8 \mathrm{~m} / 1$ and it is attenuated in the modified models.

2) The sudden break of cable member and the process of internal force redistribution apparently brought about a vibratory response on the structure. This transient vibratory response could be significant, and detrimental to the residual strength of the cable members. The condition may also influence the behaviour of the truss and pipe members. The dynamic effect must be considered in structural design.

3) In other to realistically portray the behaviour of the structure in the design or analysis of CSPS structures, the dynamic effect due to sudden break of a cable member is necessary. Two indices were evaluated to establish the collapse mitigation strategy, the dynamic increasing factor and a modified version, termed a dynamic factor. From the results of the analytical processes, while the $D I F$ evaluation method can be utilized for members other than the cables as recommended in other studies[11], the $D F$ is suggested in this study to offer a more realistic evaluation index for cable members. However, due to the different vibratory responses among members, both $D I F$ and $D F$ will be useful in the practical design of CSPS structure.

4) The study of the sudden break of cable-supported structures using static load is considered having a relatively localized dynamic effect which occurred around the region of the broken member and the region with higher internal force redistribution. On the contrary, applying dynamic load such as wind and seismic could produce a different result of the redistributed internal force in the structure. Thus, the influence of applied load and the resulting internal force redistribution in the event of a sudden break of a cable member should be verified before the application of $D I F$ and $D F$ for the design of the CSPS structure.

5) Considering that the method suggested by other studies and the PTI in the evaluation of qualitative error account more on the static effect, a modified expression was proposed to account for the dynamic effect. The proposed method utilized the difference between vibratory response and the static response factored with a DIF of 2.0 expressed as a percentage of vibratory response. The error margins of the results from the two methods suggested unrealistic results, thus portrayed limitation of the implicit solver for the evaluation of the sudden break of cable member of the CSPS structure. However, suggested method using DIF of 2.0 is considered unsuitable for cable members of the CSPS structure due to the recorded margin of error in both methods. This forms a basis for further research.

\section{Acknowledgements}

This study is supported by Hebei Province Full-time Top-level Talents Introduction Project (Grant No. 2020HBQZYC013), and National Key Research and Development Program of China (Grant No. 2018YFC0705500, 2018YFC0705504). Their financial support for this work is highly recognized.

\section{Reference}

[1] D. A. Christensen and R. D. McGee, "Irrigation drive unit," U.S. Patent No. 7,229,032. 12 Jun. 2007.

[2] N. J. Gimsing and C. T. Georgakis, "Cable supported bridges: Concept and design," John Wiley \& Sons, 2011

[3] M. P. Agwoko, Z. Chen, and H. Liu, "Experimental and Numerical Studies on Dynamic Characteristics of Long-Span Cable-Supported Pipe Systems," International Journal of Steel Structures, 2020/11/13 2020.

[4] Z. Chen, "Suspen-dome Structure," ed: Science Press, Beijing, China, 2010

[5] C. Mozos and A. Aparicio, "Parametric study on the dynamic response of cable stayed bridges to the sudden failure of a stay, Part I: Bending moment acting on the deck," Engineering Structures, vol. 32, no. 10, pp. 3288-3300, 2010.

[6] C. Mozos and A. Aparicio, "Parametric study on the dynamic response of cable stayed bridges to the sudden failure of a stay, Part II: Bending moment acting on the pylons and stress on the stays," Engineering Structures, vol. 32, no. 10, pp. 3301-3312, 2010.

[7] M. Wolff and U. Starossek, "Cable loss and progressive collapse in cable-stayed bridges," vol. 5, no. 1, pp. 17-28, 2009.

[8] X. Wang, Z. Chen, Y. Yu, and H. Liu, "Numerical and experimental study on loaded suspendome subjected to sudden cable failure," vol. 137, pp. 358-371, 2017.

[9] B. Asgarian, S. D. Eslamlou, A. E. Zaghi, and M. Mehr, "Progressive collapse analysis of power transmission towers," Journal of Constructional Steel Research, vol. 123, pp. 31-40, 2016.

[10] C. M. Mozos and A. C. Aparicio, "Numerical and experimental study on the interaction cable structure during the failure of a stay in a cable stayed bridge," Engineering Structures, vol. 33, no. 8, pp. 2330-2341, 2011/08/01/2011.

[11] P. T. I, Guide specification, "Recommendations for Stay Cable Design, Testing and Installation," Post-tensioning Institute Committee on Cable stayed bridge, Fifth Edition, DC45.1-12, 2007

[12] Y. Zhou and S. Chen, "Time-progressive dynamic assessment of abrupt cable-breakage events on cable-stayed bridges," vol. 19, no. 2, pp. 159-171, 2014

[13] Y. Zhou and S. Chen, "Numerical investigation of cable breakage events on long-span cable-stayed bridges under stochastic traffic and wind," Engineering Structures, vol. 105, pp. 299-315, 2015.

[14] Y. Zhou and S. Chen, "Framework of nonlinear dynamic simulation of long-span cable-stayed bridge and traffic system subjected to cable-loss incidents," Journal of Structural Engineering, vol. 142, no. 3, p. 04015160, 2016.

[15] Z. H. Chen, X. X. Wang, H. B. Liu, and Y. J. Yu, "Failure test of a suspendome due to cable rupture," vol. 15, no. 1, pp. 23-29, 2019

[16] B. S. 5950, "British Standards Institution: Structural use of steel work in buildings, Part1 Code of practice for design - Rolled and welded sections." London(UK); 2002.

[17] D. Stevens, B. Crowder, D. Sunshine, K. Marchand, R. Smilowitz, E. Williamson and M. J. Waggoner, "DoD research and criteria for the design of buildings to resist progressive collapse," vol. 137, no. 9, pp. 870-880, 2011.

[18] K. Marchand, A. McKay, and D. J. Stevens, "Development and application of linear and non-linear static approaches in UFC 4-023-03," in Structures Congress 2009: Don't Mes with Structural Engineers: Expanding Our Role, 2009, pp. 1-10.

[19] J. O. Malley, C. J. Carter, and C. M. Saunders, "Seismic design guidelines and Provision for steel-framed buildings: FEMA 267/267A and 1997 AISC Seismic Provisions," Earthquake spectra, vol. 16, no. 1, pp. 179-203, 2000.

[20] M. S. Zarghamee, S. Bolourchi, and D. W. Eggers, "NIST NCSTAR 1-6D: Federal Building and Fire Safety Investigation of the World Trade Center Disaster: Global Structural Analysis of the Response of the World Trade Center Towers to Impact Damage and Fire," in National Institute of Standards and Technology (US), 2005, no. NIST NCSTAR 1-6D: National Institute of Standards and Technology (US).

[21] W. G. Corley, "Lessons learned on improving resistance of buildings to terrorist attacks," vol. 18 , no. 2 , pp. $68-78,2004$

[22] H. S. Lew, R. Bukowski, N. J. Carino, and H. S. Lew, Design, construction, and maintenance of structural and life safety systems. US Department of Commerce, Technology Administration, National Institute of ..., 2005 .

[23] W. Xue and S. Liu, "Design optimization and experimental study on beam string structures," Journal of Constructional Steel Research, vol. 65, no. 1, pp. 70-80, 2009.

[24] GB, "Code for Design of Steel Structures" GB5017-2017; 2017.

[25] X. Wang, Z. Chen, Y. Yu, and H. Liu, "Numerical and experimental study on loaded suspendome subjected to sudden cable failure," Journal of Constructional Steel Research, vol. 137, pp. 358-371, 2017.

[26] S. Yan, X. Zhao, Y. Chen, Z. Xu, and Y. Lu, "A new type of truss joint for prevention of progressive collapse," vol. 167, pp. 203-213, 2018

[27] A.N.S.Y.S. Inc, "ANSYS LS-DYNA user's guide," ANSYS Inc, Pennsylvania, US, 2017.

[28] A. Documentation, "Release notes: Explicit dynamics analysis. Release 17.1," 2016.

[29] L. M. Tian, J. P. Wei, J. P. Hao, and X. Wang, "Method for evaluating the progressive collapse resistance of long-span single-layer spatial grid structures," Adv. Steel Constr, vol. 15 , no. 1 , pp. 109-115, 2019 


\title{
MECHANICAL BEHAVIOR AND CATENARY ACTION OF RESTRAINED STEEL BEAM UNDER FIRE
}

\author{
Run-Min Ding ${ }^{1}$, Sheng-Gang Fan ${ }^{1, *}$, He-Yang Gui ${ }^{2}$, Cheng-Liang Liu ${ }^{3}$ and Hang Zhou ${ }^{1}$ \\ ${ }^{1}$ Key Laboratory of Concrete and Prestressed Concrete Structures of Ministry of Education, School of Civil Engineering, Southeast University, Jiulonghu Campus, Nanjing 211189, China \\ ${ }^{2}$ China Northwest Architecture Design and Research Institute Co. Ltd, Xi'an 710018, China \\ ${ }^{3}$ East China Architectural Design \& Research Institute, Shanghai 200002, China \\ *(Corresponding author: E-mail: 101010393@seu.edu.cn)
}

\section{A B S T R A C T}

To investigate the mechanical behavior and catenary action of restrained steel beam under fire, experiments were performed on five H-section restrained steel beams exposed to ISO-834 standard fire. At first, mechanical property tensile tests were performed on 3 room-temperature specimens and 8 high-temperature specimens, and variation laws of the material properties of steel materials with temperature rising were investigated by the high-temperature steady-state tests. Through the fire experiments, the temperature data, mid-span deflections and failure modes of all specimens were obtained. The experimental results show that: (1) a restrained steel beam is prone to in-plane buckling failure under fire; (2) the loading ratio $\mathrm{n}$ and axial restraint stiffness $\mathrm{Kx}$ have great influences on the catenary action of restrained steel beam under fire; (3) when the loading ratio $n$ is constant, the greater the axial restraint stiffness $\mathrm{Kx}$, the later the catenary action occurs; when the axial restraint stiffness $\mathrm{Kx}$ is constant, the greater the loading ratio $\mathrm{n}$, the earlier the catenary action occurs.

A R T I C LE H I S T O RY

\begin{tabular}{l} 
Received: $\quad$ 17 July 2020 \\
$\begin{array}{l}\text { Revised: } \\
\text { Accepted: }\end{array} \quad$ 30 March 2021 \\
K E Y W O R D S \\
\hline Steel beams with constraints; \\
Mechanical behavior; \\
Catenary action; \\
Loading ratio; \\
Axial restraint stiffness
\end{tabular}

Copyright $\odot 2021$ by The Hong Kong Institute of Steel Construction. All rights reserved

\section{Introduction}

Design methods for the buildings at room temperature have been well established. But the building safety is always under the threat of fires. Fig. 1 displays the fire statistics of China in the past ten years [1], and most of the economic loss and casualties are caused by structural fires. Therefore, the mechanical behavior and fire resistance of engineering buildings under fire have attracted increasing attention by researchers in China and abroad.

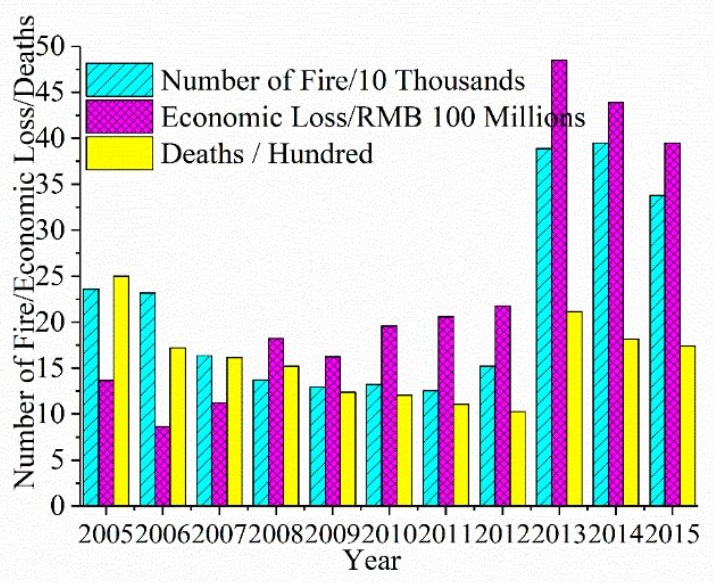

Fig. 1 Statistics of fire situation in China

The existing researches [2-3] primarily focus on the material properties of steel at high temperatures and the mechanical behavior of single component under fire exposure. However, the problem of fire safety of the whole structure cannot be simply divided into the fire resistance of single members. The BRE conducted a series of fire tests on an 8-story steel frame in Cardington [4], and the results show that: the steel beam considering the structural integrity action has a higher fire-resistant performance than the simply supported steel beam; and in the whole structure, the catenary action is mainly caused by the constraints applied at both ends of steel beam, which can greatly improve the bearing capacity of beam.

Numerous studies have been carried out on the fire-resistant performance of restrained steel beam at elevated temperatures, and relevant design methods have been proposed. However, a comprehensive and systematic study on the formation mechanism and judgement principle of catenary action has not been conducted. Burgess et al. [5] conducted experiments on the behaviors of steel beam under fire exposure. The research suggested that the bearing capacity of a steel beam at high temperatures can be greatly improved when its both ends can provide strong constraints. Usmani et al. [6] theoretically analyzed the deformation and internal force in the restrained steel beam caused by thermal expansion with the consideration on the axial and rotational restraint stiffness, and a formula for calculating the deformation and internal force in the beam was given. Through fire tests, Liu et al. [7] investigated the influencing factors on the fire resistance of restrained steel beams, including loading ratio, axial and rotational constraints, which indicated that the fire-resistant performance of restrained steel beam is better than that of unrestrained steel beam due to end constraints of beam. Moss et al. [8] performed finite element analysis on a group of restrained steel beams and composite beams under fire exposure, and it was found that the end constraint condition of steel beam has a considerable effect on its fire resistance. Wang and Yin [9-13] investigated the formation process and mechanism of catenary action in the steel beam; and a simplified calculation formula for the deflection of steel beam was established considering the catenary action. Through numerical simulation and analysis, Dwaikat and Kodur [14] proposed a method for evaluating the fire-resistant performance of restrained steel beam by taking a lot of influencing factors in account, such as end constraint, connection construction and temperature gradient. Li et al. [15-18] found that there are large internal temperature forces in the restrained steel beam under fire, and the distribution of stress and strain in the section was given. In addition, a simple method was presented to calculate the maximum deflections of steel beam under high temperatures. Cong and $\mathrm{Li}$ et al. $[19,20]$ tested $6 \mathrm{H}-$ section steel beams under fire exposure to investigate the effects of load intensity and end constraints on the fire resistance of beam. During the test, some specimens produced obvious catenary action, and the coupling of local buckling and lateral-torsional buckling occurred in the steel beam under the combined action of axial force and restraining moment. Luan and Xi [21] analyzed the behaviors of steel beam subjected to fire under different restraint conditions and obtained the influencing laws of restraint conditions on the critical temperature of beam. Ma [22] studied the catenary effect of honeycombed steel beam with end restraint under fire, and he compared and analyzed the mechanical behaviors of honeycombed beam and solid-web beam under fire. Iqbal et al. [23] proposed a simplified analytical method to predict the mechanical behavior of restrained steel beam under fire. Du et al. [24] put forward a modified method to calculate the temperature rising curve of steel beam exposed to natural fire. Liu [25] investigated the catenary actions of restrained corrugated web steel beams with both uniform temperature distribution and non-uniform temperature distribution across the section. The fire resistance design suggestions of corrugated web 
beams with or without end restraints and different cross-section temperature distribution were given, and the fire resistance design of corrugated web beams with different cross-section temperature distribution was transformed into that of flat web steel beams with uniform temperature distribution.

To study the catenary action in the restrained steel beam under fire, the experiments were conducted on $5 \mathrm{H}$-section restrained steel beams in the fire test furnace, and the furnace temperatures, specimen temperatures and mid-span deflections of all specimens were obtained. The influencing factors of the catenary action of restrained steel beam under fire were explored, and the influences of loading ratio and axial restraint stiffness were emphatically investigated.

\section{Mechanical properties of materials}
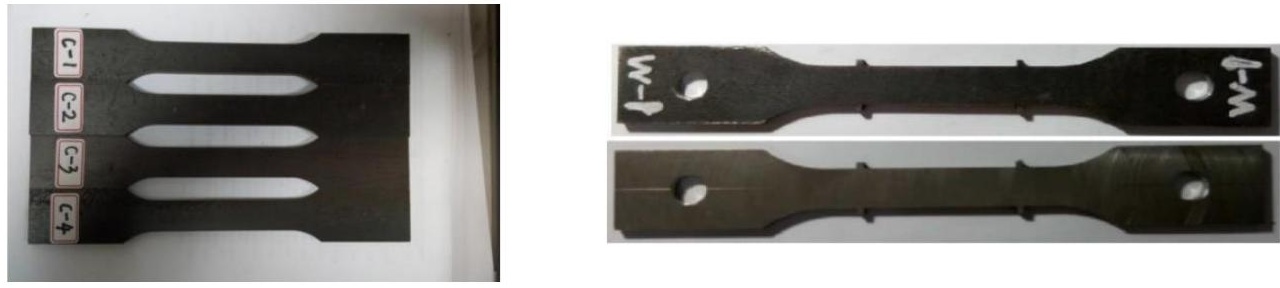

(a) Room-temperature test coupons
Because there is no essential difference in material properties between Q235 and steel materials with higher yield strength, and Q235 has a lower cost, the restrained steel beams in this test are made of Q235. A series of tensile tests were conducted to accurately obtain the mechanical properties of Q235 at different temperatures.

\subsection{Test coupons}

The tensile coupons that tested at room temperature and high temperatures were fabricated according to the requirements of Metallic materials-Tensile testing Part1: Method of test at room temperature [26] and Metallic materialsTensile testing Part2: Method of test at elevated temperature [27], respectively. Fig. 2 shows the finished test coupons. Table 1 and Table 2 provide the number and size of test coupons at room temperature and high temperatures, respectively.

Fig. 2 Material mechanical property test coupons

Table 1

Number, size and mechanical test results of test coupons at room temperature

\begin{tabular}{|c|c|c|c|c|c|c|c|c|c|}
\hline \multirow[b]{2}{*}{ Number } & \multicolumn{2}{|c|}{ Original size } & \multicolumn{3}{|c|}{ Measured size } & \multicolumn{4}{|c|}{ Mechanical property parameter value } \\
\hline & $\begin{array}{c}\text { Thickness } t_{0} \\
\quad / \mathrm{mm}\end{array}$ & $\begin{array}{l}\text { Width } b_{0} \\
\quad / \mathrm{mm}\end{array}$ & $\begin{array}{c}\text { Thickness } t \\
/ \mathrm{mm}\end{array}$ & $\begin{array}{l}\text { Width } \\
b \\
/ \mathrm{mm} \\
\end{array}$ & $\begin{array}{c}\text { Area } A \\
/ \mathrm{mm}^{2}\end{array}$ & $\begin{array}{c}\text { Yield strength } \\
f_{\mathrm{y}} / \mathrm{N} / \mathrm{mm}^{2}\end{array}$ & $\begin{array}{l}\text { Ultimate strength } \\
\qquad f_{\mathrm{u}} / \mathrm{N} / \mathrm{mm}^{2}\end{array}$ & $\begin{array}{c}\text { Elastic modulus } \\
E / \mathrm{N} / \mathrm{mm}^{2}\end{array}$ & Elongation / \% \\
\hline C-1 & 8 & 20 & 7.50 & 19.98 & 149.85 & 293 & 429.3 & $2.07 \times 10^{5}$ & 38.19 \\
\hline $\mathrm{C}-2$ & 8 & 20 & 7.53 & 20.02 & 150.75 & 285 & 423.5 & $2.04 \times 10^{5}$ & 36.83 \\
\hline C-3 & 5.5 & 20 & 5.43 & 19.98 & 108.49 & 305 & 443.7 & $2.17 \times 10^{5}$ & 39.40 \\
\hline C-4 & 5.5 & 20 & 5.44 & 20.03 & 108.96 & 310 & 444.5 & $2.11 \times 10^{5}$ & 38.57 \\
\hline
\end{tabular}

Table 2

Number, size and Mechanical test results of test coupons at high temperatures

\begin{tabular}{|c|c|c|c|c|c|c|c|c|c|c|}
\hline \multirow[b]{2}{*}{ Number } & \multirow[b]{2}{*}{$\begin{array}{c}\text { Temperature } \\
\text { condition } \\
/{ }^{\circ} \mathrm{C}\end{array}$} & \multicolumn{2}{|c|}{ Original size } & \multicolumn{2}{|c|}{ Measured size } & \multicolumn{3}{|c|}{ Mechanical property parameter value } & \multicolumn{2}{|c|}{ Reduction factor } \\
\hline & & $\begin{array}{c}\text { Thick } \\
t_{0} \\
/ \mathrm{mm}\end{array}$ & $\begin{array}{l}\text { Width } \\
b_{0} \\
/ \mathrm{mm}\end{array}$ & $\begin{array}{l}\text { Thick } \\
t \\
/ \mathrm{mm}\end{array}$ & $\begin{array}{l}\text { Width } \\
b \\
/ \mathrm{mm}\end{array}$ & $\begin{array}{c}\text { Yield strength } \\
f_{\mathrm{yT}} \\
\mathrm{N} / \mathrm{mm}^{2}\end{array}$ & $\begin{array}{c}\text { Ultimate } \\
\text { strength } \\
f_{\mathrm{uT}} \\
\mathrm{N} / \mathrm{mm}^{2} \\
\end{array}$ & $\begin{array}{c}\text { Elastic } \\
\text { modulus } \\
E_{\mathrm{T}} \times 10^{5} \mathrm{~N} / \mathrm{mm}^{2}\end{array}$ & $f_{\mathrm{y} \mathrm{T}} / f_{\mathrm{y}}$ & $E_{\mathrm{T}} / E$ \\
\hline $\mathrm{W}-0$ & 20 & 4 & 15 & 3.84 & 14.94 & 309 & 439 & 2.05 & 1.000 & 1.000 \\
\hline $\mathrm{W}-1$ & 100 & 4 & 15 & 3.93 & 14.91 & 305 & 438 & 2 & 0.987 & 0.976 \\
\hline $\mathrm{W}-2$ & 200 & 4 & 15 & 3.92 & 14.94 & 295 & 534 & 1.85 & 0.955 & 0.902 \\
\hline $\mathrm{W}-3$ & 300 & 4 & 15 & 3.89 & 14.95 & 298 & 521 & 1.67 & 0.965 & 0.815 \\
\hline $\mathrm{W}-4$ & 400 & 4 & 15 & 4.02 & 14.8 & 302 & 398 & 1.42 & 0.977 & 0.693 \\
\hline W-5 & 500 & 4 & 15 & 4.04 & 14.86 & 220.6 & 263 & 1.294 & 0.714 & 0.631 \\
\hline W-6 & 600 & 4 & 15 & 3.99 & 14.9 & 130.1 & 140.4 & 0.736 & 0.421 & 0.359 \\
\hline W-7 & 700 & 4 & 15 & 3.98 & 15.04 & 65.3 & 66.94 & 0.193 & 0.211 & 0.094 \\
\hline W-8 & 800 & 4 & 15 & 3.97 & 14.82 & 43.45 & 47.66 & 0.175 & 0.141 & 0.085 \\
\hline
\end{tabular}

There are 13 tensile coupons in total, of which 4 are room-temperature coupons and the other 9 are high-temperature coupons. Room-temperature coupons $\mathrm{C}-1$ and $\mathrm{C}-2$ were cut from the flange of steel beam, and coupons C-3 and $\mathrm{C}-4$ were cut from the web of steel beam. For high-temperature coupons, each temperature condition corresponds to one coupon.

\subsection{Test method}

Room-temperature tensile tests were conducted by following the relevant requirements in the code [26]. The loading of the tensile tests was controlled by displacement and divided into two stages. In the first stage of loading process, the initial elastic modulus and yield strength were mainly measured, and the test coupons were stretched to yield at a speed of $0.5 \mathrm{~mm} / \mathrm{min}$. In the second stage of loading process, the ultimate tensile strength was measured and the test coupons were stretched to fracture at a speed of $4 \mathrm{~mm} / \mathrm{min}$. The tensile deformation of the gauge length of test coupon was measured by a normal temperature extensometer.

The high-temperature tensile test includes two methods: steady-state test and transient-state test $[28,29]$. In the steady-state test method, the coupon is heated to a predetermined temperature and keep it constant, then tensile load is increased until the coupon is damaged. In the transient-state test method, the coupon is loaded to a constant stress level at room temperature, then the temperature is increased at a certain speed until the coupon is damaged. In this study, the mechanical properties of the material at different temperatures were 
tested through the steady-state method, with the controlled temperature conditions chosen as $20{ }^{\circ} \mathrm{C}, 100{ }^{\circ} \mathrm{C}, 200{ }^{\circ} \mathrm{C}, 300{ }^{\circ} \mathrm{C}, \ldots, 800{ }^{\circ} \mathrm{C}$. The existing results $[30,31]$ showed that the furnace temperature is nearest to the surface temperature of coupon when the heating rate of coupon is set at a speed of $20{ }^{\circ} \mathrm{C} / \mathrm{min}$.

According to the requirements in the code [27], the steps of the steady-state test are listed as follows: (1) The heating furnace is heated to a controlled temperature condition at a speed of $20^{\circ} \mathrm{C} / \mathrm{min}$ and then the temperature is kept constant for $30 \mathrm{~min}$ to ensure that the measured furnace temperature is as consistent as possible with the surface temperature of coupon. (2) In the process of heating-up and heat-preservation, the testing device should be constantly adjusted to ensure that the load applied by the testing machine is 0 , that is, the coupon is allowed to expand freely. (3) Finally, the coupon is loaded to damage by displacement control, and the temperature remains unchanged within the whole loading period. The loading process is controlled by displacement and can also be divided into two stages, and the specific loading method is the same as the tensile tests at room temperature.

\subsection{Test results}

The failure phenomena in the tensile tests at room temperature and high temperatures are illustrated in Fig. 3: (1) Every coupon underwent a long plastic deformation stage from tensile to fracture, there was distinct necking phenomenon after fracture, and the material exhibited excellent extensibility. (2) For high-temperature tensile coupons, the surface of coupon showed a bright original color at $200{ }^{\circ} \mathrm{C}$; at $300{ }^{\circ} \mathrm{C} \sim 500^{\circ} \mathrm{C}$, the surface color of coupon changed from light yellow to dark blue; and at $600{ }^{\circ} \mathrm{C} \sim 800{ }^{\circ} \mathrm{C}$, the surface color of coupon became dark and there was a film on the surface. Finally, the surface color of coupon gradually changed from dark black to dark brown with further increase in temperature.

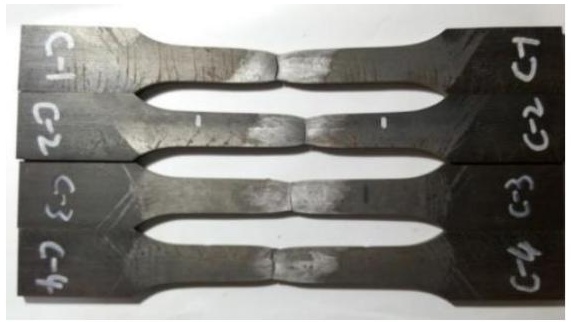

(a) Room-temperature test coupons

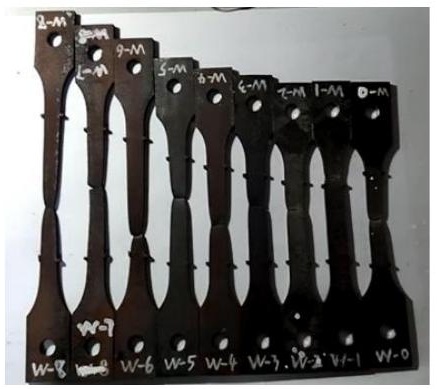

(b) High-temperature test coupons

Fig. 3 Failure phenomenon of the material mechanical property test coupons

The tensile test results at room temperature and high temperatures are given in Table 1 and Table 2, respectively. The stress-strain curves of test coupons are shown in Fig. 4(a) and (b). From Tables 1 and 2 and Fig. 4, the following conclusions can be obtained: (1) With temperature rising, the yield plateau of steel gradually disappears. Because the research object of this paper is the catenary action of restrained steel beam under fire, which belongs to the range of large deformation of components, the maximum strain of steel material in the restrained steel beam under fire may exceed $2 \%$. (2) At a temperature range of $200{ }^{\circ} \mathrm{C} \sim 300{ }^{\circ} \mathrm{C}$, the coupon appears the phenomenon of blue brittle, and the ultimate strength of steel is improved. Thereafter the yield strength and ultimate strength gradually decrease with temperature rising. At temperature of $600{ }^{\circ} \mathrm{C}$, the degradation of the strength of steel is obvious. At temperature of $800{ }^{\circ} \mathrm{C}$, the strength of steel is only equal to approximately $10 \%$ of the strength at normal temperature. (3) The elastic modulus of steel descends with temperature rising. At temperature of $800{ }^{\circ} \mathrm{C}$, the elastic modulus of steel has an obvious degradation.

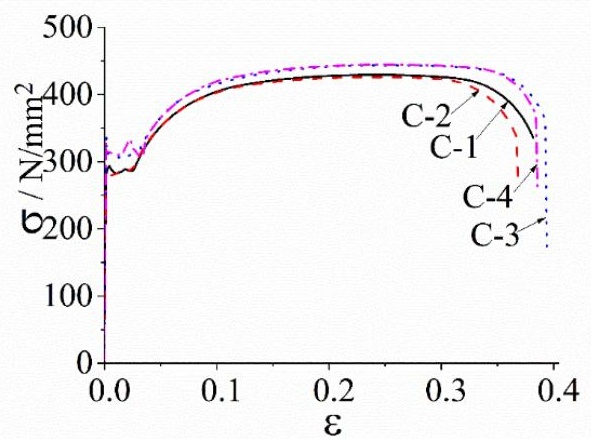

(a) Room-temperature test coupons

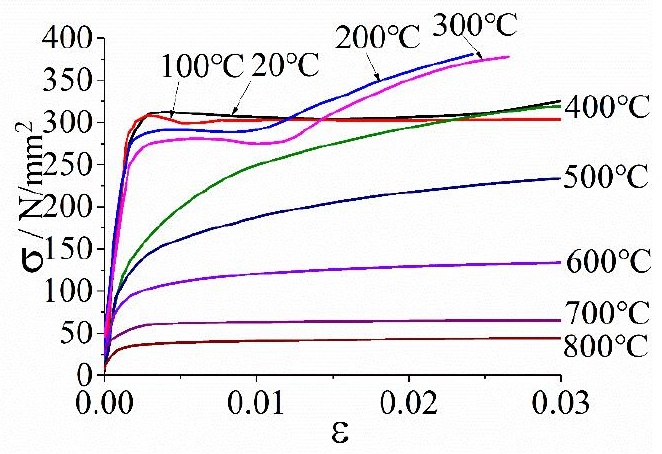

(b) High-temperature test coupons

Fig. 4 Stress-strain curves of test coupons

Table 2 gives the measured reduction coefficients for elastic modulus and yield strength of steel at high temperatures, and they were compared with the recommended values given by the Eurocode 3 (EN 1993-1-2) [32] and Chinese Technical code for fire safety of steel structure in buildings (CECS 200: 2006) [33], as shown in Fig. 5. It can be seen that from Fig. 5: (1) At different temperatures, the experimental values of yield strength reduction coefficient of steel are lower than those specified in the Eurocode 3 [32], but they are similar to those specified in the Chinese Technical code [33]. (2) At different temperatures, the experimental values of elastic modulus reduction coefficient of steel are similar to those specified in the Eurocode 3 [32], but substantially lower than those specified in the Chinese Technical code [33].

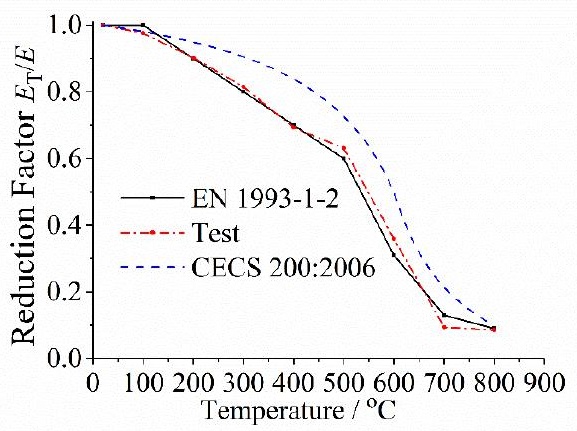

(a) Elastic modulus

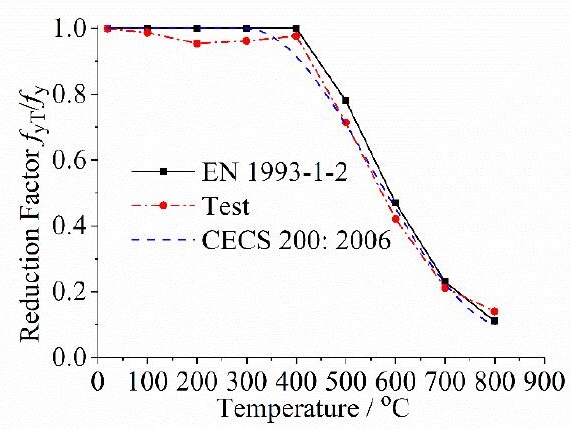

(b) Yield strength

Fig. 5 Comparisons of the reduction coefficients of steel at high temperatures 


\section{Fire test of steel beam with constraint}

Three-side heated tests were conducted on five $\mathrm{H}$-section restrained steel beams to investigate the influences of loading ratio and axial restraint stiffness on the development of catenary action. The failure mode, temperature data, midspan vertical deformation and loading-point vertical deformation of each specimen were obtained.

\subsection{Testing device}

The fire tests were carried out in a horizontal fire test furnace system, consist of heating equipment, loading equipment and data acquisition control equipment.
The heating equipment is composed of a furnace cavity, flame nozzle and thermocouple. The furnace cavity can be divided into left and right parts by setting refractory brick wall in the middle. In view of the size of the specimen, the fire test was only carried out through half furnace cavity, and its size is 3.13 $\mathrm{m} \times 1.88 \mathrm{~m}$ (length $\times$ width). The half furnace cavity has 4 flame nozzles and 4 thermocouples, which are employed for the heating-up of furnace cavity and air temperature monitoring, respectively. The temperature rise of the fire test furnace follows the ISO-834 fire curve, and the furnace is heated by burning natural gas. The exhaust ducts are arranged at the bottom of the furnace, which can keep the pressure in the furnace cavity stable and the temperature distribution uniform. Fig. 6(a) and (b) show the overall appearance and internal cavity of the horizontal fire furnace respectively.

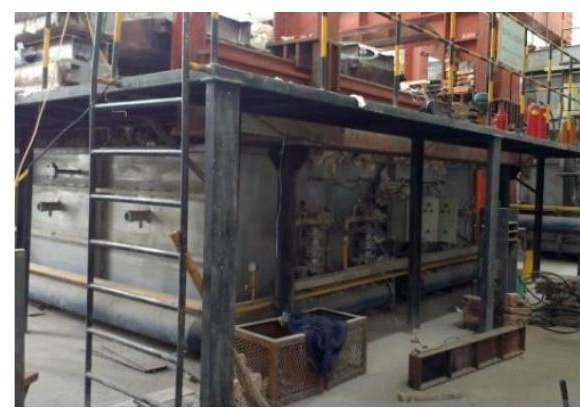

(a) Appearance of fire furnace

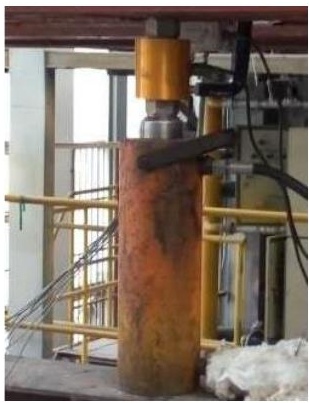

(d) Hydraulic jack and pressure senso

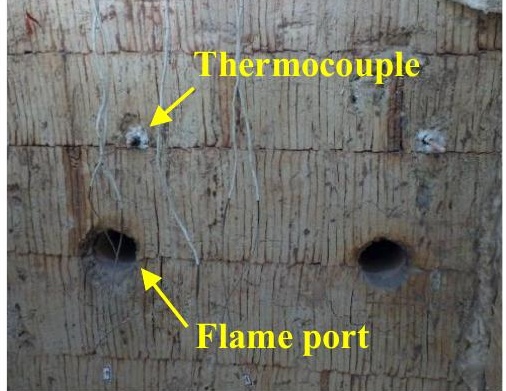

(b) Fire furnace interior

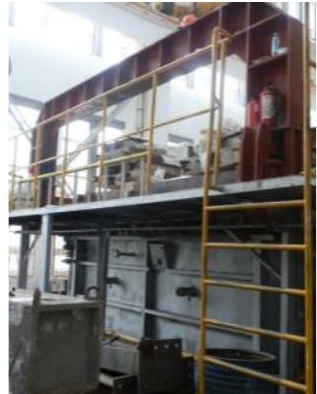

(c) Reaction frame

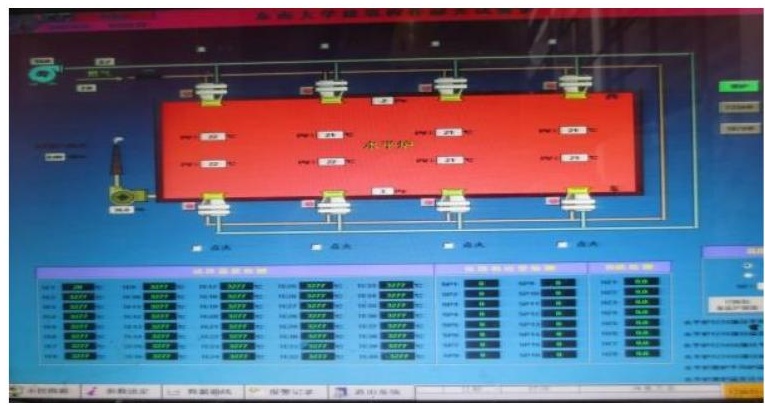

(e) Data presentation equipment

Fig. 6 Horizontal fire test equipment

The loading equipment mainly includes a $300 \mathrm{kN}$ hydraulic jack, a $200 \mathrm{kN}$ pressure sensor and a $500 \mathrm{kN}$ vertical reaction frame, as shown in Fig. 6(c) and (d). In the restrained steel beam fire test, the vertical load value applied to the specimen is relatively small. To accurately control all load levels, a $200 \mathrm{kN}$ pressure sensor was used in this fire test.

The data acquisition equipment is mainly composed of load collector, displacement collector and temperature collector, as shown in Fig. 6(e). The load

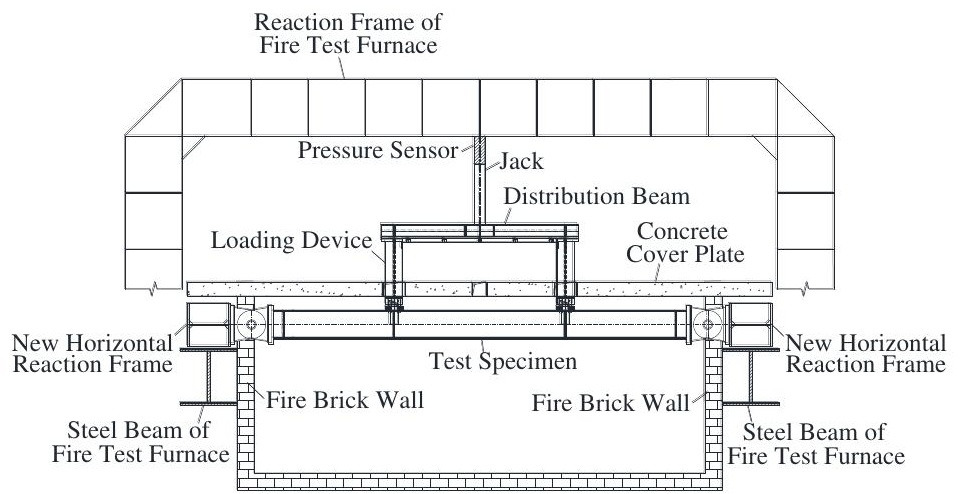

(a) Elevation was controlled to be constant and monitored by the pressure sensor, so the load collector is not utilized during the test. The specimen deformations were recorded by the displacement collector. Through 17 thermocouples arranged on each specimen and 4 thermocouples set in the furnace, the temperature acquisition controller can record and control all temperature data. Fig. 7(a) and (b) show the overall fire test devices of restrained steel beams.

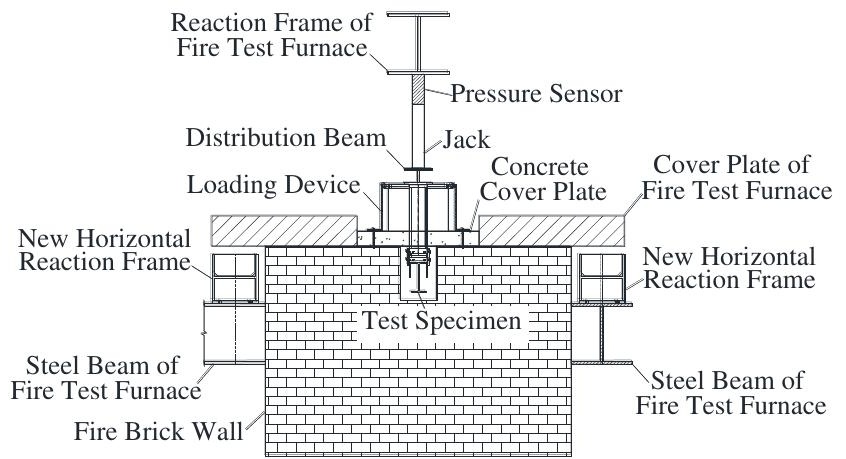

(b) Profile

Fig. 7 Overall fire test devices of restrained steel beams

\subsection{Design and manufacture of horizontal reaction frame}

To accurately simulate the different end constraint conditions of restrained steel beam under fire, a horizontal reaction frame was added to provide different axial restraint stiffnesses for the specimens. Fig. 8(a) shows the arrangement of the horizontal reaction frame set with "Constraint position 1" and "Constraint 
position 2". During the test, different sizes of axial restraint stiffness can be provided for the end of the specimen by changing the constraint position on the horizontal reaction frame, and the axial restraint stiffness provided by Constraint position 2 is greater than the axial restraint stiffness provided by Constraint position 1. Through numerical simulation and mechanical method, the axial restraint stiffnesses provided by Constraint positions 1 and 2 can be calculated, which are $1.29 \times 10^{8} \mathrm{~N} / \mathrm{m}$ and $2.087 \times 10^{8} \mathrm{~N} / \mathrm{m}$, respectively.
Fig. 8(b) illustrates the finished horizontal reaction frame composed of four edge beams. Edge beam A and Edge beam B adopt an H-shaped section, the section size is HW $300 \times 300 \times 10 \times 15$ and the material is Q345B, as shown in Fig. 8(c) and (d), respectively. The edge beams are connected with each other by flange joints. To prevent the four corners of the horizontal reaction frame from warping during the test, the Edge beams A and B are connected with the top steel beams of the furnace using split bolts at the four corners.

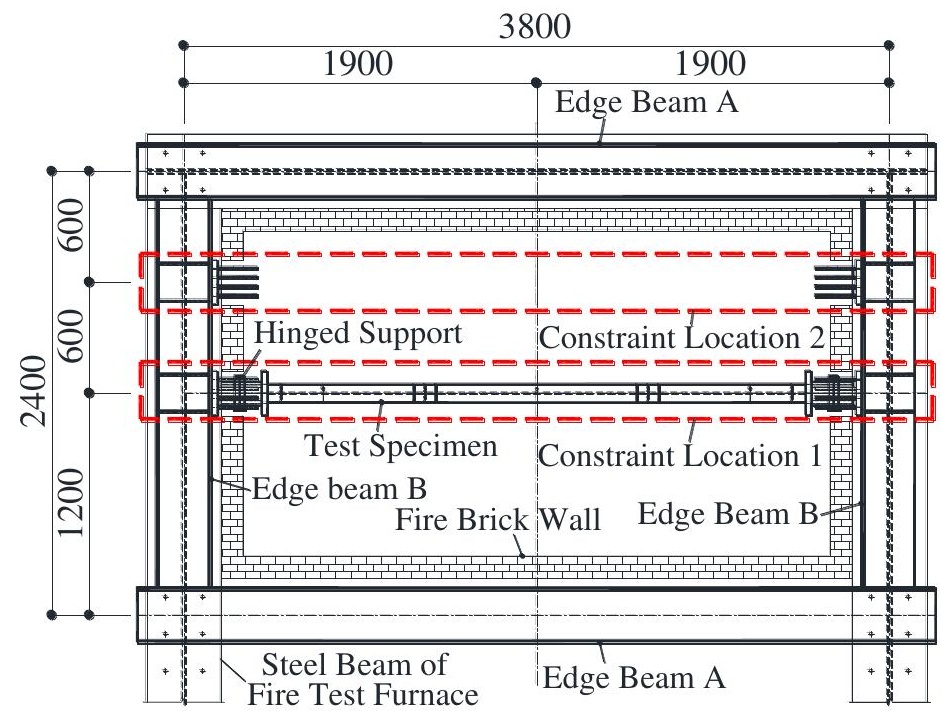

(a) Layout of horizontal reaction frame

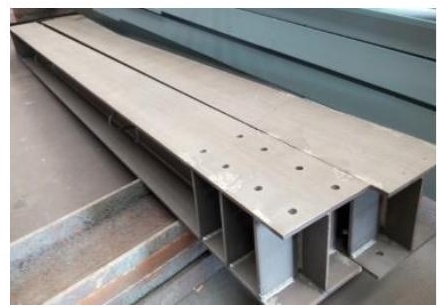

(c) Edge beam $\mathrm{A}$

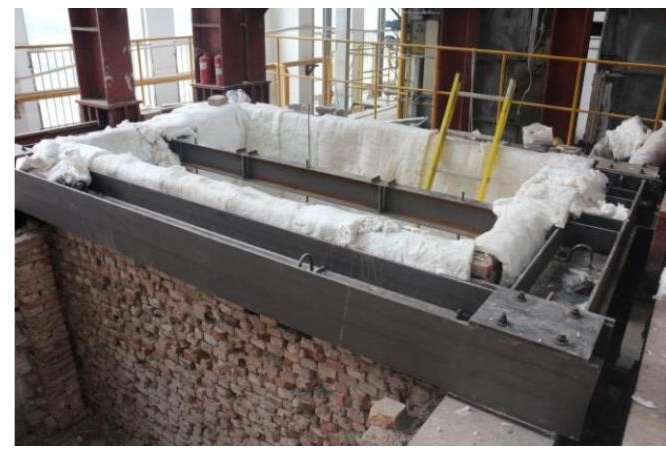

(b) Reaction frame appearance

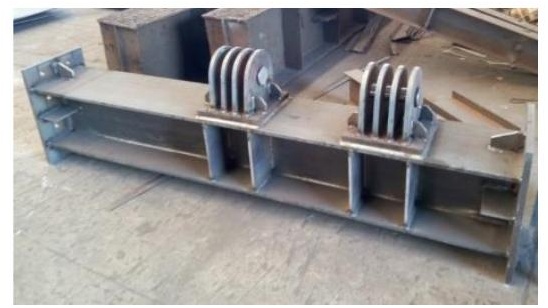

(d) Edge beam B

Fig. 8 New added horizontal reaction frame under fire test furnace

\subsection{Test specimens}

Q235B steel was selected as the material of the specimens, and the crosssection was the hot-rolled H-section. The length of specimen was selected as 3.2 $\mathrm{m}$ in considering of the furnace cavity size. To investigate the catenary action of restrained steel beam under fire, the specimen should be controlled to occur inplane bending deformation during the test, and the out-of-plane global instability or local buckling failure of plate should be avoided as far as possible. The finite element software ABAQUS [34] is used to simulate the restrained steel beam for many times, and the cross section of specimen was determined as HN200 $\times$ $100 \times 100 \times 5.5 \times 8$. According to the test method of references [35-39], the restrained steel beam fire test adopt the two-point loading mode, and the loading points are located at $1 / 3$ of the span. Two plates were welded to form a slot for fixing the loading device at the loading point of specimen. Fig. 9 illustrates the detailed dimensions of the specimen, and Fig. 10 shows the finished specimens.

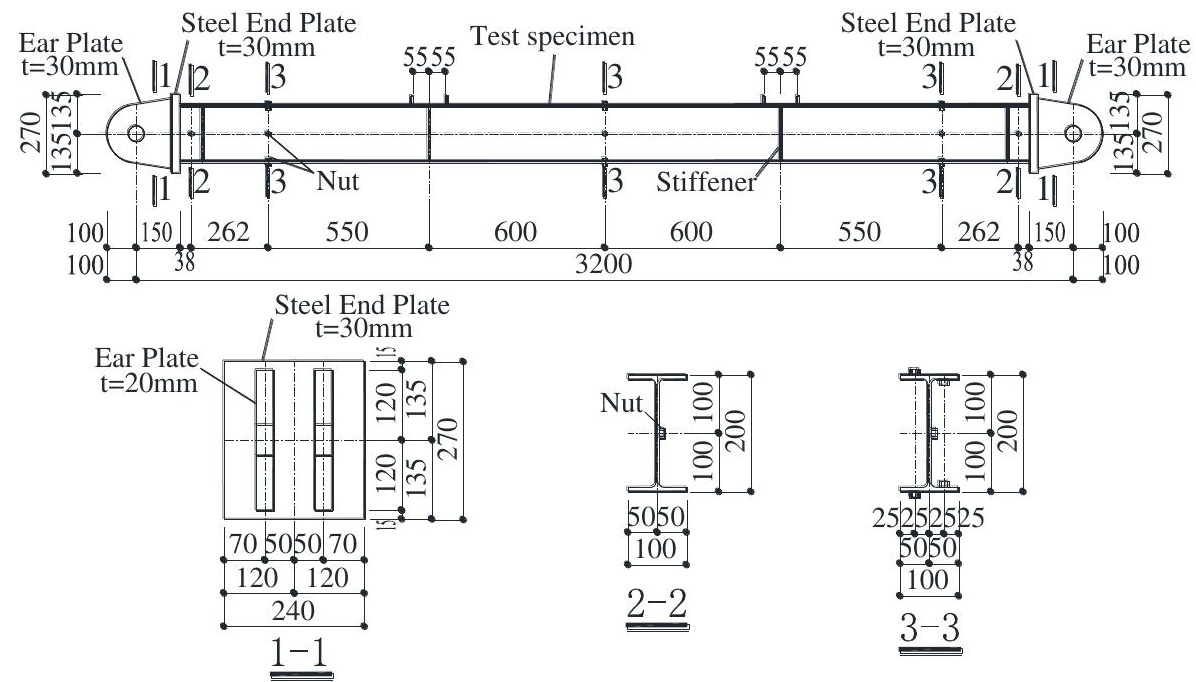

Fig. 9 Detailed dimensions of specimen 


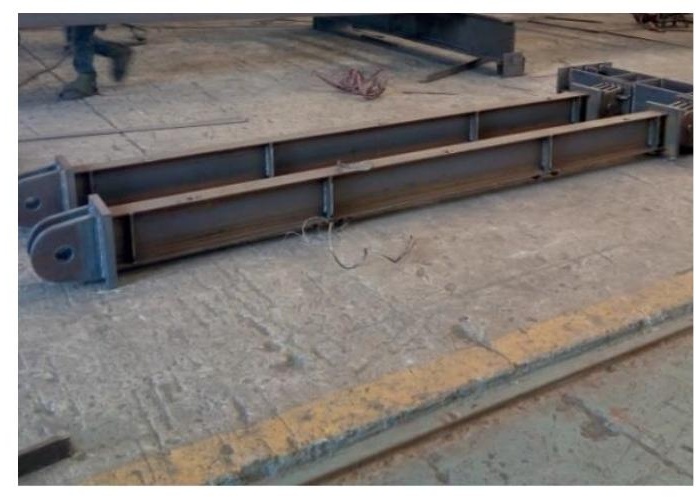

Fig. 10 Finished specimens

The detailed information for each specimen is shown in Table 3. To investigate the effect of loading ratio on catenary action, the specimens can be divided into two groups, B-1 and B-2 are in one group (with the same axial restraint stiffness $1.29 \times 10^{8} \mathrm{~N} / \mathrm{m}$, but different loading ratios), B-3 and B-4 are in the other (with the same axial restraint stiffness $2.087 \times 10^{8} \mathrm{~N} / \mathrm{m}$, but different loading ratios). To investigate the effect of axial restraint stiffness on catenary action, the specimens can also be divided into two groups, B-1 and B-3 are in one group (with the same loading ration 0.48 , but different axial restraint stiffnesses), B-2 and B-4 are in the other (with the same loading ration 0.34, but different axial restraint stiffnesses). The specimen B-5 is a repeat test of B-1, to verify the correctness of test results.

For specimens B1 B5, the thermocouple measurement points were put on five sections (section 1 5) along the length direction of the specimen, respectively $38 \mathrm{~mm}, 300 \mathrm{~mm}, 1450 \mathrm{~mm}, 2600 \mathrm{~mm}$, and $2862 \mathrm{~mm}$, away from the left end. For sections 2, 3 and 4, four thermocouple measurement points are set on the inner and outer sides of the flanges, and one on the middle of the web. For sections 1 and 5, only one thermocouple measurement point is put on the web. Among them, the thermocouple measurement points of section 2, section 3 and section 4 are mainly used to measure the temperature distribution around the same section and the temperature distribution along the length direction of different sections. Section 1 and section 5 are located near the supports and wrapped under fireproof cotton. Each specimen has a total of 17 thermocouple measurement points on its surface, as shown in Fig. 11.

Table 3

Detailed design parameters of test specimens

\begin{tabular}{ccccc}
\hline Specimen number & Sectional dimension & $\begin{array}{c}\text { Length } \\
(\mathrm{m})\end{array}$ & Loading ratio & Constraint position \\
\hline B-1 & & 3.2 & 0.48 & 1 \\
B-2 & & 3.2 & 0.34 & $1.29 \times 10^{8}$ \\
B-3 & HN200 $\times 100 \times 5.5 \times 8$ & 3.2 & 0.48 & 2 \\
B-4 & & 3.2 & 0.34 & 2 \\
B-5 & & 3.2 & 0.48 & $2.087 \times 10^{8}$ \\
\hline
\end{tabular}

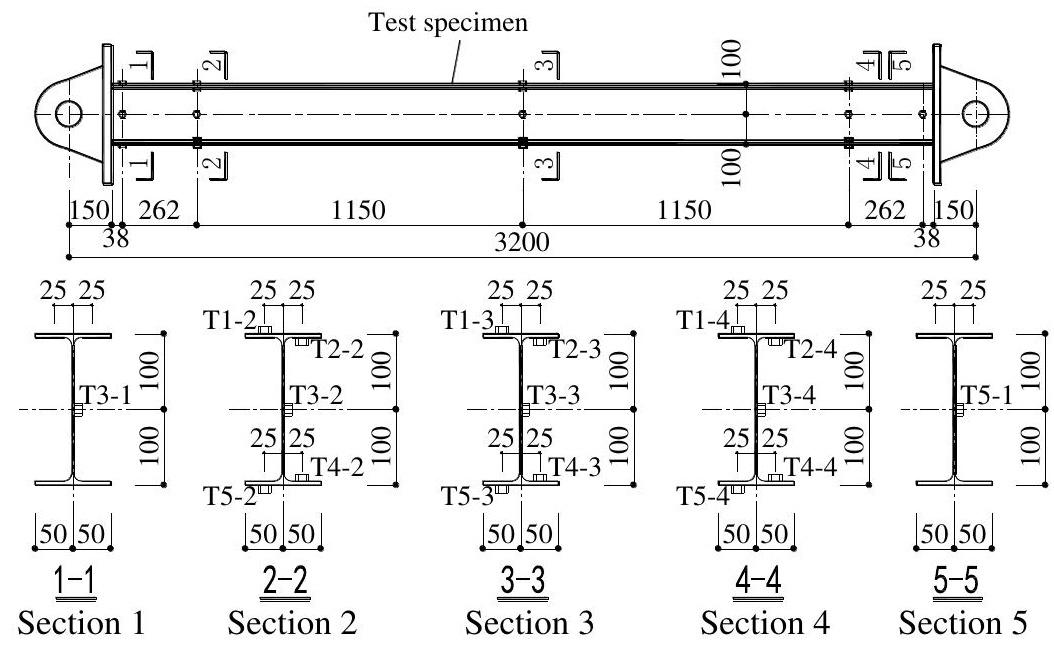

Fig. 11 Thermocouple measurement points arranged on the surface of specimen

The loading ratio $n$ is the ratio between the maximum mid-span bending moment caused by external load $M_{\max }$ and the flexural capacity of beam at room temperature $M_{\mathrm{u}}$, as shown in Eq. (1). The loading ratio $n$ of specimen is a crucial parameter to restrained steel beam fire test. In this study, the bearing capacity test of steel beam at room temperature was not carried out, the flexural capacity of beam $M_{\mathrm{u}}$ was calculated by finite element software ABAQUS [34].

$n=\frac{M_{\max }}{M_{\mathrm{u}}}$

In the event of an excessive loading ratio, the recorded data points will be limited and the specimen will be prematurely destroyed; in the event of an small loading ratio, the test time and the test cost will be excessive. Considering these factors, the loading ratio $n$ was selected as 0.34 and 0.48 in this fire test.

\subsection{Test procedure}

The specific steps of restrained steel beam fire test are as follows: 1) Install the self-made horizontal reaction frame.

2) Install test specimen. To simulate the 3 -side heated fire condition of the steel beam with constraints, the upper flange of specimen was wrapped with fireproof wool. Fig. 12 shows the test specimen after installation.

3) Arrange loading device. The loading system consisted of the distribution beam, $300 \mathrm{kN}$ hydraulic separate jack and $200 \mathrm{kN}$ pressure sensor. Fig. 13 shows the arrangement of the loading system.

5) Link up thermocouple wires and linear displacement meter to the data acquisition device.

6) Apply load on the test specimen and keep the load constant.

7) Heat up the fire test furnace by ISO-834 standard fire curve and record data.

8) End the experiment. According to the relevant provisions of the Internal Standard ISO 834 [40], the failure criteria for beam members under fire is that the mid-span deformation exceeds $L^{2} /(400 d) \mathrm{mm}$ or the mid-span deformation speed reaches $L^{2} /(9000 d) \mathrm{mm} / \mathrm{min}$ ( $d$ is section height of the beam, $L$ is the net span of the beam). That is, when the mid-span vertical deformation of steel beam meets the criteria, it is considered that the steel beam fails under fire. However, this paper is focused on the development of catenary action in the restrained steel beam under fire. In accordance with the above criteria, the restrained steel beam may not occur catenary action before the end of test. Therefore, in the restrained steel beam fire test, the steel beam should be deformed as much as possible. In view of the limitations of the test conditions, the end condition of fire test for each specimen is preliminarily set as: the deformation value at mid span of the 
specimen exceeds $L / 14$.

9) Observe the experimental phenomena.

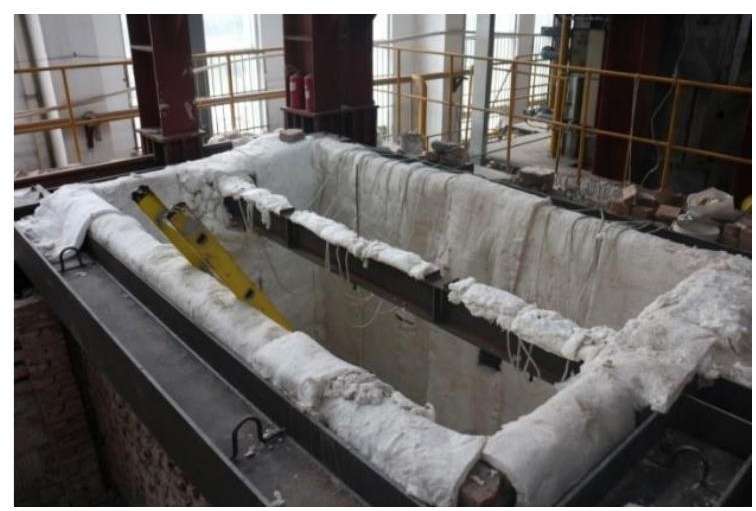

Fig. 12 Installation of the specimen

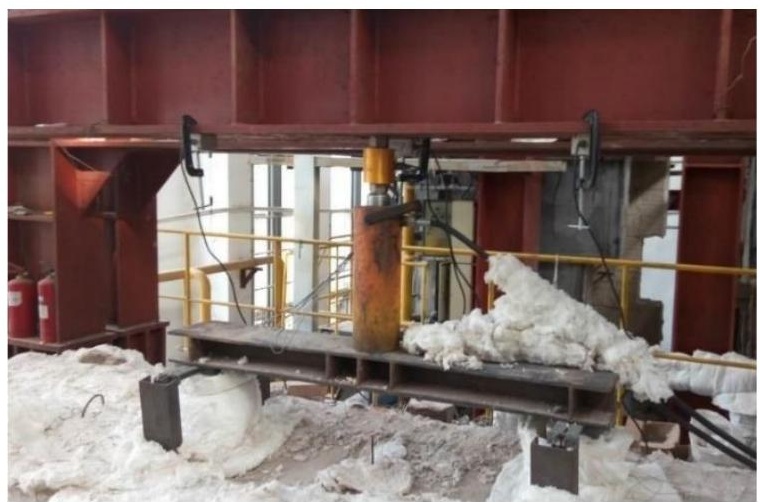

Fig. 13 Arrangement of the loading devices

\subsection{Experimental phenomena}

The specimens (B-1 B-5) had similar experimental phenomena: (1) the air temperature of fire test furnace had a rapid increase; (2) at the beginning of heating, the specimen temperature was obviously lower than the furnace temperature and increased slowly; and (3) the mid-span vertical deformation of specimen grew slowly at first. Due to limited space, only the specific experimental phenomena of specimen B-1 was described.

During the fire test on specimen B-1, the following experimental phenomena can be observed by the data acquisition system: (1) At the beginning of test, as the surface temperature of specimen increased, the mid-span vertical deformation of specimen grew slowly. (2) In approximately 8 mins, the furnace temperature rose to $574{ }^{\circ} \mathrm{C}$. While the surface temperature of specimen had a slow increase, the mid-span vertical deformation of specimen rapidly increased. (3) In approximately $13 \mathrm{mins}$, the furnace temperature rose to $640{ }^{\circ} \mathrm{C}$, and the vertical deformation at mid span of specimen was $244 \mathrm{~mm}$, which was greater than $228 \mathrm{~mm}(L / 14=228 \mathrm{~mm}$, that is the end condition of test). The specimen was judged to be failed. (4) After the end of test, the mid-span deformation of specimen gradually rebounded and was finally maintained at $213 \mathrm{~mm}$.

After the end of test, when the furnace temperature dropped to room temperature, the fire test furnace was opened, and the experimental phenomena and failure mode of specimen B-1 were observed as follows: (1) The specimen mainly had in-plane bending deformation, and the mid-span deformation was large, which was far beyond the specification limits, as shown in Fig. 14(a). (2) A small out-of-plane shift of the upper and lower flanges, which was approximately $13 \mathrm{~mm}$, can be observed at the mid span, as revealed in Fig. 14(b); (3) The specimen surface under fire became reddish brown, and the web became gray-black. The color of the non-fire area (protection of fire-resistant wool) was the same as the color of normal steel (room temperature). (4) Tiny grains were observed on the flange and web of the specimen, as shown in Fig. 14(c).

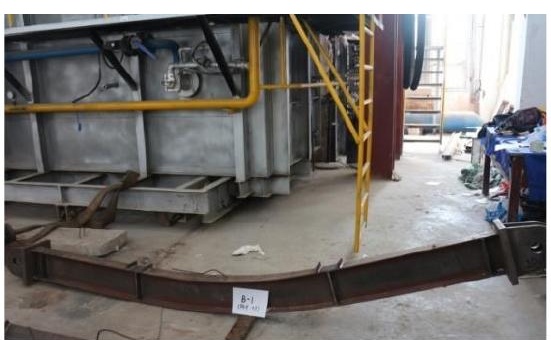

(a) Overall deformation

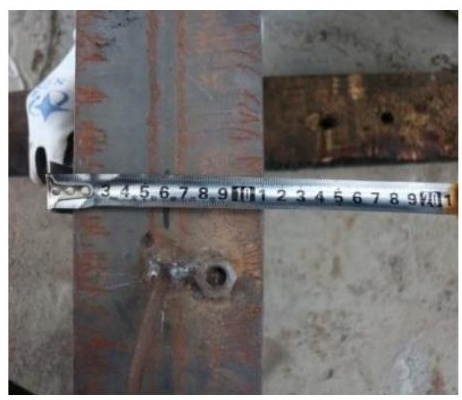

(b) Out-of-plane lateral deformation

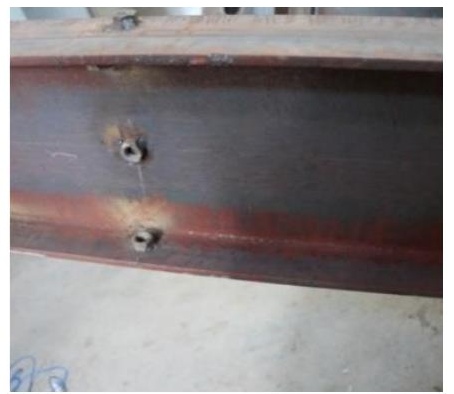

(c) Local tiny grains

Fig. 14 Test phenomena of specimen B-1

The failure mode of specimens B-1 B-5 is shown in Fig. 15. According to Fig. 15: (1) After the failure of the five specimens, the mid-span deformation value considerably exceeded the standard limit. The deformation modes of all specimens were equivalent. (2) All five specimens exhibited distinct catenary action after the fire test. (3) Because the fire duration and surface temperature of the specimens were almost equivalent, the surface color of the specimens was similar.
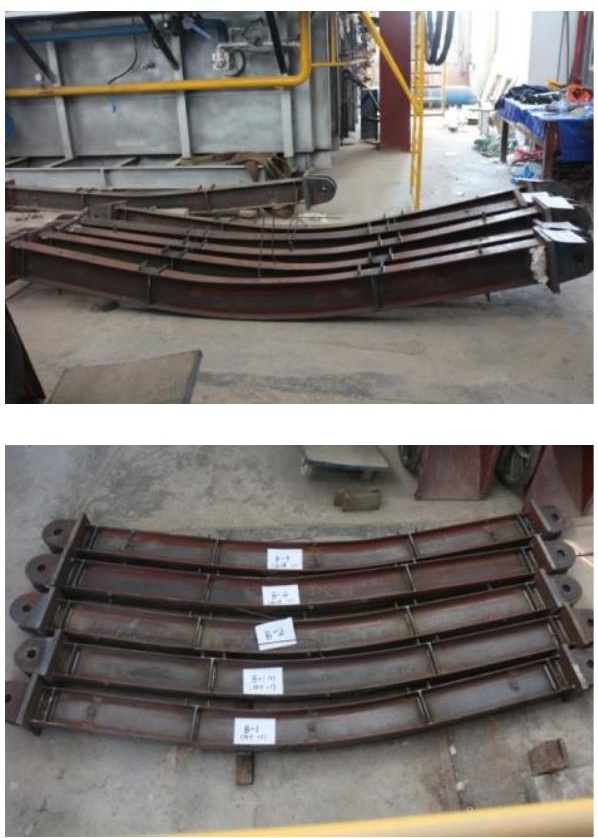


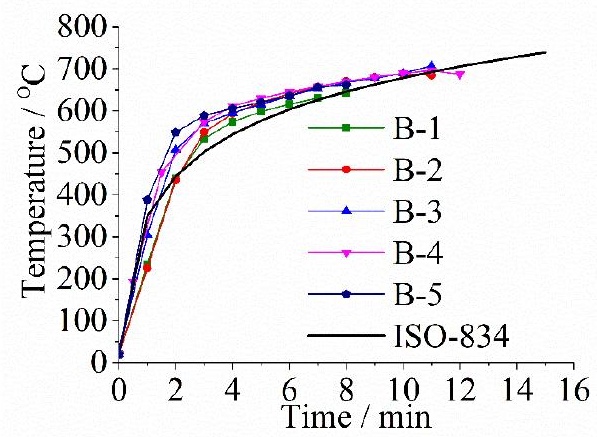

Fig. 16 Furnace temperature curves of specimens B-1 B-5

\subsection{Experimental results}

\subsubsection{Furnace temperature}

The ISO-834 standard fire curve is very rapid at the initial stage, the temperature should be heated up to $300{ }^{\circ} \mathrm{C}$ within $1 \mathrm{~min}$. But it is difficult for horizontal fire test furnace to rise to this temperature in such a short time.
Therefore, in the actual heating process of fire test, the manual control mode is used to preheat the furnace chamber. When the furnace temperature reaches $200 \sim 300{ }^{\circ} \mathrm{C}$, the fire test furnace is switched to the automatic control mode to raise the temperature by following the ISO-834 fire curve. Four thermocouples that installed in the horizontal fire furnace are used to measure the air temperature of fire furnace. Fig. 16 illustrates the furnace temperature - time curves of all specimens and ISO-834 curve, without displaying the temperature data before auto control stage. From Fig. 16, it can be seen the furnace temperature curves of five specimens are similar to ISO-834 curve, and the variation trend is consistent.

\subsubsection{Surface temperature of specimen}

For specimens B-1 B-5, the temperature rising curves of all measurement points set on the specimens are shown in Fig. 17(a) (e). The five temperature measurement points along the height direction of specimen are respectively denoted as T1, T2, T3, T4 and T5. The temperature values of T1, T2, T3, T4 and T5 are the average temperature values of the corresponding positions in section 2 , section 3 and section 4, respectively. For instance, the temperature value of $\mathrm{T} 1$ is the average of the temperature values of measurement points T1-2, T1-3 and $\mathrm{T} 1-4$, and the temperature values of $\mathrm{T} 2, \mathrm{~T} 3, \mathrm{~T} 4$ and $\mathrm{T} 5$ can be similarly calculated. $T_{\mathrm{E}}$ is the average temperature value of the measured points in section 1 and section 5 .

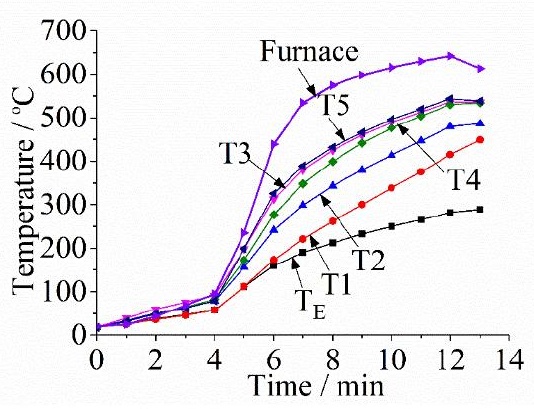

(a) B-1

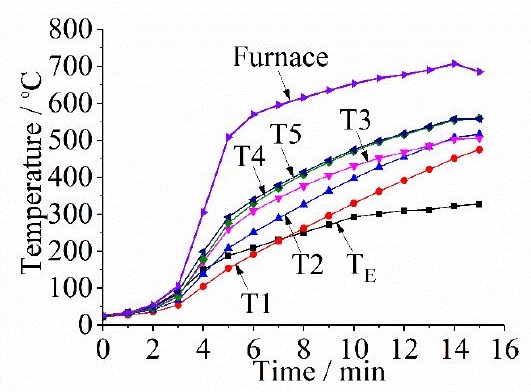

(c) B-3

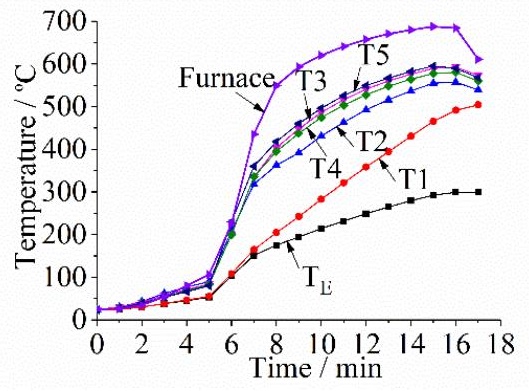

(b) B-2

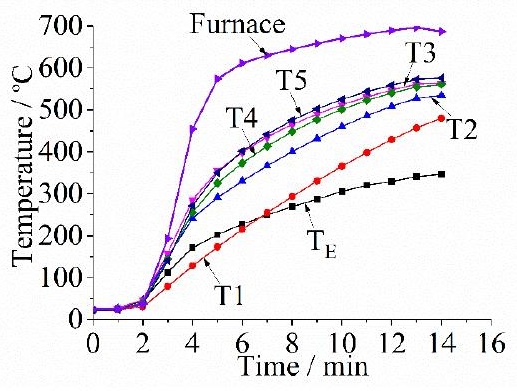

(d) B-4

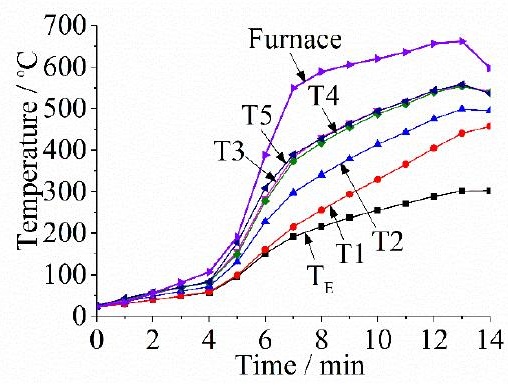

(e) B-5

Fig. 17 Surface temperature rising curves of specimens B-1 B-5

For specimens B-1 $\sim$ B-5, the following conclusions can be obtained from Fig. 17: (1) The furnace temperature is higher than the temperature values measured at the surface of specimen. In the early stage of heating, the difference between the furnace temperature and specimen temperature is large; but in the late stage of heating, the gap between the two decreases, and the curves tend to be similar. (2) The average temperature of the measurement points at the support of specimen $\mathrm{T}_{\mathrm{E}}$ is below $300{ }^{\circ} \mathrm{C}$, which verifies the effectiveness of the support wrapped with fireproof rock wool and ensures that the temperatures at two supports are kept low during the test; (3) The temperature of the measurement point T1 is lower than other measurement points (T2, T3, T4 and T5), and a distinct temperature gradient can be observed along the cross-sectional height direction, which verifies that the specimen is subjected to fire on three sides. 


\subsubsection{Mid-span vertical displacement of specimen}

For specimens B-1 B-5, the mid-span vertical deformation-time curve of each specimen is shown in Fig. 18. As shown in Fig. 18, the heating process of the specimens can be divided into four stages: the initial stage, the middle stage, the late stage and the cooling stage.

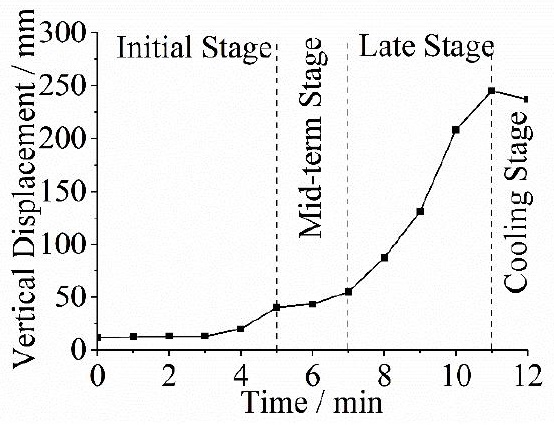

(a) B-1

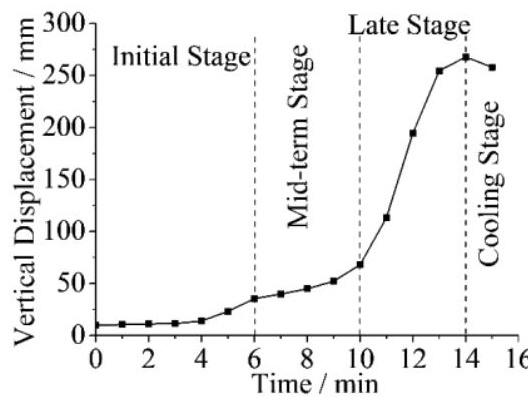

(b) B-2

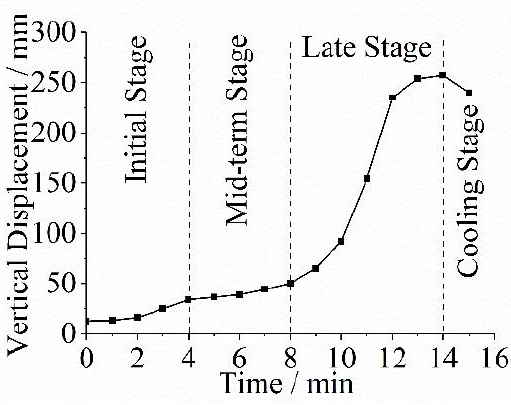

(c) B-3

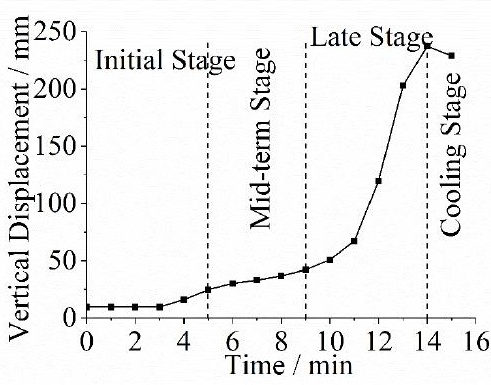

(d) B-4

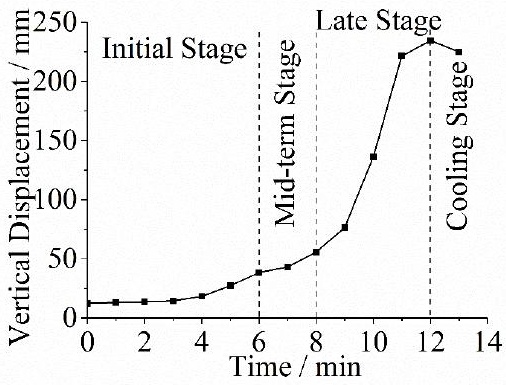

(e) B-5

Fig. 18 Mid-span vertical deformation curve of specimen

(1) In the initial stage (period of slow growth in vertical displacement), the furnace temperature and specimen surface temperature are very low. The specimen stiffness has no attenuation, and the growth rate of vertical displacement in the mid-span is slow. The furnace temperature continually rises, as well as the specimen surface temperature. The specimen stiffness begins to decay, and the increase in the mid-span vertical displacement is accelerated.

(2) In the middle stage (period of continuous growth in vertical displacement), the specimen surface temperature rapidly increases with a continual increase in furnace temperature. The specimen stiffness significantly decreases, and the vertical displacement in the mid-span continues to increase. But for temperature growth rate, the upper flange is faster than the lower flange, which causes the thermal expansion and deformation rate of the upper flange to be greater than the thermal expansion and deformation rate of the lower flange. An inverted arch appeared in the mid-span. The increase in mid-span vertical displacement is restrained to some extent, and the growth rate of the mid-span vertical displacement decreases.

(3) In the late stage (period of rapid growth in vertical displacement), the temperatures are very high and the specimen stiffness presents a distinct attenuation. The vertical displacement in the mid-span rapidly increases until the specimen is failed.

(4) In the cooling stage (period of recovery of elastic deformation), with the decrease of furnace temperature, the surface temperature of specimen decreases, and the stiffness of specimen has some recovery. The vertical displacement of the specimen decreases, and finally no longer changes.

\subsection{Analysis of experiment data}

3.7.1. Comparison of mid-span vertical displacement of specimens under different loading ratios

According to Table 3, two sets of specimens are selected: in the first group, the constraint conditions at both ends of specimens B-1 and B-2 are Constraint Position 1; in the second group, the constraint conditions at both ends of specimens B-3 and B-4 are Constraint Position 2. In the same group, the two specimens have the same section size and constraint conditions, but different loading ratios. Fig. 19 shows the comparison of mid-span vertical displacement of specimens under different loading ratios in two groups.

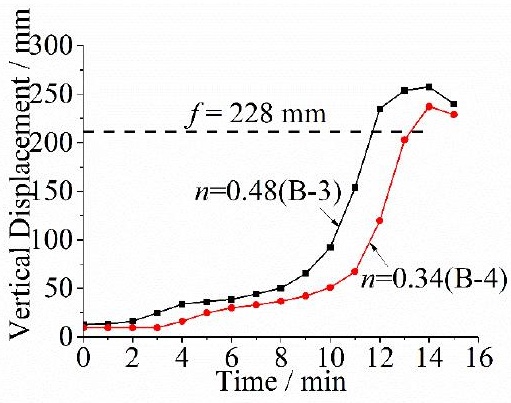

(b) B-3 and B-4

(a) B-1 and B-2

Fig. 19 Comparison of mid-span vertical deformation under different loading ratios

From Fig. 19, it can be seen that the loading ratio has great influences on the development of catenary action of restrained steel beam under fire. When the specimens have the same axial restraint stiffness, with the increase of loading ratio, the catenary action will happen earlier in the restrained steel beam and the phenomenon will be more distinct. 
3.7.2. Comparison of mid-span vertical displacement of specimens under different axial constraints

According to Table 3, two groups of specimens can be selected: in the first group, the loading ratio $n$ of specimens B-1 and B-3 is 0.48 ; in the second group, loading ratio $n$ of specimens B-2 and B-4 is 0.34 . In the same group, the two

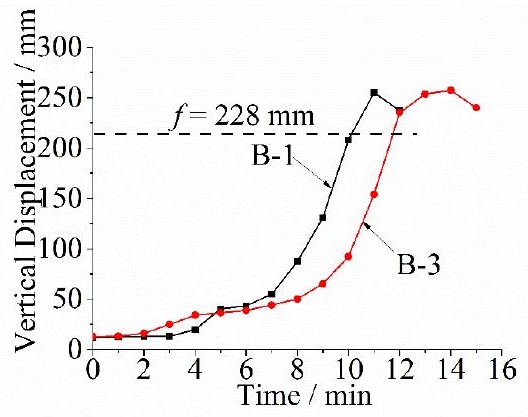

(a) B-1 and B-3 specimens have the same section size and loading ratio, but different constraint conditions at the ends of specimen. Fig. 20 shows the comparison of the midspan vertical displacement of specimens under different axial constraints in two groups.

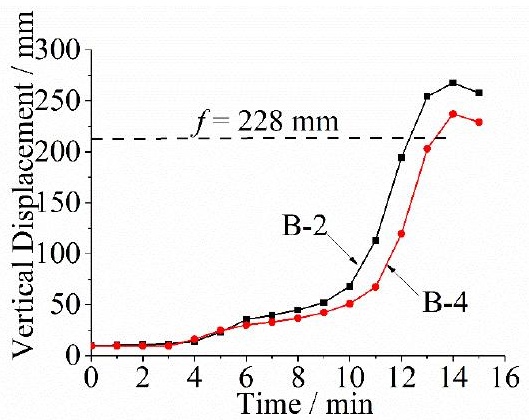

(b) B-2 and B-4

Fig. 20 Comparison of mid-span vertical deformation under different axial restraint stiffnesses

From Fig. 20, it can be seen that the axial restraint stiffness has great influence on the catenary action of restrained steel beam under fire. When the specimens have the same loading radio, with the increase of axial restraint stiffness, the catenary action will happen earlier in the restrained steel beam and the phenomenon will be more distinct.

3.7.3. Comparison between mid-span vertical displacement and loading-point vertical displacement

Fig. 21 illustrates the comparison between mid-span vertical displacement and loading-point vertical displacement of specimens B-1 B-4. According to Fig. 21, (1) In the initial and middle stages, the mid-span vertical displacement

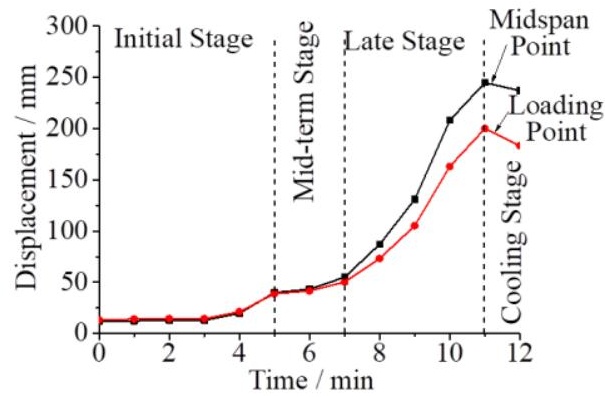

(a) B-1

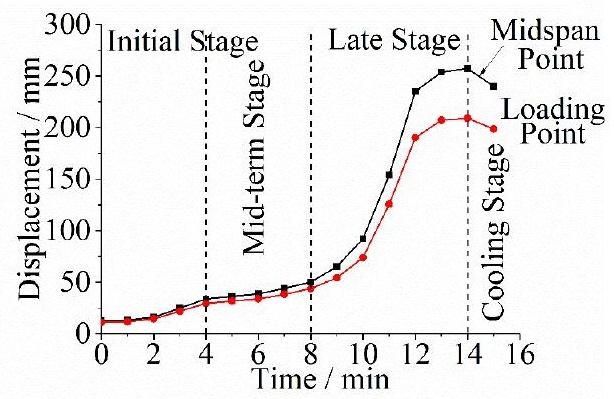

(c) B-3 of specimen is the same as the loading-point vertical displacement of specimen (2) In the later stage, the increase rate of vertical displacement at mid-span is greater than the increase rate of vertical displacement at loading point, and the difference between mid-span vertical displacement and loading-point vertical displacement is larger and larger. This phenomenon can be explained as follows: in the later stage, Due to the high internal temperature of the specimen, the specimen stiffness has a distinct attenuation, the mid-span deformation sharply increases; a large axial tension force occurs in the section of specimen, and the deformation mode changes from mode A to mode B, as shown in Fig. 22(a) and (b), which indicates that the specimen has produced distinct catenary action.

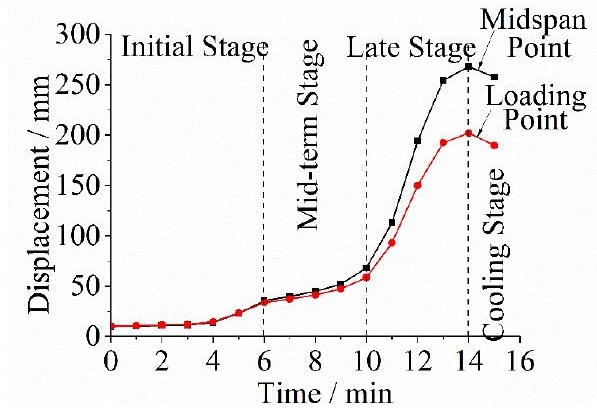

(b) B-2

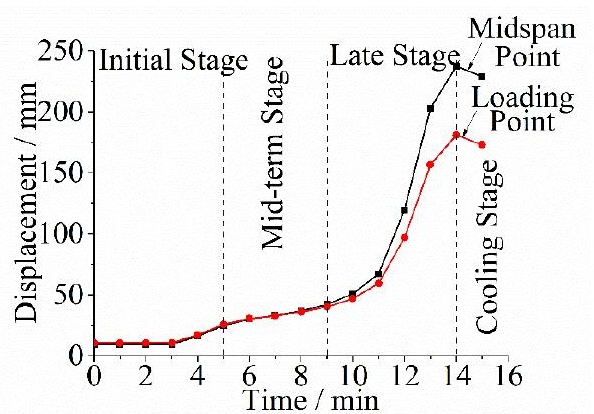

(d) B-4

Fig. 21 Mid-span / loading point vertical deformation of specimen

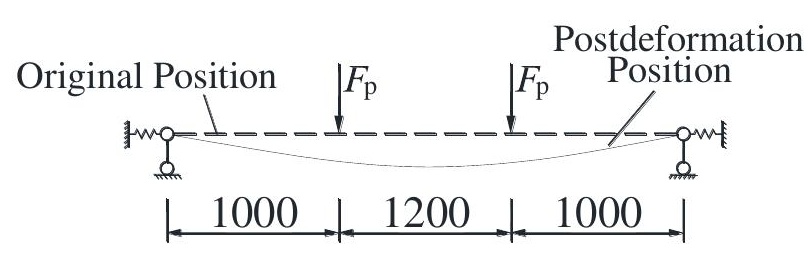

(a) Mode A

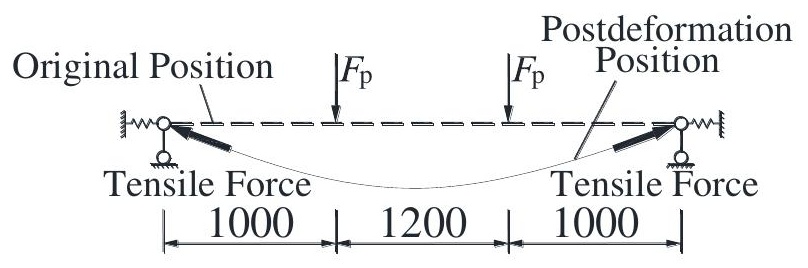

(b) Mode B 


\subsection{Failure modes and results of specimens}

The fire test results of five $\mathrm{H}$-section restrained steel beam specimens B-1 $\sim$ B-5 are shown in Table 4, including the mid-span vertical displacement, failure temperature and failure mode. The mid-span vertical displacement limit is $1 / 14$ of beam span, which indicates the failure of specimen in the fire test. The failure temperature of each specimen is shown in Table 4. The method to determine the failure temperature of specimen is described as follows: firstly, the heating-up time before the failure of specimen can be given according to Fig. 18, and then the corresponding temperature value can be obtained according to the heatingup time through Fig. 17.

\section{Table 4}

The damage indicators of specimens

\begin{tabular}{|c|c|c|c|c|c|c|c|}
\hline \multirow{2}{*}{ Number } & \multirow{2}{*}{$\begin{array}{c}\text { Load radio } \\
n\end{array}$} & \multirow{2}{*}{$\begin{array}{l}\text { Constraint } \\
\text { position }\end{array}$} & \multicolumn{3}{|c|}{ Mid-span vertical displacement $/ \mathrm{mm}$} & \multirow{2}{*}{$\begin{array}{c}\text { Failure } \\
\text { Temperature } \\
/{ }^{\circ} \mathrm{C} \\
\end{array}$} & \multirow{2}{*}{ Failure mode } \\
\hline & & & Limit & Max & Cool & & \\
\hline B-1 & 0.48 & Position 1 & 228 & 244 & 213 & 509 & In-plane overall bending \\
\hline B-2 & 0.34 & Position 1 & 228 & 267 & 231 & 559 & In-plane overall bending \\
\hline B-3 & 0.48 & Position 2 & 228 & 255 & 224 & 516 & In-plane overall bending \\
\hline B-4 & 0.34 & Position 2 & 228 & 238 & 206 & 575 & In-plane overall bending \\
\hline B-5 & 0.48 & Position 1 & 228 & 234 & 203 & 531 & In-plane overall bending \\
\hline
\end{tabular}

As shown in Table 4, (1) the mid-span vertical displacements of specimens B-1 B-5 exceeded $1 / 14$ of the span before they were damaged, which indicates that all specimens occoured obvious catenary action during the test; (2) for restrained steel beams with the same axial restraint stiffness but different loading ratio, the loading ratio has a great influence on the development of catenary action and the failure temperature of specimen; the greater the loading ratio, the earlier the catenary action happens in the specimen, the lower the failure temperature; (3) for restrained steel beams with the same loading ratio but different axial restraint stiffness, the axial restraint stiffness has a certain influence on the development of catenary action and the failure temperature of specimen; the greater the axial restraint stiffness, the later the catenary action happens in the specimen, and the higher the buckling temperature; and (4) the failure modes of specimens B-1 B-5 in the fire test are all in-plane overall bending.

\section{Conclusion}

In this paper, the development of catenary action in the restrained $\mathrm{H}$-section steel beam under fire is experimentally investigated. The following conclusions can be obtained from the experiment:

(1) In the test, the surface temperature distribution of specimen conforms to the condition of fire on three sides, there is an obvious temperature gradient along the height of specimen section, and the surface temperature decreases from bottom to top; the surface temperature distribution of specimen is uniform along the length of specimen.

(2) In the restrained steel beam fire test, when the specimens failed, the

\section{References}

[1] China Public Security Fire Department. 2014 China fire statistics yearbook. Beijing, Chinese People's Public Security University Press; 2014.

[2] Li G Q, Wu B, Han L H. Development of the Research on Fire-Resistance of Structures. Progress in Steel Building Structures, 2006,8(1):1-13

[3] Wei D, Sun X S, Liu Y H, et al. Advances in Study on Fire Resistance of Steel Structures. Progress in Steel Building Structures, 2006,8(4):17-22

[4] Wang Y C. An analysis of the global structural behaviour of the Cardington steel-framed building during the two BRE fire tests. Engineering Structures, 2000; 22(5):401-412.

[5] Burgess I W, Rimawi J El, Plank R J. Studies of the behaviour of steel beams in fire. Journal of Constructional Steel Research, 1991; 19(4): 285-312.

[6] Usmani A S, Lamont S, et al. Fundamental principles of structural behavior under the thermal effects. Fire safety journal, 2001; 36(8): 721-744.

[7] Liu T C H, Fahad M K, Davies J M. Experimental investigation of behaviour of axially restrained steel beams in fire. Journal of Constructional Steel Research, 2002; 58(9):12111230

[8] Moss P J, Buchanan A H, Seputro J, et al. Effect of support conditions on the fire behaviour of steel and composite beams. Fire and materials, $2004 ; 28(2-4): 159-175$

[9] Wang Y C. The importance of considering whole structural behaviour in fire. International Symposium on Structures in Fire, 2002; 10: 119-132.

[10] Yin Y Z, Wang Y C. A numerical study of large deflection behaviour of restrained steel beams at elevated temperatures. Journal of Constructional Steel Research, 2004; 60(7): 1029-1047.

[11] Yin Y Z, Wang Y C. Analysis of catenary action in steel beams using a simplified hand calculation method, Part 1: theory and validation for uniform temperature distribution. Journal of Constructional Steel Research, 2005; 61(2): 183-211.

[12] Yin Y Z, Wang Y C. Analysis of catenary action in steel beams using a simplified hand calculation method, Part 2: validation for non-uniform temperature distribution. Journal of Constructional Steel Research, 2005; 61(2): 213-234

[13] Wang Y C. A review of the behavior of steel structures in fire and a suggestion for future experiment. Proceedings of the international seminar on steel structure in fire, Shanghai, 2001; 40-55.

[14] Dwaikat M M S, Kodur V K R. A performance based methodology for fire design of restrained steel beams. Journal of Constructional Steel Research, 2011; 67(3): 510-524.

[15] Li G Q, He J L, Jiang S C. Fire-resistant experiment and theoretical calculation of a restrained vertical deformation at mid span exceeded $1 / 14$ of beam span, and obvious catenary action appeared in the specimen. Therefore, it is appropriate to select the mid-span deformation of specimen to reach $1 / 14$ of beam span as the judgement condition for the occurrence of catenary action in the restrained steel beam under fire.

(3) The axial restraint stiffness and loading ratio have great influences on the development of catenary action in a restrained steel beam under fire. The larger the loading ratio, the earlier the catenary action occurs in the specimen, the lower the failure temperature of specimen; the larger the axial restraint stiffness, the later the catenary action occurs in the specimen, the higher the failure temperature.

\section{Data availability statement}

Some or all data, models, or code that support the findings of this study are available from the corresponding author upon reasonable request.

\section{Acknowledgments}

The authors gratefully acknowledge the financial support of the National Natural Science Foundation of China (No. 51378105 and No. 51878146), National Key Research and Development Program of China (No 2017YFC0703802). The research was also sponsored by Qing Lan Project in Jiangsu Province and Scientific Research Foundation of Graduate School of Southeast University.

steel beam. China Civil Engineering Journal, 2000; 33(4): 23-26.

[16] Li G Q, Guo S X. Analysis of restrained steel beams subjected to temperature increasing and descending Part I: Theory. Journal of Disaster Prevention and Mitigation Engineering, 2006; 26(3): 241-250.

[17] Guo S X, Li G Q. Analysis of restrained steel beams subjected to temperature increasing and descending Part II: Validation and Parametrical Analysis. Journal of Disaster Prevention and Mitigation Engineering, 2006; 26(4): 359-368.

[18] Li G Q, Guo S X. Analysis of restrained steel girders with large deflection subjected to elevated temperature. Journal of Tongji University (Natural Science), 2006; 34(7): 853-858.

[19] Cong S P. Experimental investigation of behaviour of H-Section steel beam under fire. Thesi (Master). QingDao: School of Civil Engineering, QingDao University of Technology; 2004.

[20] Li X D, Dong Y L, Cong S P. Anti-fire experimental research on H-section steel beams. Building Structure, 2006; 8: 94-102.

[21] Luan Y P, Xi F. Comparative analysis of different restrained beams in fire condition. Journal of Shandong Jianzhu University, 2012; 27(5): 477-482.

[22] Ma N. Catenary action of the restrained castellated steel beams in a fire. Thesis (Master) Jinan: School of Civil Engineering, Shandong University; 2015.

[23] Iqbal N, Heistermann T, Veljkovic M, Lopes F. Axial force and deformation of a restrained steel beam in fire - Description and validation of a simplified analytical procedure. Advanced Steel Construction, 2016; 12(2): 174-193

[24] Du E, Shu G, Tang Y, et al. Experimental investigation on temperature evolution of steel beams in natural fires. Advanced Steel Construction, 2020; 16(4): 328-336.

[25] Liu C. Catenary action of restrained corrugated web steel beams in a fire. Thesis ( $\mathrm{PhD})$. Jinan: School of Civil Engineering, Shandong University; 2017.

[26] National Standard of the People's Republic of China. Metallic materials-Tensile testing Part 1: Method of test at room temperature (GB/T 228.1-2010). Beijing, China Standards Press; 2010.

[27] National Standard of the People's Republic of China. Metallic materials-Tensile testing Part2: Method of test at elevated temperature (GB/T 228.2-2015). Beijing, China Standards Press; 2015.

[28] Wang W Y, Wang K, Kodur V K, Wang B. Mechanical properties of high strength Q690 steel at elevated temperature. Journal of Materials in Civil Engineering, 2018; 30(5):04018062.

[29] $\mathrm{Li} \mathrm{Y,} \mathrm{Li} \mathrm{W} \mathrm{G,} \mathrm{Zhang} \mathrm{X} \mathrm{H,} \mathrm{et} \mathrm{al.} \mathrm{Modeling} \mathrm{of} \mathrm{temperature} \mathrm{dependent} \mathrm{yield} \mathrm{strength} \mathrm{for}$ stainless steel considering nonlinear behavior and the effect of phase transition. Construction and Building Materials, 2018; 159: 147-154. 
[30] Chen W, Ye J H. Steady state experimental investigation of G550 high strength cold-formed steel material at elevated temperatures. China Civil Engineering Journal, 2012; 45(6): 33-42.

[31] Fan S G, Jia L L, Lyu X, Sun W J, Chen M H, Zheng J C. Experimental investigation of austenitic stainless steel material at elevated temperatures. Construction and Building Materials, 2017; 155: 267-285.

[32] Eurocode 3: Design of steel structures-Part 1-2: General rules-structural fire design. European Committee for Standardization, ENV 1993-1-2, CEN, Brussels, 2005.

[33] National Standard of the People's Republic of China. Technical code for fire safety of steel structure in buildings (CECS 200:2006). Beijing, China Planning Press; 2006.

[34] ABAQUS. ABAQUS/Standard user's manual volumes I-III and ABAQUS CAE Manual, version 6.4. Pawtucket (USA): Hibbitt, Karlsson \& Sorensen, Inc.; 2003.

[35] Guo S X. The behaviour of restrained steel beam during heating and cooling and the damage of beam-to-column connection Thesis (PHD). Shanghai: School of Civil Engineering, Tongji University; 2006

[36] Xia X F. Theoretical analysis and experimental research on fire resistance of stainless steel beam. Thesis (Master). NanJing: School of Civil Engineering, Southeast University; 2014

[37] Fan S G, He B B, Xia X F, et al. Fire resistance of stainless steel beams with rectangular hollow section: Experimental investigation. Fire Safety Journal, 2016; 81 (1): 17-31.

[38] Gardner L, Baddoo N R. Fire testing and design of Stainless Steel Structures. Journal of Constructional Steel Research, 2006; 62(6): 532-543

[39] Ernest C Y T, Young B. Performance of cold-formed stainless steel tubular columns at elevated temperatures. Engineering Structures, 2008; 30 (1): 2012-2021.

[40] Internal Standard ISO 834. Fire-resistance tests - Elements of building construction — Part 1: General requirements (ISO 834-1:1999). ISO, 1999. 


\title{
STRESS RESPONSE AND INITIAL STIFFNESS OF SIDE PLATE CONNECTIONS TO WCFT COLUMNS
}

\author{
Han-Chao Liu ${ }^{1,2}$, Ji-Ping Hao ${ }^{1, *}$, Qiang Xue ${ }^{1,2}$ and Yu-Qi Huang ${ }^{1,2}$ \\ ${ }^{I}$ School of Civil Engineering, Xi'an University of Architecture \& Technology, Xi'an 710055, China \\ ${ }^{2}$ Design Institute of Xi' an University of Architecture \& Technology, Xi'an 710055, China \\ *(Corresponding author: Email: hao-jp168@163.com)
}

\section{A B S T RA C T}

To study the mechanism of load transfer in double-side-plate connections between I-beams and wall-type concrete-filled steel tubular columns, a pseudo-static experiment and finite element analysis were conducted for two full-scaled specimens. The results revealed that the primary load was transmitted along an S-shaped path in the side plate, and the primary strain occurred in an X-shaped region between the left and right steel beam flanges. The shear force in the steel beam web was transmitted first to the side plate centre and then to the joint area, where the side plate, steel tube web, and concrete all resisted the internal force. Based on principal component methods, a calculation formula was established for initial rotational stiffness that comprehensively considers the influence of the tensions, compression, and shear deformation of the cover plate, side plate, and web. Comparing this formula with an existing model showed that the proposed formula is suitable for new types of side plate joints. Moreover, it can accurately calculate the initial rotational stiffness of the joint, thus providing a reliable basis for future engineering design.

\section{A R T I C LE H I S T O RY}

$\begin{array}{ll}\text { Received: } & 26 \text { November } 2020 \\ \text { Revised: } & 26 \text { April } 2021 \\ \text { Accepted: } & 26 \text { April } 2021\end{array}$

$\begin{array}{ll}\text { Revised: } & 26 \text { April } 2021 \\ \text { Accepted: } & 26 \text { April } 2021\end{array}$

\section{K E Y W O R D S}

Wall-type concrete-filled steel

tubular column;

Double side plate

Load transfer mechanism;

Initial rotational stiffness;

Principal component method

\section{Introduction}

High energy consumption, heavy pollution, and low quality have significantly hindered advancements in the traditional construction industry in China [1]. To address this issue, prefabricated steel structures that offer environmental sustainability, industrialisation, and standardisation have been developed [2]. To meet the general requirements for large-space, low-consumption, and high-quality housing, in this study we combined existing technologies and developed a wall-type concrete-filled steel tubular (WCFT) column building system [1-4].

During the Northridge Earthquake of 1994 in the United States and the Kobe Earthquake of 1995 in Japan, we learned significant lessons about the damage that can occur, particularly to steel structures [5]. To ensure adequate strength, stiffness, and ductility, various connections have been proposed. Among these, the most promising is the side plate method, which offers outstanding behaviour and numerous advantages [6]. Such side plates were first tested by Sabo et al. [7-8]; however, the specimens tested exhibited poor performance owing to their size and configuration. Improved side plate designs were subsequently tested by Houghton and Crawford et al. [6-11], who used a pair of parallel full-depth side plates to connect beams to wide-flange columns. Their results demonstrated a joint rotation capacity that met the 2010 American Institute of Steel Construction requirements. Moreover, the ductility and rotation capacity of the joint were significantly improved by using an optimised weld connection. Faridmehr et al. [12] tested the cyclic characteristics of eight full-scale unstiffened extended end-plates with variable parameters and one side plate moment connection. They found that the performance of the side plate moment connection was superior to that of the end-plates.

Jalai et al. [13-15] proved that steel moment-resisting frames (SMRFs) with side plate connections have good seismic performance, and proposed and calibrated a connection model to represent the side plate connection behaviour. Liu et al. [16] established a new double side-plate I-beam on a WCFT column and investigated its seismic performance. Huang et al. [17] evaluated three full-scale WCFT column joints under cyclic loads and studied the mechanical characteristics of the joint panel zone under shear. They found that the side plate joint exhibits preferable deformation performance and possesses an energy dissipation capacity.

Research methods on connections typically fall into three categories, all of which were utilised in this study: experimental research, numerical simulations, and the component method [18-19]. The component method divides joints into several basic components. Each component is simulated by a one-dimensional spring element, and the overall mechanical behaviour of the joint is calculated by combining the springs in series and in parallel. The quantitative component combination expressions for many common components are listed in the
British standard BS EN 1993-1-8:2005. Furthermore, Weynand [20], Nethercot [21-25] and other researchers studied and extended the component method to varying degrees.

Although the behaviours of side plate connections have been extensively investigated, most of the research has concentrated on I-beam connections to wide flanges or box columns. To the best of our knowledge, no analytical or experimental investigation has been conducted on the transfer mechanism and initial rotational stiffness for I-beam connections to WCFT columns. This is a new type of member section, with small cross-sectional thicknesses and width-to-thickness ratios no greater than 1:4 [3]. Moreover, a new double-side plate (DSP) connection [26-27] is herein proposed based on the characteristics of the section formed on connection with the WCFT column (Fig. 1)

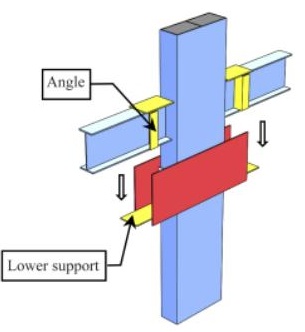

(a) Installation view

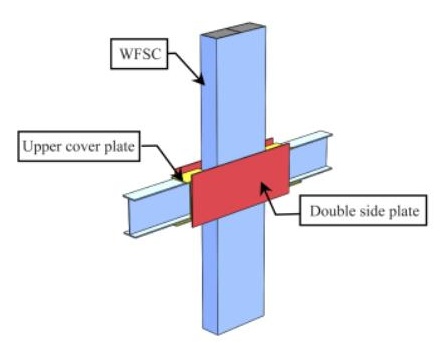

(b) Axonometric view

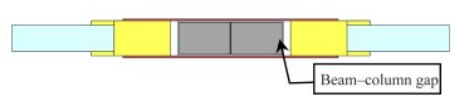

(c) Top view

Fig. 1 Double-side-plate connection overview. (a) Installation illustration, (b) axonometric projection, and (c) top view of the connection 
In this study, we analysed the load transfer mechanism of these joints through both experimental research and numerical simulations. Additionally, the component method was introduced to the side plate joint analysis for the first time. To accomplish this objective, the basic components of the joint force transmission were identified and clarified, and the calculation formula for initial rotational stiffness of the joint was derived using the principles of component transmission. The research results obtained in this study can be used to improve the design theory of this type of joint and provide a research basis for its application to WCFT column structures.

\section{Transfer mechanism}

In this section, we discuss how the nonlinear finite element analysis software ABAQUS was used to establish a fine finite element model (FEM) of the proposed joint. Additionally, a reasonable material constitutive model is used to analyse the transfer mechanism of the joint.

\subsection{Model parameters}

The beam-column section of the model was obtained from WCFT column and steel beam sections in real-world engineering situations. The column cross-section was $200 \times 600 \mathrm{~mm}^{2}$, the wall thickness was $8 \mathrm{~mm}$, and the height was $2800 \mathrm{~mm}$. The beam cross-sectional size was $\mathrm{H} 350 \times 175 \times 7 \times 11$, and the length was $1600 \mathrm{~mm}$. According to the relevant specifications [28], the steel material properties were tested; the corresponding material properties for each plate are given in Table 1. The compressive strength of the concrete was obtained through standard cube tests, and the average compressive strength of the concrete used to fill the WCFT column was determined to be $32.3 \mathrm{MPa}$ by standard cube tests.

Table 1

Measured mechanical properties of steel

\begin{tabular}{|c|c|c|c|c|c|c|}
\hline Component & $\begin{array}{l}\text { Thickness } \\
(\mathrm{mm})\end{array}$ & $\begin{array}{c}f_{\mathrm{sm}} \\
/ \mathrm{MPa}\end{array}$ & $\begin{array}{c}f_{\mathrm{su}} \\
/ \mathrm{MPa}\end{array}$ & $\begin{array}{c}E_{\mathrm{s}} \\
/ \mathrm{MPa}\end{array}$ & $\begin{array}{c}\delta \\
/ \% \\
\end{array}$ & $\begin{array}{l}f_{\text {su }} \\
/ f_{\text {su }}\end{array}$ \\
\hline Column partition & 4.60 & 318.5 & 475.2 & $2.05 \times 10^{5}$ & 40.1 & 1.49 \\
\hline Column siding & 7.68 & 317.9 & 481.9 & $2.08 \times 10^{5}$ & 40.1 & 1.52 \\
\hline Beam web & 6.72 & 317.2 & 449.2 & $2.09 \times 10^{5}$ & 37.1 & 1.42 \\
\hline Beam flange & 10.23 & 283.2 & 434.6 & $2.03 \times 10^{5}$ & 41.6 & 1.53 \\
\hline Stiffener & 5.56 & 228.1 & 355.0 & & 27.0 & 1.56 \\
\hline Side plate & 9.67 & 315.4 & 454.4 & $2.06 \times 10^{5}$ & 27.5 & 1.54 \\
\hline Angle & 5.72 & 250.8 & 396.0 & - & 27.7 & 1.58 \\
\hline
\end{tabular}

Notes: $f_{\mathrm{sm}}$ is yield strength, $f_{\mathrm{su}}$ is tensile strength, $E_{\mathrm{s}}$ is elastic modulus, $\delta$ is elongation.

\subsection{Refined finite element model}

\subsubsection{Element types and meshing}

The steel tube, steel beam, and side plate each utilised 4-node reduced integral shell element S4R with six degrees of freedom, while the concrete utilised an 8-node reduced integral solid element C3D8R with three translational degrees of freedom. Notably, S4R and C3D8R have good adaptability for most nonlinear analyses [29]. Optimal mesh density was determined by mesh convergence analysis to reduce calculation time and ensure sufficient accuracy.

A considerable difference exists between the proposed double side-plate joint and conventional beam-column joint structures in terms of the multiple plate overlaps. Simplifying the overlapping of plates with the column and the beam as a single thicker plate will enlarge the plate contribution. If each of these plates is represented by two separate plates, the DOFs of the two plates must be coupled at the boundary position, and the corresponding nodes must be restrained separately. If they are not properly set, additional constraint stiffness will be introduced, causing the calculation results to deviate from the actual stress situation. After many trial calculations and verifications, each overlapping plate was modelled according to its actual location in space, and a weld element was set at the boundary between them. Thus, the overlapping plates only connected with each other through the weld at the boundary position, while the stresses within were relatively independent and connected.

\subsubsection{Contact analysis model}

The concrete is divided into two parts by a steel plate partition, each of which establishes a contact relationship with either the steel tube or partition steel plate. The contact is limited by the slip surface-to-surface contact, and the normal direction of the contact interface is hard contact. Arbitrary contact pressure can be transmitted through the master-slave contact, and when the contact pressure is zero, the two sides are separated. In the contact model, the tangential behaviour adopts an improved isotropic Coulomb friction model, and the tangential friction coefficient is 0.6 [3].

\subsubsection{Boundary}

In the FEM, constraints are placed on the three translational displacements of the bottom reference point, the rotational displacements along the vertical axis, and the out-of-plane displacements of the column top reference point. Thus, the out-of-plane and vertical displacement of the beam end are restrained (Fig. 2).

\subsubsection{Material constitutive model}

To accurately simulate the mechanical properties, a mixed hardening constitutive model [30] is adopted for steel portions and welds under cyclic loads, which includes both nonlinear follow-up and isotropic strengthening portions. The concrete in the WCFT columns is restrained by the steel tubes, which becomes clear with increasing steel yield strength and decreasing width-to-thickness ratios for the steel plates. The stress-strain relationship of the confined concrete is based on its damage plasticity model in accordance with the Binici model [31]. The resulting FEM and weld elements for the DSP used in this study, denoted as DSP1, are shown in Figs. 2(a) and (b), respectively.

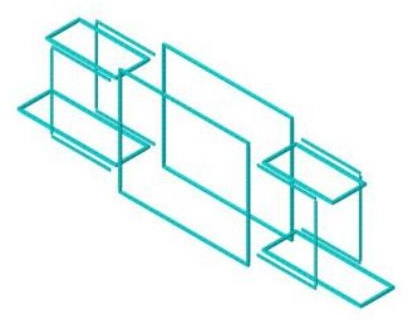

(b) Weld elements of DSP1 


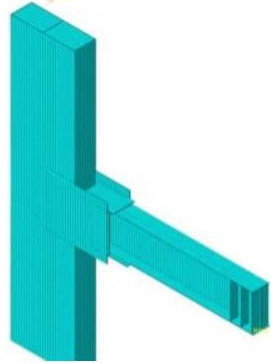

(c) Model of DSP2

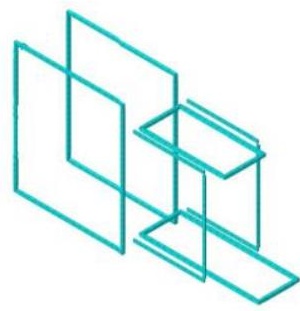

(d) Weld elements of DSP2

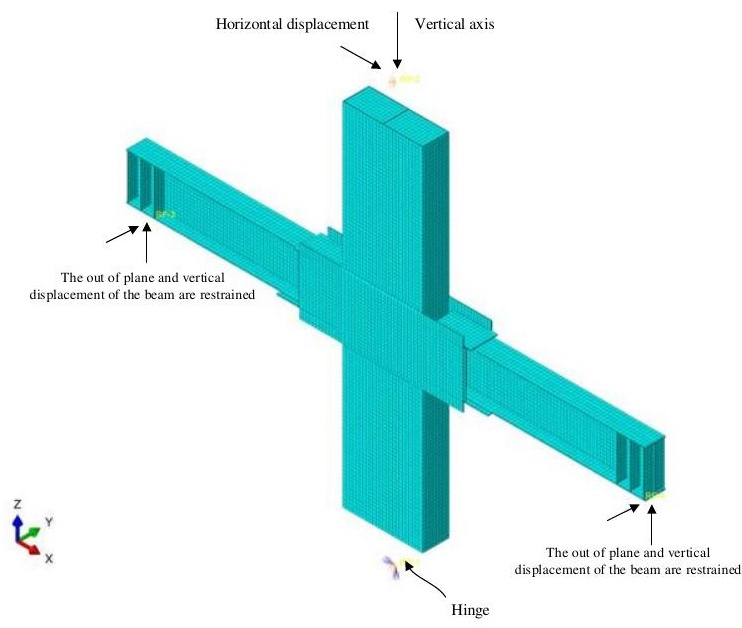

(e) Boundary

Fig. 2 Finite element models for (a-b) DSP1 and (c-d) DSP2, including (a-c) the overall model of each specimen as well as (b-d) weld elements.

\subsection{Transfer mechanism analysis}

The principal stress distribution for the peak joint forward load is shown in Fig. 3. The principal tensile stress (Fig. 3(a)), in the horizontal direction of the upper flange of the left steel beam is transmitted first to the side plate through the weld, and then to the joint through the side plate. Some of the principal tensile stress is transmitted to the wall column web through the weld, and some

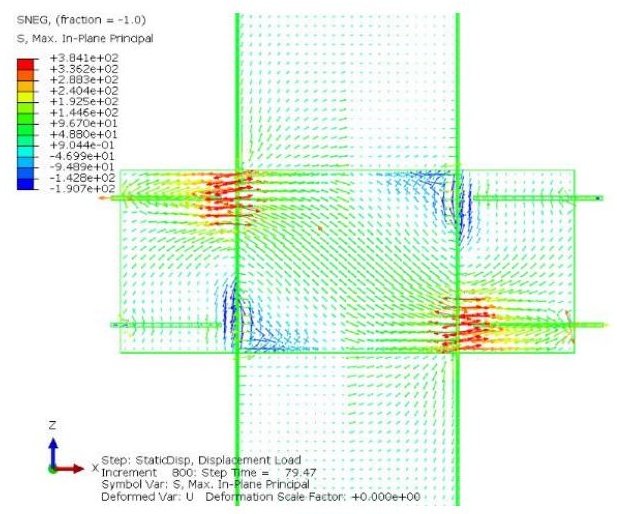

(a) is passed directly downward to the lower flange of the right steel beam. The principal compressive stress (Fig. 3(b)) follows a similar transmission path, from the lower flange of the left steel beam to the upper flange of the right steel beam through the side plate and joint regions. The web shears of the steel beam are transmitted to the middle of the side plate first, and then to the joint region. The side plate, steel tube web, and concrete all resist the internal force in the joint region.

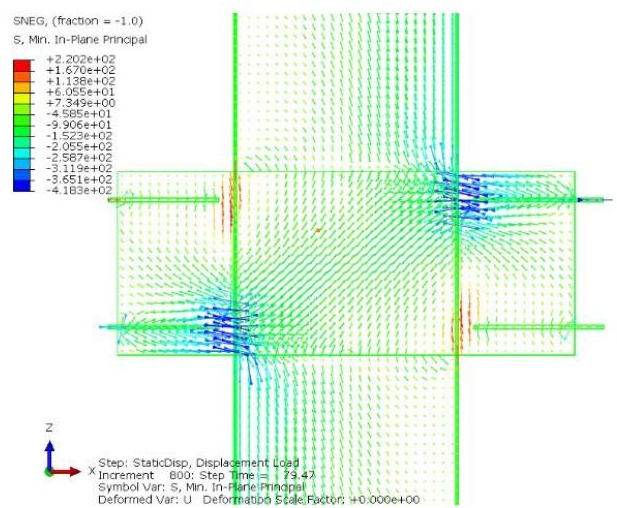

(b)

Fig. 3 DSP1 Transmission path. Principal (a) tensile and (b) compressive load transfers

The side plate stress distribution corresponding to the peak load is shown in Fig. 4. The shear force and moment at the end of the beam-column is approximately transformed into the coupled forces acting on the geometric centre of the upper and lower flanges and the shear force acting on the web. In Fig. 4(a), we observe that the side plate bears the majority of the force transmitted from the steel beam flange in the horizontal direction, exhibiting tension and pressure bands. The stress gradually transmits from the flange to the side plate along the connection weld, and then through this weld to the WCFT column, while the side plate stress gradually decreases. As shown in Fig. 4(b), the side plate also bears the majority of the vertical force transmitted by the wall column flange through the vertical weld. This stress is the largest at the corner connecting the side plate with the column flange. Notably, the compressive stress is greater than the tensile stress under axial pressure. With an increasing distance from the vertical weld, the vertical stress on the side plate decreases rapidly.

Figs. 4(c) and (d) present the principal stress distribution of the side plate, indicating that the principal tensile stress is primarily transmitted in an oblique manner from the upper flange of the left steel beam to the lower flange of the right steel beam through the joint region. The principal compressive stress is primarily transmitted obliquely from the lower flange of the left steel beam to the upper flange of the right steel beam through the joint region. Additionally, the steel beam web shear force is transmitted to the side plate through the connecting angle steel, creating a diagonal principal stress zone in the connection between the steel beam and side plate that is roughly perpendicular to the principal stress direction of the joint region. Therefore, the overall principal load transfer path in the side plate is approximately S-shaped. The 
shear stress distribution and the von Mises equivalent stress in the side plate are shown in Figs. 4(e) and (f), respectively. The shear stress is largest in the joint; however, it is still smaller than the shear yield of the steel. Fig. 4(f) demonstrates that the side plate in the column range is effectively elastic. The side plate at the beam-column gap transfers all forces to the beam end, resulting in maximal stress. The side plate in the corresponding position on the steel beam flange exceeds the yield stress and thus enters a yield state. Further, the side plate in the corresponding position on the steel beam web transmits the shear force and has a low stress level, thus forming the 'elastic core'. Fig. 4(g) shows the principal strain distribution of the side plate. Notably, the principal tensile and compressive strains are consistent with the stress distribution, forming an X-shaped distribution between the left and right steel beam flanges. Fig. 4(h) shows the cumulative plastic strain distribution on the side plate produced at the beam-column gap. Owing to the stress concentration, the cumulative plastic strain of the weld joint corner between the side plate and column is large. Thus, special attention should be given to this condition so that damage to the corner weld can be avoided in this design.

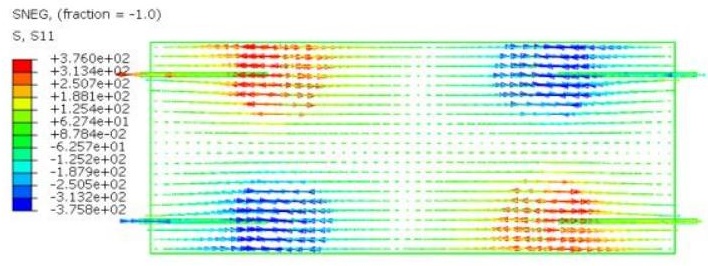

(a)

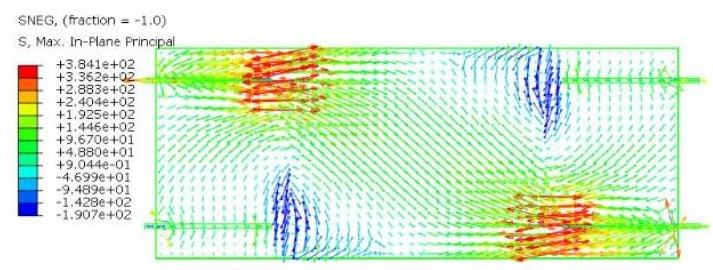

(c)

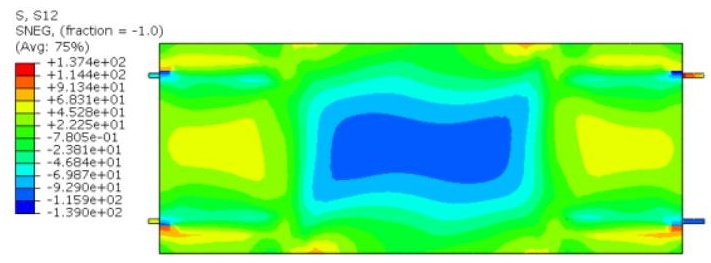

(e)

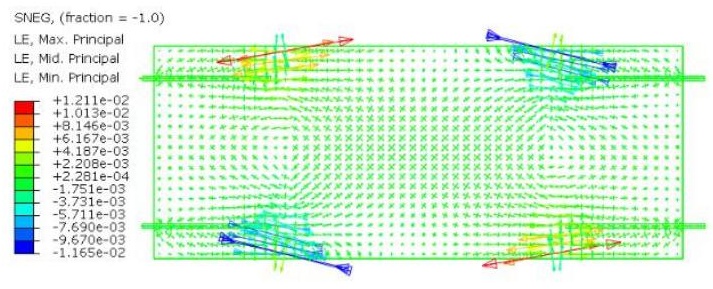

(g)

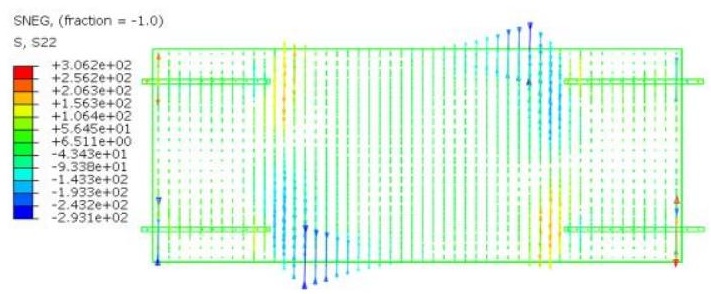

(b)

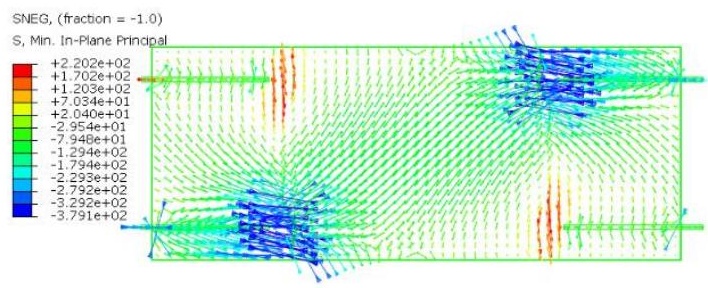

(d)

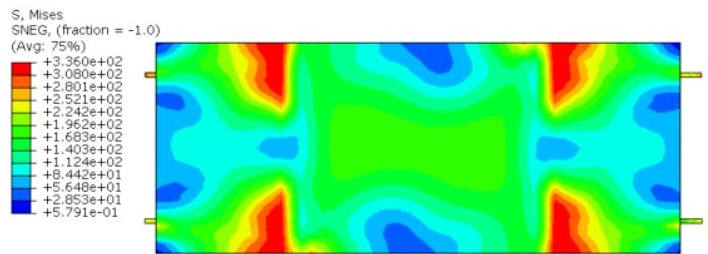

(f)

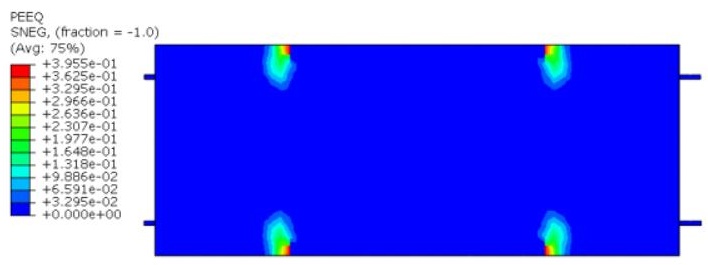

(h)

Fig. 4 Stress distribution on the side plate in DSP1. (a) Horizontal stress, (b) vertical stress, (c) principal tensile stress, (d) principal compressive stress, (e) shear stress, (f) von Mises stress equivalent, (g) principal strain, (h) cumulative plastic strain

(a)

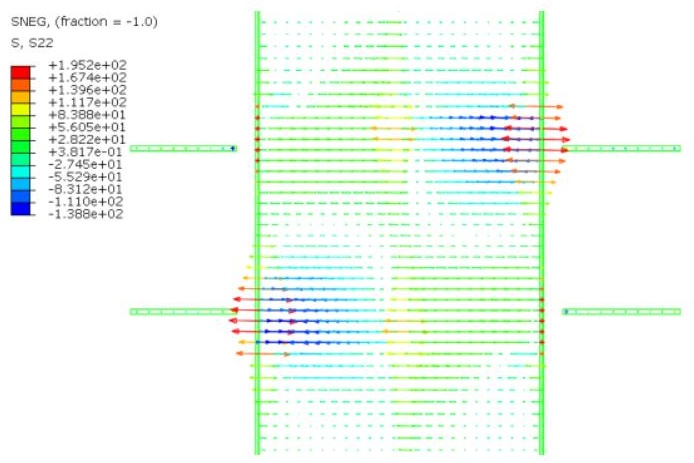

(b)

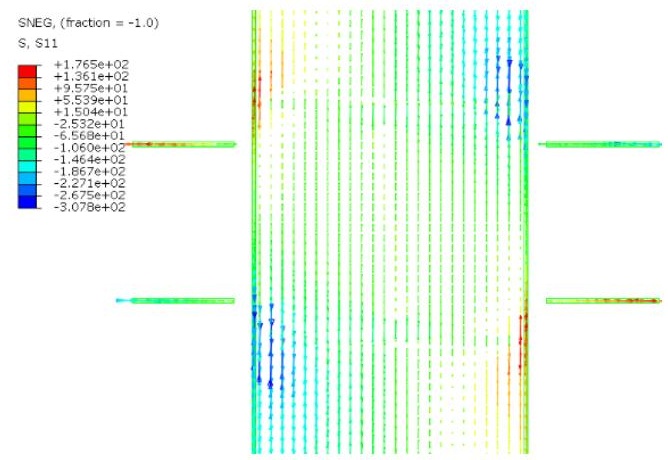


(c)

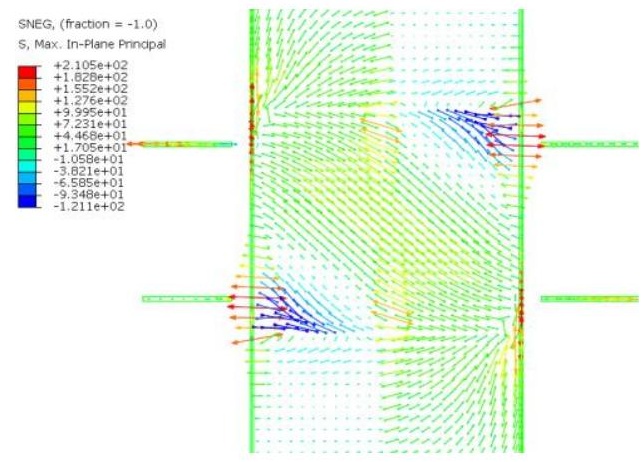

(e)

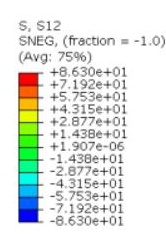

(g)

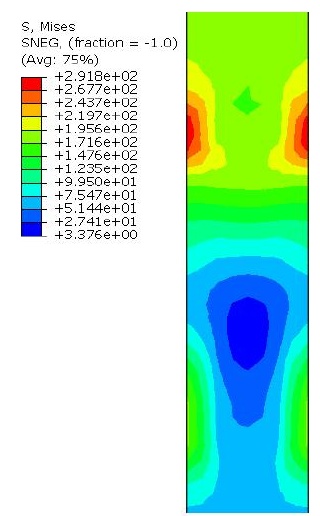

(d)

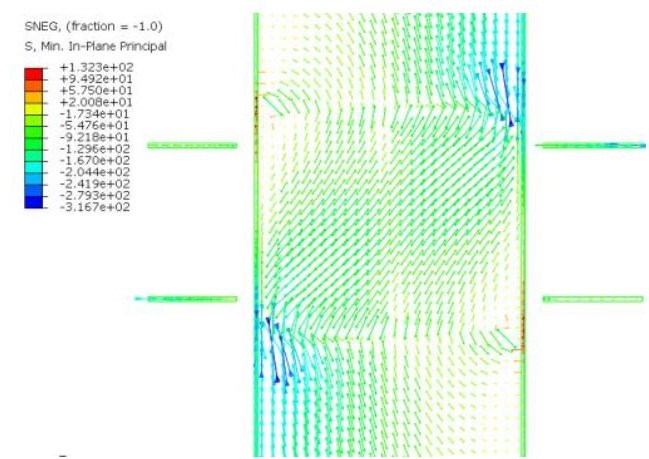

(f)

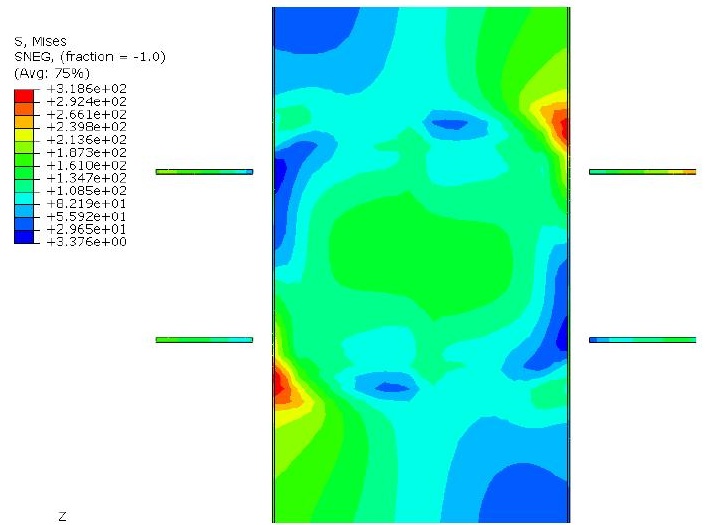

(h)

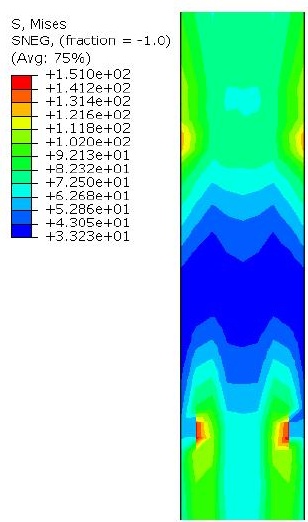

Fig. 5 Stress distribution of steel tube in DSP1. (a-f) Steel tube web (a) horizontal stress, (b) vertical stress, (c) principal tensile stress, (d) principal compressive stress, (e) shear stress, (f) von Mises stress; $(\mathrm{g}-\mathrm{h})$ von Mises stress of the steel tube $(\mathrm{g})$ flange and $(\mathrm{h})$ diaphragm

Fig. 5 shows the steel tube stress distribution corresponding to the peak load. As shown in Fig. 5(a), the horizontal stress is concentrated at the position corresponding to the compression flange of the steel beam. Here, the steel tube web primarily bears the compressive stress transmitted from the side plate through the weld, causing deformation relative to the internal concrete. Because the corner of the steel tube is restrained by the concrete, this deformation trend is prevented, and high tensile stress is generated. The adjacent position exhibits compressive stress with a large stress gradient. Contrarily, the horizontal stress at the position corresponding to the steel beam tension flange is relatively uniform. The steel tube is separated from the concrete under the tensile stress, thus this stress is uniformly transmitted to the steel tube web.

Fig. 5(b) reveals that the vertical stress in the steel tube is transmitted to the side plate through the weld. Consequently, the stress level in the joint region is significantly lower than in the adjacent position. The principal tensile and compressive stress distribution diagrams of the steel tube web are shown in Figs. 5(c) and (d), respectively. Near the joint, the steel tube web exhibits oblique principal tensile stress and principal compressive stress bands under the column and beam action. Because there is still axial pressure in the column, the principal compressive stress is greater than the principal tensile stress. At the position corresponding to the steel beam compression flange, the steel tube is restrained by concrete, and the stress is relatively concentrated. The steel tube diaphragm position is also affected by this condition, and the local stress is high. Fig. 5(e) provides the shear stress of the steel tube web, and Figs. 5 (f)-(h) show the von Mises equivalent stresses of the steel tube web, flange, and diaphragm, respectively. The shear stress is primarily observed near the joint and is in an elastic state. A large stress is exhibited in the corner of the welding position between the steel tube web and side plate, and the adjacent steel enters a yield state. The equivalent stress of the steel tube flange and diaphragm are effectively elastic.

Fig. 6 shows the stress distribution of concrete in the joint region. There is slippage on the contact interface of the steel tube and concrete, and the stress of the concrete in the two chambers is relatively independent and neither can achieve the combined stress performance. From Figs. 6(a) and (b), it is clear that the concrete bears the majority of the horizontal compressive stress from the steel beam flange and the bending vertical stress of the column. Figs. 6(c) and (d) show the principal tensile and compressive stress of the concrete core, respectively. The tensile stress near the joint reaches the tensile cracking stress, and the local compressive stress at the position corresponding to the steel beam compression flange reaches the concrete compressive strength, but the range is small. Notably, the principal stress for concrete near the joint is smaller than that in the adjacent position. The damage to concrete near the joint is shown in Figs. 6(e) and (f), and the concrete exhibits cracking and compression damage in a small area of stress concentration. Figs. $6(\mathrm{~g})$ and $(\mathrm{h})$ show the contact friction and pressure distribution, respectively, for the concrete surface near the joint. Clearly, the steel tube at the position corresponding to the steel beam compression flange transmits a large pressure to the concrete. Furthermore, the diaphragm of the steel tube forms an effective restriction for the concrete, and the contact pressure is large. 
(a)

(d)

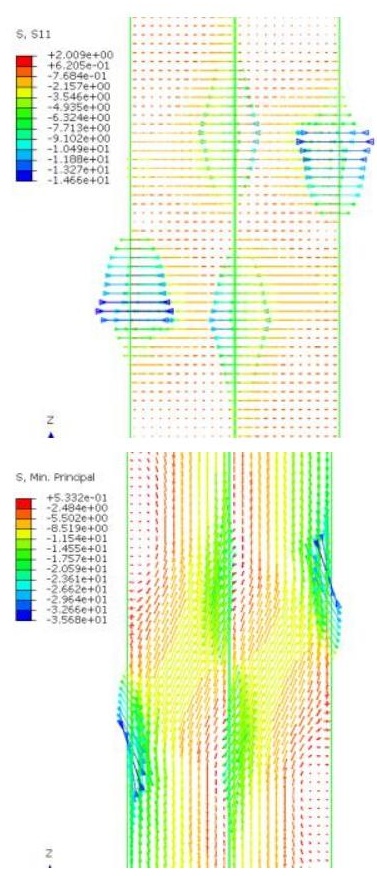

(g)
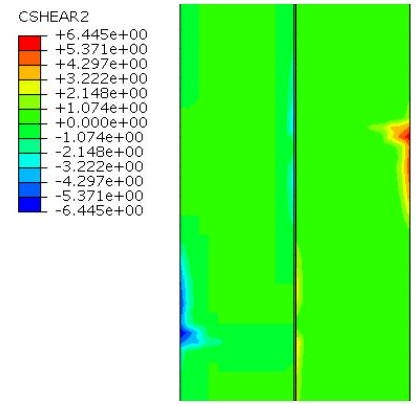

(b)

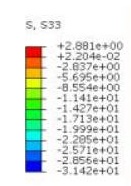

(e)

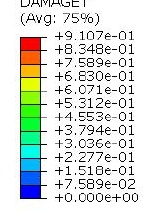

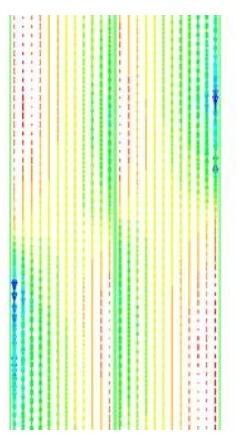

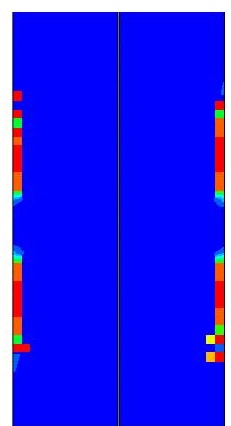

(h) (c)

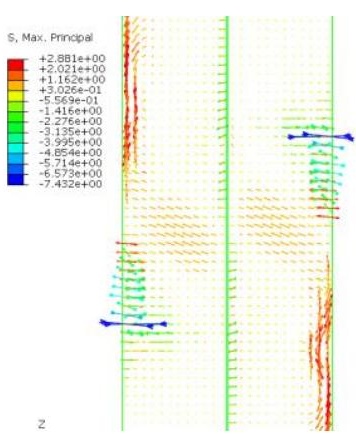

(f)
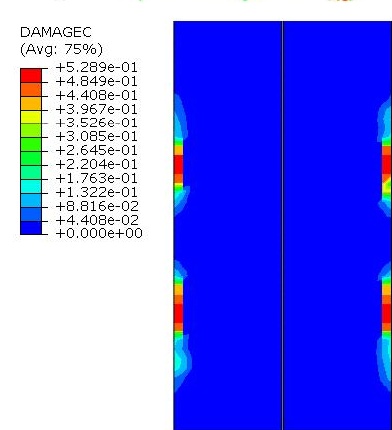

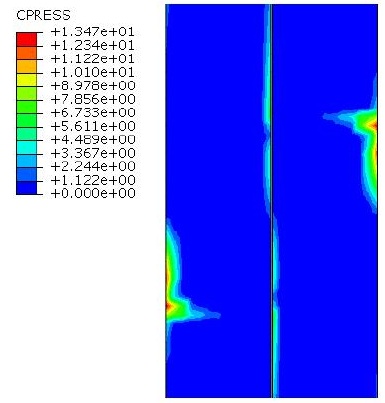

Fig. 6 Stress distribution of concrete in DSP1. (a) Horizontal stress, (b) vertical stress, (c) principal tensile stress, (d) principal compressive stress, (e) tensile damage, (f) compressive damage, $(\mathrm{g})$ surface friction, and $(\mathrm{h})$ surface pressure

\section{Initial rotational stiffness analysis}

Rotational stiffness is a key parameter in describing moment-rotation curves. Generally, joint rotation can be divided into rotations caused by bending and shear deformations [32]. The primary tension components of the joint include the tension in the steel beam flange and cover plate near the side plate, the tension in the side plate, and the tension in the column web. The primary compression components include compression of the steel beam flange and cover plate near the side plate, compression of the side plate itself, and compression in the column web. The main shear components include side plate shear, column web shear, and concrete shear.

In this study, a simplified connection model (Fig. 7) was developed. The joint rotation caused by bending deformation is simplified as the spring model shown in Fig. 7, and the joint bending is converted into a coupled pair of tension and pressure. According to the principles of the component method [25], individual tension and pressure components can be simplified as a single spring element along the centroid direction.

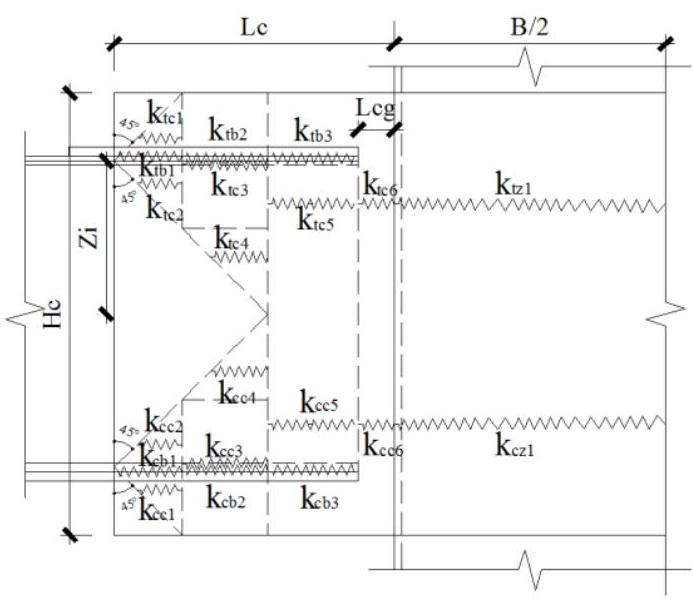

(a)

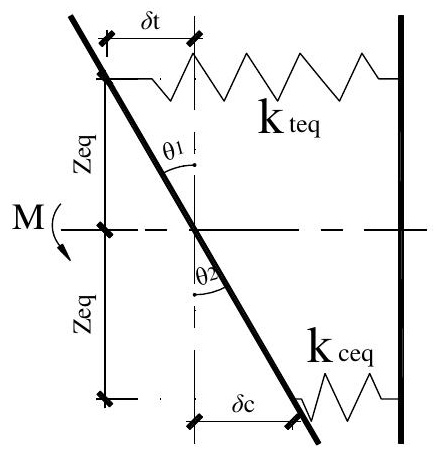

(b)

Fig. 7 Simplified spring model. (a) Tension and compression spring elements, and (b) equivalent spring elements. $\mathrm{k}_{\mathrm{tci}}$, $\mathrm{k}_{\mathrm{tbi}}$, and $\mathrm{k}_{\mathrm{tzi}}$ are the tensile stiffnesses of the side plate, steel

beam/cover plate, and side plate/column web, respectively; $\mathrm{k}_{\mathrm{cci}}, \mathrm{k}_{\mathrm{cbi}}$, and $\mathrm{k}_{\mathrm{czi}}$ are the compression stiffnesses of the side plate, steel beam/cover plate, and side plate/column web, respectively; $\mathrm{k}_{\mathrm{teq}}$ and $\mathrm{k}_{\mathrm{ceq}}$ are the equivalent tension and compression stiffnesses, respectively of the spring element; $Z_{\mathrm{i}}$ is the distance between the centroid of each spring element and the beam centre, and $Z_{\mathrm{eq}}$ is the equivalent distance between the centroid of each spring element and the beam centre 
Corresponding to Fig. 7(b), the following equations are established according to the respective resultant force equivalence and bending distance equivalence:

$$
\begin{aligned}
& k_{t e q} Z_{t e q} \theta_{1}=\sum_{\mathrm{i}=1}^{6} k_{t c i} Z_{t c i} \theta_{1}+\sum_{\mathrm{i}=1}^{3} k_{t b i} Z_{t b i} \theta_{1}+k_{t z 1} Z_{t z 1} \theta_{1} \\
& k_{t e q} Z_{t e q}^{2} \theta_{1}=\sum_{\mathrm{i}=1}^{6} k_{t c i} Z_{t c i}^{2} \theta_{1}+\sum_{\mathrm{i}=1}^{3} k_{t b i} Z_{t b i}^{2} \theta_{1}+k_{t z 1} Z_{t z 1}^{2} \theta_{1} \\
& k_{c e q} Z_{c e q} \theta_{2}=\sum_{\mathrm{i}=1}^{6} k_{c c i} Z_{c c i} \theta_{2}+\sum_{\mathrm{i}=1}^{3} k_{c b i} Z_{c b i} \theta_{2}+k_{c z 1} \mathrm{Z}_{c z 1} \theta_{2} \\
& k_{c e q} Z_{c e q}^{2} \theta_{2}=\sum_{\mathrm{i}=1}^{6} k_{c c i} Z_{c c i}^{2} \theta_{2}+\sum_{\mathrm{i}=1}^{3} k_{c b i} Z_{c b i}^{2} \theta_{2}+k_{c z 1} Z_{c z 1}^{2} \theta_{2}
\end{aligned}
$$

Combining Eqs. (1 to 4 ) yields:

$$
\begin{aligned}
Z_{t e q}= & \frac{\sum_{i=1}^{6} k_{t c i} Z_{t c i}^{2}+\sum_{i=1}^{3} k_{t b i} Z_{t b i}^{2}+k_{t z 1} Z_{t z 1}^{2}}{\sum_{i=1}^{6} k_{t c i} Z_{t c i}+\sum_{i=1}^{3} k_{t b i} Z_{t b i}+k_{t z 1} Z_{t z 1}} \\
Z_{c e q}= & \frac{\sum_{i=1}^{6} k_{c c i} Z_{c c i}^{2}+\sum_{i=1}^{3} k_{c b i} Z_{c b i}^{2}+k_{c z 1} Z_{c z 1}^{2}}{\sum_{i=1}^{3} k_{c c i} Z_{c c i}+\sum_{i=1}^{3} k_{c b i} Z_{c b i}+k_{c z 1} Z_{c z 1}}
\end{aligned}
$$

$$
k_{t e q}=\frac{\left(\sum_{i=1}^{6} k_{t c i} Z_{t c i}+\sum_{i=1}^{3} k_{t b i} Z_{t b i}+k_{t z 1} Z_{t z 1}\right)^{2}}{\sum_{i=1}^{6} k_{t c i} Z_{t c i}^{2}+\sum_{i=1}^{3} k_{t b i} Z_{t b i}^{2}+k_{t z 1} Z_{t z 1}^{2}}
$$

$$
k_{c e q}=\frac{\left(\sum_{i=1}^{6} k_{c c i} Z_{c c i}+\sum_{i=1}^{3} k_{c b i} Z_{c b i}+k_{c z 1} Z_{c z 1}\right)^{2}}{\sum_{i=1}^{6} k_{c c i} Z_{c c i}^{2}+\sum_{i=1}^{3} k_{c b i} Z_{c b i}^{2}+k_{c z 1} Z_{c z 1}^{2}}
$$

The characteristics of new joints produce a very large in-plane stiffness for concrete, compared with the other components, hence the rotation caused by moment deformation in concrete is ignored. Under a pure bending moment, the areas of the joint under tension and compression are symmetrical, and they constitute the tensile and compressive rigidity of the plate. The tensile and compression calculation models and stiffnesses are identical; thus, $Z_{\text {teq }}=Z_{c e q}$, $k_{\text {teq }}=k_{\text {ceq }}$. The mechanical model of the tension plate is shown in Fig. 8 .

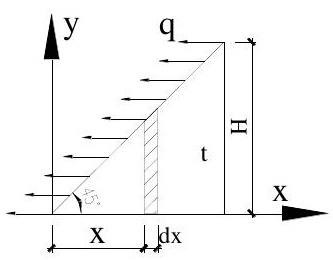

(a) Tension of triangular plate

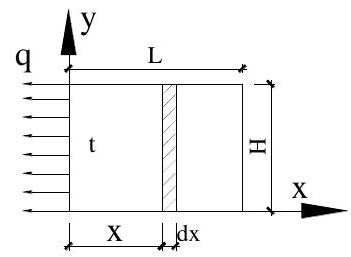

(b) Tension of rectangular plate
Fig. 8 Mechanical model of plate. Illustrations of the tension of (a) triangular and (b) rectangular plates.
According to material mechanics principles, the calculation formula for the tensile stiffness of a plate is Eq. (9). The tension stiffness of the triangular plate (Fig. 8(a)) is calculated according to Eqs. (10 to 14),

$k=\frac{F}{\Delta L}$

$d A=x t$

$d F=d A \times q=x t q$

$\Delta d x=\frac{d F \times d x}{E d A}=\frac{q}{E} d x$

$\Delta L=\int_{0}^{H} \frac{q}{E} d x=\frac{q H}{E}$

$k_{t, t r i}=\frac{F}{\Delta L}=E t$

Similarly, the tensile stiffness of the rectangular plate (Fig. 8(b)) is calculated as:

$k_{t, \text { rec }}=\frac{E H \mathrm{t}}{L}$

Based on Fig. 7 and Eqs. (14 and 15), the spring element parameters can be defined as follows:

$k_{t c 1}=2 E t_{c 1}, \quad k_{t c 2}=2 E t_{c 2}, \quad k_{t c 4}=2 E t_{c 4} \quad k_{t c 3}=\frac{4 E t_{c 3}\left[H_{c}-\left(H_{b}-t_{f}\right)\right]}{2\left(H_{b}-t_{f}\right)-H_{c}}$

$k_{t c 5}=\frac{2 E t_{c 5} H_{c}}{2 L_{c}-\left(H_{b}-t_{f}\right)-2 L_{\mathrm{cg}}}$

$k_{t c 6}=\frac{E t_{c 6} H_{c}}{L_{c g}}, \quad k_{t b 1}=\frac{2 E\left(t_{f} B_{f}+t_{g} B_{g}\right)}{H_{c}-\left(H_{b}-t_{f}\right)}$

$k_{t b 2}=\frac{2 E\left(t_{f} B_{f}+t_{g} B_{g}\right)}{2\left(H_{b}-t_{f}\right)-H_{c}}, \quad k_{t z 1}=\frac{4 E H_{c}\left(t_{c}+t_{z}\right)}{B}$

$k_{t b 3}=\frac{4 E\left(t_{f} B_{f}+t_{g} B_{g}\right)}{2 L_{c}-\left(H_{b}-t_{f}\right)-2 L_{c g}}$

$Z_{t c 1}=\frac{H_{c}+2\left(H_{b}-t_{f}\right)}{6}, \quad Z_{t c 2}=\frac{4\left(H_{b}-t_{f}\right)-H_{c}}{6}$

$Z_{t c 3}=\frac{H_{b}-t_{f}}{2}, \quad Z_{t c 4}=\frac{2\left(H_{b}-t_{f}\right)-H_{c}}{3} Z_{t c 5}=Z_{t c 6}=Z_{t z 1}=\frac{H_{c}}{4}$

$Z_{t b 1}=Z_{t b 2}=Z_{t b 3}=\frac{H_{b}-t_{f}+t_{g}}{2}$

where $H_{b}$ is steel beam height, $t_{f}$ is the beam flange thickness, $t_{g}$ is the cover plate thickness $B_{g}$ is the cover plate width, and $B_{f}$ is the beam flange width. $Z_{\text {teq }}$ 
and $k_{\text {teq }}$ can be obtained by substituting these spring parameters into Eqs. ( 5 to 8).

Referring to [27], the shear stiffness can be calculated as:

$$
k_{v}=\frac{E A_{v c}}{2(1+v) \beta Z_{v}}
$$

where $A_{v c}$ is the shear area, $Z_{v}$ is the shear section height, and $\beta$ is the coefficient related to the connected shear variable. For a side column, one side is sheared, and $\beta=1$. For a middle column, if the bending moment at the beam end is equal and the direction is opposite, $\beta=0$, but if the direction is equal, $\beta$ $=2$.

The shear components of the side plate joints include side plate shear, column side plate/web shear, and concrete shear. The characteristics of new joints produce very large in-plane shear stiffness for concrete compared with the other components. Hence, the rotation caused by shear deformation in concrete is ignored. The parameters of each shear component are as follows

$$
\begin{aligned}
& k_{v, \text { sideplate }}=\frac{E\left(L_{c}-L_{c g}\right) 2 t_{c}}{2(1+v)\left(H_{b}-2 t_{f}\right)} \\
& k_{v, w e b}=\frac{2 E\left(B_{\mathrm{zc}} t_{c}+B t_{z}\right)}{2(1+v) \beta\left(H_{b}-2 t_{f}\right)}
\end{aligned}
$$

(a)

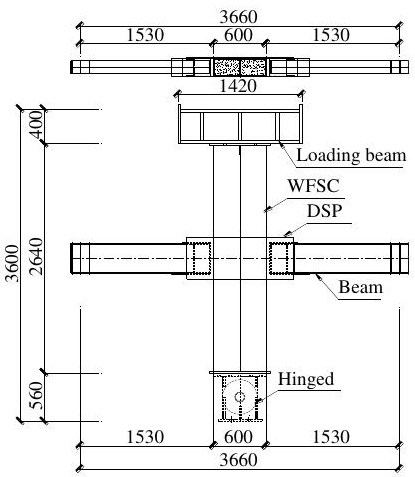

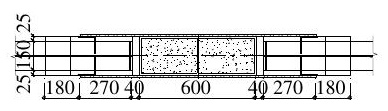

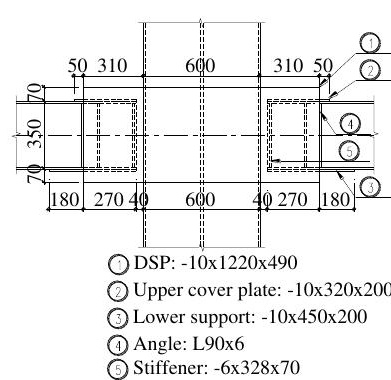

(b)

$\theta_{V}=M\left(\frac{1}{k_{v, \text { sideplate }}\left(H_{b}-2 t_{f}\right)^{2}}+\frac{1}{k_{v, \text { web }}\left(H_{b}-2 t_{f}\right)^{2}}\right)$

Then, the overall initial rotational stiffness for the proposed new joint is:

$S=\frac{M}{\theta}=\frac{1}{\frac{1}{k_{t e q}\left(z_{t e q}+Z_{c e q}\right)^{2}}+\frac{1}{k_{c e q}\left(z_{c e q}+Z_{c e q}\right)^{2}}+\frac{1}{k_{v, s p}\left(H_{b}-2 t_{f}\right)^{2}}+\frac{1}{k_{v, w e b}\left(H_{b}-2 t_{f}\right)^{2}}}$

\section{Experiments and FEM Verification}

To verify the validity of the proposed analysis, we conducted pseudo-static experiments for two full-scale DSP specimens (denoted DSP1 and DSP2), which were based on beam and column models from real-world engineering applications. We performed a multi-parameter extended analysis of this FEM; the parameters of the test and FEM are shown in Table 2 and Fig. 9, respectively. The material properties of each component are provided in Section 1.1, and the axial compression load was $1713.33 \mathrm{kN}$.

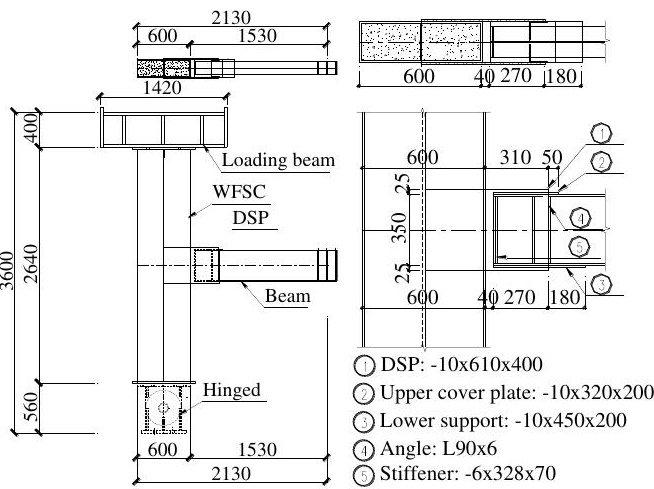

Fig. 9 Specimen details. All dimensions are given in mm. Overall and partial details are provided for (a) DSP1 and (b) DSP2

\begin{tabular}{|c|c|c|c|c|c|c|c|c|c|c|c|}
\hline Model & $\begin{array}{c}\text { Side plate } \\
\text { height } \\
H_{c} / \mathrm{mm}\end{array}$ & $\begin{array}{c}\text { Side plate } \\
\text { thickness } \\
t_{c} / \mathrm{mm}\end{array}$ & $\begin{array}{c}\text { Side plate } \\
\text { extension } \\
\text { length } L_{c} / \mathrm{mm}\end{array}$ & $\begin{array}{c}\text { beam-column } \\
\text { gap length } \\
L_{c g} / \mathrm{mm}\end{array}$ & $\begin{array}{l}\text { Beam } \\
\text { height } \\
H_{b} / \mathrm{mm}\end{array}$ & $\begin{array}{c}\text { Beam } \\
\text { flange } \\
\text { thickness } \\
t_{f} / \mathrm{mm} \\
\end{array}$ & $\begin{array}{c}\text { Cover plate } \\
\text { thickness } \\
t_{g} / \mathrm{mm}\end{array}$ & $\begin{array}{c}\text { Beam } \\
\text { flange } \\
\text { width } \\
B_{f} / \mathrm{mm} \\
\end{array}$ & $\begin{array}{c}\text { Cover plate } \\
\text { width } \\
B_{g} / \mathrm{mm}\end{array}$ & $\begin{array}{l}\text { Column } \\
\text { width } \\
B / \mathrm{mm}\end{array}$ & $\begin{array}{c}\text { Column } \\
\text { web } \\
\text { thickness } \\
t_{z} / \mathrm{mm}\end{array}$ \\
\hline DPS1 & 490 & 10 & 310 & 40 & 350 & 10 & 10 & 150 & 200 & 600 & 8 \\
\hline DPS2 & 400 & 10 & 310 & 40 & 350 & 10 & 10 & 150 & 200 & 600 & 8 \\
\hline DPS1-1 & 520 & 10 & 310 & 40 & 350 & 10 & 10 & 150 & 200 & 600 & 8 \\
\hline DPS1-2 & 460 & 10 & 310 & 40 & 350 & 10 & 10 & 150 & 200 & 600 & 8 \\
\hline DPS1-3 & 430 & 10 & 310 & 40 & 350 & 10 & 10 & 150 & 200 & 600 & 8 \\
\hline DPS2-1 & 490 & 6 & 310 & 40 & 350 & 10 & 10 & 150 & 200 & 600 & 8 \\
\hline DPS2-2 & 490 & 8 & 310 & 40 & 350 & 10 & 10 & 150 & 200 & 600 & 8 \\
\hline DPS2-3 & 490 & 10 & 310 & 40 & 350 & 10 & 10 & 150 & 200 & 600 & 8 \\
\hline DPS2-4 & 490 & 12 & 310 & 40 & 350 & 10 & 10 & 150 & 200 & 600 & 8 \\
\hline DPS2-5 & 490 & 14 & 310 & 40 & 350 & 10 & 10 & 150 & 200 & 600 & 8 \\
\hline DPS2-6 & 490 & 16 & 310 & 40 & 350 & 10 & 10 & 150 & 200 & 600 & 8 \\
\hline
\end{tabular}

Table 2

Parametric definition of the model 


\subsection{Testing system and method}

According to the provisions of JGJ/T101-2015 [33], a pseudo-static experiment can use a column-end loading test device (Fig. 10) to consider the $\mathrm{P}-\Delta$ effect. A force-displacement dual-control loading system is used to transition specimens from the elastic stage to failure. The loading process begins with axial pressure applied, in stages, to the top of the specimen while the shaft pressure is maintained as constant by a voltage stabilisation system. A reciprocating horizontal load is then applied in stages to the specimen top. The distance between the loading point and column bottom is $3000 \mathrm{~mm}$.

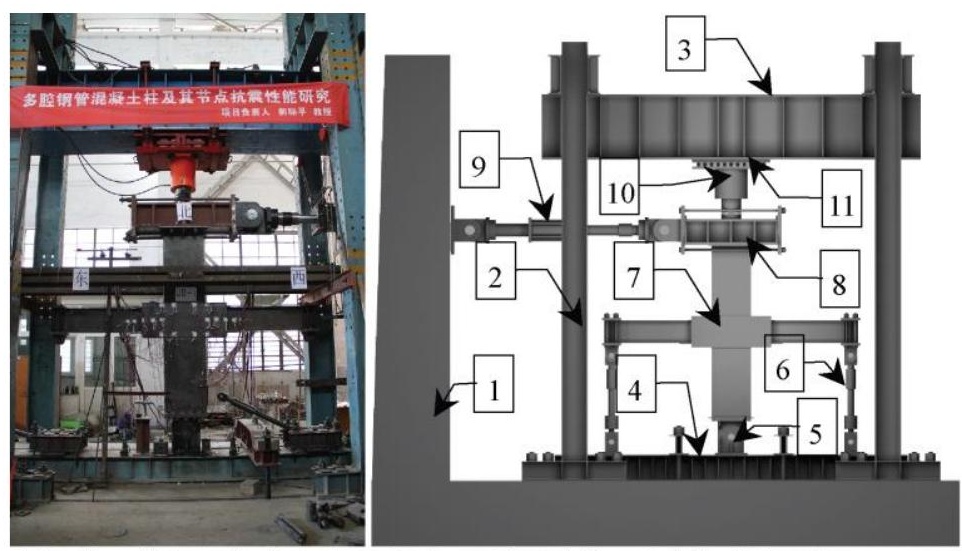

1: Reaction wall; 2 : reaction frame; 3 : reaction beam; 4 : base; 5 : hinge; 6 : rigid rod; 7 : specimens;

8: loading beam; 9 : servo actuator; 10 : jack; and 11: sliding roller

Fig. 10 Test device

The force applied to the specimen was controlled before yielding. The horizontal loading level was $20 \%$ of the predicted yield load, and each load was repeated once. When the specimen deformation speed increased significantly or when the strain, collected by a displacement meter and strain gauges at multiple points on the beam end or side plate, reached the material yield strain, the specimen was determined to have yielded. The corresponding displacement was identified as the joint yield displacement. After yielding, the specimens were subjected to displacement control and were loaded at 0.5 times the yield displacement. Each displacement was repeated three times. When the horizontal load decreased to $85 \%$ of the peak load, or the axial bearing capacity could not be maintained, the loading was considered complete.

During these tests, we measured the axial force and horizontal load exerted on the top of the column, the displacement and angle of the specimen, and the strain of the beam end and side plate. The local buckling development of the steel tube wall plate, longitudinal weld cracking of the steel tube itself, and concrete crushing were also observed and recorded. The measurement setup is summarised in Fig. 11.

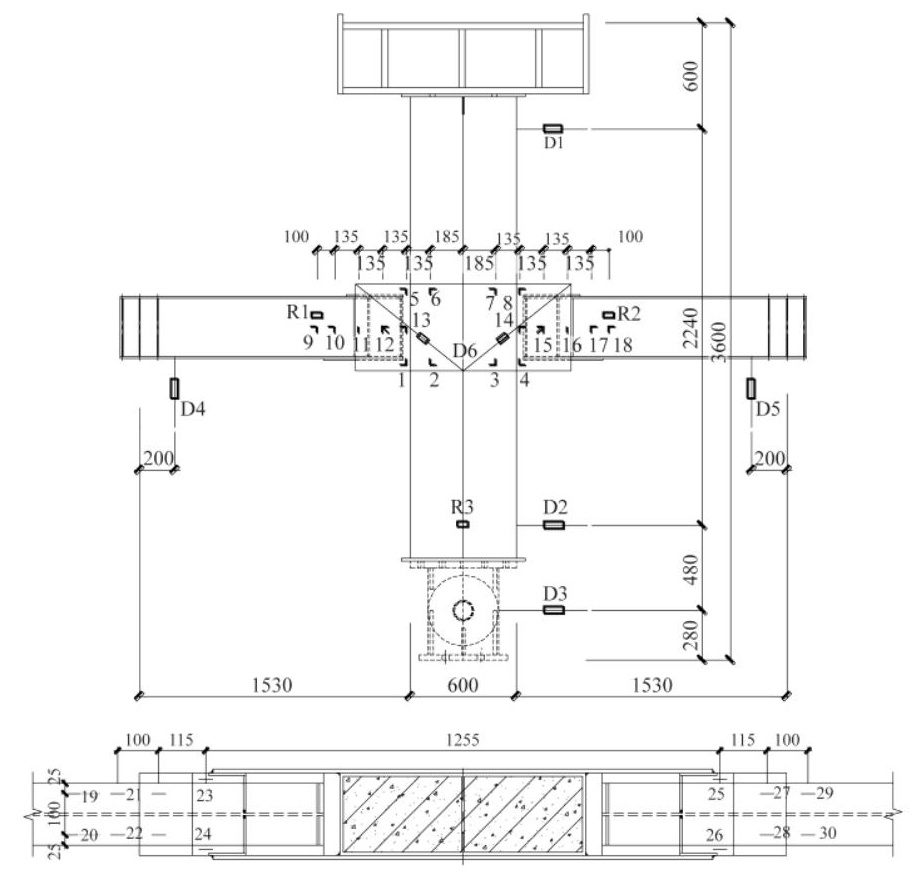

D1: magnetostrictive displacement meter; D2-D5: horizontal displacement meters;

D6: cross-displacement meter; R1-R3: inclinometers; and 1-30: strain gauges

Fig. 11 Measurement types and locations

The horizontal load applied to the specimen and the displacement of the column top were collected by the servo actuator (Fig. 11). The main control measuring point was D1, which was $2700 \mathrm{~mm}$ above the bottom section of the column. The cross-displacement meter, D6, measured the shear deformation of the specimen joints. Inclinometers R1 and R2 were placed $525 \mathrm{~mm}$ from the column wall and were used to measure the section angle of the plastic hinge area of the test piece beam. Inclinometer R3 was placed $480 \mathrm{~mm}$ from the centre of the hinge and was used to measure the section angle of the bottom section of the test column. Strain gauges, numbered 1-30, were used to measure the strain development of the beam end and side plates and evaluate the plastic development of each component.

\subsection{Comparison of load transfer mechanism}

Calculating yield strain with the information in Table 1 yielded values of 1395,1517 , and $1531 \mu \mathrm{m}$ in the beam flange, beam web, and side plate, respectively. These results were compared to the strain results collected by gauges placed at various locations during the test (Fig. 11), and with the peak load results observed in Fig. 12. 


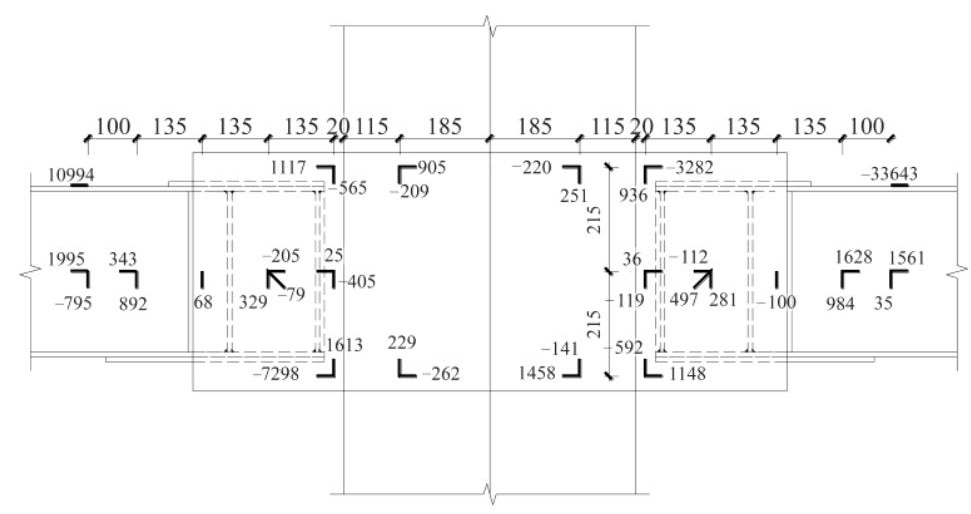

(a) Measured strains at peak loads (DSP1)

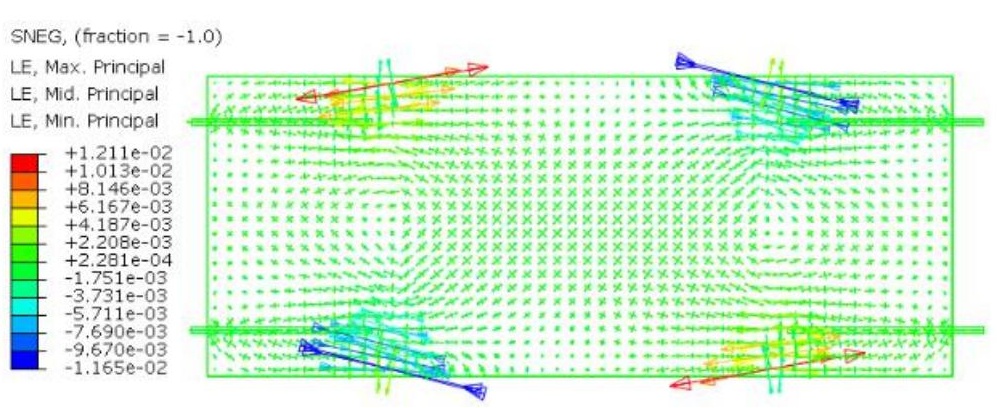

(b) Analysed strains at peak loads (DSP1)

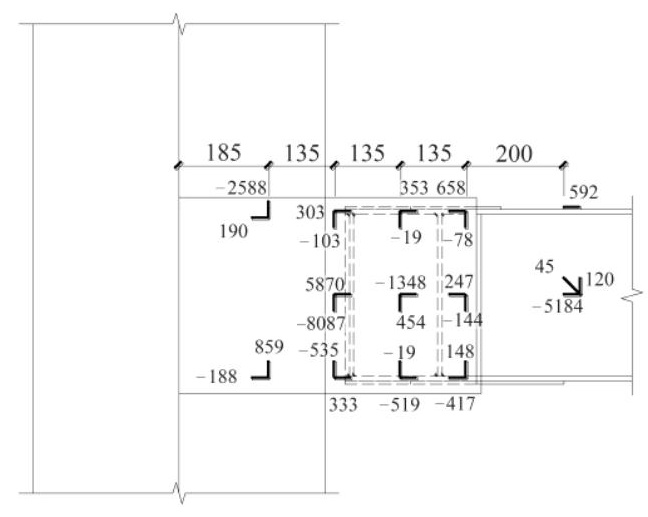

(c) Measured strains at peak loads (DSP2)
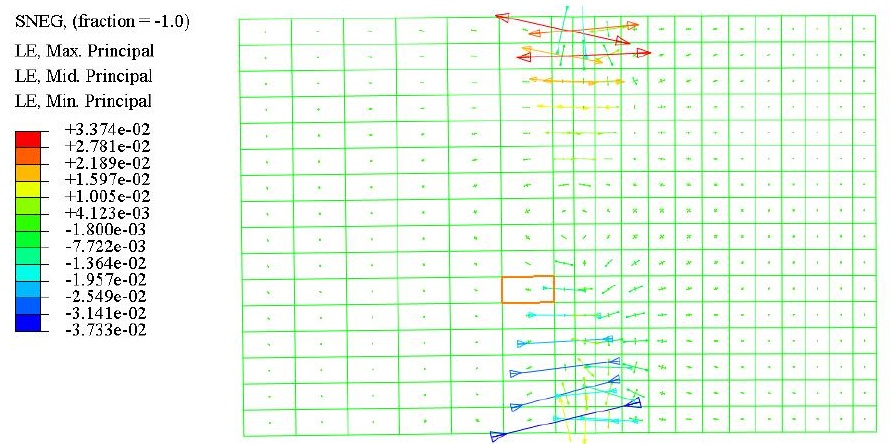

(d) Analysed strains at peak loads (DSP2)

Fig. 12 Transfer mechanism comparison

Several conclusions can be drawn from these results. First, at peak load, the beam end strain of DSP1 was 20 times higher than the yield strain. The web strain also exceeded the yield strain, and the entire section thus entered the yield state, forming a plastic hinge. Furthermore, the strains on the lower and upper sides at the beam-column gap also entered the yield state, although most areas of the side plate remained in the elastic stage. Therefore, the side plate could add strength to the joint region.

Second, most of the side plate strain for DSP2 exceeded the yield strain, while the beam flange strain was small. Additionally, the tensile strain was measured on the bottom side plate at the beam-column gap, rather than the expected compressive strain. This is because of the side plate buckling at the beam-column gap, which caused tensile strain to develop.

Third, in comparing the strain of the side plates on the two test pieces, DSP1 and DSP2, it is clear that decreasing the side plate height caused more areas on the DSP2 side plates to approach and reach the yield strain. Thus, plastic formed on the side plates at the beam-column gap. In comparing Figs. 12(a) and (b) and Figs. 12(c) and d), it is evident that the principal tensile and compressive strains on the side plate are consistent with the stress distribution, 
forming an X-shaped distribution between the left and right steel beam flanges. This indicates that these experiments supported the force transmission mechanism proposed in this study.

\subsection{Initial stiffness comparison}

Table 3

Verification results

\begin{tabular}{|c|c|c|c|}
\hline Model & $S_{\text {exp }}$ & $S_{\text {int }}$ & $\mathrm{S}_{\text {int }} / \mathrm{S}_{\exp }$ \\
\hline DPS1 & $5.56 \times 10^{10}$ & $6.11 \times 10^{10}$ & 1.09 \\
\hline DPS2 & $5.18 \times 10^{10}$ & $6.09 \times 10^{10}$ & 1.17 \\
\hline DPS1-1 & $5.64 \times 10^{10}$ & $6.12 \times 10^{10}$ & 1.08 \\
\hline DPS1-2 & $5.47 \times 10^{10}$ & $6.11 \times 10^{10}$ & 1.11 \\
\hline DPS1-3 & $5.29 \times 10^{10}$ & $6.10 \times 10^{10}$ & 1.15 \\
\hline DPS2-1 & $5.24 \times 10^{10}$ & $4.73 \times 10^{10}$ & 0.90 \\
\hline DPS2-2 & $5.40 \times 10^{10}$ & $5.51 \times 10^{10}$ & 1.02 \\
\hline DPS2-3 & $5.66 \times 10^{10}$ & $6.59 \times 10^{10}$ & 1.16 \\
\hline DPS2-4 & $5.74 \times 10^{10}$ & $6.70 \times 10^{10}$ & 1.16 \\
\hline DPS2-5 & $5.80 \times 10^{10}$ & $6.83 \times 10^{10}$ & 1.17 \\
\hline DPS2-6 & $5.86 \times 10^{10}$ & $6.91 \times 10^{10}$ & 1.17 \\
\hline \multicolumn{3}{|c|}{ Average } & 1.10 \\
\hline \multicolumn{3}{|c|}{ Standard deviation } & 0.08 \\
\hline
\end{tabular}

$\mathrm{S}_{\exp }$ is the test and finite element analysis results, $\mathrm{S}_{\text {int }}$ is the theoretical calculation results.
This analysis demonstrates that, because the theoretical formula used in this article does not consider factors such as initial defects and weld defects, it yields values greater than the experimental and numerical simulation results, although the results are relatively similar. The theoretical calculated value and ratio of the experimental and simulated values $\left(\mathrm{S}_{\text {int }} / \mathrm{S}_{\text {exp }}\right)$ has an impressive average of 1.1 and a low standard deviation of 0.08 .

In this study, the force transmission mechanism of a joint was analysed through both experimental research and numerical simulation. The component method was also introduced into the analysis of side plate joints, for the first time. The basic components of the joint force transmission were clarified, and a formula for calculating the initial rotational stiffness of the joint derived using the principle of component transmission. The following conclusions were drawn:

(1) The transmission path of the new side plate joint is as follows. The bending moment of the steel beam is simplified as the force couple acting along the flange to the side plate. After the side plate horizontal stress is transmitted to the joint, part of it is transmitted to the wall column web through the weld and part of it is directly transmitted to the lower flange of the right the side plate, and the principal strain exhibits an X-shaped distribution between the left and right steel beam flanges. The shear force in the steel beam web is transmitted to the middle of the side plate first, and then to the joint region. The side plate, steel tube web, and concrete resist the internal force in the joint region.

(2) The side plate at the beam-column gap transfers all forces at the beam end, exhibiting maximal stress and large accumulated plastic strain values. Special care should thus be taken to avoid damage in this region of the design.

(3) The formula for calculating initial rotational stiffness, established through the principle of component transmission method, is applicable to the new proposed joint. Comparing calculation results and experimental and numerical simulation results demonstrates that the formula can accurately calculate the initial rotational stiffness of the joint, thus providing a basis for engineering design and subsequent research.

The research results obtained in this study can be used to improve the design theory of the proposed joint and provide a research basis for its application to WCFT column structures.

\section{Acknowledgements}

\section{Conclusion} steel beam. The principal stress is transmitted along an S-shaped path through
According to European Code EC3 [34], the secant stiffness is taken as the initial rotational stiffness of a joint when the bending moment is $2 / 3 \times \mathrm{M}_{j, r d}$. We thus calculated the initial stiffness of each model according to (19) and compared it with the experimental and FEM results, as shown in Table 3. editing

We would like to thank Editage (www.editage.cn) for English language

\section{Funding}

This work was supported by the National Key R\&D Program of China (grant number 2017YFC0703800), and the Shaanxi Provincial Department of Construction Science and Technology Development Plan Project (grant number 2016-K86)

\section{References}

[1] Hao J.-P., Sun X.-L., Xue Q. and Fan C.-L., "Research and application of prefabricated stee structure building system", J. Eng. Mech. 34, 1, 1-13, 2017http://doi.org/10.6052/j.issn.1000-4750.2016.08.ST14.

[2] Hu B., Liu B., Wei K., et al., "Advantages of steel structure construction in the development of assembled buildings", J. Fujian Building Materials, 2, 31-33, 2020.

[3] Sun X.-L., Hao J.-P., Xue Q., Fan C.-L., Liu H.-C. and He M.-N., "Experimental study on seismic behaviour of walled concrete-filled steel tubular columns", J. Build. Struct., 39, 6 , 92-101, 2018. http://doi.org/10.14006/j.jzjgxb.2018.06.010.

[4] Hao J., Xue Q., Huang Y., et al., "Research of prefabricated building based system theory", Xi'an Univ, of Arch, \&, Tech (Natural Science Edition), 51, 1, 14-20+26, 2019. http://doi.org/10.15986/j.1006-7930.2019.01.003.

[5] Miller D.K., "Lessons from damage to steel buildings during the Northridge earthquake", Eng. Struct., 20, 4-6, 249-260, 1998. https://doi.org/10.1016/S0141-0296(97)00032-1.

[6] Houghton D.L., "Steel frame connection technology of the new millennium: satisfying heightened performance expectations with simplicity and reliability at low cost", Proc. 12th World Conference on Earthquake Engineering (12WCEE), Auckland, New Zealand, January - February 2000

[7] Sabol T.A., Engelhardt M.D., Aboutaha R.S. and Frank K.H., "Overview of the AISC Northridge moment connection test program", Proc. 11 $11^{\text {th }}$ World Conference on Earthquake Engineering, Acapulco, Mexico, June 1996.

[8] Engelhardt M.D. and Sabol T.A., "Reinforcing of steel moment connections with cover plates: benefits and limitations", Eng. Struct., 20, 4-6, 510-520, 1998 https://doi.org/10.1016/S0141-0296(97)00038-2.

[9] Houghton D.L., "The sideplate moment connection system: a design breakthrough eliminating recognized vulnerabilities in steel moment-resisting frame connections", Proc $2^{\text {nd }}$ World Conference on Steel Construction, San Sebastian, Spain, May 1998.

[10] Houghton D.L. and Karnes J.E., "Effective mitigation of progressive collapse in steel frame buildings using ductile high-capacity girder-to-column moment connection exhibiting discrete structural continuity across a failed column", Proc. Societies of American Military Engineers (SAME), National Symposium on Comprehensive Force Protection, Charleston, South Carolina, November 2001.

[11] Houghton D.L., "Prototype cyclic testing of the Side Plate ${ }^{\mathrm{TM}}$ moment connection system", Northridge Earthquake Research Conference, Los Angeles, CA, August 1997.

[12] Faridmehr I., Tahir M.M., Osman M.H. and Azimi M., "Cyclic behaviour of fully-rigid and semi-rigid steel beam-to-column connections", Int. J. Steel Struct., 21, 365-385, 2020 https://doi.org/10.1007/s13296-019-00290-8.

[13] Yakhchalian, M. "Investigation of cyclic behavior of two-sided moment connections with double-I columns and side plates", M.Sc. Thesis, Amirkabir University of Technology, Tehran, Iran, 2007 (in Persian). 
[14] Shiravand, M. "Experimental investigation of rigid beam-to-column connections in small-span bridges retrofitted against earthquake", Quarterly of Civil Engineers Association (Iran), 25, 61-69, 2007

[15] Jalali S.A., "Probabilistic seismic demand assessment of steel moment frames with side-plate connections", Scientia Iranica A, 19, 27-40, 2012.

[16] Liu H., "Seismic performance of a wall-type concrete-filled steel tubular column with a double side-plate I-beam connection", Thin-Walled Structures, 159, 1-17, 2021.

[17] Huang Y., "Mechanical behaviors of side-plate joint between walled concrete-filled steel tubular column and H-shaped steel beam", Advanced steel construction, 16, 346-353, 2020

[18] Chen S.Z. and Wang Z., "Application of modified and improved component method in the constitutive relation research for steel connections", South China University of Technology, Guangzhou, 2015.

[19] Chen Y.-Z, Tong L., Chen Y., et al, "Research developments of component method for behavior of joints in steel structures", J. Architect. and Civ. Eng., 29, 3, 81-89, 2012. https://doi.org/10.3969/j.issn.1673-2049.2012.03.013

[20] Weynand K. and Jaspart J.P., "Extension of the component method to joints in tubular construction", University of Liege, Belgium, 2001.

[21] Faella C., Piluso V. and Rizzano G., "Experimental analysis of bolted connections: snug versus preloaded bolts", J. Struct. Eng., 124, 7, 765-774, 1998 http://10.1061/(ASCE)0733-9445(1998)124:7(765).

[22] Simoes Da Silva L. and Coelho A.G., "A ductility model for steel connections", J. Constr Steel Res. 57(1), 45-70, 2001. https://doi.org/10.1016/S0143-974X(00)00009-2.

[23] Beg D., Zupancic E. and Vayas I., "On the rotation capacity of moment connections", J. Constr. Steel Res. 60(3), 601-620, 2004. https://doi.org/10.1016/S0143-974X(03)00132-9.

[24] Gill B. and Bayo E., "An alternative design for internal and external semi-rigid composite joints. Part 2: Finite element modelling and analytical study", Eng. Struct., 30, 1, 232-246, 2008. https://doi.org/10.1016/j.engstruct.2007.03.010.

[25] Lemonis M.E. and Gantes C.J., "Mechanical modeling of the nonlinear response of beam to column joints", J. Constr. Steel Res., 65, 4, 879-890, 2009. https://doi.org/10.1016/j.jcsr.2008.11.007

26] Hao J.-P., Fan C.-L., Liu H.-C., et al., "Wall-type concrete-filled steel tube concrete column steel beam double side plate connection node", ZL201821266047.2 [P] .2019-04-2.

[27] Hao J.-P., Xue Q., He M.-N., Liu H.-C., et al., "Assembled double-side plate connection node of multi-cavity concrete-filled steel tube concrete column", ZL201820370974.2 [P] 11-6, 2018.

[28] GB/T 288.1-2010, Metallic Materials: Tensile Testing at Ambient Temperature, China Standards Press, Beijing, China, 2010

[29] ABAQUS, ABAQUS Analysis User's Manual, Providence, RI, Dassault Systèmes Corp., 2012

[30] Shi Y.-J., Wang M. and Wang Y.-Q., "Experimental and constitutive model study of structural steel under cyclic loading", J. Constr. Steel Res., 67, 8, 1185-1197, 2011 https://doi.org/10.1016/j.jcsr.2011.02.011.

[31] Tao Z., Wang Z.-B. and Yu Q., "Finite element modelling of concrete-filled steel stub columns under axial compression", J. Constr. Steel Res. 89(5), 121-131, 2013 https://doi.org/10.1016/j.jcsr.2013.07.001.

[32] Wu Z., Zhang S. and Jiang S., "Calculation model of initial rotational stiffness of steel beam-to-column bolted end-plate connections", Eng. Mech. 26(6), 226-256, 2009. http://doi.org/1000-4750(2009)06-0226-07.

[33] Specification for seismic test of buildings: JGJ/T 101-2015. Beijing: China Architecture \& Building Press, 2015.

[34] EN 1993-1-8:2005, Eurocode 3: Design of Steel Structures. Part 1-8: Design of Joints, 1993. 


\title{
PROGRESSIVE COLLAPSE RESISTANCE OF STEEL FRAMED BUILDINGS UNDER EXTREME EVENTS
}

\author{
Guo-Qiang Li ${ }^{1}$, Jing-Zhou Zhang ${ }^{2}$, Liu-Lian Li ${ }^{3}$, Bin-Hui Jiang ${ }^{4}$, Tao-Chun Yang ${ }^{5}$ and Jian Jiang 6 ,* \\ ${ }^{1}$ State Key Laboratory for Disaster Reduction in Civil Engineering, Tongji University, 1239 Siping Road, Shanghai 200092, China \\ ${ }^{2}$ College of Civil Engineering, Tongji University, 1239 Siping Road, Shanghai 200092, China \\ ${ }^{3}$ The First Construction Engineering Company LTD. of China Construction Second Engineering Bureau, No. 9 Kechuangsi Street, Beijing 100176, China \\ ${ }^{4}$ School of Civil Engineering, Central South University, 68 South Shaoshan Road, Changsha 410075, China \\ School of Civil Engineering and Architecture, University of Jinan, Jinan 250022, China; \\ ${ }^{6}$ Jiangsu Key Laboratory of Environmental Impact and Structural Safety in Engineering, China University of Mining and Technology, Xuzhou 221116, China. \\ * (Corresponding Author.E-mail: jian.jiang@cumt.edu.cn)
}

\section{A B S T RA C T}

This paper presents experimental and theoretical investigations on progressive collapse behavior of steel framed structures subjected to an extreme load such as fire, blast and impact. A new capacity-based index is proposed to quantify robustness of structures. An energy-based theoretical model is also proposed to quantify the effect of concrete slabs on collapse resistance of structures. The experimental results show that the dynamic amplification factors of frames subject to impact or blast are much less than the conventional value of 2.0. The collapse process of frames in fire can be either static or dynamic depending on the restraint conditions and load levels. It is necessary to account for the failure time and residual strength of blast-exposed columns for assessing the collapse resistance of structures subject to explosion. Two collapse modes of steel frames under blast or impact are found: connection-induced collapse mode and column-induced collapse mode. In case of fire, a frame may collapse due to either column buckling or pulling-in effect of beams. The energy dissipation from elongation of slab reinforcement and additional resultant moment greatly contribute to the collapse resistance of structures.
A R T I C L E H I S T O R Y

$\begin{array}{ll}\text { Received: } & \text { 29 September } 2020 \\ \text { Revised: } & \text { 13 March } 2021 \\ \text { Accepted: } & \text { 13 March } 2021\end{array}$

\section{K E Y W O R D S}

Progressive collapse;

Steel framed building;

Blast;

Impact;

Fire

Experimental study

Copyright $\odot 2021$ by The Hong Kong Institute of Steel Construction. All rights reserved.

\section{Introduction}

Design and research on progressive collapse of building structures have developed for more than 50 years since the collapse of Ronan Point apartment in London in 1968 (Fig. 1a) [1]. The term "progressive collapse" is defined as "the spread of an initial local failure from element to element, eventually resulting in the collapse of an entire structure or a disproportionately large part of it" [2]. The requirement for preventing progressive collapse of structures was first specified in the UK design code [3], by providing a categorization of building types/occupancies to design buildings to sustain an extent of localized failure under extreme loads without progressive collapse. Similar design approaches were given in Eurocodes [4]. The collapse of Murrah federal building in 1995 (Fig. 1b) and especially that of World Trade Center towers in 2001 (Fig. 1c) [5] under terrorist attack have significantly advanced the development of U.S. codes for mitigating progressive collapse of buildings $[2,6,7]$. Afterwards there have been growing interests in understanding the progressive collapse behavior of high-rise buildings [8].

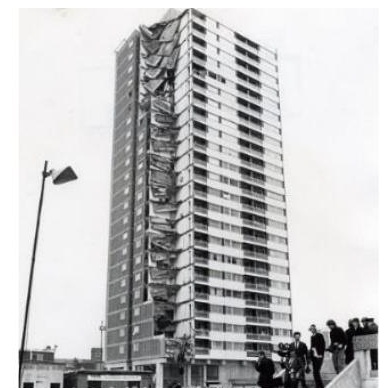

(a) Ronan Point apartment

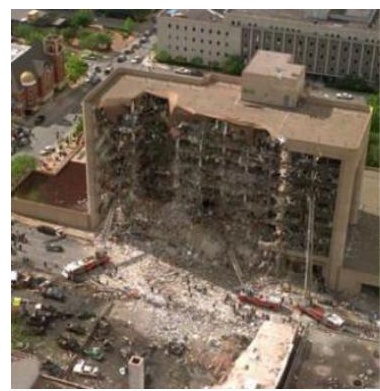

(b) Murrah federal building

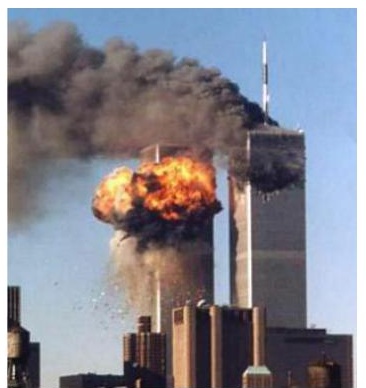

(c) World Trade Center

Fig. 1 Events of progressive collapse of buildings under extreme loading conditions

There is numerous research on the progressive collapse resistance[9] of structures under extreme loading conditions, such as blast, impact, and fire. In the case of blast or impact, the local failure is generally simulated by immediately removing columns, and the resistance of the remains are assessed to ensure alternative load-transfer paths to bridge over the missing columns. Numerous quasi-static experiments have been conducted [10-13]. Yang and Tan [10] investigated the behavior of steel beam-column connections by removing a column at center. Lew et al. [11] studied the collapse performance of frame assemblies with two kinds of moment resisting connections. Tsitos et al. [12] evaluated the applicability of design methods in earthquake engineering to progressive collapse design of steel structures by testing scaled steel frames. Xie and Shu [13] carried out experiments on three-dimensional steel frames to study the variation of internal forces due to removal of a column. The sudden removal of a column may cause dynamic effect on the behavior of structures, which cannot be accurately represented by these quasistatic tests. Many attempts have thus been made to simulate the induced dynamic effect in the process of column removal and collapse [14-19]. Xie [14] simulated the failure of the middle column by using a cylinder, and tests on three planar frames were conducted. Chen et al. [15] used a chain block to suddenly remove a perimeter column in the test on a full-scale steel frame. The influence of concrete slabs on its collapse resistance was studied. Xiao et al. $[16,17]$ simulated the sudden column removal by dislodging concrete blocks inserted in the middle of a column. The load transfer path and failure mechanism of a scaled concrete frame under column removals were investigated. However, in these dynamic tests, the duration of column removal time was not short enough where the dynamic effect induced on the damaged structure was not well represented. For most of numerical studies reported in the literature on the progressive collapse of structures due to blast or impact [20-22], there has been a general lack of validation against experimental data.

The alternate path method assumes that the column is removed immediately regardless of the magnitude and duration of blast loads. In practice, although the duration of explosion on structural members is very 
short (in millisecond), the duration of response of the member under explosion to failure may be longer depending on material properties and geometry dimensions. It is unreasonable to neglect the failure process of members in all cases. Furthermore, the damaged components may have some residual bearing capacity. The failure time and residual capacity of the damaged members will affect the resistance of a structure against progressive collapse. One objective of this paper is to study these issues.

In the case of fire, the failure of steel members and slab in the fire compartment is deemed as local failure for progressive collapse, which cannot be simulated by simply removing these heated components [23]. This is firstly because that the fire duration (in hour) is much longer than blast (in millisecond). The structural fire behavior is thus a quasi-static process before the failure of the heated members. Secondly, when a structure collapses in fire (i.e. collapse time) is one key factor in addition to whether and how it collapses. This collapse time is dependent on the failure process of heated members which interacts with surrounding members at ambient temperatures. Previous studies focus on figuring out collapse mechanisms of structures [24-42]. It has been found that the progressive collapse will be triggered by the failure of the heated columns, followed by lateral drift and failure of adjacent cool columns, respectively. The catenary action in the heated beams and tensile membrane action in the heated slabs may play an important role in resisting the collapse of structures. The collapse modes are significantly affected by load ratio, strength of beams relative to columns, slab, connection, and fire scenario. A high load ratio will cause a global downward collapse due to failure of all columns on one floor [27-29]. A relative strong beam may also result in a global downward collapse due to a more uniform load redistribution in the columns [27]. A heated beam may have a pulling-out effect on columns at low temperatures[30], and pulling-in effect at high temperatures [30]. The tensile membreane action from slabs and increasing reinforcement in the slab may facilitate the load transfer between columns [32]. A fire along edge bay is more prone to cause collapse than a central-bay fire [34, 35]. A thermo-mechanical model of composite slabs was proposed by using reduced-order shell elements [36,37], and the membrane action mechanism and fire resistance of composite slabs were investigated $[39,40]$. Recently, there is a growing concern to investigate the potential collapse of buildings in the cooling phase of a fire [32, $38,41]$ and subject to a travelling fire [43]. However, the above conclusions are drawn based on numerical results rather than experimental results. The existing experimental studies are stopped at a relatively small level of displacements (without collapse) due to the limited laboratory conditions or safety concerns. There is still lacking of non-standard fire tests on real-scale structures $[44,45]$. Another important issue is the mitigation measures against fire-induced collapse. It has been found that it is feasible to employ bracing systems and fire protections to mitigate or prevent structural collapse [46]. Therefore, it is essential to conduct fire tests designed with collapse as the ultimate limit state to verify the concluded collapse mode and to validate the numerical models.

Analytical studies have been conducted to quantify the robustness of structures, which are generally divided into structural attributes-based measures $[8,47,48]$ and structural behavior-based measures [49-55]. The former involves the demand-capacity ratio or ductility of connections, while the latter concerns load-bearing capacity, redundancy, key displacement, etc. However, there is still a lack of generalized methodologies for quantify the collapse resistance of realistic structures [23,56,57]. Most existing robustness indexes do not fully account for the influence of structural characteristics, dynamic effect and local damage. Moreover, most robustness quantifications are based on elastic analyses by excluding plastic internal force redistribution in the structure.

This paper presents experimental, numerical and analytical investigations on the progressive collapse behavior of steel framed buildings subject to impact, blast, and fire, respectively. Experiments were conducted on steel frames to study its progressive collapse resistance under impact loads, where an instantaneous knock-out scheme was used to simulate the removal of columns. A new capacity-based index was proposed to quantify the robustness of steel framed buildings. The blast-induced collapse behavior of structures was investigated, where the effect of failure time and residual strength of the blast-exposed column on the collapse resistance was studied. Fire tests on steel frames were carried out to study the collapse behavior of structures exposed to localized fires. Parametric studies were conducted to investigate the influence of dynamic effect, load ratio, beam section, fire scenario on the collapse resistance. An energy-based theoretical model was also proposed to quantify the effect of reinforced concrete slab on the collapse resistance of structures.

\section{Collapse behavior of buildings subject to impact}

\subsection{Experimental study}

Experiments were conducted on three planar steel frames with two storeys and four bays (scale ratio of 1:3) by removing a middle column on the ground floor, as illustrated in Fig. 2 [62]. The out-of-plane displacements of the frame were restrained. The dimensions of the test frames and structural components are listed in Table 1 . The beam and column members were made of H-type sections, where, for example, $\mathrm{H} 80 \times 50 \times 3 \times 4$ represents a $\mathrm{H}$-section with a depth of $80 \mathrm{~mm}$, flange width of $50 \mathrm{~mm}$, web thickness of $3 \mathrm{~mm}$ and flange thickness of $4 \mathrm{~mm}$, respectively. The case FRAME1 is to study the behaviour of the critical beam-column region with fully welded connections under a removal of a middle column. While FRAME2 and FRAME3 focused on the effect of columns on the collapse resistance of the frames where the beam-to-column connections were further strengthened by stiffeners to avoid connection failure. Weight baskets were attached to the beams to simulate the mechanical gravity loads (Fig. 2b). This is to avoid the detaching and slipping of the loading system from the specimen at large displacements. Each basket in the middle two bays and side bay had a weight of about $7.2 \mathrm{kN}$ and $4 \mathrm{kN}$, respectively.

In this study, a sudden removal of the target column was achieved by a specially designed mechanism with a pendulum hammer, as illustrated in Fig. $2 \mathrm{~b}$. This is to satisfy the requirement that the removal period should be no more than $1 / 10$ of the period of the dominant response mode [7,8]. Fig. 3 shows the details of the mechanism made up by a three-hinged strut. A brittle locking rod made of glass was first inserted in the column to keep the column straight and maintain its function. A pendulum hammer was released from a designated position to strike the column and break the glass rod, which triggered the hinge mechanism and thus removal the column (Fig. 3b). The experimental results showed that the column removal duration was around $0.02 \mathrm{~s}$, compared to $0.5 \mathrm{~s}$ for the natural period of the frame.

The deformed shapes of the frame specimens after the column removal is shown in Fig. 4. The strong beam-weak column frame FRAME2 failed as the columns failed in bending and compression, whereas FRAME1 and 3 exhibited large permanent deformations. The displacement-time curves of the three steel frame specimens at the column-removal location are shown in Fig. 5. The measured maximum dynamic deflections were $252 \mathrm{~mm}, 454 \mathrm{~mm}$ and $249 \mathrm{~mm}$ for FRAME1-3, respectively. The corresponding permanent deflections were $228 \mathrm{~mm}, 443 \mathrm{~mm}$ and $225 \mathrm{~mm}$, respectively. The experimental results showed that strong connections can effectively enhance collapse resistance of steel frames. A frame with strong beams and weak columns was prone to collapse due to failure of the columns adjacent to the removed column The catenary action of beams facilitated the dynamic load transfer from the removed column to its surrounding columns.

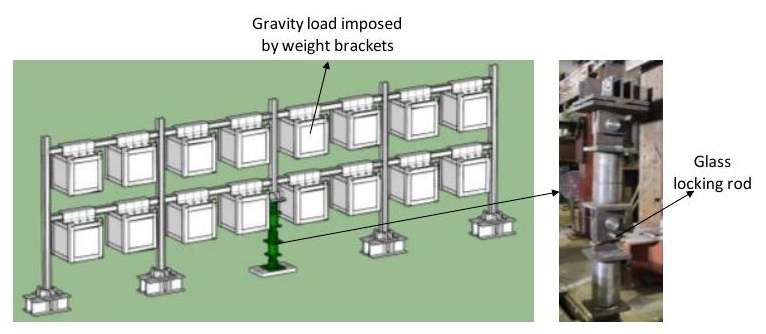

(b) gravity loading and column removal

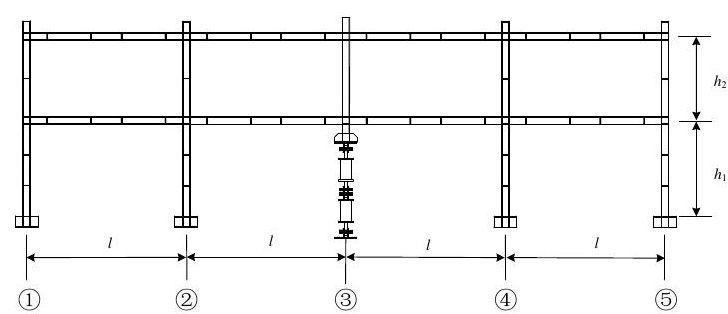

(a) frame dimension

Fig. 2 Schematic of the tested steel frame under impact 


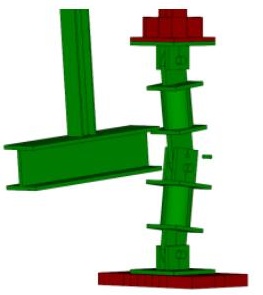

(a) break of the glass rod

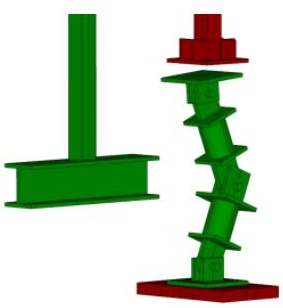

(b) formation of hinge mechanism

Fig. 3 Schematic of the column-removal mechanism

Table 1

Dimensions of the steel frame specimens

\begin{tabular}{|c|c|c|c|c|c|}
\hline \multirow[b]{2}{*}{ Specimen } & \multirow[b]{2}{*}{$\begin{array}{l}\text { Beam section } \\
(\mathrm{mm})\end{array}$} & \multirow[b]{2}{*}{$\begin{array}{l}\text { Column section } \\
(\mathrm{mm})\end{array}$} & \multicolumn{2}{|c|}{ Story height } & \multirow[b]{2}{*}{$\begin{array}{c}\text { Span length } l \\
(\mathrm{~mm})\end{array}$} \\
\hline & & & $\begin{array}{c}h_{1} \\
(\mathrm{~mm})\end{array}$ & $\begin{array}{c}h_{2} \\
(\mathrm{~mm})\end{array}$ & \\
\hline FRAME1 & $\begin{array}{l}\text { Middle bay: } \mathrm{H} 54 \times 50 \times 4 \times 4 \\
\text { Side bay: } \mathrm{H} 80 \times 50 \times 3 \times 4\end{array}$ & $\mathrm{H} 100 \times 100 \times 6 \times 8$ & 1227 & 1054 & 2100 \\
\hline FRAME2 & H54 $\times 50 \times 4 \times 4$ & H $54 \times 50 \times 4 \times 4$ & 1227 & 1054 & 2054 \\
\hline FRAME3 & $\mathrm{H} 54 \times 50 \times 4 \times 4$ & $\mathrm{H} 100 \times 100 \times 6 \times 8$ & 1227 & 1054 & 2100 \\
\hline
\end{tabular}

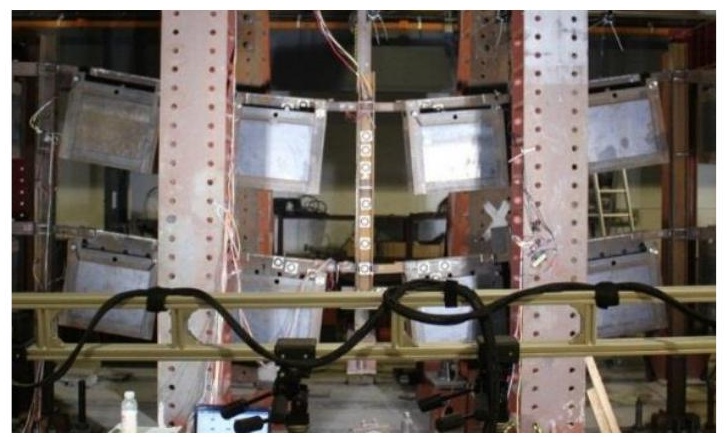

Fig. 4 Deformation of the frame specimen (FRAME1)

\subsection{Theoretical study}

\subsubsection{Concept of new robustness index}

The resistance of a structure against progressive collapse under a local failure is defined as "robustness". Structural robustness is the ability of the structure to redistribute the loads sustained by the failed members, and to remain stable after subjecting to local failure [59]. A capacity-based robustness index was proposed in Eq. (1) by comparing the imposed load on the original intact structure (Fig. 6a) and the residual capacity of the damaged structure (Fig. 6b) [60]:

$I_{r o b}=\frac{\left(q_{2 m}-\gamma q_{1 m}\right)}{q_{2 m}}=\frac{\left(q_{2 d m}-q_{1 m}\right)}{q_{2 d m}}$

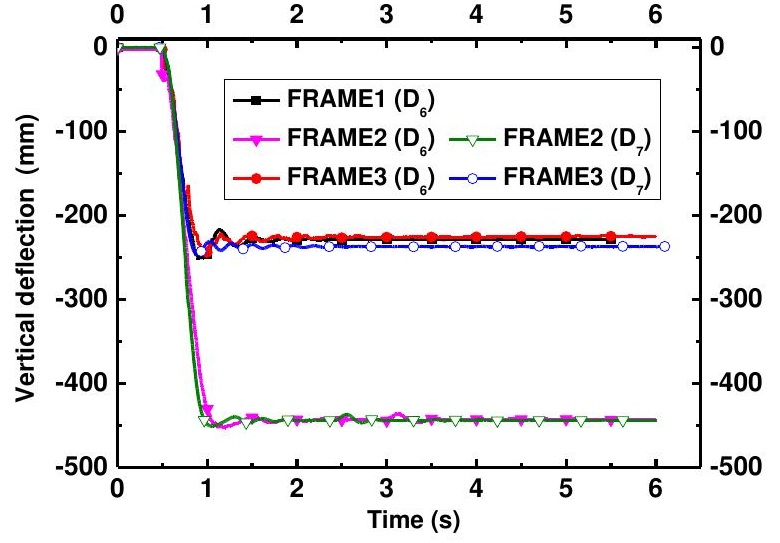

Fig. 5 Time histories of vertical deflection at the top of the removed column

where $q_{1 \mathrm{~m}}, q_{1 \mathrm{~s}}$ is the load imposed in the middle and side bays of the intact structure (Fig. 6a), respectively; $q_{2 \mathrm{~m}}, q_{2 \mathrm{~s}}$ is the static ultimate load in the middle and side bays of the damaged structure until failure (Fig. 6b), respectively; $\gamma$ is a dynamic amplification factor; $q_{2 \mathrm{dm}}$ is the dynamic critical load in the middle bays of the damaged structure until failure, which can be determined by $q_{2 d m}=q_{2 \mathrm{~m}} / \gamma$.

The proposed robustness index in Eq. (1) can explicitly account for the dynamic effect and redistribution of plastic resistance forces. If $I_{\mathrm{rob}} \leq 0$, the ultimate load of a damaged structure is less than the imposed load on the intact structure, leading to collapse of the frame lacking of necessary robustness. If $I_{\text {rob }}>0$, the frame is robust and may not collapse. The closer the $I_{\text {rob }}$ to 1 , the larger the ultimate load than the initial load imposed on the frame, and the better the robustness of the frame.
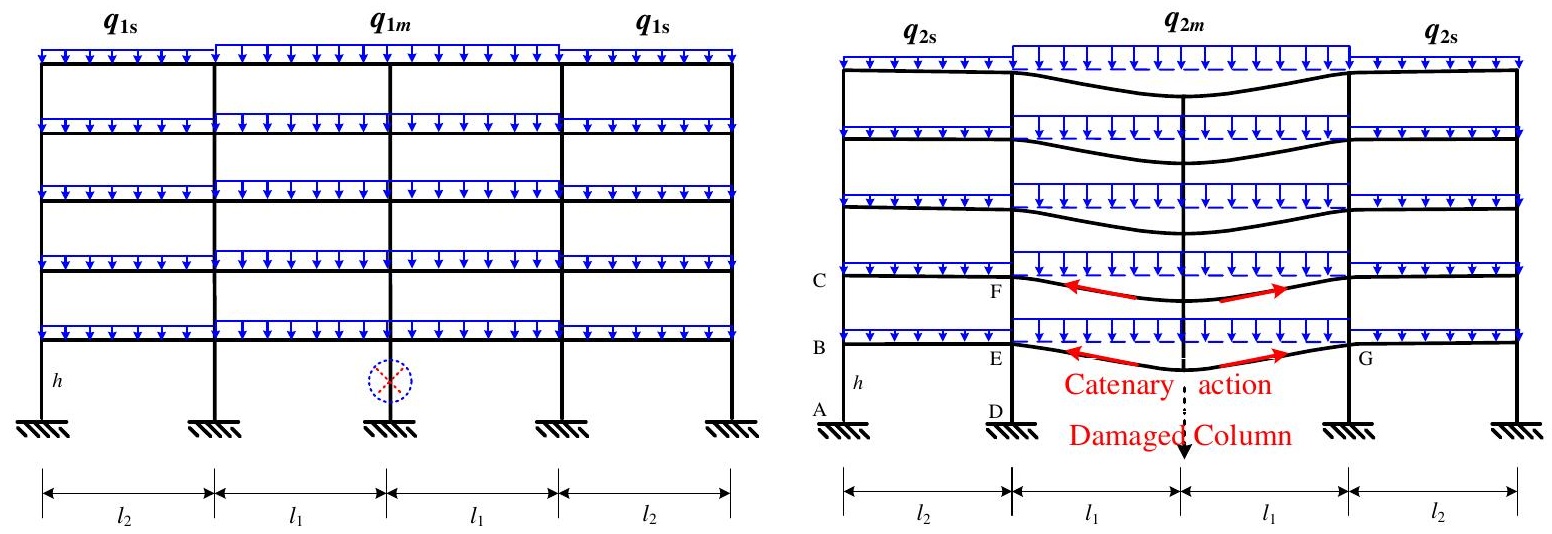

Fig. 6 Schematic of robustness index

(b) damaged structure 


\subsubsection{Dynamic amplification factor and collapse mode}

The determination of $I_{\text {rob }}$ depends on the dynamic amplification factor $\gamma$ and collapse mode [61]. Finite element models were established in ABAQUS and validated against experimental results. A push-down analysis was then carried out for the three tested steel frames. The predicted static load corresponding to a vertical displacement equal to the measured value of $0.252 \mathrm{~m}$ is $P_{1 \mathrm{~m}}=4.42 \mathrm{kN}$, compared to the applied load of $3.3 \mathrm{kN}$. Thus, the dynamic amplification factor can be determined as $\gamma_{1}=4.42 / 3.3=1.34$. Similarly, the dynamic amplification factors of FRAME2 and FRAME3 were determined as $\gamma_{2}=4.23 / 3.85=1.10$ and $\gamma_{3}=4.57 / 3.85=1.19$, respectively. It is worth noting that the dynamic amplification factors are much less than a conventional value of 2.0. This can be attributed to the energy dissipation from the development of plastic deformations in the frame.

Two collapse modes were found depending on the behaviour of connections and columns, as shown in Fig. 7. If the collapse of the frame is triggered by fracture of beams or connections, the collapse of the frame will be limited in the damaged bays, which is defined as a confined collapse mode (Fig. 7a). If the connection is sufficiently strong and ductile, the local failure will spread beyond to the surrounding columns, leading to a propagating collapse mode (Fig. 7b).

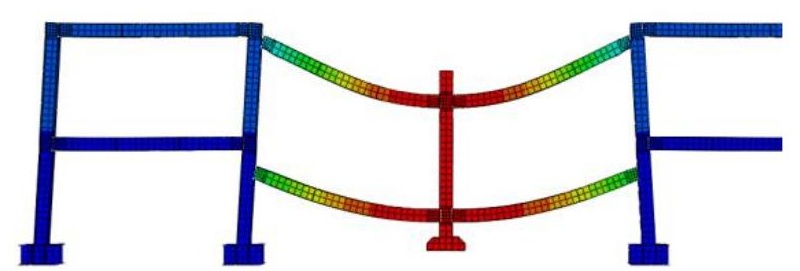

(a) confined collapse mode

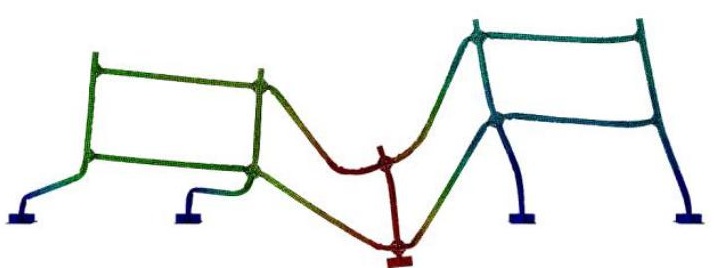

(b) propagating collapse mode

Fig. 7 Two collapse modes of steel frames

\subsubsection{Parametric studies}

Parametric studies were conducted to investigate the influencing of strain rate of materials, damping ratio, sizes of beams and columns, and location of removed columns. The details can be found in the reference [60]. The results showed that: (1) For a confined collapse mode, the influence of material strain rate was larger than that of the damping ratio; (2) For the propagating collapse mode, the influence of damping was larger than that of strain rate; (3) the ultimate load and robustness increased with increasing damping ratios; (4) The ultimate load and robustness for a middle column removal was larger than that for a side-bay column removal.

\section{Collapse behavior of buldings subject to blast}

This section addressed the influence of failure time and residual bearing capacity of the damaged column on the resistance of the whole structure

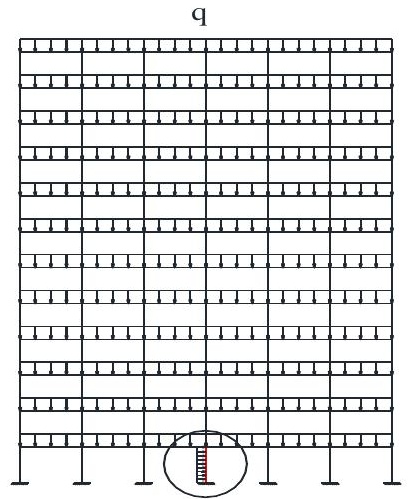

Fig. 8 A steel frame subjected to explosion on a ground floor column

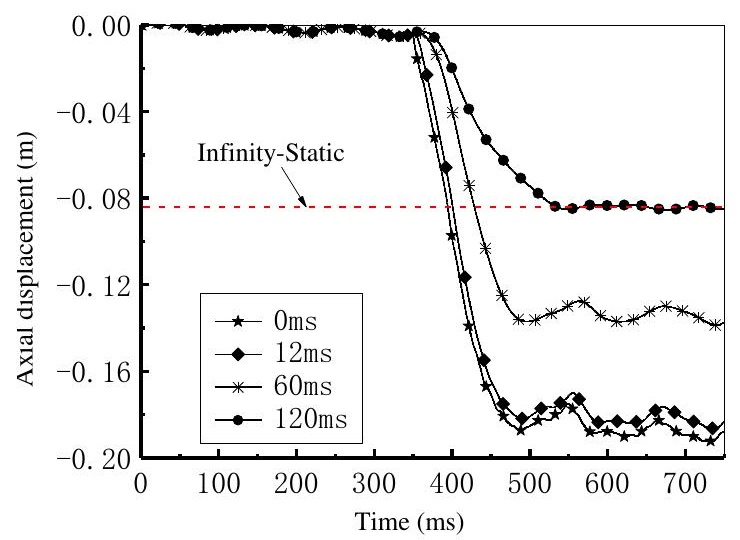

Fig. 10 Vertical displacement of the column versus time for different failure times against progressive collapse. A 2D steel frame of six bays and twelve storey was modeled in this study, as shown in Fig. 8 [62]. The span and storey height of the frame were taken as $4.5 \mathrm{~m}$ and $3 \mathrm{~m}$, respectively. The I-type steel beams and columns were taken as $\mathrm{I} 400 \times 200 \times 8 \times 10 \mathrm{~mm}$ and $\mathrm{I} 500 \times 500 \times 12 \times 15 \mathrm{~mm}$, respectively. A vertical uniformly distributed load of $q=75 \mathrm{kN} / \mathrm{m}$ was applied on all the beams, and a lateral blast load on the ground floor column. For an identified blast load acting on the column, the axial force in the column may decrease from its initial value $N_{0}$ to $N^{\prime}$ as show in Fig. 9. After the explosion, the frame will continue to deform under the vertical loads and thus the damaged column reaches its residual load-bearing capacity $N_{\mathrm{r}}$. The influence of the failure time $t_{0}$ and residual bearing capacity $N_{\mathrm{r}}$ of the blast-exposed column on the vertical displacement of the frame was studied as follows.

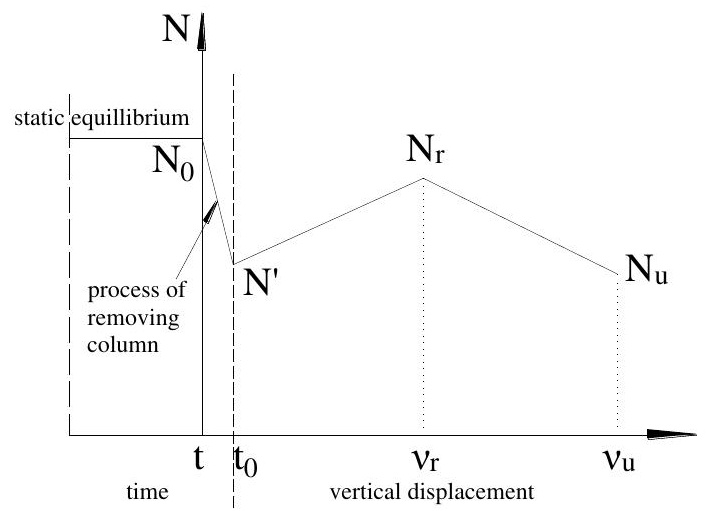

Fig. 9 Variation of the axial force in the column under explosion

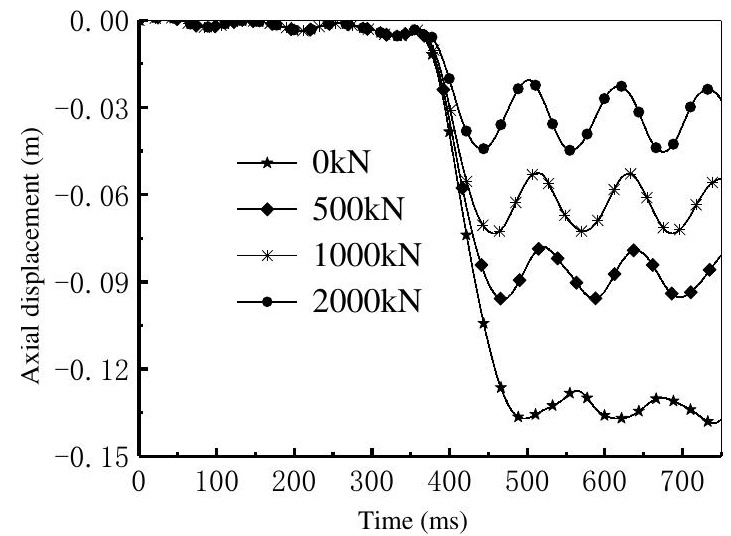

Fig. 11 Comparison of axial displacements of columns for different residual capacities 


\subsection{Influence of failure time to}

The residual bearing capacity model $\left(N_{\mathrm{r}}=8000 \mathrm{kN}\right)$ of the column under explosion in Fig. 9 was used in this case. Five cases of failure time of the column were adopted $(0 \mathrm{~ms}, 12 \mathrm{~ms}, 60 \mathrm{~ms}, 120 \mathrm{~ms}$, infinity). Comparison of the axial displacement at the column top for the five failure cases is shown in Fig. 10. The longer the failure time of the column, the less the displacement of the structure. When the failure time was infinite, the displacement is equivalent to the static response. Obvious dynamic effects were observed for an immediate removal $(0 \mathrm{~ms})$. The response for a removal of $12 \mathrm{~ms}$ almost coincided with the immediate removal. This indicates that only if the failure time is within certain range (e.g. $60 \mathrm{~ms}$ ), it is important to consider the effect of failure time of columns.

\subsection{Influence of residual load-bearing capacity $\mathrm{Nr}$}

The same failure time of $60 \mathrm{~ms}$ was taken. Four conditions of residual load-bearing capacity $N_{\mathrm{r}}$ of the column were considered $(0 \mathrm{kN}, 500 \mathrm{kN}, 1000 \mathrm{kN}$, $2000 \mathrm{kN}$ ). Fig. 11 shows the variation of axial displacements of the column for the four residual capacity cases. It showed that the larger the residual bearing capacity of the column, the less the displacement of the structure given the same failure time. Therefore, the existence of the residual bearing capacity can enhance the collapse resistance of structures. Therefore, it is important to consider the residual bearing capacity of the damaged column under explosion for assessing the collapse resistance of structures.

An equivalent spring model and SDOF model were proposed by the authors to simplify the analysis of progressive collapse of steel framed structures. The equivalent spring model includes two independent steps: (1) determine the failure process (failure time and residual load-bearing capacity) of the column under blast based on a member-level model; (2) replace the damaged column with an equivalent spring model considering the column failure process, and analyze the behavior of the remaining structure. The SDOF model is to further simplify the analysis, and to analytically determine the failure time and residual load-bearing capacity of columns under blast. The detailed development and verification of these two models are presented in the reference [62].

\section{Collapse behavior of buildings subject to fire}

\subsection{Experimental study}

Fire tests were carried out to investigate the collapse resistance of steel frames under localized fires [63]. Three planar steel frames (Frames 1, 2 and 3) were designed and tested, as shown in Fig.12. The test frames had 4 bays and 2 storeys. The spans of the two middle and edge bays were $2.2 \mathrm{~m}$ and $2.0 \mathrm{~m}$, respectively. The column in the middle of the ground floor (gridline 3) was heated by an electric furnace. Frame 1 had a larger rectangular tube section of middle bay columns $(150 \times 50 \times 5)$, compared to $60 \times 40 \times 3.5$ of Frame 2 and Frame 3. A larger gravity load was applied on Frame 3 . The electric furnace is designed to allow dynamic performance and large deflection of the test frames (Fig. 12b). Gravity loadings were imposed to the frame by hanging weight baskets on the beam (Fig. 12b). Welded beam-to-column connections were used.

The vertical displacements at the top of the heated columns of the three frames were measured and compared in Fig. 13. It shows that the displacement descended gradually in Frame 1 while changed rapidly in Frames 2 and 3. This indicates that the heated column in Frame 1 failed in a quasi-static way, whereas those of Frames 2 and 3 failed in a dynamic way. This is because of the stronger axial restraint stiffness of the heated column in Frame 1 and less load level imposed to Frame 1. Besides, Frames 2 and 3 regained equilibrium after failure of the heated column, when the displacement reached around $55 \mathrm{~mm}$ and $420 \mathrm{~mm}$, respectively, as shown in Fig. 14.

The experimental results showed that, depending on the restraining condition and loading level, the failure process of a restrained steel column in fire could be either static or dynamic. Ignoring the dynamic effect on structural behavior under fire may greatly underestimate the maximum displacement of structures, thus leading to an unsafe design.

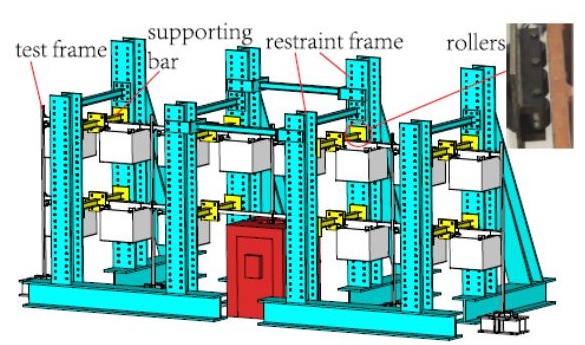

(b) loading system

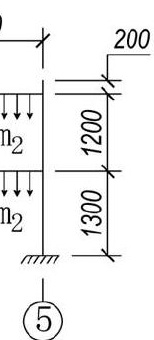

(5)

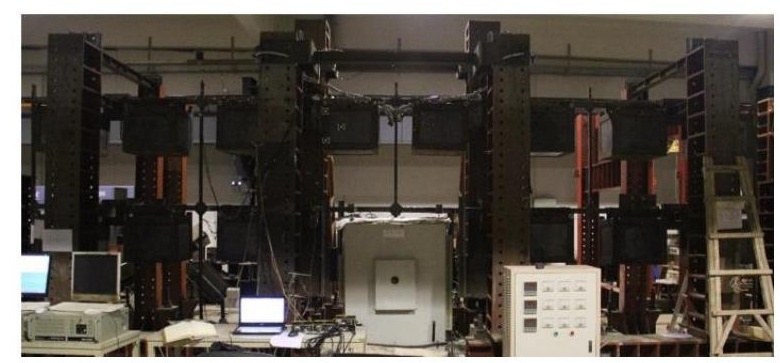

(c) on-site setup

Fig. 12 Layout of fire tests on steel frames

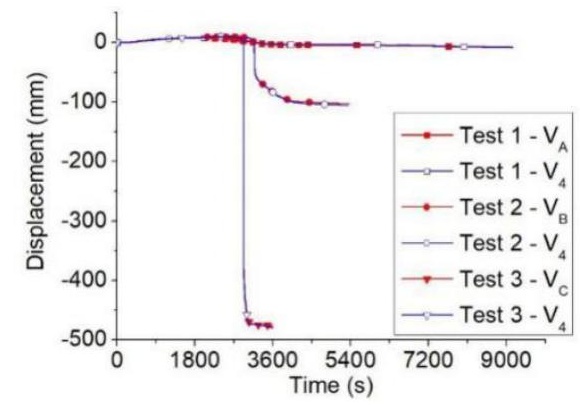

Fig. 13 Comparison between two displacement measurement systems for the vertical displacement at the top of the frames

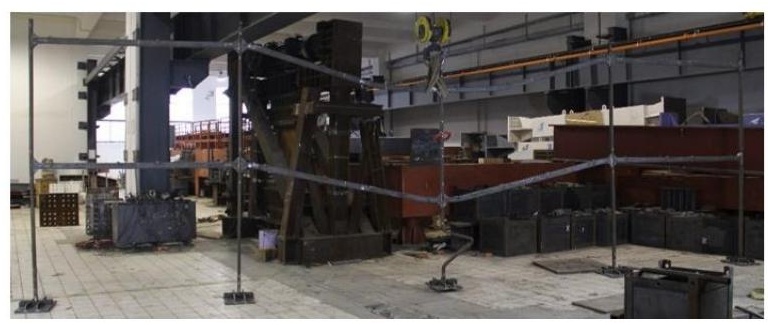

Fig. 14 Deformation of Frame 3 after test 


\subsection{Numerical study}

Numerical simulation of the test frames using the software ABAQUS was conducted to further investigate the collapse mechanism of the test frames [63]. Fig. 15 shows the numerical model and the analysis results of test frame 3 . It shows that the numerical analysis results agreed well with the test results in terms of both the deformation shape and the displacement of the test frame.

Parametric studies were conducted to study the influence of damping and the strain rate of material on the performance of steel frames under localized fires by using the numerical model of Frame 2. The results showed that the damping with damping ratios ranging from 0 to $10 \%$ had a negligible influence on the performance of frames as shown in Fig. 16. The influence of material strain rate was significant for the cases when the heated column failed in a dynamic way as shown in Fig. 17. Neglecting the strain rate effect in the numerical modelling may significantly overestimate the maximum displacement at top of the heated column.

The validated numerical models were further used to study the collapse modes of frames through amplifying the applied gravity load. As shown in Fig. 18a, after the failure of the heated column, the deflection of beams above the column was small. The failure of the heated column resulted in an increment of compressive axial forces in the adjacent column, leading to their buckling. This collapse mode can be defined as Column-buckling failure mode, which may occur when the beams are strong and the initial load ratio is high [31]. Fig. $18 \mathrm{~b}$ shows large deflections of beams, and obvious lateral displacements of the adjacent columns. This mode can be identified as Pulling-in force induced failure [31]. This collapse mode is prone to occur for the frames with weak beam sections [31]
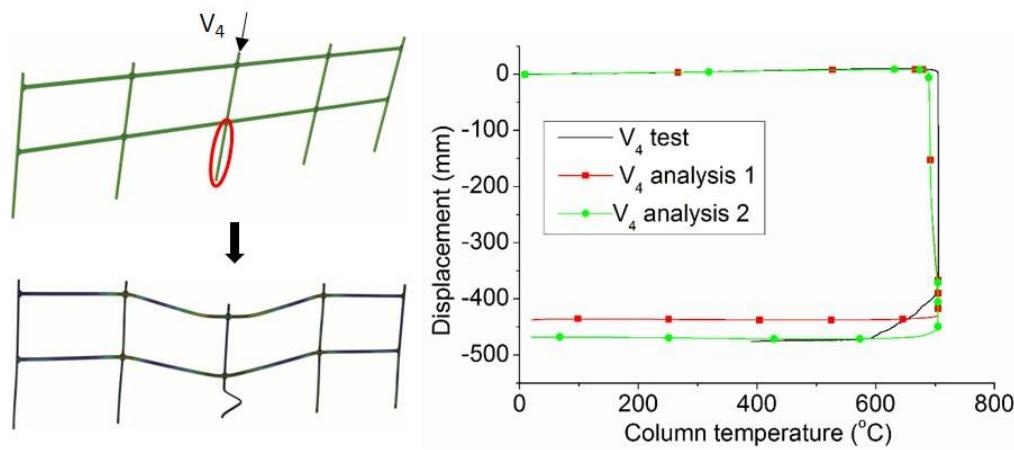

Fig. 15 Numerical analysis of Frame 3

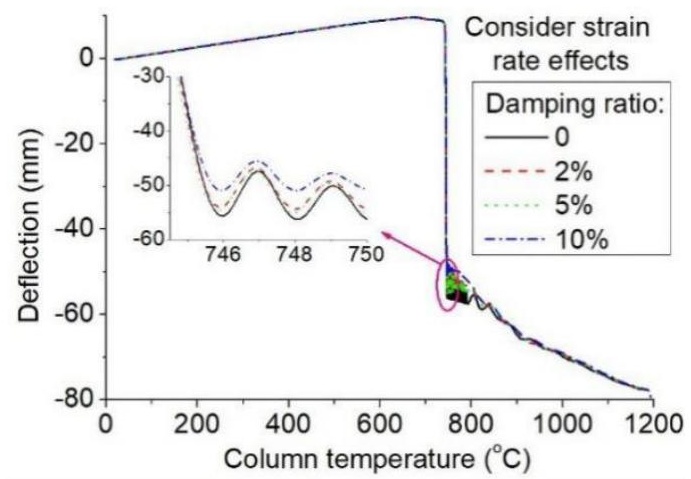

Fig. 16 Effect of damping on vertical displacement (V4) at top of the heated column

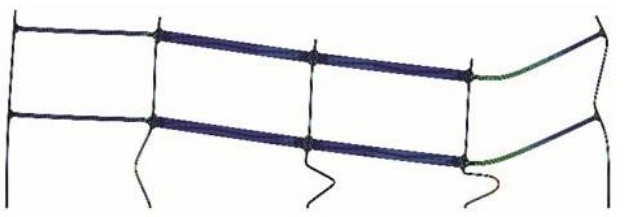

(a) column buckling failure mode (Frame 1)

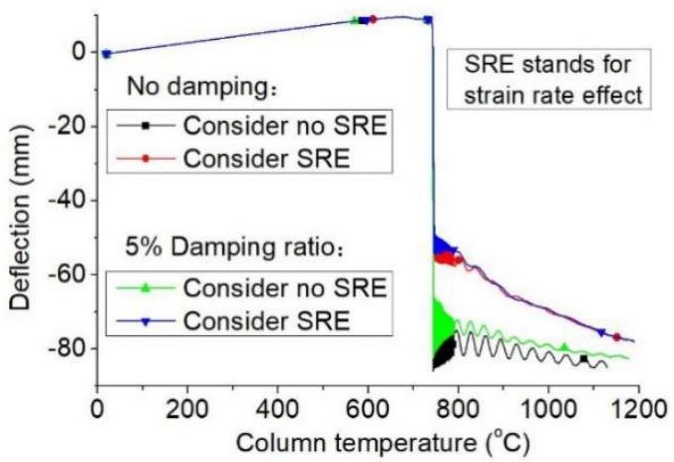

Fig. 17 Effect of strain rate effect on vertical displacement (V4) at top of the heated column

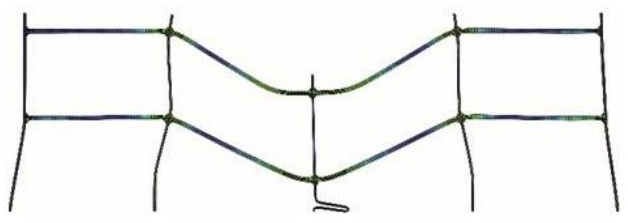

(b) pull-in force induced failure mode (Frames 2 and 3)

Fig. 18 Failure modes of the test frames

\section{Effect of slabs and beams on collapse resistance}

When a structure experiences large deformations, a secondary load resisting mechanisms such as the tensile membrane action in slabs and catenary action in beams will be mobilized as an effective means against collapse. This section presents an experimental study on a 3D steel frame due to an edge-column loss. Moreover, energy-based analytical approaches were proposed to quantify the collapse resistance of steel structures in the event of a general middle and side column loss scenario, as shown in Fig. 19.

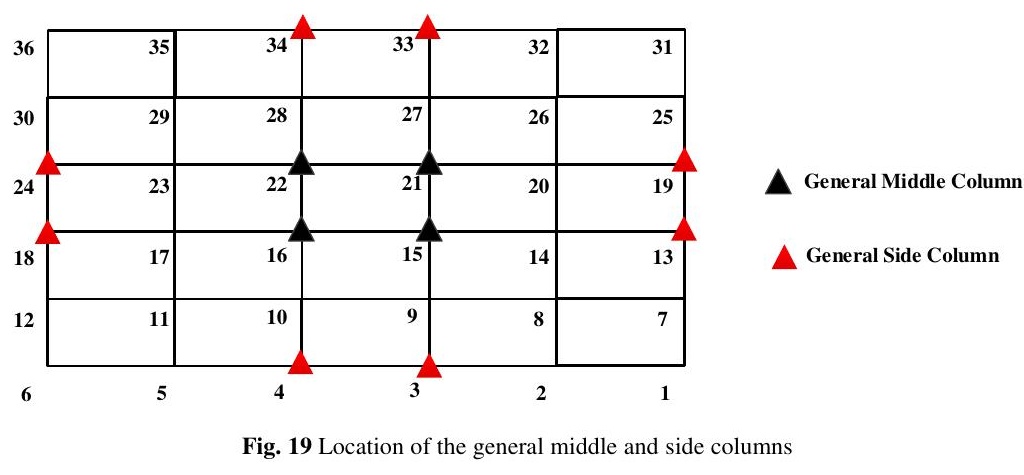




\subsection{Experimental study}

The specimen was a single-storey, two-bay steel frame with flat concrete slabs [67], as shown in Fig. 20. The height is $1.3 \mathrm{~m}$. The transverse and longitudinal spans of the slab are $1.8 \mathrm{~m}$ and $2.4 \mathrm{~m}$, respectively, as illustrated in
Fig. 21. The test setup is shown in Fig. 22. A force was applied at the columnremoval location by the actuator, as shown in Fig. 23. A force-controlled loading rule was used and when the load exceeded $80 \mathrm{kN}$, displacementcontrolled loading rule was employed.

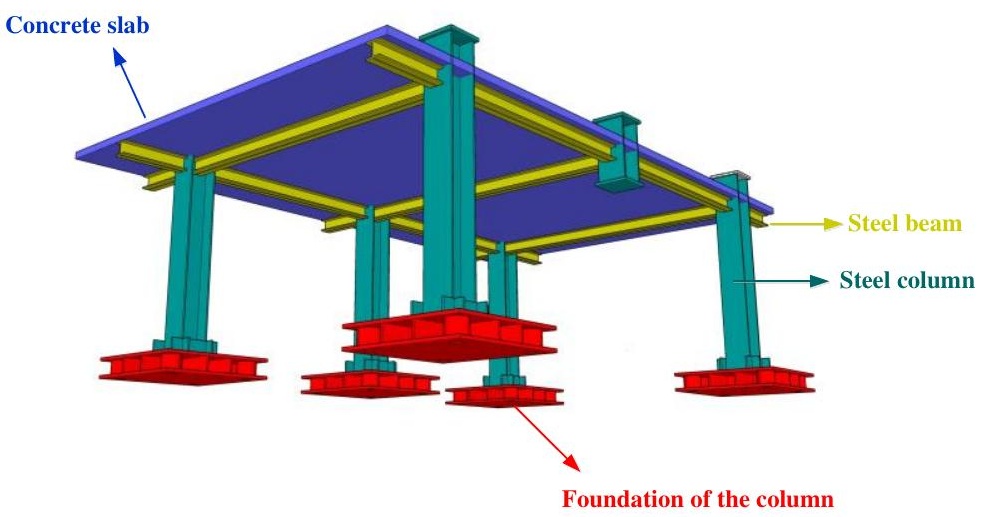

Fig. 20 The test specimen

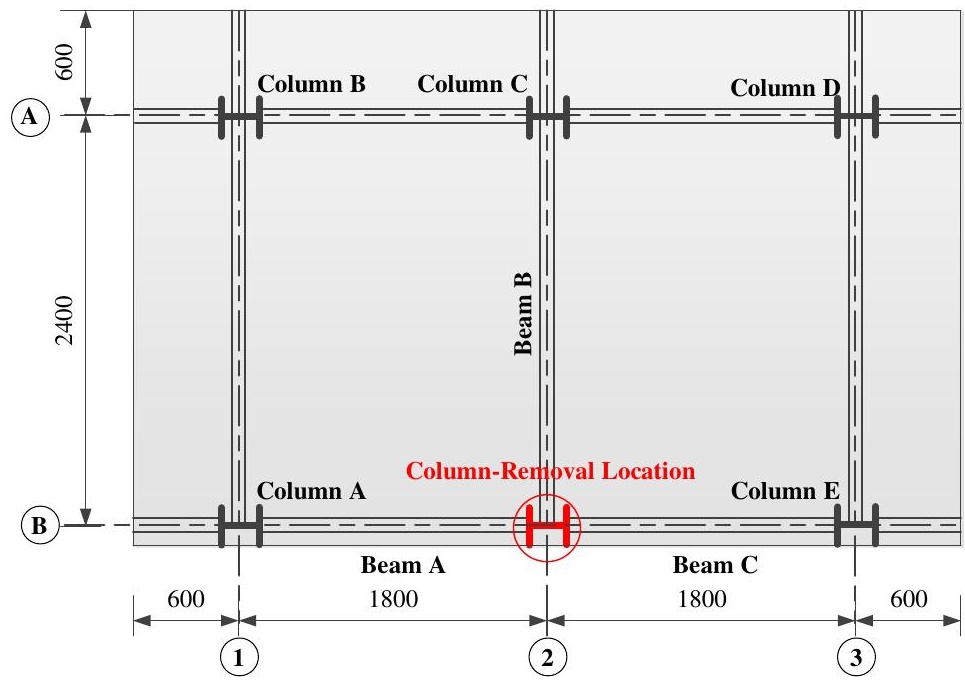

Fig. 21 Plan view of the tested frame. (Dimensions in mm.)

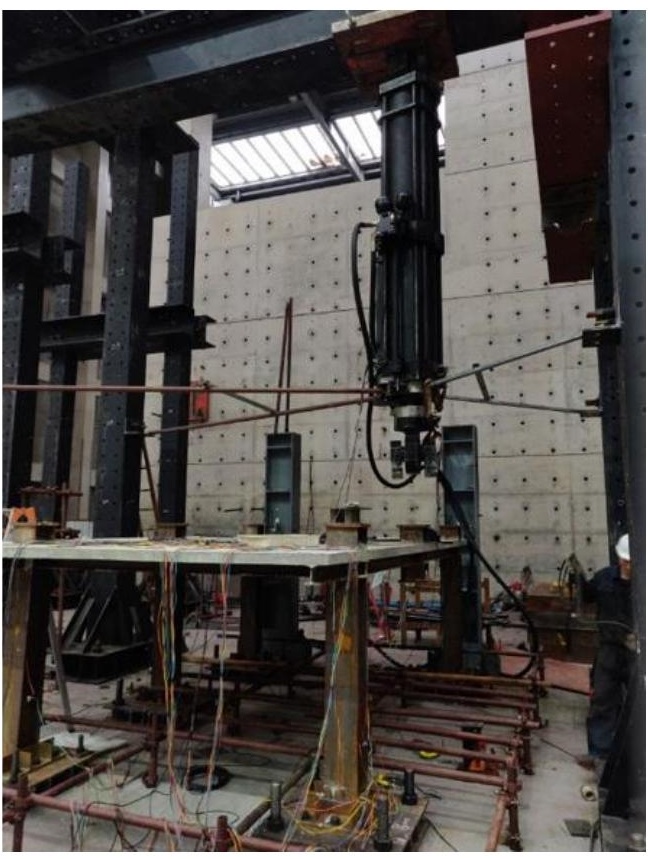

(a) On-site layout

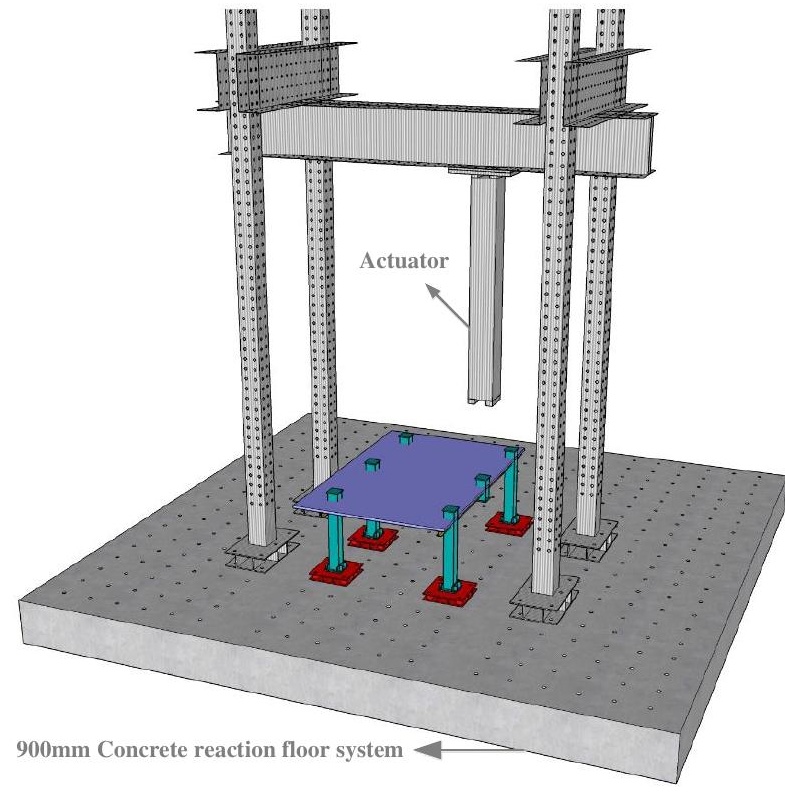

(b) Schematic layout

Fig. 22 Test setup 


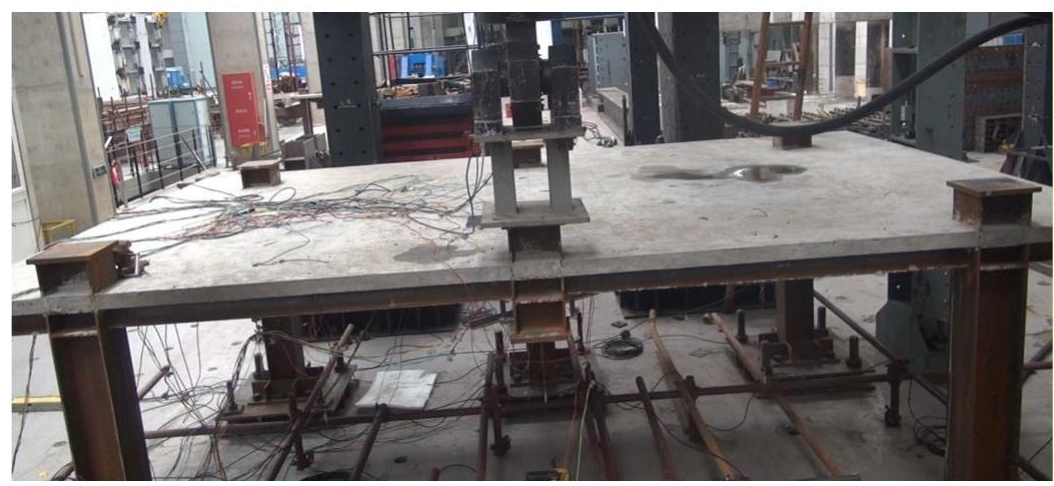

Fig. 23 Connection between the actuator and the specimen

The displacement-resistance relationship of the frame is shown in Fig. 24. The collapse resistance and final displacement are $227 \mathrm{kN}$ and $606 \mathrm{~mm}$, respectively. Three stages were found for the curve: elastic-plastic stage, transition stage, an catenary action stage. It was found that the collapse resistance of the frame was about 2.8 times greater than its plastic bearing capacity.

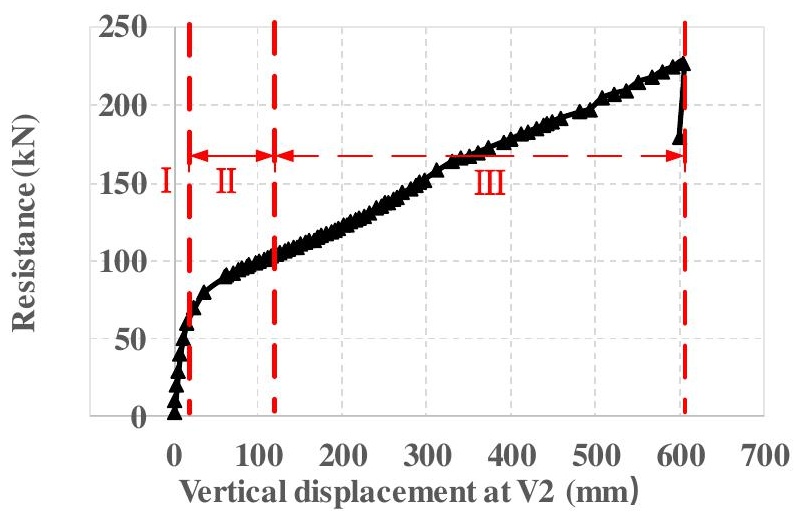

Fig. 24 Resistance-vertical displacement curve of the tested frame

The final deformation shapes of the frame are shown in Fig. 25 Fig. 27. As shown in Fig. 25, a main crack which elliptically distributed along the edges was found on the slab top. Obvious spalling of concrete from the column-removal location to the corner columns was observed. The failure of the frame was governed by fracture of the bottom flange of steel beams, as shown in Fig. 26. The deformation shape of the column at corner is shown in Fig. 27. There was severe local buckling at the bottom of the column.

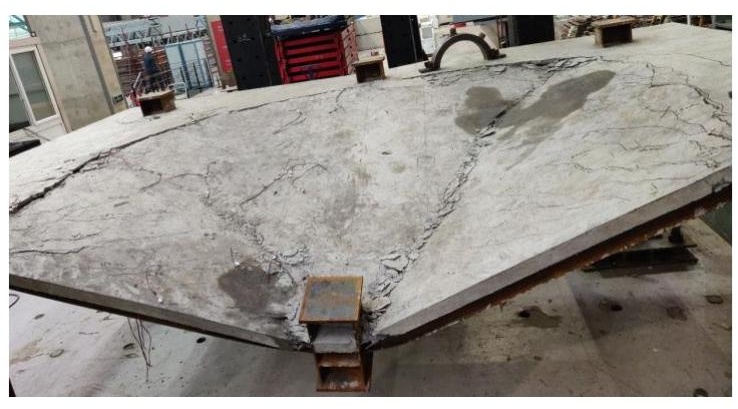

(a) Front view

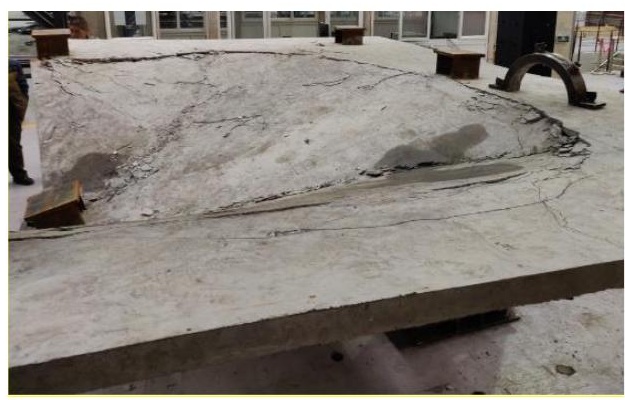

(b) Right view

Fig. 25 Final deformation shape of slabs

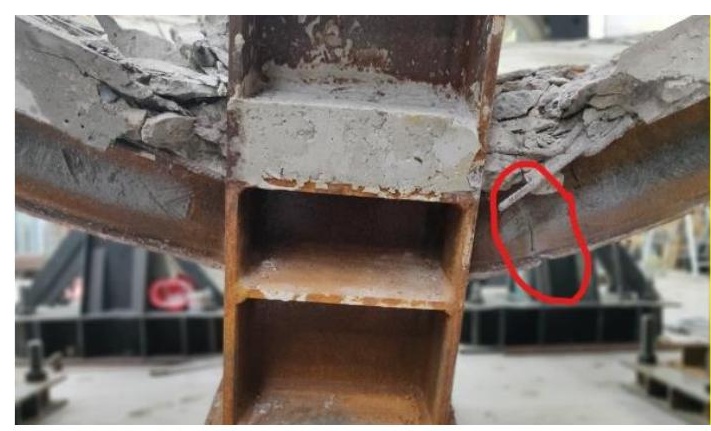

Fig. 26 Fracture of steel beams

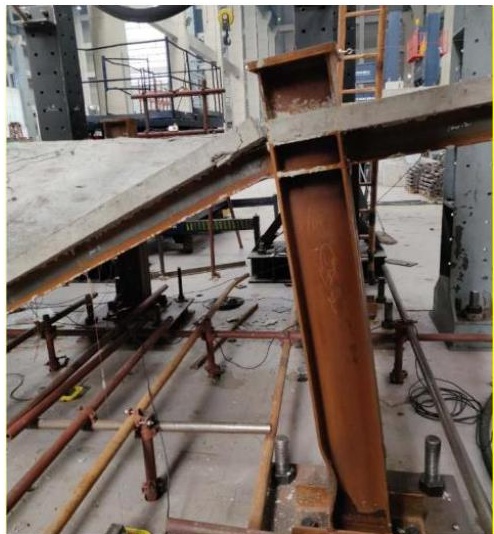

Fig. 27 Lateral displacement of columns 


\subsection{Analytical study}

\subsubsection{Model simplification}

To save computational cost, the collapse resistance of the remaining framed-structure after column loss is represented by the corresponding simplified substructures. Fig. 28 Fig. 29 show the simplifications of the

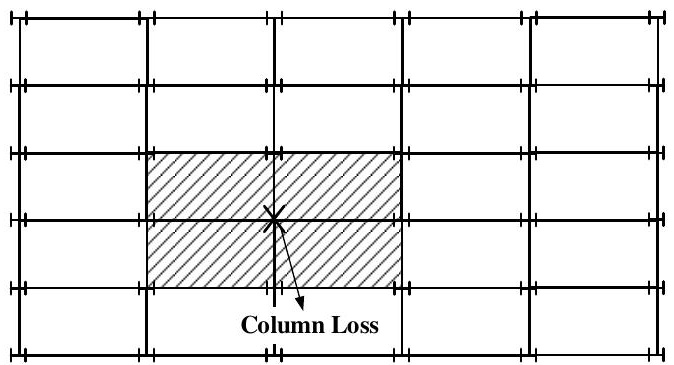

(a) original structure for general middle column loss scenario substructures for general middle and side column loss scenarios, respectively. For the general middle column loss scenario, the boundary conditions for the four edges of the substructure are fully restrained considering that the axial and rotational restraints provided by the surrounding slabs and beams are relatively strong. Similarly, for the general side column loss scenario, three edges of the substructure are fully restrained.

Fig. 28 Model simplification for general middle column loss scenario [65]

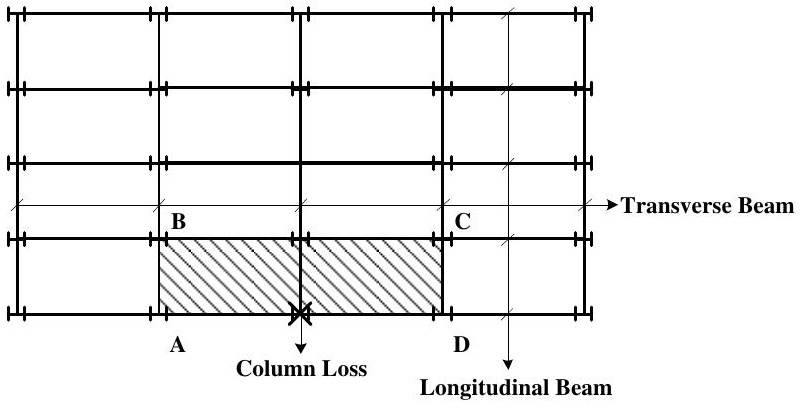

(a) original structure for general side column loss scenario

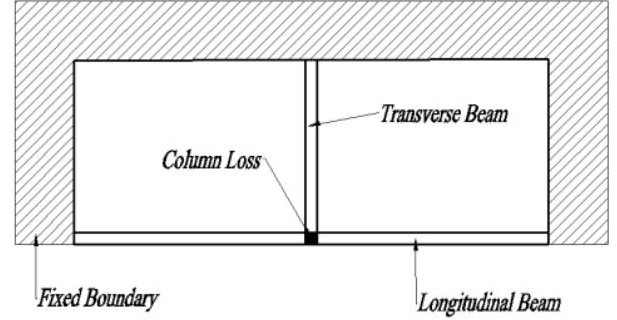

(b) simplified slab-beam substructure for general side column loss scenario

Fig. 29 Model simplification for general side column loss scenario [66]

\subsubsection{Analytical model}

The failure modes of the substructure under the removal of middle and side columns are shown in Fig. 30. For the middle-column removal scenario, the failure mode of the composite beam-slab substructure is shown in Fig. 30 (a) [65]. This substructure can be divided into four rigid segments by the positive yield lines AI, CI, EI and GI. An elliptical and negative yield line was hypothesized to emerge along the edges of the substructure. For the sidecolumn removal, the failure mode is indicated in Fig. 30(b) [66]. The

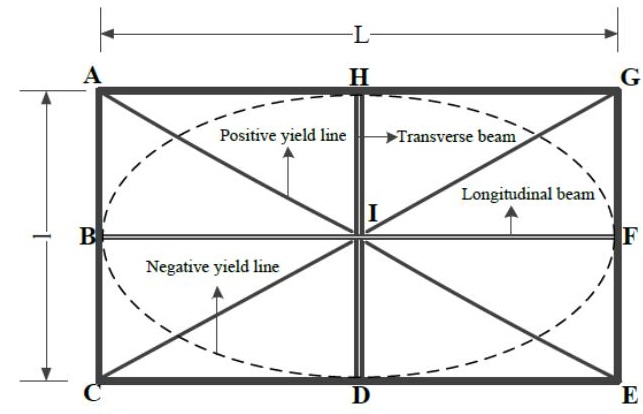

(a) failure mode for general middle column loss scenario substructure is divided into three rigid segments by the positive yield lines AJ and $\mathrm{KC}$, and the negative yield lines BL and MD were used to emerge for the unevenly distributed deformation. Note that the resistance of steel beams at the limit state is dominated by catenary action, which indicates that the bending action is negligible. Thus, the formation of plastic moment hinges was ignored in the assumed failure mode of steel beams.

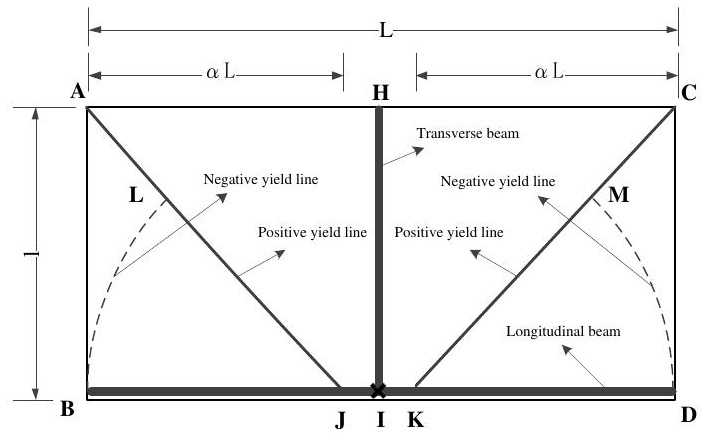

(b) failure mode for general side column loss scenario

Fig. 30 Failure modes for general middle and side column loss scenario $[64,65]$

For calculating the collapse resistance of the beam-slab substructure in the proposed energy-based method, the following three internal energy dissipations were considered: (1) elongation of reinforcement bars in the slab along yield lines and steel beams; (2) additional resultant moment due to the tensile membrane force in the slab and tensile force in the beam; (3) sectional bending moment along the yield lines. The detailed deduction of this analytical approach can be found in the references $[65,66]$. The ultimate capacity of the substructure can be obtained using the proposed energy-based method. For the general middle column loss, the ultimate capacity is given by:

$$
\begin{aligned}
& F=\left(C_{x e}\left(T_{x} l+2 F_{u L}\right)+C_{y e}\left(T_{y} L+2 F_{u T}\right)+4 C_{a} T_{y} L b \frac{v}{l}+4 \frac{F_{u T}}{l} v\right. \\
& \left.+4 C_{a} T_{x} l b \frac{v}{L}+4 \frac{F_{u L}}{L} v+4 C_{y m} M_{y} \frac{L}{l}+4 C_{x m} M_{x} \frac{l}{L}+4 M_{y}^{\prime} \frac{L}{l}+4 M_{x}^{\prime} \frac{l}{L}\right)
\end{aligned}
$$

For the general side column loss, it is given by:

$$
\begin{aligned}
& F=\left(C_{x e}\left(T_{x} l+2 F_{u L}\right)+2 C_{y a} T_{y} L b \frac{v}{2 l}+2 C_{x a} T_{x} l b \frac{v}{\alpha L}+2 F_{u L} \frac{v}{\alpha L}\right. \\
& \left.+2 C_{y m} M_{y} \alpha \frac{L}{l}+2 C_{x m} M_{x} \frac{l}{\alpha L}+2 M_{x}^{\prime} \frac{l}{\alpha L}\right)
\end{aligned}
$$


where $C_{x e}$ and $C_{y e}$ represent the contribution from the extended reinforcement and beams, respectively; $C_{a}$ represents the contribution from additional bending moments caused by membrane forces in slabs; $C_{y m}$ and $C_{x m}$ represent the influence of the membrane force on the yield bending moment of slabs, respectively.

To capture the main mechanical characteristics of the substructures at large deflections, a tri-linear displacement-resistance relationship was proposed. As shown in Fig. 31, $v_{A}, v_{B}$ and $v_{C}$ are the displacement corresponding to the end of the elastic-plastic stage, transition stage and failure displacement, respectively. $q_{A}$ is the plastic capacity of the substructure, which can be determined by yield-line theory. The determinations of displacements $v_{A}$ and $v_{B}$ are included in Ref. [65, 66].

\subsubsection{Verification}

The performance of the proposed analytical method was verified by validated numerical models, wherein the effect of structural parameters such as aspect ratio and thickenss of slabs, reinforcement ratio of slabs, height of beam section on the progressive collapse of beam-slab composite substructures were considered. The detailed parameters of substructures for removal of a middle and side column are given in Tables 2 and 3, respectively. The comparisons of analytical and numerical displacement-resistance relationships of the substructures under removal of a middle and side column were shown in Ref. [65] and Ref. [66], respectively. The errors of the predicted ultimate bearing capacity of the substructures are shown in Tables 4 , respectively. The proposed method provided accurate predictions on the ultimate bearing capacity of the substructure, with the relative errors less than $15 \%$.

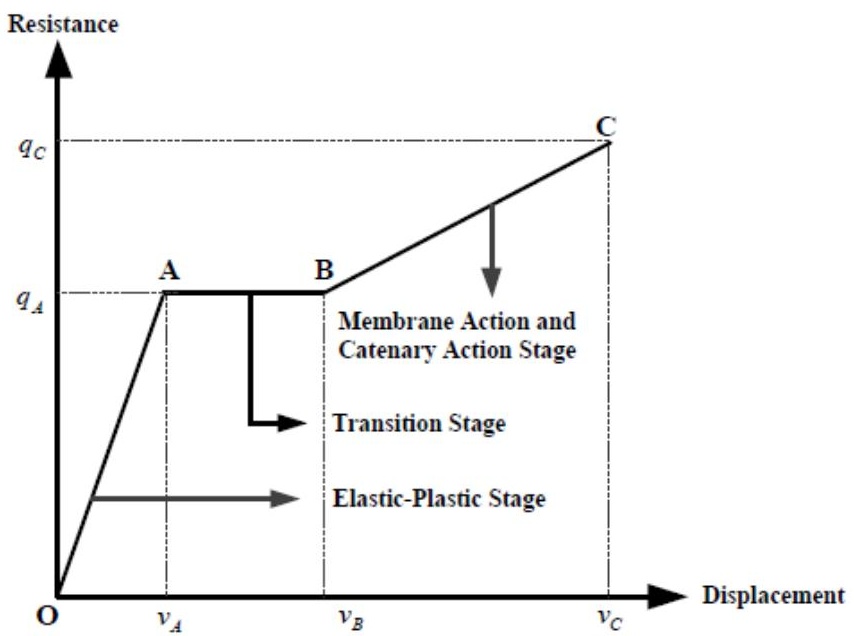

Fig. 31 Simplified resistance-displacement curve

Table 2

Dimensions and reinforcement of the composite substructures for middle column loss scenario

\begin{tabular}{|c|c|c|c|c|c|c|}
\hline \multirow{2}{*}{ No. } & \multirow{2}{*}{ Variable } & \multirow{2}{*}{$\begin{array}{l}\text { Planar Size } \\
(\mathrm{L} \times 1)(\mathrm{mm})\end{array}$} & \multirow{2}{*}{$\begin{array}{l}\text { Slab Thickness } \\
\qquad(\mathrm{mm})\end{array}$} & \multicolumn{2}{|c|}{ Reinforcement } & \multirow{2}{*}{ Beam Section } \\
\hline & & & & Top & Bottom & \\
\hline $\mathrm{S} 1$ & Control specimen & $4000 \times 3000$ & 100 & $\Phi 12 @ 120$ & $\Phi 12 @ 180$ & $200 \times 100 \times 5.5 \times 8$ \\
\hline $\mathrm{S} 2$ & & $4000 \times 2500$ & 100 & $\Phi 12 @ 120$ & $\Phi 12 @ 180$ & $200 \times 100 \times 5.5 \times 8$ \\
\hline $\mathrm{S} 3$ & Aspect ratio & $4000 \times 3500$ & 100 & Ф12@120 & Ф12@180 & $200 \times 100 \times 5.5 \times 8$ \\
\hline S4 & & $4000 \times 4000$ & 100 & $\Phi 12 @ 120$ & $\Phi 12 @ 180$ & $200 \times 100 \times 5.5 \times 8$ \\
\hline S5 & & $4000 \times 3000$ & 75 & $\Phi 12 @ 120$ & $\Phi 12 @ 180$ & $200 \times 100 \times 5.5 \times 8$ \\
\hline S6 & Slab thickness & $4000 \times 3000$ & 125 & $\Phi 12 @ 120$ & Ф12@180 & $200 \times 100 \times 5.5 \times 8$ \\
\hline S7 & & $4000 \times 3000$ & 150 & $\Phi 12 @ 120$ & $\Phi 12 @ 180$ & $200 \times 100 \times 5.5 \times 8$ \\
\hline S8 & & $4000 \times 3000$ & 100 & Ф14@120 & $\Phi 14 @ 180$ & $200 \times 100 \times 5.5 \times 8$ \\
\hline S9 & Rebar ratio & $4000 \times 3000$ & 100 & Ф8@120 & Ф8@180 & $200 \times 100 \times 5.5 \times 8$ \\
\hline S10 & & $4000 \times 3000$ & 100 & Ф10@120 & $\Phi 10 @ 180$ & $200 \times 100 \times 5.5 \times 8$ \\
\hline S11 & & $4000 \times 3000$ & 100 & Ф12@120 & $\Phi 12 @ 180$ & $120 \times 100 \times 5.5 \times 8$ \\
\hline $\mathrm{S} 12$ & Beam section height & $4000 \times 3000$ & 100 & Ф12@120 & $\Phi 12 @ 180$ & $160 \times 100 \times 5.5 \times 8$ \\
\hline $\mathrm{S} 13$ & & $4000 \times 3000$ & 100 & Ф12@120 & Ф12@180 & $240 \times 100 \times 5.5 \times 8$ \\
\hline
\end{tabular}

Note: Dimensions in mm. $\Phi$ denotes the diameter of reinforcement bars.

Table 3

Dimension and reinforcement of composite substructures for side column loss scenario

\begin{tabular}{|c|c|c|c|c|c|c|}
\hline \multirow{2}{*}{ No. } & \multirow{2}{*}{ Variable } & \multirow{2}{*}{$\begin{array}{l}\text { Planar Size } \\
(\mathrm{L} \times 1)(\mathrm{mm})\end{array}$} & \multirow{2}{*}{$\begin{array}{l}\text { Slab Thickness } \\
(\mathrm{mm})\end{array}$} & \multicolumn{2}{|c|}{ Reinforcement } & \multirow{2}{*}{ Beam Section } \\
\hline & & & & Top & Bottom & \\
\hline SS1 & Control specimen & $4000 \times 2000$ & 100 & $\Phi 12 @ 120$ & $\Phi 12 @ 180$ & $200 \times 100 \times 5.5 \times 8$ \\
\hline $\mathrm{SS} 2$ & & $4000 \times 1750$ & 100 & $\Phi 12 @ 120$ & $\Phi 12 @ 180$ & $200 \times 100 \times 5.5 \times 8$ \\
\hline $\mathrm{SS} 3$ & Aspect ratio & $4000 \times 2250$ & 100 & $\Phi 12 @ 120$ & $\Phi 12 @ 180$ & $200 \times 100 \times 5.5 \times 8$ \\
\hline $\mathrm{SS} 4$ & & $4000 \times 2500$ & 100 & $\Phi 12 @ 120$ & Ф12@180 & $200 \times 100 \times 5.5 \times 8$ \\
\hline SS5 & & $4000 \times 2000$ & 75 & $\Phi 12 @ 120$ & Ф12@180 & $200 \times 100 \times 5.5 \times 8$ \\
\hline SS6 & Slab thickness & $4000 \times 2000$ & 125 & $\Phi 12 @ 120$ & $\Phi 12 @ 180$ & $200 \times 100 \times 5.5 \times 8$ \\
\hline SS7 & & $4000 \times 2000$ & 150 & Ф12@120 & Ф12@180 & $200 \times 100 \times 5.5 \times 8$ \\
\hline SS8 & & $4000 \times 2000$ & 100 & Ф14@120 & $\Phi 14 @ 180$ & $200 \times 100 \times 5.5 \times 8$ \\
\hline SS9 & Rebar ratio & $4000 \times 2000$ & 100 & Ф16@120 & Ф16@180 & $200 \times 100 \times 5.5 \times 8$ \\
\hline SS10 & & $4000 \times 2000$ & 100 & Ф10@120 & Ф10@180 & $200 \times 100 \times 5.5 \times 8$ \\
\hline SS11 & & $4000 \times 2000$ & 100 & Ф12@120 & Ф12@180 & $120 \times 100 \times 5.5 \times 8$ \\
\hline $\mathrm{SS} 12$ & Beam section height & $4000 \times 2000$ & 100 & $\Phi 12 @ 120$ & Ф12@180 & $160 \times 100 \times 5.5 \times 8$ \\
\hline SS13 & & $4000 \times 2000$ & 100 & $\Phi 12 @ 120$ & Ф12@180 & $240 \times 100 \times 5.5 \times 8$ \\
\hline
\end{tabular}


Table 4

\begin{tabular}{|c|c|c|c|c|c|c|c|}
\hline \multicolumn{4}{|c|}{ Relative errors of analytical collapse resistance for middle column loss } & \multicolumn{4}{|c|}{ Relative errors of analytical collapse resistance for side column loss } \\
\hline No. & $\begin{array}{c}\text { Numerical } \\
\text { Collapse Resistance } \\
(\mathrm{kN})\end{array}$ & $\begin{array}{c}\text { Analytical } \\
\text { Collapse Resistance } \\
(\mathrm{kN})\end{array}$ & $\begin{array}{c}\text { Relative Error } \\
(\%)\end{array}$ & No. & $\begin{array}{c}\text { Numerical } \\
\text { Collapse Resistance } \\
(\mathrm{kN})\end{array}$ & $\begin{array}{c}\text { Analytical } \\
\text { Collapse Resistance } \\
(\mathrm{kN})\end{array}$ & $\begin{array}{c}\text { Relative Error } \\
(\%)\end{array}$ \\
\hline S1 & 1031 & 1011 & $1.9 \%$ & SS1 & 520.5 & 500.2 & $3.9 \%$ \\
\hline $\mathrm{S} 2$ & 1027 & 907 & $11.7 \%$ & SS2 & 522.9 & 481.7 & $7.9 \%$ \\
\hline S3 & 1037 & 1053 & $-1.5 \%$ & SS3 & 512.5 & 502.5 & $1.9 \%$ \\
\hline S4 & 1024 & 1105 & $-7.9 \%$ & SS4 & 515.9 & 525.7 & $-1.9 \%$ \\
\hline S5 & 954 & 823 & $13.7 \%$ & SS5 & 512.4 & 460.5 & $10.1 \%$ \\
\hline S6 & 1106 & 1141 & $-3.2 \%$ & SS6 & 539.8 & 543.1 & $-0.6 \%$ \\
\hline S7 & 1211 & 1321 & $-9.1 \%$ & SS7 & 555.3 & 589.4 & $-6.1 \%$ \\
\hline S8 & 1122 & 1129 & $-0.6 \%$ & SS8 & 554.5 & 532.5 & $4.0 \%$ \\
\hline S9 & 884 & 829 & $6.2 \%$ & SS9 & 582.2 & 578.9 & $0.6 \%$ \\
\hline $\mathrm{S} 10$ & 957 & 917 & $4.2 \%$ & SS10 & 488.3 & 454.3 & $7.0 \%$ \\
\hline S11 & 1012 & 1081 & $-6.8 \%$ & SS11 & 524.5 & 549.3 & $-4.7 \%$ \\
\hline $\mathrm{S} 12$ & 1018 & 1041 & $-2.3 \%$ & SS12 & 523.6 & 519.8 & $0.7 \%$ \\
\hline $\mathrm{S} 13$ & 1056 & 949 & $10.1 \%$ & SS13 & 498.5 & 431.2 & $13.5 \%$ \\
\hline
\end{tabular}

\subsubsection{Further discussion}

To further investigate the collapse resistance of substructures for removal of a middle and side column, the three terms of internal energy dissipations were calculated, including those from elongation of reinforcement in slabs and steel beams $W_{i n 1}$, additional resultant moment $W_{i n 2}$ and sectional moment of slabs $W_{i n 3}$ at the limit state. Fig. 32 and 33 show the proportions of these three

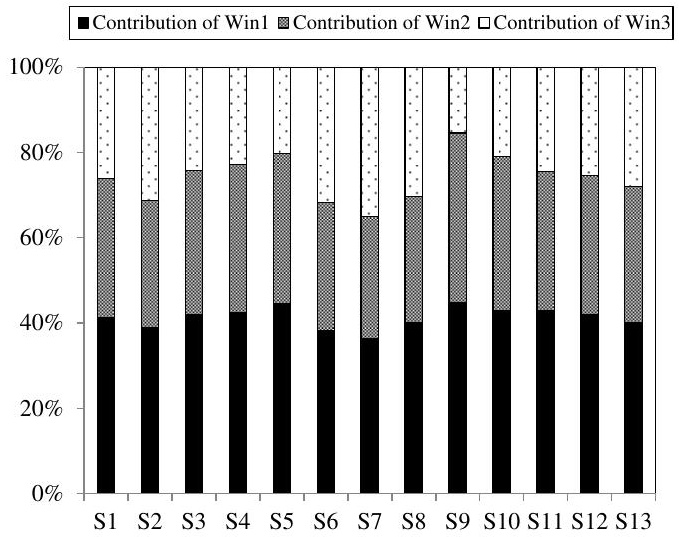

Fig. 32 Contributions from $\mathrm{W}_{i n 1}, \mathrm{~W}_{i n 2}$ and $\mathrm{W}_{i n 3}$ to the collapse resistance for middle column removal

To further verify the reliability of the proposed method, the analytical contribution percentage of the concrete slab at the ultimate limit state was compared with that of the numerical results. The numerically predicted contribution of slabs to collapse resistance was obtained by subtracting the resistance of the steel beams from the total value of the beam-slab substructure. The comparisons of the numerical and analytical slab contribution for middle and side column loss scenario are shown in Fig. 34 Fig. 35, respectively. It was found that the contribution from slabs at the collapse limit state ranged

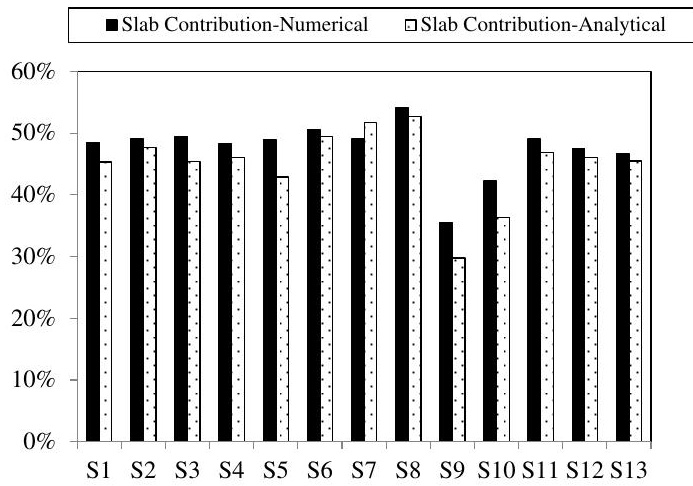

Fig. 34 Comparison of the contribution of slabs to the collapse resistance for middle column loss internal energy dissipations for the middle and side column removal, respectively. It can be concluded that the first two energy dissipations contributed more to the collapse resistance at large deflections. For the case of middle column loss, they accounted for $65 \%$ to $75 \%$ of the total energy dissipation, respectively. For side column loss, they occupied more than $70 \%$ of the total dissipation.

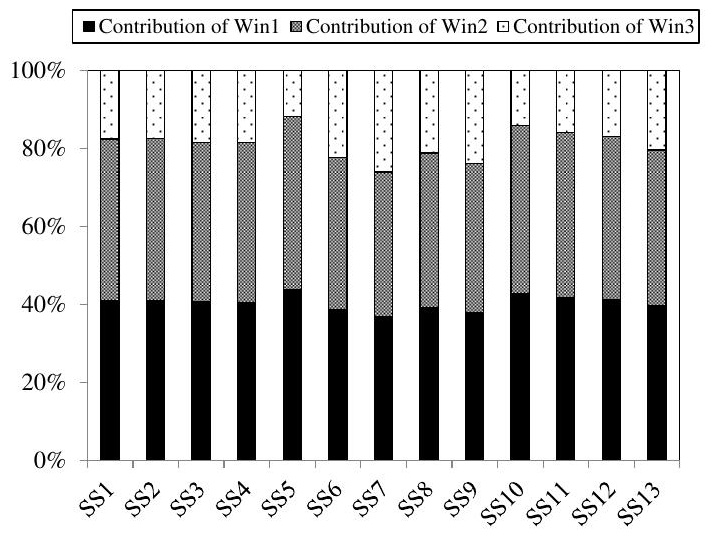

Fig. 33 Contributions from $\mathrm{W}_{i n 1}, \mathrm{~W}_{i n 2}$ and $\mathrm{W}_{i n 3}$ to the collapse resistance for side column removal

from $30 \%-50 \%$ of the total resistance, and it was mainly affected by the reinforcement ratio of slabs. When the reinforcement ratio was increased by $36 \%$, the slab-induced contribution correspondingly increased by $17 \%$ for middle column loss and $14 \%$ for side column loss. A reduction of reinforcement ratio by $56 \%$ led to decline of slab-induced contribution by $34 \%$ (middle column loss) and $31 \%$ (side column loss). The section height of beams had little effect on the beam-induced contribution to the collapse resistance of the substructure.

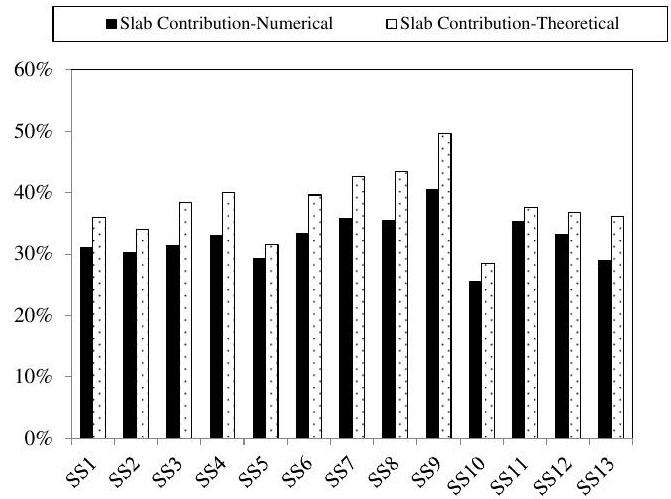

Fig. 35 Comparison of the contribution of slabs to the collapse resistance for side column loss 


\section{Conclusions}

This paper investigated progressive collapse behavior of steel framed buildings under impact, blast, and fire, respectively. Experimental, numerical and analytical studies were conducted to investigate the collapse mechanism and influencing factors. The following conclusions can be drawn:

(1) Under blast or impact, two collapse modes of steel frames were found depending on the behaviour of beams, connections and columns: beam or connection-induced collapse mode due to fracture of connections and column-induced collapse mode due to buckling of adjacent columns. In the case of fire, a similar column buckling collapse mode occurred for strong beams and high load ratio. Otherwise, the frame will collapse in a pull-in force-induced mode due to large deflection of beams.

(2) The dynamic amplification factors of frames subject to impact or blast (up to 1.35) were much less than the conventional value of 2.0, due to the energy dissipation during the plastic deformations developed in the frame. In contrast, the collapse process of frames in fire can be either static or dynamic depending on the restraint conditions and load level. It is therefore important to exactly simulate the dynamic effect of structures under extreme loads to ensure conservative conclusions.

(3) A capacity-based robustness index was proposed by comparing the imposed load on the intact structure to the residual capacity of the damaged structure. This index explicitly accounted for the dynamic effect and plastic deformation

(4) The failure process of a steel column in fire could either be quasistatic or dynamic, which is dependent on the restraint condition provided by the surrounding structural components and the load level.

(5) The influence of strain rate of material needs to be considered in the numerical modelling of structures in fire for the cases that the heated components fail in a dynamic way. Ignorance of this influence may lead to significant overestimation of the maximum deflection of the structure.

(6) Damping showed little effect on the behavior of steel frames in localized fires. Therefore, it is suggested to ignore the effect of damping for assessing progressive collapse resistance of steel frames under localized fires.

(7) An energy-based analytical approach was proposed to consider the effect of slabs and beams on the collapse behavior of structures. It was found that the energy dissipations due to the elongation of reinforcement and steel beams as well as additional resultant moment greatly contributed to the collapse resistance of the subassemblies. The slab-induced contribution was mainly affected by the slab reinforcement ratio ranging from $30 \%-50 \%$ of the total resistance.

(8) For impact or blast actions, it was found that the effect of damping on the collapse resistance depended on the collapse mode. It was larger in the column-induced collapse mode compared to beam-induced collapse mode. The ultimate load and robustness increased with increasing damping ratios. However, the damping had a negligible influence on the collapse behaviour of structures exposed to fire.

(9) It is important to consider the failure time and residual strength of blast-exposed columns for predicting the collapse resistance of structures subject to explosion.

\section{Acknowledgements}

The work presented in this paper was supported by the National Natural Science Foundation of China with grants 52078478 and 51878506 .

\section{References}

[1] Pusgley A, Griffiths H. and Saunders O. Report of the Inquiry into the Collapse of Flats at Ronan Point. Canning Town, 1968.

[2] American Society of Civil Engineers Standard 7 Minimum Design Loads for Buildings and Other Structures, American Society of Civil Engineers (ASCE), 2005.

[3] The Building Regulations: Approved Document A3: Disproportionate Collapse. Department for Transport, Environment and the Regions, DTLR, 2010.

[4] EN 1991-1-7. Actions on structures - Part 1-7: General actions -Accidental actions, European Committee for Standardisation, Brussels, 2010.

[5] McAllister T. and Corley G. World Trade Center Building performance study: Data collection, preliminary observations, and recommendations. Federal Emergency Management Agency, 2002.

[6] Design of Buildings to Resist Disproportional Collapse. Unified Facilities Criteria (UFC) 4023-03, US Department of Defense (DoD), 2010.

[7] Disproportional Collapse Analysis and Design Guidelines for New Federal Office Buildings and Major Modernization Projects, US General Services Administration (GSA), 2003.

[8] Manual for the Systematic Risk Assessment of High-risk Structures against Disproportionate Collapse. The Institute of Structural Engineers (IStructE), UK, 2013.

[9] Yu H , Izzuddin B A, Zha X X. Progressive collapse of steel-framed buildings: Influence of modelling approach[J]. Advanced Steel Construction, 2010, 6(4):932-948.

[10] Yang B. and Tan K.H., "Experimental tests of different types of bolted steel beam-column joints under a central-column-removal scenario", Engineering Structures, 54, 112-130, 2013.

[11] Lew H.S., et al., "Performance of steel moment connections under a column removal scenario. I: Experiments", Journal of Structural Engineering, 139(1), 98-107, 2012.

[12] Tsitos A., et al., "Experimental investigation of progressive collapse of steel frames under multi-hazard extreme loading", Proceedings of 14th World Conference on Earthquake Engineering, 2008.

[13] Xie F.Z. and Shu G.P., "Quasi-static experimental research on progressive collapse of space steel frames", Journal of PLA University of Science and Technology (Natural Science Edition), 14(2), 195-201, 2013. (in Chinese)

[14] Xie F.Z., "Analysis and assessment and experimental research on progressive collapse of steel frame structure". Ph.D dissertation, Southeast University, 2012. (in Chinese)

[15] Chen J. et al., "Experimental Study on the Progressive Collapse Resistance of a Two-Story Steel Moment Frame", Journal of Performance of Constructed Facilities, 26(5), 567-575, 2012.

[16] Xiao Y. et al., Collapse test of a 3-story half-scale RC frame structure. Structures Congress, ASCE, Reston, VA, 2013.

[17] Li F.W. et.al., "Experimental and analytical study on progressive collapse of RC frame with sudden side columns removal", China Civil Engineering Journal, 04(04), 9-18, 2014. (in Chinese)

[18] Sasani M. and Sagiroglu S., "Progressive Collapse Resistance of Hotel San Diego", Journal of Structural Engineering, 134(3), 478-488, 2008

[19] Sasani M. et al., "Progressive Collapse Resistance of an Actual 11-Story Structure Subjected to Severe Initial Damage", Journal of Structural Engineering, 137(9), 893-902, 2011.

[20] Krauthammer T., "Blast-resistant structural concrete and steel connections", International Journal of Impact Engineering, 22(9), 887-910, 1999.

[21] Lee C.H. et al., "Simplified nonlinear progressive collapse analysis of welded steel moment frames", Journal of Constructional Steel Research, 65(5), 1130-1137, 2009.

[22] Kripakov N.P., Sun M.C. and Donato D.A., "ADINA applied toward simulation of progressive failure in underground mine structures", Computers \& Structures, 56(2), 329344, 1995.

[23] Jian Jiang and Guo-Qiang Li. (2018) Progressive collapse of steel high-rise buildings exposed to fire: Current state of research. International Journal of High-rise Buildings, 7(4):375-387.

[24] Porcari G.L.F., Zalok E. and Mekky W., "Fire induced progressive collapse of steel building structures: A review of the mechanisms", Engineering Structures, 82, 261-267, 2015.

[25] Lange D., Roben C. and Usmani A.S., "Tall Building Collapse Mechanisms Initiated by Fire: Mechanisms and Design Methodology”, Engineering Structures, 36, 90-103, 2012.

[26] Fang C., Izzuddin B.A., Elghazouli A.Y. and Nethercot D.A., "Robustness of steelcomposite building structures subject to localized fire", Fire Safety Journal, 46, 348-363, 2011.

[27] Sun R.R., Huang Z.H. and Burgess I., "Progressive Collapse Analysis of Steel Structures under Fire Conditions", Engineering Structures, 34, 400-413, 2012.

[28] Jiang J., Li G.Q. and Usmani A.S. "Progressive collapse mechanisms of steel frames exposed to fire", Advances in Structural Engineering, 17(3), 381-398, 2014.

[29] Jiang J., Li G.Q. and Usmani A.S., "Effect of bracing systems on the fire-induced progressive collapse of steel structures", Fire Technology, 51, 1249-1273, 2015.

[30] Ali H.M., Senseny P.E. and Alpert R.L., "Lateral displacement and collapse of single-storey steel frames in uncontrolled fires", Engineering Structures, 26, 593-607, 2004.

[31] Jiang B.H., Li G.Q. and Usmani A.S., "Progressive collapse mechanisms investigation of planar steel moment frames under localized fire", Journal of Constructional Steel Research, $115,160-168,2015$.

[32] Agarwal A., and Varma A.H., "Fire induced progressive collapse of steel building structures: The role of interior gravity columns", Engineering Structures, 58, 129-140, 2014.

[33] Jiang J. and Li G.Q., "Progressive collapse analysis of 3D steel frames with concrete slabs exposed to localized fire", Engineering Structures, 149, 21-34, 2017.

[34] Sun R.R., Burgess I.W., Huang Z.H. and Dong G. "Progressive failure modelling and ductility demand of steel beam-to-column connections in fire", Engineering Structures, 89, 66-78, 2015.

[35] Jiang J. and Li G.Q., "Disproportional Collapse of 3D Steel-framed Structures Exposed to Various Compartment Fires”, Journal of Constructional Steel Research, 138, 594-607, 2017.

[36] Jian Jiang, Joseph Main, Jonathan Weigand and Fahim Sadek*. Reduced-order modeling of composite floor slabs in fire. I: Heat transfer analysis. Journal of Structural Engineering. 2020, 146(6): 04020080

[37] Jian Jiang, Joseph Main, Jonathan Weigand and Fahim Sadek*. Reduced-order modeling of composite floor slabs in fire. II: Thermal-structural analysis. Journal of Structural Engineering. 2020, 146(6): 04020081.

[38] Cowlard A., Bittern A., Abecassis-Empis C. and Torero J. Fire safety design for tall buildings. Proceedings of the 9th Asia-Oceania Symposium on Fire Science and Technology, Procedia Engineering, 62, 169-181, 2013.

[39] Jian Jiang, Adam Pintar, Jonathan M. Weigand, Joseph A. Main, and Fahim Sadek. (2019) Improved Calculation Method for Insulation-based Fire Resistance of Composite Slabs. Fire Safety Journal, 105, 144-153

[40] Jian Jiang and Guo-Qiang Li*. (2018) Parameters Affecting Tensile Membrane Action of Reinforced Concrete Floors subjected to Elevated Temperatures. Fire Safety Journal, 96: 5973.

[41] Jian Jiang, Wenyu Cai, Guo-Qiang Li*, Wei Chen and Jihong Ye. (2020) Disproportionate Collapse of steel-framed gravity buildings under Parametric Fires.Steel and Composite Structures (in press).

[42] Jiang B., Li G.Q. and Izzuddin B., "Dynamic performance of axially and rotationally restrained steel columns under fire", Journal of Constructional Steel Research, 122, 308$315,2016$.

[43] Behnam B., and Rezvani F.H., "Structural evaluation of tall steel moment-resisting structures in simulated horizontally travelling postearthquake fire", Journal of Performance of Constructed Facilities, DOI:10.1061/(ASCE)CF.1943-5509.0000696, 2015.

[44] Jian Jiang, Chenghao Wang, Guo-biao Lou, Guo-qiang Li. (2018) Quantitative Evaluation of Progressive Collapse Process of Steel Portal Frames in Fire. Journal of Constructional Steel Research, 150: 277-287.

[45] Guo-biao Lou, Chenghao Wang, Jian Jiang*, Yaqiang Jiang, Liangwei Wang, Guo-qiang Li. (2018) Fire Tests on Full-scale Steel Portal Frames Against Progressive Collapse. Journal of Constructional Steel Research, 145: 137-152. (SCI: )

[46] Jian Jiang and Guo-Qiang Li*. (2019) Mitigation of Fire-induced Disproportionate Collapse of Steel Framed Structures Using Bracing Systems. Advanced Steel Construction, 15(2), 192-202.

[47] Agarwal J., Blockley D. and Woodman N., "Vulnerability of structural systems", Structural Safety, 25(3), 263-286, 2003

[48] Huo J.S. et al. "Analysis of dynamic behavior and ductility of steel moment frame 
connections", Journal of Civil Architectural \& Environmental Engineering, 34, 149-154, 2012. (in Chinese)

[49] Frangopol D. and Curley J., "Effects of Damage and Redundancy on Structural Reliability", Journal of Structural Engineering, 113(7), 1533-1549, 1987.

[50] Beeby A., "Safety of structures, and a new approach to robustness", Structural Engineer, 77(4), 16-21, 1999

[51] Smith J.W., "Structural robustness analysis and the fast fracture analogy", Structural engineering international, 16(2), 118-123, 2006

[52] JZ Zhang, GQ Li, J Jiang. 2020. Dynamic effects on steel frames with concrete slabs under a sudden edge-column removal scenario, Journal of Structural Engineering; 146 (9), 04020185

[53] JZ Zhang, GQ Li, J Jiang, WJ Zhang. 2019. Collapse resistance of composite framedstructures considering effects of slab boundary restraints, Journal of Constructional Steel Research; 158, 171-181.

[54] GQ Li, JZ Zhang, J Jiang. 2020, Multi-storey composite framed-structures due to edgecolumn loss, Advanced Steel Construction; 16 (1), 20-29.

[55] GQ Li, JZ Zhang, J Jiang. 2020, Collapse resistance of steel frames with concrete slabs due to penultimate-side column loss, Advances in Structural Engineering, 23 (7), 1473-1486.

[56] Lu D.G. et al., "Robustness assessment for progressive collapse of framed structures using pushdown analysis methods", International Journal of Reliability and Safety, 6(1-3), 15-37, 2012.

[57] Jian Jiang, Qijie Zhang, Liulian Li, Wei Chen, Jihong Ye, Guo-Qiang Li. (2020) Review on Quantitative Measures of Robustness for Building Structures Against Disproportionate Collapse. International Journal of High-rise Buildings, 9(2): 159-186.

[58] Li G.Q., Li L.L., Jiang B.H. and Lu Y., "Experimental study on progressive collapse resistance of steel frames under a sudden column removal scenario", Journal of
Constructional Steel Research, 147, 1-15, 2018.

[59] Vlassis A. et al., "Progressive collapse of multi-storey buildings due to failed floor impact", Engineering Structures, 31(7), 1522-1534, 2009.

[60] Li L.L., Li G.Q., Jiang B.H. and Lu Y., "Analysis of robustness of steel frames against progressive collapse", Journal of Constructional Steel Research, 143, 264-278, 2018.

[61] Tsai M.H. and Lin B.H., "Dynamic amplification factor for progressive collapse resistance analysis of an RC building", The Structural Design of Tall and Special Buildings, 18(5), 539-557, 2009.

[62] Li G.Q., Zhang Y., Yang T.C., Jiang J., Lu Y. and Chen S.W., "Effects of Blast-induced Column Failure Pattern on Collapse Behavior of Steel Frames", Advanced Steel Construction, 14(3): 376-390, 2018.

[63] Jiang B., Li G.Q., Li L. and Izzuddin B., "Experimental studies on progressive collapse resistance of steel moment frames under localized furnace loading", Journal of Structural Engineering, DOI: 10.1061/(ASCE)ST.1943-541X.0001947, 2017.

[64] Jiang B., Li G.Q., Li L. and Izzuddin B., "Simulations on progressive collapse resistance of steel moment frames under localized fire", Journal of Constructional Steel Research, 138, 380-388, 2017.

[65] Zhang J.Z. and Li G.Q., "Collapse Resistance of Steel Beam-Concrete Slab Composite Substructures Subjected to Middle Column Loss", Journal of Constructional Steel Research, 145, 471-488, 2018.

[66] Li G.Q., Zhang J.Z. and Jian Jiang J., "Analytical modeling on collapse resistance of stee beam-concrete slab composite substructures subjected to side column loss", Engineering Structures, 169, 238-255, 2018.

[67] JZ Zhang, GQ Li, J Jiang, (2020), Collapse of steel-concrete composite frame under edgecolumn loss-Experiment and its analysis, Engineering Structures 209, 109951. 